\title{
Risk-based design of large-scale flood defence systems
}

\author{
PROEFSCHRIFT
}

ter verkrijging van de graad van doctor

aan de Technische Universiteit Delft,

op gezag van de Rector Magnificus prof. dr. ir. J.T. Fokkema,

voorzitter van het College voor Pomoties,

in het openbaar te verdedigen op maandag 20 januari 2003 om 16:00 uur

door

Hessel Gerrit VOORTMAN

civiel ingenieur

geboren te Borculo 

Dit proefschrift is goedgekeurd door de promotor:

Prof. ir. drs. J.K. Vrijling

Samenstelling promotiecommissie:

Rector Magnificus,

Voorzitter

Prof. ir. drs. J.K. Vrijling,

Technische Universiteit Delft, promotor

Prof. dr. M.H. Faber, Eidgenössische Technische Hochshule Zürich

Prof. dr. C. Guedes Soares Instituto Superior Técnico Lisboa

Prof. dr.-ing. H. Oumeraci,

Prof. dr. A. van der Veen, Technische Universität Braunschweig Universiteit Twente

Prof. ir. A.C.W.M. Vrouwenvelder

Technische Universiteit Delft

Dr. ir. P.H.A.J.M. van Gelder

Technische Universiteit Delft

This work has been supported by:

Dutch Ministry of Public Works and Water Management:

Dutch Institute of Marine and Coastal zone management, contract RKZ-642

Division of Road and Hydraulic Engineering, contract DWW-1528

\section{$\geqslant$ Delft Cluster}

Delft Cluster, contract DC 02.02.03

Front cover: three stages of failure of a coastal flood defence; failure of a block revetment, damage to inner slope and water flowing through a breach (photo's: collection of the Hydraulic Engineering Section, Faculty of Civil Engineering and Geosciences, Delft University of Technology).

Copyright $(\subset$ by H.G. Voortman

Printed by PrintPartners Ipskamp BV, the Netherlands

ISBN 90-9016433-2

This thesis is also published in the series 'Communications on Hydraulic and Geotechnical Engineering', Faculty of Civil Engineering and Geosciences, Delft University of Technology, Report no. 02-3, ISSN 0169-6548 



\section{SUMMARY: RISK-BASED DESIGN OF LARGE-SCALE FLOOD DEFENCE SYSTEMS}

The appropriate level of protection provided by a flood defence system is ideally obtained by balancing the cost of protection against the risk reduction in the protected area. Based on this idea, risk-based design methods have been developed over the past decades. On closer inspection, it appears that the concept of risk-based design is well developed but that in applications strong schematisations and simplifications are applied. The simplifications cast some doubt on the validity of the results that are obtained. This study aims to make risk-based design applicable to large-scale flood defence systems. The focus lies on the development of a general framework, in which in principle all information available may be used to establish the appropriate protection level in a given situation.

To come to a workable framework for risk-based decision-making, it should first be recognised that a variety of different decisions are made to come to the appropriate level of protection. The types of decisions range from decisions on the geometry of an individual flood defence structure to decisions on the acceptable flooding probability of an area, given economic and societal consequences of flooding. In this study, the decision process is split in three levels:

- Level A: decision-making on the appropriate probability of flooding on the level of protected areas. On this decision level, the cost of protection on the level of the full system and the consequences of flooding in the protected area are considered;

- Level B: decision-making on the failure probability per individual structure in the protection system for a given value of the probability of flooding. On this decision level the allocation of a given flooding probability to individual sections of the system is obtained by minimisation of the construction costs of the full system;

- Level C: decision-making on the geometry of an individual flood defence structure for a given probability of failure. Considering the cost of elements of the cross section and a set of failure modes, the construction costs of an individual section of the protection system are minimised.

The proposed three level structure may act in two different directions. In the process of establishing the appropriate protection level of a flood-prone area, levels C and B provide the information on the cost of protection for a range of protection levels. This information is used on level $\mathrm{A}$ in combination with estimates of the consequences of flooding to come to an acceptable level of protection of the area. On the other hand, if the level of protection on level A is fixed (by law), the tools on level B and C can be used to design the protection system in such a way that it matches legal requirements against minimum costs.

In this study, the method of reliability-based optimisation is proposed as a tool to find the optimal design of a flood protection system on levels B and C. Well-known reliability methods in combination with optimisation routines are used to find the minimum cost of protection for any protection level.

Reliability-based design of a flood defence structure is not possible if the environmental conditions are not properly quantified. For coastal flood defences, the hydraulic design conditions dominate the reliability of a flood defence structure. It appears that existing methods to describe the joint statistics of hydraulic conditions are not always consistent with the physical behaviour of water levels and wave conditions. An alternative method is proposed in this study. The method combines 
statistical models with parametric physical models, which provides more insight in the behaviour of extreme conditions than methods used to date.

Several options for the quantification of the probability distribution of flooding consequences are explored and compared to each other. A method is proposed in which the environmental conditions, the effect of primary and secondary flood defences and the spatial distribution of the value of the area are all accounted for in establishing the estimates of the flooding consequences.

Quantitative methods to define acceptable flooding probabilities on decision level A have been obtained from literature. Four methods are applied in this study:

- Limiting the added probability of death;

- Cost-benefit analysis;

- Utility analysis;

- Life quality analysis.

Based on observed statistics on causes of death, an acceptable value for the flooding probability may be defined. This has been done on the basis of earlier studies.

A cost-benefit model for flood protection is established on the basis of estimated consequences of flooding and cost of protection. In establishing the two main elements of the cost-benefit model, the proposed reliability-based design method for flood defences plays a dominant role.

An exponential utility model is used to include risk aversion in the cost-benefit model of flood protection. The elements of the model are the same as for the cost-benefit model. Therefore, also this model depends on a proper quantification of the cost of protection and the consequences of flooding.

The life quality index is a social indicator that combines the gross domestic product per capita and the life expectancy. The gross domestic product per capita is found from the elements of the cost-benefit model. The effects of flooding on the life expectancy at birth are quantified using an analogy to time-dependent reliability analysis.

Application of the risk-based design method to the coastal flood protection system of the province Groningen shows that the method indeed enables the risk-based design of large-scale flood defence systems. An analysis of the acceptable flooding probabilities shows that the models that include the cost of protection lead to optimal flooding probabilities that are no more than two orders of magnitude apart. A definition based on observed death statistics neglects the cost of protection and may lead to an acceptable flooding probability that is up to seven orders of magnitude lower.

The methods for reliability-based design on decision levels $\mathrm{B}$ and $\mathrm{C}$ can in principle be applied in practice to perform cost-effective design under the constraint of a required probability of failure. Extension of the models on these two levels is possible in the definition of failure modes and the description of hydraulic conditions.

Application of the models on decision level A requires more research on models for acceptable safety levels. In the current state of development, the results of the models on level A may be used as input in the debate on acceptable levels of protection against flooding.

H.G. Voortman 


\section{SAMENVATTING: RISICO-GEBASEERD ONTWERP VAN GROOTSCHALIGE WATERKERINGSSYSTEMEN}

Het geschikte beschermingsniveau dat geboden wordt door een waterkeringssysteem wordt in het ideale geval gevonden door de kosten van bescherming af te wegen tegen de reductie van het risico in het beschermde gebied. Op basis van dit concept zijn in de afgelopen decennia risico-gebaseerde ontwerpmethoden ontwikkeld. Bij nadere beschouwing blijkt dat het concept goed is uitgewerkt, maar dat in de toepassing sterke schematisaties en vereenvoudigingen worden gebruikt. Door de toegepaste vereenvoudigingen ontstaat twijfel over de geldigheid van de bereikte resultaten. Deze studie heeft als doel de risico-gebaseerde ontwerpmethode toepasbaar te maken voor grootschalige waterkeringssystemen. De nadruk ligt op de ontwikkeling van een algemeen raamwerk waarin in principe alle beschikbare informatie kan worden gebruikt om te komen tot een keuze van een geschikt beschermingsniveau in een gegeven situatie.

Voor de ontwikkeling van een werkbare methode is het zinvol te onderkennen dat, om te komen tot het geschikte beschermingsniveau, een groot aantal verschillende soorten beslissingen worden genomen. De beslissingen variëren van het ontwerpen van een geschikte geometrie van een individuele waterkering tot beslissingen over de acceptabele kans op overstroming van een gebied, gegeven de economische en maatschappelijke gevolgen van overstroming. In deze studie is het beslisproces gesplitst in drie niveau's:

- Niveau A: beslissingen over de acceptabele kans op overstroming op gebiedsniveau. Op dit niveau spelen de kosten van bescherming van het gehele systeem en de gevolgen van overstromen een rol;

- Niveau B: beslissingen over de ontwerp-faalkans van een individuele waterkering, gegeven een te halen overstromingskans op gebiedsniveau. De verdeling van een gegeven overstromingskans over onderdelen van het beschermingssysteem (dijkring) wordt vastgesteld door minimalisatie van de constructiekosten op systeemniveau;

- Niveau C: beslissingen over de geometrie van een individuele waterkering, gegeven een ontwerp-faalkans van de constructie. De kosten van onderdelen van de dijkdoorsnede, alsmede een set faalmechanismen worden beschouwd om te komen tot een optimaal ontworpen geometrie van een individuele waterkeringssectie.

De voorgestelde structuur werkt in twee richtingen. In het proces van vaststellen van het geschikte beschermingsniveau van een gebied op niveau A kunnen de niveaus B en $\mathrm{C}$ worden gebruikt voor bepaling van de kosten van bescherming voor een reeks van beschermingsniveaus. Wanneer het beschermingsniveau op niveau A (wettelijk) is vastgelegd kunnen op niveau $\mathrm{B}$ en $\mathrm{C}$ dezelfde methoden worden gebruikt om het waterkeringsysteem zodanig te ontwerpen dat de wettelijke eis wordt gehaald tegen minimum kosten.

De methode van betrouwbaarheidsgebaseerde optimalisatie wordt in deze studie voorgesteld als gereedschap voor ontwerpoptimalisatie op niveau B en C. Bekende methoden voor betrouwbaarheidsanalyse en optimalisatie worden gecombineerd tot een methode voor de bepaling van de minimum kosten als functie van het beschermingsniveau. 
Betrouwbaarheidsgebaseerd ontwerpen van een waterkering is onmogelijk zonder een degelijke kwantificering van de natuurrandvoorwaarden. De betrouwbaarheid van waterkeringen aan de kust wordt voornamelijk bepaald door de hydraulische randvoorwaarden. De tot nu toe voorgestelde methoden voor de beschrijving van de hydraulische randvoorwaarden lijken niet altijd consistent met het fysisch gedrag van waterstanden en golfcondities. Om die reden is een alternatieve methode voorgesteld in deze studie. De voorgestelde methode combineert statistische modellen met parametrische fysische modellen. De methode biedt meer inzicht in het gedrag van extreme condities dan de tot op heden voorgestelde methodes.

Een aantal opties voor de kwantificering van de gevolgen van overstroming is ontwikkeld en onderling vergeleken. In deze studie wordt een methode voorgesteld waarin de natuurrandvoorwaarden, het effect van primaire en secundaire waterkeringen en de ruimtelijke verdeling van de waarde van het gebied worden meegenomen in de vaststelling van de schatting van de gevolgen van overstroming.

Uit een literatuurstudie zijn kwantitatieve methoden gedestilleerd voor de beslissing over het beschermingsniveau op beslisniveau A. Vier methoden worden in deze studie toegepast:

- Limiteren van de toegevoegde kans op overlijden;

- Kosten-baten analyse;

- Nuts-functie analyse;

- Kwaliteit-van-leven analyse.

Gebaseerd op een analyse van waargenomen doodsoorzaken kan een acceptabele kans op overstromen worden gedefiniëerd. In deze studie is gebruik gemaakt van bestaande invullingen van deze methode.

Op basis van de kosten van bescherming en de geschatte gevolgen van overstroming is een kosten-baten model voor waterkeringen ontwikkeld. Bij het kwantificeren van de twee elementen van het kosten-baten model speelt de voorgestelde betrouwbaarheidsgebaseerde ontwerpmethode een dominante rol.

Een exponentiële nutsfunctie is in deze studie gebruikt voor de modellering van risico-aversie in het kosten-baten model. De elementen van het nutsmodel zijn verder gelijk aan die van het kosten-baten model. Om die reden is ook deze methode afhankelijk van een juiste kwantificering van de kosten van bescherming en de gevolgen van overstroming.

De kwaliteit-van-leven index is een maatschappelijke indicator die het bruto nationaal product per hoofd en de levensverwachting bij geboorte combineert. Het bruto nationaal product per hoofd als functie van de mate van bescherming tegen overstroming wordt gekwantificeerd met het kosten-baten model. Het effect van bescherming tegen overstroming op de levensverwachting bij geboorte wordt gekwantificeerd door gebruik te maken van de analogie met tijdsafhankelijke betrouwbaarheidsanalyse.

De risico-gebaseerde ontwerpmethode is toegepast op het waterkeringssysteem van de provincie Groningen. De methode blijkt goed werkbaar voor het optimaliseren van grootschalige waterkeringssystemen. Een analyse van de acceptabele kans op overstromen leidt tot ontwerp-overstromingskansen die minder dan twee ordes van grootte verschillen, zolang de kosten van bescherming in ogenschouw worden genomen. De definitie van de acceptabele overstromingskans op basis van waargenomen doodsoorzaken negeert de kosten van bescherming en leidt tot een 
overstromingskans die tot zeven ordes van grootte lager ligt dan het kosten-baten optimum.

De betrouwbaarheidsgebaseerde ontwerpmethoden op niveau B en niveau C zijn in hun huidige staat van ontwikkeling reeds geschikt voor het kosten-effectief ontwerpen van waterkeringen. Daarvoor is de definitie van een faalkansnorm noodzakelijk. De methoden op deze twee niveau's kunnen verder worden uitgebreid door uitbreiding met meer faalmechanismen en een gedegen beschrijving van de multi-variate statistiek van de natuurrandvoorwaarden.

Toepassing van de risico-gebaseerde methode op niveau A noodzaakt tot het uitvoeren van onderzoek naar modellen voor acceptabele veiligheidsniveaus. In de huidige staat van ontwikkeling zijn resultaten van modellen op niveau A vooral geschikt als onderdeel van het debat over acceptabele niveaus van bescherming tegen overstroming.

H.G. Voortman 


\section{PREFACE}

An important aspect of Civil Engineering is the construction of bridges. Sometimes, a Civil Engineer is literally involved in the construction of a bridge, but more often is he involved in bridging the gaps between societal requirements and desires and the technical possibilities of his profession.

This study falls in the second group. The analysis of acceptable levels of protection against flooding is typically a subject where society meets (and sometimes clashes with) technology. In principle, the design of a flood protection system should reflect the loads posed by the natural environment, the economic consequences of flooding, possible loss of life in case of flooding and several other requirements. Although conceptually agreed upon, it is not so easy to bring this concept into practice. This study aims to develop quantitative methods for decision-making on flood protection by providing a consistent framework for analysis and filling in several elements of the framework.

The study was performed in the framework of $\mathrm{PhD}$-research while I was employed as a research assistant by the Section of Hydraulic Engineering at the Faculty of Civil Engineering and Geosciences of Delft University of Technology. I would like to thank my promotor, Han Vrijling, for the fruitful cooperation in various projects for over six years. By providing a lot of freedom in my research in combination with his constant demand for proper explanation, he has contributed importantly to this study. Further, I would like to thank my colleague Pieter van Gelder, who fought himself through a number of drafts of the thesis.

The support of the Dutch Ministry of Public Works and Water Management and of the Delft Cluster is gratefully acknowledged. I thank John de Ronde, Bram Roskam, Jan van Marle, Joska Andorka Gal, Koos Doekes, Annemargreet de Leeuw, Patrick Tönjes, Martine Brinkhuis-Jak, Alex Roos and Ed Calle for their cooperation.

In the development and programming of the failure modes, I cooperated with Andreas Kortenhaus of the Technical University of Braunschweig, Germany. His hospitality and cooperation is gratefully acknowledged. With my good friend Gerard Gaal (a real bridge engineer) I had numerous discussions on my research, usually while enjoying a beer in the sunshine. I thank my colleage and university room-mate, Mohammed Yossef, for our discussions on society and politics and for suffering my "loud music" and "loud key-board".

Working in the background of our section were Mark Voorendt, Corine Franken, Adeeba Ramdjan, Chantal van Woggelum and Linda van Veen. Their help, ranging from administrative duties to rehabilitating crashing computers is gratefully acknowledged.

I thank Harrie Kuijper of ARCADIS Infra for his support and coaching when I was finding my way in a new job and at the same time finalising this thesis.

Finally, I thank Marjan for enriching my life so much. Since we met, this is the third time that I have been working on a graduation and she has supported me fully every time. I hereby promise that I will try to let this be the last graduation.

Hessel Voortman

Delft, May 2002 


\section{TABLE OF CONTENTS}

Summary: Risk-based design of large-scale flood defence systems................i

Samenvatting: Risico-gebaseerd ontwerp van grootschalige waterkeringssystemen iii

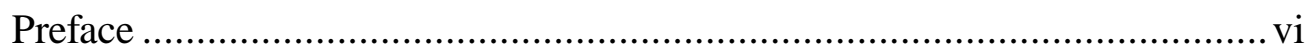

List of annexes............................................................................

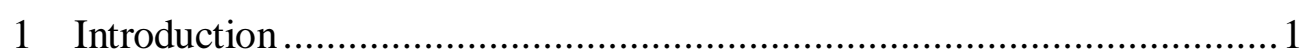

1.1 The need for flood defences.................................................... 1

1.2 Short history of flood protection in the Netherlands..........................2

1.3 Recent developments in decision-making on flood protection............. 7

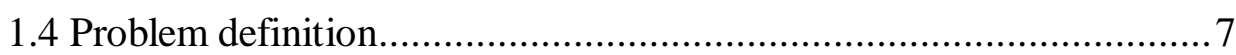

1.5 Outline of risk-based design of flood defences .............................. 8

1.6 Goals of this study.................................................................... 12

1.7 Fundamentals of this study ....................................................... 13

1.8 Outline of the thesis................................................................... 15

2 Quantitative methods for decision-making on flood protection .............. 19

2.1 Outline of decision-making on flood protection............................... 19

2.2 Cost-benefit analysis ............................................................... 21

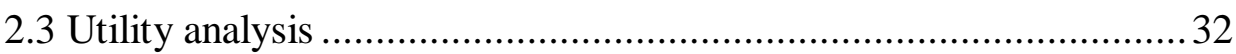

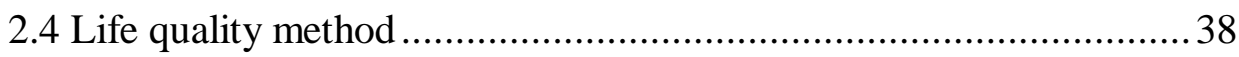

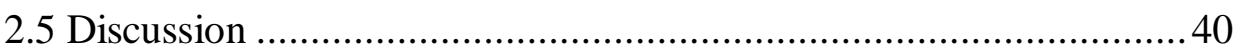

3 Methodology of reliability-based design of flood defences ....................43

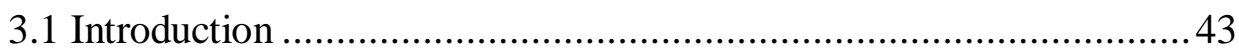

3.2 Qualitative reliability analysis of flood defence systems (level B)..... 44

3.3 Reliability evaluation of a flood defence structure (level C) ..............45

3.4 Reliability-based optimisation of flood defence structures (level C) .. 50

3.5 Reliability-based optimisation of flood defence systems (level B).....52

3.6 A computer program for reliability-based optimisation of flood defences

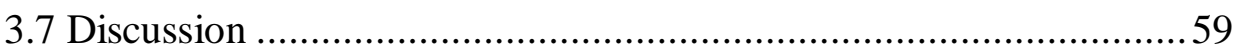

4 Quantifying the consequences of flooding........................................61

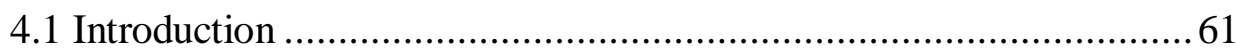

4.2 A conceptual model for direct damage as a consequence of flooding 62

4.3 Methodology of quantitative analysis of direct flooding damage.......65

4.4 Schematisation of a flood-prone area for the estimation of direct flooding damage 69

4.5 Quantifying loss of life due to flooding ...................................... 76 
4.6 Quantifying economic consequences of flooding 82

4.7 Discussion 83

5 A model for the joint probability distribution of hydraulic conditions in the coastal zone 85

5.1 Introduction 85

5.2 A conceptual model for the joint probability distribution of hydraulic conditions 86

5.3 Selection of probability models and dependence models 91

5.4 Schematisation of wind field and North Sea basin 100

5.5 Deriving omni-directional statistics from a directional model ......... 102

5.6 Discussion 106

6 Calibration of the joint probability distribution of hydraulic conditions for the dike ring groningen 107

6.1 Introduction 107

6.2 Overview of case study area and input data 107

6.3 Selection of calibration data 111

6.4 Calibration of the probability distributions of wind speed and astronomical tide 115

6.5 Calibration of models for wind setup and water level. 118

6.6 Calibration of the wave model ................................................. 128

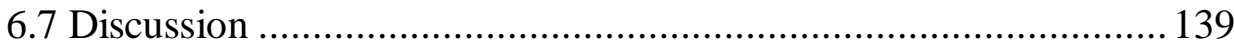

7 Reliability-based design of two flood defence structures in groningen .. 141

7.1 Introduction 141

7.2 Case description 141

7.3 Deterministic design of a flood defence structure 145

7.4 Reliability-based design of flood defences at Ommelander and Eemshaven 151

7.5 Discussion 173

8 Risk-based design of the coastal flood protection system of Groningen. 175

8.1 Introduction 175

8.2 Description of input data ....................................................... 175

8.3 Cost of protection on system level.............................................. 179

8.4 Analysis of the acceptable flooding probability ............................ 187

8.5 Comparison of models for acceptable flooding probability ............. 196

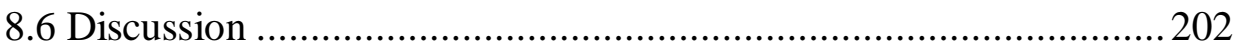

9 Conclusions and recommendations ................................................. 203

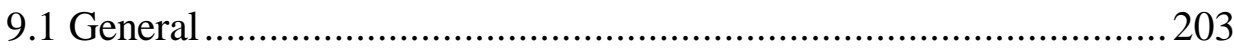


9.2 Quantifying the joint distribution of hydraulic design conditions ....204

9.3 Reliability-based design of flood defences .................................. 204

9.4 Quantifying the consequences of flooding .................................2205

9.5 Risk-based decision-making on the flooding probability (level A) ..206

9.6 Recommendations for future research ........................................ 208

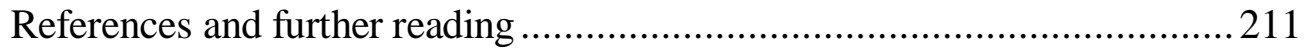

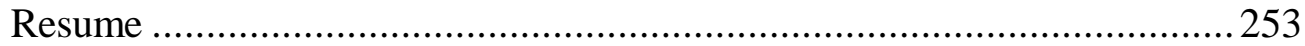

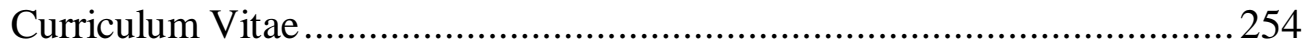





\section{LIST OF ANNEXES}

A.1 Fault tree for a dike section.................................................... 217

A.2 Sensitivity measures................................................................ 221

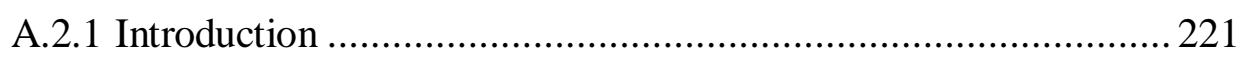

A.2.2 Sensitivity of the reliability per failure mode............................. 221

A.2.3 Sensitivity of the system reliability......................................... 222

A.3 Limit state functions........................................................... 225

A.3.1 Overflowing and wave overtopping ..................................... 225

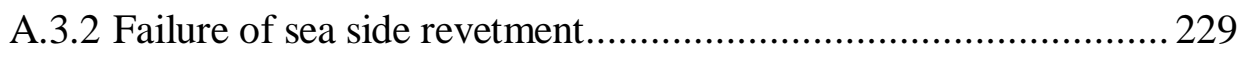

A.3.3 Piping ......................................................................... 230

A.3.4 Uplifting of land side clay cover ........................................ 231

A.4 Deriving the probability distribution of tides from harmonic components 233

A.5 Patching the wind data of station Huibertgat .............................. 237

A.6 Stochastic model for the dike ring Groningen.............................. 239

A.7 Description of the probabilistic Fortran library .............................251

A.7.1 Introduction .................................................................. 251

A.7.2 Programming philosophy and structure of the library.................251

A.7.3 Overview of main routines in the library ................................. 252 



\section{INTRODUCTION}

"Society blunders towards an optimum" J.K. Vrijling

\subsection{The need for flood defences}

The sea has always had an enormous attraction on human society. Already in ancient times, powerful societies like Carthago, Athens and Rome thanked at least part of their power to their close position to the sea and their dominance of it (Naerebout and Singor, 1995). Also in modern times, the majority of the world's population and the majority of economic activity is found in the close vicinity of the sea.

A nearby sea does not only provide benefits, but also poses an important risk to man and his environment. In the past, flooding disasters have struck human society all over the world and in the future they may be expected to do so again. At first glance it seems that society behaves irrational by accepting such risks. However, as stated before, there is also the potential of great prosperity. Apparently, society has implicitly decided that the profits outweigh the risk and reality has shown that this is often the case. This does not mean that the verdict is final. Changes in the environment and in society itself have always led to periodical updates of the decision. Very often, such decisions are forced upon society by the occurrence of disaster. Conceptually, the societal decision making process can be described as a feedback system (figure 1).

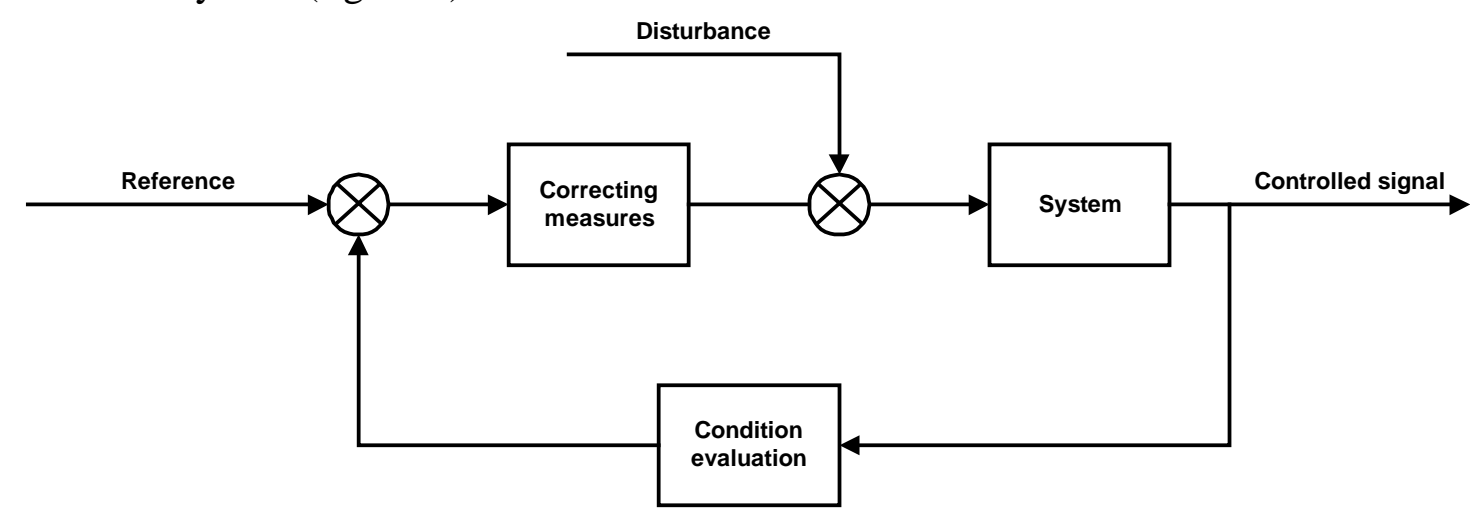

Figure 1: Feedback system (see e.g. Nixon, 1953)

In a feedback system, the controlled output signal is monitored and compared to a reference signal. A difference between the reference signal and the output signal leads to correcting measures that influence the behaviour of the monitored system. The output signal is a combination of the system output and some external disturbance. Wilde (1994) uses the concept of the feedback system to describe the behaviour of individuals taking subconscious decisions on risks. Societal decision processes can be modelled using the same concept.

In the Netherlands, the current situation with respect to flood defence can be viewed as the result of such a societal feedback process. Archaeological evidence shows traces of human occupation in the area now called the Netherlands as early as 500 BC. Works to control the water were already carried out in Roman times. After the decline and fall of the Roman empire, also the population declined and a number of areas were depopulated completely. Therefore around $800 \mathrm{AD}$, there was hardly any human influence on the landscape present (De Boer et al., 1992). For this reason, Van de Ven 
(1996) puts the starting point of the history of Dutch water management around 800 $\mathrm{AD}$, since at that time the processes started that ultimately shaped the current Dutch landscape.

Currently, approximately two third of the Dutch land area lies below mean sea level. This situation is the result of the geological conditions and human interference for over thousand years. Human intervention was generally motivated by an increasing population, which led to the occupation of formerly unused land. Drainage of soft soils and digging up peaty soils for fuel led to a lowering of the land level. Combined with sea level rise in the aftermath of the last ice age, the Netherlands suffered major floods and lost considerable land areas as early as the 1100s. As a response, the first flood defences were built and the drainage systems further developed. Thus, a process started where society was continuously adapting the protection system to a changing environment (figure 2).

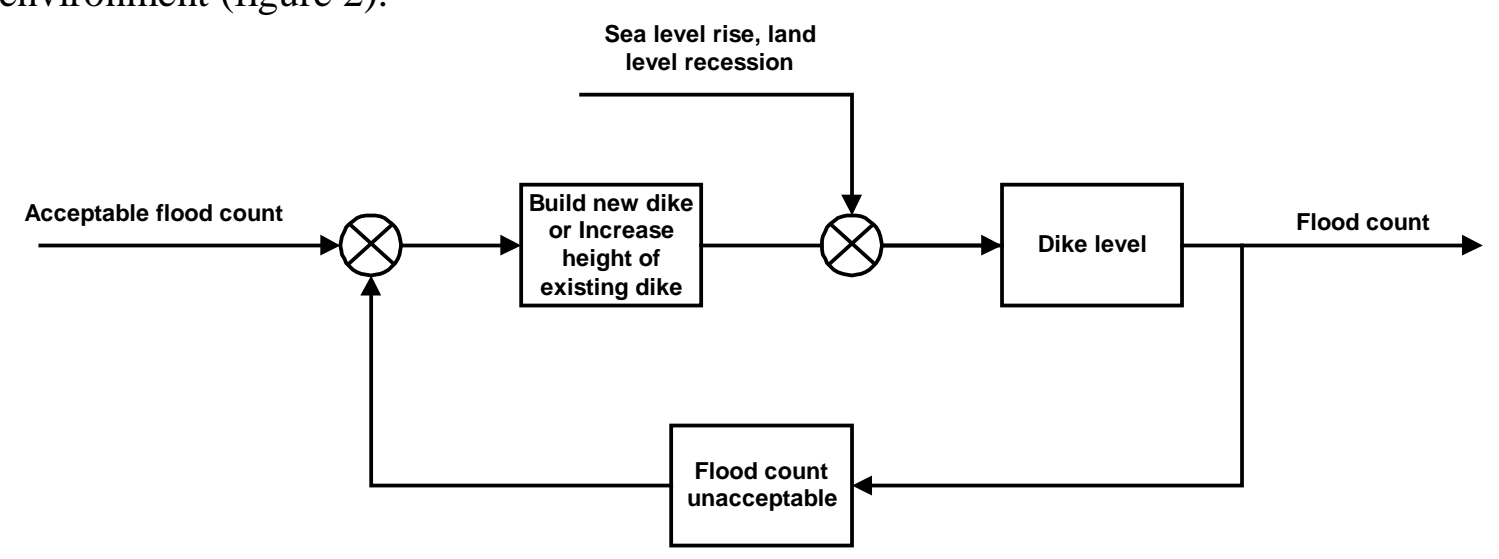

Figure 2: Societal feedback process in the primitive stages of flood protection

It is important to note that in this stage, the people suffering the floods were also the ones deciding on the level of the flood defences. Every community was protecting itself from floods. The decision-making cycle was short and transparent to all people involved. Floods were frequent, so that simple counting was sufficient to estimate the frequency of occurrence of floods. The effects of flooding were known to everyone, as well as the countermeasures that could be taken.

The acceptable flood count indicated in figure 2 was not an explicit number. Rather, the people experienced that floods happened "too often" without explicitly quantifying the number of occurrences.

The process sketched above has continued and evolved, together with the country itself. Today, the majority of the Dutch population lives in areas that are threatened by floods. Also the major part of economic activities takes place under sea level, including the economic boost of the late 1990s (NRC, 2000).

\subsection{Short history of flood protection in the Netherlands}

\subsubsection{Before 1953}

The societal decision process concerning the protection against flooding disaster shows an increasing demand on the performance of the flood defence system over time. One can say that the flood defence system tends to grow in conjunction with societal development. As scientific and technical knowledge increase, the ways in which the flooding risk is judged also change over time. 
In the beginning, flood defences appear to be designed by a trial-and-error process. Confronted with repeated flooding of the land, individuals or communities constructed their housing on artificial hills (dwelling mounds) and later on protected larger areas by simple dikes. The building efforts began local, but the people soon discovered that local protection was not useful if water could still enter the area from other sides. Gradually, the locally constructed flood defences were extended until closed dike rings came into being. The dike ring is still the administrative basis of the Dutch flood defence policy (figure 3).

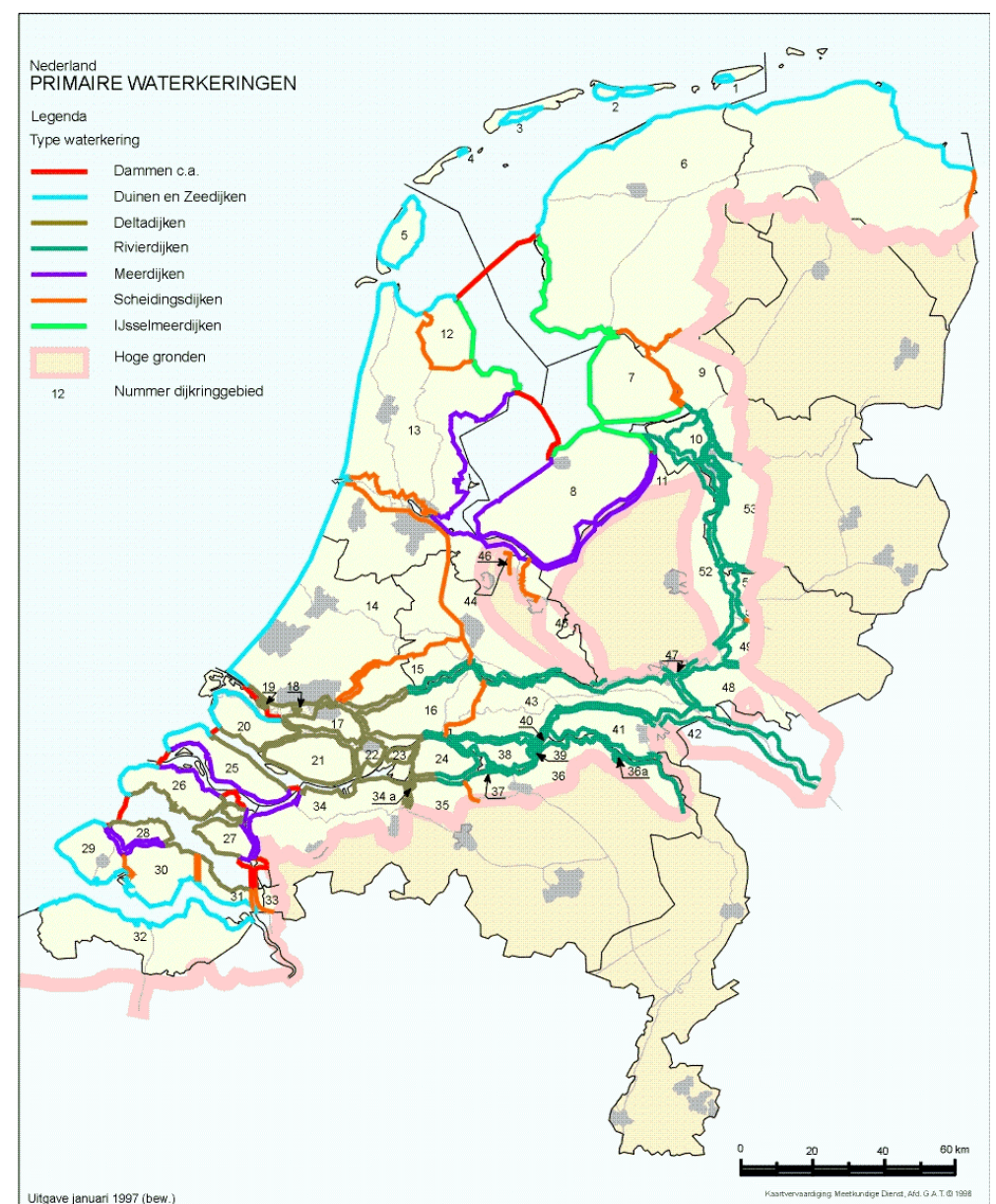

Figure 3: Dike rings: the basis of the Dutch flood defence policy (Flood Defence Act, 1995)

Over the centuries, technological advances led to considerably improved methods of dike construction. The definition of design loads remained based on observed water levels until far in the 20th century. Measurement programs of water levels were implemented, the first in Amsterdam in the $17^{\text {th }}$ century (van Malde, 1992). Design crest levels of the flood defences were established by requiring an extra height above the observed maximum water level. The minimum extra height was generally taken as 1 meter. In areas with wave action, the extra height was larger and generally based on experience. The necessity of dike reinforcement usually was only recognised if the water level exceeded the known maximum (figure 4) or failure of the defence system occurred. 


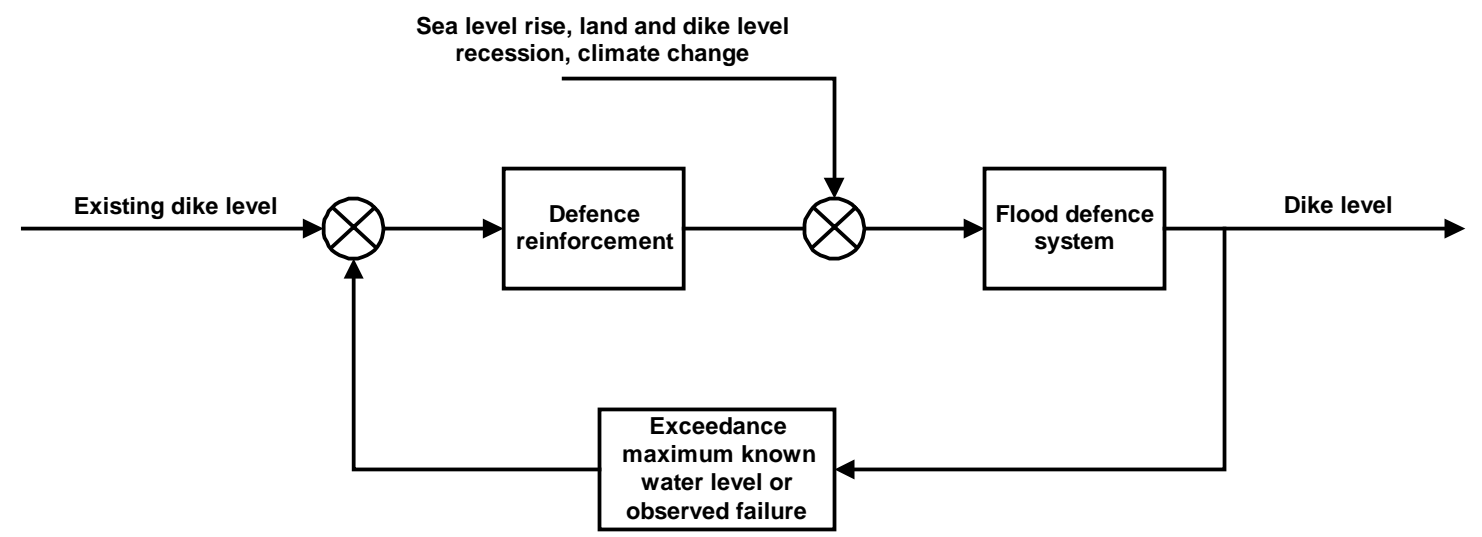

Figure 4: Traditional approach to calculating the flood defence level using observed water levels

In conjunction with the development of society, specialisation took place so that the number of people actively involved in the decision process became smaller. The general public was often unaware of the importance of flood defences until disaster struck again.

The statistical analysis of observations of environmental variables was not recognised to be applicable to the water level observations until the early twentieth century. In 1939, Wemelsfelder published a statistical analysis of the water levels at Hook of Holland and concluded that the then observed maximum water level (and thus the basis for dike design at the time) had a mean exceedance frequency of $1 / 50$ per year (Wemelsfelder, 1939). On that basis, a small group of scientists and engineers argued that a dike reinforcement program was necessary. Based on the results of Wemelsfelder, Huitema (1947) showed that the design water levels in the whole country had a high probability of exceedance. However, in the aftermath of the war, society was preoccupied with other problems than the protection against flooding. Progress was made in the technology needed for closing tidal inlets in 1945 and 1946 when the bombed flood defences of the island of Walcheren were closed (Den Doolaard, 1948; d'Angremond and Schiereck, 2001). This experience was used in closing the estuaries Braakman (1951) and Brielse Gat (1952) but the necessity of reinforcing the existing flood defences was not generally recognised until in 1953 the Netherlands again suffered a major flooding disaster.

\subsubsection{The Delta Committee: 1953-1960}

In the night of 31 January to 1 February 1953, an extreme storm hit the North Sea, causing the highest water levels observed to date. Especially in the South-East part of the North Sea, large floodings took place. In Britain and Belgium, several hundred people lost their lives. In the Netherlands, over 1800 people perished. The economic damage was estimated at 1.5 billion Dutch Guilders (Rijkswaterstaat and Dutch Meteorological Institute (1961), Slager (1992)). Following the disaster, a committee was formed to give advice to the government on the protection against flooding. The studies of this "Delta Committee" lead to a number of measures, summarised in the Delta Report (Delta Committee, 1961a). The main points of the advice were:

- The estuaries in the South-West, where the biggest damage was caused, should be closed off from the North Sea by dams, thus shortening the coast line and increasing the safety;

- Design water levels were defined, based on statistical analysis of water levels. The design frequency of the water level was set to $10^{-4}$ per year for the dike ring 
Central-Holland. Based on economic considerations, design frequencies were defined for all other dike rings in the Netherlands as well;

- Every individual element in the defence system should meet the design requirements. In most cases this meant that reinforcement was necessary.

The most visible and well-known result of the committee's work is of course the implementation of the Delta program, which led to the construction of a number of dams to close tidal basins and major reinforcement of most existing flood defences. Arguably more important was the culture change that had started in the 1930s with the closure of the Zuiderzee and that was greatly enhanced during the execution of the Delta Program. Scientific research in laboratories gradually supplemented experience and empirical knowledge. The scale of the Delta Project enforced the development of new design methods and probabilistic methods entered hydraulic engineering. In the decades following the Delta Committee, the societal decision process evolved towards the scheme shown in figure 5 .

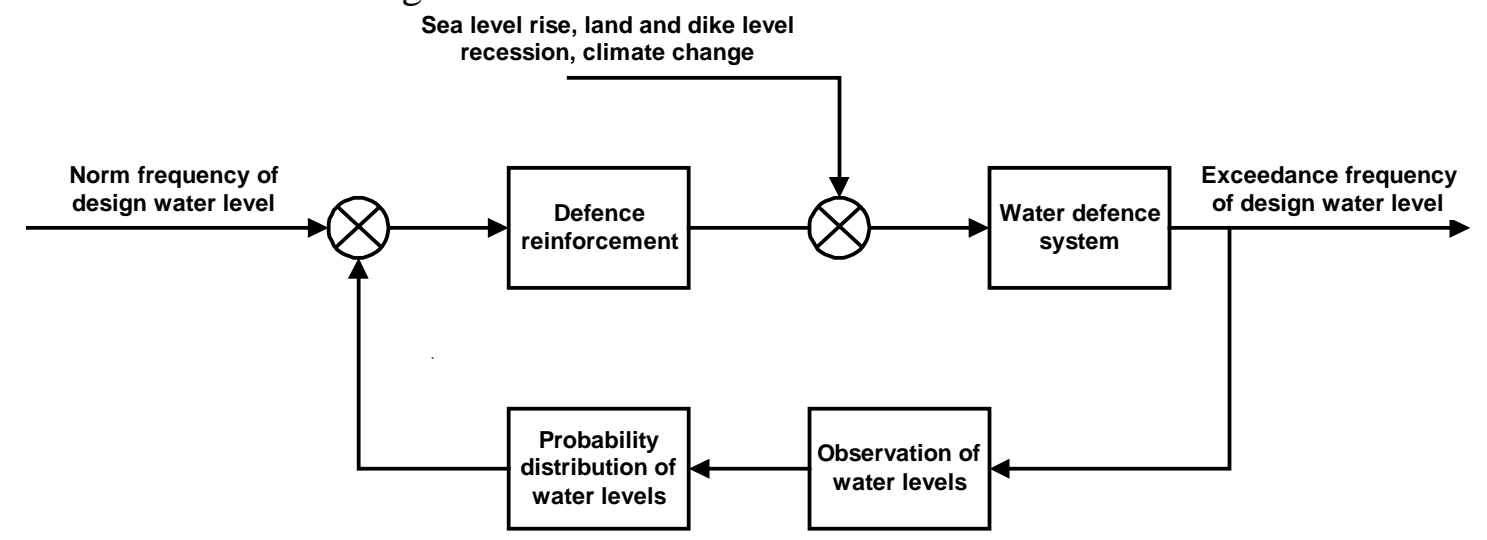

Figure 5: Feedback process based on exceedance frequency of water level

The Delta Committee established the economic optimal exceedance frequency of the design water level by an analysis of the risk of flooding and the costs of protection (van Dantzig (1956) and Delta Committe (1961b)). However, in its final report a design frequency lower than the economic optimal value was adopted for the following reasons (Delta Committee, 1961a):

- Exceedance of the design water level does not immediately lead to collapse of the flood defences;

- The risk-based design water level is based on a schematised situation and the simplification may lead to an overestimation of the risk.

The first point states, in modern terminology, that the exceedance probability of the water level is not equal to the failure probability of the structure. Indeed, at the time the Delta Committee performed its work, methods to deal with more than one stochastic variable in a risk-based optimisation were not available. The failure probability conditional on exceedance of the design water level remained unquantified and was qualitatively accounted for by adopting a lower than optimal exceedance frequency of the water level. The analysis was performed using analytical tools only, which necessitated the strong schematisation of the problem.

Though the committee made a strong recommendation for the design frequencies to be adopted, the committee was aware of the fact that safety levels should be dependent on the value of the protected area and even suggested that in some cases more strict design criteria might be derived from econometric analysis: "For primary flood defences, that protect vital or exceptionally high economic values, a design 
water level higher than suggested here might be appropriate" (Delta Committee, 1961a; pg. 32). It appears that the committee suggests some flexibility in the choice of the design frequency, depending on the consequences of flooding. Nevertheless, in the decades following the Delta Committee, the design frequencies were more and more interpreted as fixed values, and design and maintenance of flood defences was more and more aimed at preserving the defence system to a level where it could withstand the load levels proposed by the Delta Committee.

\subsubsection{After the Delta Committee: 1960 to present}

The 1960s and 1970s saw a considerable development of reliability calculation methods, starting with Turkstra $(1962,1970)$. The development took place primarily in structural engineering, but was adopted in flood defence design during the design of the Eastern Scheldt Storm Surge Barrier (Vrijling and Bruinsma (1980) and Mulder and Vrijling (1980)). The main difference with the design water level approach of the Delta Committee is that in reliability-based methods it is possible to take more than one random variable into account, which could solve one of the shortcomings of the econometric approach of the Delta Committee. The total effect of the uncertainties of all relevant variables is summarised in the failure probability of the structure or structure member that is analysed. In the course of this development, the approach was explored for dike design in the 1980s (Bakker and Vrijling, 1980). However, the legislative safety requirements are still prescribed as probabilities of exceedance of the design water level and thus the full probabilistic approach has not been officially adopted to date. Probabilistic methods are sometimes applied but a required failure probability for flood defences is not defined in Dutch law. Though the information content of a failure probability is considerably different from the old design frequency, the design frequencies of the Delta Committee are often interpreted as design failure probabilities for lack of a real probability requirement.

In the 1990s a new flood defence act was prepared and adopted in 1996. The Flood Defence Act is the successor of the Delta Law of 1956. Where the Delta Law was intended to improve the protection against flooding, the Flood Defence Act is intended to guarantee that protection into the far future. It is for this reason that a five year check of all flood defences in the Netherlands is now compulsory. With the Flood Defence Act, for the first time in history a part of the societal feedback process is formalised in legislation (figure 6).

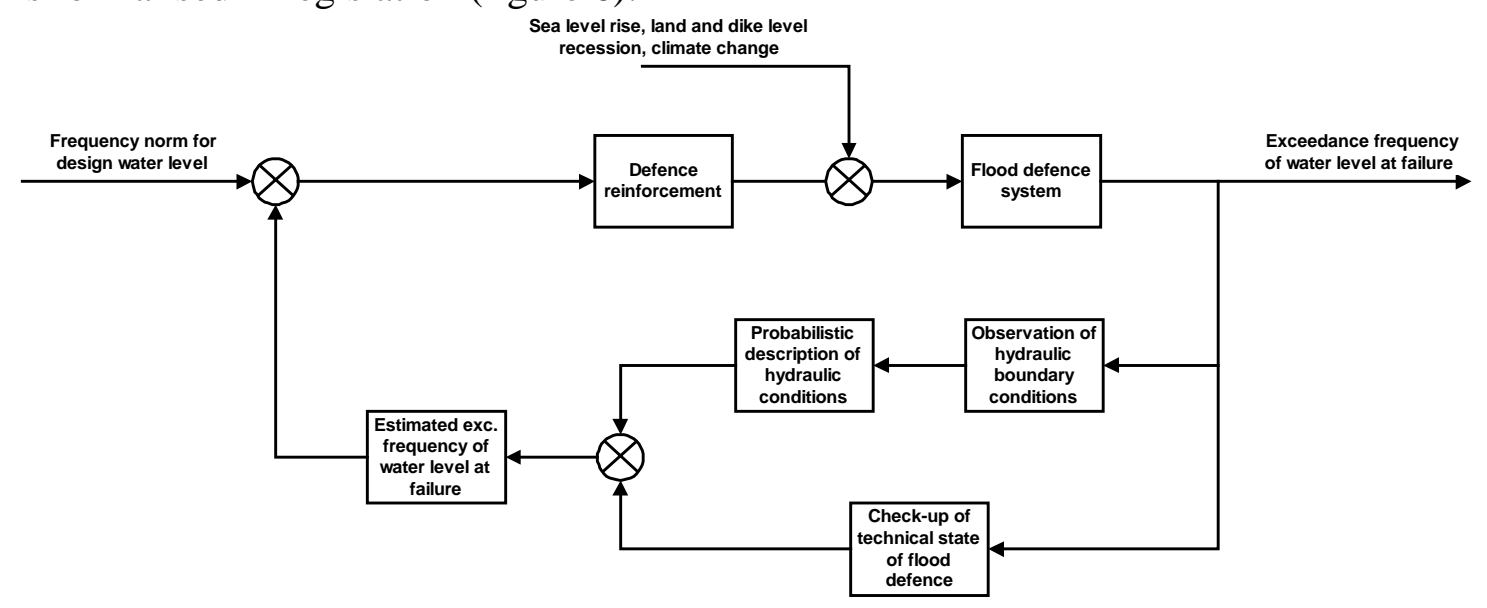

Figure 6: Feedback system under the flood defence act 


\subsection{Recent developments in decision-making on flood protection}

In the Delta Law and its successor, the Flood Defence Act, the design requirements for flood defences are defined on the level of individual dike sections. This means that every individual dike section should meet the design requirement. An alternative is already foreseen in the flood defence act, in the form of the flooding probability approach. The flooding probability approach sets a requirement on the probability of flooding of the area, regardless of the system of flood defence structures around it. This opens the possibility to vary the design requirements of individual sections, depending on the consequences of failure and the costs of reinforcement. Figure 7 provides an overview of this approach.

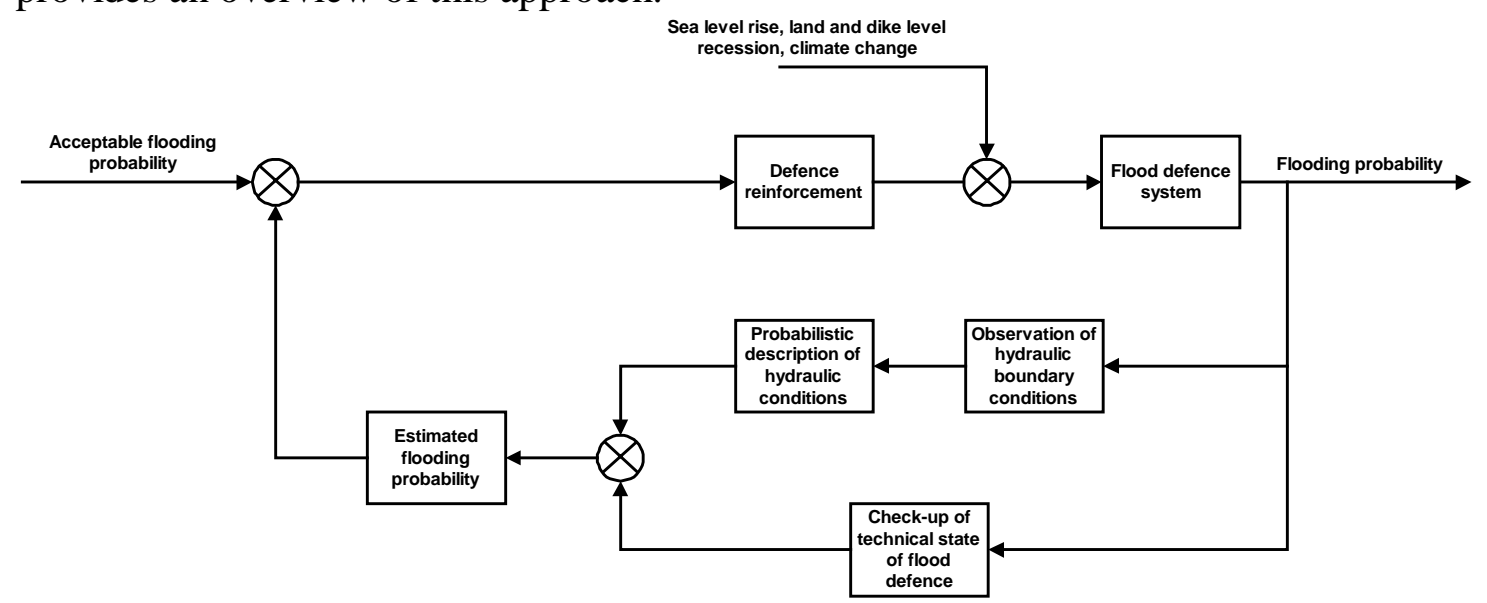

Figure 7: Flooding probability approach, evaluation of the safety per area

The flooding probability incorporates even more information than the failure probability of an individual section. Therefore, defining requirements in terms of flooding probabilities is not a matter of engineering alone, but should incorporate societal debate on appropriate safety levels (see TAW, 2000). It may be expected that in the course of defining acceptable flooding probabilities, also the failure probabilities for individual sections will be defined.

One step further from the flooding probability approach is the flooding risk approach, where not only the probability of occurrence of events is taken into account, but also the consequences of the event. This approach can provide input in the societal debate needed for the definition of acceptable flooding probability levels or can be a design approach in itself. To enable the use of the risk-based design approach in practice, further development of the method is necessary.

\subsection{Problem definition}

Society is in a continuous process of decision-making on the protection against flooding. Developments in science and technology have led to a demand for a quantitative method for judging flooding risk.

Qualitatively, it is clear that the safety level of flood defences should reflect the demands posed by nature and society. A quantitative method to analyse appropriate safety levels for flood-prone areas is conceptually available in the form of the riskbased design method for flood defences (see van Gelder, 1999 for an overview). For practical application of this method, a way to deal with large-scale complex flood defence systems needs to be developed. This is the subject of this study. 


\subsection{Outline of risk-based design of flood defences}

A risk-based approach to the design of water defences typically incorporates not only the flooding probability, but also the consequences of flooding. Figure 8 shows the approach as a feedback system.

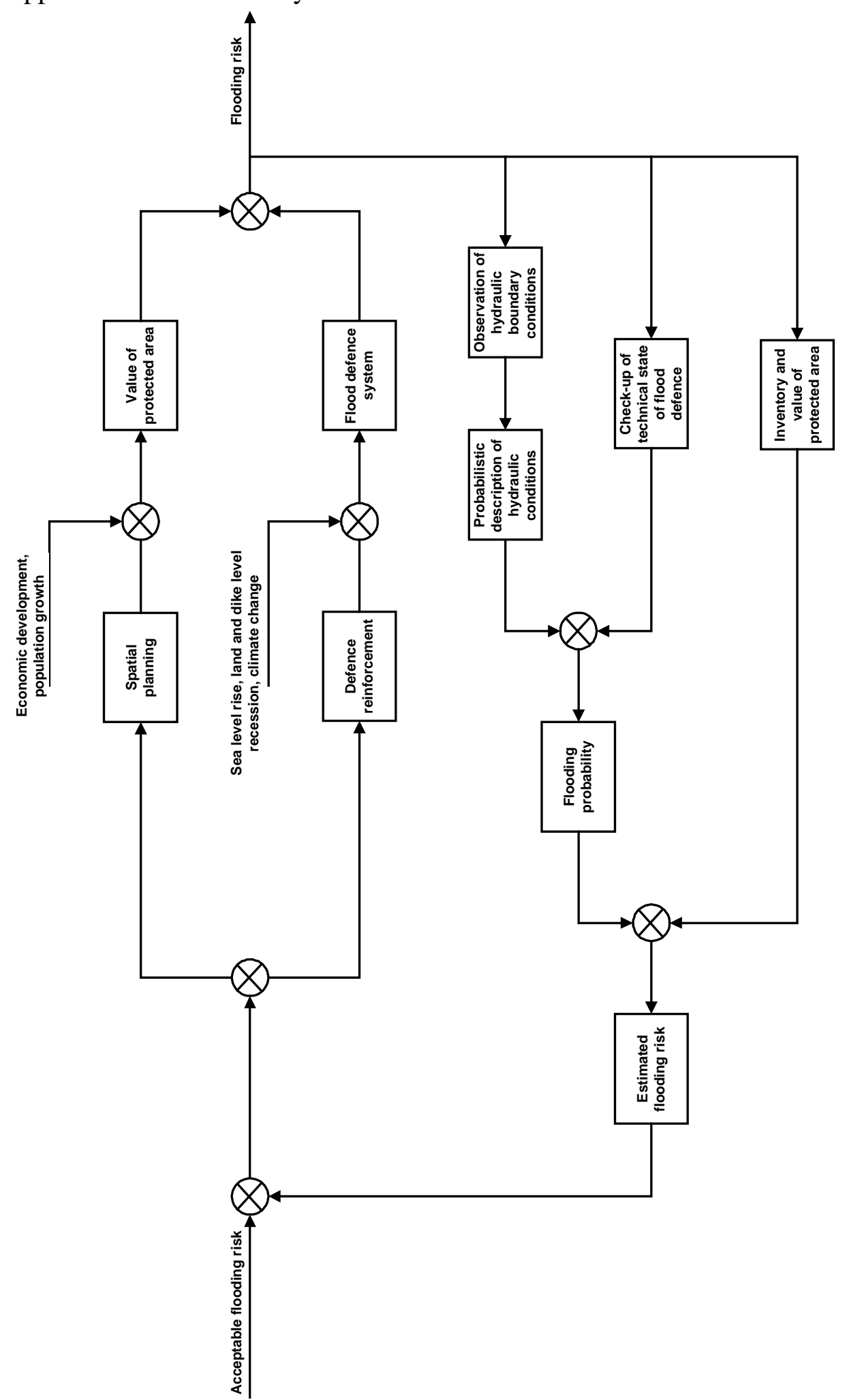

Figure 8: The flooding risk approach as a feedback system 
The advantages of the flood-risk approach are the following:

- The choice of the safety levels can be further rationalised if the consequences of flooding and the costs of protection are made explicit;

- Risk-based approaches exist also in other fields where safety levels have to be defined (for instance traffic safety), so that a risk-based approach to flooding safety opens the possibility of comparison of risk levels.

A drawback of the risk-based approach is that it is hard to communicate to nonspecialists. Therefore, as the methods to evaluate flooding risk become more elaborate and more specialised, there is also an increased need for communication with decision-makers and ultimately with the general public. Furthermore, there are a number of consequences of flooding that can not be quantified easily. Nevertheless, judging the quantifiable aspects of flooding and flood protection in a quantitative riskbased method can provide important insights in the possibilities and limitations of flood protection.

Looking in more detail to a flood-prone area and its protection system of flood defences, it is possible to define characteristic properties for both the area and the flood defence system that are relevant for the determination of an appropriate risk level (table 1).

Table 1: Important characteristics for a risk-based approach to flooding risk

\begin{tabular}{ll}
\hline Flood defence system & Protected area \\
\hline Level of protection (failure probability) & Population \\
Investment & Invested capital \\
Cost of maintenance and repair & Yearly turn-over \\
Ecological value & Ecological value \\
Cultural value & Cultural value \\
\hline
\end{tabular}

Increasing the safety level generally leads to sacrifices on the side of the flood defence system in terms of costs and potential loss of ecological and cultural values, while at the same time the increased safety level leads to benefits (limiting losses) on the side of the protected area.

A risk-based approach attempts to balance the sacrifices made on the side of the flood defence system with the accompanying benefit in the protected area. In a purely economic sense, this can be made explicit in the concept of risk-based cost-benefit analysis. In this approach, the costs of the flood defence system are explicitly balanced against the economic consequences of flooding in the area. Thus an economic optimal safety level is achievable. The concept was first applied by van Dantzig (1956) in the course of the studies of the Delta Committee. Recently, the concept of risk-based economic optimisation has been combined with modern methods of reliability analysis. Applications in coastal engineering have been published by Bakker and Vrijling (1980), Burcharth et al (1995), Voortman et al (1998, 1999a, 1999b) and Vrijling et al (1998).

The earlier applications of risk-based cost-benefit analysis generally show the following characteristics:

- The approach is used for optimisation of the cross section of a breakwater or flood defence and not for optimisation of large-scale systems;

- The number of design variables is limited to a maximum of three; 
- The influence of non-economic risks is either neglected (van Dantzig) or considered to be not important because of the characteristics of the application area.

Alternatives for cost-benefit analysis are available. A few will be introduced in this study.

The first and most primitive approach to decision-making on flood protection was the trial-and-error process outlined in figure 2. At first glance, the risk-based approach outlined in figure 8 appears to be unrelated to the process in the first days when flood protection was established (historic process). However, risk levels are still the result of the combination of the natural boundary conditions and the protection system that is in place. The scheme outlined in figure 8 shows risk-based decision-making on a high level of abstraction, but the low-level decisions on the design of the elements of the protection system itself still have to be made. The most important difference with the historic process is that different types of decisions on different levels of detail are made by distinct groups of decision-makers. This brings with it a necessity for communication that was absent in the historic process.

It is useful to attempt to structure the different types of decisions in a multi-level framework. Starting point for the multi-level model is the defence system (or dike ring) itself, which is defined as a connected set of flood defence structures (or components) protecting an area from flooding. The system may consist of the following components:

- Dunes;

- Dikes;

- Special structures.

When designing a flood defence structure, preference is usually given to existing natural defences like dunes, followed by earth structures like dikes. The relative costs of every type of protection plays an important role in this choice. Special structures are found only at locations where:

- The dike ring intersects with other functions, such as shipping traffic or discharge of excess water from the area;

- Space is too limited to build a dike or a dune.

In the process of decision-making on flood protection, decisions of a varied character and on different levels of detail are made by a number of actors which in the end leads to a decision on the overall flood risk level of the area, whether quantified or not. For this study, a distinction is made in three levels:

- Level A, decision-making on the acceptable flooding probability of an area;

- Level B, decision-making on the allocation of the flooding probability to individual structures in the defence system;

- Level C, decision-making on the geometry of an individual structure.

The multi-level decision process may be illustrated in a fault tree (figure 9). The concept of the fault tree is introduced in chapter 3. 


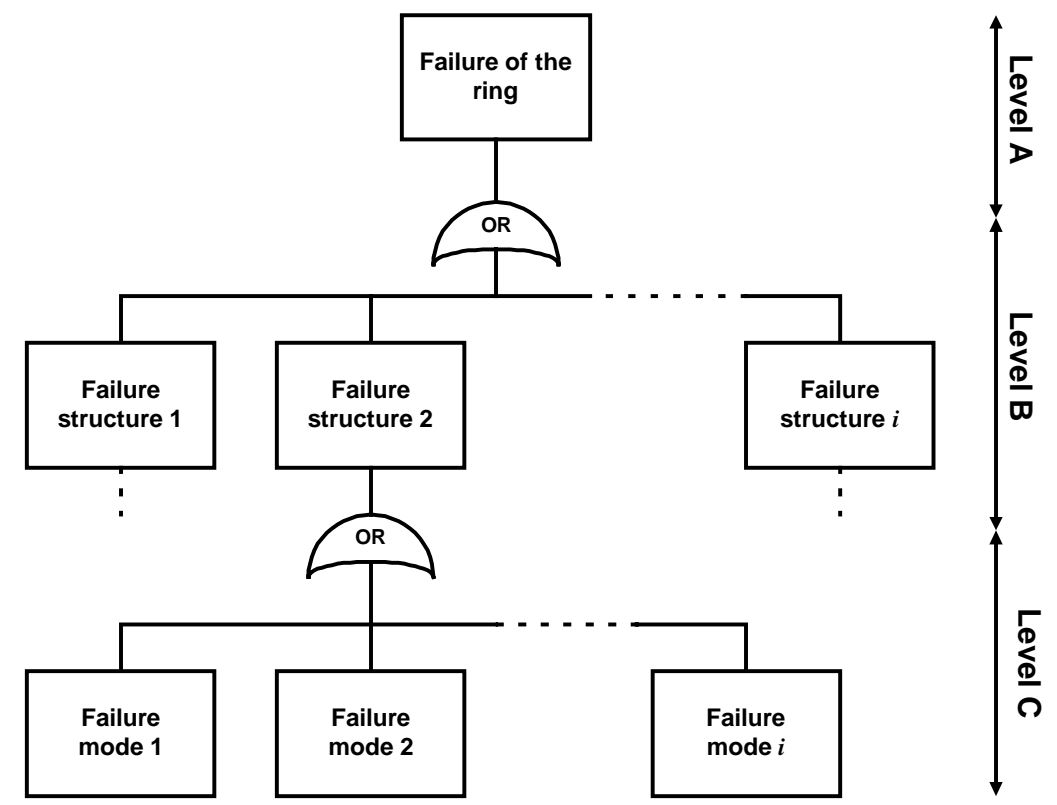

Figure 9: Multi-level decision-making and the fault tree of a flood-prone area

On level A decisions are made concerning the acceptability of flooding with regard of the consequences for society. The probability of occurrence of damage due to flooding is weighed against the sacrifices made to provide protection against flooding. In principle, all aspects of flooding are weighed together. Table 1 shows that not all consequences of flooding can be quantified. The same is true for the sacrifices made to provide protection. Quantitative methods for risk-based decision-making can be applied on this level, bearing in mind that the quantifiable aspects of flood protection form only a part of the information that decision-makers need to take into account. Nevertheless, structuring the quantifiable information by means of risk-based methods may facilitate the decision-making process. The societal feedback processes illustrated in figures 2 through 8 all describe decision making on level A.

On level $\mathrm{B}$ and even more on level $\mathrm{C}$, detailed technical information plays an important role in the decision-making process. At the same time, the consequences of flooding play a less important role on these two levels. The decision-makers involved will generally have a technical background and may be found at governmental bodies (managers) or consultancy firms. The technical information that plays a dominant role on levels $\mathrm{B}$ and $\mathrm{C}$ is also needed for decision-making on level $\mathrm{A}$. To facilitate decision-making on level $\mathrm{A}$, the technical information generated on levels $\mathrm{B}$ and $\mathrm{C}$ will have to be condensed to a lower level of detail, preferably without loosing information. Figure 10 shows the three decision levels, the level specific information that is used as well as the possible outcomes of every decision level. 


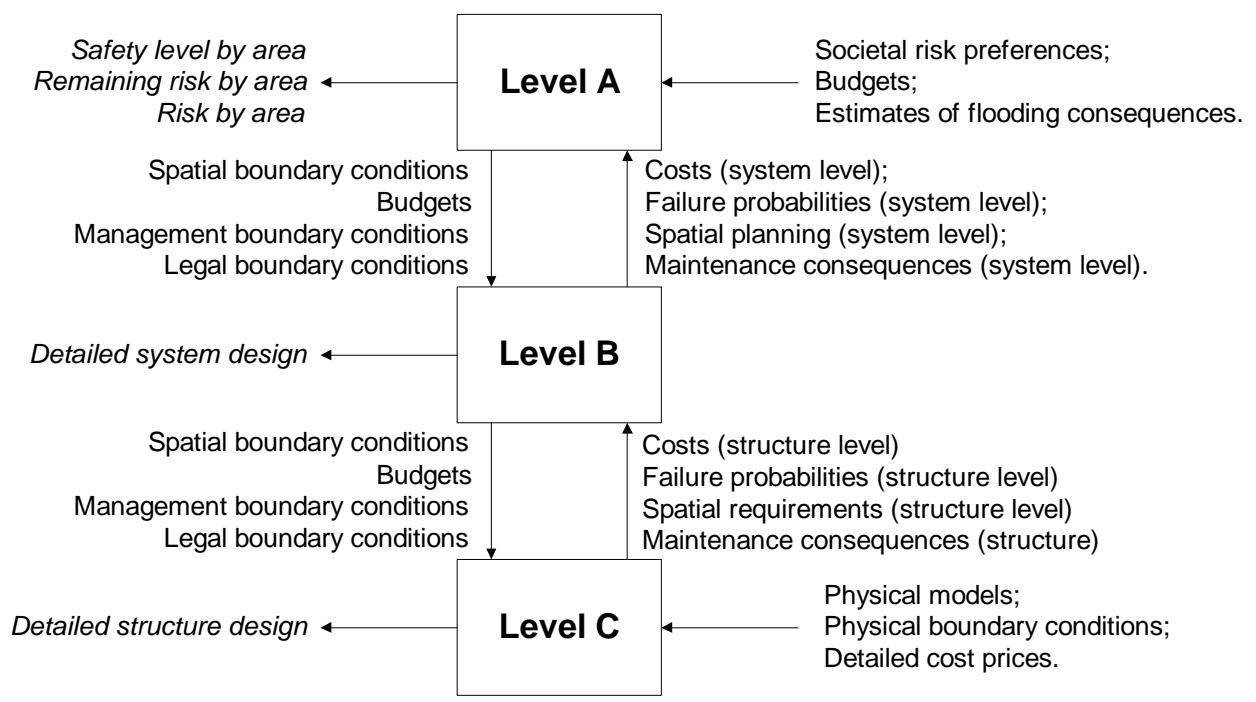

Figure 10: Overview of the three level decision model

Figure 10 shows that the three decision levels are dependent. Information feeds from one level to the other. Generally, the lower levels feed the higher levels with aggregated technical information, whereas the higher levels feed the lower levels with design requirements and societal needs.

The structure of the decision-making process is obviously idealised. As indicated before, there is currently a discrepancy between the safety levels in the Dutch Flood Defence Act and the type of safety levels generally used in engineering practice. A decision on acceptable safety levels in an appropriate form on level A is urgently needed to resolve this undesirable situation.

\subsection{Goals of this study}

The goal of this study is to develop quantitative risk-based design methods for largescale flood defence systems. To achieve this goal, several sub-goals are distinguished.

On level A, the costs of protection are weighted against the consequences of flooding in the widest sense. Coupled to decision level A is the first goal of this study:

1. Identification and analysis of a number of alternative methods for quantitative decision-making on flood protection.

The outline of the risk-based method in the previous section showed that decisionmaking on level A necessitates the quantification of costs of protection and consequences of flooding. This leads to the next two goals of this study:

2. Development of a method for quantifying the cost of protection for a large-scale system of flood defences;

3. Development of methods for the quantification of the consequences of flooding.

To enable quantitative decision-making, costs and consequences of flooding need to be expressed as functions of the performance of the protection system. In this study, the flooding probability is chosen as a measure of the performance on system level. Quantification of the flooding probability will be performed by well-known methods for reliability analysis. The minimum costs as a function of the protection level will be established by combining reliability-based methods with cost minimisation. The method is developed for application both at level B and C. 
The reliability-based design of a single flood defence structure (level C) is possible only if an appropriate description of the hydraulic boundary conditions is established. This leads to the fourth goal of this thesis:

4. Development of a stochastic model for the description of hydraulic boundary conditions for the design of flood defence structures in coastal areas.

The four goals of the thesis all cover different elements of risk-based decisionmaking, ranging from the models to establish the weighting between different aspects of a decision on flood protection to a detailed analysis of hydraulic conditions in the coastal zone. To risk-based decision-making, all elements are of equal importance. As stated before, the appropriate level of protection against flooding is a function of the natural environment and the properties of society. This study aims to integrate all aspects in one framework for decision-making.

\subsection{Fundamentals of this study}

The methods developed in this study are based on a few important fundamentals, that will be introduced in this section. The first important basic principle is the choice of the failure probability as a measure of performance of a flood defence structure or system of structures. The failure probability on system level can be viewed as an advanced definition of the flood count (figure 2). The probability concept is necessary simply because flooding is so infrequent that counting of flooding events is (luckily) no longer available as a basis for decision-making. Because it is hard to communicate the concept of the failure probability to non-specialists, it is sometimes argued that for this reason probability measures should not be used at all. Such an argument forgets an important group involved in the process of decision-making; the specialists themselves. In today's society, a limited group of experts has to take responsibility for the design, construction and maintenance of flood protection systems. This group needs objective criteria for the performance of the systems so that, if necessary, a specialist can show that his work complies with existing knowledge and regulation. The failure probability concept is suitable for the definition of performance levels. Alternatives that are developed to the same level of sophistication appear not to be available to date.

The second fundamental of this study is the choice of the Bayesian interpretation of the failure probability. The interpretation of the failure probability is the subject of some debate (see Savage, 1972 for background information). Basically, there are two important interpretations of probability. The first is the frequentistic interpretation, which defines the failure probability as the relative frequency of failure. Estimation of the probability of failure in a strict frequentistic sense is possible only if a large number of identical structures is observed for a number of years. The number of failures divided by the total number of structures then provides an estimate of the failure probability. It may be clear that such an approach is impossible in Civil Engineering.

The second interpretation is the Bayesian viewpoint, which defines the failure probability as a degree of belief in failure of the structure. The Bayesian viewpoint enables the quantification of a failure probability without the necessity of performing the experiment outlined in the previous paragraph. In a Bayesian approach, all relevant information that enables the quantification of degrees of belief is used. Finally, all degrees of belief are transferred to one number indicating the degree of belief in failure of the structure, the failure probability. A very simple example is the 
design of a flood defence structure on the basis of the water level in front of the structure. Performing the frequentistic experiment is impossible, since building a large set of identical structures is impossible and not cost effective. Instead, observations of the water level can be performed. The (frequentistic) observation data can be used to establish a probability distribution of the water level. In this way, the degree of belief in the possible water levels is obtained on the basis of frequentistic information. The second element in the Bayesian approach is then a physical model describing the behaviour of the structure for different water levels. Combination of the probability distribution of the water level with the model then leads to an estimate of the likelihood of failure of the structure. In this study, the Bayesian interpretation will be used. Frequentistic information (data) will be used as much as possible to establish the elements of the reliability analysis.

The third fundamental of this study is that the failure probabilities are calculated including all relevant uncertainties. Very often, a distinction is made in different types of uncertainty (van Gelder, 1999):

- Inherent uncertainty;

- (Physical) model uncertainty;

- Statistical uncertainty.

Inherent uncertainty is generally introduced as being a property of nature. Even with unlimited information it will still be impossible to predict the maximum water level occurring next year. Models describing physical processes are generally imperfect, resulting in a spread around the model when a comparison is made with field data. Finally, statistical uncertainty stems from the fact that extreme conditions have to be estimated from data records that are in principle too small to do so.

It is sometimes argued that in a probabilistic analysis only inherent uncertainty should be taken into account. Part of the arguments used to support this thesis is that physical models may be expected to improve with time and that thus also the failure probabilities will be reduced with time. Furthermore, the reduction of statistical uncertainty is a simple matter of waiting as observation records get longer every day. In this study, the opposite position is taken: all uncertainties should be included in the estimate of the failure probability. The reasons for this are illustrated by a simple thought experiment.

Consider a rectangular basin over which winds blow in one direction only. The wind causes an increase of the water level on the downwind side of the basin. Observations are performed of both water level and wind speed. In this situation, there are two possibilities to obtain the distribution of the water level:

- By direct statistical analysis of the observed water levels;

- By combining the probability distribution of wind speed with a relevant physical model.

Obviously, within the range of the observations the two estimates of the water level distributions should be equal. Realising that physical models are often imperfect, in the second option an estimate of the model uncertainty is necessary. If this uncertainty is neglected, the water level distribution will not match the water level distribution obtained from statistical analysis. This experiment thus illustrates two things:

- The distinction in different types of uncertainty is not a property of nature but of the analyst. In the example, part of the inherent uncertainty in the first option pops up as model uncertainty in the second option; 
- Consistency between the two types of analysis can only be achieved if "inherent" and "model" uncertainties are both included.

A similar argument is valid for statistical uncertainty. Neglecting this uncertainty suggests a level of information on extreme conditions that is in fact unachievable. One (future) extreme observation may thus force a review of the statistical analysis, which would lead to inconsistencies between analyses made at different points in time. Including statistical uncertainty in the decision-making process is the only rational way of dealing with the fact that our information and level of knowledge is limited.

\subsection{Outline of the thesis}

Risk-based design of flood defence systems is a wide subject. The four main parts of the material contained in this thesis are:

- Methods for quantitative decision-making on flood protection;

- Reliability-based design of flood defence structures;

- Estimation of the consequences of flooding;

- Quantification of the joint probability distribution of hydraulic conditions.

The thesis is divided in nine chapters. Figure 11 shows graphically the relations between the chapters. 

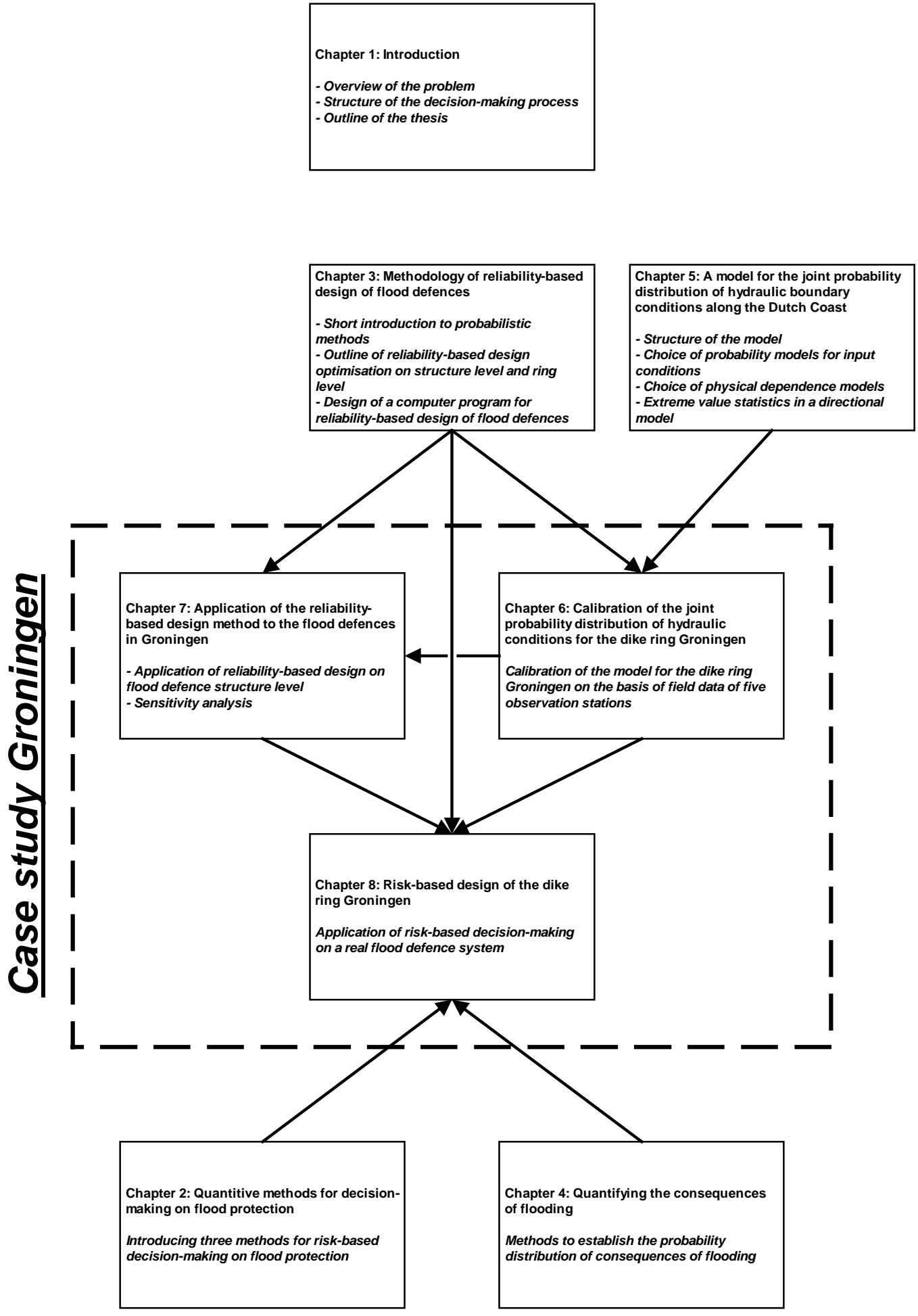

Figure 11: Graphical overview of the thesis 
The work contained in this thesis is aimed at the application of risk-based decisionmaking to large-scale flood defence systems. The theoretical background is provided in chapters 2, 3, 4 and 5. Chapters 6, 7 and 8 deal with the application of the theory to a case study, the dike ring Groningen. Finally, chapter 9 contains the conclusions and recommendations that result from this study.

Chapter 2 introduces three risk-based methods with which risk-based decision-making may be performed. The application of risk-based methods requires the quantification of:

- Cost of protection;

- Probability distribution of flooding consequences.

Chapter 3 deals with the concept of reliability-based optimisation of flood defence structures and flood defence systems. The methods outlined in chapter 3 can be applied to quantify the cost of protection as a function of failure probability, both on structure level and on system level.

Chapter 4 introduces methods to quantify the probability distribution of flooding consequences. The first part of chapter 4 introduces a conceptual model to quantify the damage factor distribution for a flood-prone area. The second part of chapter 4 deals with the quantification of two specific aspects of flooding consequences; economic consequences and loss of life.

The application of reliability-based methods necessitates the quantification of the joint probability distribution of load and strength variables. Especially in shallow seas, water levels and wave conditions are strongly influenced by the wind field and therefore a strong dependence between water level and wave conditions is observed. In chapter 5, a model for the joint probability distribution of the hydraulic conditions along the Dutch Coast is developed on the basis of a combination of statistical and physical models. In chapter 6 , the model is calibrated for the dike ring Groningen.

The theory of reliability-based design in chapter 3 and the description of hydraulic conditions in chapters 5 and 6 are combined in chapter 7. Two specific locations of the dike ring Groningen are designed using the reliability-based optimisation method with the joint probability distribution of hydraulic conditions forming an important part of the input. A sensitivity analysis is performed, indicating the importance of a variety of inputs to the optimal design of a dike structure on the two selected locations.

Risk-based design of the dike ring Groningen is performed in chapter 8. The input for the process is obtained by application of the methods of chapters 3 and 4 and using the description of hydraulic boundary conditions of chapters 5 and 6 . Thus, the expected value of the consequences of flooding (flooding risk) and the cost of protection are both quantified as a function of the probability of flooding of the area. The three models for defining the acceptable flooding probability introduced in chapter 2 are applied to the dike ring Groningen in chapter 8. A sensitivity analysis for the optimal design is performed. 



\section{QUANTITATIVE METHODS FOR DECISION-MAKING ON FLOOD PROTECTION}

"To boldly optimise what no one has optimised before"

After Star Trek, G. Roddenberry

\subsection{Outline of decision-making on flood protection}

A society in an area that is threatened by floods needs to take decisions concerning its level of protection regularly (chapter 1). Such a decision involves evaluating the sacrifices made for (extra) protection against the risk reduction in the area. Quantitative methods for decision-making on flood protection may facilitate the decision-making process. This chapter deals with such methods. In the three level structure of decision-making, the methods in this chapter fall in level A.

A quantitative method for decision-making on flood protection consists of two distinct elements:

- A function providing a measure for the usefulness of protection as a function of the level of protection;

- An acceptance rule indicating the acceptability of a given value of the aforementioned function.

A function for the usefulness of protection can only be established if the costs of protection, the consequences of flooding and the level of protection can be quantified. The level of protection may be expressed in a number of ways, but from a technical point of view the failure probability of the protection system seems to be the best candidate.

Inspection of the possible consequences of flooding shows that there are a number of consequences of flooding that are not easily quantified. Examples are the ecological and sociological effects of flooding. Therefore, quantitative methods in principle can not deal with the full complexity of the decision problem. Quantitative methods prove useful nonetheless, because they may be applied to structure and summarise a major part of the information available for decision-making. In that way, the decisionmaking process is facilitated. Recognising that a quantitative method does not cover all aspects of the decision on flood protection, in this study the methods will be used to indicate ranges of acceptable protection levels.

The earliest application of a quantitative method for decision-making on flood protection is the application of cost-benefit analysis by van Dantzig (1956). In costbenefit analysis, a decision is deemed acceptable if the benefits exceed the cost of protection. Costs and benefits are expressed completely in monetary terms. In his analysis, van Dantzig used the exceedance probability of the design water level as a measure of the performance of the protection system. The usefulness of a given protection level is given by the sum of the direct cost of protection and the expected value of the losses due to flooding (risk).

Methods for the calculation of the reliability of structures have seen a considerable development over the last decades (see chapter 3 for more details). It is now technically possible to quantify the probability of failure of a system of flood defence structures, leading to the probability of flooding of the protected area (TAW, 2000). The concept of van Dantzig's cost-benefit analysis of flood protection is still valid 
today but it seems appropriate to use the flooding probability as a measure of the performance of the protection instead of the exceedance probability of the design water level.

Cost-benefit analysis in principle is limited to quantifiable aspects of the decision and necessitates that all consequences of flooding are measured in monetary terms. There are several dimensions of flooding risk that can in principle be quantified, but not necessarily in monetary terms. An important aspect that falls in this group is the risk of loss of life due to flooding. Furthermore, it is observed that disastrous events become less acceptable to the general public if the magnitude of the consequences is larger. This behaviour is referred to as risk aversion.

One way to deal with monetary and non-monetary aspects of flood protection is to define constraints on the solution space, which limits the range of acceptable flooding probabilities to values that are deemed acceptable in the light of the non-monetary consequences of flooding. Observed risk aversion may be included in the definition of the constraint (Vrijling et al., 1995, 1998b).

A second way to deal with monetary and non-monetary aspects in one model is by defining a measure of utility that can be calculated as a function of the actual consequences of the decision. Thus, all aspects of the decision are measured in one variable and quantitative modelling is possible. A utility function can be defined in such a way that risk aversion is included. The aforementioned cost-benefit method is a special case of utility analysis.

Utility models form a mathematically consistent basis for decision-making on flood protection. To be useful for decision-making purposes the utility model should be defined in such a way that the model reflects the preferences of society. It is this requirement that forms a serious obstruction in the application of utility models for decision-making on flood protection. The Life Quality Method, proposed by Nathwani et al (1997) appears closely related to utility methods. Decisions concerning risk are judged using a social indicator called the life quality index, which combines the effects of the decision on the life expectancy at birth and the gross domestic product per capita. From a practical point of view, this is a convenient method since the properties of the life quality model may be established from observed values of the properties of society. A disadvantage of this approach is that the validity of the model is very hard to verify.

In this chapter, the three types of methods will be introduced, starting with costbenefit analysis in section 2.2. Both unconstrained and constrained cost-benefit analysis are shown. An example of decision-making on flood protection is included. The example is based on the work of van Dantzig (1956).

Secondly, utility modelling is introduced in section 2.3. In an example, utility modelling is used to show the effect of risk-aversion in the cost-benefit analysis of flood protection.

Thirdly, the life quality method is used for decision-making on flood protection. In an example, the cost-benefit model forms the basis to quantify the effects of flood protection on the gross domestic product. The life expectancy as a function of flooding probability is found from an analysis of Dutch death statistics.

The discussion of the methods assumes that the cost of protection and the expected benefits and losses are known as a function of the flooding probability. In practice, quantifying the cost of protection as a function of the flooding probability is a 
problem in itself. Chapter 3 deals with the quantification of the cost of protection in detail by introducing the concept of reliability-based optimisation of flood defence systems.

Quantifying the benefits and losses in a flood-prone area is also a problem that needs more consideration than is given in this chapter. Chapter 4 is concerned with the quantification of the consequences of flooding.

\subsection{Cost-benefit analysis}

\subsubsection{A cost-benefit model for flood protection}

Consider an area that is potentially threatened by floods. Such an area is in principle always found in one of the following two states:

- The area is not recently flooded. The area is economically active, capital has been invested and there are economic benefits generated;

- The area is flooded. Losses have occurred as a consequence of the flood and the generation of economic benefits is interrupted.

Capital investments will be made in the area, which increases the value of the area. In case of flooding, a part of the investments will be lost. If flooding occurs later, the damage will be larger. Assuming the growth rate of investments to be equal to the economic growth rate, the maximum flooding damage as a function of time is given by:

$$
d(t)=d_{0}\left(1+r_{e}+i\right)^{t}
$$

Where:

$d_{0}$ : $\quad$ Maximum potential damage at $t=0$;

$r_{e}: \quad$ Economic growth rate;

$i$ Inflation;

$t: \quad$ Time.

In the following, the loss of capital investment will be denoted "direct economic damage". Note that the damage is measured in monetary units of time $t$.

In the undisturbed condition, the area will generate economic benefits. As a consequence of economic growth and inflation, the yearly benefits increase over time:

$$
b(t)=b_{0}\left(1+r_{e}+i\right)^{t}
$$

Where $b_{0}$ denotes the yearly benefits at $t=0$. Like the direct economic damage, the benefits are measured in monetary units at time $t$.

Due to flooding, the generation of benefits is interrupted. In the following, loss of benefits with respect to the undisturbed condition will be denoted "indirect economic damage".

The yearly probability of flooding of the area is given by the flooding probability $P_{\text {flood }}$. The direct economic damage is a fraction $c_{d}$ of the maximum direct economic damage. Indirect economic damage is in part caused by direct economic damage and in part by macro-economic effects. The part caused by the direct economic damage is assumed to be described by the aforementioned factor $c_{d}$. The macro-economic effects are assumed to be direct proportional to the direct damage in the area itself and are quantified by the factor $c_{b}$. Therefore, the total indirect economic damage as a 
function of the reference level of benefits is given by the multiplication of $c_{b}$ and $c_{d}$. More details on the estimation of economic damage are given in chapter 4 .

Each of the two states of nature results in a pay-off. Table 2 gives an overview.

Table 2: Pay-off, probability and expected pay-off for two states of a flood-prone area in year $t$

\begin{tabular}{llll}
\hline State of nature & Pay-off & Probability & Expected pay-off \\
\hline No flooding & $b(t)$ & $1-P_{\text {flood }}$ & $\left(1-P_{f l o o d}\right) \cdot b(t)$ \\
Flooding & $\left(1-c_{d} \cdot c_{b}\right) \mathrm{b}(\mathrm{t})-c_{d} d(t)$ & $P_{\text {flood }}$ & $P_{f l o o d}\left(\left(1-c_{d} \cdot c_{b}\right) \mathrm{b}(\mathrm{t})-c_{d} d(t)\right)$ \\
\hline
\end{tabular}

From table 2, the expected value of the yearly pay-off is easily found:

$$
b_{\text {exp }}(t)=b(t)-P_{\text {flood }}\left(c_{d} c_{b} b(t)+c_{d} d(t)\right)
$$

The construction of a flood protection system directly influences the value of the flooding probability $P_{\text {flood }}$. Inspection of equation (3) shows that a decrease of $P_{\text {flood }}$ increases the expected value of the sum of benefits and damage. On the other hand, a protection system may be expected to be more costly if the flooding probability is lower. The cost of the protection system is given as a function of the flooding probability by a function $I\left(P_{\text {flood }}\right)$.

Once installed, a protection system is effective for a number of years. The period for which the protection system is thought to be effective is denoted the reference period. The reference period $T$ is chosen in the design stage of the protection system. In a cost-benefit framework, a decision on the protection level is supported by comparison of the sum of the capitalised yearly expected pay-off (equation (4)) to the investment in the protection system; in formula:

$$
B_{\text {ref }}\left(P_{\text {flood }}, T\right)=-I\left(P_{\text {flood }}\right)+\sum_{t=0}^{T} \frac{b(t)}{(1+r)^{t}}-\sum_{t=0}^{T} \frac{P_{\text {flood }}\left(c_{d} c_{b} b(t)+c_{d} d(t)\right)}{(1+r)^{t}}
$$

Where $r$ denotes the market interest rate, which includes inflation.

Equation (4) assumes the flooding probability to be constant in time. A more general measure of the yearly probability of flooding is the hazard rate $h$, which is a function of time and the flooding probability in the design stage. The cost-benefit model is in that case given by:

$$
B_{\text {ref }}\left(P_{\text {flood;des }}, T\right)=-I\left(P_{\text {flood;des }}\right)+\sum_{t=0}^{T} \frac{b(t)}{(1+r)^{t}}-\sum_{t=0}^{T} \frac{h\left(t, P_{\text {flood;des }}\right)\left(c_{d} c_{b} b(t)+c_{d} d(t)\right)}{(1+r)^{t}}
$$

Where $P_{\text {flood;des }}$ denotes the design flooding probability.

One cause of the hazard rate to change in time is time-dependent behaviour of the flood defence system itself or the materials it is made of. A second cause is a change of climate over time which causes the loads on the structure to change. In the remainder of this study, a constant flooding probability over time will be used.

\subsubsection{Supporting decision-making on flood protection using the cost-benefit model}

The cost-benefit model derived in the previous section contains three distinct elements:

- Cost of protection;

- Lifetime benefits; 
- Economic risk, consisting of the sum of the expected values of direct and indirect economic damage.

Figure 12 visualises the three elements of the cost-benefit model.

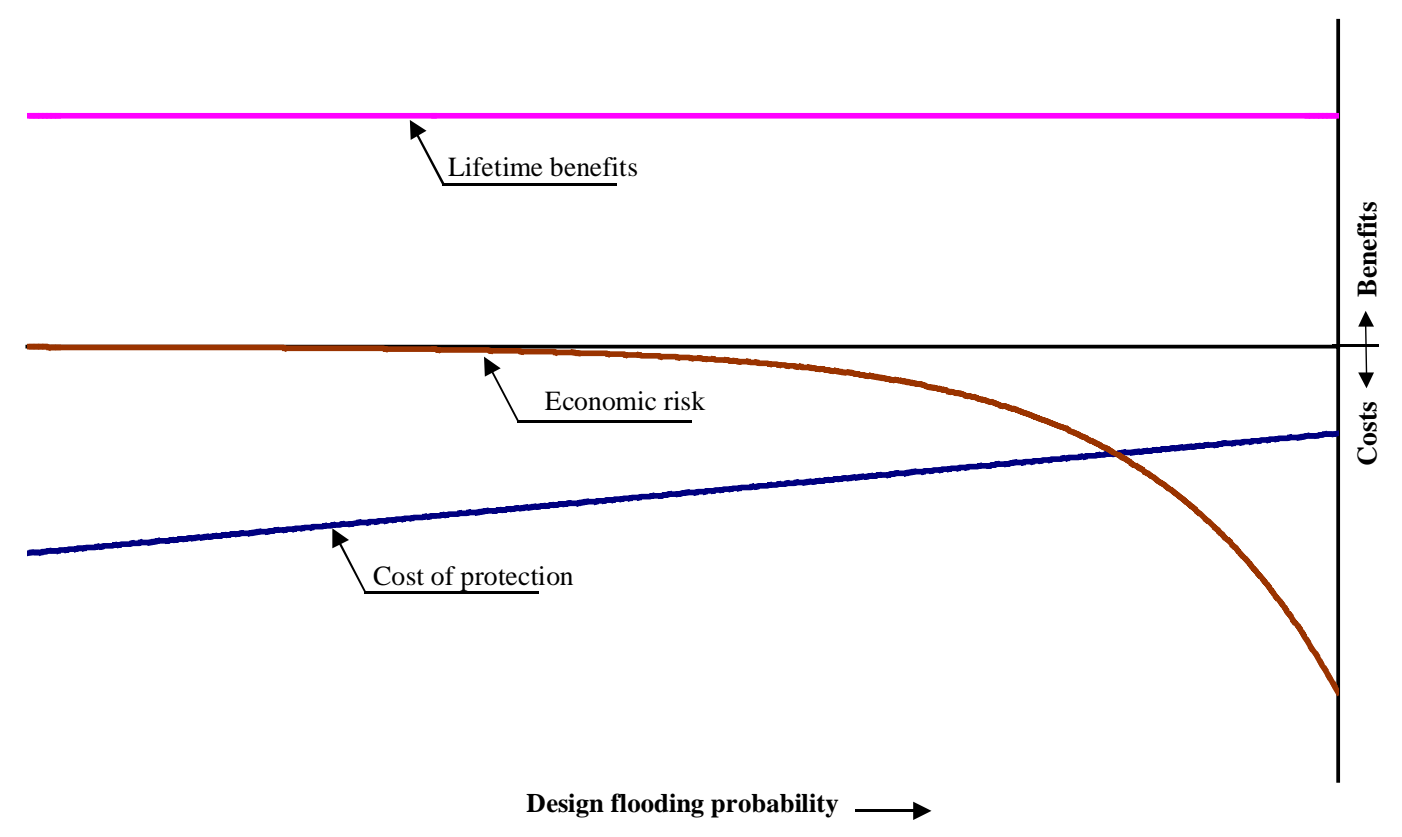

Figure 12: Elements of the cost-benefit model for flood protection ${ }^{l}$

To support decision-making on flood protection, the cost-benefit model alone is insufficient. Rules need to be established that indicate whether a given value of the flooding probability is acceptable in view of the resulting value of the cost-benefit model and/or constraints on the flooding probability itself. Such a rule is in this study denoted an "acceptance rule". In principle, there are two ways by which an acceptance rule may limit the acceptable value of the flooding probability:

- By limiting the flooding probability directly to a maximum value;

- By requiring a predefined level of costs, benefits or the sum of both.

The simplest acceptance rule is found if a constraint is given for the flooding probability and minimisation of the direct cost of protection is required. This option will be denoted acceptance rule 1 (figure 13).

\footnotetext{
${ }^{1}$ Costs are indicated as negative values and benefits as positive values. Van Dantzig (1956) considered costs only and defined costs as positive. As a consequence of the difference in definition, figure 12 shows van Dantzig's model upside down.
} 


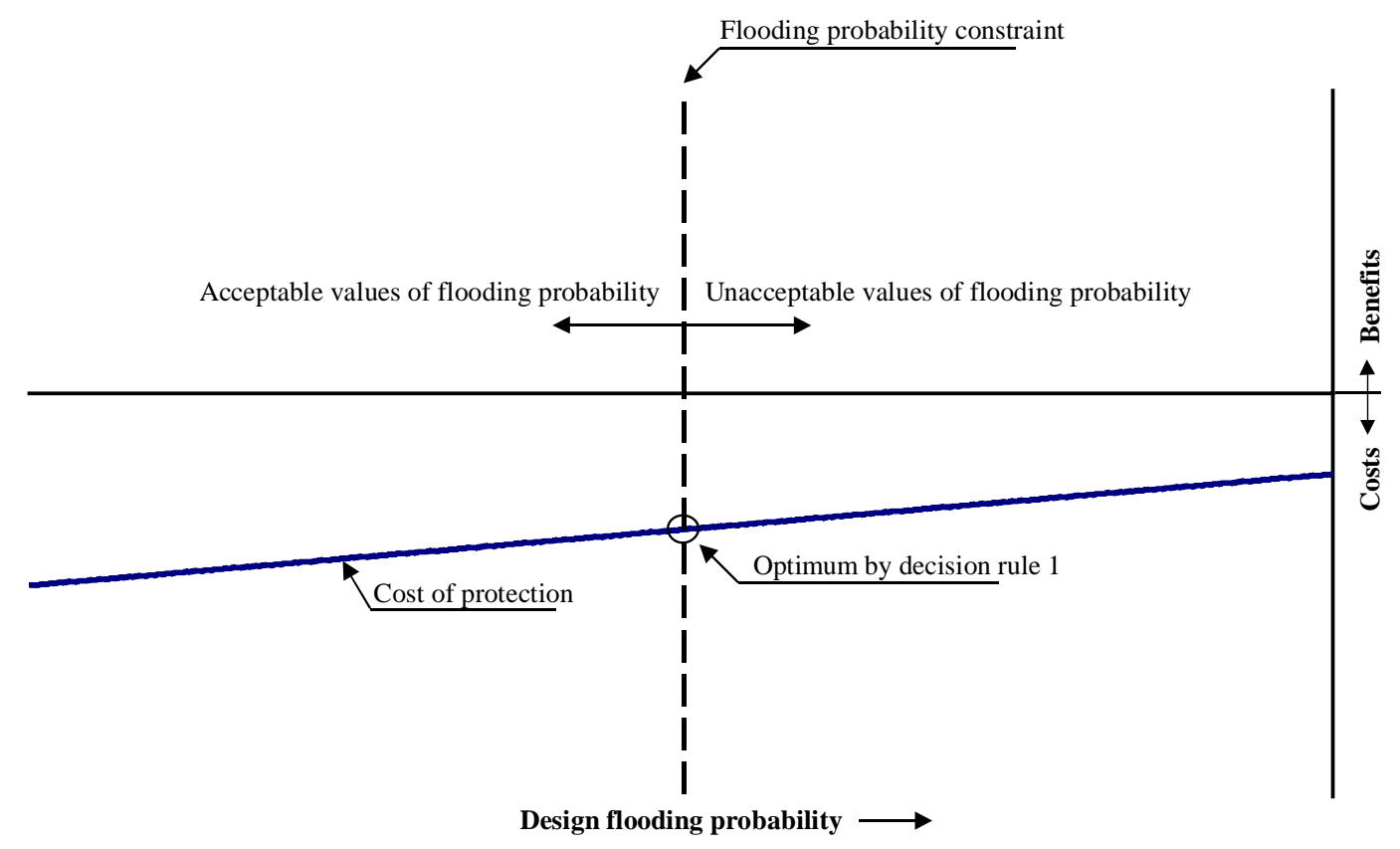

Figure 13: Acceptance rule 1, combination of direct cost of protection and a probability constraint

Application of acceptance rule 1 does not provide information on the appropriate safety level from an economic point of view because the increase of benefits or the decrease of economic risk is not considered. The design flooding probability will always equal the constraint, since the direct costs of protection increase with decreasing flooding probability.

Adding the direct cost of protection and the economic risk excluding indirect economic damage leads to the definition of the lifetime costs:

$$
C_{\text {ref }}\left(P_{\text {flood }}, T\right)=-I\left(P_{\text {flood }}\right)-\sum_{t=0}^{T} \frac{P_{\text {flood }} c_{d} d(t)}{(1+r)^{t}}
$$

Equation (6) can be derived from the general cost-benefit model by neglecting the lifetime benefits and the indirect damage in case of flooding. The model can be applied for decision-support by requiring minimisation of the absolute value of the lifetime costs. This will be denoted acceptance rule 2. This type of acceptance rule has been used in a number of applications, among which van Dantzig (1956), ) Vrijling et al (1998a) and Voortman et al (1998, 1999a, 1999b). 


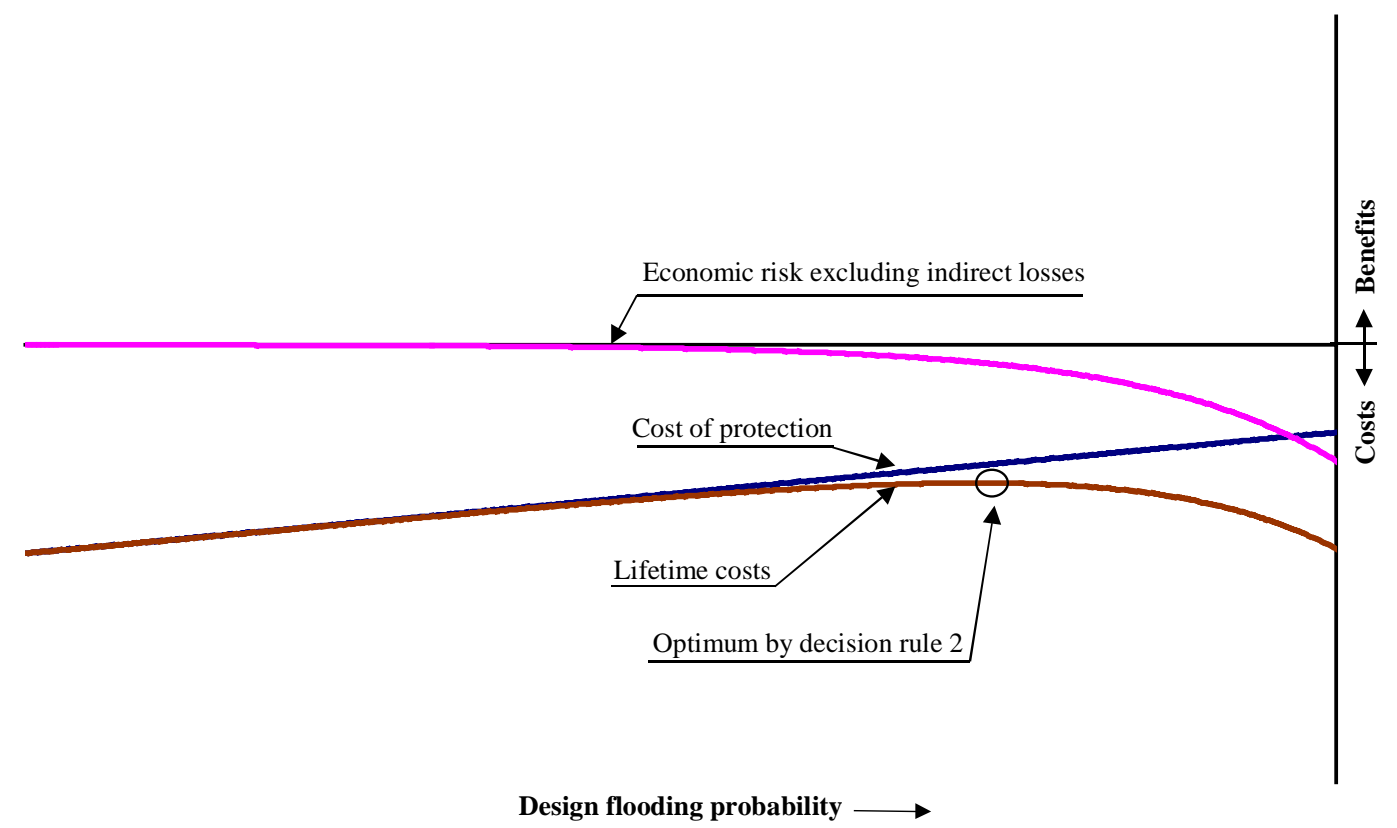

Figure 14: Acceptance rule 2: minimisation of lifetime costs without probability constraint

The requirement of minimisation of the lifetime costs may be combined with a direct limitation of the solution space in the form of a constraint on the flooding probability $P_{\text {flood }}$. In that case, the minimum of the constraint and the optimal flooding probability provides the design flooding probability.

If the full cost-benefit model is used, a number of acceptance rules can be derived. In acceptance rule 3 , the sum of costs and benefits over the reference period are required to be non-negative. If the maximum of the model is larger than zero, acceptance rule 3 leads to an interval of acceptable flooding probabilities (figure 15).

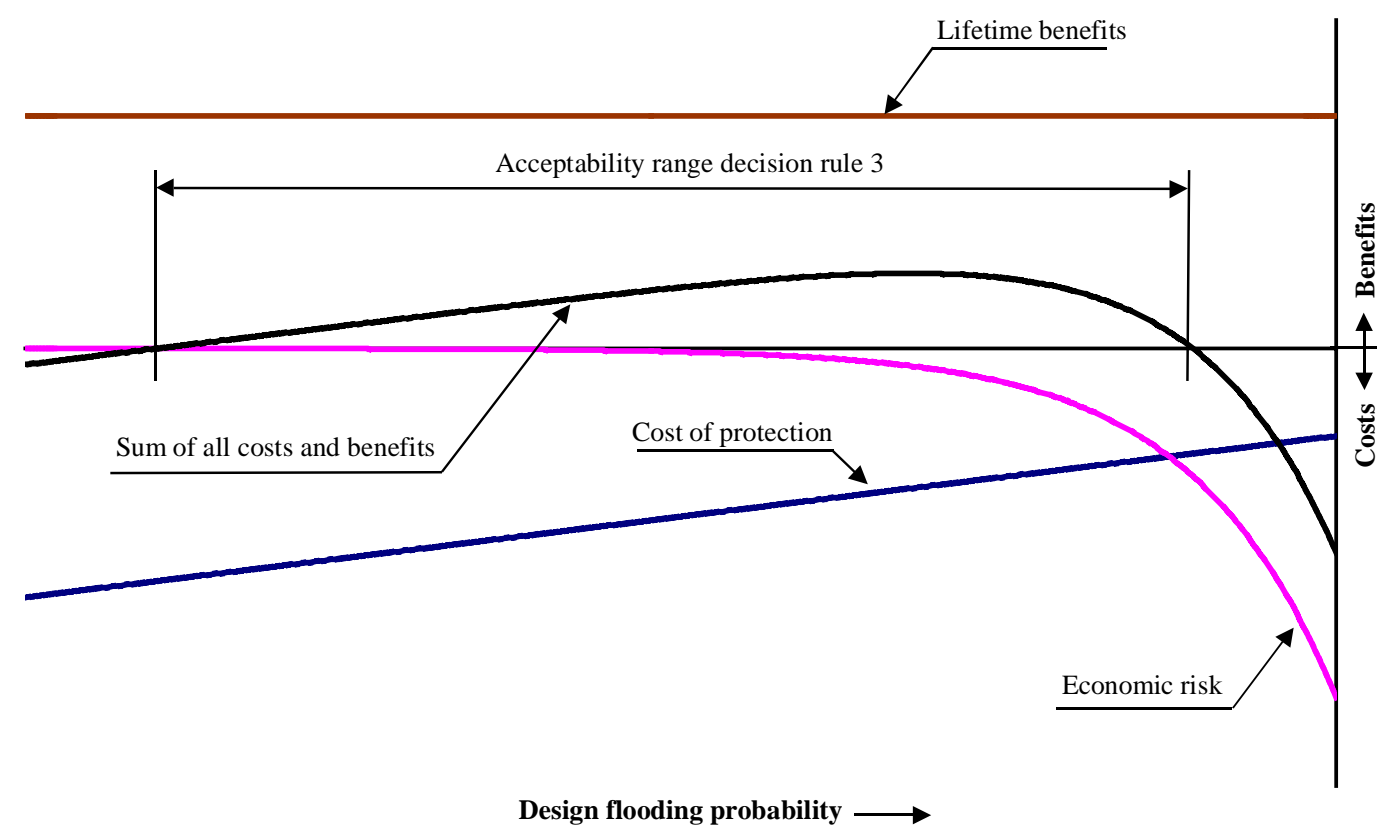

Figure 15: Acceptance rule 3, requiring non-negative sum of costs and benefits

In general, a flood-prone area already has a level of protection and is economically active. In that case, it appears rational to require the sum of costs and benefits to be 
larger than or equal to the sum of costs and benefits in the existing situation. This leads to acceptance rule 4 that can be written as:

$$
B_{\text {ref }}\left(P_{\text {flood }}, T\right) \geq \sum_{t=0}^{T} \frac{b(t)}{(1+r)^{t}}-\sum_{t=0}^{T} \frac{P_{\text {flood } ; 0}\left(c_{d} c_{b} b(t)+c_{d} d(t)\right)}{(1+r)^{t}}
$$

Where $P_{\text {flood; } 0}$ denotes the existing flooding probability of the area.

Figure 16 visualises the result of acceptance rule 4 . If the maximum of the costbenefit model is above the existing cost-benefit level, the result of acceptance rule 4 is an interval of acceptable flooding probabilities. The existing cost-benefit level is a function of the existing flooding probability $P_{\text {flood; } 0}$ and is therefore a constant if plotted against the design flooding probability $P_{\text {flood }}$.

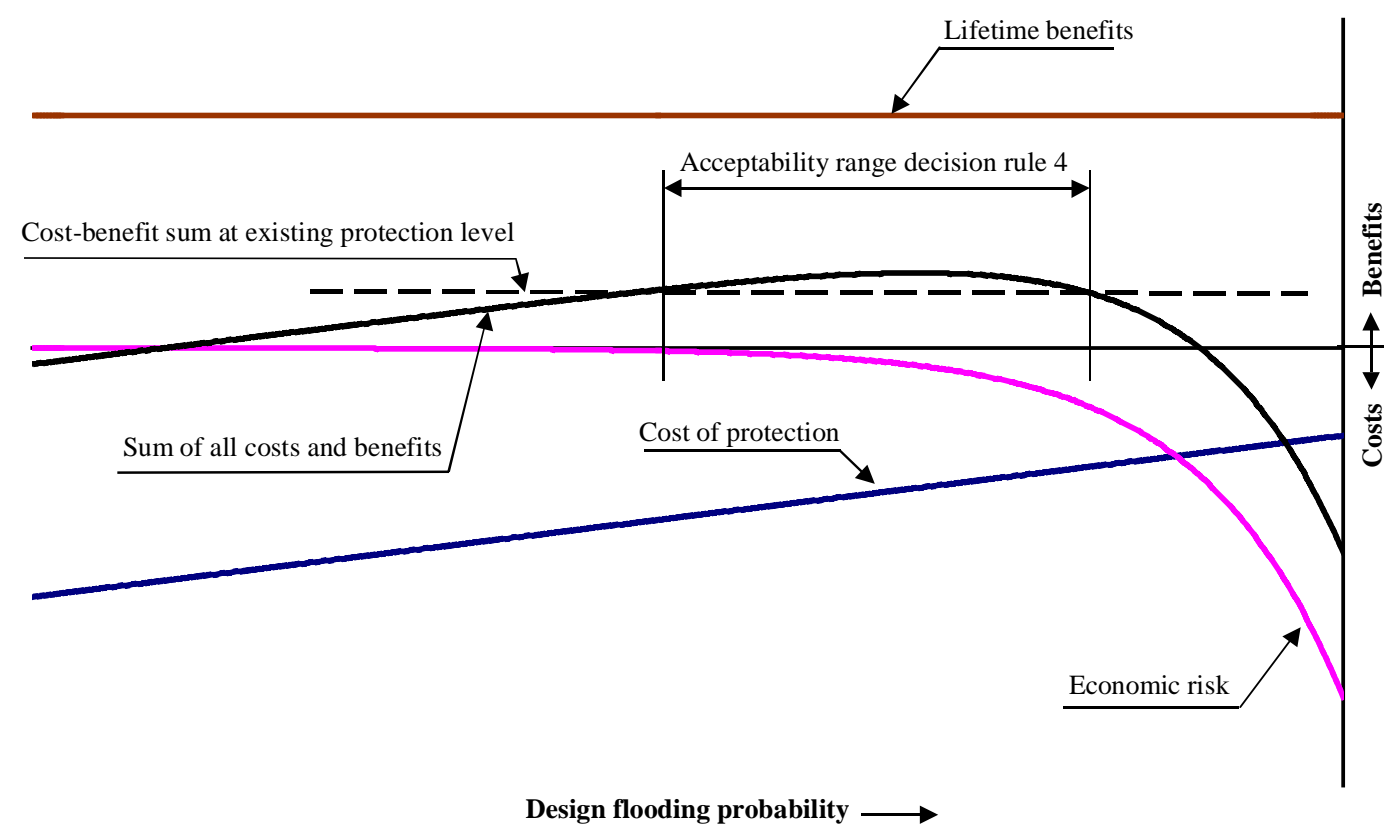

Figure 16: Acceptance rule 4, requiring an increase of the sum of costs and benefits in comparison to existing level

If the existing cost-benefit level is positive, the range of acceptable flooding probabilities resulting from acceptance rule 4 is a sub-set of the range obtained by rule 3 .

Instead of requiring a minimum level of the sum of costs and benefits, the cost-benefit model may also be applied to find the design flooding probability that maximises the sum of costs and benefits over the reference period. Figure 17 shows and example of this approach that will be denoted acceptance rule 5 . 


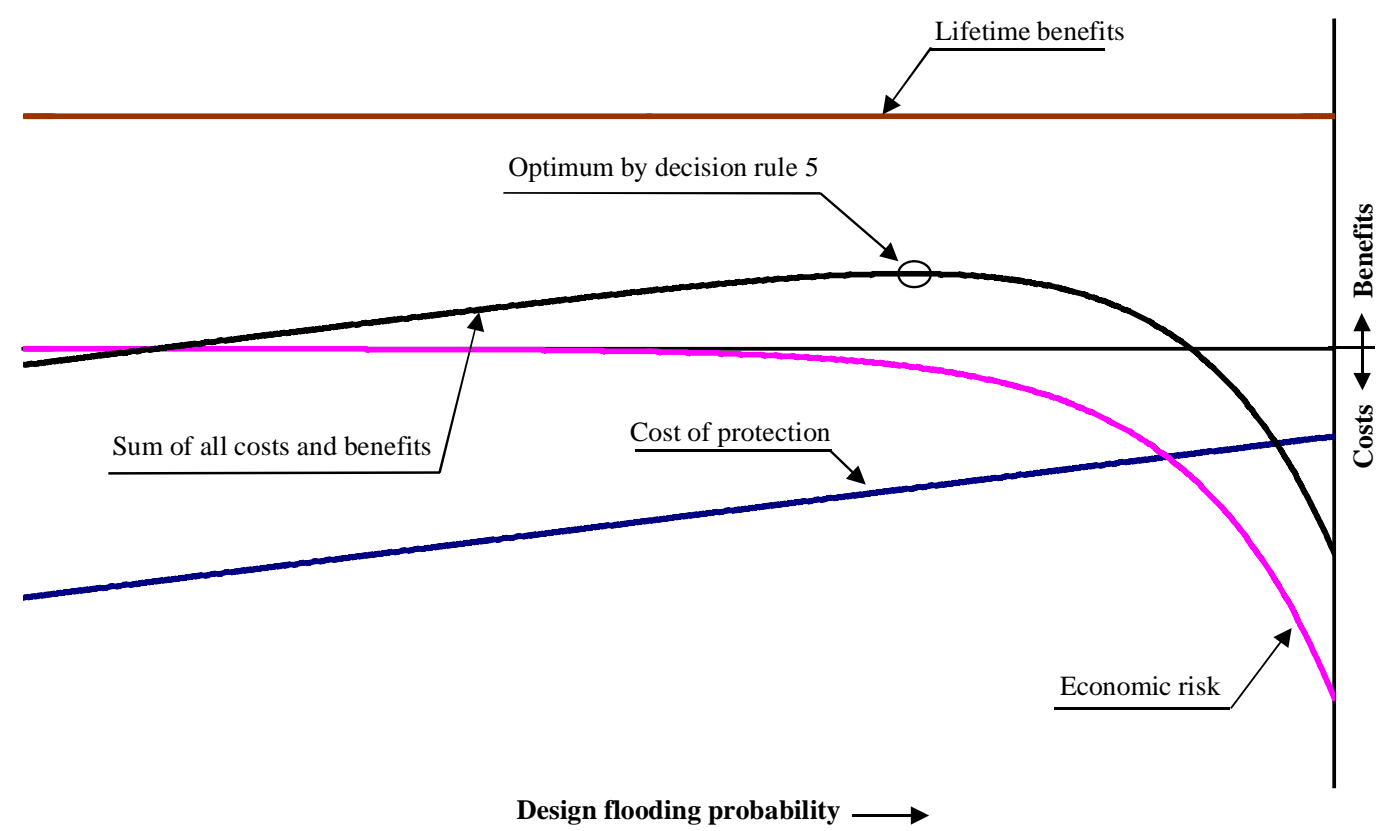

Figure 17: Acceptance rule 5, maximising the sum of costs and benefits

If the cost-benefit model has a positive maximum higher than the existing cost-benefit level of the area, the optimal flooding probability obtained by acceptance rule 5 lies within the acceptability ranges indicated by acceptance rules 3 and 4 .

Table 3 summarises the five acceptance rules developed in this section.

Table 3: Summary of five cost-benefit based acceptance rules

\begin{tabular}{|c|c|c|}
\hline Nr. & Acceptance rule & Properties \\
\hline 1 & $\begin{array}{l}\min _{P_{\text {flood }}} I\left(P_{\text {flood }}\right) \\
\text { s.t. } P_{\text {flood }} \leq P_{\text {flood;max }}\end{array}$ & $\begin{array}{l}\text { Investment minimisation. Non-trivial } \\
\text { solution only if } P_{\text {flood;max }}<1\end{array}$ \\
\hline 2 & $\begin{array}{l}\min _{P_{\text {flood }}} I\left(P_{\text {flood }}\right)+\sum_{t=0}^{T} \frac{P_{\text {flood }} c_{d} d(t)}{(1+r)^{t}} \\
\text { s.t. } P_{\text {flood }} \leq P_{\text {flood; } \text { max }}\end{array}$ & $\begin{array}{l}\text { All benefits excluded. Lifetime cost } \\
\text { minimisation. }\end{array}$ \\
\hline 3 & $\begin{array}{l}B_{\text {ref }}\left(P_{\text {flood }}, T\right) \geq 0 \\
\text { s.t. } P_{\text {flood }} \leq P_{\text {flood } ; \max }\end{array}$ & $\begin{array}{l}\text { Full model used. Results in a range of } \\
\text { acceptable safety levels. }\end{array}$ \\
\hline 4 & $\begin{array}{l}B_{\text {ref }}\left(P_{\text {flood }}, T\right) \geq \sum_{t=0}^{T} \frac{b(t)}{(1+r)^{t}}-\sum_{t=0}^{T} \frac{P_{\text {flood } ; 0}\left(c_{d} c_{b} b(t)+c_{d} d(t)\right)}{(1+r)^{t}} \\
\text { s.t. } P_{\text {flood }} \leq P_{\text {flood; } \text { max }}\end{array}$ & $\begin{array}{l}\text { Full model used. Safety level range is a } \\
\text { subset of acceptance rule } 3 \text { if cost-benefit } \\
\text { maximum is positive. }\end{array}$ \\
\hline 5 & $\begin{array}{l}\max _{P_{\text {flood }}} B_{\text {ref }}\left(P_{\text {flood }}\right) \\
\text { s.t. } P_{\text {flood }} \leq P_{\text {flood } ; \max }\end{array}$ & $\begin{array}{l}\text { Safety level optimisation by lifetime } \\
\text { benefit maximisation. Full model used. }\end{array}$ \\
\hline
\end{tabular}

All acceptance rules include a constraint on the flooding probability. Unconstrained decision-making is obtained in all cases if $P_{\text {flood;max }}=1$. 


\subsubsection{Example of cost-benefit analysis of flood protection}

The following example illustrates the application of risk-based cost-benefit analysis in decision-making on flood protection. The example is based on the work of van Dantzig (1956), but the analysis has been posed in the three-level decision structure introduced in chapter 1 . A decision has to be made on the acceptable design flooding probability $P_{\text {flood }}$ of a flood-prone area. The input for this example is shown in table 3.

Table 4: Parameter values after van Dantzig (1956)

\begin{tabular}{lll}
\hline Parameter & Description & Value \\
\hline$\alpha$ & Shift parameter water level distribution & $1.96 \mathrm{~m}$ \\
$\beta$ & Scale parameter water level distribution & $0.33 \mathrm{~m}$ \\
$I_{0}$ & Initial cost of dike heightening & $110 \mathrm{MEuro}$ \\
$I^{\prime}$ & Cost increment of dike heightening & $40.1 \mathrm{MEuro} / \mathrm{m}$ \\
$b_{0}$ & Yearly turn-over in case of undisturbed situation & $6800 \mathrm{MEuro} / \mathrm{year}$ \\
$d_{0}$ & Direct damage in case of flooding & $24200 \mathrm{MEuro} / \mathrm{event}$ \\
$c_{d}$ & Damage factor direct damage & 1 \\
$c_{b}$ & Damage factor indirect damage & 1 \\
$r_{i n t}$ & Interest rate & $5.5 \%$ \\
$i$ & Inflation & $2 \%$ \\
$r_{e}$ & Rate of economic growth & $2 \%$ \\
$T$ & Reference period & 100 years \\
$P_{\text {flood } ; 0}$ & Existing flooding probability & $10^{-4} /$ year \\
\hline
\end{tabular}

In chapter 1, a multi-level structure for decision-making is introduced. The three decision levels are:

- Level A: decision-making on the flooding probability of the area as a function of the cost of protection and the consequences of flooding;

- Level B: decision-making on the failure probability for individual structures in the defence system (dike ring) for given flooding probability;

- Level C: decision-making on the failure probability per failure mode within a structure for given failure probability of the structure.

The ultimate goal of the analysis is a decision on the flooding probability of the area on level A. Such a decision cannot be made without decisions on levels B and C. Therefore, the analysis starts with analysing the costs of protection of an individual structure on level $\mathrm{C}$, leading to an estimate of the cost of protection per structure as a function of the failure probability per structure. Using the result of level $\mathrm{C}$, a similar analysis can be performed on level B leading to the cost of protection as a function of the flooding probability of the area. Finally, the result of the analysis on level B is used on level A to decide on the acceptable flooding probability by the cost-benefit model. Apart from the use of the three level model of the decision-making process and the choice of the reference period, the case study is equivalent to the analysis by van Dantzig (1956).

On the lowest decision level (level C), the costs of a flood defence component are derived as a function of the design failure probability of the component. In the analysis by van Dantzig, failure of a structure is defined as the situation where the actual water level exceeds the design water level. The limit state function ${ }^{2}$ for this failure mode is given by:

\footnotetext{
${ }^{2}$ The concept of the limit state function is explained in chapter 3.
} 
$g_{v \text { Dantzig }}\left(h_{\text {des }}, h_{w}\right)=h_{\text {des }}-h_{w}$

Where:

$h_{\text {des }}: \quad$ Prescribed design water level;

$h_{w}$ : Actual water level.

Failure of the structure is indicated by negative values of the limit state function:

$g_{\text {vantzig }}\left(h_{\text {des }}, h_{w}\right) \leq 0 \Leftrightarrow h_{\text {des }} \leq h_{w}$

The probability distribution of water levels is described by an exponential distribution:

$$
F_{\underline{h_{w}}}(\eta)=1-e^{-\frac{\eta-\alpha}{\beta}}
$$

In this case there is only one failure mode, one design variable $\left(h_{\text {des }}\right)$ and one random load variable $\left(h_{w}\right)$. Therefore, the probability of failure as a function of the design variable can be derived analytically by substitution of (9) in (10):

$P_{f}\left(h_{d e s}\right)=e^{-\frac{h_{d e s}-\alpha}{\beta}}$

Where $h_{\text {des }}$ denotes the design water level for the structure.

The investment in the component as a function of the design water level is given by a linear function:

$$
I\left(h_{d e s}\right)=I_{0}+I^{\prime} h_{\text {des }}
$$

Substitution of the inverse of equation (11) in the investment function finally leads to the cost of protection as a function of the existing flooding probability and the design flooding probability:

$$
I\left(P_{f}\right)=I_{0}+I^{\prime} \beta \ln \left(\frac{1}{P_{f}}\right)
$$

Equation (13) is the current case study the end result of the level $\mathrm{C}$ analysis. The investment in one dike section is a function of the required safety level, the distribution of the natural boundary conditions and the economic boundary conditions. This illustrates how equation (13) summarises a number of natural and economic boundary conditions in one function.

On level B, the costs of the system of flood defence components has to be written as a function of the total probability of failure of the system $\left(P_{\text {flood }}\right)$. Van Dantzig did not consider individual structures in the ring but analysed the ring as if it is one structure. This implies that $P_{\text {flood }}=P_{f}$, so that the result of the level B analysis is the same as the result of the level $\mathrm{C}$ analysis and is given by:

$$
I\left(P_{\text {flood }}\right)=I_{0}+I^{\prime} \beta \ln \left(\frac{1}{P_{\text {flood }}}\right)
$$

On level A, the costs of the protection system are compared to the lifetime benefits and lifetime economic risk by forming the cost-benefit model on system level. Using the cost-benefit model (equation (4)) and substituting the result of the level B analysis leads to : 


$$
B_{\text {ref }}\left(P_{\text {flood }}, T\right)=-I_{0}-I^{\prime} \beta \ln \left(\frac{1}{P_{\text {flood }}}\right)+\sum_{t=0}^{T} \frac{b(t)}{(1+r)^{t}}-\sum_{t=0}^{T} \frac{P_{\text {flood }}\left(c_{d} c_{b} b(t)+c_{d} d(t)\right)}{(1+r)^{t}}
$$

Where:

$b(t)$ : $\quad$ Yearly benefits as a function of time;

$d(t)$ : Maximum direct damage as a function of time;

$c_{d}$ : $\quad$ Damage factor direct damage;

$c_{b}$ : Damage factor indirect damage;

$r: \quad$ Interest rate;

$i: \quad$ Inflation;

$r_{e}: \quad$ Growth rate of the economy.

The five acceptance rules shown in table 2 will now be applied to this situation using the parameters shown in table 3. Since the investment in the protection system is a strictly decreasing function of the design flooding probability, acceptance rule 1 simply reproduces the investment function. This is caused by the fact that there is in this case only one design variable to be optimised. If the geometry of a flood defence structure is described by two or more design variables, acceptance rule 1 can be used to derive the cost of the structure as a function of its failure probability. Chapter 3 deals with this type of application of acceptance rule 1 .

Using acceptance rule 2, the benefits are excluded from the analysis. The outcome of the cost-benefit model is always negative. Figure 18 shows values of the cost-benefit model as a function of the flooding probability.

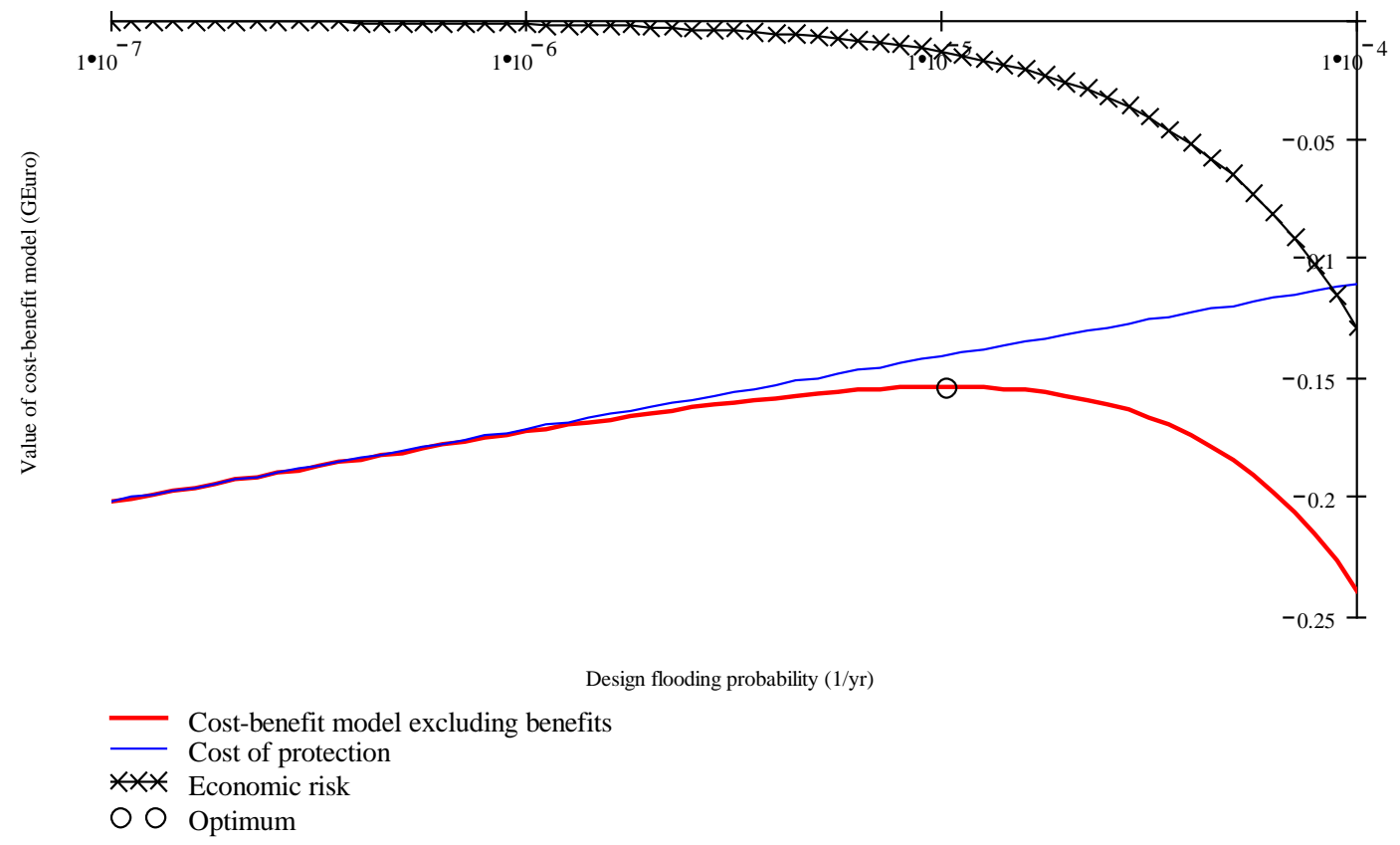

Figure 18: Optimisation of the flooding probability by lifetime cost minimisation (cost-benefit model combined with acceptance rule 2)

The optimum flooding probability according to acceptance rule 2 equals $1 \cdot 10^{-5}$ per year.

In acceptance rules 3, 4 and 5 the full cost-benefit model is used. Acceptance rule 3 requires the lifetime sum of costs and benefits to be non-negative. Figure 19 shows the value of the cost-benefit model for a wide range of flooding probabilities, 
indicating the result of acceptance rule 3. The cost of protection and the economic risk are not shown separately.

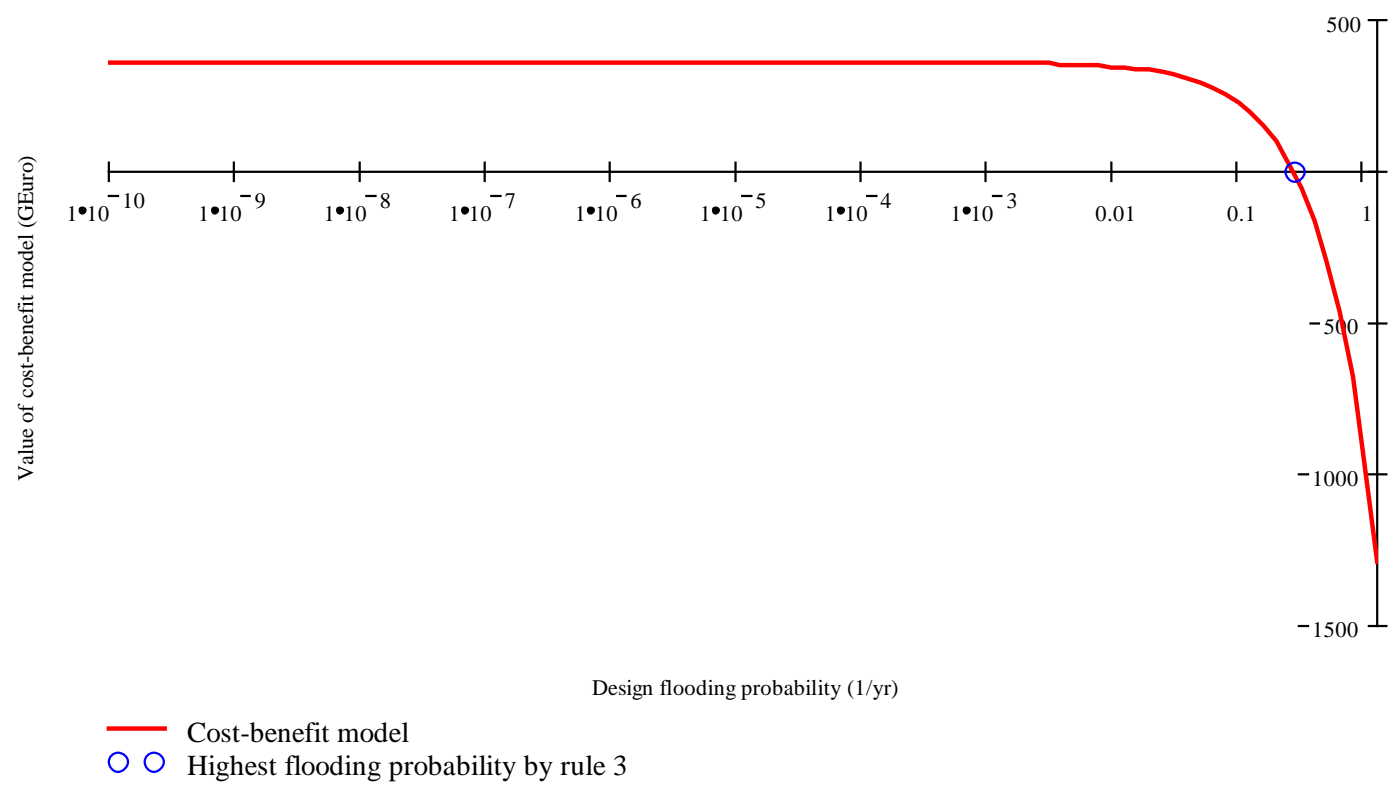

Figure 19: Analysis of acceptable flooding probability by requiring a non-negative value of the sum of costs and benefits (acceptance rule 3)

In principle, acceptance rule 3 provides two bounds on the flooding probability, namely the flooding probabilities corresponding to the two roots of the cost-benefit model. In this case study, the shape of the model is such that the lower value of the flooding probability takes an extremely low value. From a practical point of view, no lower bound on the flooding probability is provided by acceptance rule 3 in this case. The upper bound according to acceptance rule 3 is indicated in figure 19. The upper acceptable value of the flooding probability by rule 3 equals 0.22 per year.

Acceptance rule 4 requires the lifetime benefits to be higher than the lifetime benefits if no change is implemented. In this case study, an assumed value of the existing flooding probability $P_{\text {flood;0 }}$ is used (table 3 ).

Acceptance rule 5 defines the acceptable flooding probability as the value where the cost-benefit level is maximised. The results of acceptance rules 4 and 5 are shown together in figure 20. 


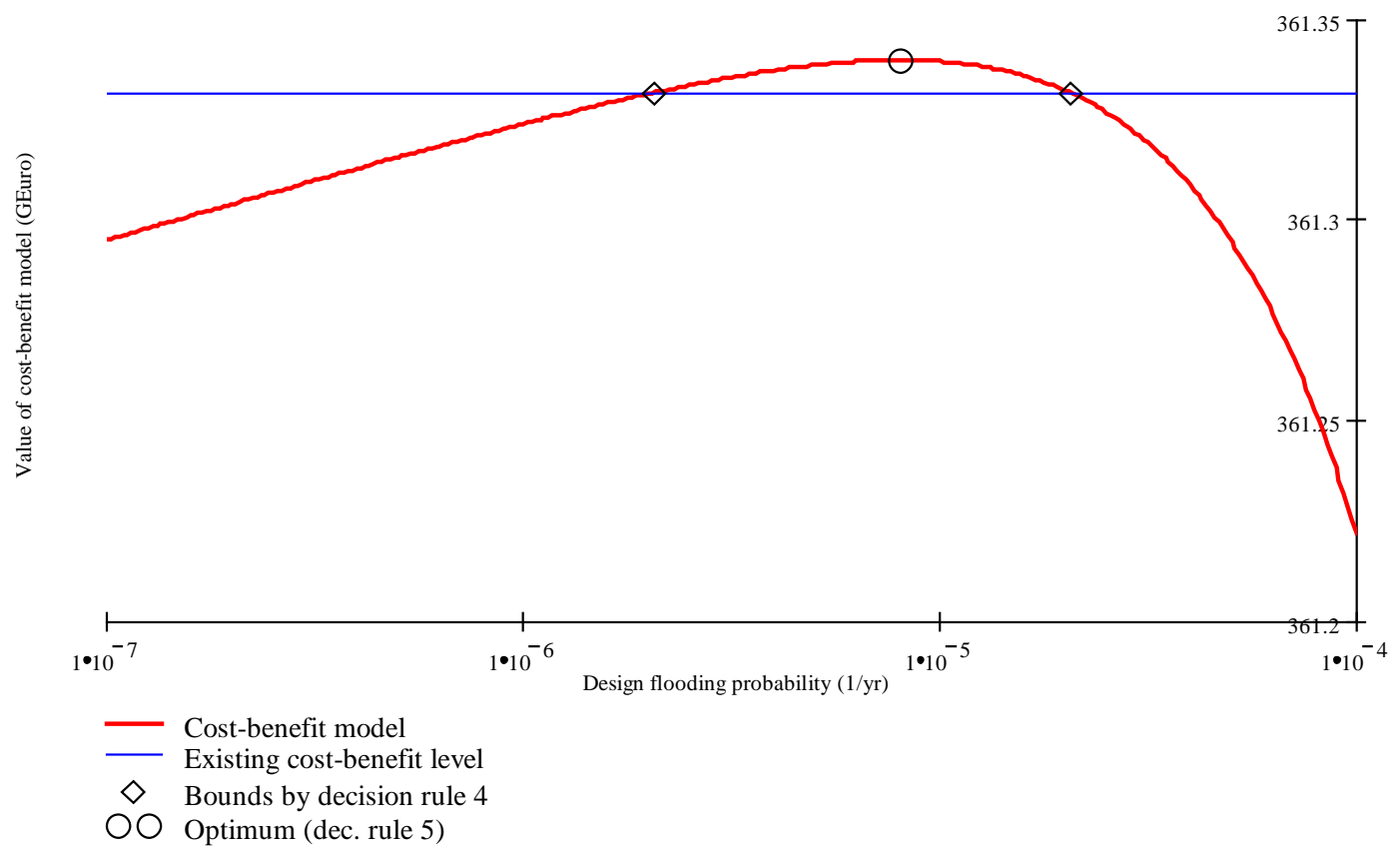

Figure 20: Analysis of acceptable flooding probability by comparison to the existing level of the sum of costs and benefits (acceptance rule 4) and by maximisation of the sum of costs and benefits (acceptance rule 5)

The lower bound on the design flooding probability by rule 4 equals $2.1 \cdot 10^{-6}$ per year. The upper bound by rule 4 is $2.1 \cdot 10^{-5}$ per year. The optimum flooding probability obtained by rule 5 equals $8.0 \cdot 10^{-6}$ per year.

The existing cost-benefit level is a function of the existing flooding probability only. When plotted as a function of the design flooding probability the existing cost-benefit level appears as a horizontal line. Because the maximum value of the cost benefit model is higher than the existing cost-benefit level, the optimal flooding probability according to rule 5 lies between the bounds indicated by rule 4. A summary of the safety levels resulting from acceptance rules 2 through 5 is given in table 5 .

Table 5: Overview of acceptable flooding probabilities resulting from cost-benefit analysis in a case study after van Dantzig (1956)

\begin{tabular}{lccc}
\hline Acceptance rule & \multicolumn{3}{c}{ Acceptable flooding probability (1/yr) } \\
\cline { 2 - 4 } & Minimum & Optimum & Maximum \\
\hline 1 & n.a. & n.a. & n.a. \\
2 & n.a. & $1.0 \cdot 10^{-5}$ & n.a. \\
3 & 0 & n.a. & 0.22 \\
4 & $2.1 \cdot 10^{-6}$ & n.a. & $2.1 \cdot 10^{-5}$ \\
5 & n.a. & $8.0 \cdot 10^{-6}$ & n.a. \\
\hline
\end{tabular}

\subsection{Utility analysis}

\subsubsection{Introduction to utility theory}

In the previous section, risk-based cost-benefit analysis is introduced as a basis for supporting decision-making on flood protection levels. A more general form of quantitative decision modelling is by utility analysis, of which cost-benefit analysis is a special case. An introduction to decision theory by utility modelling may be found in Keeney and Raiffa (1976), French (1988) or CUR (1997). 
There are two reasons why a more general utility model may be a better basis for decision-making than a cost-benefit model:

- Cost-benefit analysis necessitates quantification of all costs and consequences of the decision in monetary terms. This may not always be possible or appropriate;

- Cost-benefit analysis assumes that the attitude of the decision-maker towards the costs and consequences of the decision are independent of their actual values (risk-neutrality). This is not necessarily true.

Both cost-benefit analysis and utility analysis can in principle only deal with measurable costs and consequences of the decision. In utility analysis, non-monetary measurable consequences are expressed in a subjective measure of the usefulness of the decision (utility). The same is done for the monetary consequences so that ultimately all costs and consequences are measured in the same variable. Once the utility model is established, acceptance rules as introduced for the cost-benefit model can be applied to define the appropriate level of protection against flooding.

It is often observed that the attitude of the decision-maker towards the costs and consequences of the decision is not independent of the actual value of costs and consequences $^{3}$. In general, two types of behaviour can be observed:

- Risk-prone decision-making. Costs are valued lower than they actually are and benefits are valued higher than they actually are;

- Risk-averse decision-making. Costs are valued higher than they actually are and benefits are valued lower than they actually are.

The boundary between the two types of behaviour is risk-neutral decision-making. In risk-neutral decision-making the perceived value of costs and benefits are direct proportional to their actual values. Risk attitudes of the decision maker can be included in a utility model. The decisions of a risk-neutral decision-maker can be modelled by a function that expresses utility as a linear function of the costs and benefits of the decision. The decisions of a risk-averse decision-maker are modelled by a concave utility model and the decisions of a risk-prone decision-maker by a convex model. Figure 21 shows three examples.

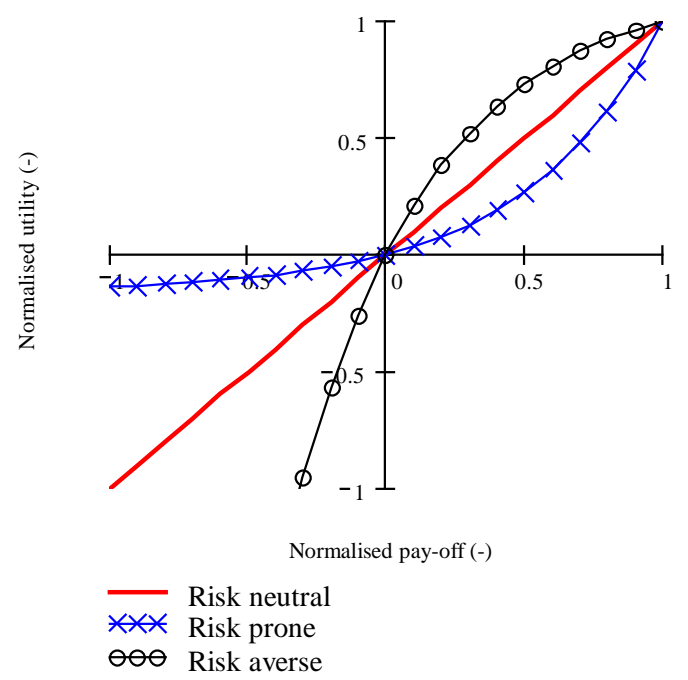

Figure 21: Examples of utility models for three decision-makers with different risk attitudes

\footnotetext{
${ }^{3}$ Note that costs and consequences in this case are not limited to monetary aspects but may represent any quantifiable effect of the decision.
} 
In a general decision problem, the decision-maker has several alternative courses of actions to choose from. The outcome of the decision depends on the action taken and on factors outside the control of the decision-maker, usually denoted "states of nature". A state of nature will generally not occur with certainty but will have a probability of occurrence. Therefore, the pay-off of a given course of action is uncertain. The distribution of the utility is a function of the distribution of the pay-off and the utility function. Figure 22 shows a fictitious example.

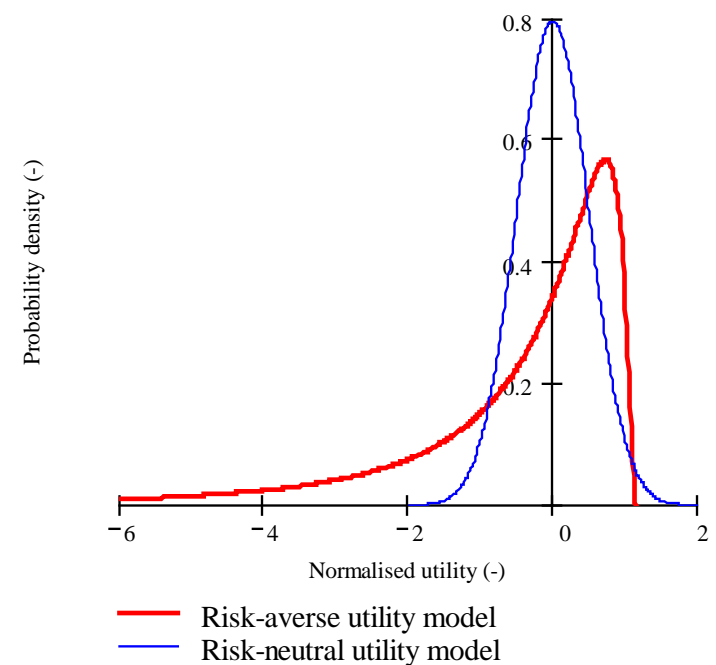

Figure 22: Two examples of the probability distribution of utility derived from the probability distribution of pay-off and a utility function

The probability distribution of normalised utility is equal to the distribution of normalised pay-off for a risk-neutral utility model. For a symmetric distribution of pay-off, a risk-averse utility model leads to a skewed distribution of utility. Decision theory assumes that a rational decision-maker will choose his actions such that the expected value of his utility is maximised. Inspection of figure 22 shows that due to the risk-averse utility model probability mass is shifted both to higher values and lower values of utility. The net effect is a shift to lower values of utility, reducing the expected value of utility. As a consequence, a risk-averse decision-maker will perceive lower utility if the uncertainty of the pay-off is larger. Figure 23 shows the effect assuming the pay-off to be described by a normal distribution with mean 0 .

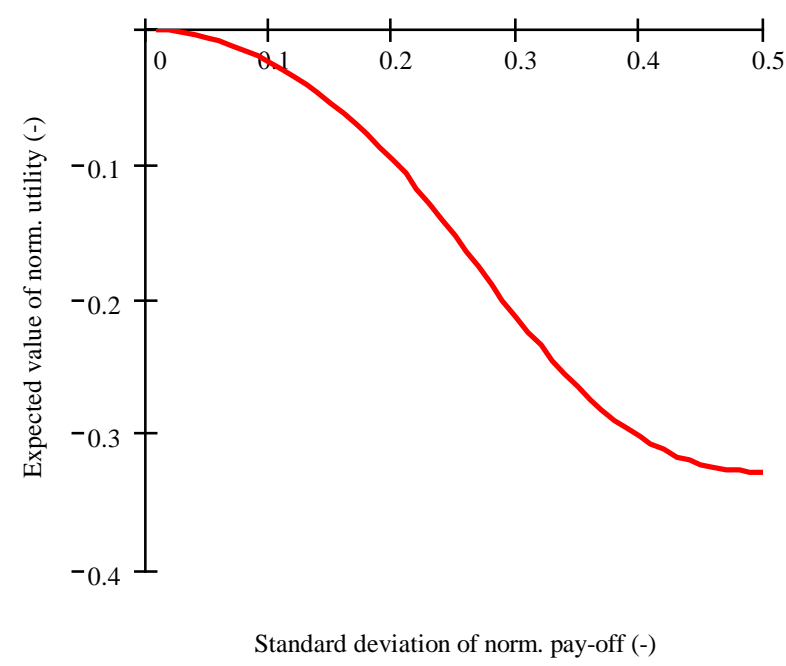

Figure 23: Example of expected utility as a function of standard deviation of pay-off for a utility function modelling a risk-averse decision-maker 
In decision-making on flood protection, the states of nature considered are:

- No flooding of the area;

- Flooding of the area.

A decision on the flood protection level directly influences the probabilities of occurrence of the states of nature and thus the distribution of pay-off. Utility modelling can be used to include risk aversion in the cost-benefit analysis of flood protection. Inspection of the cost-benefit model in the previous section indicates that there are three elements in the cost-benefit model:

- The cost of protection as a function of protection level;

- The economic risk over the reference period;

- The benefits over the reference period.

In the following, the cost of protection will be considered as certain. The uncertainty of the costs of flooding and the benefits over the reference period are a function of the flooding probability. Assuming a binomial distribution of the pay-off, the standard deviation is given by:

$$
\sigma_{B}=\sqrt{x^{2} P_{\text {flood }}\left(1-P_{\text {flood }}\right)}
$$

Where:

$P_{\text {flood: }} \quad$ Flooding probability;

$x: \quad$ Normalised pay-off.

Under the assumption of a binomial distribution of the pay-off of flood protection, the uncertainty is a function of the flooding probability $P_{\text {flood }}$ only. Figure 24 shows the uncertainty normalised for the summed economic damage.

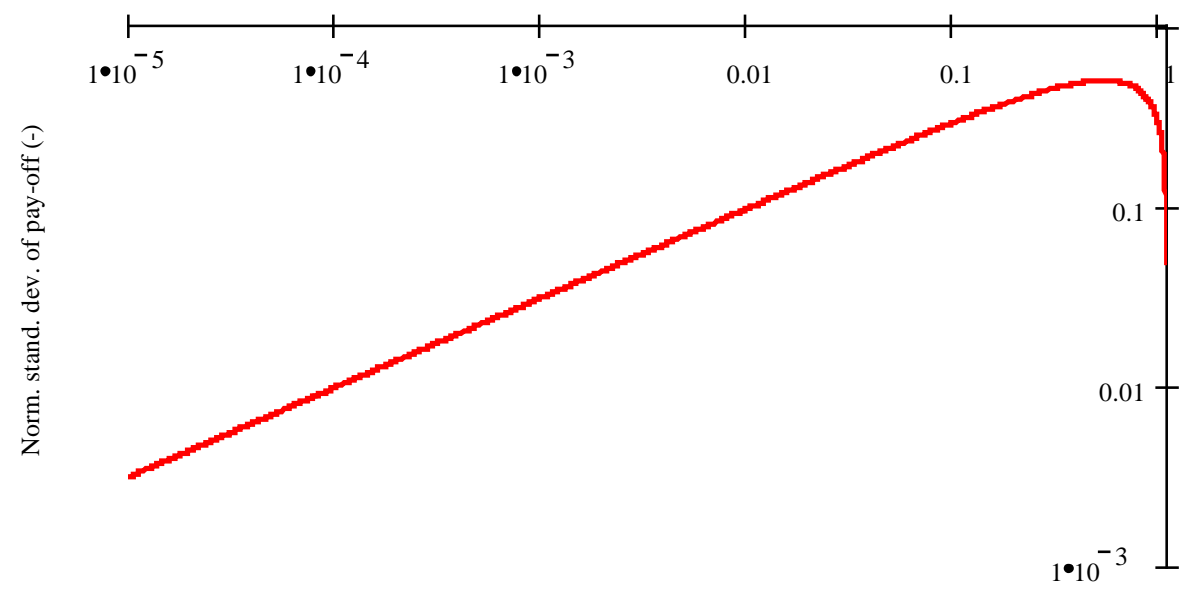

Flooding probability $(1 / \mathrm{yr})$

Figure 24: Normalised uncertainty of pay-off as a function of flooding probability

If the pay-off follows a binomial distribution, the uncertainty of the pay-off obtains a maximum at $P_{\text {flood }}=0.5$. To the right side of the maximum, the uncertainty decreases because flooding is more and more certain. At the same time, also the expected value of the pay-off decreases. It can be easily proven that for values of $P_{\text {flood }}$ lower than 0.5 a decrease of $P_{\text {flood }}$ consistently decreases the uncertainty on the pay-off. The expected value of the pay-off is also a decreasing function of the flooding probability. In comparison to a risk-neutral decision-maker, a risk-averse decision-maker attempts not only to increase the expected value of the pay-off, but also to reduce the uncertainty on the pay-off. A risk-averse decision-maker will therefore choose higher 
protection levels than a risk-neutral one. Effectively, the risk-averse decision-maker is exchanging an uncertain pay-off (cost in case of flooding, benefits) with a certain (negative) pay-off, the cost of protection.

\subsubsection{Example of utility analysis of flood protection}

The cost-benefit model used in section 2.2 is a risk-neutral model for quantitative decision-making on flood protection. Utility theory can be used to extend the model with a measure of risk aversion. To that end, a utility function of the exponential type is used (see Ang and Tang, 1990):

$$
u(x)=\left\{\begin{array}{c}
\frac{1-e^{-\gamma x}}{1-e^{-\gamma}}, \gamma \neq 0 \\
x, \gamma=0
\end{array}\right.
$$

Where:

$x$ : $\quad$ Normalised pay-off;

$\gamma$. Measure for risk aversion.

The utility model in equation (17) was applied to flood protection earlier by van Gelder (1999). The parameter $\gamma$ in the model is a measure for the risk aversion. Pratt (1964) defines the local risk aversion as (see French, 1988):

$$
r(x)=-\frac{\frac{\mathrm{d}^{2} u}{\mathrm{~d} x^{2}}}{\frac{\mathrm{d} u}{\mathrm{~d} x}}
$$

According to the definition of Pratt, a utility model indicates risk neutral behaviour if $r(x)=0$. Positive values of $r(x)$ indicate risk-averse behaviour and negative values riskprone behaviour. Substitution of the utility model of equation (17) in equation (18) leads to:

$$
r(x)=\gamma
$$

The result of the analysis of risk aversion indicates that the model indicates constant risk aversion over the full domain of $x$.

The exponential utility model can be combined with the cost-benefit model in the previous section to include risk aversion in the cost-benefit analysis. In every year, two states of nature should be distinguished (section 2.2). The pay-off corresponding to every state of nature is given in table 2 . For every pay-off, the corresponding utility can be calculated.

The expected utility within one year capitalised to $t=0$ is then given by:

$$
u_{\text {exp }}\left(P_{\text {flood }}, t\right)=\left(1-P_{\text {flood }}\right) u\left(\frac{b(t)}{v(1+r)^{t}}\right)+P_{\text {flood }} u\left(\frac{\left(1-c_{d} c_{b}\right) b(t)-c_{d} d(t)}{v(1+r)^{t}}\right)
$$

Where:

$P_{\text {flood: }} \quad$ Flooding probability;

$b(t): \quad$ Benefits as a function of time;

$d(t)$ : $\quad$ Maximum direct damage as a function of time;

$c_{d}$ : $\quad$ Damage factor direct damage; 
$\begin{array}{ll}c_{b}: & \text { Damage factor indirect damage; } \\ v & \text { Normalisation factor. }\end{array}$

The normalisation factor $v$ is chosen equal to the maximum benefits at $t=0$.

If an investment in the protection system is made, the direct cost of protection should be included in the utility model. Therefore, the expected utility for $t=0$ is given by:

$$
\begin{aligned}
u_{\text {exp } ; 0}\left(P_{\text {flood }}\right)=\left(1-P_{\text {flood }}\right) & u\left(\frac{-I\left(P_{\text {flood }}\right)+b_{0}}{v}\right)+\ldots \\
& \ldots+P_{\text {flood }} u\left(\frac{-I\left(P_{\text {flood }}\right)+\left(1-c_{d} c_{b}\right) b_{0}-c_{d} d_{0}}{v}\right)
\end{aligned}
$$

Where $I$ denotes the direct cost of protection.

The expected value of the utility over the reference period is now given by:

$U_{\text {ref }}\left(P_{\text {flood }}, T\right)=u_{\text {exp } ; 0}\left(P_{\text {flood }}\right)+\sum_{t=1}^{T} u_{\text {exp }}(t)$

According to the utility model, negative pay-off is weighted heavier than positive payoff. The formulation of the model is chosen such that the risk-neutral case $(\gamma=0)$ equals the cost-benefit model of section 2.2. Acceptance rules similar to the ones in table 3 can be used to derive acceptable flooding probabilities from the utility model. In this example, only acceptance rule 5 will be applied. Acceptance rule 5 requires the total expected utility over the reference period to be maximised. Figure 25 shows the utility as a function of the flooding probability for $\gamma=2$.

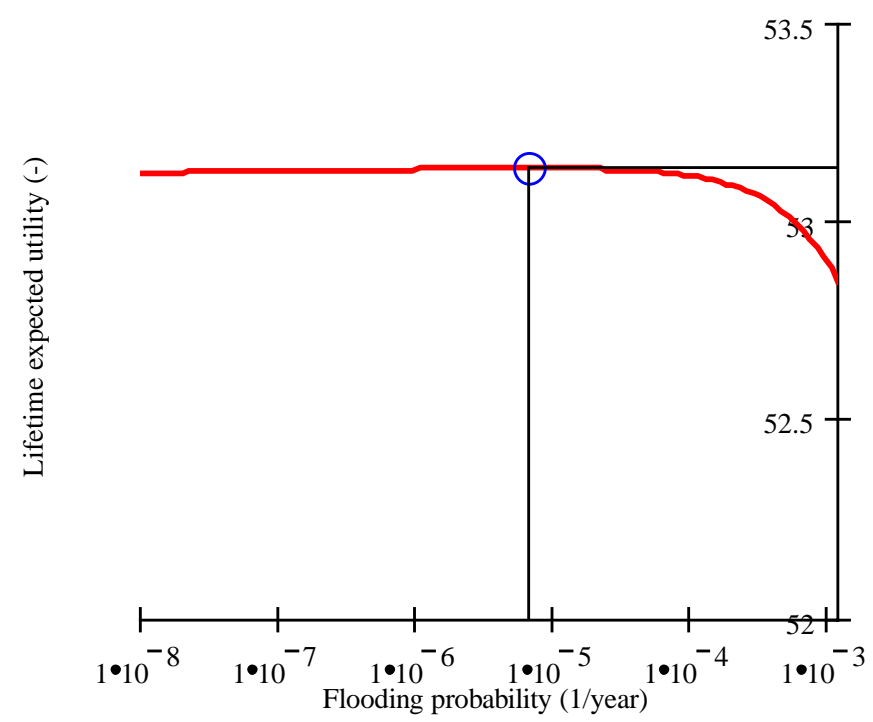

Figure 25: Total expected utility over the reference period as a function of flooding probability

In the previous section it is shown that risk averse decision-making demands a reduction of the uncertainty on the pay-off at the cost of a reduction of the expected value of the pay-off. This effect is illustrated in table 6 . The table summarises the results of optimisation of the flooding probability for three values of the risk aversion parameter $\gamma$. 
Table 6: Results of optimisation of the flooding probability using a utility model including risk aversion

\begin{tabular}{llllll}
\hline$\gamma(-)$ & $\begin{array}{l}\text { Flooding } \\
\text { probability } \\
(\mathbf{1} / \mathbf{y r})\end{array}$ & $\begin{array}{l}\text { Cost of } \\
\text { protection } \\
\text { (GEuro) }\end{array}$ & $\begin{array}{l}\text { Exp. lifetime } \\
\text { benefits } \\
\text { (GEuro) }\end{array}$ & $\begin{array}{l}\text { St. dev. of } \\
\text { lifetime benefits } \\
\text { (GEuro) }\end{array}$ & $\begin{array}{l}\text { Coeff. of var. of } \\
\text { lifetime benefits } \\
\text { (\%) }\end{array}$ \\
\hline 0 & $8.0 \cdot 10^{-6}$ & 0.143 & 361.29 & 0.50 & 0.14 \\
1 & $3.7 \cdot 10^{-7}$ & 0.184 & 361.26 & 0.11 & 0.03 \\
2 & $6.4 \cdot 10^{-9}$ & 0.238 & 361.21 & 0.014 & 0.004 \\
\hline
\end{tabular}

As risk aversion increases, the optimal flooding probability decreases and as a consequence of this the cost of protection increases. The increased cost of protection reduces the total expected lifetime benefits. The uncertainty on the summed lifetime benefits decreases.

\subsection{Life quality method}

\subsubsection{Introduction to the life quality method}

In the previous section, utility theory was introduced as a method to include riskaversion and/or multiple attributes in a quantitative decision supporting method. Though utility theory is appealing because it facilitates decision analysis in a mathematical way, it appears that the problem of dealing with societal attitudes towards multiple attribute risks is only shifted to the necessity of establishing an appropriate utility model for every aspect of the risk.

An approach that shows similarities to utility modelling is the life quality method, proposed by Nathwani et al (1997). In this approach, decision-making on safety levels is supported by analysing the effects of the decision on the life quality index (LQI), which is given by:

$l=g^{w} e^{1-w}$

Where:

g: $\quad$ Gross domestic product (GDP) per capita;

$e: \quad$ Life expectancy at birth;

w: $\quad$ Relative lifetime spent working.

Nathwani et al. apply as a starting point the hypothesis that every individual makes choices concerning the relative lifetime spent working to generate wealth and the relative lifetime spent for other activities. The individual choices of all economic actors are reflected in the gross domestic product per capita $g$, the life expectancy $e$ and the mean relative lifetime spent working $w$. For developed countries, $w$ generally is in the order of $1 / 8$. The formula for the life quality index shows similarities to a multiple attribute utility model, but since the input for the LQI consists of expected values, the flooding probability appears under the exponent. This also implies that the life quality model does not include effects of uncertainty on lifetime or gross domestic product.

The acceptance rules established in section 2.2 for the cost-benefit model can be applied to the life quality model as well. Nathwani et al define responsible decisions as decisions that do not decrease the existing value of the life quality index. That acceptance rule corresponds to acceptance rule 4 in this study. An application of the life quality approach to the design flooding probability of a land-reclamation project is described by Voortman et al (2001c). Other applications are due to Rackwitz (2001a, b and c). 


\subsubsection{Example of decision-making on flood protection using life quality modelling}

The life quality model can be combined with the cost-benefit model to derive a twoattribute model for decisions on flood protection. The expected gross domestic product per capita (GDP) over time is a function of the development of the economy and the development of the population. Excluding the cost of protection, the capitalised GDP per capita over time is given by:

$$
g\left(P_{\text {flood }}, t\right)=\frac{\left(b_{0}-P_{\text {flood }}\left(b_{0}+d_{0}\right)\right)\left(1+r_{e}+i\right)^{t}}{N_{p ; 0}\left(1+r_{p}\right)^{t}(1+r)^{t}}
$$

Where:

$b_{0}$ : $\quad$ Yearly benefits at $t=0$;

$d_{0}$ : $\quad$ Potential flooding damage at $t=0$

$r_{e}$ : $\quad$ Growth rate of economy;

$i$ : Inflation;

$r: \quad$ Interest rate;

$N_{p ; 0}: \quad$ Population at $t=0$;

$r_{p}: \quad$ Growth rate of population.

In some years, society decides to invest in flood protection which leads to a temporary set-back in the GDP. In such a year, the GDP per capita is approximately given by:

$g\left(P_{\text {flood }}, t\right)=\frac{\left(-I\left(P_{\text {flood }}\right)+b_{0}-P_{\text {flood }}\left(b_{0}+d_{0}\right)\right)\left(1+r_{e}+i\right)^{t}}{N_{p ; 0}\left(1+r_{p}\right)^{t}(1+r)^{t}}$

Where $I$ denotes the investment made in the protection system.

Based on observed death statistics, the influence of an added cause of death on the life expectancy at birth can be quantified (chapter 4). Thus, the life expectancy can be written as a function of the flooding probability. An approximating function valid for an added probability of death of $10^{-3}$ per year is given by (Voortman et al., 2001c and chapter 4):

$e\left(P_{\text {flood }}, c_{\text {cas }}\right)=e_{0}-C \cdot P_{\text {flood }} c_{\text {cas }}$

Where:

$e_{0}$ : $\quad$ Observed life expectancy at birth;

$P_{\text {flood: }} \quad$ Flooding probability;

$c_{\text {cas }}: \quad$ Damage factor for casualties (see chapter 4 for details);

$C$ : $\quad$ Constant with a value of $10^{3.5} \mathrm{yr}$.

Substitution of (24) and (26) in the definition of the life quality index leads to a flow of the life quality index over time:

$l\left(t, P_{\text {flood }}, c_{\text {cas }}\right)=g(t)^{w}\left(e\left(P_{\text {flood }}, c_{\text {cas }}\right)\right)^{1-w}$

The summed life quality over the reference period is then given by:

$L\left(P_{\text {flood }}, c_{\text {cas }}, T\right)=\sum_{t=0}^{T} l\left(t, P_{\text {flood }}, c_{\text {cas }}\right)$ 
The life quality model will be applied to the case study after van Dantzig. Additional input is necessary for the life quality model. The additional input is given in table 7 .

Table 7: Additional parameters for life quality modelling

\begin{tabular}{lll}
\hline Parameter & Description & Value \\
\hline$w$ & Observed amount of time spent working & $1 / 8$ \\
$e_{0}$ & Life expectancy at birth without flooding (this study) & 75.8 years \\
$r_{p}$ & Population growth rate (assumed) & $0 \%$ \\
$N_{p}$ & Population & 6.000 .000 \\
\hline
\end{tabular}

Figure 26 shows the results of the life quality model applied to the case study.

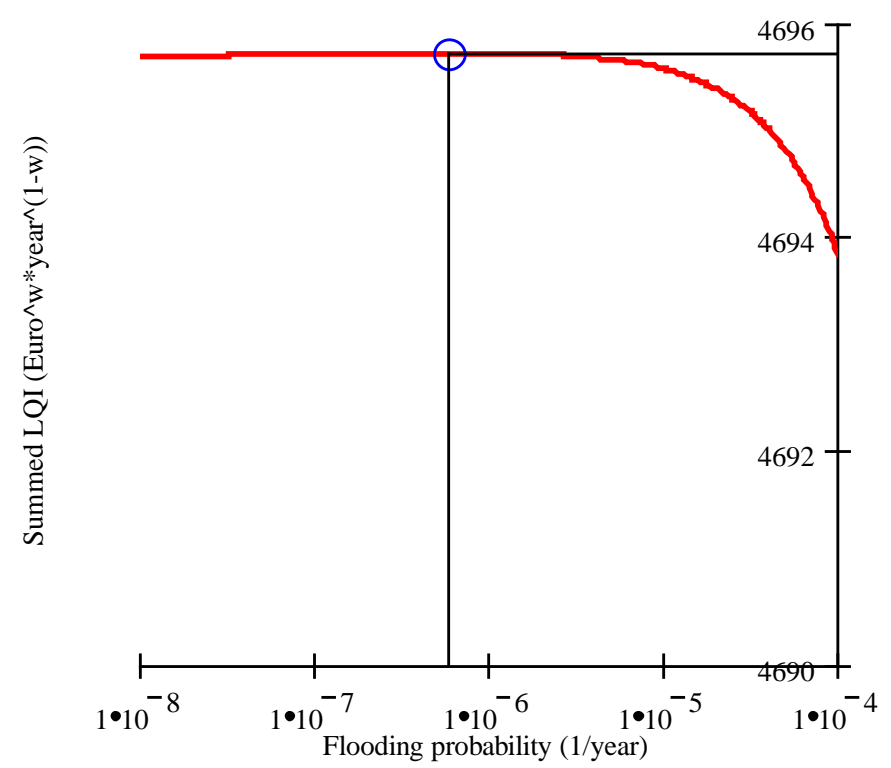

Figure 26: Application of life quality index to a case study after van Dantzig (1956)

The optimal flooding probability using the life quality model equals $6.3 \cdot 10^{-7}$ per year. Table 8 shows a comparison of the life quality approach to the cost-benefit approach.

Table 8: Comparison of cost benefit analysis and life quality analysis for a case study after van Dantzig

\begin{tabular}{lllll}
\hline Model & $\begin{array}{l}\text { Flooding probability } \\
\left(\mathbf{1 0}^{-7} / \mathbf{y r}\right)\end{array}$ & $\begin{array}{l}\text { Cost of protection } \\
(\text { GEuro) }\end{array}$ & $\begin{array}{l}\text { Exp. lifetime } \\
\text { benefits (GEuro) }\end{array}$ & $\begin{array}{l}\text { Loss of life } \\
\text { expectancy }\left(\mathbf{1 0}^{-4} \mathbf{~} \mathbf{~ r s}\right)\end{array}$ \\
\hline CB & 80.0 & 0.143 & 361.29 & 25.9 \\
LQI & 6.25 & 0.169 & 361.28 & 1.98 \\
\hline
\end{tabular}

\subsection{Discussion}

Decision-making on flood protection is a complex task, where choices between radically different costs of protection and consequences of flooding have to be weighed against each other. In literature, a variety of quantitative decision-support models can be found. A selection is introduced in this chapter. The most well-known and presumably the most widely adopted approach is cost-benefit analysis. In costbenefit analysis, constraints on the solution space may be adopted to reflect risk preferences of society. Risk-averse behaviour and multiple attributes of risk may be analysed using a utility approach. Alternatively, the life quality method, which shows similarities to utility modelling, may be used. 
A problem common to all models is the choice of the parameters. In cost-benefit analysis, the interest rate, inflation and growth rate are not constant in time. The value of these parameters influence the values of the acceptable flooding probability. A similar argument is applicable to utility modelling, where risk-aversion is modelled by a utility curve. The shape of the utility curve and its parameters are ideally chosen such that the risk-preferences of society or a relevant sub-group of the society are reflected. While the macro-economic figures necessary for cost-benefit modelling may be estimated on the basis of historical data, the risk-aversion of a large group of people appears hard to establish. Furthermore, risk-attitudes may be expected to change if a disaster occurs, or contrary if the previous disaster is further in the past. Though the life quality method is based on macro-economic properties that can be observed and analysed, the assumption that the model is a valid reflection of societal risk preferences may obviously be challenged. The life quality method is a twoattribute model and the extension to more attributes does not appear to be straightforward. Finally, the life quality model does not include effects of uncertainty on the outcomes of the decision.

Despite the objections that can be brought in against any of the models described in this chapter, they may fulfill a role in decision-making on flood protection. There is no model which delivers the one and only solution, but all provide condensed information on the effects on the acceptable safety level of cost of protection, riskaversion and value of protected area. Furthermore, life quality modelling includes the effects on life expectancy, utility modelling may be extended to reflect effects on life expectancy or casualty numbers and cost benefit analysis can be extended with probability bounds. In this way, all models may provide insight in the problem that hopefully helps decision-makers in adopting a more rational approach to decisionmaking on flood protection.

A consequence of adopting a quantitative model for decision support is that it is always possible to express one risk into another. Using the quantitative models of this chapter, the cost of reduction of uncertainty (utility model) or the cost of a life year saved (LQI) can be established. Especially expressing loss of life in monetary terms is often thought of as an unethical thing to do. However, if choices regarding safety levels are made, trade-offs between life, money and other consequences of flooding are being made. This fact remains irrespective of how the decision is made. Quantitative models as presented in this chapter only makes the trade-offs explicit.

Independent of the type of decision-support model adopted, the costs of protection and the expected value of the consequences of flooding (risk) have to be quantified. In the simple examples outlined in this chapter this could be done analytically, but in more complex situations an analysis on the lowest decision level (level C) is necessary to estimate the cost of protection. This type of analysis is the subject of chapter 3.

The quantification of the consequences of flooding generally needs more work than was shown in this chapter. Chapter 4 deals with this subject.

In chapter 8, a more extensive case study is presented in which also the sensitivity of the solution to the input parameters is studied. 



\section{METHODOLOGY OF RELIABILITY-BASED DESIGN OF FLOOD DEFENCES}

"There is no approximation more crude than a deterministic one."

A.C.W.M. Vrouwenvelder

\subsection{Introduction}

The failure probability is a measure for the likelihood of failure of a structure or system of structures. Quantitative reliability methods can be applied to find the failure probability in a given situation. Reliability methods may form part of a design process. Two design approaches in which quantitative reliability methods play a role can be distinghuished:

- Reliability-based design;

- Risk-based design.

In this study, reliability-based design is defined as a design approach where the probability of failure is used as a measure of the performance of the structure. A maximum failure probability is defined and the structure should meet the requirement. Risk-based design is defined as a design approach where the costs of protection are explicitly weighed against the risk reduction in the protected area. In contrast with reliability-based design, the failure probability for which the structure is designed is flexible and depends on the consequences of failure. In the three level decision model introduced in chapter 1, risk-based design is performed only on level A. On levels B and $\mathrm{C}$, reliability-based design is applied. This chapter deals with reliability-based design of flood defences on levels B and C.

To perform a quantitative reliability analysis of a flood defence system, large-scale systems have to be broken down into smaller sub-systems or structures. Therefore, the reliability analysis starts with a qualitative analysis on system level (level B). A single structure may fail in many different ways. Therefore, on level $\mathrm{C}$ a further break-down of the event "failure of the structure" in single failure modes is performed.

The result of the qualitative analysis is a breakdown of the system in elements and a breakdown of every element in individual failure modes. The failure modes and their relation to failure of the structure and the structures and their relation to overall failure of the system can be represented in fault trees. Quantitative analysis starts at the level of failure modes with the definition of limit state functions and the description of the joint probability distribution of random input variables. From a quantification of the probability of occurrence of every failure mode, the total probability of failure of every structure and of the system can be found. To find a cost-effective design that meets the predefined failure probability requirement, reliability-based optimisation can be performed.

Qualitative analysis of flood defence systems is introduced in section 3.2. Section 3.3 deals with quantitative reliability analysis of a flood defence structure. The methods introduced are also applicable on system level. Sections 3.4 and 3.5 deal with the application of reliability-based optimisation on structure level and on system level.

In most cases, numerical tools will be necessary to perform the calculations involved in reliability-based design. Section 3.6 introduces the design of a numerical 
optimisation tool aimed at reliability-based design of flood defences on structure and on system level. The chapter closes with a discussion.

\subsection{Qualitative reliability analysis of flood defence systems (level B)}

A reliability analysis should start with a definition of the main function that is considered in the reliability analysis. A large number of different functions may be assigned to a flood defence system. A few examples are:

- Retention of high water levels;

- Facilitating land traffic;

- Ecological functions (migratory routes for wildlife, biotope for a number of species).

From the viewpoint of reliability analysis, the primary function of a flood defence system is the retention of high water levels. It should be noted that in special cases the water retaining function will not be the primary function in the design process. This is especially so in case of the special-purpose structures (ship locks, discharge sluices) where the water retaining function poses a legal constraint rather than the prime function for which the structure is designed (see TAW (2002) for more details). Since this study considers reliability analysis with respect to the protection against flooding, the water retaining function will in the following be used as the primary function.

On the highest level of abstraction, failure of a structure is defined as function loss. Therefore, failure of a water retaining structure is described by:

\section{"Water enters the area uncontrolled".}

A dike ring generally consists of a variety of structures, varying in structural concept and geometry. Furthermore, natural boundary conditions (hydraulic and geotechnical) will vary if the system runs over considerable length. For the purpose of reliability analysis, the system therefore has to be broken down in well-defined components. Failure of the system occurs if one or more components fail. The interaction between failure of a component and failure of the system can be summarised in a fault tree. Figure 27 gives an overview. The undesirable event in the top of the tree is generally denoted "top event".

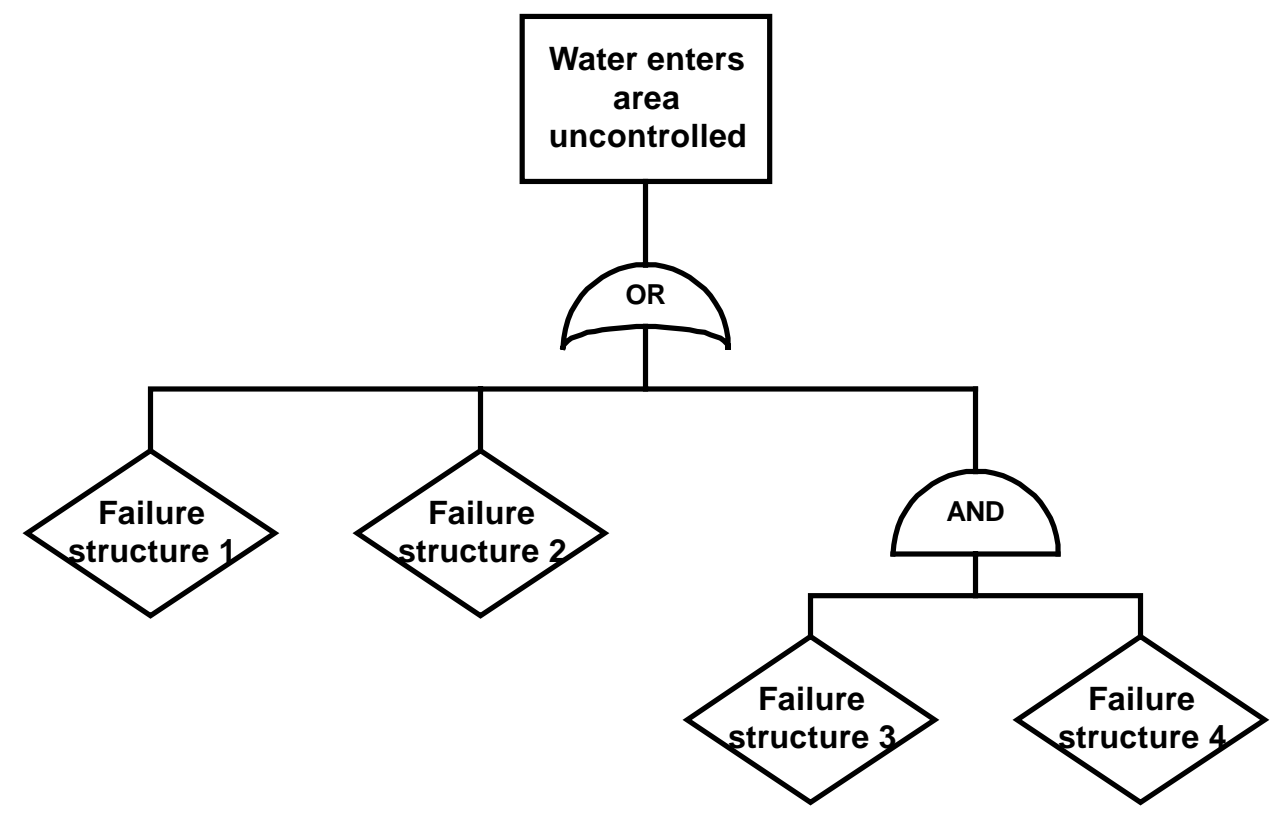

Figure 27: Example fault tree of a dike ring 
A failure path is defined as a combination of failures that leads to the occurrence of the top event. In the example fault tree the possible failure paths are as follows:

- Failure structure 1;

- Failure structure 2;

- Failure of structure 3 and structure 4.

Two structures or failure modes form a parallel system if only failure of both leads to failure of the system. On the other hand, two structures or failure modes form a series system if failure of one leads to failure of the system. In figure 27, structures 3 and 4 form a parallel system. The parallel system of 3 and 4 is placed in series with structures 1 and 2.

\subsection{Reliability evaluation of a flood defence structure (level C)}

Breaking down the dike ring into individual structures is generally insufficient to enable a quantitative reliability analysis of the system. Therefore, every individual structure has to be analysed further with respect to its possible causes of failure (failure modes). Also on the level of individual structures, a fault tree can be used to visualise the failure modes and their interactions. Annex 1 contains a fault tree for a dike structure.

To enable a quantitative analysis of the reliability of the structure, every failure mode has to be cast in a mathematical form. An often suitable form of a limit state function is given by:

$g(\mathbf{z}, \mathbf{x})=R(\mathbf{z}, \mathbf{x})-S(\mathbf{z}, \mathbf{x})$

Where:

z: $\quad$ Vector of design variables;

$\mathbf{x}: \quad$ Vector of random input variables;

$R: \quad$ Resistance of the structure;

$S: \quad$ Load on the structure.

The value of the limit state function for given values of $\mathbf{x}$ and $\mathbf{z}$ is denoted the margin:

$M=g(\mathbf{z}, \mathbf{x})$

The limit state function is defined such that negative values of the margin indicate failure by the failure mode described by the limit state function. On the lowest level in the fault tree, every failure mode has to be written in the form of equation (29) if a quantitative analysis is to be performed. Once the limit state functions are defined, there are two fundamentally different ways to judge the performance of the structure:

- Deterministic analysis;

- Probabilistic analysis.

In deterministic analysis, the margins are calculated for one or more discrete sets of values for the load and strength variables. To judge whether the structure fails as a consequence of failure by one failure mode, the interaction of the failure modes in the fault tree has to be accounted for when comparing the values of the respective margins. Figure 28 shows an example of deterministic analysis. 


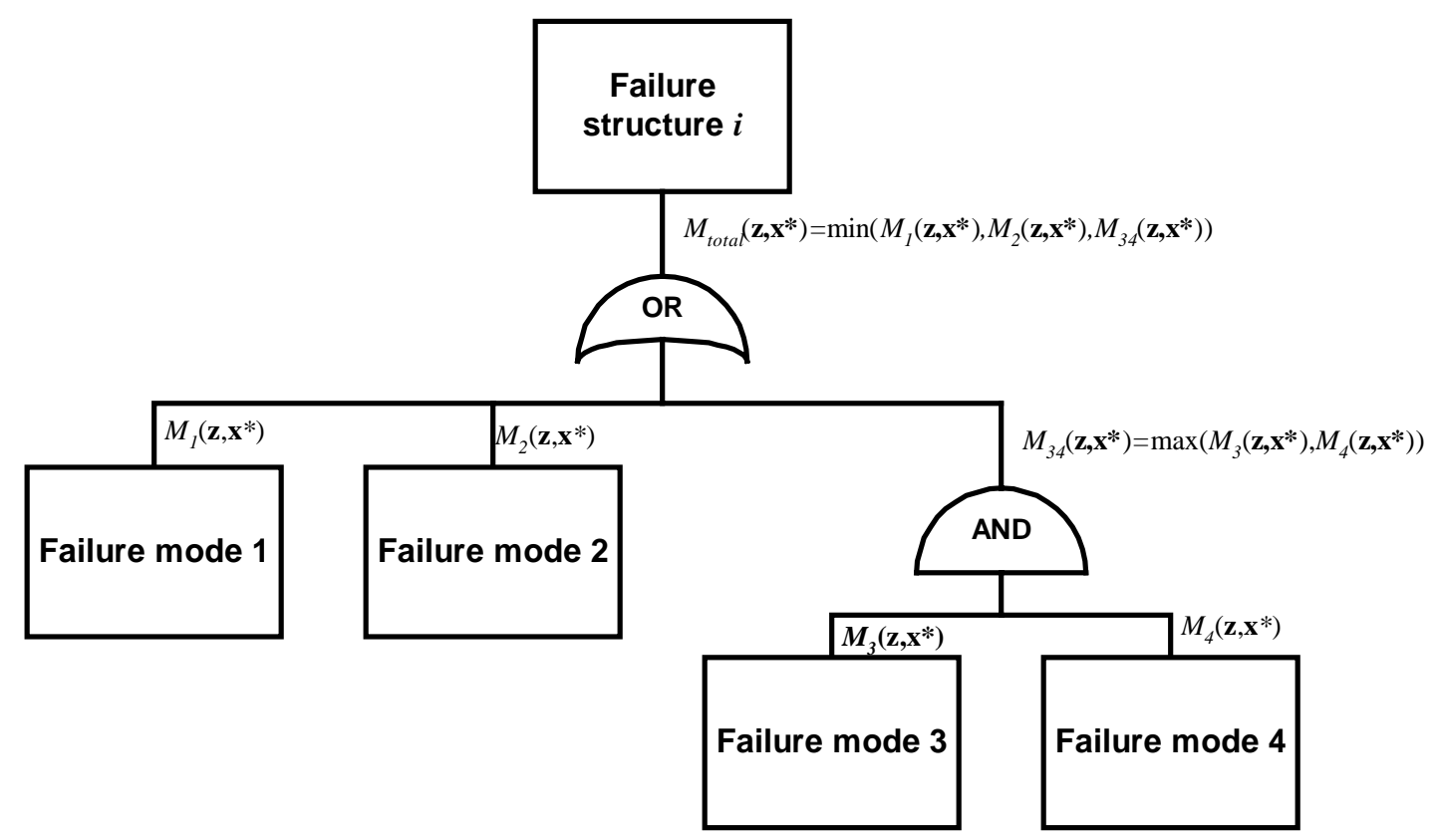

Figure 28: Deterministic analysis of a fault tree

Failure of the structure is indicated by negative values of the total margin $M_{\text {total }}$. Generally, the choice of the characteristic set of values $\mathbf{x}^{*}$ reflects to an extend the stochastic nature of the load and strength variables contained in $\mathbf{x}$. Nevertheless, the result of a deterministic analysis of a design is binary; the structure fails under the prescribed load and strength combination or it does not. No estimate of the likelihood of failure is given in any way by this type of methods. Reliability-based design or probabilistic design on the other hand explicitly takes the uncertainties in load, strength and physical models into account. The probability of occurrence of one failure mode is a function of the vector of design variables $\mathbf{z}$ and the random variables $\mathbf{x}$ by:

$$
P_{f ; i}(\mathbf{z}, \mathbf{x})=P\left(g_{i}(\mathbf{z}, \mathbf{x})<0\right)=\int_{g_{i}(\mathbf{z}, \mathbf{x})<0} f_{\underline{\mathbf{x}}}(\mathbf{x}) \mathrm{d} \mathbf{x}
$$

Where $f_{\underline{\mathbf{x}}}(\mathbf{x})$ denotes the joint probability density function of the random input variables.

The integral in equation (31) can generally not be solved analytically. Over the years a number of numerical methods have been developed to solve equation (31). Generally a distinction is made between level III methods and level II methods ${ }^{4}$ (JCSS, 1981). In level III, the integral is solved directly by a numerical method. This may be performed by Riemann-integration or Monte Carlo integration.

The concept of level II methods was proposed by Cornell (1967b). In level II methods, the joint probability density function in (31) is transformed to a space of normally distributed independent variables and the limit state function is replaced by its first-order Taylor approximation in one point. In the original proposal of Cornell, the estimate of the probability of failure depends upon the formulation of the limit state function. Hasofer and Lind (1974) developed a definition of the linearisation point such that the failure probability estimate is invariant with respect to the limit

\footnotetext{
${ }^{4}$ Level I encompasses the deterministic design method using characteristic values of the basic variables and a set of safety factors. Both level II and level III methods can be used to calibrate a level I method.
} 
state formulation. Based on the result of Hasofer and Lind, level II methods rapidly found application in a variety of fields, for two prime reasons:

- The methods are highly computational efficient;

- The methods provide all information necessary for the development of reliabilitybased structural codes.

A detailed explanation of the methods is given in a number of books on reliability theory. A few examples are Thoft-Christensen and Baker (1982), Madsen et al. (1986), Ditlevsen and Madsen (1996) and Melchers (1999). An overview of the methods focused on application in coastal engineering is given in Oumeraci et al. (2001). For this study the methods have been programmed in a library in Fortran 90. An overview is given in annex 7. More details are given Voortman (2002).

Equation (31) provides the probability of occurrence of one failure mode only. The probability of failure of the system depends on the probabilities of failure of the individual failure modes and on the dependence between the failure modes. Dependence between failure modes occurs if one random variable influences more than one failure mode. For special cases of dependence, analytical solutions of the system probability of failure can be found (Cornell, 1967a). Table 9 shows the system probability as a function of a vector of failure probabilities $\mathbf{p}$.

Table 9: Analytical solutions to the system probability of failure

\begin{tabular}{llll}
\hline System type & $\begin{array}{l}\text { Mutually exclusive } \\
\text { components }\end{array}$ & Independent components & $\begin{array}{l}\text { Fully dependent } \\
\text { components }\end{array}$ \\
\hline Series & $P_{f ; \text { sstem }}=\sum_{n=1}^{N} p_{n}$ & $P_{f ; \text { sssem }}=1-\prod_{n=1}^{N}\left(1-p_{n}\right)$ & $P_{f ; \text { system }}=\max (\mathbf{p})$ \\
Parallel & $P_{f ; \text { sstem }}=0$ & $P_{f ; \text { system }}=\prod_{n=1}^{N} p_{n}$ & $P_{f ; \text { system }}=\min (\mathbf{p})$ \\
\hline
\end{tabular}

For arbitrary dependence between the components of the system, the analytical solutions provide upper and lower bounds to the exact probability of failure (see table 10).

Table 10: Use of analytical solutions as bounds on the system probability of failure

\begin{tabular}{lll}
\hline System type & Upper bound & Lower bound \\
\hline Series & Mutually exclusive components & Fully dependent components \\
Parallel & Fully dependent components & Mutually exclusive components \\
\hline
\end{tabular}

Mutually exclusive components are rarely encountered in civil engineering. If mutual exclusiveness can be excluded, the result for independent components can be used as an upper bound for a series system and a lower bound for a parallel system.

In most practical cases, the bounds are far apart so that for a given set of failure probabilities $\mathbf{p}$ still a wide range of possible values of the system probability of failure exists. Furthermore, it can generally not be proven that the dependence between the failure modes fulfils one of the three special cases. Alternative bounds on the system probability of failure have been established (see Ditlevsen, 1979 for an overview). Furthermore, a variety of numerical methods to estimate the system probability of failure are available both on level III and level II (see for instance Melchers, 1999 for an overview). 
A direct calculation of the system probability of failure is possible when applying level III methods. The probability of failure of a series system of failure modes is given by:

$$
P_{f ; \text { series }}(\mathbf{z}, \mathbf{x})=\int_{\min (\mathbf{g}(\mathbf{z}, \mathbf{x}))<0} f_{\underline{\mathbf{x}}}(\mathbf{x}) \mathrm{d} \mathbf{x}
$$

The probability of failure of a parallel system of failure modes is given by:

$$
P_{f ; \text { parallel }}(\mathbf{z}, \mathbf{x})=\int_{\max (\mathbf{g}(\mathbf{z}, \mathbf{x}))<0} f_{\underline{\mathbf{x}}}(\mathbf{x}) \mathrm{d} \mathbf{x}
$$

For an arbitrary system, the definition of the failure boundary can be found by following the deterministic analysis of the fault tree (figure 28). The level III algorithm for calculation of the system probability of failure is completely equivalent to the algorithm that is used in the analysis of an individual failure mode. Integration takes place in the space of the input variables. Dependence between the failure modes is accounted for automatically, since in the definition of failure all failure modes are considered.

If level II methods are applied, every failure mode has to be analysed individually. Based on the result of the analysis, every failure mode can be written as a linear function of a vector of standard normal variables:

$g_{i}(\mathbf{u}) \approx M_{i}=\beta+\alpha_{i 1} u_{1}+\alpha_{i 2} u_{2}+\ldots+\alpha_{i N} u_{N}$

Where:

$\beta$ : $\quad$ Reliability index;

$\alpha_{i j}$ : $\quad$ Influence factor of failure mode $i$ to variable $j$;

$u_{j}$ : $\quad$ Random variable following standard normal distribution.

Equation (34) will be denoted the standard form of a limit state function. Since the function is linear and all random input variables are normally distributed, also the margin by failure mode $M_{i}$ follows a normal distribution. Dependence between normally distributed variables can be expressed by the correlation coefficient. For two failure modes written in the form of equation (34), the correlation is given by (CUR, 1997):

$\rho_{i j}=\sum_{n=1}^{N} \rho_{v a r ; n i j} \alpha_{i n} \alpha_{j n}$

Where $\rho_{\text {var; } n i j}$ describes the correlation between the realisations of variable $n$ in failure mode $i$ and the realisations of variable $n$ in failure mode $j$.

Hohenbichler and Rackwitz (1983) proposed a method to estimate the probability of failure of a system of failure modes written in the standard form. The method will be briefly introduced here. The probability of failure of a parallel system of two failure modes is given by:

$$
P\left(M_{i}<0 \cap M_{j}<0\right)=P\left(M_{i}<0\right) P\left(M_{j}<0 \mid M_{i}<0\right)
$$

Where $M_{i}$ denotes the margin for failure mode $i$. 
The probability of failure of a parallel system is given by the multiplication of the probability of failure of one failure with the conditional probability of failure of the second failure mode. The probability of failure of a series system of failure modes is given by:

$$
\begin{aligned}
& P\left(M_{i}<0 \cup M_{j}<0\right)=P\left(M_{i}<0\right)+P\left(M_{j}<0\right)-P\left(M_{i}<0 \cap M_{j}<0\right)= \\
& =P\left(M_{i}<0\right)+P\left(M_{j}<0\right)-P\left(M_{i}<0\right) P\left(M_{j}<0 \mid M_{i}<0\right)
\end{aligned}
$$

To quantify the probability of failure of a series system, again the probability of failure of the parallel system of the two failure modes needs to be quantified. All terms in equations (36) and (37) are known, with the exception of the probability of failure of $j$ conditional on failure of $i$. The procedure proposed by Hohenbichler and Rackwitz is aimed at estimating this probability. To this end, the following system of limit state functions is formed:

$$
\begin{aligned}
& g_{i}(\mathbf{u})=\beta_{i}-u_{1} \\
& g_{j}(\mathbf{u})=\beta_{j}-\rho_{i j} u_{1}-\sqrt{1-\rho_{i j}^{2}} u_{2}
\end{aligned}
$$

Where:

$\beta$ : $\quad$ Safety index per failure mode;

$\rho: \quad$ Correlation coefficient calculated by equation (35);

$u$ : $\quad$ Standard normal variable.

For the system in equation (38) to be equivalent to the original system of two failure modes, the reliability of the individual failure modes and the correlation between the failure modes needs to be equal to that of the original system. This can easily be verified. For component $i$, failure is defined as:

$\beta_{i}<u_{1}$

Since $u_{l}$ follows a standard-normal distribution, the reliability index of component $i$ indeed equals $\beta_{i}$.

For component $j$, failure is defined by:

$$
\beta_{j}<\rho_{i j} u_{1}+\sqrt{1-\rho_{i j}^{2}} u_{2}
$$

The right-hand side of equation (40) is a linear function of two normal variables. It is therefore possible to replace the right-hand side by a single normal variable $\tilde{u}$. The mean of $\tilde{u}$ is given by:

$\mu_{\tilde{u}}=\rho_{i j} \mu_{1}+\sqrt{1-\rho_{i j}^{2}} \mu_{2}=0$

The standard deviation of $\tilde{u}$ is given by:

$$
\sigma_{\tilde{u}}=\sqrt{\left(\frac{\mathrm{d} \tilde{u}}{\mathrm{~d} u_{1}} \sigma_{1}\right)^{2}+\left(\frac{\mathrm{d} \tilde{u}}{\mathrm{~d} u_{2}} \sigma_{2}\right)^{2}}=\sqrt{\rho_{i j}^{2}+\left(1-\rho_{i j}^{2}\right)}=1
$$

The result shows that the right-hand side of equation (40) represents a standard-normal variable. By using equation (39) it is easily verified that the reliability index of component $j$ indeed equals $\beta_{j}$. 
The correlation between the two components is given by (equation (35)):

$\rho_{i j}=\sum_{n=1}^{N} \alpha_{i n} \alpha_{j n}=1 \cdot \rho_{i j}+0 \cdot \sqrt{1-\rho_{i j}^{2}}=\rho_{i j}$

Equations (39) through (43) show that the system of failure modes in equation (38) is completely equivalent to the original system, both with respect to the reliability of the individual failure modes and the correlation between the failure modes.

To evaluate the probability of failure of mode $j$ conditional on failure of mode $i$, the information that mode $i$ has failed is included in the limit state function of $j$ by replacing variable $u_{l}$ by:

$\tilde{u}_{1}=\Phi^{-1}\left(1-\Phi\left(u_{1}\right) \Phi\left(-\beta_{i}\right)\right)$

Where $\Phi$ denotes the standard normal distribution.

Substitution of (44) in the limit state function for failure mode $j$ leads to:

$g_{j}(\mathbf{u})=\beta_{j}-\rho_{i j} \Phi^{-1}\left(1-\Phi\left(u_{1}\right) \Phi\left(-\beta_{i}\right)\right)-\sqrt{1-\rho_{i j}^{2}} u_{2}$

Applying a level II method to equation (45) leads to an estimate of the probability of failure by mode $j$ conditional on failure by mode $i$. Depending on the type of system, the system probability of failure is subsequently found by application of equation (36) or equation (37). For systems with more than two elements, an iterative procedure can be applied (see Hohenbichler and Rackwitz, 1983). With this method it is possible to reduce a system of failure modes of any size and any type to a limit state function in the standard form.

The method of Hohenbichler and Rackwitz assumes that the system can be split in a number of discrete elements. In some cases, random variables show a continuous variation over space. In those cases, discrete elements can not be defined but continuous dependence functions need to be introduced. In the special case where the random variables are described by a normal or log-normal distribution, a correlation function can be used (Vanmarcke, 1977). This approach appears suitable for the description of the spatial distribution of resistance variables of flood defence structures.

Hydraulic conditions in front of flood defences generally show a strong dependence from location to location. The dependence can be explained by the fact that the same physical processes determine the hydraulic conditions. In case of flood defences along rivers, the loads strongly depend on the discharge upstream. In coastal regions, the wind conditions dominate the hydraulic conditions. The local conditions depend on the properties of the driving process and on local conditions, like orientation of the structure, bathymetry etc. It is for this reason that a description of the hydraulic conditions can not be based on correlation functions of the type proposed by Vanmarcke. A method to describe the joint probability distribution of water level, wave height and wave period as a function of space is outlined in chapters 5 and 6 .

\subsection{Reliability-based optimisation of flood defence structures (level C)}

In a design process, a number of alternative structural concepts will be generated and judged with respect to their applicability to the situation. Within one structural concept, a number of alternative geometries may be possible. For every geometry, the failure probability can be estimated using the methods outlined in the previous 
section. To decide whether a geometry is applicable, an acceptable value of the failure probability should be prescribed. The combination of the calculated failure probabilities and the probability requirement defines the solution space where acceptable design alternatives may be found. Mathematically, the set of acceptable geometries is given as:

$$
D=\left\{\mathbf{z} \mid P_{f}(\mathbf{z}) \leq P_{f ; \max }\right\}
$$

Where:

z: $\quad$ Vector of design variables;

$P_{f ; m a x}: \quad$ Maximum acceptable failure probability of the structure.

Equation (46) describes an infinite number of acceptable geometries of the structural alternative. Additional geometric requirements may be set, but the combination of all constraints will generally still leave a large number of geometries to be acceptable. For a final choice it is useful to analyse the costs of every alternative geometry within the solution space. From the viewpoint of rational decision-making the costs should be minimised, provided the design satisfies all requirements. Combination of the investment with a reliability requirement leads to the cheapest design that just suffices the reliability requirement. This is denoted the optimal design. Figure 29 shows the investment contours, the probability constraint and the corresponding optimal design for a fictitious sea dike.

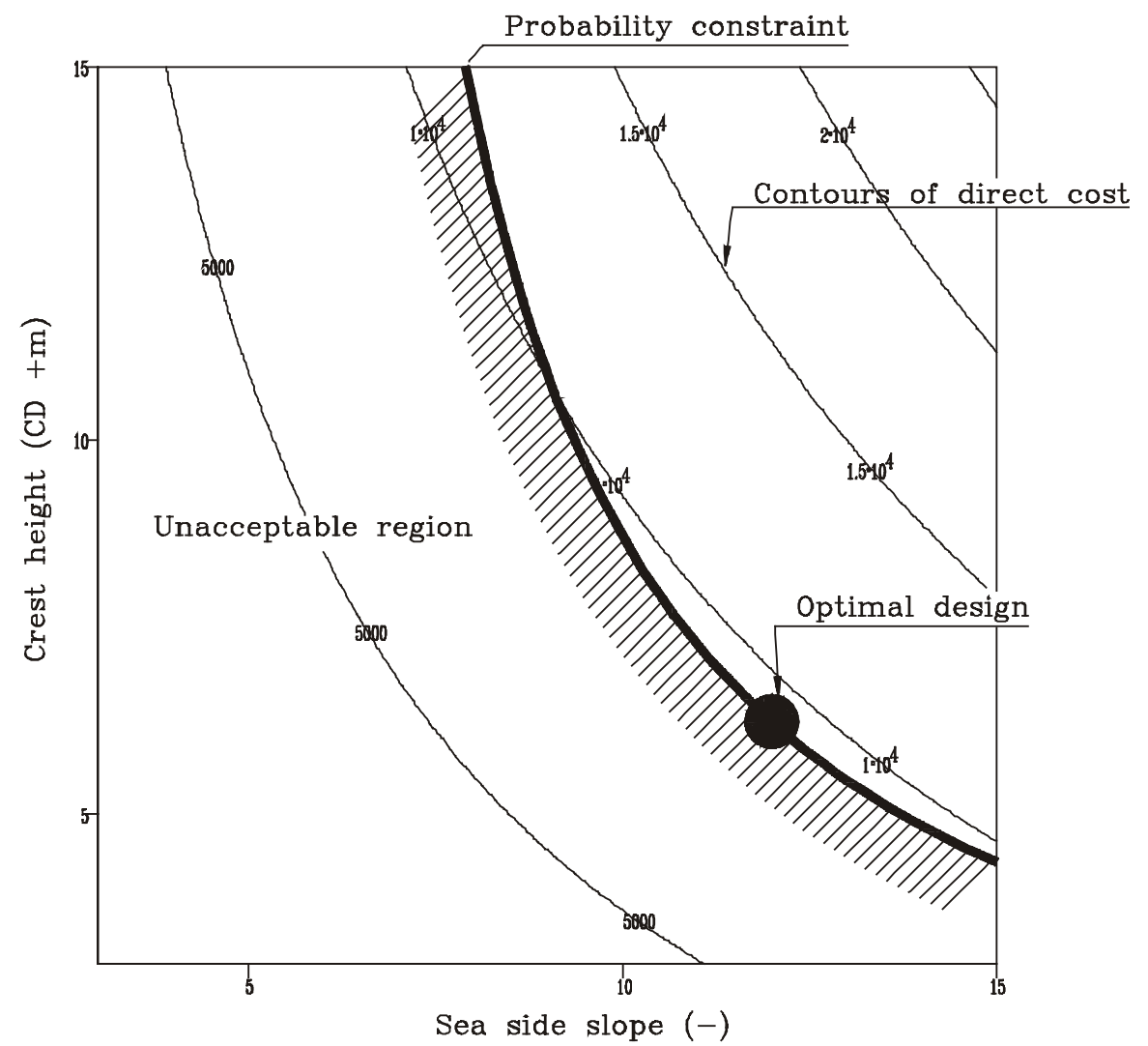

Figure 29: Reliability-based optimisation of a flood defence structure 
Optimisation of a flood defence structure in this way is an application of acceptance rule 1 (chapter 2). Mathematically, the process is written as:

$$
\begin{aligned}
& \min _{\mathbf{z}} I_{i}(\mathbf{z}) \\
& \text { s.t. } P_{f ; i}(\mathbf{z}, \mathbf{x}) \leq P_{f ; \max }
\end{aligned}
$$

Where:

$i$ : $\quad$ Counter of the component of the flood defence system;

I: $\quad$ Direct cost of construction of the component;

$P_{f:} \quad$ Failure probability;

$P_{f ; \text { max }}: \quad$ Maximum failure probability;

z: $\quad$ Vector of design variables;

$\mathbf{x} \quad \quad$ Vector of random input variables.

Since in most cases, more than one combination of failure modes can be responsible for failure of the structure, a system analysis as outlined in the previous section is necessary to evaluate the failure probability for every alternative geometry.

Methods for finding minima of more-dimensional functions (optimisation methods) may be used to find the optimal design. More details are given in section 3.6. In a general design problem, not only variables describing the geometry of the structure are design variables. Alternative choices may also be available for the materials used in construction. Different structural concepts should be dealt with separately. For one structural concept, the costs and failure probability can be expected to be described by continuous differentiable functions of the design variables. In that case an optimum can generally be found by application of well-known optimisation methods. A final choice between alternatives can then be based on a comparison of the properties of the optimal design within every structural concept. Laenen (2000) used this approach to choose between two breakwater types for the port of Rotterdam.

\subsection{Reliability-based optimisation of flood defence systems (level B)}

The reliability-based optimisation of a full system of flood defences (dike ring) can be performed along the same lines as the reliability-based optimisation of a structure (level B analysis, chapter 1). The optimisation problem for such a case is written as:

$$
\begin{aligned}
& \min _{\mathbf{z}} I_{s y s}(\mathbf{z})=\sum_{i=1}^{N} I_{i}(\mathbf{z}) \\
& \text { s.t. } P_{f ; s y s}(\mathbf{z}, \mathbf{x}) \leq P_{f ; \max }
\end{aligned}
$$

Where:

$I_{i}$ : $\quad$ Investment in component $i$;

$P_{f ; s y s}: \quad$ System probability of failure;

$P_{f ; \max }: \quad$ Maximum probability of failure;

$\mathbf{z}: \quad$ Vector of design variables;

$\mathbf{x}: \quad$ Vector of random input variables.

The vector $\mathbf{z}$ now contains all design variables of all structures in the system. The result of the optimisation is the optimal geometry of all structures. For every structure the failure probability and the cost can be derived, based on the known geometry. Since this fundamental case uses the system itself as a starting point and derives the 
properties of the underlying components from the system optimisation, this approach is denoted the top-down approach.

The top-down approach is the most obvious method when thinking about optimisation of large-scale systems. The approach is attractive if the number of design variables in the system is fairly limited. An example of a top-down optimisation of a large system is the probabilistic optimisation of a land reclamation in the North Sea (Stroeve and Sies, 2001). For most large-scale systems, the method becomes less transparent and possibly hard to handle from a computational point of view. An alternative formulation of the system optimisation is in the space of failure probabilities of the underlying components:

$$
\begin{aligned}
& \min _{\mathbf{p}} I_{s y s}(\mathbf{p})=\sum_{n=1}^{N} I_{n}\left(p_{n}\right) \\
& \text { s.t. } P_{f ; s y s}(\mathbf{p}, \mathrm{A}) \leq P_{f ; \max }
\end{aligned}
$$

Where $\mathbf{p}$ is a vector of failure probabilities of the structures in the system and A is a matrix of influence factors.

Formulated in this way, the number of dimensions in the system optimisation is reduced to the number of structures in the system. The problem is that the investment $I$ in a structure as a function of its failure probability is not available. This function can be found by application of reliability-based optimisation on structure level (level C).

For the minimum according to equation (49) to be equivalent to the minimum according to equation (48), the investment function per structure needs to describe the minimum investment as a function of the structure's failure probability. The investment functions can be derived by reliability-based optimisation of every structure (section 3.3) using a range of values for the probability constraint. The system probability of failure is found from the failure probabilities of the components of the system and the matrix of influence factors, using one of the methods outlined in section 3.3.

Since the system optimisation is in this case based on an analysis of every component separately, this approach is denoted the bottom-up approach. Not only is the bottomup strategy more transparent than the top-down strategy, it also appears to be computationally more efficient in most cases. Most procedures for minimisation of functions use a sequence of one-dimensional minimisations (line minimisations) to obtain the minimum of the objective function. The bottom-up approach is computationally more efficient if the total number of line minimisations needed to find the optimum is smaller than in case of the top-down approach. According to Press et al. (1992), the number of line minimisations necessary to find the minimum of a $N$-dimensional function is $\boldsymbol{O}\left(N^{2}\right)$. Assume a dike ring with $M$ structures, every structure having $K$ design variables. The total number of design variables in the topdown approach then equals $M K$. With the result of Press et al. this leads to $M^{2} \boldsymbol{O}\left((K)^{2}\right)$ line minimisations to optimise the design of the dike ring with a top-down method.

In case of bottom-up optimisation, optimisation per section has to be performed for a number of safety levels (denoted $P$ ). The number of line minimisations for one safety level and one structure is $\boldsymbol{O}\left(K^{2}\right)$. Therefore, the total number of line minimisations necessary to obtain the cost function per structure is $P \boldsymbol{O}\left(K^{2}\right)$. The total number of line minimisations necessary for system optimisation then equals $M P \boldsymbol{O}\left(K^{2}\right)$. Under the 
assumption that the number of function evaluations is the same for all line minimisations, bottom-up optimisation is computationally more efficient if:

$$
M P \cdot \boldsymbol{O}\left(K^{2}\right)<M^{2} \boldsymbol{O}\left(K^{2}\right) \Leftrightarrow M P<M^{2} \Leftrightarrow P<M
$$

The result shows that bottom-up optimisation is more efficient if the number of safety levels evaluated for every structure is lower than the number of structures in the system. In practice, the computational burden involved in deriving the cost function per structure is larger than the computational burden involved in optimising a system by equation (49). The reason for this is that on system level all failure modes are set in standard form and no iteration is necessary to establish the reliability of the system. Therefore, as a practical rule the number of dimensions in the component optimisations should be kept as low as possible, even if this leads to an increase of the number of dimensions in the system optimisation.

\subsection{A computer program for reliability-based optimisation of flood defences}

In order to perform the reliability-based optimisation of flood defences as outlined in sections 3.4 and 3.5, a computer program has been developed, implementing the mathematical concepts of equations (47) and (49). The basis of reliability-based optimisation is the choice of the probability of failure as a performance measure and the capital investment as a measure of costs. The main building blocks of a tool for reliability-based optimisation are therefore:

- A procedure generating design alternatives;

- A function providing the failure probability as a function of design variables;

- A function describing the investment as a function of the design variables.

The building blocks of reliability-based optimisation outlined above fit together as indicated in figure 30 (after Voortman et al., 1998). 


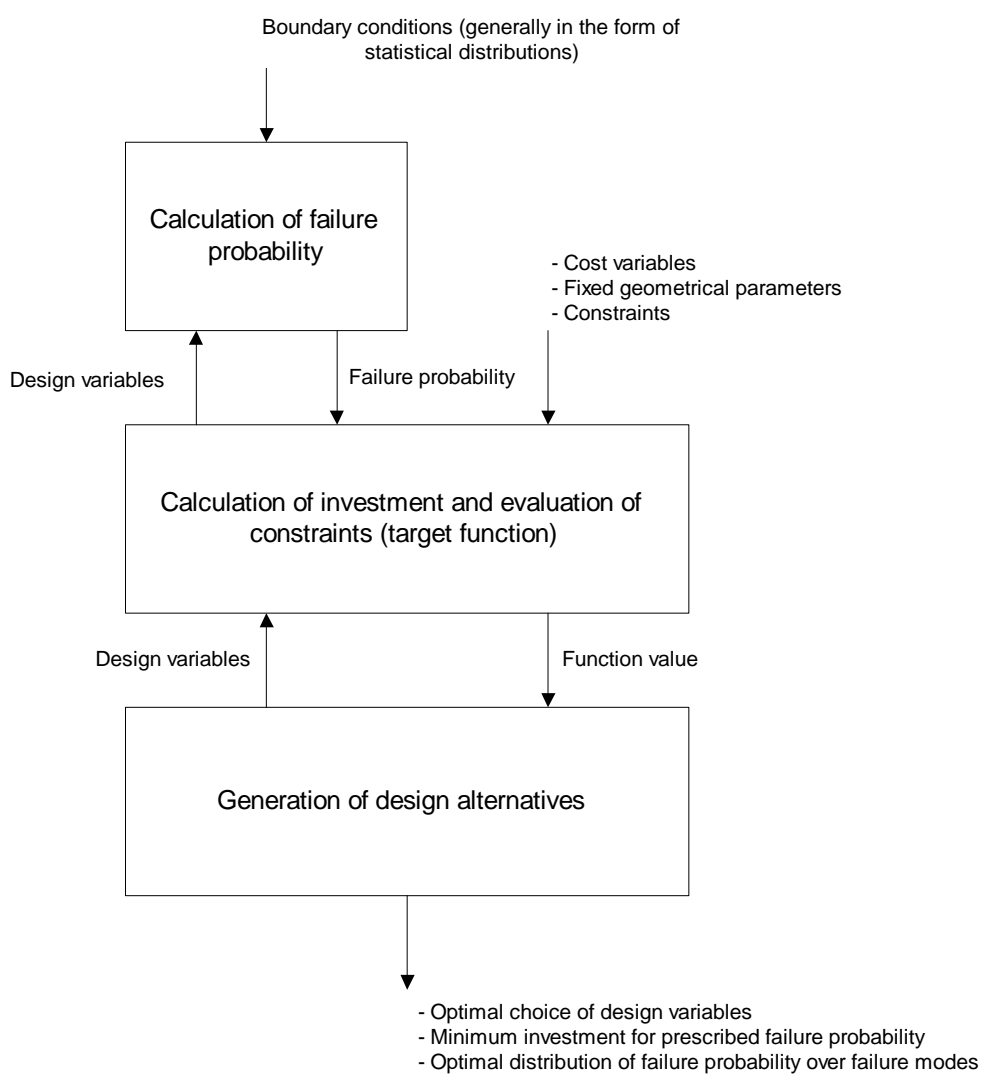

Figure 30: Building blocks of a numerical optimisation tool for flood defences and information flow between the blocks

The optimisation tool outlined in figure 30 can be applied in a top-down approach and in a bottom-up approach. In the bottom-up approach, the same tool can be used on the level of structures (level C) and on the level of the system (level B).

The block "generation of design alternatives" consists of a numerical optimisation method solving the minimisation problem of equation (47) or (49). To evaluate the objective function, an evaluation of construction cost and the reliability of the structure is necessary. The minimisation routine iterates toward the optimal solution, calling the cost calculation and the reliability evaluation as necessary.

The design of the optimisation tool in figure 30 shows that methods have to be chosen for two main parts of the optimisation routine:

- The reliability evaluation method;

- The optimisation routine.

The calculation of failure probabilities on all levels is performed by level II methods. The prime reason for this choice is the high computational efficiency of these methods. An additional advantage of level II methods is that it is relatively easy to derive the gradient of the reliability index with respect to the design variables, which facilitates the combination with a numerical optimisation method (see also Enevoldsen and Sørensen, 1994).

A number of numerical optimisation methods may be applied to find the optimal design. The simplest and most transparent approach is denoted the direct-search approach. In this method, a number of alternative geometries are generated in the space of the decision variables. For every design, the costs and failure probability are calculated. The design with the lowest cost that does not violate the constraints is 
chosen as the optimal design. The resulting optimum will slightly deviate from the mathematical optimum, but from a practical point of view this is generally acceptable. Successful applications of the direct search approach in coastal engineering are reported by Laenen (2000) and Segers (2001).

The direct-search approach is numerically inefficient, primarily because information from previous trial points is not considered in the choice of the next trial point. Numerical optimisation routines other than direct-search attempt to estimate the shape of the objective function and to determine a next trial point on that basis. For reasons of computational efficiency, this type of methods should be preferred if the number of elements of $\mathbf{z}$ is larger than say three or four. In addition to the higher computational efficiency, the accuracy with which the optimal design is obtained is generally considerably higher. However, the accuracy with which a structure can be constructed is generally lower than the accuracy of the calculation. From a practical point of view, only the higher computational efficiency is therefore a reason to apply other than direct-search methods.

The optimisation method used in this study is a variable metric method due to Davidon, Fletcher and Powell with an updating formula due to Broyden-FletcherGoldfarb-Shanno (BFGS, see Gill et al., 1981; Press et al., 1992). The constraint on the failure probability of the structure is incorporated by adding a penalty to the direct cost of the structure if the reliability is insufficient. The objective function is denoted an augmented cost function and is given by:

$$
F(\mathbf{z})=I(\mathbf{z})+\lambda \max \left[\begin{array}{c}
\left(\beta_{\text {min }}-\beta(\mathbf{z})\right)\left|\beta_{\text {min }}-\beta(\mathbf{z})\right| \\
0
\end{array}\right]
$$

Where:

$\begin{array}{ll}\mathbf{z}: & \text { Vector of design variables; } \\ I: & \text { Investment as a function of design variables; } \\ \lambda: & \text { Penalty parameter; } \\ \beta: & \text { Reliability index; } \\ \beta_{\min }: & \text { Minimum reliability index. }\end{array}$

The second term in the right-hand side of equation (51) adds a penalty to the cost of the structure if the design violates the probability constraint. Therefore, the method is denoted a penalty function method (see Gill et al. (1981) for details). The method is illustrated for the example problem of section 3.4. Inspection of figure 29 shows that the cost of the structure is an increasing function of the two design variables. The failure probability is a decreasing function of the design variables and therefore also the penalty is a decreasing function of the design variables. The properties of the investment and the penalty function imply that a minimum of the augmented cost function can be found. The position of the minimum (the optimal design) depends upon the value of the penalty parameter $\lambda$. A too low value of the penalty parameter leads to a geometry that deviates from the exact solution. Figure 31 shows the contours of the augmented cost function in a case where the penalty parameter is chosen too low. The exact solution corresponds to the solution shown in figure 29. 


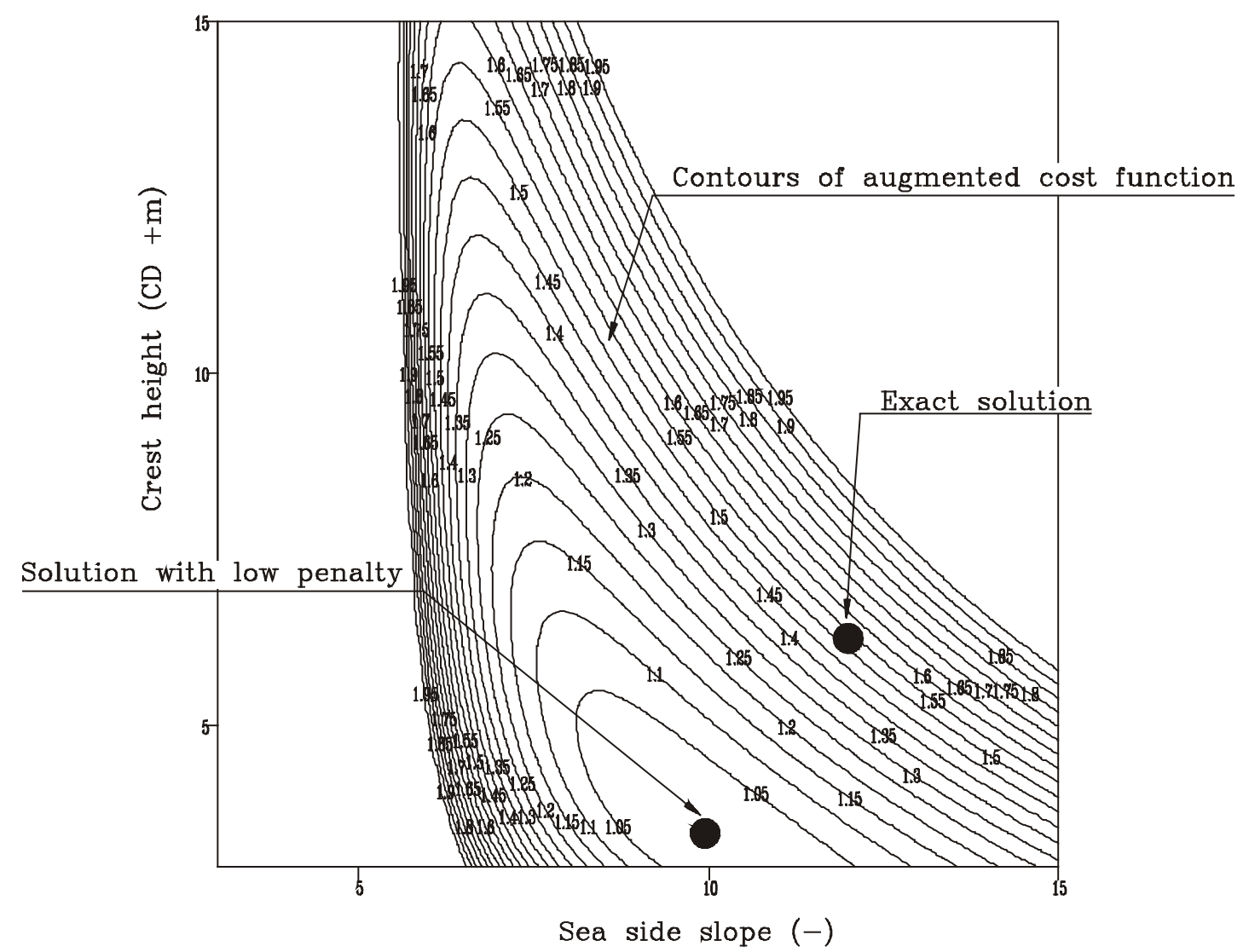

Figure 31: Contours of augmented cost function with a low penalty parameter

If the penalty parameter $\lambda$ is chosen too high, the minimisation problem becomes illconditioned. Practically, this means that around the minimum a large area exists with almost parallel contours of the augmented cost function. Due to the shape of the function, the minimum of the function is ill-defined (figure 32) and numerical procedures will generally fail to find the correct optimum. 


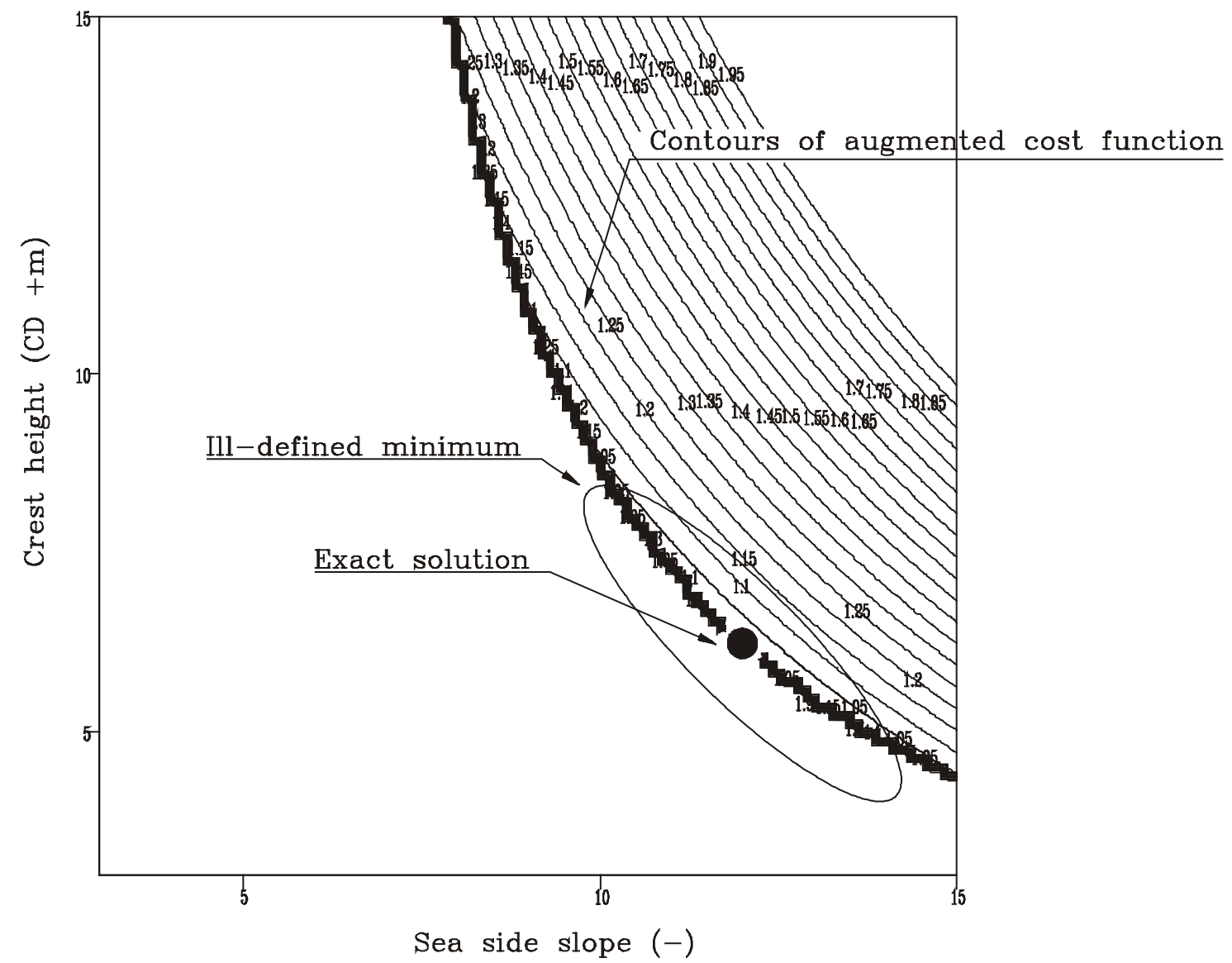

Figure 32: Contours of augmented cost function with a high value of the penalty parameter

A numerical optimisation routine will be able to find the minimum in the illconditioned case only if the starting point of the optimisation is chosen sufficiently close to the optimum. Therefore it is necessary to device a method to establish a starting point close to the optimum.

A method to obtain accurate optimisation results is found by starting the optimisation with a low penalty parameter so that ill-conditioning does not occur. After finalising the optimisation, the penalty parameter is increased. The already established optimal point is used as the starting point. By using the result of an earlier optimisation as the starting point, the starting point is already close to the minimum of the new optimisation. The procedure is repeated until the penalty function takes a sufficiently low value in comparison to the cost function.

Ill-conditioning may also occur if the difference between the elements of the augmented cost function is very large. The procedure is typically used to find optimal designs for failure probabilities ranging from $10^{-1}$ per year to $10^{-6}$ per year. This is a difference of five orders of magnitude. An appropriate optimisation strategy for the high failure probability may therefore fail if applied to a low failure probability. To avoid this problem the penalty function is defined on the basis of reliability indices, which for the same range of failure probability differ less than an order of magnitude. The relation between the reliability index and the failure probability is established through the inverse standard-normal distribution:

$\beta=\Phi^{-1}\left(P_{f}\right)$

Where $P_{f}$ denotes the failure probability. 
Gradient evaluation of the objective function is performed by obtaining the derivatives of investment to design variable and of the reliability index to the design variable. With this information, the gradient of the objective function can be calculated by:

$$
\nabla F(\mathbf{z})=\nabla I(\mathbf{z})-2 \lambda \max \left[\begin{array}{c}
\left(\beta_{\min }-\beta(\mathbf{z})\right) \\
0
\end{array}\right] \nabla \beta(\mathbf{z})
$$

The calculation of the investment for every design alternative is performed by straight-forward calculation of volumes or areas of well-defined parts of the cross section of the flood defence. The gradient of the reliability index in equation (53) is calculated by the methods outlined in annex 2 .

\subsection{Discussion}

The quantitative models to support decision making on flood protection all imply that the direct costs of protection are given as a function of the protection level. The protection level itself is quantified by a flooding probability. Despite the fact that the concept of van Dantzig's approach can still be considered valid, the definition of costs on the basis of the water level distribution alone can be considered insufficient in the light of current knowledge. The reliability-based optimisation methods outlined in this chapter can be applied to establish the direct costs of flood protection as a function of flooding probability. To this end, the optimisation according to equation (48) should be performed for a range of values of $P_{f ; m a x}$. Thus, the cost information necessary in quantitative decision making can be brought to the same level of sophistication as the underlying probabilistic methods.

Apart from possible application in a risk-based design method, the methods can also be applied in a system where legislative requirements for flood protection are defined as maximum failure probabilities per flood defence component. In that case, optimisation according to equation (48) may be performed to find the design that fulfils the legislative requirement against minimum costs. 



\section{QUANTIFYING THE CONSEQUENCES OF FLOODING}

"In this connection, it is relevant to point out that the cost of the raw materials in a human body is a couple of dollars"

Arthur C. Clarke, Profiles of the future (1962)

\subsection{Introduction}

A number of quantitative models for supporting decision-making on flood protection were introduced in chapter 2. The models are all based on an estimate of the cost of protection and estimates of the consequences of flooding. Decision-making on the basis of the expected value or any other characteristic value of the consequences of flooding necessitates the quantification of the probability distribution of the flooding consequences. This is the subject of this chapter.

A flood generally leads to a variety of consequences. A few examples are (see also Rijkswaterstaat and Dutch Meteorological Institute, 1961; Slager, 1992):

- Casualties;

- Fear and anxiety among people;

- Loss of economic value;

- Direct damage to flood defences;

- (Irreversible) loss of land;

- Loss of historically valuable objects/sites;

- Loss of natural and ecological values.

Quantifying the distribution of the effects of flooding is typically a multi-disciplinary activity. This is illustrated in table 11 where a number of elements of the distribution of flooding consequences are listed together with their corresponding discipline.

Table 11: Elements of the probability distribution of the consequences of flooding

\begin{tabular}{ll}
\hline Aspect & Discipline \\
\hline Probability of flooding & Engineering \\
Behaviour of a flood & Engineering \\
Effects of flooding on structures & Engineering \\
Behaviour of people during the flooding process & Sociology and psychology \\
Direct effects of loss of production capacity & Economy \\
Indirect effects on the macro-economy & Economy \\
Health effects in the aftermath of flooding & Medicine \\
Behaviour of individuals before, during and after flooding & Psychology \\
Behaviour of groups of individuals & Sociology \\
Effects on life expectancy & Demography \\
Effects of loss of archaeological sites/historic objects & History, archaeology \\
\hline
\end{tabular}

Several aspects of the effects of disaster have been studied in most disciplines mentioned in table 11, although not always applied to flooding. In the Netherlands, multi-disciplinary research into flooding consequences has recently started (Delft Cluster, 2001).

Generally, an analysis will ultimately be aimed at decision-making on flood protection levels. This necessitates a quantification of the effects of flooding in an affected area as well as a quantification of the probability of occurrence of damage of any kind. These are typically engineering aspects of the analysis of flooding 
consequences. Several elements of the analysis from an engineering point of view have already been developed. It nevertheless appears useful to develop an overall scheme in an attempt to integrate all elements in one framework.

In general, a distinction can be made between direct damage and indirect damage due to flooding. Direct damage is defined as damage caused by contact with the flood water. Indirect damage is a consequence of direct damage. Therefore, the first step in a quantitative analysis of flooding consequences should be the quantification of the direct damage. To quantify the direct consequences of flooding, the damage in the affected area must be modelled as a function of the properties of a flood.

Arguably the most important consequences of flooding are loss of economic value and loss of life. Loss of life may be quantified in a few different ways. Section 4.5 provides an introduction to a few important concepts. Relations between different measures of loss of life are shown.

A review of literature on cost-benefit analysis shows that the definition of costs and benefits as well as the scope of a cost-benefit analysis are not straight-forward but necessitate a few important choices. Section 4.6 attempts to structure the concepts commonly distinguished in economy and provides some aspects on the choice of the method.

The discussions in this chapter are limited to quantifiable aspects of flooding consequences. Non-quantifiable aspects may play an important role in the public debate on the protection against flooding. However, at this point it is not clear how to integrate these aspects in a quantitative model of flooding risk. This does not mean that these aspects can or should be excluded to begin with. It rather means that a quantitative method as presented in this chapter is only one element in the decisionmaking process on flood protection, as was already indicated in chapter 1 .

\subsection{A conceptual model for direct damage as a consequence of flooding}

The properties of a dike ring area are the result of the interaction between natural processes and human intervention over the centuries (see chapter 1). For 53 areas in the Netherlands, the definition of the flood defence ring is laid down in the flood defence act and has thus a legal status. The flood defences that are defined in the law are referred to as primary flood defences.

Historically, the primary flood defences are only the last in a successive series of flood defence systems. In most areas, historic flood defences are still present in the landscape and will influence the behaviour of a flood. These older flood defences are referred to as secondary flood defences. Also natural differences in terrain level and artificial soil bodies (roads, railroads) will affect the behaviour of a flood. Ultimately the properties of the flood determine the direct flooding damage. Therefore, in an analysis of the probability distribution of flooding consequences, suitable schematisations of the flood and the affected area have to be developed in order to deal with the relevant aspects of flood and area to a sufficient level of detail. In figure 33, a conceptual model of flooding of an area is presented that may serve as a starting point for a quantitative analysis of the probability distribution of flooding consequences. The scheme is based on a situation where the defence ring of a floodprone area is breached in one location. 


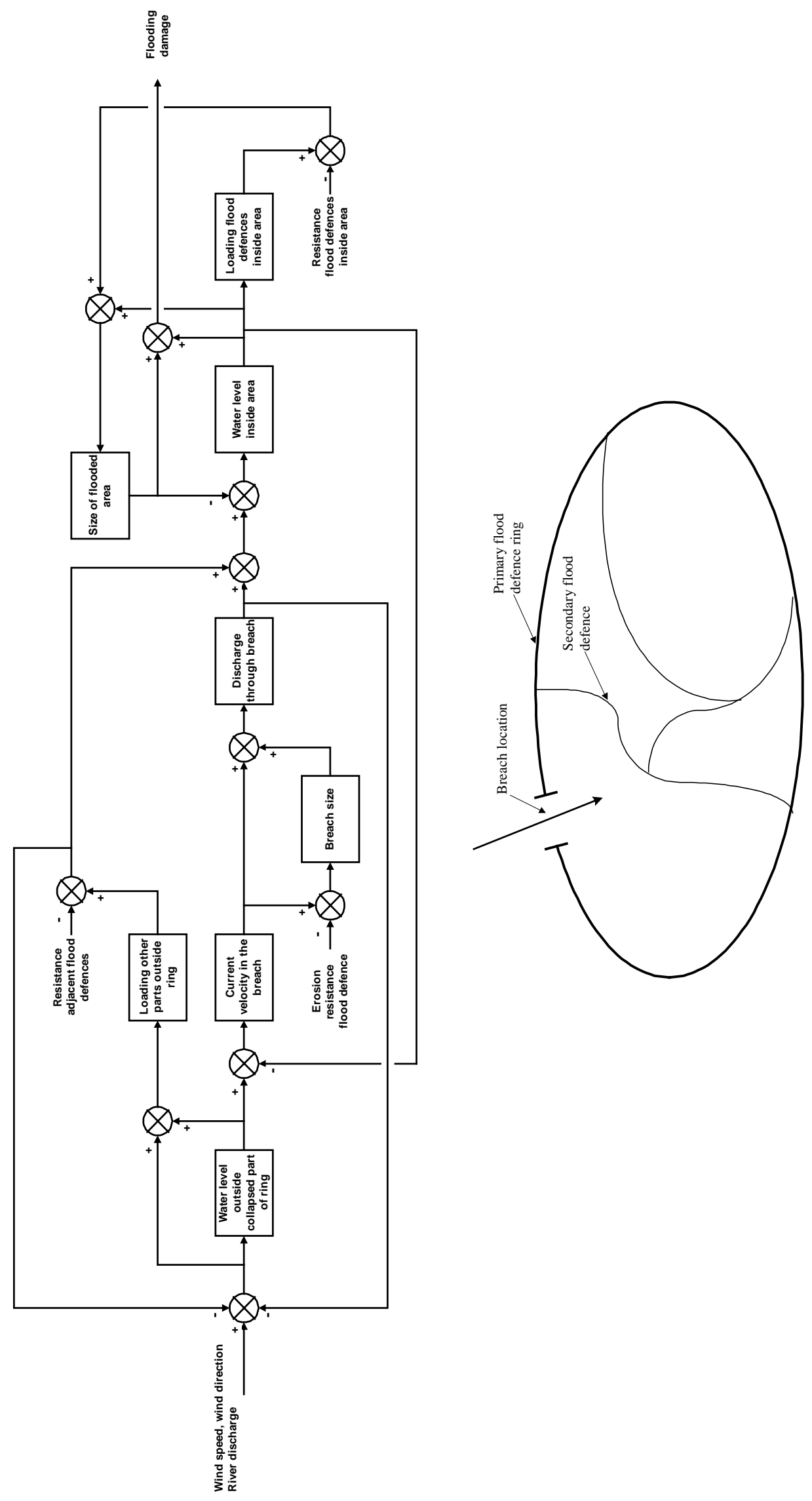

Figure 33: Conceptual model of the development of damage due to flooding 
The scheme in figure 33 is not complete, but is intended to visualise the most important processes leading to flooding damage after a part of the primary flood defence ring has failed. Starting in the right-hand side of figure 33, the damage due to flooding is influenced by two factors; the size of the flooded area and the water level in the area ${ }^{5}$. The size of the flooded area generally increases with increasing water level. The presence of historic flood defences inside the area may limit the spatial scale of the flood. In that case, collapse of one or more flood defences inside the area causes an increase of the size of the flooded area. An increased size of the flooded area has a negative influence on the water level itself.

The water level inside the area is influenced by the discharge through the breach and the discharge through breaches in adjacent parts of the primary defence ring. The breach discharge depends on the current velocity in the breach and the size of the breach. The development of the breach size itself is positively influenced by an increased current velocity in the breach and negatively influenced by increased erosion resistance of the remains of the breached flood defence (see also Visser, 1998).

The current velocity in the breach depends on the water levels outside and inside the flood defence. An increase of the water level outside the defence causes an increase of the current velocity in the breach. The influence of the water level inside the area depends on the difference in water level outside and inside the defence. When the water level difference is large, an increase of the inside water level has no influence. If the water level difference is small, tail-water effects cause a decrease of the current velocity if the inside water level increases.

The water level outside the ring is primarily governed by the wind field in case of flooding from sea and by the river discharge in case of flooding from a river. In coastal areas a transition zone exists where, going upstream along the river, the river influence increases and the sea influence decreases. In this zone, the loading on the flood defences is the result of the combined effect of the two primary sources of loading.

Next to the primary loading sources, a number of feedback processes influence the water level outside the dike ring. To begin with, the existence of a breach discharge negatively influences the outside water level. The magnitude of this effect depends on the magnitude of the breach discharge in comparison to the size of the water body. If the breach discharge is small with respect to the size of the water body, the effect on the outside water level is limited. This will generally be the case when the area is flooded from sea. When the area is flooded from a river, a considerable reduction of the water level may be caused by the breach flow, until the affected area is completely filled.

Breaching of adjacent flood defence structures may also lead to a reduction of the outside water level. Therefore, a feedback loop is present where the resistance of adjacent flood defences influences the outside water level. The outside water level in turn influences the loading on the adjacent structures.

Further inspection of figure 33 will reveal a number of other feedback processes taking place during the development of a flood.

\footnotetext{
${ }^{5}$ In some cases also the first derivative of the water level over time and the current velocities are important.
} 


\subsection{Methodology of quantitative analysis of direct flooding damage}

The decision models in chapter 2 are all based on an estimate of the damage in case of flooding. As shown in the previous section, the translation of outside loading conditions to damage in the area can be considered to take place through a complicated process where a number of factors interact and influence each other. The process ultimately results in a size of the flooded area and a water depth, which differs throughout the area because of differences in terrain level.

The distribution of flooding damage can generally be described by a probability density function with two or more peaks (figure 34).

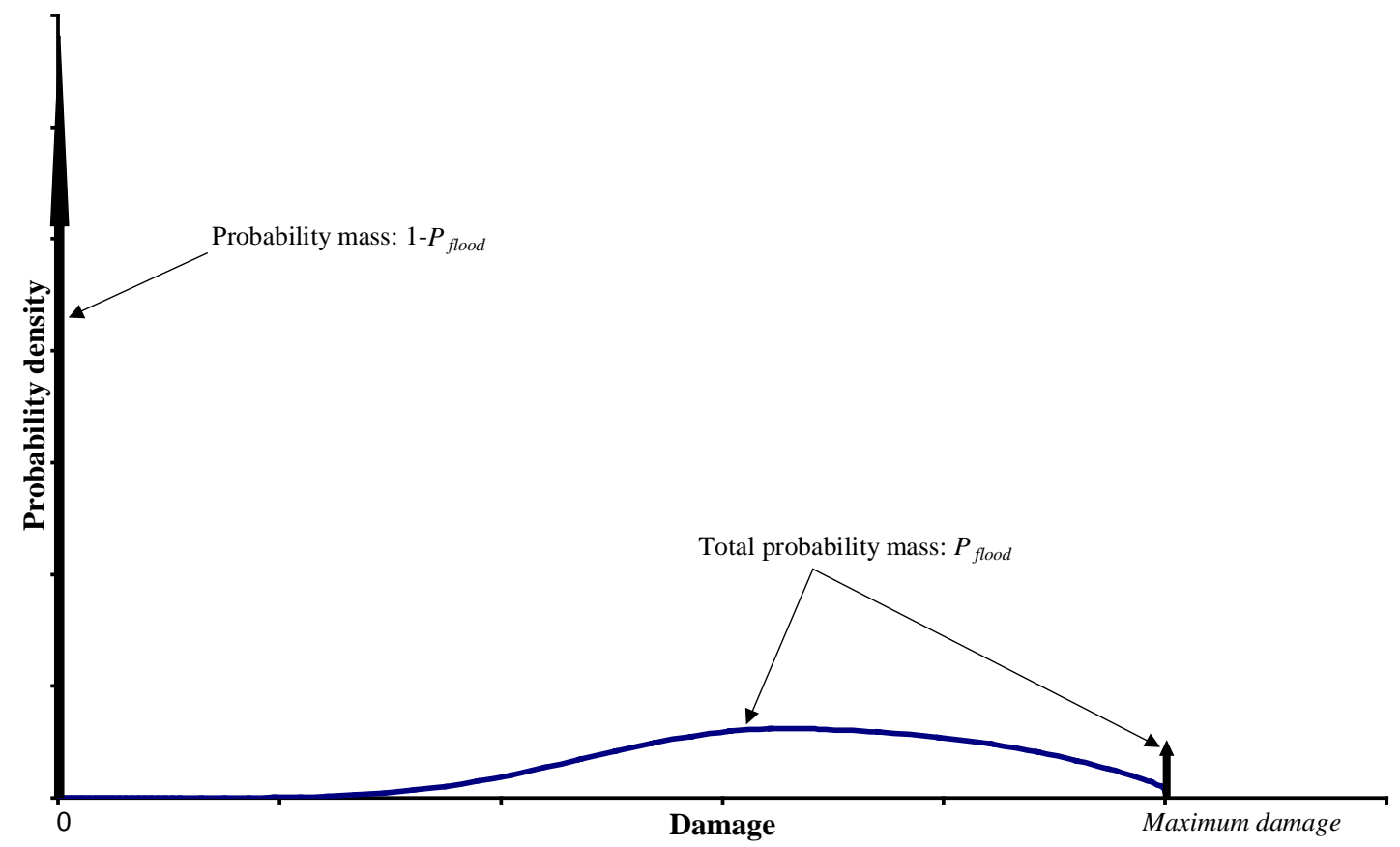

Figure 34: Example of the flooding damage distribution of a flood-prone area

At damage value 0 (no damage) a peak is present with a probability mass equal to the complement of the flooding probability. The probability mass of the peaks at non-zero damage values together have a probability mass equal to the flooding probability. The distribution of non-zero values of flooding damage depends on several factors, among which the way in which the area is flooded and the magnitude of the flood. The conditional distribution of the flooding damage may be found by defining damage factors as a function of flooding properties.

The damage in case of flooding depends on the properties of the flood and on the value of the area ${ }^{6}$. The value of the area is independent of the properties of the flood. It is therefore convenient to define a dimensionless measure of flooding damage that is a function of the flooding properties. This measure is denoted the damage factor and is given by (see also CUR/TAW, 1990):

$c=\frac{D}{D_{\max }}$

Where:

\footnotetext{
6 "Value" should be interpreted broadly. It may represent economic value, population numbers and/or several other aspects of damage.
} 
$D: \quad$ Flooding damage;

$D_{\max }$ : Maximum possible flooding damage.

The maximum possible flooding damage is generally taken equal to the value of the full inventory of the area. The damage factor $c$ can be considered a function of:

- Maximum water depth during the flood;

- Speed of water level increase, denoted flooding speed;

- Current velocity;

- Wind speed;

- Wind direction.

In general, the maximum water depth determines the direct economic flooding damage (Vrisou van Eck et al., 2000). At locations far from a breach, the water level in combination with the flooding speed determines whether people will be able to save themselves from drowning (Jonkman, 2001). In the vicinity of a breach, high current velocities will occur which will cause heavy damage to buildings and may prevent people from being able to save themselves (Abt et al., 1989; Lind and Hartford, 2000). Thus, current velocities have an effect on both the economic consequences and on the casualty numbers, but generally on a limited spatial scale. If the area remains flooded for a longer time, the probability of occurrence of strong winds over the flooded area becomes important, since wave loads may cause additional damage to property.

In order to find the distribution of the consequences of flooding as outlined above, it is necessary to find the distribution of the damage factor for every type of flooding damage. If the distribution of the damage factor is known, the distribution of the damage is easily found by multiplication with the maximum damage in the area. If the damage factor is explicitly written as a function of water level, flooding speed, current velocity, wind speed and wind direction, the distribution of the damage factor can be found from the joint probability distribution of the flooding properties by application of probabilistic methods outlined in chapter 3. An example may clarify this approach.

Consider an area with a terrain level at chart datum protected by a dike. Failure of the dike occurs if the outside water level exceeds a critical level. Failure is therefore described by the limit state function:

$g\left(h_{c r}, h_{w}\right)=h_{c r}-h_{w}$

Where:

$h_{c r}: \quad$ Critical water level;

$h_{w}$ : Water level.

The critical water level and the water level are both random variables. The distributions are given in table 12.

Table 12: Distributions of the random variables in an example damage factor calculation

\begin{tabular}{llll}
\hline Variable & Distribution type & Shift & Scale \\
\hline$h_{w}$ & Exponential & $1.96 \mathrm{~m}$ & $0.33 \mathrm{~m}$ \\
$h_{c r}$ & Normal & $0 \mathrm{~m}$ & $0.5 \mathrm{~m}$ \\
\hline
\end{tabular}


The assumption will be made that, in case of flooding, the water level inside and outside the area are equal. In that case, the distribution of the water level inside the area can be calculated directly from the distributions of the two basic variables by:

$F_{\underline{h_{p}}}(\eta)=1-\int_{\eta}^{\infty}\left(1-F_{\underline{h_{w}}}(\xi)\right) f_{\underline{h_{c c}}}(\xi) \mathrm{d} \xi$

In more complicated cases, probabilistic methods outlined in chapter 3 may be used to derive the distribution of the water level inside the area. Figure 35 shows the distribution of the water level inside the area as derived from equation (56).

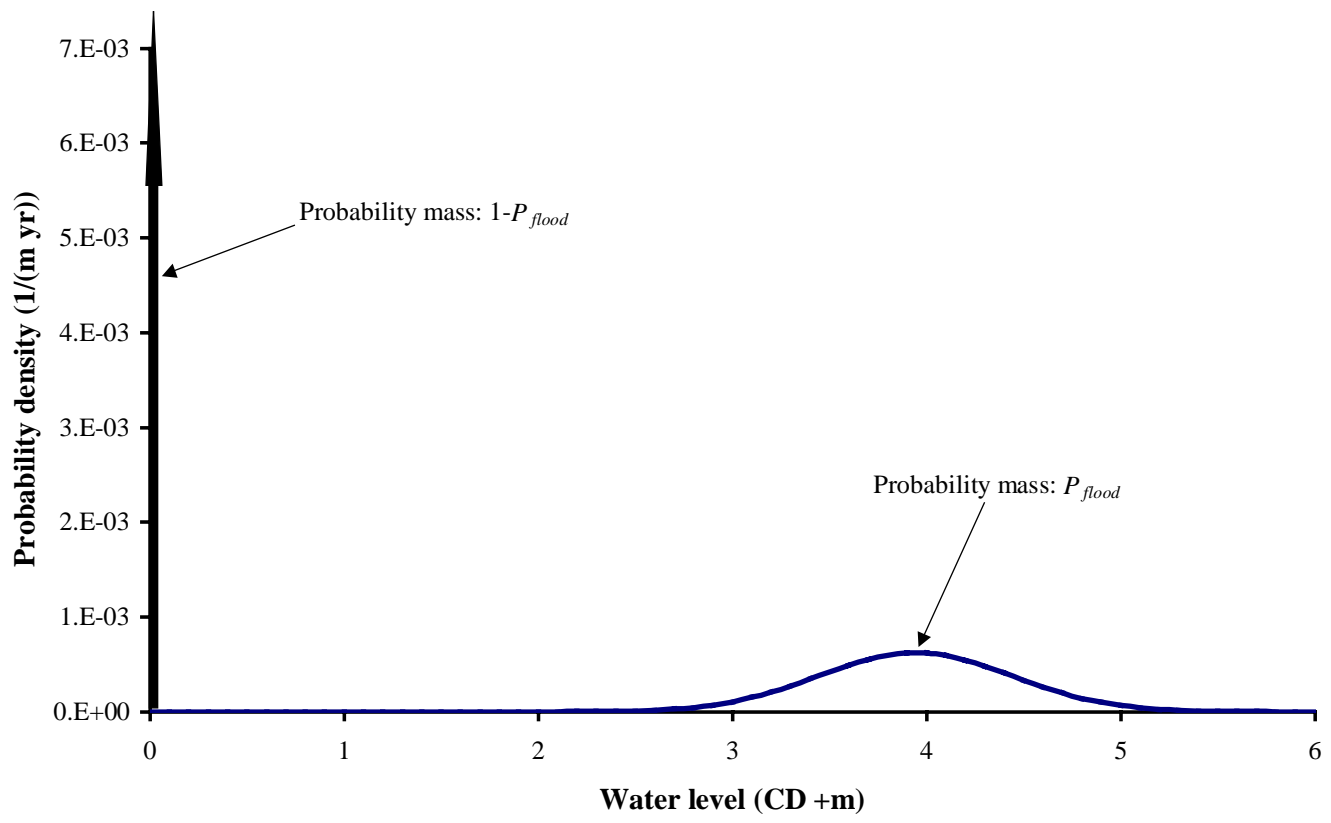

Figure 35: Probability density of the water level inside a flood-prone area

Water levels inside the area higher than chart datum lead to flooding of the area. The total probability mass at water levels higher than chart datum equals the flooding probability $P_{\text {flood }}$.

Delft Hydraulics (1994) provides a function for flooding damage to dwellings which is a function of the water level only (figure 36).

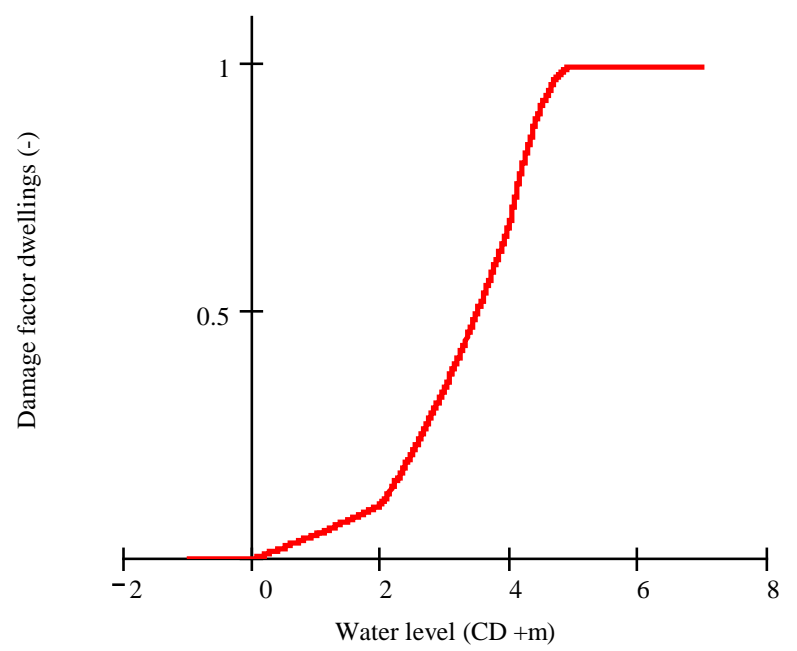

Figure 36: Damage function for dwellings 
Combination of the damage function with the distribution of the water level inside the area directly leads to the distribution of the damage factor (figure 37).

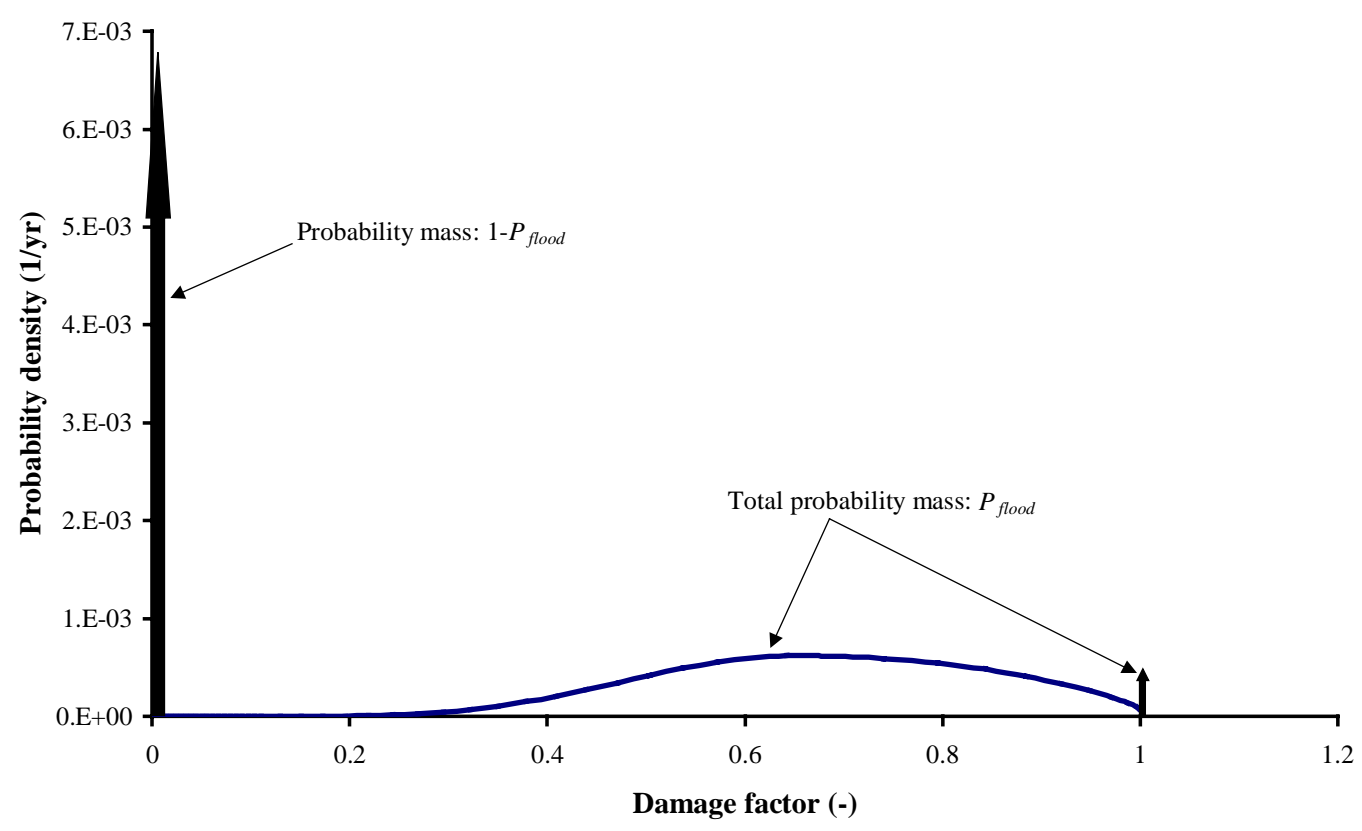

Figure 37: Probability density of the damage factor for dwellings as derived in a simple example

The example shows a case where the damage factor is a function of the water level only. To derive the probability distribution of the damage factor, the quantification of the marginal distribution of the water level inside the area is therefore sufficient. For other types of damage, the joint probability distribution of the flooding properties needs to be established. Voortman and Jak (2001) demonstrated the analysis of flooding consequences for a simple case study, where parametric physical models could be used to describe the flooding properties. In more complicated cases, numerical models may be applied to quantify the flooding properties (see RWS, 2001 for an example).

An upper bound estimate of the damage factor distribution is found when the flooding consequences are described by a step function of the water level in the affected area (figure 38).

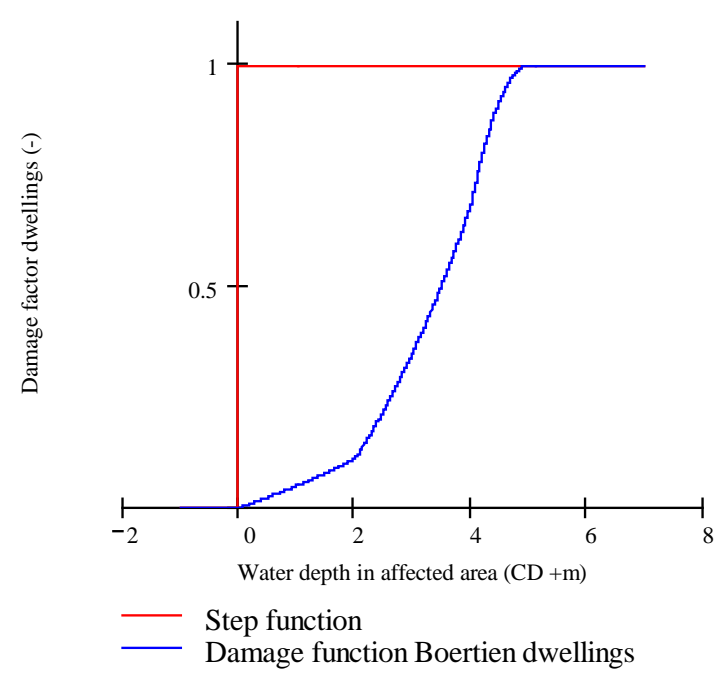

Figure 38: Damage function for dwellings and step function 
The step function provides damage factors of 0 if no flooding occurs and 1 if flooding occurs. As a result the distribution of flooding damage follows a binomial distribution (figure 39).

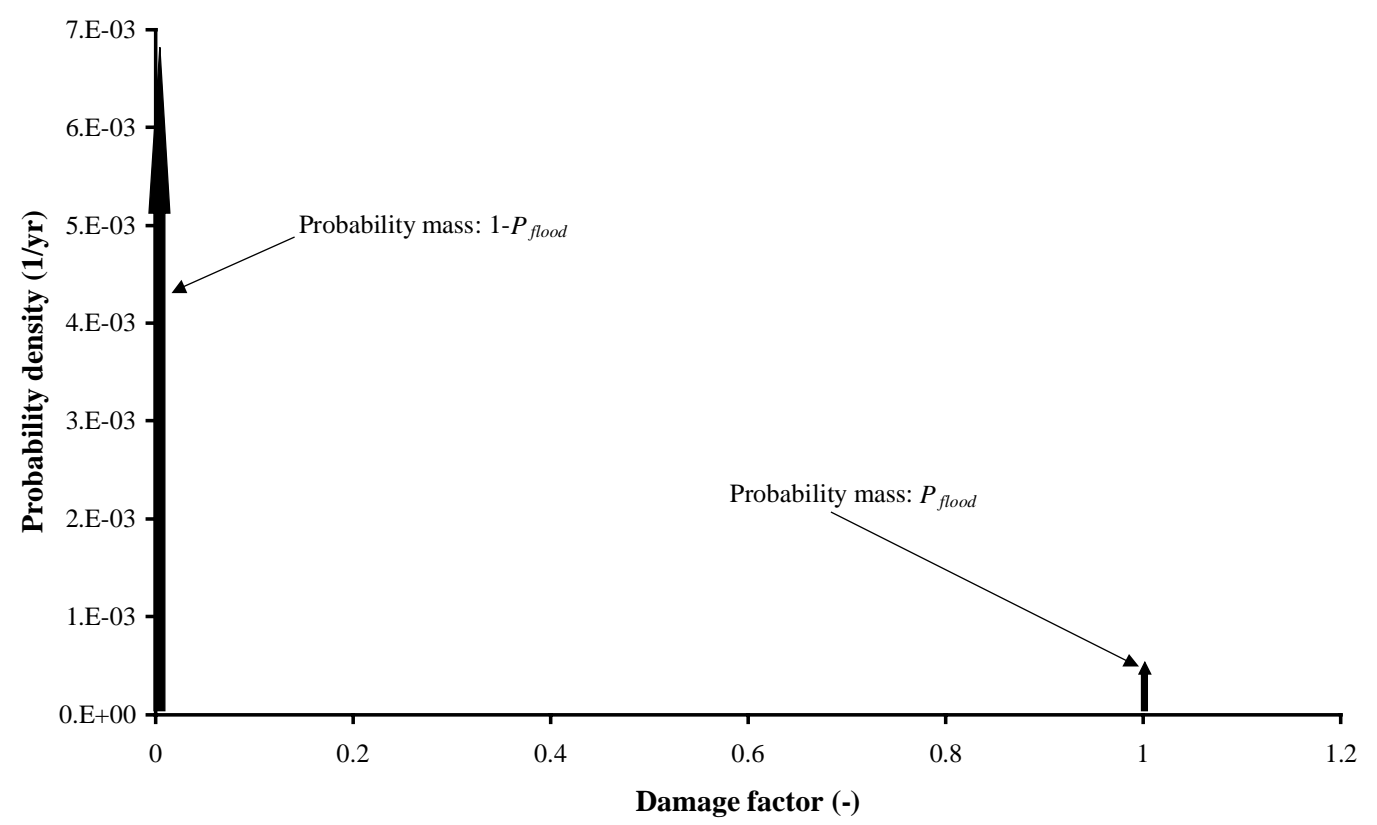

Figure 39: Damage factor distribution resulting from the use of a stepped damage function

Although it is a crude approach, the analysis of flooding damage distributions by means of step functions is useful since the information included in it is also necessary for a more detailed analysis. Therefore, the upper bound approach could form a first step in the analysis of the damage factor distribution. The following section shows the quantification of the damage factor distribution for a fictitious area based on the upper bound approach.

\subsection{Schematisation of a flood-prone area for the estimation of direct flooding damage}

\subsubsection{Options for schematisation of the area}

Summarising the previous two sections, the probability distribution of direct flooding damage is determined by:

- The properties of the flood itself through the damage factor;

- The value of the area.

Only the damage factor is a function of the flooding properties. In the previous section, the damage factor distribution was derived for a very simple case. In more complicated cases, a suitable schematisation of the area and the behaviour of the flood needs to be found, so that the probability distribution of the damage factor can be established. Three options for the schematisation of a flood-prone area may be defined:

- Schematisation of the dike ring as a whole;

- Schematisation in a set of flooding scenarios;

- Schematisation in a set of sub-areas.

The schematisation of the dike ring as a whole is the oldest and simplest option. In this case spatial variation of the flooding probability is neglected. The probability of failure of the outer ring is considered to be a measure of the flooding probability for 
every location in the protected area. In combination with stepped damage functions, the damage factor distribution takes the form shown in figure 39.

Breaching of the primary flood defence does not necessarily lead to a complete loss of all value in the area. Height differences in the area and the presence of secondary flood defences may limit the spatial scale of the flood. Furthermore, in large areas the flooding speed may be so low that people are able to save themselves and part of their property from the flood. Therefore the dike ring schematisation may be too crude in a number of cases. An alternative is the schematisation in a set of flooding scenarios (RWS, 2001). This option appears to be inspired upon the reliability analysis of a dike ring where a number of separate dike sections are analysed with respect to their reliability. On this basis, a flooding scenario is defined as failure of one or more sections of the ring. The consequences of flooding are quantified by running a numerical model providing a detailed description in space and time of the flooding process. A serious drawback of this approach is the deterministic analysis of the flooding process contained in the numerical model. The model of section 4.2 shows that secondary flood defences may or may not fail in case of flooding which has an effect on the behaviour of the flood. It appears that the existing numerical flooding models do not include the possibility of failure of secondary defences. If possible failure of defences inside the area is to be considered, the definition of a flooding scenario as given above is incomplete.

An alternative for the flooding scenario approach is a schematisation in a set of subareas. In this approach, the distribution of flooding properties is analysed for a number of distinct locations inside the area, starting with a detailed analysis of the flooding probability per sub-area. The selection of sub-areas follows from an analysis of differences in terrain level and the location of secondary flood defences in the area.

\subsubsection{Application of three different schematisations to a fictitious flood-prone area}

To explore the applicability of different schematisations of a flood-prone area, a fictitious example will be used (figure 40).

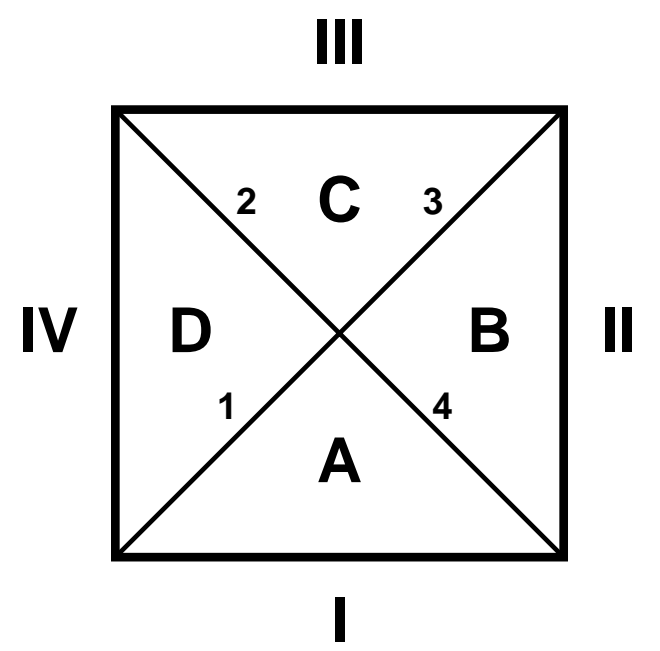

Figure 40: Plan of a fictitious dike ring with four primary and four secondary flood defences

The area considered has a square shape. The outer defence ring is split in four sections denoted I through IV. Inside the area, four inner flood defences are present, denoted 1 through 4. Due to the inner flood defences, the area is split into four sub-areas, denoted A through D. 
As indicated in section 4.3, an important element of the probability distribution of the damage factor is the flooding probability itself. When using stepped damage functions, establishing the flooding probability for every sub-area A through D is sufficient to find an estimate of the probability distribution of the damage factor. In the following, the analysis of the damage factor distribution will be performed on this basis. The use of more elaborate damage functions is an extension of the approach outlined here.

When applying the dike ring schematisation to this problem, the probability of flooding is given by the probability of failure of the outer ring only. If any part of the ring fails, the damage factor for the full area equals 1 . Figure 41 shows the result derived with a probability of failure of the outer defence sections of $10^{-4}$ per year.

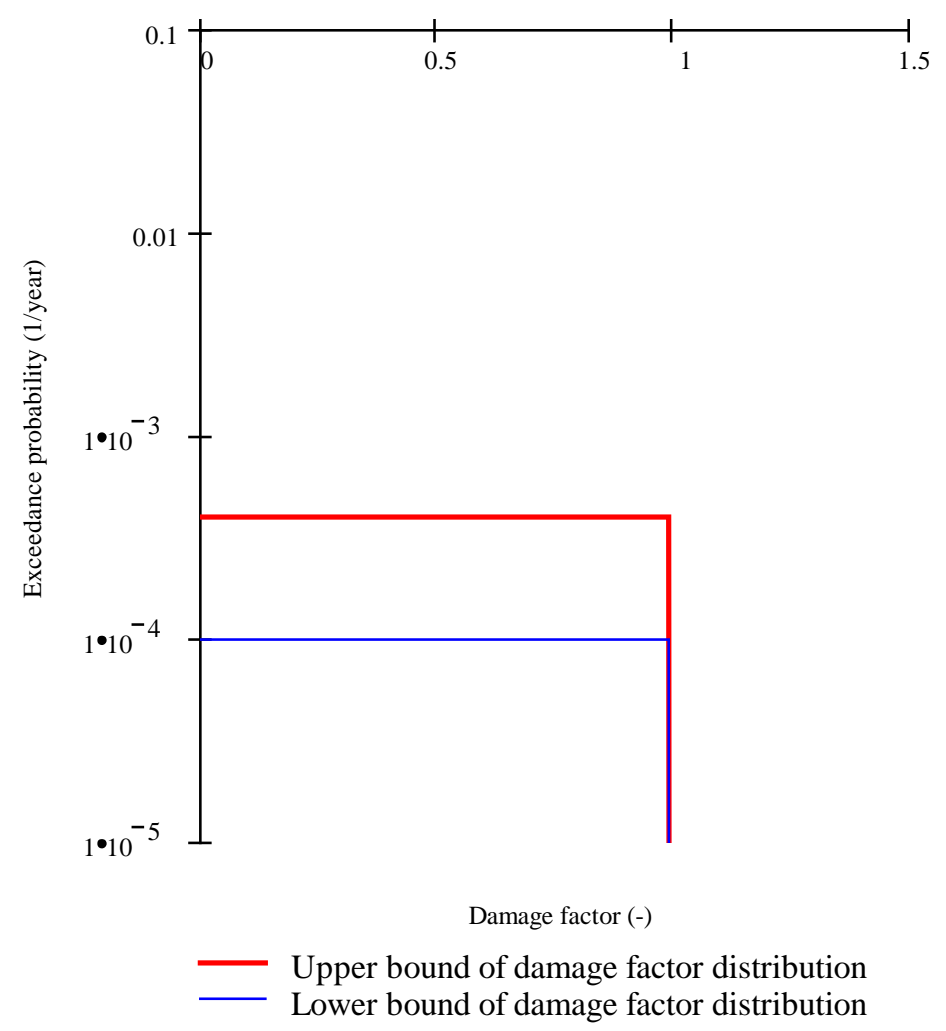

Figure 41: Distribution of the area-wide damage factor by the dike ring schematisation

The actual failure probability of the full ring depends on the probability of failure of the four primary defence sections and their dependence (see chapter 3). An upper and lower bound estimate of the flooding probability can be derived. Figure 41 shows the cumulative distribution function of the damage factor. The distribution of the damage factor is of the form shown in figure 39 .

The dike ring schematisation provides an upper bound on the damage factor estimate. Any failure of the outer ring is assumed to lead immediately to the maximum direct damage in the area. Estimates obtained by other schematisations may be lower than the estimate obtained in the dike ring approach, but never higher.

One option for a more detailed analysis of the consequences of flooding is to analyse closely the effects of failure in different locations along the primary defence ring. This is the schematisation by flooding scenario (RWS, 2001). A scenario is defined as failure of one or more sections of the primary ring. Accounting for all possible combinations of failures of one, two, three or four sections of the outer ring leads in 
this case to a total of 15 scenarios. However, due to the presence of secondary flood defences inside the area, the direct damage in case of the occurrence of one scenario does not take a unique value. This is illustrated by the event tree for the scenario "failure of section I" in figure 42.

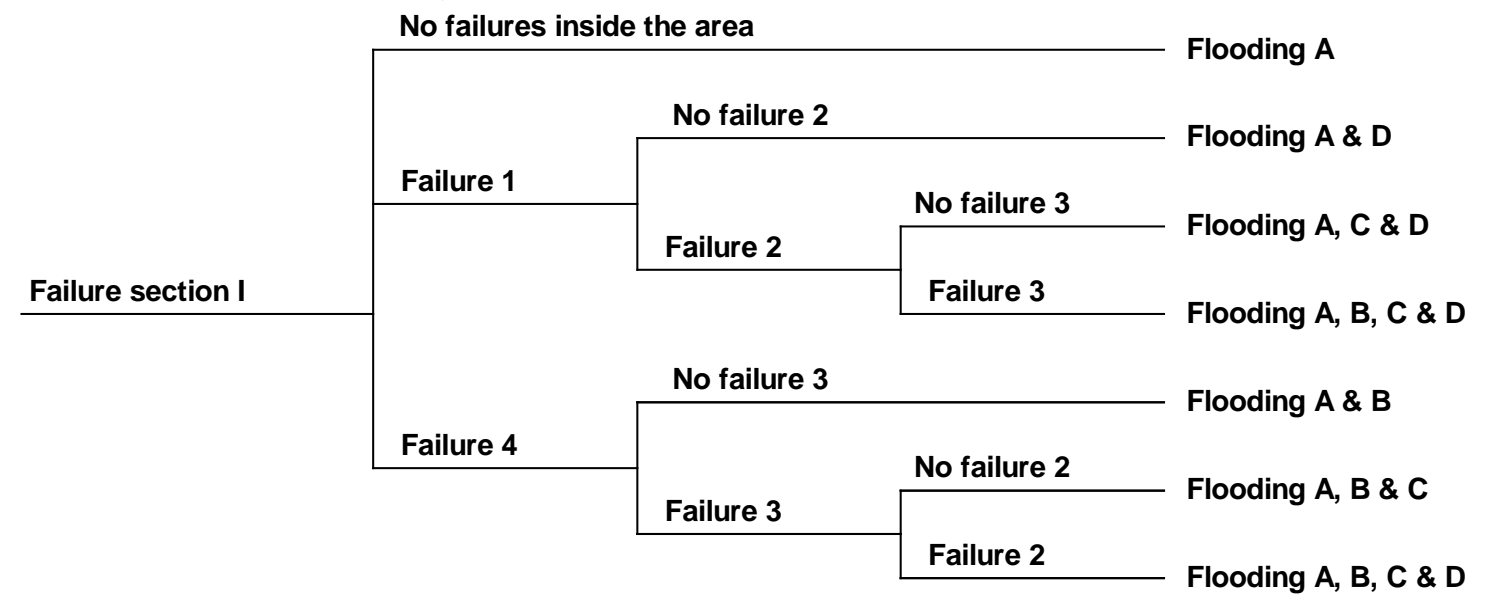

Figure 42: Event tree for failure of section I of the fictitious dike ring of figure 40

The scenario "failure of section I" in fact involves seven different sub-scenarios, ranging from flooding of area A only to flooding of all areas A through D. Similar trees can be developed for failure of other sections and for combinations of failure of more than one section of the primary defence ring. An analysis of all combinations of failures provides an estimate of the total number of distinct flooding scenarios (table 13).

Table 13: number of distinct flooding scenarios for a simple dike ring

\begin{tabular}{llll}
\hline $\begin{array}{l}\text { Number of failures } \\
\text { primary sections }\end{array}$ & $\begin{array}{l}\text { Number of scenarios } \\
\text { primary ring }\end{array}$ & $\begin{array}{l}\text { Number of distinct } \\
\text { scenarios inside ring }\end{array}$ & $\begin{array}{l}\text { Total number of } \\
\text { scenarios }\end{array}$ \\
\hline 1 & 4 & 7 & 28 \\
2 & 6 & 5 & 30 \\
3 & 4 & 2 & 8 \\
4 & 1 & 1 & 1 \\
\hline Total & 15 & & 67 \\
\hline
\end{tabular}

In the analysis of scenarios inside the ring, only those scenarios that influence the spatial scale of the flood have been counted. For instance, in case of failure of sections I and II, failure of section 4 does not influence the spatial scale of the flood and has therefore not been counted as a scenario. The fact that any flood defence (primary or secondary) may fail in different ways has been neglected. Nevertheless, the total number of distinct scenarios is high, despite the fact that the example is very simple.

Inspection of the event tree in figure 42 shows that a number of scenarios leads to the same magnitude of consequences, since they lead to the same sub-areas to be flooded. Furthermore, the event tree shows that there is dependence between the scenarios, because a number of failures are part of more than one scenario. Summarising, the scenario approach suffers from two sources of dependence, through the dependence between failure events and through the overlap of consequences of failure. Establishing a correct estimate of the flooding damage by the scenario approach appears to be a task that rapidly becomes impracticable in view of this double source of dependence. In RWS (2001) the problems are circumvented by the selection of a limited number of scenarios. RWS (2001) justly recognises that this approach 
introduces subjectivity in the calculation that may influence the estimate of flooding damage.

An alternative solution to the problem is the development of a schematisation which excludes one of the two sources of dependence. The schematisation in a set of subareas is such an approach. Instead of analysing the multitude of scenarios that may follow failure of one of the sections of the outer ring, all combinations of failures that lead to flooding of one sub-area are analysed. Figure 43 shows the fault tree for the event "flooding of sub-area A". Similar fault trees may be established for flooding of other sub-areas.

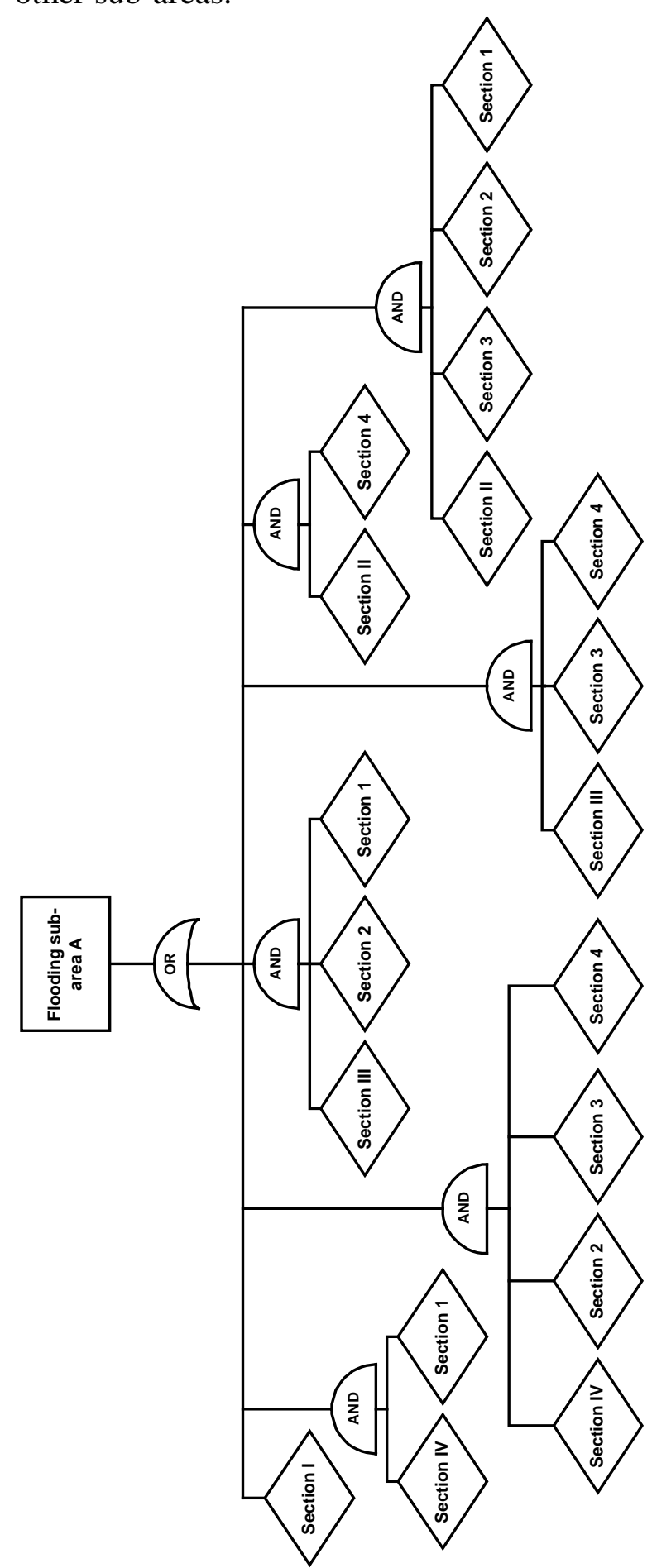

Figure 43: Fault tree for the event "flooding of sub-area A" in the dike ring of figure 40 
Dealing with dependence between failure modes in a system analysis belongs to the realm of known reliability methods (see chapter 3). Dependence between the consequences of failure is excluded from the beginning, since the probability of occurrence of damage in distinct locations of the area is analysed. Combinations of flooding damage in different locations may be analysed by application of methods for system reliability analysis. Also in the analysis of combinations of damage, only the dependence through the probabilities of failure plays a role. Establishing the schematisation in a set of sub-areas generally requires a detailed analysis of the geographical situation in the area. Nevertheless, it appears that further quantification of the flood damage distribution is highly facilitated by this approach.

Using the sub-area schematisation, the effect of secondary flood defences on the flooding probability per sub-area is quantified. Figure 44 shows the flooding probability of sub-area A as a function of the probability of failure of the secondary defences. The primary flood defences are considered to have a failure probability of $10^{-4}$ per year.

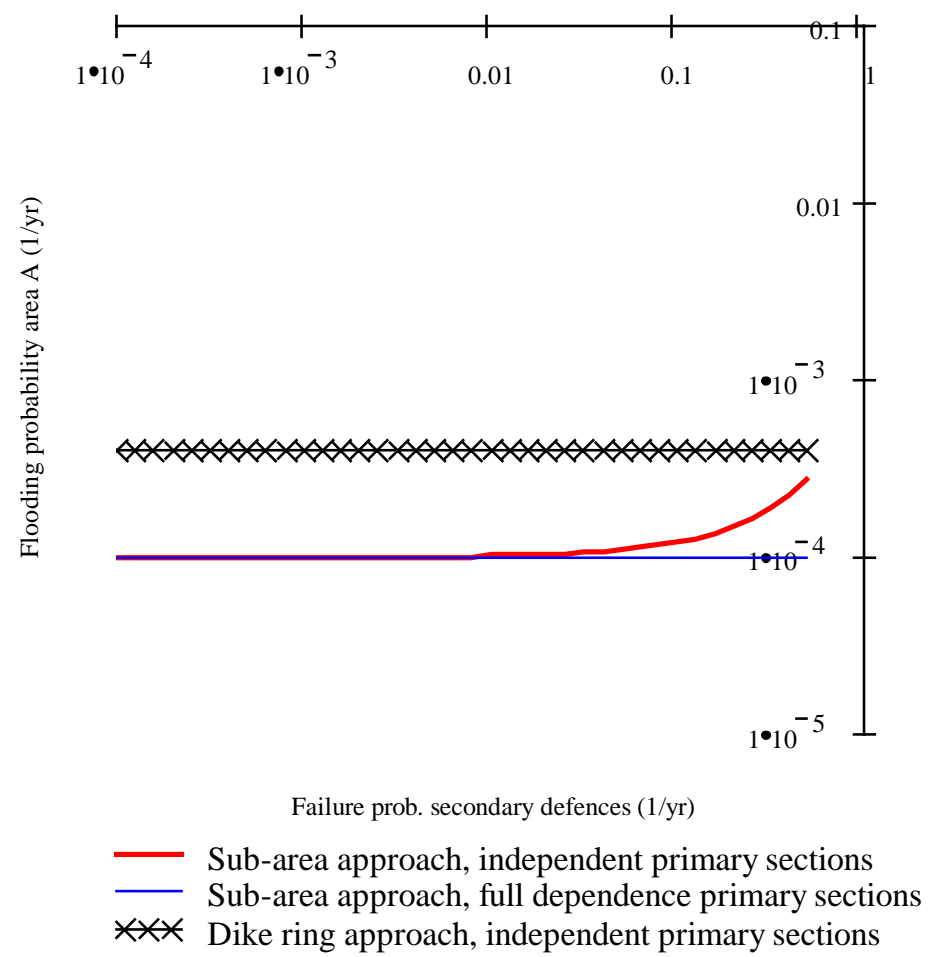

Figure 44: Flooding probability of sub-area A as a function of the failure probability of secondary defences

The probability of flooding of sub-area A depends on the failure probabilities of the sections of primary and secondary flood defences and on the dependence between them. In figure 44 the secondary defences are considered independent of the primary defences. The sub-area approach is shown for two cases of dependence of the primary defences. For comparison, the result of the dike ring approach with independent primary sections is shown. If the sections of the primary defence ring are independent, the secondary flood defence strongly influence the probability of flooding per subarea. If the conditional failure probabilities of the secondary flood defences are lower than $10^{-2}$, the flooding probability of the area is equal to the failure probability of the adjoining section of the primary defence ring. This means that in that case it is unlikely that the area is flooded due to a failure of sections II through IV in combination with one or more failures of secondary defences. 
If the sections of the primary ring are fully dependent, the probability of flooding of area $\mathrm{A}$ is not influenced by the presence of the secondary defences. Full dependence implies that all primary sections fail as one and therefore any failure implies immediate flooding of all sub-areas A through D.

If the flooding probability per sub-area is known, the probabilities of flooding of one or more sub-areas can be established by analysing the probability of occurrence of flooding of a combination of sub-areas. The probability of flooding of one sub-area or more is given by:

$$
P(N \geq 1)=P(A \cup B \cup C \cup D)
$$

Where $N$ denotes the number of sub-areas flooded. Flooding of a sub-area is indicated by the sub-area letter.

Similarly, the probability of flooding of two or more, three or more and four or more areas is given by:

$$
\begin{aligned}
& P(N \geq 2)=P((A \cap B) \cup(A \cap C) \cup(A \cap D) \cup(B \cap C) \cup(B \cap D) \cup(C \cap D)) \\
& P(N \geq 3)=P((A \cap B \cap C) \cup(A \cap B \cap D) \cup(A \cap C \cap D) \cup(B \cap C \cap D)) \\
& P(N \geq 4)=P(A \cap B \cap C \cap D)
\end{aligned}
$$

Applying the methods for reliability analysis of systems to different combinations of flooded sub-areas leads to the distribution of the number of flooded sub-areas shown in figure 45 .

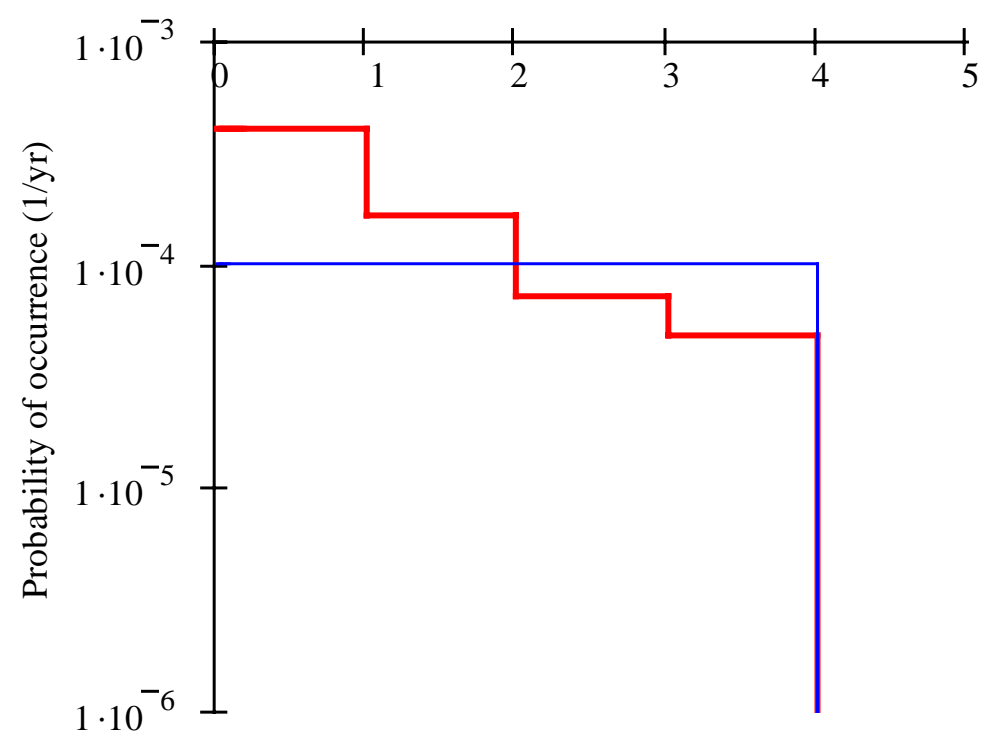

Number of sub-areas flooded (-)

Sections primary defence independent
Sections primary defence fully dependent

Figure 45: Distribution of the number of flooded sub-areas (failure probabilities: primary sections $10^{-4}$ per year, secondary sections $10^{-1}$ per event)

If the sections of the primary defence are independent, the secondary flood defences influence the probability distribution of the number of flooded areas. The probability of flooding of the full area is reduced by approximately one order of magnitude. In 
case of full dependence between the sections of the primary flood defence ring, there is no effect of the secondary flood defences.

Using the probability distribution of the number of flooded areas, the distribution of the area-wide damage factor can be derived. The result in figure 46 is derived under the assumption that the value of the area is homogeneously distributed over the four sub-areas. In that case, the area-wide damage factor in case of flooding of one subarea equals 0.25 .

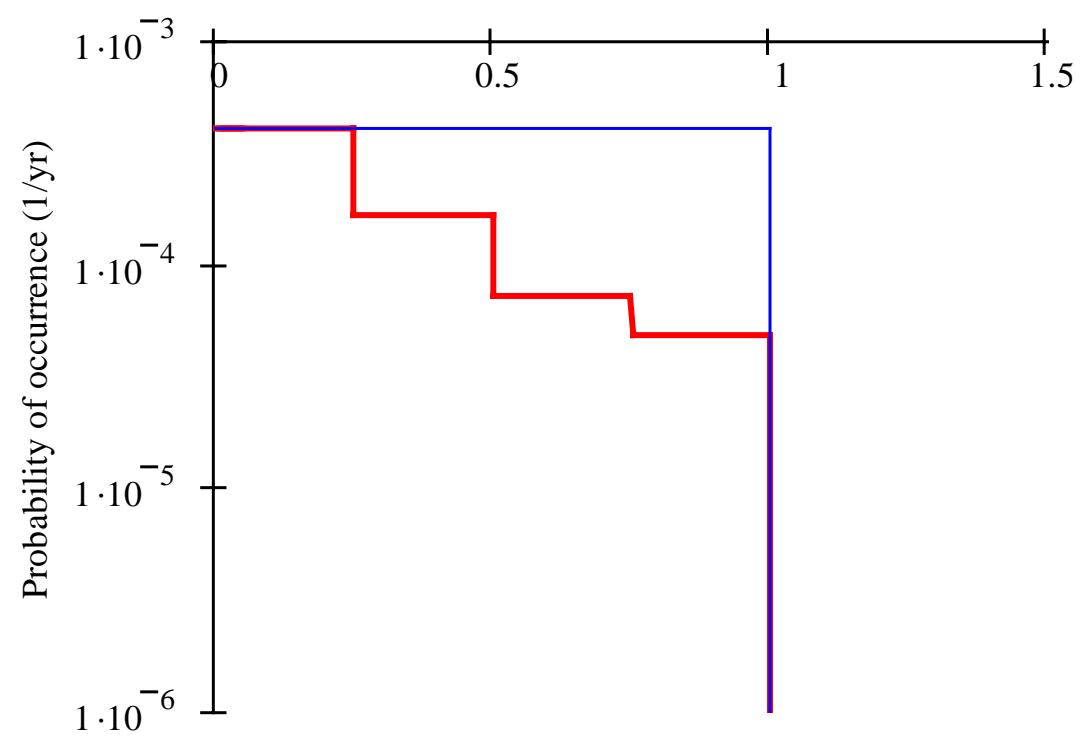

Area wide damage factor (-)

Sections primary defence independent

Dike ring approach, sections independent

Figure 46: Distribution of area-wide damage factor derived by sub-area schematisation

Figure 46 shows that a considerable reduction of the damage estimate may be achieved in comparison to the dike ring approach. Table 14 shows the expected value and the standard deviation of the damage factor for the dike ring approach and the sub-area approach.

Table 14: Characteristic values of the damage factor distribution for different values of the failure probability of secondary defences

\begin{tabular}{lll}
\hline $\begin{array}{l}\text { Failure prob. secondary } \\
\text { defences (1/event) }\end{array}$ & Mean damage factor $(-)$ & $\begin{array}{l}\text { Standard deviation damage } \\
\text { factor }(-)\end{array}$ \\
\hline 1 (ring approach) & $4 \cdot 10^{-4}$ & $2 \cdot 10^{-2}$ \\
$10^{-1}$ & $1.7 \cdot 10^{-4}$ & $1 \cdot 10^{-2}$ \\
\hline
\end{tabular}

Compared to the dike ring approach, the expected value and the standard deviation of the damage factor are reduced by a factor 2 when using the sub-area approach.

\subsection{Quantifying loss of life due to flooding}

\subsubsection{Probability distribution of the yearly number of casualties}

Risk of loss of life due to flooding materialises due to a number of people perishing prematurely due to the occurrence of a flood. An important measure of loss of life due to flooding is the probability distribution of the yearly number of casualties. The measures for acceptable risk of loss of life by Vrijling et al. $(1995,1998 b)$ are given 
as direct limitations on the probability distribution of the yearly number of casualties. The distribution of the yearly number of flooding casualties can be found from the flooding probability and the damage factor for casualties.

A damage factor for casualties couples the properties of the flood and possibly the response of people to the fraction of the population drowning in case of flooding (see Jonkman, 2001 for more details):

$c_{c a s}=\frac{N_{d}}{N_{p}}$

Where:

$N_{d}: \quad$ Total number of casualties;

$N_{p}$ : $\quad$ Population size in the affected area.

The definition of the casualty factor is completely in line with the general definition of the damage factor in section 4.3. The methods outlined in there may be used to establish the probability distribution of the casualty factor.

From the probability distribution of the casualty factor, the expected value of the casualty factor can be obtained. Because the number of casualties is a linear function of the casualty factor, the expected yearly number of casualties is given by:

$E\left(N_{d}\right)=N_{p} E\left(c_{\text {cas }}\right)=P_{\text {flood }} N_{p} E\left(c_{\text {cas }} \mid\right.$ flood $)$

Where $P_{\text {flood }}$ denotes the flooding probability of the area.

Other characteristic values of the distribution of the number of casualties can also be derived from the known distribution.

\subsubsection{Loss of life expectancy at birth due to flooding}

An alternative measure for the risk of loss of life is the loss of life expectancy at birth caused by flooding. This measure of loss of life is used in the life quality model of Nathwani et al. (1997). To use the life quality model for decision-making on flood protection, the effect of flooding on the life expectancy needs to be quantified.

The analysis of life expectancy for a given population and the effects of added causes of death are the subject of mathematical demography (see Keyfitz, 1977 for an overview). In this study, an alternative method of analysis is used using the analogy with time-dependent reliability analysis (see for instance Melchers, 1999).

The life expectancy at birth is defined as the expected value of the time to death and is given by:

$e=\int_{0}^{\infty} \tau \cdot f_{\underline{T}}(\tau) \mathrm{d} \tau$

Where $f_{\underline{T}}(t)$ denotes the probability density function of the time to death.

Equation (61) shows that, in order to find the life expectancy, it is necessary to find the probability density function of the time to death. The probability density function of the time to death can be established from the observed death rate or hazard rate in the population. The hazard rate is defined as the probability of death in a short interval, given a certain age is reached: 


$$
h(t)=P(t<T<t+\mathrm{d} t \mid T>t)=\frac{P(t<T<t+\mathrm{d} t)}{1-P(T<t)}
$$

Where $T$ denotes the age at death.

The hazard rate is an observable quantity. In a population, it is found for discrete age groups by:

$$
h_{\text {emp }}(t)=\frac{N_{d ; e m p}(t)}{N_{p}(t)}
$$

Where:

$h_{\text {emp }}$ : Empirical hazard rate;

$t$ : $\quad$ Age in age group;

$N_{\text {d;emp }}: \quad$ Observed number of deaths;

$N_{p}: \quad$ Size of age group.

A mathematical relation between the hazard rate and the distribution of the time to death opens the possibility to derive the distribution of time to death from the hazard rate. Such a relation is easily established by inspecting equation (62) more closely. The numerator of equation (62) is the probability that the time of death falls in the interval $\langle t, t+\mathrm{d} t\rangle$ and is therefore equal to the probability density function of the time to death $f_{\underline{T}}(t)$. By similar reasoning, the denominator is found to be equal to the complement of the cumulative distribution function of the time to death $F_{\underline{T}}(t)$. Thus, the relation between the hazard rate and the distribution of the time to death is given by:

$$
h(t)=\frac{f_{\underline{T}}(t)}{1-F_{\underline{T}}(t)}
$$

A solution to equation (64) is given by (Melchers, 1999):

$$
F_{\underline{T}}(t)=1-e^{-\int_{0}^{t} h(\tau) \mathrm{d} \tau}
$$

The fact that equation (65) is a solution to equation (64) is easily verified by substitution of equation (65) in equation (64).

With equation (65) all elements to derive the life expectancy from observed death rates are available. In the following the method is used to derive the distribution of time to death and the life expectancy of the Dutch population. Observed agedependent death rates are obtained from the database of the Dutch Central Bureau of Statistics (CBS on internet). The data of the year 1995 has been used in the analysis. Figure 47 shows the observed age-dependent death rate and an approximating function. 


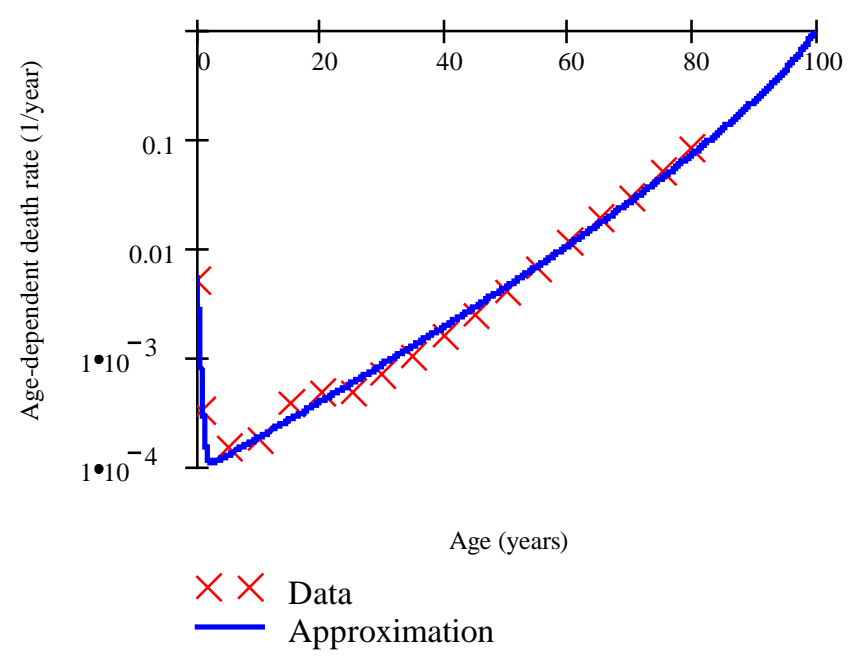

Figure 47: Observed age-dependent death rates and approximating function

The approximating function is of the following form:

$$
h(t)=A e^{-B t}+C e^{-(D(T-t))^{E}}
$$

The termination age $T$ has been chosen at 100. The function has been forced through the death rates at ages 0 and 100. Thus, the parameters $A$ and $C$ are fixed. The other parameters are determined by a least-squares fit to the data. Table 15 provides an overview of the parameters.

Table 15: Parameters of the age-dependent death rate model

\begin{tabular}{llll}
\hline Parameter & Unit & Value & Remark \\
\hline$A$ & 1/year & $5.313 \cdot 10^{-3}$ & Taken at observed value for $t=0$ \\
$B$ & $1 /$ year & 3.119 & \\
$C$ & 1 year & 1.0 & Chosen value (death rate at termination age) \\
$D$ & $1 /$ year & 0.168 & \\
$E$ & 1 & 0.791 & \\
$T$ & year & 100 & Termination age, chosen value \\
\hline
\end{tabular}

Substitution of equation (66) in equation (65) provides the probability density function of the time to death of the Dutch population in 1995 (figure 48).

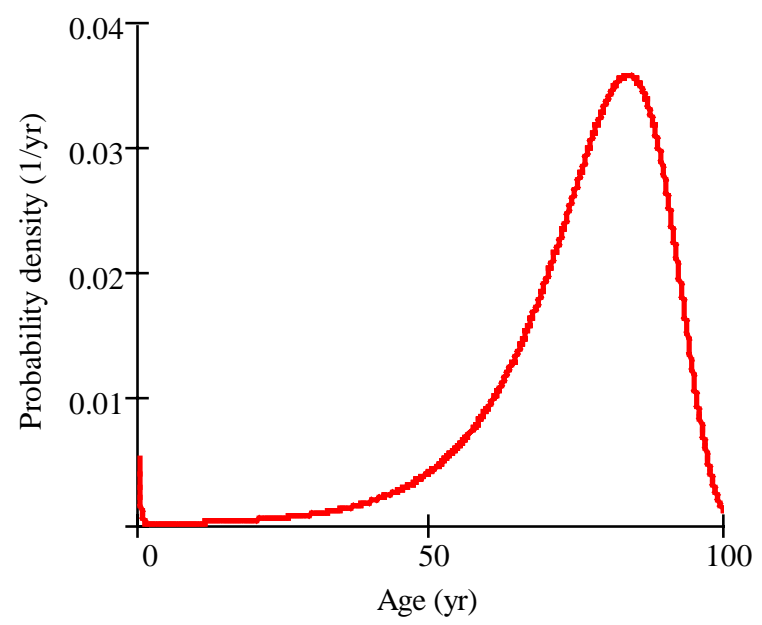

Figure 48: Probability density function of the age at death of the Dutch population based on observed death rates of 1995 
Application of equation (61) provides the life expectancy at birth. The estimate derived in this study is 75.8 years.

An external cause of death changes the age-dependent death rate in the population. The effect is given by an extra probability of death that is added to the age-dependent death rate:

$$
h_{\text {new }}(t)=h(t)+P_{d}
$$

Where $P_{d}$ is the added probability of death per year ${ }^{7}$.

For different values of the added probability of death, the life expectancy at birth can be obtained by application of the method outlined above. Figure 49 shows the result.

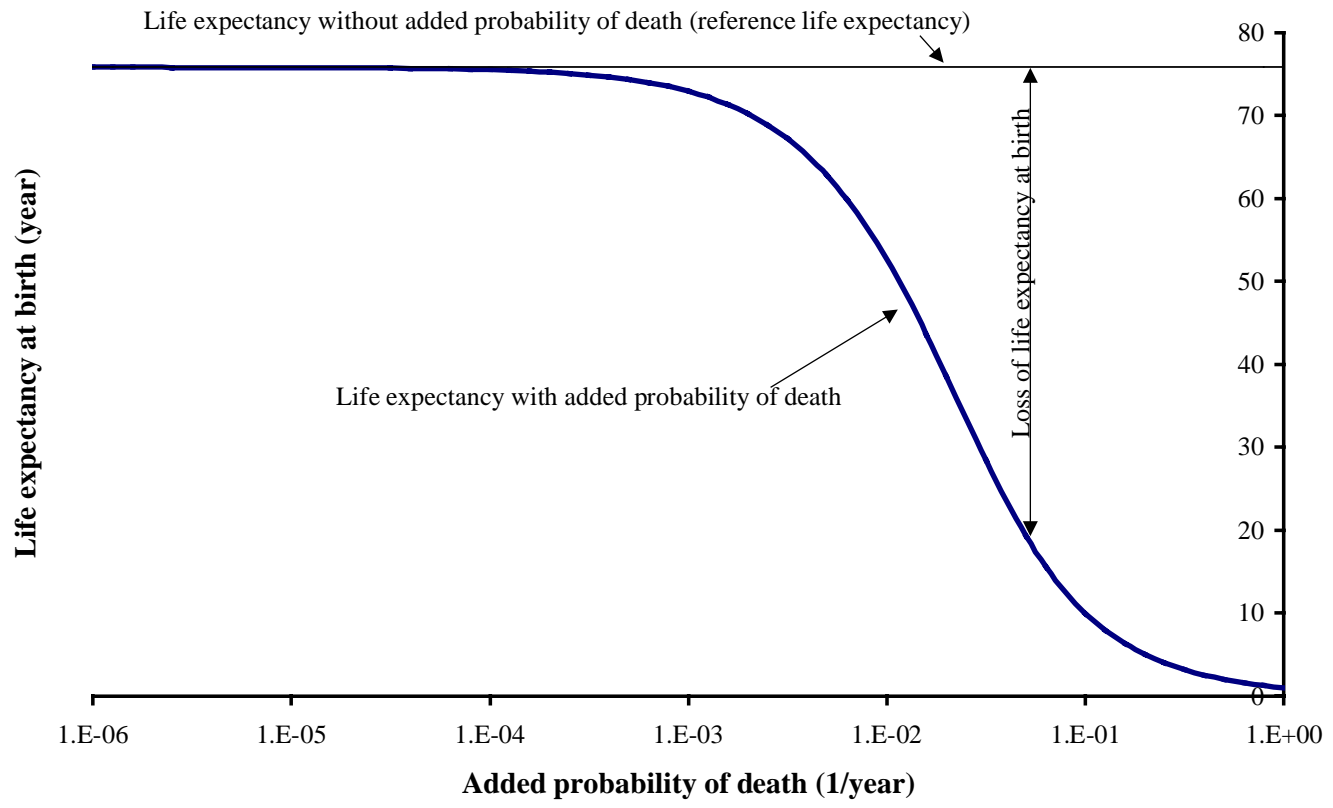

Figure 49: Life expectancy at birth as a function of added probability of death

The added probability of death causes a loss of life expectancy. Figure 50 shows the loss of life expectancy as a function of the added death probability.

\footnotetext{
${ }^{7}$ In this study $P_{d}$ is considered to be independent of age. This does not compromise the generality of the method to derive the effects of flooding risk on the life expectancy.
} 


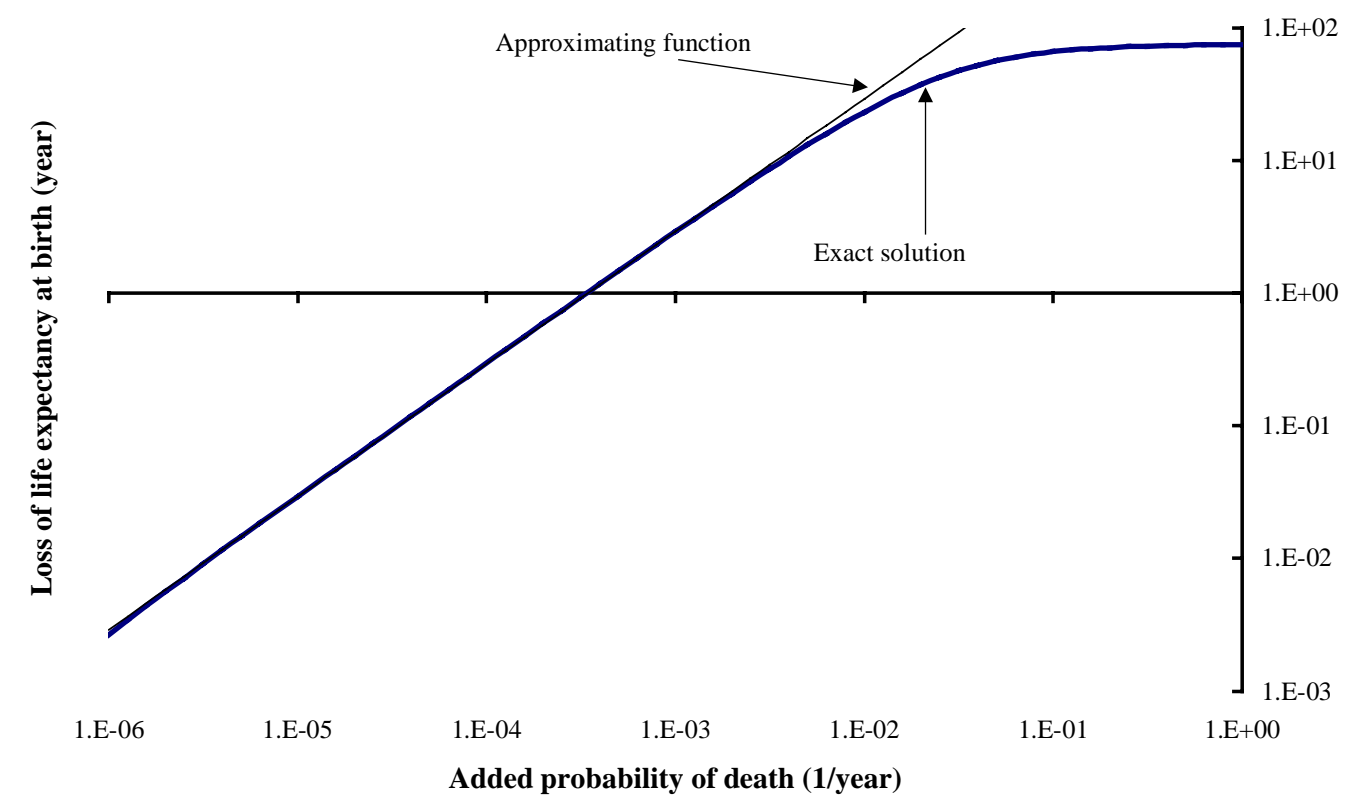

Figure 50: Loss of life expectancy at birth as a function of added probability of death

Deriving the life expectancy as a function of added probability of death is quite laborious. An approximating function can be derived from the full analysis for values of the added probability of death smaller than $10^{-2}$ per year ${ }^{8}$, which is well in the range of application. In the approximation, the life expectancy at birth is given by:

$e\left(P_{d}\right)=e_{0}-\Delta e\left(P_{d}\right)$

Where:

$e_{0}: \quad$ Reference life expectancy;

$\Delta e: \quad$ Loss of life expectancy caused by added probability of death.

An approximation of the loss of life expectancy is shown in figure 50. The approximation is given by:

$\Delta e\left(P_{d}\right)=C \cdot P_{d}$

Where $C$ is a constant with a value of $2914 \mathrm{yr}^{2}$.

In general, there is no reason to assume that $P_{d}$ takes a fixed (deterministic) value. The random variation of $P_{d}$ needs to be accounted for in the analysis of the life expectancy. It can be shown that deriving the expected (or average) value of $P_{d}$ is sufficient to find the life expectancy at birth, as long as $P_{d}$ is smaller than approximately $10^{-2}$ per year. To this end, consider that the life expectancy (equation (68)) is a linear function of the reference life expectancy and the loss of life expectancy due to the added probability of death. Therefore, the life expectancy is simply given by subtracting the expected (or average) value of the loss of life expectancy from the reference life expectancy. The loss of life expectancy is a linear function of the added probability of death $P_{d}$. Because of the linearity of equation (69) the average loss of life expectancy for an added death probability smaller than $10^{-2}$ per year is easily obtained by:

\footnotetext{
${ }^{8}$ To put this number into perspective: in the Dutch population of 1995 this added probability of death implies 160.000 casualties per year.
} 


$$
E(\Delta e)=C \cdot E\left(P_{d}\right)
$$

Equation (70) shows that indeed the expected value of $P_{d}$ provides sufficient information to find the average loss of life expectancy, as long as only reasonable values of $P_{d}$ are considered.

With the results derived up to this point, the problem of quantifying the effects of flooding risk on the life expectancy at birth is reduced to finding the expected value of the added probability of death as a consequence of flooding. The added probability of death can be found from the casualty factor $c_{c a s}$ and the flooding probability $P_{\text {flood }}$ by:

$$
P_{d}=c_{\text {cas } \mid \text { flood }} P_{\text {flood }}
$$

The casualty factor is a dimensionless measure of the number of casualties in case of flooding. Generally, $c_{c a s}$ is a random quantity of which the distribution may be derived by the methods outlined earlier in this chapter. To find the expected value of the added probability of death it is again sufficient to note that equation (71) is a linear function of the casualty factor, so that the average added probability of death is given by:

$$
E\left(P_{d}\right)=P_{\text {flood }} E\left(c_{\text {cas }} \mid \text { flood }\right)
$$

Equation (72) completes the set of mathematical relations that is necessary to quantify the life expectancy as a function of the flooding probability $P_{\text {flood }}$. The result is applied in the case study in chapter 8.

\subsection{Quantifying economic consequences of flooding}

In the following, a brief overview of the quantification of economic consequences of flooding will be given. More information is given among others in Penning-Rowsell et al. (1992, 1994), Eijgenraam et al. (2000) and van der Veen et al. (2001).

The economic consequences in part consist of direct economic damage and partly of indirect economic damage. Direct economic damage is defined as damage that is caused directly by contact with the flood water. The damage factor introduced in section 4.3 and analysed in section 4.4 is aimed at the quantification of this type of damage. Indirect economic damage is defined as the damage that is caused by the primary damage due to relations that exist between the flooded area and the rest of the economy. The estimate of both direct and indirect damage depends, next to the estimate of the damage factor, on the following two aspects:

- The definition of the measure of costs;

- The scope of the analysis.

In economic theory, two definitions of costs are encountered. The first is the financial definition of cost, where the cost is defined as the replacement value of the inventory that is lost. The second definition is the economic definition of cost (or opportunity cost) that defines the cost as the added value that would have been obtained had the inventory not been lost prematurely. Depending on the definition of the cost, the damage estimate may differ.

The scope of the analysis is the definition of the group or area within the economy that is considered part of the analysis. The definition of the scope of the analysis influences the damage estimates because transfers within the group do not change the total value within the group and do therefore not influence decisions made on the 
basis of such an analysis ${ }^{9}$. An example may clarify how the definition of the scope influences the damage estimate.

If an area is flooded, the production capacity present in the area is reduced as an effect of the direct damage due to flooding. The final estimate of the indirect damage due to flooding depends on the relations of the area with the rest of the economy and the definition of the scope. Suppose only the area itself and its economic actors are included. In that case, the indirect damage due to flooding is equal to the summed loss of income of all producers in the affected area.

Outside the affected area, other producers may depend on products from the affected area. On the other hand, outside the area competitors selling the same product may be present. If the scope of the analysis is widened to include the macro-economy outside the area, producers depending on products from the area will also suffer a setback in production capacity. This increases the indirect damage in comparison to the first case. Competitors outside the affected area will probably see an increase of their production and sales as a consequence of damage in the affected area. This effect decreases the total indirect damage.

It may be clear that the quantification of the macro-economic effects of flooding requires extensive modelling. This type of modelling falls outside the scope of this study. The damage factors for direct and indirect damage introduced in the costbenefit model in chapter 2 are pragmatic solutions to establish damage estimates and to explore the effect of the damage estimates on the acceptable flooding probability.

\subsection{Discussion}

To facilitate decision-making on flood protection levels, there is a need to quantify the consequences of flooding where possible. A distinction is made between direct and indirect damage, where the first denotes the damage as a consequence of contact with the flood water and the second denotes the damage that is a consequence of the direct damage.

A conceptual model of flooding damage as a function of natural boundary conditions is developed. It appears that existing models for the flooding process only cover a part of the full process. Especially the quantification of the effect of secondary flood defences is lacking in most cases. A schematisation of a flood-prone area, specifically aimed at the quantification of the effects of secondary defences on the flood damage distribution is proposed. Application to a simple case study shows that a detailed analysis of the properties of the flooding within the area may lead to reduced damage estimates.

Loss of life can be quantified in two alternative ways. What measure should be chosen depends completely on the model that is used to judge the acceptability of the risk. The distribution of the yearly number of flooding casualties can be established directly from the flooding probability and the damage factor for casualties. The bounds on acceptable risk proposed by Vrijling et al. $(1995,1998 \mathrm{~b})$ can be compared directly to the probability distribution of flooding casualties.

The flooding probability in combination with the damage factor for casualties influences the age-dependent death rate within the population. The modified age-

\footnotetext{
${ }^{9}$ An analogy in engineering is the definition of the control volume when establishing a balance equation of any kind. Transfer of energy, mass or any other quantity within the control volume drops from the equation in that case.
} 
dependent death rate can be used to derive the life expectancy at birth as a function of flooding probability and casualty factor. To quantify the average loss of life expectancy at birth, only the flooding probability and the expected value of the casualty factor are needed. The life expectancy as a function of flooding probability can be used in the life quality model by Nathwani et al. (1997) to judge the acceptability of a certain level of protection against flooding.

The estimates of economic consequences of flooding depend on the choice of the scope of the study and on the definition of cost. Macro-economic effects of flooding can be considered a consequence of primary flooding damage. 


\section{A MODEL FOR THE JOINT PROBABILITY DISTRIBUTION OF HYDRAULIC CONDITIONS IN THE COASTAL ZONE}

"Darlin' I don't know why I go to extremes"

Billy Joel

\subsection{Introduction}

Quantitative methods for decision-making on flood protection are introduced in chapter 2. To apply such methods in practice, the cost of protection as a function of the failure probability of the protection system needs to be quantified. Chapter 3 introduces the method of reliability-based optimisation through which the cost of protection can be established.

Reliability-based optimisation of a flood defence structure involves performing quantitative reliability analysis of a number of alternative geometries of the structure. Chapter 3 shows that for a reliability analysis it is necessary to establish the joint probability distribution (JPDF) of the stochastic variables that describe the load and resistance of the structure. Earlier case studies show that for coastal structures, the uncertainty on the hydraulic boundary conditions (water level, wave conditions) dominate the reliability of the structure (see Vrijling et al., 1998a; Voortman et al., 1998, 1999b). This chapter deals with a general model for the description of the joint probability distribution of the hydraulic boundary conditions for flood defences in the coastal zone.

The choice of variables for the description of the hydraulic boundary conditions is determined by the models chosen to define the limit state functions for a flood defence structure. For the limit state functions chosen in this study (chapters 7 and 8 , annex 3), the following three aspects of the hydraulic conditions need to be quantified:

- Water level;

- Wave height;

- Wave period.

Strong winds cause extreme wave conditions, characterised by high wave heights and long wave periods. Furthermore, in a shallow sea like the North Sea, the wind causes a considerable increase of the water level with respect to the astronomic tide (wind setup). Because wind setup and wave conditions depend on the same driving force, a strong dependence between the two is observed under extreme conditions. From the point of view of design of a flood defence structure, especially the extreme conditions are important which implies that the dependence between hydraulic conditions needs to be accounted for.

Over the years a number of methods for the description of the JPDF of long-term hydraulic conditions have been proposed, among which the methods by Ochi (1978), Vrijling and Bruinsma (1980), Fang and Hogben (1982), Haver (1985), Mathisen and Bitner-Gregersen (1990), Athanassoulis et al. (1994), Ferreira and Guedes Soares (1995), Morton and Bowers (1997), De Haan and De Ronde (1997), Repko et al. (2001), Hawkes et al. (2002) and Webbers et al. (2003). 
It appears that most methods for the description of long-term hydraulic conditions are concerned with wave parameters only. Only the methods proposed by Vrijling and Bruinsma (1980), Hawkes et al. (2002) and Webbers et al. (2003) include the water level next to the wave parameters. Furthermore, it appears that in general the dependence structure between the hydraulic parameters is derived solely from the data. In the design of flood defences, the interest lies in the extreme hydraulic conditions that are scarce by definition. Observations therefore appear to provide a weak basis for the dependence structure under extreme conditions.

An alternative approach is proposed by Vrijling and Bruinsma (1980) and developed further by Repko et al. (2001) and Webbers et al. (2003). In this approach a parametric dependence model is developed on the basis of physical concepts. In that way, the shape of the dependence structure is fixed and only a limited number of parameters need to be estimated from the data.

The approach of Vrijling and Bruinsma forms the foundation of the work in this chapter. A model will be proposed in which the probability distributions of the three hydraulic variables are described as a function of the probability distribution of the driving force, i.c. the wind speed. The concept of the model and the model structure are outlined in section 5.2. In order to quantitatively describe the joint probability distribution of hydraulic conditions, a number of parametric probability models and parametric dependence models needs to be chosen. Section 5.3 deals with this subject. Some considerations on calibration of the model are given in section 5.4. The chapter closes with a discussion in section 5.6.

\subsection{A conceptual model for the joint probability distribution of hydraulic conditions}

The hydraulic conditions just in front of a flood defence structure can be considered to be the result of two influences:

- The weather system, determining the hydraulic conditions in a large area throughout the North Sea;

- The local bathymetry, influencing the transfer of offshore conditions to the structure and influencing local generation of wind setup and waves.

At some distance offshore, if the water depth is sufficiently large, the weather system can be considered the dominating factor for the hydraulic conditions. Influence of the bathymetry mainly occurs in a relatively small region near the coast. Based on this image of the hydraulic conditions, Vrijling and Bruinsma (1980) devised a conceptual model showing the relations between weather system, hydraulic conditions offshore and hydraulic conditions nearshore for the Eastern Scheldt Storm Surge Barrier. Figure 51 shows the conceptual model of Vrijling and Bruinsma generalised for use in the Dutch coastal zone. 


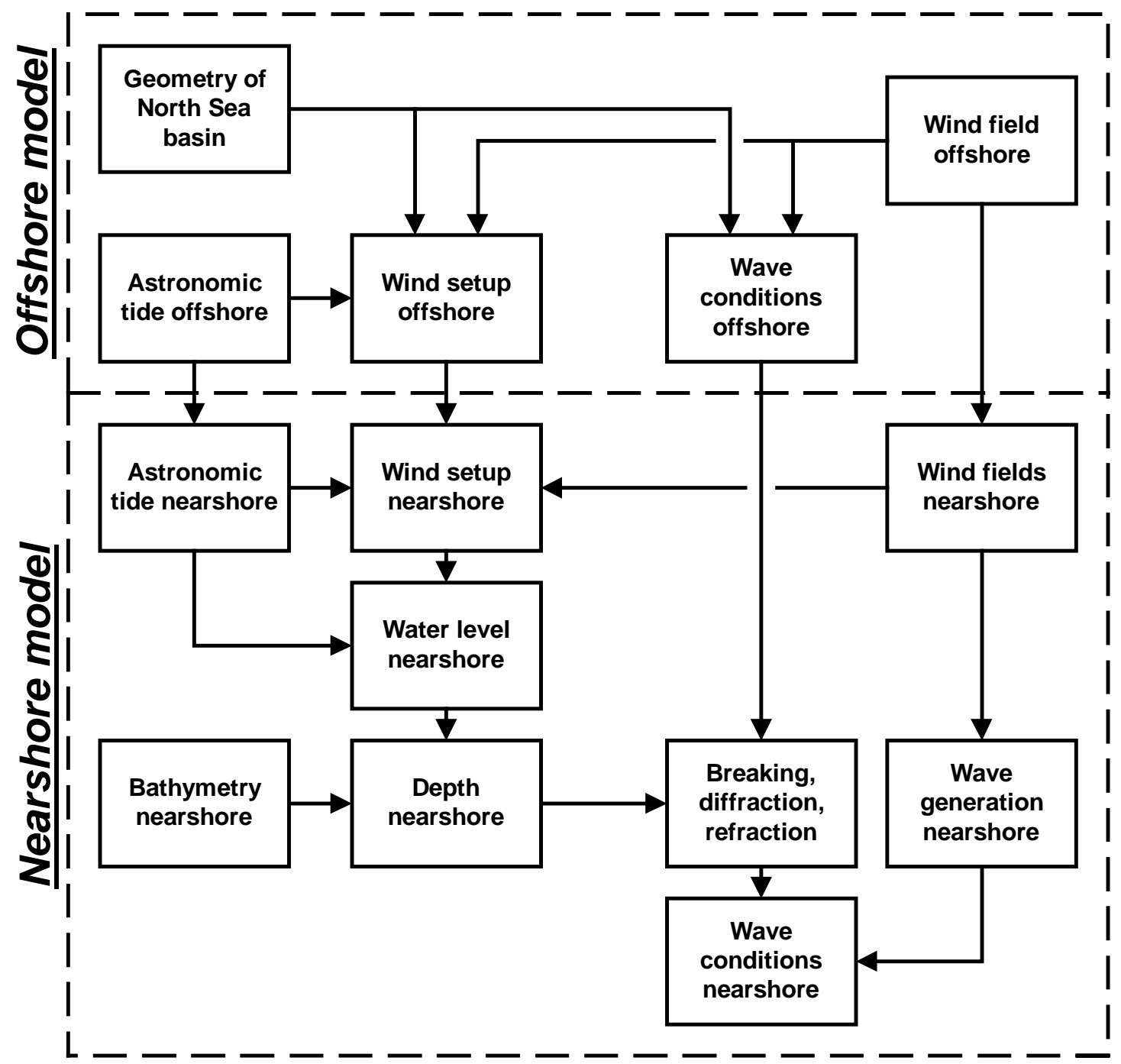

Figure 51: Conceptual model of hydraulic boundary conditions for a flood defence structure (after Vrijling and Bruinsma, 1980)

The model of figure 51 provides a qualitative overview of the relations that exist between the weather system, the hydraulic conditions offshore and the hydraulic conditions nearshore. For use in the reliability analysis of a flood defence structure, it is necessary to develop a quantitative model on the basis of figure 51 .

Vrijling and Bruinsma (1980) used the water level offshore as the input variable and described the wave conditions as a function of the water level. The dependence model was derived on the basis of parametric physical models. Vrijling and Bruinsma observed that both water level and wave conditions are wind-driven and are therefore dependent. Nevertheless, they based their description of the JPDF of hydraulic conditions on the water level instead of the wind field. The reason for this is that at the time a long series of water level observations was available, but that joint observations of wind speed, water level, wave height and wave period were scarce. Furthermore, there was a need for the results to be consistent with prevailing estimates of the probability distribution of the water level (Vrijling, personal communication).

In the present study, the wind speed is chosen as the input parameter. There are a few reasons for this choice: 
- The water level is influenced both by the astronomic tide and by the wind field. It is doubtfull whether a pure statistical analysis is valid for data that reflectsthe influence of more than one process;

- A basis for the choice of the distribution of the wind speed is available in the form of the study of Wieringa and Rijkoort (1983). A similar basis for the choice of the distribution of other possible input variables appears not to be available.

A model will be developed where the JPDF of hydraulic conditions nearshore is written as a function of:

- Properties of the wind field;

- Geometry of the North Sea basin;

- Astronomic tide;

- Bathymetry nearshore.

Parametric physical models will be used to describe hydraulic effects as a function of the wind speed, astronomic tide and basin geometry. Physical models can be assumed to hold both under measured conditions and under extreme conditions. Therefore, models based in physics can support the shape of the JPDF also in conditions that have never been measured. The shape of the distribution derived in such a method is in part explained by the adopted hypotheses about the physical behaviour of the measured variables.

A description of both the water level and the wave conditions on the basis of the wind field automatically leads to a physically relevant description of the dependence between water level and wave conditions. The JPDF can be used directly in the reliability evaluation of a flood defence structure. The marginal probability distributions of every variable can also be obtained from the joint model. Although the marginal distributions can not be used for the reliability analysis of a flood defence structure, they can be used for comparison of the results of the JPDF to the results of other methods of analysis; specifically the classical peaks-over-threshold method.

The structure of the quantitative model of the JPDF of hydraulic boundary conditions used in this study is shown in figure 52. 


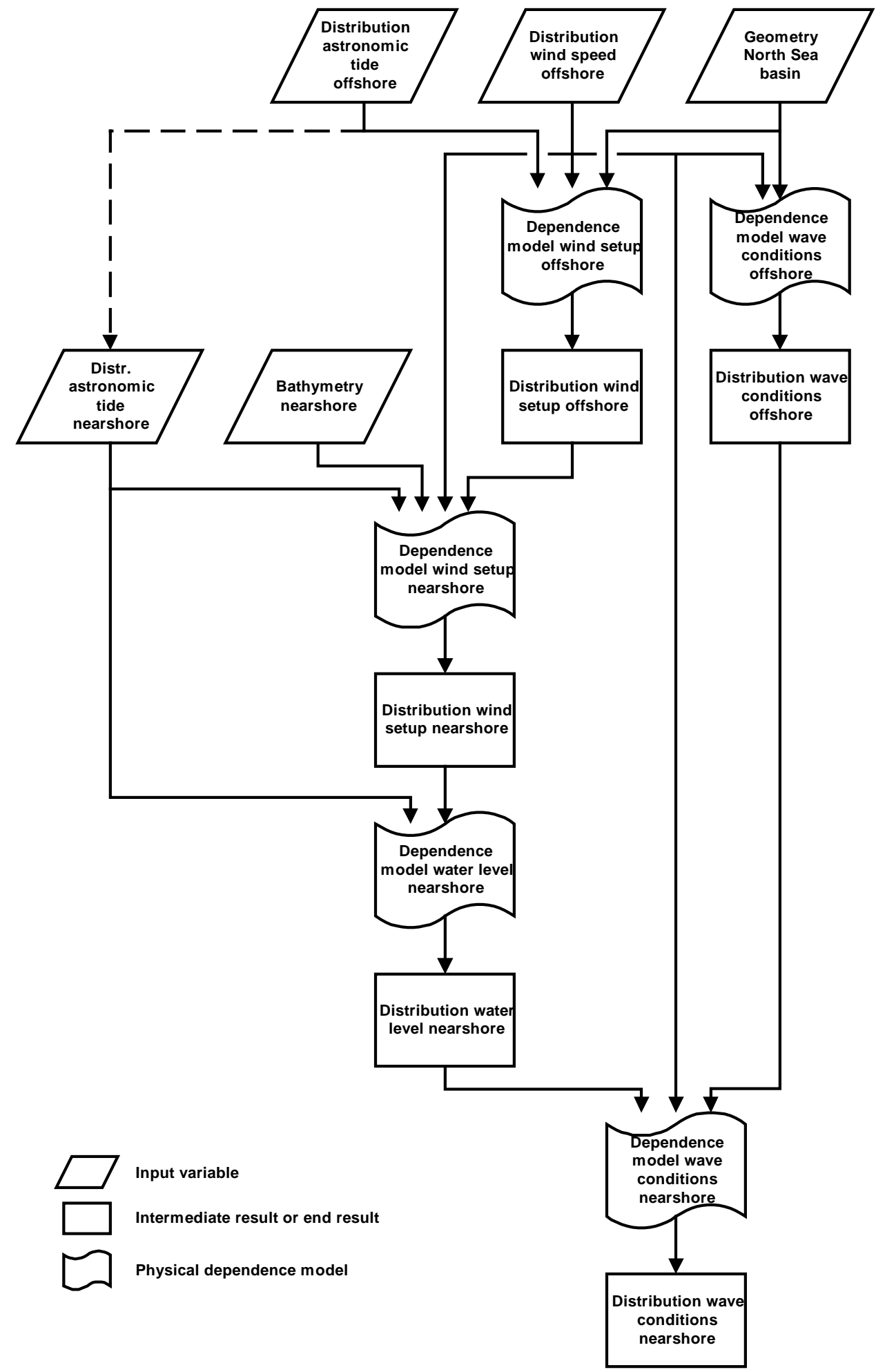

Figure 52: Structure of a quantitative model for the description of the joint probability distribution of hydraulic boundary conditions 
Starting from the input conditions in the top of figure 52, the first set of outputs consists of the JPDF of the hydraulic conditions offshore. Mathematically, the joint probability density of the hydraulic conditions offshore is written as:

$$
f_{\underline{u}, \underline{h_{a}}, \underline{h_{o s}}, \underline{H_{s ; o s}}, \underline{T_{p ; o s}}}(v, \zeta, \eta, \xi, \tau)=f_{\underline{h_{o s} \mid u, h_{a}}}(\eta) f_{\underline{H_{s ; o s} \mid u}}(\xi) f_{\underline{T_{p}} \mid u}(\tau) f_{\underline{u}}(v) f_{\underline{h_{a}}}(\zeta)
$$

Where:

$u$ : $\quad$ Wind speed;

$h_{a}: \quad$ Astronomic tide;

$h_{o s}: \quad$ Wind setup offshore;

$H_{s ; o s}: \quad$ Significant wave height offshore;

$T_{p ; o s}$ : $\quad$ Spectral peak period of the wave field offshore.

The physical models provide a transformation of the joint distribution function of wind speed and astronomic tide to the joint distribution of the hydraulic conditions offshore. Therefore, a shorter notation of equation (73) is given by:

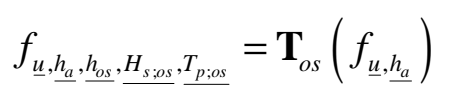

Where $\mathbf{T}_{o s}$ denotes the transformation by the offshore dependence models.

Equation (73) is based on the fact that the joint probability density function of a set of variables can be written as the multiplication of a set of conditional probability density functions and the probability density functions of the input variables. In equation (73), the probability density functions are written conditional on the wind speed and the astronomic tide. The conditional distribution of any hydraulic variable is obtained by combining a physical dependence model with the probability density functions of the wind speed and the astronomic tide. The behaviour of the physical model depends on the geometry of the basin. Therefore, in the description of the conditions offshore, the following elements need to be established:

- Probability distribution of the wind speed offshore;

- Probability distribution of the tide offshore;

- Basin geometry representative for the North Sea basin;

- Dependence model for wind setup offshore as a function of wind speed and astronomic tide;

- Dependence model for offshore wave conditions (wave height, wave period) as a function of the offshore wind speed.

In the offshore model, the assumption is made that the offshore depth is so large that the influence of the water level on the wave conditions is negligible.

Following similar reasoning as for the conditions offshore, the conditions nearshore can be viewed as transformed offshore conditions. In the transformation from offshore to nearshore, the wind again plays a role. The probability density function of the conditions nearshore is written as (os: offshore, $n s$ : nearshore):

$$
f_{\underline{u_{n s},}, \underline{h_{w ; n s}}, \underline{H_{s ; n s}}, \underline{T_{p, n s}}}=\mathbf{T}_{x, y}\left(f_{\underline{u_{o s} s}}, \underline{h_{w ; o s}}, \underline{H_{s ; o s}}, \underline{T_{p ; o s}}\right)
$$

Where:

T: $\quad$ Transformation function;

$u$ : $\quad$ Wind speed;

$h_{w}$ : Water level; 
$H_{s}$ : $\quad$ Significant wave height;

$T_{p}$ : $\quad$ Wave peak period;

$x, y: \quad$ Spatial coordinates.

To quantify the distribution of the conditions nearshore, the following elements of the model need to be established:

- The probability distributions of the hydraulic conditions offshore;

- The probability distribution of the tide nearshore;

- A dependence model for the wind setup nearshore as a function of setup offshore, tide and basin geometry;

- A dependence model for the water level nearshore as a function of wind setup nearshore and astronomic tide;

- A dependence model for the local wave conditions as a function of the wind, the wave conditions offshore and the local water level.

The physical models used for modelling the dependence between hydraulic conditions are the same for all locations. The calibration of the models may differ due to local conditions like:

- Depth;

- Orientation of the structure;

- Location with respect to sheltering elements (like offshore islands).

For these reasons, the transformation $\mathbf{T}$ can be considered to depend upon the location considered.

\subsection{Selection of probability models and dependence models}

\subsubsection{General}

The JPDF of hydraulic conditions nearshore shown in figure 52 provides the hydraulic boundary conditions as a function of wind speed, astronomical tide and basin geometry. The input values in general can not be known with certainty. Therefore, input variables need to be described by probability models ${ }^{10}$. Dependence models describe a hydraulic variable as a function of one or more input variables. Dependence models can be derived by considering the physical processes leading to certain hydraulic conditions.

In this section the selection of models used in the description of the JPDF of hydraulic conditions is described. Table 16 shows an overview of the models necessary to quantify the JPDF of hydraulic boundary conditions.

Table 16: Overview of models necessary to describe the joint probability distribution function of hydraulic conditions

\begin{tabular}{lll}
\hline Variable & Type of variable & Model describing variable \\
\hline Wind speed & Input & Probability model \\
Astronomic tide & Input & Probability model \\
Basin geometry & Input & Probability model \\
Model uncertainties & Input & Probability model \\
Wind setup offshore & Intermediate & Dependence model \\
Wave height offshore & Intermediate & Dependence model \\
Wave period offshore & Intermediate & Dependence model \\
\hline
\end{tabular}

\footnotetext{
${ }^{10}$ A deterministic variable is a very special case of a random variable, so the statement holds
} 


\begin{tabular}{lll}
\hline Variable & Type of variable & Model describing variable \\
\hline Wind setup nearshore & Intermediate & Dependence model \\
Water level nearshore & Output/Intermediate & Dependence model \\
Wave height nearshore & Output & Dependence model \\
Wave period nearshore & Output & Dependence model \\
\hline
\end{tabular}

Probability models and dependence models may both be obtained from literature. Section 5.3.2 deals with the probability models used in the JPDF of hydraulic conditions. Section 5.3.3 deals with the dependence models used in the description of conditions offshore. Section 5.3.4 deals with dependence models used in the description of conditions nearshore.

\subsubsection{Probability models for input conditions}

In the description of the JPDF of hydraulic conditions, probability models are needed for the description of:

- Wind speed;

- Astronomic tide;

- Basin geometry;

- Model uncertainties.

A number of parametric probability models is available for the description of the inputs. Earlier research can be used in a number of cases to support the choice of a model for the description of an input variable.

Rijkoort (1983) performed research into the statistical properties of wind speed. In Rijkoort's study, an analysis of the applicability of different parametric distribution functions for the description of wind speeds is performed. Rijkoort concludes that the Weibull distribution is the most suitable for the description of wind speeds. Based on this result, wind speeds will in this study be described by a Weibull distribution.

Tidal water levels can be described by harmonic components (Godin, 1972). Harmonic components in turn can be used to establish the distribution of the tidal water level (see annex 4). An approximate probability model for the tidal water level at the time of a storm is given by:

$$
F_{\underline{h_{a}}}(\eta)=p_{t r} \Phi\left(\frac{\eta-\mu_{l o}}{\sigma_{l o}}\right)+\left(1-p_{t r}\right) \Phi\left(\frac{\eta-\mu_{h i}}{\sigma_{h i}}\right)
$$

Where:

$\Phi: \quad$ Standard normal distribution;

$p_{t r}: \quad$ Weighting factor;

$\mu_{l o}, \mu_{h i}: \quad$ Expected values of low and high tide;

$\sigma_{l o}, \sigma_{h i}: \quad$ Standard deviation of low and high tide.

The basin geometry is described by the basin length (fetch) and the basin depth. Basin properties will be described as deterministic variables. Because of the irregular shape of the North Sea basin, the basin geometry depends on the wind direction. More details are given in section 5.4.

Probability models and dependence models will not be able to capture the full complexity of the processes in nature. Therefore, when a model is compared to field data, some scatter around the model will be present. This model uncertainty is known under different names, depending on the type of model considered. In case of physical dependence models, the scatter is usually referred to as model uncertainty. In case of 
statistical models, the scatter is referred to as statistical uncertainty (see van Gelder, 1999). Since models that perfectly describe nature are non-existent, the calibration of any model is incomplete if the model uncertainty is not properly addressed.

Because of the necessity of describing model uncertainties and statistical uncertainties, model calibration is performed in two steps. In the first step, probability models and dependence models will be calibrated such that they describe the expected value of field observations. This is done by choosing appropriate values of predefined calibration parameters.

In the second step, an estimate of the distribution of the model or statistical uncertainty is made. For physical dependence models, the distribution of the model uncertainty can be established by forming a dataset of model errors. A dataset of model errors is obtained by comparing the value resulting from the calibrated model to the value observed in the field. Well-known methods can then be used to fit a parametric probability model to the data of the model errors. Very often, a normal distribution provides an accurate description of the model error.

Uncertainty on a probability model (statistical uncertainty) is obtained in a procedure known as the bootstrap-method. For more details, reference is made to Efron (1982), Efron and Tibshirani (1993) or van Gelder (1999).

\subsubsection{Dependence models for hydraulic conditions offshore}

In the JPDF of hydraulic conditions, the hydraulic conditions offshore are described on the basis of probability models for the input (section 5.3.2) and dependence models for:

- Wind setup offshore;

- Wave height offshore;

- Wave period offshore.

Scientific research into the behaviour water levels and waves in extreme wind conditions has led to a large number of models to choose from (see Booij et al (1999) and Roelvink et al (1994) for examples). However, the possible choices are in this study reduced drastically by one practical requirement. In the process of reliability evaluation of a flood defence structure, a very large number of calculations with the JPDF are performed. Therefore, the evaluation of a dependence model should have a low computational burden. It appears that this limits the choice to parametric models. Parametric dependence models, like the more advanced models, should be calibrated against field data. An estimate of the model error can be obtained to account for observed differences between model and field data. Advanced models may be used to verify the parametric models in conditions that have not been measured (i.c. extreme conditions), provided the advanced model is calibrated against field data and an estimate of the model uncertainty of the advanced model is given.

Table 17 provides an overview of the parametric models used in this study to describe the JPDF of hydraulic conditions offshore. 
Table 17: Overview of parametric models used to describe the joint probability model of hydraulic boundary conditions offshore

\begin{tabular}{lll}
\hline Wind effect & Model & Reference \\
\hline Wind setup & Equilibrium wind effect & Weenink (1958) \\
Water level & Superposition of wind setup and astronomical tide & Wemelsfelder (1939), Vrijling \\
& & and Bruinsma (1980) \\
Wave height & SMB-model & CERC (1973) \\
Wave period & SMB-model & CERC (1973) \\
\hline
\end{tabular}

Wind setup is defined as the increase of the water level with respect to the calculated astronomical tide, as a consequence of the wind field. The wind setup can therefore be calculated by subtraction of the astronomical tide from the observed water level:

$h=h_{w}-h_{a}$

Where:

$h_{w}: \quad$ Water level;

$h_{a}: \quad$ Astronomic tide for the same point in time.

Weenink (1958) performed an extensive study of the effects of wind on the water level. Weenink split the wind setup in a part depending on the wind-induced shear forces (equilibrium effect) and a part depending on the current fields induced by wind action. According to Weenink, in the North Sea the equilibrium effect dominates the process.

Weenink studied the wind setup on the North Sea by means of a numerical model. Ultimately, an analytical model was derived which describes the wind setup by splitting the North Sea basin in five sub-basins, all with their own contribution to the wind setup. On the basis of this model, Vrijling and Bruinsma derived an even simpler model of the form:

$$
h=\alpha \frac{u^{2}}{g}
$$

Where:

$\begin{array}{ll}h: & \text { Wind setup; } \\ u: & \text { Wind speed; } \\ \alpha . & \text { Empirical coefficient depending on the wind direction; } \\ g: & \text { Acceleration of gravity. }\end{array}$

A similar model can be derived directly from an analysis of the equilibrium wind setup in a two-dimensional basin in a uniform wind speed. A simple model for the water level gradient over an infinitesimal part of a two-dimensional water body is given by:

$$
\frac{\mathrm{d} h}{\mathrm{~d} x}=\frac{c u(x)^{2}}{g(d(x)+h(x))}
$$

Where:

$h$ : Wind setup;

$u$ : $\quad$ Wind speed;

g: $\quad$ Accelaration of gravity;

$d: \quad$ Depth with respect to undisturbed water level; 
Inspection of equation (79) shows that for the same depth $d$, the water level gradient decreases if the wind setup increases. Equation (79) therefore suggests a negative feedback, where an existing high wind setup limits the possibility of even higher wind setup. In case of a rectangular basin and a uniform wind speed over the basin, equation (79) can be integrated analytically, leading to an expression for the downwind wind setup:

$$
h(u, F, d)=h_{\text {upwind }}-d+\sqrt{d^{2}+2 \frac{c u^{2} F}{g}} \approx h_{\text {upwind }}+F \frac{c u^{2}}{g d}
$$

Where:

$F: \quad$ Basin length (fetch);

$h_{\text {upwind }} \quad$ Wind effect on the upwind side of the basin.

The approximating formula in equation (80) is valid as long as $d \gg h$.

The parametric model implies a uniform wind speed and a uniform depth over the full length of the basin. The value of the wind effect on the upwind side of the basin $h_{\text {upwind }}$ depends on the boundary condition on that side. Since conservation of mass must hold for the wind setup process, the possibility of inflow of water at the upwind boundary determines the boundary condition (see figure 53).

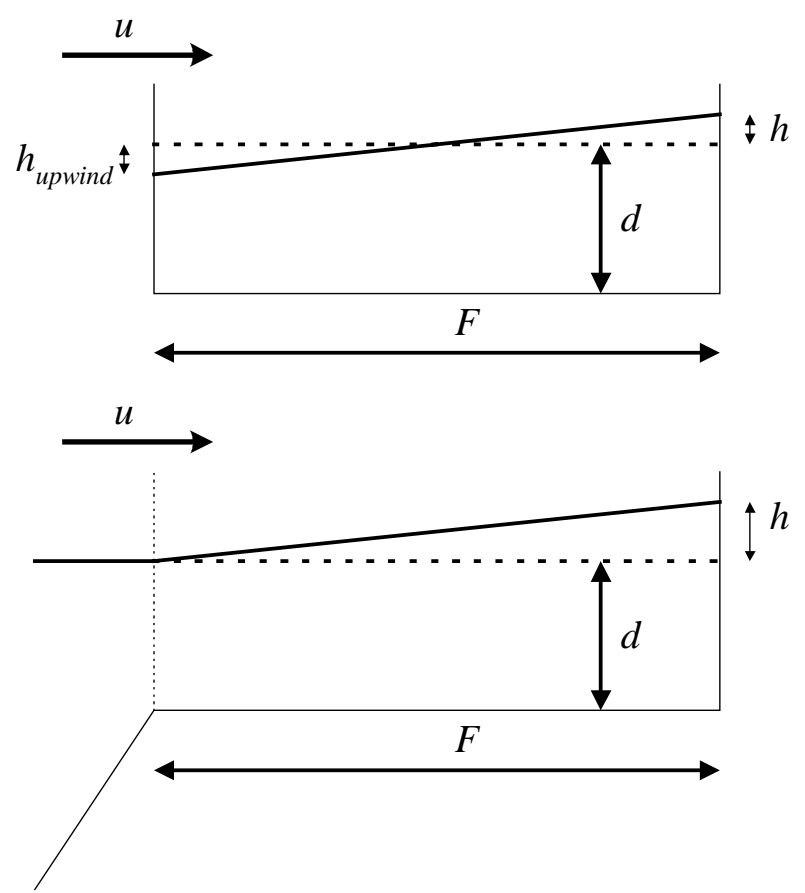

Figure 53: Longitudinal sections of a rectangular basin with wind setup. Top: enclosed basin, bottom: basin open on upwind end.

In an enclosed basin, any increase of the water level on the down wind side needs to be compensated by a decrease of the water level on the upwind side. In case of a marginal sea connected to a large ocean (figure 53, bottom panel), the large supply of water from the ocean ensures that mass is conserved without a decrease of the upwind water level. In that case $h_{\text {upwind }}$ equals zero. The second situation best resembles the North Sea, which is connected in the North-West to the Atlantic Ocean. Therefore, in the remainder of this study the value of $h_{\text {upwind }}=0 \mathrm{~m}$ will be used. 
In a situation with tides the astronomical tide influences the available depth, which in turn influences the wind setup. This effect may be crudely modelled by including the astronomic tide in the definition of the depth in the wind setup model. Adopting the modifications outlined above, the wind setup model used in this study becomes:

$$
h\left(u, F, d, h_{a}\right)=-\left(d+h_{a}\right)+\sqrt{\left(d+h_{a}\right)^{2}+2 \frac{c u^{2} F}{g}}
$$

Where $h_{a}$ denotes the astronomic tide.

The effect of a high astronomic tide is the same as that of an increase of the depth $d$; the wind setup for the same wind speed gets lower. This is in contrast to the study by Vrijling and Bruinsma (1980) who assumed independence of wind setup and astronomic tide.

The water level as a function of the wind speed is found by superposition of the wind setup on the astronomical tide.

$$
h_{w}\left(u, F, d, h_{a}\right)=h_{a}+h\left(u, F, d, h_{a}\right)
$$

In the proposed model for the JPDF of hydraulic conditions, not only wind setup and water level but also the wave height and wave period are described as a function of basin geometry and wind field. A parametric model for the calculation of wave conditions in a uniform wind field is the model due to Sverdrupp, Munk and Bretschneider (Sverdrup and Munk (1947) and Bretschneider (1952, 1958)), generally known as the SMB-model. The model is based on the dimensionless parameters given in table 18. Like the wind setup model derived previously, the SMB-model is suited for a basin with a constant depth and a constant wind speed over the length of the basin (uniform wind field).

Table 18: Definition of dimensionless parameters in the SMB-model

\begin{tabular}{lcc}
\hline Dimensionless wave height & $\widetilde{H}_{s}$ & $\frac{H_{s} g}{2}$ \\
Dimensionless wave period & $\tilde{T}$ & $\frac{T g}{u}$ \\
Dimensionless depth & $\tilde{d}$ & $\frac{d g}{u^{2}}$ \\
Dimensionless fetch & $\widetilde{F}$ & $\frac{F g}{u^{2}}$ \\
Dimensionless storm duration & $\widetilde{D}$ & $\frac{D g}{u}$ \\
\hline
\end{tabular}

The dimensionless wave conditions depend on the dimensionless basin properties by:

$$
\begin{gathered}
\tilde{H}_{s}=\tilde{H}_{\infty} \tanh \left(k_{3} \tilde{d}^{m_{3}}\right) \tanh \left(\frac{k_{1} \tilde{F}^{m_{1}}}{\tanh \left(k_{3} \tilde{d}^{m_{3}}\right)}\right) \\
\tilde{T}=\tilde{T}_{\infty} \tanh \left(k_{4} \tilde{d}^{m_{4}}\right) \tanh \left(\frac{k_{2} \tilde{F}^{m_{2}}}{\tanh \left(k_{4} \tilde{d}^{m_{4}}\right)}\right)
\end{gathered}
$$


The values of the empirical coefficients in equation (83) are derived on the basis of a large dataset of field observations and tabulated in the Shore Protection Manual (CERC, 1973). Table 19 provides an overview.

Table 19: SMB-model parameters from CERC (1973)

\begin{tabular}{ll}
\hline Parameter & Value \\
\hline$\tilde{H}_{\infty}$ & 0.283 \\
$\tilde{T}_{\infty}$ & $1.2 \cdot 2 \pi$ \\
$k_{1}$ & 0.0125 \\
$k_{2}$ & 0.077 \\
$k_{3}$ & 0.53 \\
$k_{4}$ & 0.833 \\
$m_{1}$ & 0.42 \\
$m_{2}$ & 0.25 \\
$m_{3}$ & 0.75 \\
$m_{4}$ & 0.375 \\
\hline
\end{tabular}

For a given wind speed and basin depth, the wave growth is limited either by fetch or by the storm duration. According to Holthuijsen (1980) the minimum storm duration necessary for the available fetch to be fully effective is given by:

$D_{e q}(F)=\int_{0}^{F} c_{g}^{-1}(x) \mathrm{d} x$

Where:

$c_{g}: \quad$ Group speed of the waves;

F: $\quad$ Fetch.

Wave growth continues as long as the wind speed is higher than the group speed of the waves. Therefore, the group speed in a fully developed wave field can be expected to be of the order of the wind speed. Assuming the group speed in equation (84) constant and equal to the wind speed, a fetch equivalent to the storm duration can be calculated by:

$F_{e q}=D u$

Where $D$ denotes the storm duration.

As stated before, either the fetch or the duration is limiting for wave growth. These two aspects can be combined by defining the effective fetch as:

$$
F_{\text {eff }}=\min \left[\begin{array}{c}
F \\
D u
\end{array}\right]
$$

The effective fetch in equation (86) can be written in a dimensionless form in the same way as the fetch in table 18. Thus, a simple expression including the effect of storm duration and basin length on the wave growth is established. Figure 54 shows the effect of including storm duration for a basin length of $600 \mathrm{~km}$ and a depth of 60 m. 


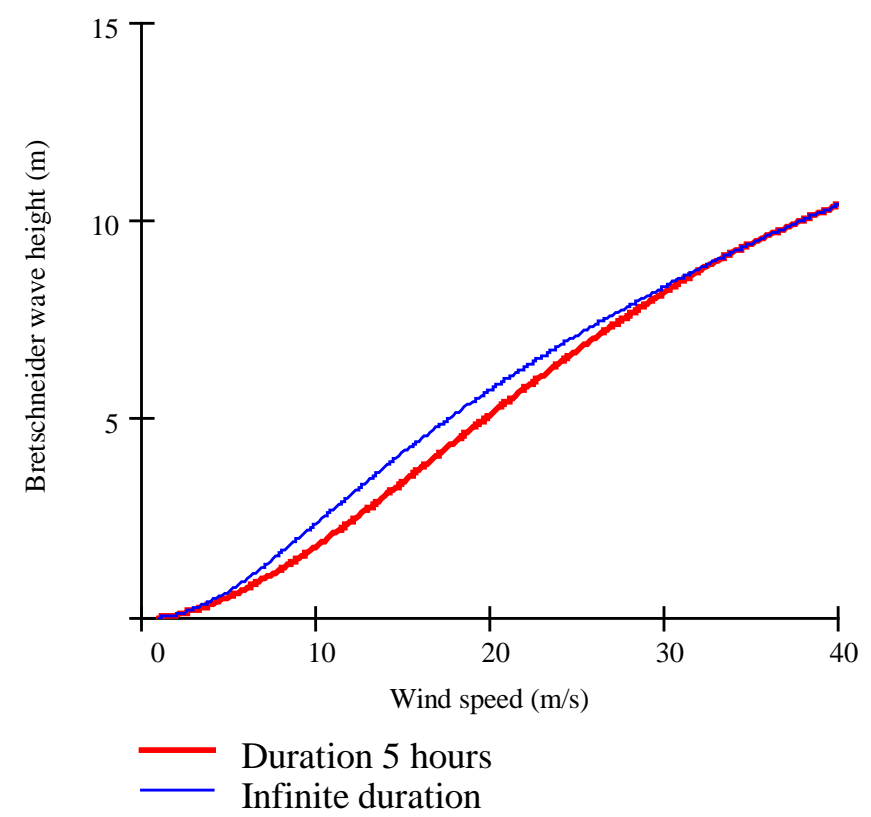

Figure 54: SMB model with and without effect of storm duration (fetch $600 \mathrm{~km}$, depth $60 \mathrm{~m}$ )

For lower wind speeds, differences in wave height up to $30 \%$ are found in this case. The gradient of the wave height to the wind speed is higher for the model that includes the storm duration.

\subsubsection{Dependence models for hydraulic conditions nearshore}

A number of methods for the calculation of wave height and wave period are available (see for example Battjes and Janssen, 1978; Goda, 1985). In this section a transformation of offshore conditions to nearshore conditions is developed on the basis of a dimension analysis. Such an approach may be used to describe the results of more advanced numerical models in a closed mathematical form. This will be shown in chapter 6.

The hydraulic conditions nearshore are derived from the wind speed, the astronomic tide and the conditions offshore by dependence models describing:

- Wind setup nearshore;

- Water level nearshore;

- Wave period nearshore;

- Wave height nearshore.

The wind setup nearshore is considered to be the result of a superposition of the wind setup offshore and locally generated wind setup. Figure 55 shows the concept. 


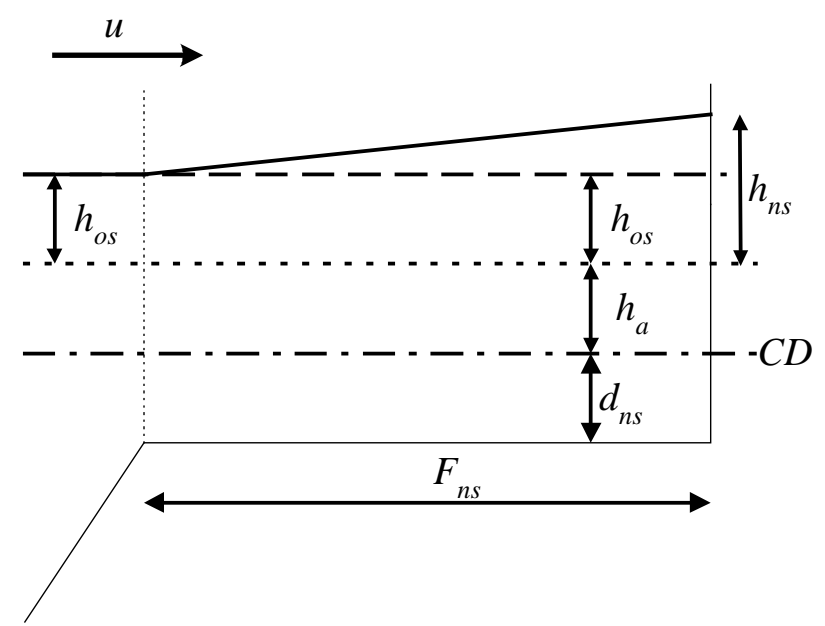

Figure 55: Definition sketch of the model for wind setup nearshore

In the model for the wind setup nearshore, the depth with respect to chart datum, the astronomic tide and the setup offshore are considered constant over the full length of the basin. Substitution in the wind setup model of equation (81) then leads to:

$$
h_{n s}\left(u, h_{o s}, h_{a ; n s}, d_{n s}, F_{n s}\right)=h_{o s}-\left(d_{n s}+h_{a ; n s}+h_{o s}\right)+\sqrt{\left(d_{n s}+h_{a ; n s}+h_{o s}\right)^{2}+2 \frac{c u^{2} F_{n s}}{g}}
$$

Where:

$u$ : Wind speed;

$h_{o s}: \quad$ Wind setup offshore;

$h_{a ; n s}: \quad$ Tide with respect to mean sea level nearshore;

$d_{n s}: \quad \quad$ Representative nearshore depth with respect to mean sea level;

$F_{n s}$ : Representative nearshore basin length.

The locally generated wind setup is negatively influenced by wind setup offshore. The water level nearshore is found by superposition of the astronomic tide and the wind setup nearshore:

$h_{w ; n s}\left(u, h_{o s}, h_{a ; n s}, d_{n s}, F_{n s}\right)=h_{a ; n s}+h_{n s}\left(u, h_{o s}, h_{a ; n s}, d_{n s}, F_{n s}\right)$

Wave conditions nearshore can be assumed to be strongly influenced by the limited water depth nearshore. In the SMB-model, the maximum wave period as a function of the water depth is given by:

$T_{\infty ; d}\left(u, d_{n s}, h_{w ; n s}\right)=\alpha \frac{u}{g} \tilde{T}_{\infty} \tanh \left(k_{4}\left(\frac{\left(h_{w ; n s}+d_{n s}\right) g}{u^{2}}\right)^{m_{4}}\right)$

With parameters according to table 19 and:

$u$ : Wind speed;

$d_{n s}: \quad \quad$ Representative nearshore depth with respect to mean sea level;

$h_{w ; n s}: \quad$ Water level with respect to mean sea level;

g: $\quad$ Acceleration of gravity;

$\alpha$. Model parameter.

This model can be used to express the local wave period as a function of the locally available water depth. 
Once the local wave period and the local water depth are established, the local wave height can be calculated if the assumption is made that the local wave height equals the maximum possible wave height. A parametric model for the maximum significant wave height is based on the work of Miche (1944):

$$
\frac{H_{s ; \max }}{L\left(d_{n s}, h_{w ; n s}, T_{n s}\right)}=s_{0 ; \max } \tanh \left(\frac{2 \pi\left(d_{n s}+h_{w ; n s}\right)}{L\left(d_{n s}, h_{w ; n s}, T_{n s}\right)}\right)
$$

Where:

$d_{n s}: \quad \quad$ Representative nearshore depth with respect to mean sea level;

$h_{w ; n s}: \quad$ Water level with respect to mean sea level;

$T_{n s}: \quad$ Wave period nearshore;

$s_{0 ; \text { max }}: \quad$ Maximum wave steepness (model parameter).

The original work of Miche described the maximum wave height of regular waves in limited depth. Van Marle (1979) used Miche's formula to establish a breaker criterion for irregular waves. To that end, the maximum significant wave height is described by the model of Miche. The value of the parameter $s_{0 \text {;max }}$ was established on the basis of field data and equals 0.093 .

\subsection{Schematisation of wind field and North Sea basin}

The dependence models outlined in the previous section describe the hydraulic boundary conditions as a function of:

- Wind speed;

- Basin geometry.

The parametric models are based on a few simplifying assumptions. Specifically, the wind is assumed to be constant in time and space (uniform wind field) and the basin geometry is simplified to a rectangular basin with a constant depth and a constant length. To describe the processes on the North Sea on the basis of such models, schematisation of the North Sea basin and the wind field is necessary.

During a storm, the wind speed and the wind direction will vary in time and space. In order to use the parametric models of section 5.3, an observed wind field needs to be schematised as a uniform wind field with a constant wind speed and wind direction. To schematise a real wind field to a uniform wind field, definitions have to be found for:

- The representative wind direction;

- The representative wind speed;

- If a suitable schematisation of the wind field is found, any wind field is characterised by two variables only.

To define the representative wind direction, it is instructive to inspect the source of wind fields. Wind fields are generated by pressure differences in the atmosphere. Especially around low-pressure areas, strong winds may be found. The wind direction in space and time strongly depends on the shape of the low-pressure area that causes the wind. Storm depressions are often thought to be close to circular. A circular depression would cause a curved wind field and in such conditions the wind direction measured in a point near the coast would show a consistent deviation of the actual wind direction further offshore. 
Inspection of weather maps of a few extreme storms on the North Sea shows that in general under extreme conditions not one but several more or less circular depressions are present. The combined effect of these depressions is the presence of an elongated area with low atmospheric pressure. On a weather map, such an area is characterised by stretched isobars over a long distance. As the wind speed is parallel to the isobars, the wind direction shows very little spatial variation under those conditions. Figure 56 shows an example where a severe storm shows a wind direction that is almost constant from the Dutch and Belgian coast to far on the Atlantic Ocean.

\section{MAANDAG 26 FEBRUARI 19901200 UTC.}

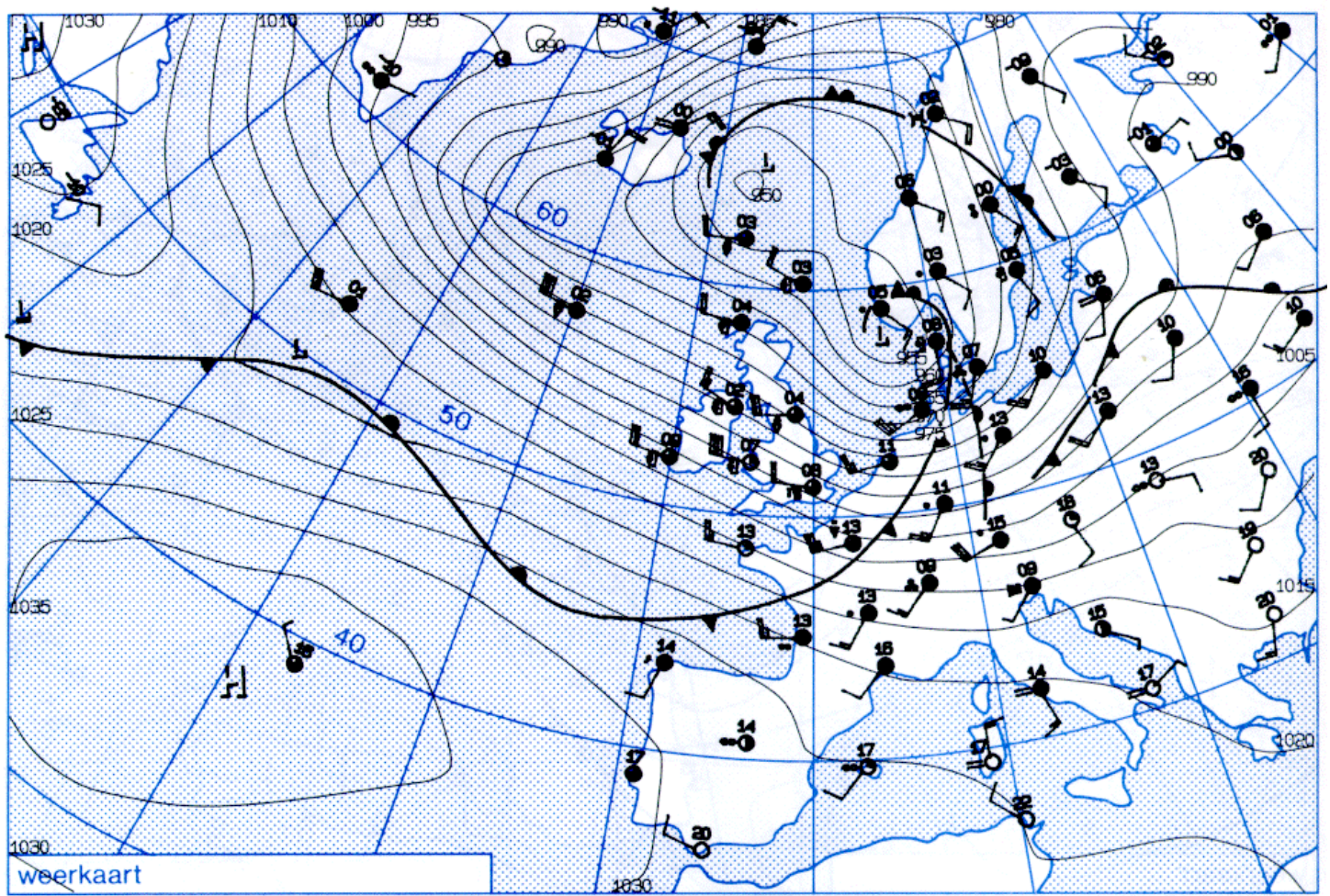

Figure 56: Weather map made by the Royal Dutch Meteorological Institute showing little spatial variation of the wind direction (26 February 1990, 12:00 GMT)

Temporal variations of the wind direction are important only if they persist for a longer time. This is caused by the fact that the hydraulic conditions do not respond immediately to any change of direction of the wind (see also van Vledder, 1990). Again based on the inspection of weather maps, extreme wind fields may be expected to show little time-dependent variation of the wind direction. Following an analysis by de Rijke (1983) the five-hour average observed wind direction is used as representative for the wind direction.

Not only the wind direction shows spatial and temporal variations. The same is true for the wind speed. Furthermore, the transfer of energy and impulse from the wind to the water depends on the shape of the boundary layer of the wind over the water, which in turn depends on the water-air temperature difference (Resio and Vincent, 1977). For wind waves, the difference between wind speed and wave group speed influences the wave growth. In this study a pragmatic approach is taken to define the representative wind speed. Again following de Rijke (1983), model calibration will in this study be performed assuming the peak five hour average wind speed at HBG as representative for the whole wind field. The schematisation of the wind field to a uniform wind field with a constant direction will for the same wind speed cause 
differences between observed and calculated hydraulic effect. These differences will be described as model uncertainty.

In the parametric models for hydraulic conditions, the basin geometry is described by two variables only: the length of the basin and the depth of the basin. The depth of the basin is considered constant over the full length. To use the models in the description of hydraulic conditions on the North Sea, the depth and length of the basin have to be chosen such that the simplified basin is equivalent to the North Sea basin. This can be achieved in a two-step process. In the first step, the North Sea is split in a set of basins, each basin corresponding to one wind direction. Model calibration can be performed for every direction such that the model provides direction-dependent probability distributions of wind setup, wave height and wave period.

\subsection{Deriving omni-directional statistics from a directional model}

\subsubsection{Deriving a formula for omni-directional statistics from a directional model}

Traditionally, the goal of statistical analysis of hydraulic conditions is the estimation of the probability of exceedance of certain conditions, irrespective of the direction of the wind. This result will in the following be denoted the omni-directional probability distribution of a hydraulic quantity. The model for the joint probability distribution of hydraulic conditions developed in this chapter provides estimates of extremes per wind direction. In order to compare the results of the directional model with the results of more traditional approaches, it is necessary to derive the omni-directional statistics of the hydraulic conditions from the directional model.

From the viewpoint of design of coastal flood defences, the interest is generally in the distribution of year maxima of the variables of interest. The probability distribution of year maxima provides estimates of the probability that the maximum observation in a year exceeds a certain level. Consider as an example a year in which $N$ independent observations of the wind setup are taken ${ }^{11}$.

The probability of exceedance of a predefined threshold $\eta$ within a year is for independent observations given by:

$$
P(\max (\mathbf{h})>\eta)=1-P\left(h_{1}<\eta \cap h_{2}<\eta \cap \ldots \cap h_{N}<\eta\right)=1-\prod_{n=1}^{N} P\left(h_{n}<\eta\right)
$$

Where:

h: $\quad$ Vector of wind setup observations;

$\eta$ : Threshold value.

The probability of exceedance of the threshold is found as the complement of the probability that no observation exceeds the threshold. The probability that no observation exceeds the threshold is found by the multiplication of the individual probabilities of non-exceedance, which in practice are found by fitting a parametric probability model to the observations.

\footnotetext{
${ }^{11}$ Independence of the observations should be ensured by taking a sufficiently long time interval between observations selected for analysis.
} 
If the individual probability of non-exceedance is in all cases described by the same distribution function then the distribution of the maxima is given by:

$$
F_{\text {extr } ; \underline{\underline{h}}}(\eta)=F_{\underline{h}}(\eta)^{N}
$$

Where $N$ denotes the number of independent observations.

Wind setup on the North Sea caused by wind fields with different directions can generally not be described by the same distribution function for the reason that the basin shape is different in different directions. The basin shape directly influences the probability distribution of the wind setup which causes direction-dependent differences in the distributions. Therefore equation (92) can not be applied in this case.

To find a valid description of the omni-directional distribution of the wind setup, consider the same set of $N$ independent observations to originate from $M$ different wind direction sectors. Simple counting of the occurrences of every sector provides the number of observations per sector $N_{s e c ; i}$. An empirical measure for the probability of occurrence of every sector is given by the number of observations per sector relative to the total number of observations:

$$
p_{s e c ; i}=\frac{N_{s e c ; i}}{N}
$$

Where $N_{s e c ; i}$ is the number of observations in sector $i$.

The expression for the probability of exceedance of the threshold is based on the basic formula of equation (91):

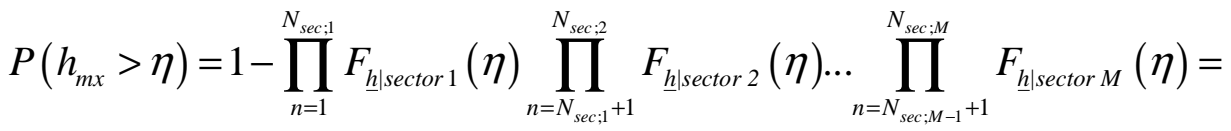

$$
\begin{aligned}
& 1-\prod_{m=1}^{M} F_{\underline{h} \mid m}(\eta)^{N_{s e c ; m}}=1-\prod_{m=1}^{M} F_{\underline{h} \mid m}(\eta)^{p_{s e c ; m} N}
\end{aligned}
$$

Where:

$h_{m x}$ : $\quad$ Year maximum of wind setup;

$\eta: \quad$ Threshold value;

$N: \quad$ Total number of observations;

$M$ : $\quad$ Number of sectors;

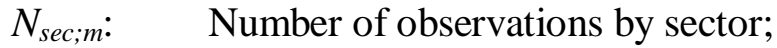

$p_{\text {sec } ; m}$ : $\quad$ Empirical probability of occurrence of the sector.

The term $F_{\underline{h l m}}(\eta)^{p_{s c ;} m^{N}}$ is the extreme value distribution of the wind setup within sector $m$. Equation (94) in fact is the formula for the probability of occurrence of the top event in the series system visualised in the fault tree of figure 57. 


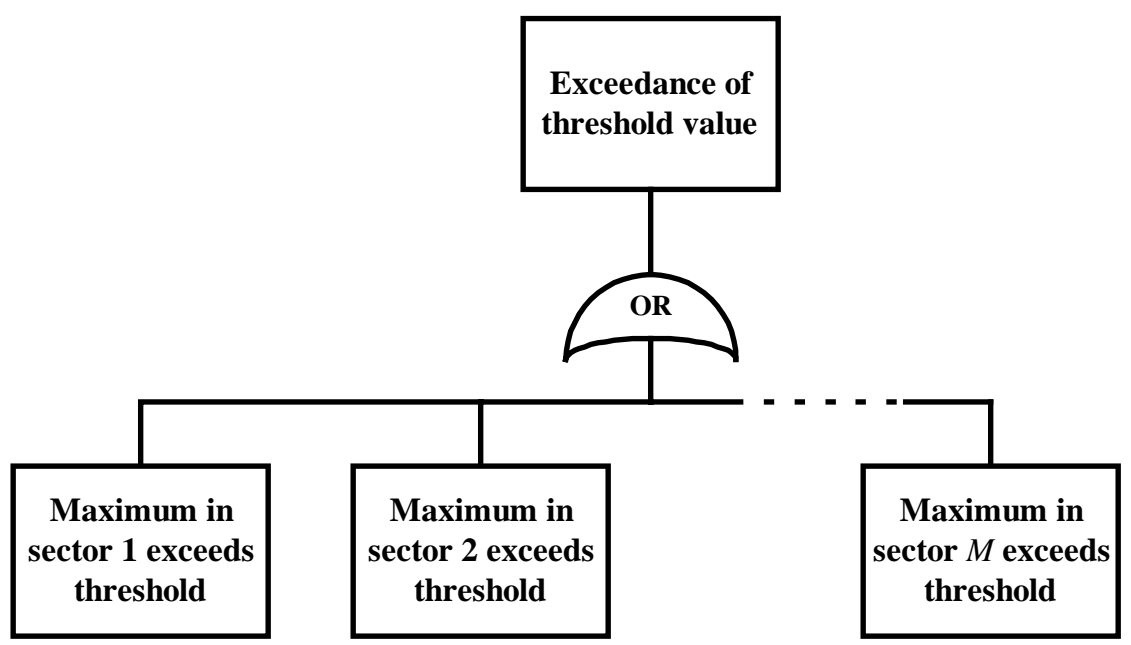

Figure 57: Fault tree representation of the extreme value analysis in a directional model

Independence should be ensured in the data selection process by taking an appropriate time interval between observations. If independence is ensured, the probability of exceedance of the threshold is described by the formula for a series system with independent components (chapter 3). This is exactly the same result as equation (94).

\subsubsection{Example of the analysis of omni-directional statistics}

To illustrate the analysis of omni-directional statistics with a directional model, the method is applied to a very simple example. Consider the L-shaped basin shown in figure 58 .

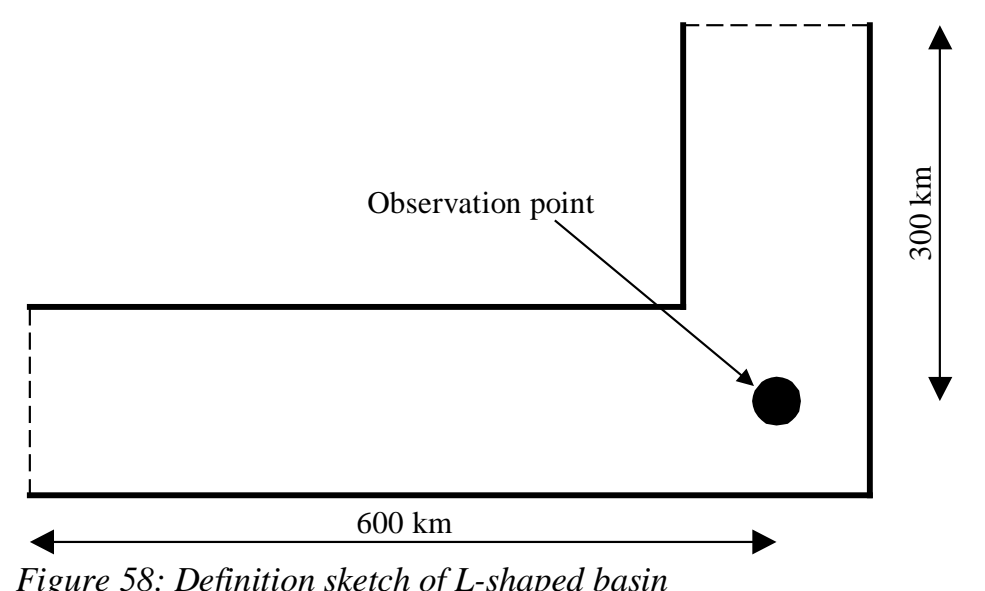

The basin consists of two open-ended basins, one with a length of $600 \mathrm{~km}$ and one with a length of $300 \mathrm{~km}$. An analysis will be made of the distribution of the wind setup at the observation station that is located at the crossing of the long and the short basin. Table 20 summarises the parameters used in this example.

Table 20: Parameters used in example of direction-dependent extreme value analysis of wind setup

\begin{tabular}{llllll}
\hline Variable & Description & Distribution type & Shift & Scale & Shape \\
\hline$u_{\text {long }}$ & $\begin{array}{l}\text { Year maximum wind speed } \\
\text { long sector }\end{array}$ & Weibull & $10 \mathrm{~m} / \mathrm{s}$ & $3 \mathrm{~m} / \mathrm{s}$ & 1.2 \\
$u_{\text {short }}$ & $\begin{array}{l}\text { Year maximum wind speed } \\
\text { short sector }\end{array}$ & & $20 \mathrm{~m} / \mathrm{s}$ & $3 \mathrm{~m} / \mathrm{s}$ & 1.2 \\
$d$ & Basin depth & Deterministic & $30 \mathrm{~m}$ & - & - \\
$h_{\text {upwind }}$ & Upwind wind setup & Deterministic & $0 \mathrm{~m}$ & - & - \\
$c$ & Empirical parameter & Deterministic & $4 \cdot 10^{-6}$ & - & - \\
\hline
\end{tabular}


The two wind directions (sectors) differ in basin length and in the shift parameter of the wind speed. Using the wind setup model (equation (81)), the distribution of the year maximum wind setup per sector can be derived directly from the distribution of the year maximum wind speed ${ }^{12}$. Figure 59 shows the probability distribution of the wind setup for the two sectors.

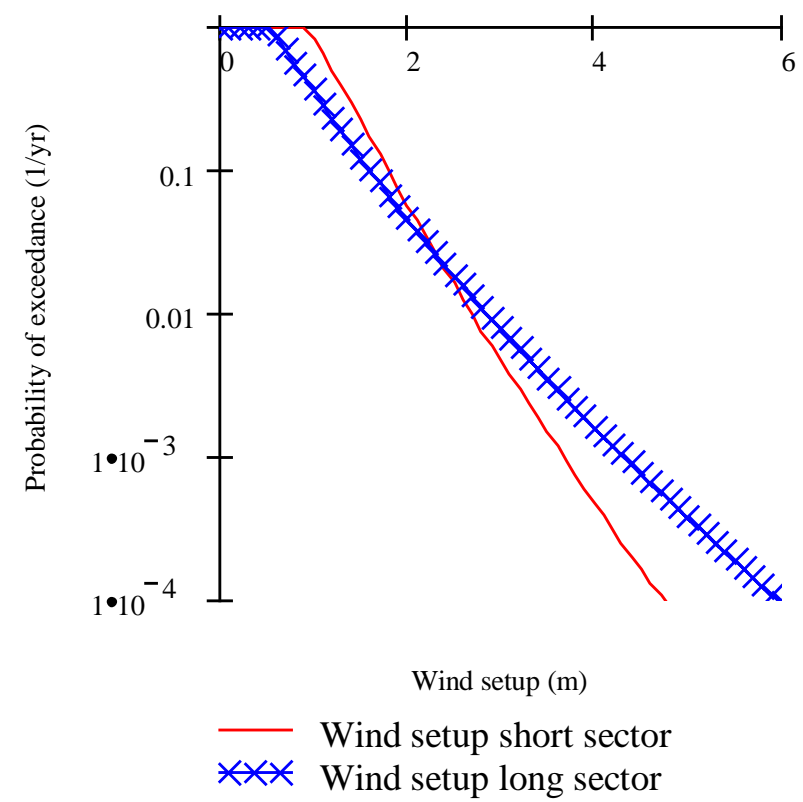

Figure 59: Probability distribution of wind setup per wind direction in an L-shaped basin

On average, the wind speed over the short basin is somewhat higher than the wind speed over the long basin. For exceedance probabilities higher than 0.02 per year, the wind setup from the short sector is somewhat higher than the wind setup from the long sector for the same value of the exceedance probability. For exceedance probabilities lower than 0.02 per year, the situation is reversed.

Using equation (94), the omni-directional distribution of the wind setup is in this case given by:

$$
F_{\underline{h} ; \text { omni }}(\eta)=F_{\underline{h} \mid \text { long }}(\eta) F_{\underline{h} \mid \text { short }}(\eta)
$$

Where:

$F_{\underline{\underline{h}} \mid \text { long }}(\eta)$ : Distribution of the year maximum wind setup from the long sector;

$F_{\underline{h} \mid s h o r t}(\eta)$ : Distribution of the year maximum wind setup from the short sector.

Note that in equation (95) the probability distributions of the year maximum wind setup are given in which $p_{s e c}$ already is accounted for. Figure 60 shows the result, together with the wind setup distributions per sector.

\footnotetext{
${ }^{12}$ Model uncertainty is neglected in this simple example.
} 


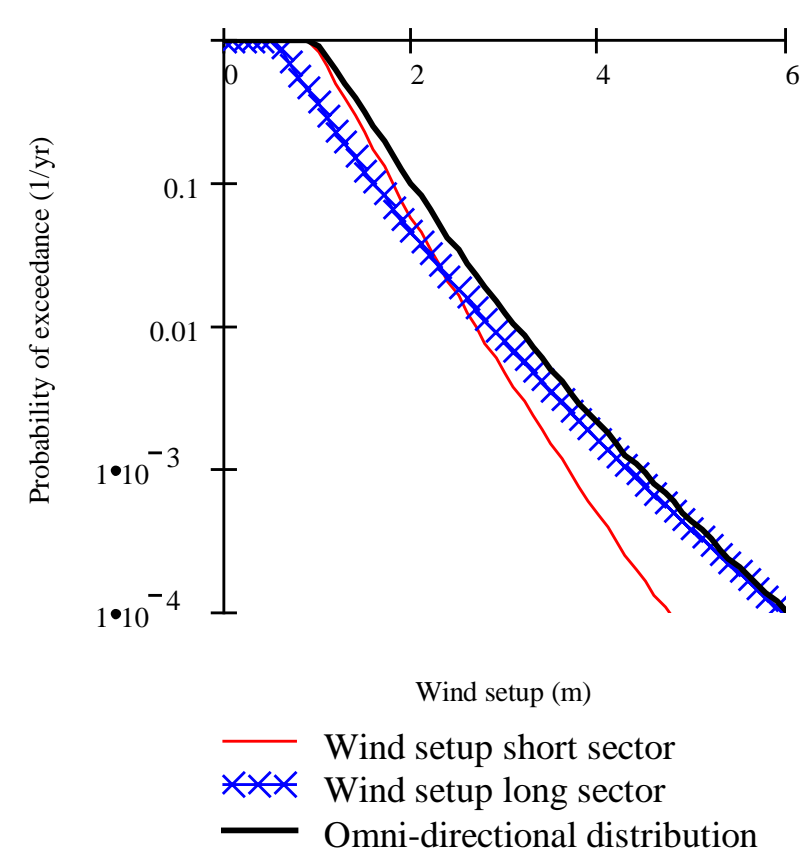

Figure 60: Probability distributions of wind setup in an L-shaped basin

For low values of the wind setup, the distribution follows the distribution of the short sector. For high values of the wind setup, the omni-directional distribution follows the distribution of the long sector. In between is a transition zone where the omnidirectional probability of exceedance of a given value of the wind setup is higher than the value by either two distribution per wind direction.

\subsection{Discussion}

In this chapter, a model for the joint probability distribution of hydraulic boundary conditions is proposed. The model is based on parametric physical models that describe water level and wave conditions as a function of the driving processes, the wind field and the astronomic tide.

Establishing accurate descriptions of extreme design conditions is a difficult task. Despite the abundance of observations available, there are only a few observations of extreme conditions. For the design of a flood defence structure, the extreme conditions are important.

Because observations of extreme conditions are scarce by definition, pure statistical estimation methods may fail to correctly describe the hydraulic conditions and the dependence between water levels and wave conditions. Parametric models based on physical concepts are expected to hold both under observed and under extreme conditions. A description of boundary conditions on that basis is therefore founded on much more information than field data alone and should be favoured over pure statistical methods.

Omni-directional distributions of extreme values of hydraulic conditions can be derived from a directional model. Closer analysis of omni-directional statistics reveals that a common method to derive extreme value distributions must be considered not valid for hydraulic conditions in the North Sea. The reason for this is that the probability distributions of hydraulic conditions are strongly dependent upon the wind direction due to the irregular shape of the North Sea basin. An alternative method is proposed in this chapter. 


\section{CALIBRATION OF THE JOINT PROBABILITY DISTRIBUTION OF HYDRAULIC CONDITIONS FOR THE DIKE RING GRONINGEN}

"This limited extrapolation [to $10^{-3}$ per year] certainly does not yet exceed the physically possible."
P.J. Wemelsfelder (1939)

\subsection{Introduction}

The theory of risk-based design of flood defence systems is developed in chapter 2. The main building blocks of the method are outlined in chapters 3 through 5 . The current chapter is the first of three chapters in which the theory will be applied to a case study. The area that will be analysed in the case study is a dike ring in the north of the Netherlands; the dike ring Groningen.

In chapter 2 it was shown that, in order to perform quantitative risk-based decisionmaking on flood protection, it is necessary to quantify the failure probability of the protection system, the cost of protection as a function of failure probability and the risk of flooding, which is also a function of the failure probability of the protection system. Chapter 3 showed that, in order to quantify the cost of protection as a function of flooding probability, one needs to be able to perform a quantitative reliability analysis of the protection system itself. The same is true for the quantification of the risk of flooding, as is shown in chapter 4. A quantitative reliability analysis of a flood defence structure can only be performed if the joint distribution of load and resistance variables is available in a quantitative form. In chapter 5 a model based on a mix of statistical and physical models is proposed to quantify the joint probability distribution of hydraulic conditions.

In this chapter, the conceptual model for hydraulic conditions developed in chapter 5 will be calibrated ${ }^{13}$ for use in the case study Groningen. Section 6.2 briefly introduces the case study. A large set of information is available for use in the calibration process. Section 6.3 outlines the process of selection of calibration data.

The model calibration itself is described in three sections. Section 6.4 describes the calibration of probability distributions of the input variables; the wind speed and the astronomic tide. The calibration of the wind setup and water level models is described in section 6.5. Section 6.6 describes the calibration of the wave model. The chapter closes with a discussion in section 6.7 .

\subsection{Overview of case study area and input data}

\subsubsection{Overview of case study area}

The goal of the analysis is to establish the joint probability distribution of the hydraulic conditions along the flood defences of the dike ring Groningen in the north of the Netherlands. Figure 61 shows the location of the case study area.

\footnotetext{
${ }^{13}$ The word "calibration" is generally used for the process of estimating the parameters of physical models. In this study, calibration is defined as the process of parameter estimation of any type of model. Estimating the parameters of a probability model is therefore also referred to as "calibration".
} 


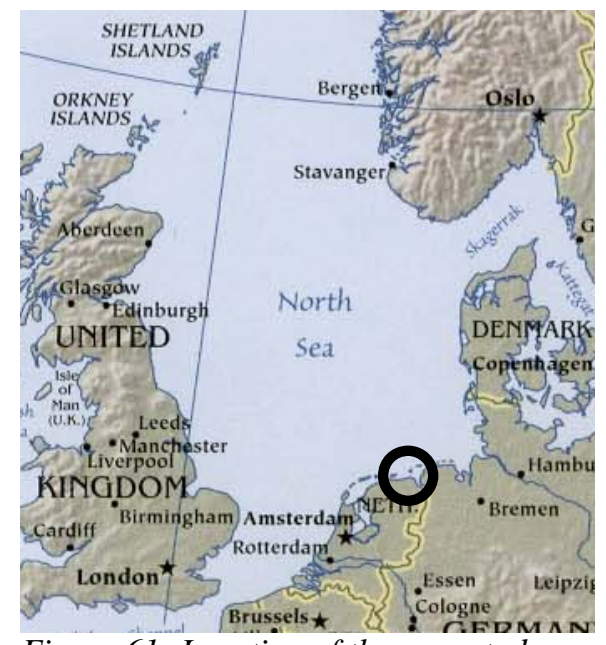

Figure 61: Location of the case study area

The coast of the dike ring Groningen borders a shallow area called the Wadden Sea. To the north, the boundary between the Wadden Sea and the much deeper North Sea is formed by a chain of islands. Figure 62 shows the case study area in more detail.

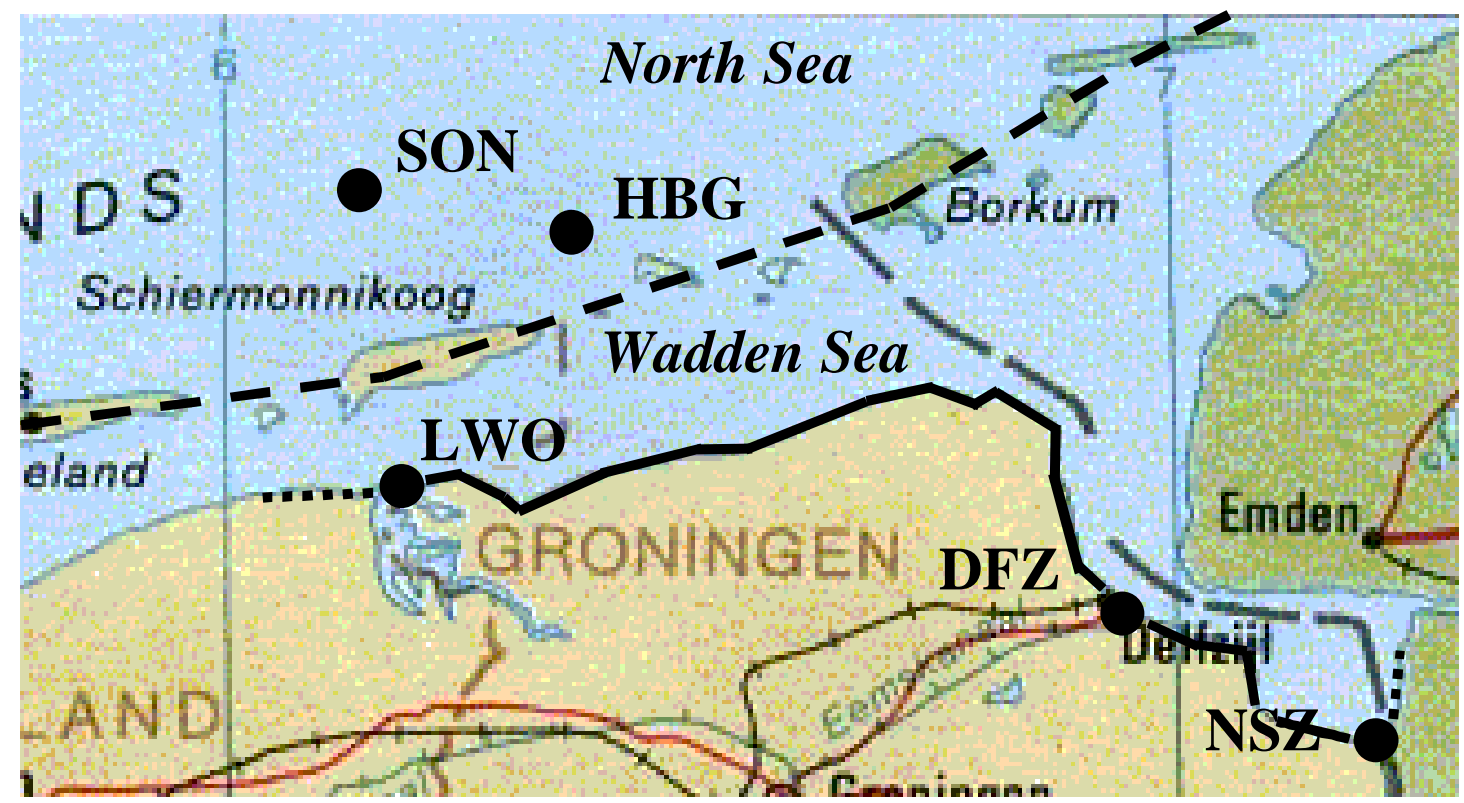

Figure 62: The case study area in more detail

The border between Wadden Sea and North Sea is indicated by a dashed line, running over the chain of islands offshore. A number of stations for the observation of wind conditions and hydraulic conditions are present in the area. At the North Sea, the station Schiermonnikoog Noord (SON) provides wave data. The station Huibertgat provides wind and water level data. Nearshore, the stations Lauwersoog (LWO), Delfzijl (DFZ) and Nieuwe Statenzijl (NSZ) provide water level data. LWO also provides wind data. A dataset of field observations of the five stations covering the period 1980-1998 is available for use in model calibration.

It is indicated in chapter 5 that tidal water levels can be described by a set of harmonic components. Harmonic components can be used to establish a probability distribution of the tidal water level during extreme wind conditions (chapter 5 and annex 4). For the water level stations in the area, the harmonic components have been obtained.

No permanent observation stations for wave conditions are present in the Wadden Sea area. Some incidental observations of wave conditions in the Wadden Sea are 
available (van Maren, 1999), but the data is too limited for proper model validation. Therefore, field data for calibration of the nearshore wave model is not available. An extensive study of the wave conditions in the Wadden Sea using a numerical model has been initiated by the Dutch Institute for Coastal and Marine Management (Alkyon, 1999). The parametric models for local wave conditions given in chapter 5 will be compared to the results of the numerical model. A qualitative comparison of the results to the observations of one extreme storm event will be performed (Jacobse, 2000).

\subsubsection{Description of field observations}

The data available from the five observation stations in the area differs from station to station. Table 21 shows an overview of the observation stations and the data that is used in this study.

Table 21: Overview of observation stations and data used

\begin{tabular}{|c|c|c|c|}
\hline Station name & Acronym & Data type used & Remark \\
\hline Huibertgat & HBG & $\begin{array}{l}\text { Wind speed, wind direction, wind setup, } \\
\text { water level, harmonic components }\end{array}$ & \\
\hline $\begin{array}{l}\text { Schiermonnikoog } \\
\text { Noord }\end{array}$ & $\mathrm{SON}$ & $\begin{array}{l}\text { Wave height, wave period, wave } \\
\text { direction, wave spectra }\end{array}$ & \\
\hline Lauwersoog & LWO & $\begin{array}{l}\text { Water level, wind setup, wind speed, wind } \\
\text { direction, harmonic components }\end{array}$ & $\begin{array}{l}\text { Wind information only } \\
\text { if } \mathrm{HBG} \text { unavailable }\end{array}$ \\
\hline Delfzijl & DFZ & $\begin{array}{l}\text { Water level, wind setup, harmonic } \\
\text { components }\end{array}$ & \\
\hline Nieuwe Statenzijl & NSZ & $\begin{array}{l}\text { Water level, wind setup, harmonic } \\
\text { components }\end{array}$ & \\
\hline
\end{tabular}

In this study, an observation period is selected where joint observations for all relevant variables are available. This limits the observation period to the period 19801998, where wave information is available. Next to the field observations, the harmonic components of the tide at the four water level stations have been obtained from the Dutch Institute for Coastal and Marine Management (Doekes, personal communication).

In this study, the wave conditions observed at Schiermonnikoog Noord (SON) and the water level observations at Huibertgat (HBG) are used to calibrate the joint probability distribution function (JPDF) of offshore hydraulic conditions. In addition to the observations of characteristic wave parameters (significant wave height, peak period), the spectra corresponding to the ten highest observations of significant wave height are used to establish relations between different characteristic wave periods. The observations at the water level stations Lauwersoog (LWO), Delfzijl (DFZ) and Nieuwe Statenzijl (NSZ) are used to calibrate the models for nearshore wind setup and water level.

The wind dataset contains observations of the potential wind speed. This is not the observed wind speed, but the wind speed that would be observed if the wind were blowing over a surface with a standardised roughness length and the observation would have been done on an elevation of $10 \mathrm{~m}$ above terrain level (Wieringa and Rijkoort, 1983). In this study, the stations Huibertgat (HBG) and Lauwersoog (LWO) are used for the calibration of the statistical models of the wind conditions.

Observation records are very often incomplete due to a variety of reasons. A reason that has a serious impact on the quality of information for a statistical analysis, is 
malfunction of the observation instrument under extreme conditions. The Dutch Ministry of Public Works has filled possible gaps in the hydraulic data, primarily by using data from nearby stations (RIKZ, 1995b). In this way, data is available for SON from the beginning of 1979 . However, continued wave observation at SON started only in 1980, so that 1979 consists for the most part of data values estimated from other stations. For this reason, the year 1979 is completely omitted in this study.

The wind records are provided by the Royal Dutch Meteorological Institute (Royal Dutch Meteorological Institute on internet). This includes translating the observed wind speed to the potential wind speed and filling possible data gaps. At the time of the analysis performed in this study, three important gaps were still present in the wind observations of HBG (see table 22).

Table 22: Missing data in HBG wind speed record (version July 2001)

\begin{tabular}{ll}
\hline Nr. & Period \\
\hline 1 & $19850802-19850809$ \\
2 & $19900907-19900716$ \\
3 & $19901111-19901115$ \\
\hline
\end{tabular}

The gaps in the wind data of HBG have been filled using data from the neighbouring station LWO. The process is shown in detail in annex 5.

\subsubsection{Description of available results of a numerical wave model}

Field data of wave conditions is scarce in the Wadden Sea. This is a serious handicap in the development of the transformation models. The information available on nearshore wave conditions is an extensive set of results obtained with the numerical wave model SWAN (Booij et al., 1999; Alkyon, 1999). The scarcity of wave observations in the Wadden Sea makes it difficult to perform a proper calibration of both the SWAN model and of the parametric models in this study. A limited validation of the SWAN model is performed by Jacobse (2000).

In this study, the parameters of the models for wave conditions nearshore will be set such that the parametric models provide estimates of the wave conditions that are conservative in comparison to the estimates provided by the SWAN model. Because of the scarcity of field data, there is no guarantee that the models are also conservative with respect to nature. It is important to be aware of this fact when interpreting the results of the models.

Table 23 shows the input data used in the SWAN calculations in the dataset.

Table 23: Overview of input used in the SWAN calculations (Alkyon, 1999)

\begin{tabular}{ll}
\hline Input variable & Range \\
\hline Wind speed $(\mathrm{m} / \mathrm{s})$ & $15-38$ \\
Wind direction $\left({ }^{\circ} \mathrm{N}\right)$ & $0-360$ \\
Water level $($ area wide, $\mathrm{CD}+\mathrm{m})$ & $1-5$ \\
Offshore significant wave height $(\mathrm{m})$ & $3-11$ \\
Offshore spectral peak period $(\mathrm{s})$ & $9.6-21.3$ \\
\hline
\end{tabular}

In the SWAN calculations, every wind speed is generally combined with three different water levels. Every wind speed and water level combination is combined with only one set of wave conditions offshore. Model output is given at points along the flood defence structure. In a stretch of $250 \mathrm{~m}$ of coastline, at least one output point is present. 


\subsection{Selection of calibration data}

\subsubsection{General}

For calibration of the JPDF of hydraulic conditions, it is necessary to select data that will be used in the calibration process. Specifically, data is needed of:

- Basin geometry;

- Joint observations of wind and hydraulic conditions offshore and nearshore.

Data on the basin geometry is obtained from the map of the North Sea (Admiralty Charts and Publications, 1997). Joint observations of wind and hydraulic conditions are obtained in a selection process based on the observed wind speed.

\subsubsection{Selection of the basin geometry}

The parametric dependence models adopted for the description of the JPDF of hydraulic conditions are valid for rectangular basins with constant depth and length. Following the process outlined in chapter 5, a basin geometry representative for the North Sea can be derived by performing model calibration per wind direction first. Based on the directional model, the omni-directional statistics can be established which in turn can be used to find one basin geometry representing the full North Sea.

To calibrate the directional model, it is necessary to obtain data on the geometry of the North Sea basin dependent on the wind direction. Figure 63 shows twelve sectors ranging from $250^{\circ} \mathrm{N}$ through $360^{\circ} \mathrm{N}$.

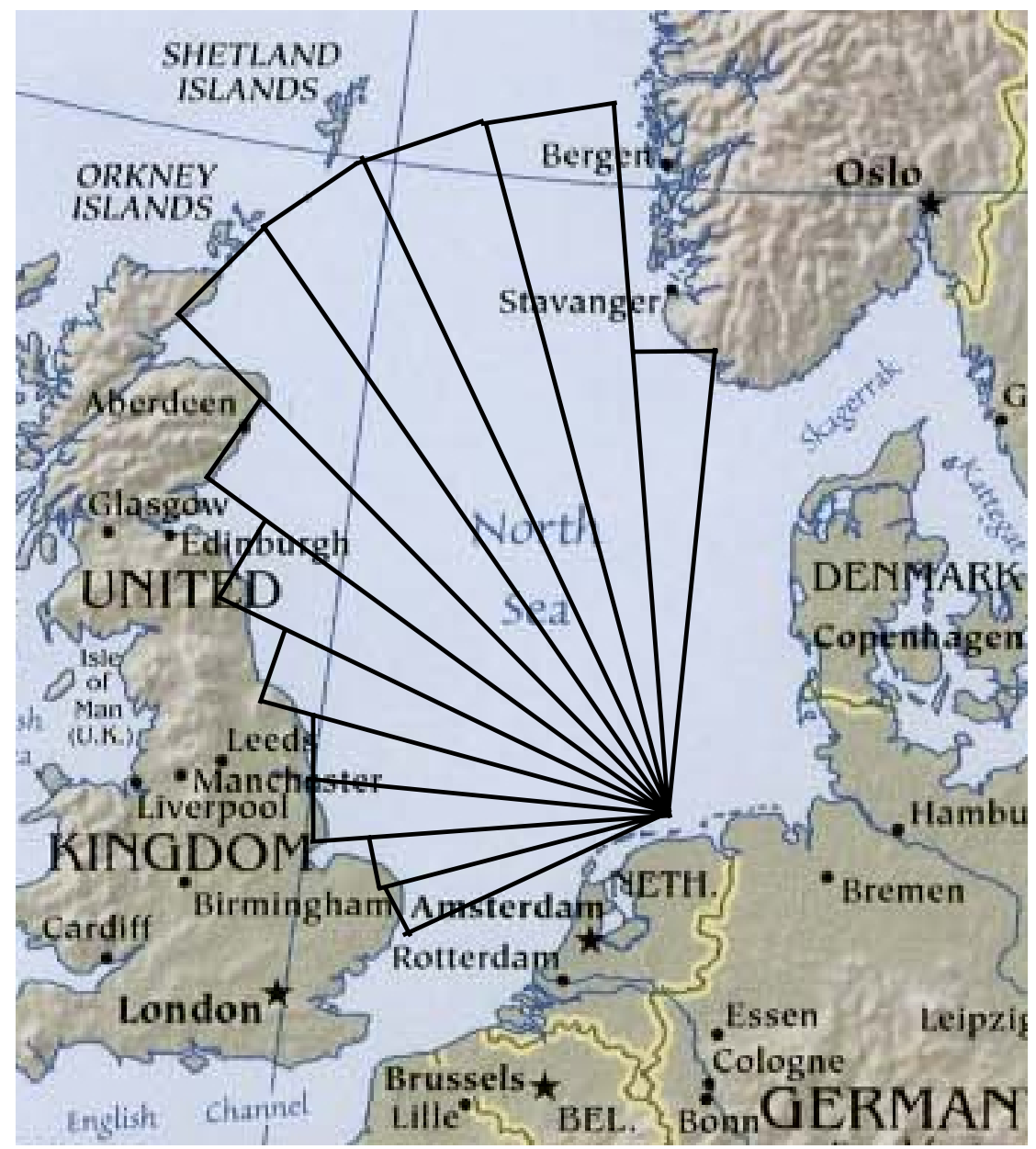

Figure 63: Twelve sectors on the North Sea, defined for the offshore observation stations SON and $H B G$ 
The basin length by sector can be obtained from the map of the North Sea (Admiralty Charts and Publications, 1997). The bottom profiles in every direction can also be obtained from the North Sea map. Figure 64 shows the bottom profiles obtained for the directions $250^{\circ} \mathrm{N}$ through $360^{\circ} \mathrm{N}$.
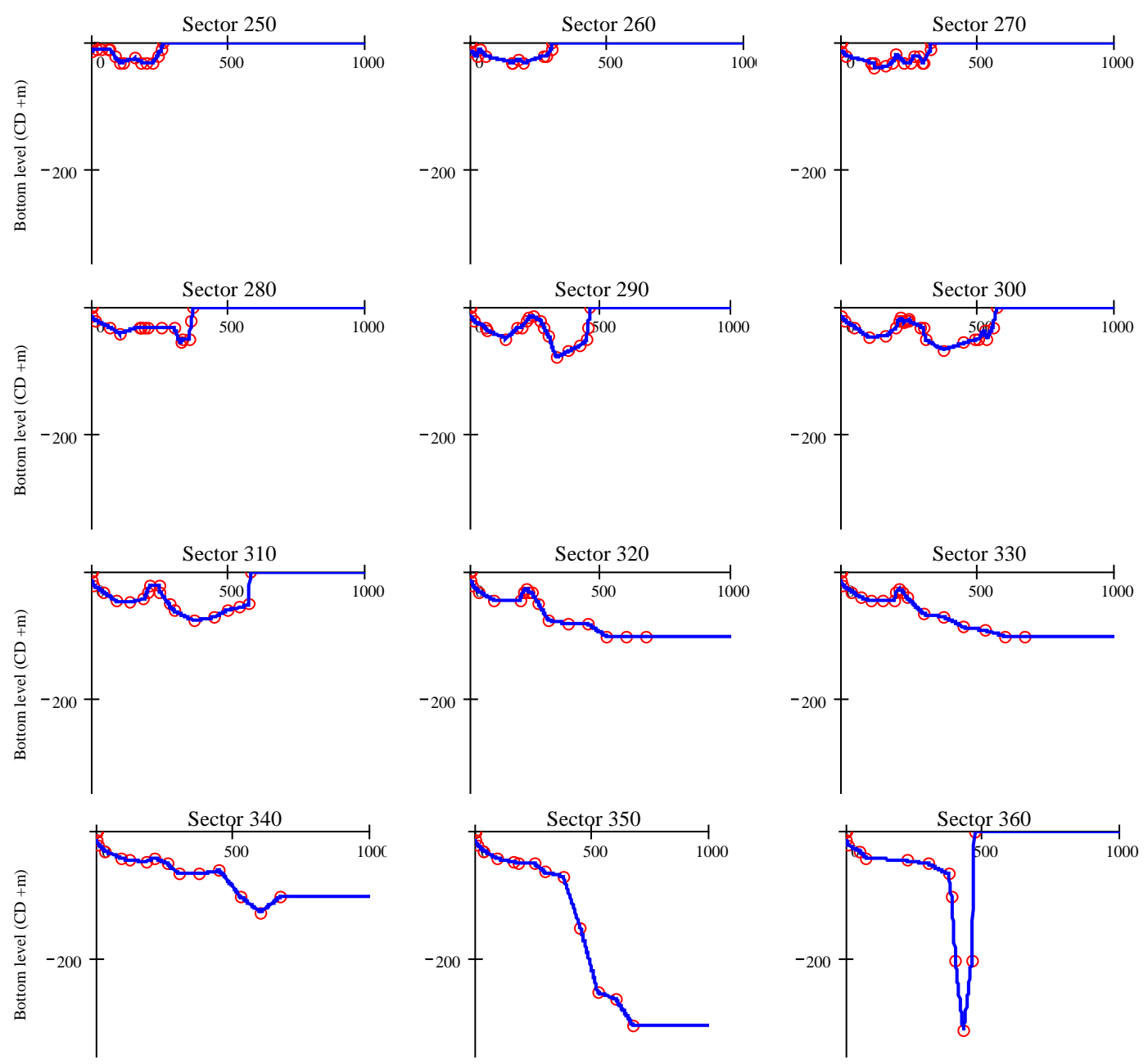

Distance to SON $(\mathrm{km})$

Distance to SON $(\mathrm{km})$

Distance to SON $(\mathrm{km})$

Figure 64: Direction-dependent bottom profiles on the North Sea

The basin length as obtained from the admiralty chart will be used directly as the basin length for the two-dimensional basin in every direction. A constant depth in every direction can not be adopted without taking into account the process that is described by the dependence model under consideration. The choice of the depth per sector will therefore be performed as part of the model calibration.

\subsubsection{Selection of data for model calibration}

For calibration of the JPDF of hydraulic boundary conditions, a set of extreme conditions has to be selected from the available observations. Also from the available results of the numerical model SWAN, a selection needs to be made.

Since extreme hydraulic conditions can be assumed to be wind-driven, it appears sensible to base the selection of field observations on the observed potential wind speed at HBG. An analysis of the time histories of wind speed and wind setup at HBG shows that in general extreme hydraulic effects are found in an interval running from two hours before till 48 hours after the peak wind speed. In most cases, the extreme 
hydraulic conditions are found within 24 hours after the wind peak. As an example, figure 65 shows time histories at HBG observed during the storm of 6 November $1985^{14}$.
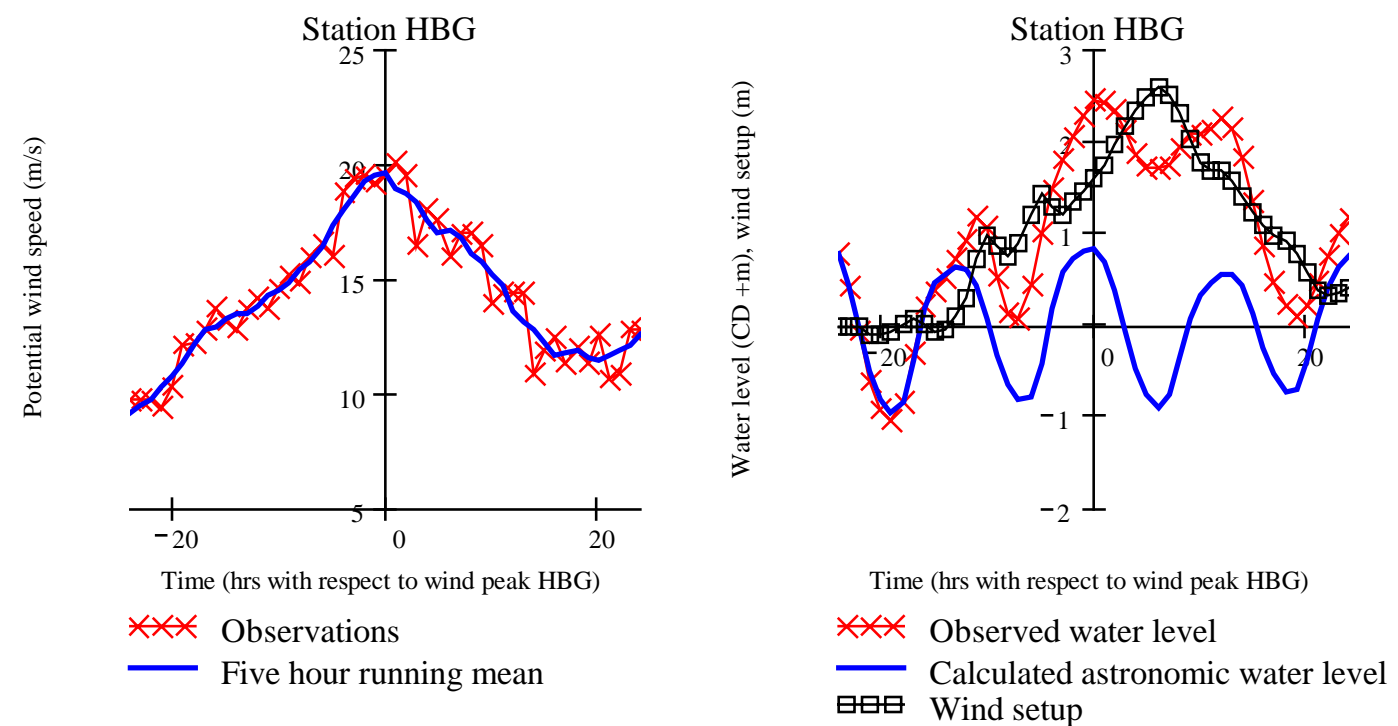

Figure 65: Time histories of wind speed, water level, astronomic tide and wind setup at observation station HBG during the storm of 6 November 1985

When plotting the time histories of the wave conditions at SON relative to the wind peak at HBG, it turns out that the extreme wave conditions at SON fall within the same time interval as the extreme water level conditions at HBG. Figure 66 shows the time histories of wave height and wave period observed at SON during the storm of 6 November 1985.
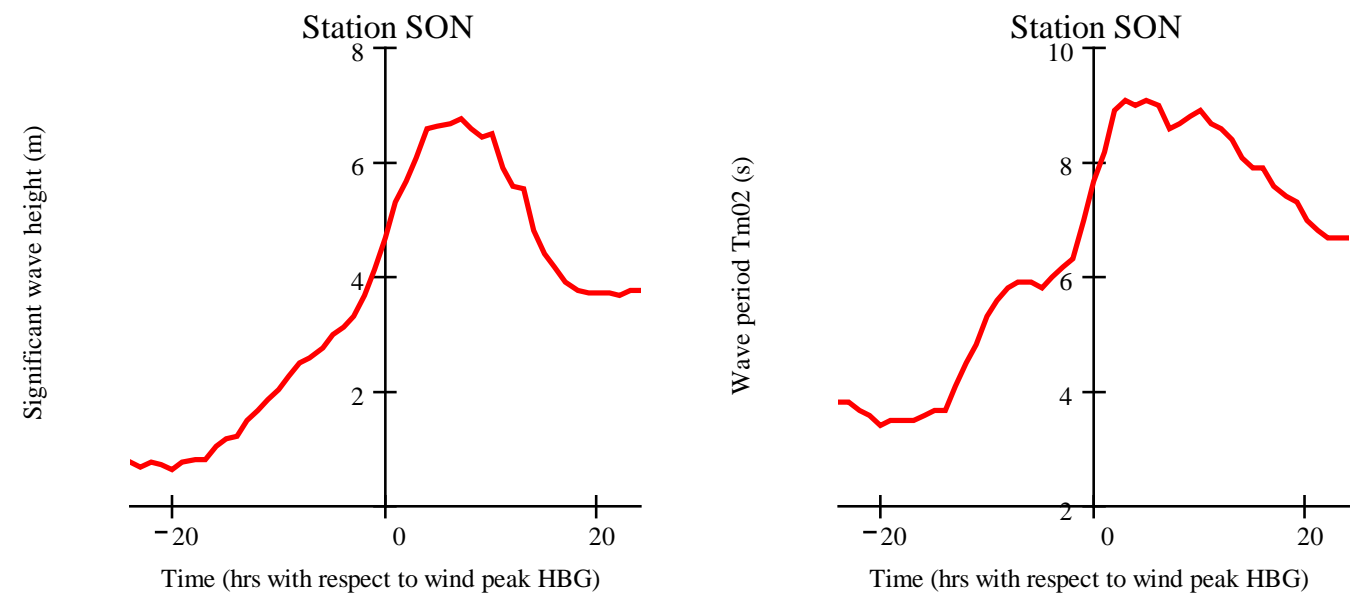

Figure 66: Time histories of wave conditions at SON as observed during the storm of 6 November 1985

Inspection of the time histories of wind setup and water level at the nearshore stations LWO, DFZ and NSZ indicates that the nearshore wind effects obtain their maximum in the same time interval as the offshore wind effects. Figure 67 shows the time

\footnotetext{
${ }^{14}$ This storm caused the highest observation of wind setup present in the dataset used in this study. The observed significant wave height is the seventh highest present in the dataset. Despite the fact that the storm has led to one of the more extreme conditions observed in this area, the storm is not listed as a storm surge by the Ministry of Public Works and Water Management. For a storm to be listed as a storm surge, the water level should exceed a predefined threshold. This did not occur on 6 November 1985 because the peak wind setup coincided with ebb tide.
} 
histories of wind setup, astronomic tide and water level as observed at three nearshore stations during the storm of 6 November 1985.

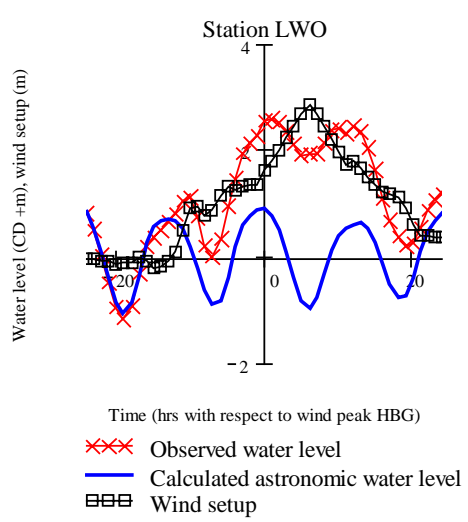

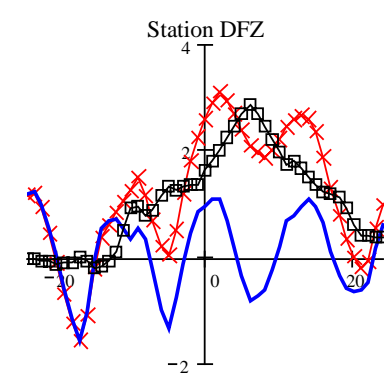

Time (hrs with respect to wind peak HBG)

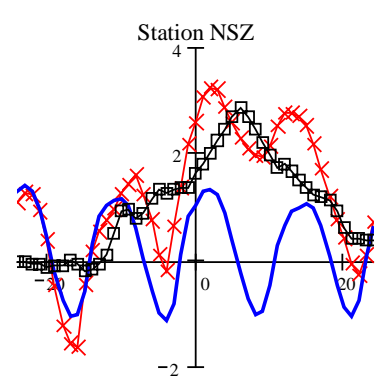

Time (hrs with respect to wind peak HBG)

Figure 67: Time histories of water level, astronomic tide and wind setup at three nearshore water level stations during the storm of 6 November 1985

Based on the time history of a storm, selection of joint observations of extreme conditions is performed as follows. A search procedure is applied to find peaks in the five hour average potential wind speed at HBG. At the wind speed peak, the following data is selected:

- Five hour average potential wind speed at the peak $\left(u_{5}\right)$;

- Five hour average wind direction corresponding to the wind peak $\left(\theta_{w}\right)$;

In an interval running from two hours before till 48 hours after the wind peak:

- Peak wind setup at HBG $(h)$;

- Astronomic tide at HBG corresponding to the peak wind setup $\left(h_{a}\right)$;

- Peak significant wave height at SON calculated from the wave spectrum $\left(H_{s}\right)$;

- Spectral wave period $T_{m 02}$ at SON corresponding to the wave height peak;

- Peak wind setup and corresponding water level at LWO $\left(h_{L W O}, h_{w ; L W O}\right)$;

- Peak wind setup and corresponding water level at DFZ $\left(h_{D F Z}, h_{w ; D F Z}\right)$;

- Peak wind setup and corresponding water level at NSZ $\left(h_{N S Z}, h_{w ; N S Z}\right)$.

Following this approach, for every wind direction datasets are selected with a total of 20 observations. No extreme conditions are to be expected for wind directions from $90^{\circ} \mathrm{N}$ through $240^{\circ} \mathrm{N}$ because these directions lead directly to the coastline. Therefore, these directions are omitted from the analysis. Furthermore, in the selection process it turns out that no extreme wind conditions are present corresponding to wind directions $10^{\circ} \mathrm{N}$ through $80^{\circ} \mathrm{N}$ so that these sectors are also omitted from further analysis.

The selection process provides estimates of the maxima of the hydraulic conditions corresponding to a peak in the wind speed. During a storm, the time of occurrence of for instance the peak wind setup may differ from the time of occurrence of the peak wave height. In the calibration of the model, it will be assumed that the peaks of all hydraulic variables occur at the same time. This is a slightly conservative approach.

The numerical wave model SWAN has been applied to relatively extreme conditions already. The results corresponding to the sectors $250^{\circ} \mathrm{N}$ through $360^{\circ} \mathrm{N}$ are used for to set the parameters of the models for wave conditions nearshore. The selection of sectors is thus in correspondence with the sectors that cause the most extreme conditions offshore. At some locations, the bottom level is higher than the lowest input water level in the SWAN calculations. Obviously, model results obtained under 
such conditions do not provide any relevant information and are excluded from further analysis.

\subsection{Calibration of the probability distributions of wind speed and astronomical tide}

\subsubsection{Calibration of the probability distribution of wind speed}

The probability distribution of the potential wind speed at HBG is calibrated to the selected data using the least-squares method (see Van Gelder, 1999 for details). Following chapter 5, the Weibull distribution is used to describe the probability distribution of the wind speed.

For the directional model, it is necessary to fit a Weibull model to the wind speed observations per wind direction. The distribution of the potential wind speed for all directions together (omni-directional distribution) can be found by analysis of a series system of sectors (chapter 5). A second method to derive the omni-directional distribution of the wind speed is by a classical peaks-over-threshold method. Within the range of the observations, the two distributions should be in reasonable agreement with each other and with the data. For reasons indicated in chapter 5, the tail estimates may deviate considerably from each other if there is a difference in the probability distribution of the wind speed per direction.

The parameters of the calibrated Weibull distribution of the wind speed per direction and omni-directional is given in table 24 .

Table 24: Result of the calibration of the probability distribution of potential wind speed at $H B G$

\begin{tabular}{cccc}
\hline Sector $\left({ }^{\circ} \mathbf{N}\right)$ & \multicolumn{3}{c}{ Parameters of Weibull model } \\
\cline { 2 - 4 } & Shift $(\mathrm{m} / \mathrm{s})$ & Scale $(\mathrm{m} / \mathrm{s})$ & Shape $(-)$ \\
\hline 250 & 12.7 & 7.06 & 2.68 \\
260 & 15.3 & 4.36 & 1.47 \\
270 & 14.2 & 3.98 & 1.39 \\
280 & 14.9 & 3.62 & 2.00 \\
290 & 11.7 & 4.82 & 1.27 \\
300 & 11.5 & 4.33 & 1.22 \\
310 & 13.4 & 2.29 & 0.92 \\
320 & 12.7 & 3.79 & 2.07 \\
330 & 13.4 & 2.84 & 1.35 \\
340 & 12.2 & 2.69 & 2.14 \\
350 & 6.87 & 6.91 & 1.51 \\
360 & 8.16 & 5.61 & 2.96 \\
Omni & 19.8 & 2.83 & 1.20 \\
\hline
\end{tabular}

Within the range of the observations, the results of the directional and the omnidirectional analysis are indeed in close agreement. In extrapolation to extreme conditions, differences in quantile estimates up to $5 \mathrm{~m} / \mathrm{s}$ may occur (figure 68). 


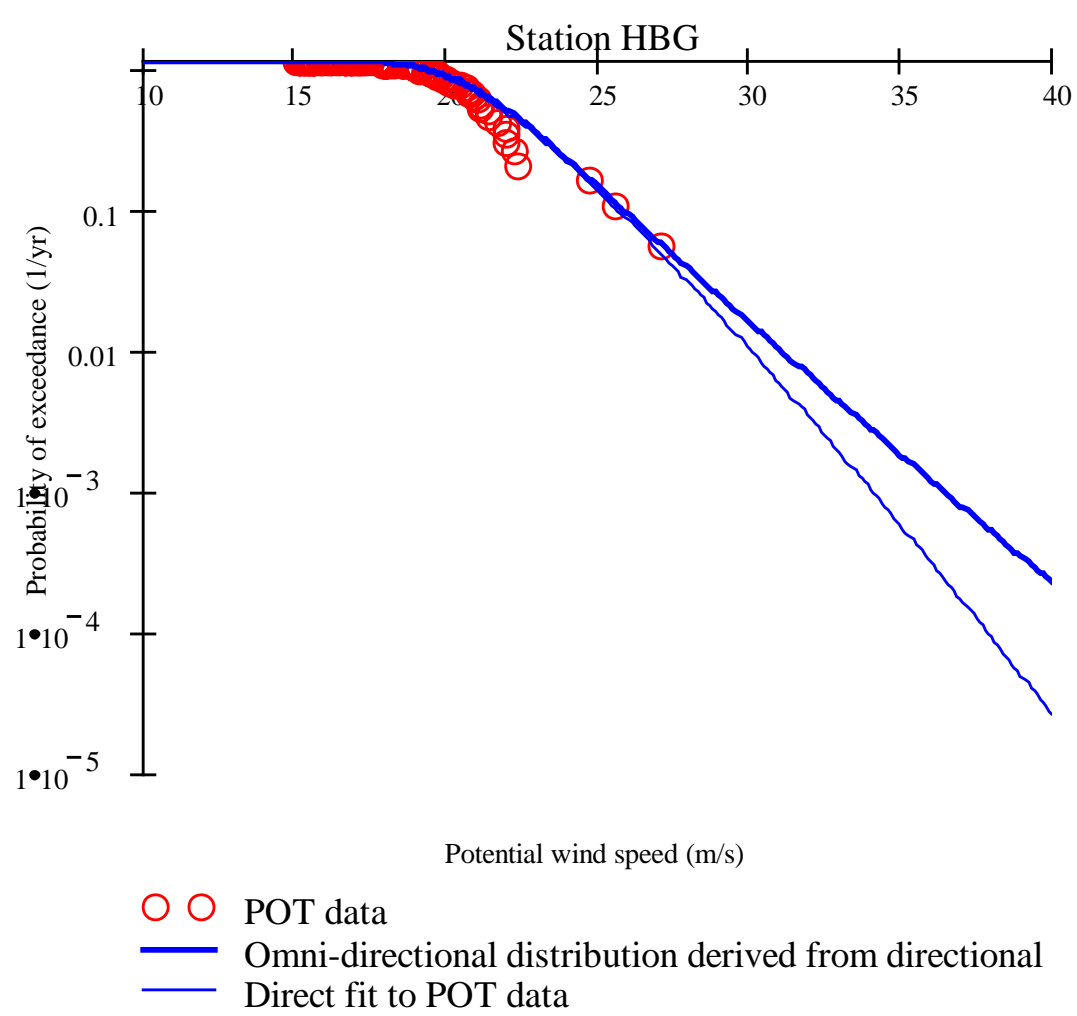

Figure 68: Probability distribution of the potential wind speed at $H B G$ as derived from the directional model and by classical POT-analysis

The series system analysis of twelve sectors according to chapter 5 leads to a valid description of the omni-directional wind speed distribution. This is indicated by the close agreement between the two estimates of the wind distribution within the range of the observations.

Due to the relatively short observation period, extreme quantile estimates of the wind speed can only be obtained by extrapolation of the calibrated probability distribution. Therefore, the estimates contain uncertainties. This type of uncertainty is known as statistical uncertainty (Efron, 1982; Efron and Tibshirani, 1993; van Gelder, 1999; chapter 5). In the calibration of the hydraulic dependence models the statistical uncertainty does not play a role, since the observations themselves are used in the calibration process. For use in the probabilistic analysis of flood defences (chapters 7 and 8) an estimate of the statistical uncertainty is necessary. The statistical uncertainty on the quantile estimates is obtained by application of the bootstrap method. The analysis is performed for the omni-directional wind speed distribution only. The results indicate that the estimates of the extreme quantiles of the wind speed at HBG can be described by log-normal distributions. Figure 69 shows a few examples. 


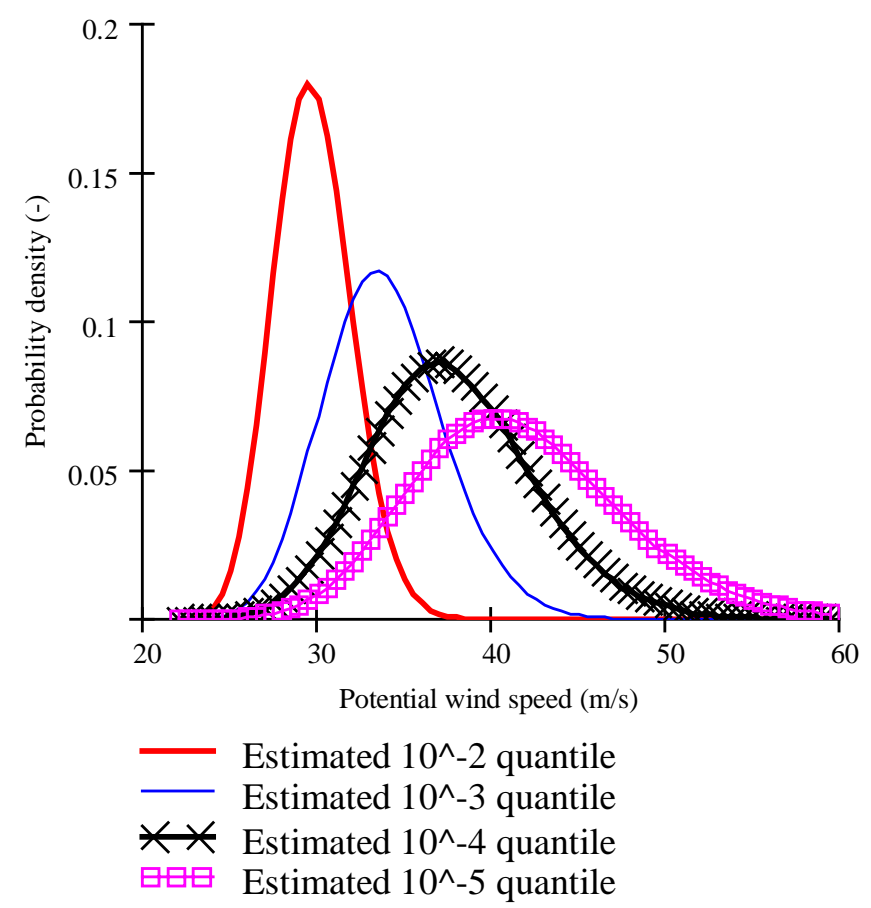

Figure 69: Log-normal densities of extreme quantiles of the wind speed at HBG as obtained from bootstrap data

For a given exceedance probability, the expected value of the wind speed is given by the Weibull distribution with parameters according to the last row of table 24 . The shift parameter of the log-normal distribution is given by the logarithm of the expected wind speed for the given quantile. The scale parameter is given by a linear function of the natural logarithm of the expected wind speed:

$s_{\underline{u} \mid p}(v)=a \ln (v)+b$

Where:

p: $\quad$ Exceedance probability of wind speed according to Weibull distribution;

$v: \quad$ Value of wind speed according to the Weibull distribution corresponding to $p$.

The parameters of the linear model describing the scale parameter are given in table 25.

Table 25: Parameters of linear model describing the statistical uncertainty of the wind speed

\begin{tabular}{ll}
\hline Parameter & Value \\
\hline$a$ & 0.21 \\
$b$ & -0.65 \\
\hline
\end{tabular}

Figure 70 shows the omni-directional wind speed distributions including statistical uncertainty. 


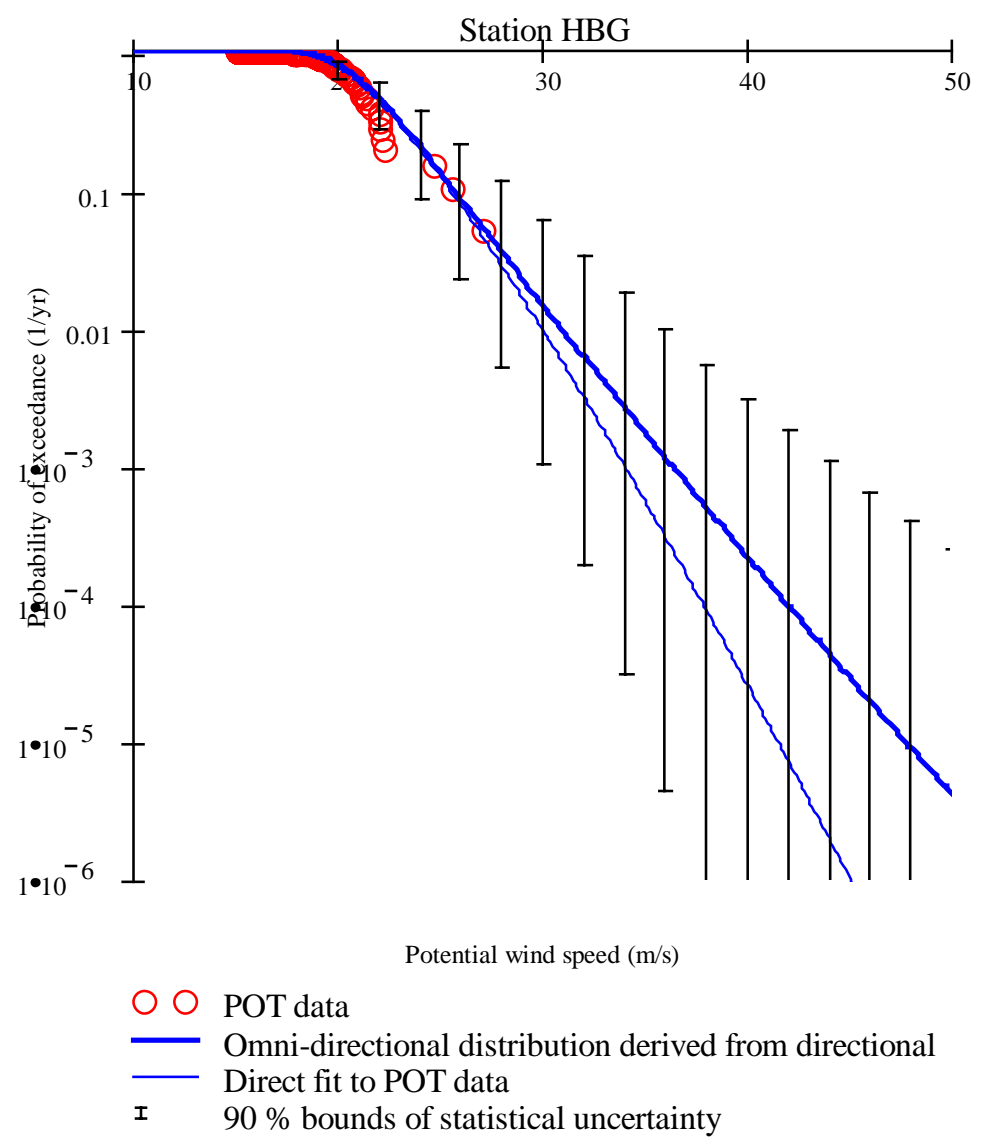

Figure 70: Omni-directional distribution of wind speed including statistical uncertainty

The omni-directional distribution derived from the direction-dependent model lies within the uncertainty bounds of the direct fit.

\subsubsection{Calibration of the probability distribution of the astronomical tide}

In chapter 5 and annex 4 a method is explained to derive the distribution of the astronomical tide from the harmonic components of the tidal water level. For the case study area, the analysis is performed for the four water level stations HBG, LWO, DFZ and NSZ. Table 26 shows the parameters of the tide distribution per station.

Table 26: Parameters of the tide distribution of three nearshore stations

\begin{tabular}{llllll}
\hline Station & $p_{t r}$ & $\mu_{l o}(\mathrm{~m})$ & $\sigma_{l o}(\mathrm{~m})$ & $\mu_{h i}(\mathrm{~m})$ & $\sigma_{h i}(\mathrm{~m})$ \\
\hline HBG & 0.43 & -0.74 & 0.40 & 0.56 & 0.50 \\
LWO & 0.57 & -0.62 & 0.50 & 0.76 & 0.42 \\
DFZ & 0.52 & -0.70 & 0.61 & 0.90 & 0.54 \\
NSZ & 0.54 & -0.70 & 0.55 & 0.84 & 0.49 \\
\hline
\end{tabular}

\subsection{Calibration of models for wind setup and water level}

\subsubsection{Calibration of a directional model for wind setup offshore}

The parametric model for wind setup developed in chapter 5 can be calibrated for the dike ring Groningen using the wind data and wind setup data obtained from station HBG. The following observations are relevant for calibration of the wind setup model:

- Five hour average potential wind speed at HBG $\left(u_{5}\right)$;

- Maximum wind setup at HBG $(h)$; 
- Tide at HBG at the time of maximum wind setup $\left(h_{a}\right)$.

Furthermore, the direction-dependent bottom profiles and the basin lengths are used. In order to calibrate the wind setup model, the following parameters have to be chosen such that the model describes the mean of the observed wind setup as a function of the wind speed:

- The depth $d$;

- The basin length $F$;

- The empirical coefficient $c$.

The basin length $F$ per direction is directly obtained from the map of the North Sea (Admiralty charts and publications, 1997) as indicated in section 6.3. The parametric wind setup model assumes a constant depth over the full length of the basin. Therefore, in the process of model calibration, a correct value of the depth has to be found such that the model reproduces the observations.

In a two-dimensional situation, the wind setup in a uniform wind field over varying depth can be obtained by solving equation (79) using a numerical method for integration of an ordinary differential equation. The resulting wind setup at the observation station HBG can then be used to derive a constant depth that gives the same value of the wind setup. This constant depth will be denoted the effective depth. The effective depth can be found by solving the follow equation for the effective depth $d_{\text {eff: }}$ :

$$
h_{f u l l}(c, u, F)=-d_{\text {eff }}+\sqrt{d_{e f f}^{2}+2 \frac{c u^{2} F}{g}}
$$

Where $h_{\text {full }}$ is the wind setup derived from numerical integration of the 2-D model.

To be able to estimate the effective depth per sector, values of $c$ and $u$ have to be assumed in advance. Since the estimates influence both sides of equation (97), the influence of these choices on the value of the effective depth is limited.

The analysis will be illustrated by looking in more detail to the sector $350^{\circ} \mathrm{N}$. Figure 71 shows the wind setup as a function of the distance to HBG for the full model and for the constant depth model using the effective depth derived by equation (97). The wind speed used is $20 \mathrm{~m} / \mathrm{s}$ and $c$ equals $4 \cdot 10^{-6}$. 

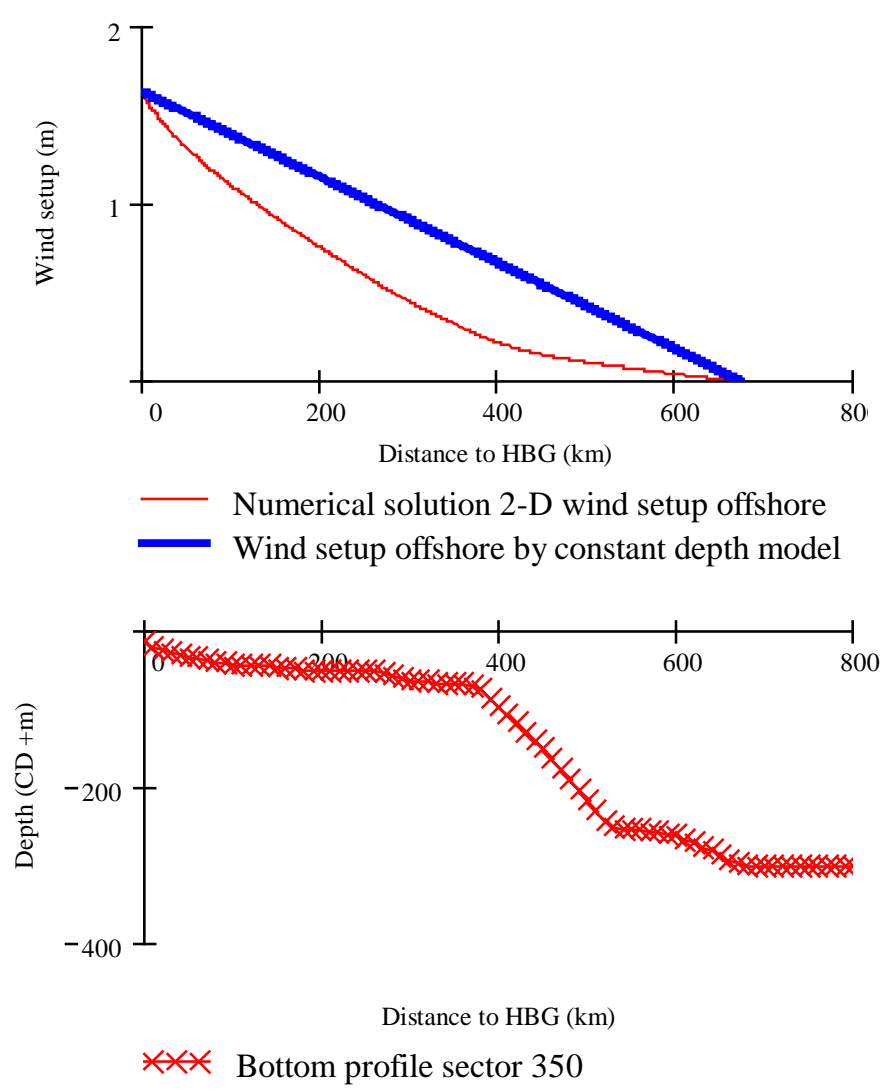

Figure 71: Results of constant depth model and full model ( sector $\left.350^{\circ} \mathrm{N}\right)$

The bottom profile in the direction $350^{\circ} \mathrm{N}$ shows a trench with a depth up to $300 \mathrm{~m}$ below mean sea level at its northern end (see figure 64). The equilibrium wind setup gets higher if the return flow is hindered by bottom friction. Bottom friction generally increases with decreasing depth. It is for this reason that the deepest parts of the profile hardly contribute to the wind setup at HBG. In establishing the effective depth, this effect is accounted for. Table 27 shows the values of the effective depth for all sectors. The mean depth of every sector is included for comparison.

Table 27: Properties of North Sea per sector (wind setup)

\begin{tabular}{cccc}
\hline Sector $\left({ }^{\circ} \mathbf{N}\right)$ & Fetch $(\mathbf{k m})$ & Mean depth $(\mathbf{m})$ & $\begin{array}{c}\text { Effective depth wind } \\
\text { setup }(\mathbf{m})\end{array}$ \\
\hline 250 & 260 & 20.5 & 16.0 \\
260 & 295 & 23.0 & 21.3 \\
270 & 270 & 26.4 & 23.2 \\
280 & 370 & 32.7 & 29.0 \\
290 & 460 & 41.0 & 31.3 \\
300 & 570 & 41.2 & 32.6 \\
310 & 580 & 50.1 & 42.7 \\
320 & 675 & 67.5 & 54.8 \\
330 & 675 & 65.1 & 53.9 \\
340 & 675 & 66.8 & 55.4 \\
350 & 675 & 120.5 & 66.4 \\
360 & 470 & 75.9 & 47.3 \\
\hline
\end{tabular}

Not surprisingly, the effective depth appears to be heavily influenced by especially the smaller depths in the profile. The effective depth is generally smaller than the mean depth and the larger the mean depth, the larger the difference. 
Substituting the effective depth in the wind setup model, final calibration is performed by choosing an appropriate value of the parameter $c$. The value of $c$ is established for all twelve sectors separately. Table 28 shows the results. The last column of the table shows the resulting values of the dimensionless parameter $\frac{c F}{d_{e f f}}$, which is a dimensionless measure for the proneness to wind setup due to the geometry of the sector.

Table 28: properties of the calibrated offshore wind setup model

\begin{tabular}{ccccc}
\hline $\begin{array}{c}\text { Sector } \\
(\mathbf{} \mathbf{N})\end{array}$ & $\begin{array}{c}\text { Fetch } \\
(\mathbf{k m})\end{array}$ & $\begin{array}{c}\text { Effective depth wind setup } \\
(\mathbf{m})\end{array}$ & $c\left(10^{-6}\right)$ & $\frac{c F}{d_{\text {eff }}}(-)$ \\
\hline 250 & 260 & 16.0 & 2.05 & 0.033 \\
260 & 295 & 21.3 & 2.50 & 0.035 \\
270 & 270 & 23.2 & 2.23 & 0.032 \\
280 & 370 & 29.0 & 2.49 & 0.032 \\
290 & 460 & 31.3 & 2.13 & 0.031 \\
300 & 570 & 32.6 & 2.17 & 0.038 \\
310 & 580 & 42.7 & 2.24 & 0.030 \\
320 & 675 & 54.8 & 2.26 & 0.028 \\
330 & 675 & 53.9 & 2.33 & 0.029 \\
340 & 675 & 55.4 & 1.76 & 0.021 \\
350 & 675 & 66.4 & 1.76 & 0.018 \\
360 & 470 & 47.3 & 1.51 & 0.015 \\
\hline
\end{tabular}

The value of $c$ shows some variation over the sectors. This indicates that the definition of the effective depth as shown earlier does not fully cover the direction-dependent variations of the process. This may be due to the upwind boundary conditions as indicated in section 5.3. Sectors with a land mass on the upwind side generally show smaller values of the parameter $c$.

Inspection of the last column shows that for the station $\mathrm{HBG}$, the sectors $250^{\circ} \mathrm{N}$ to $310^{\circ} \mathrm{N}$ are prone to high wind setup because of the basin shape ${ }^{15}$. In the sectors $320^{\circ} \mathrm{N}$ through $360^{\circ} \mathrm{N}$, the proneness to high wind setup decreases, probably due to a combination of larger depths in the northern ends of these sectors (Norwegian trench) and limited basin length. It is important to note that the proneness to wind setup as described here does not cover the influence of directional variation of the wind climate, but only effects caused by the basin properties. Figure 72 shows a comparison of the modelled wind setup to the observed wind setup for all twelve sectors.

\footnotetext{
${ }^{15}$ In comparison to the study of Vrijling and Bruinsma (1980) the westerly and southwesterly wind directions have a much larger effect on the wind setup. This is caused by the fact that the location analysed in this study (HBG) lies approximately $200 \mathrm{~km}$ north of the location studied by Vrijling and Bruinsma (Eastern Scheldt). Basin lengths in westerly and southwesterly directions are two to three times larger at HBG than at Eastern Scheldt, which explains the larger effect of wind from these directions on the wind setup at HBG.
} 


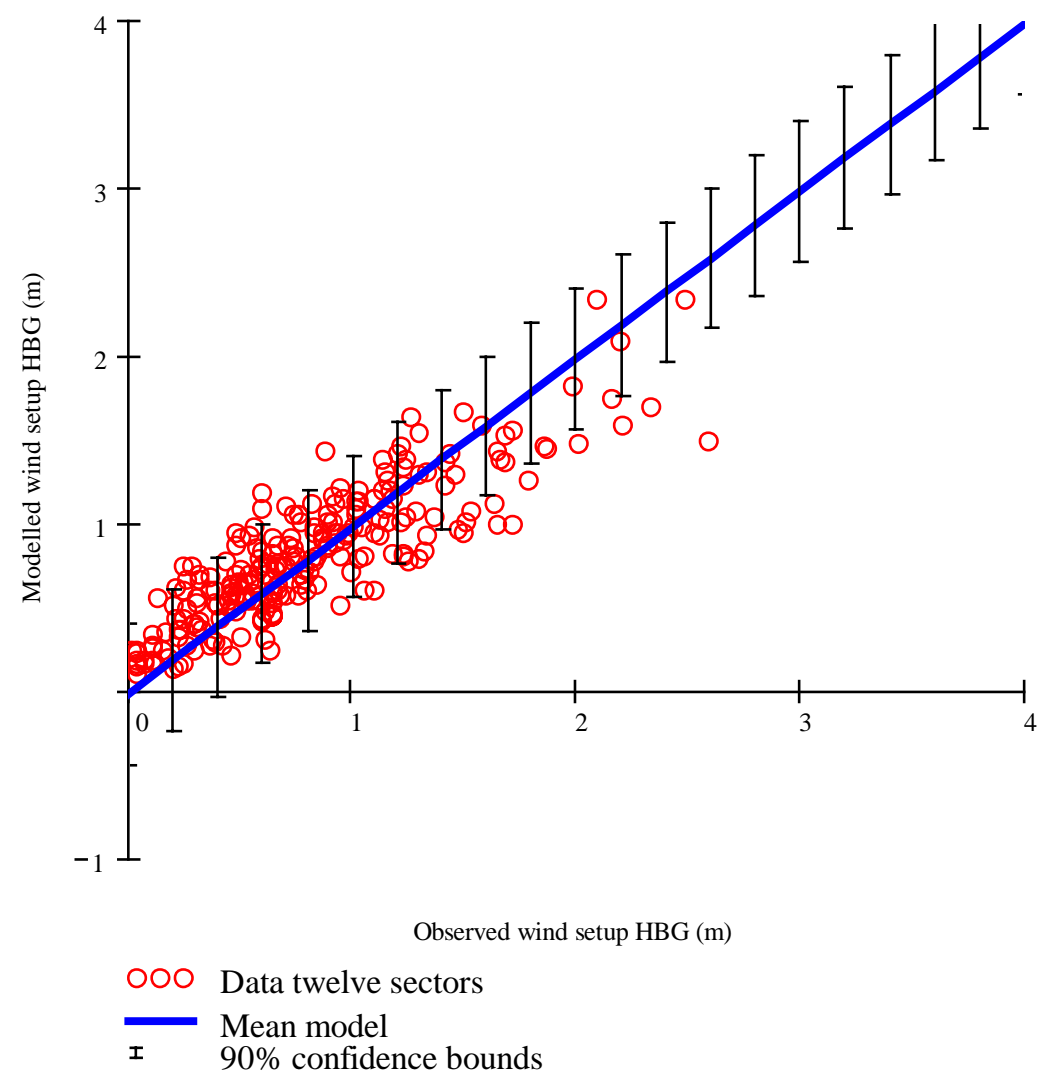

Figure 72: Modelled wind setup at $H B G$ as a function of observed wind setup at $H B G$

The calibrated model describes the expected value of the observations as a function of the wind speed, but a spread around the model is still present. The spread is described by an additive model error:

$$
\Delta=h-h_{\text {model }}
$$

The distribution of the model uncertainty is given in table 29 .

Table 29: Distribution of model uncertainty of wind setup at $H B G$

\begin{tabular}{l|l} 
& Value \\
\hline Distribution type & Normal \\
Mean & $0.0 \mathrm{~m}$ \\
Standard deviation & $0.26 \mathrm{~m}$
\end{tabular}

Following chapter 5, the water level is described by adding the wind setup to the astronomical tide. Therefore, for a description of the water level no further model calibration is necessary.

Marginal distributions of wind setup and water level at station HBG can be derived from the directional model using the procedure outlined in chapter 5. Because of the shape of the North Sea basin, the parameters of the probability distribution of the wind setup offshore depend on the wind direction. Therefore, differences in the tail estimates in comparison to a classical POT-analysis should be expected.

Figure 73 shows four different estimates of the distribution of wind setup at HBG. The first estimate is obtained from the calibrated JPDF using the method outlined in chapter 5 . The second estimate is the empirical distribution given by plotting a set of data selected with a classic peaks-over-threshold method. The third estimate is 
obtained by fitting a Weibull distribution to the POT-data followed by (incorrect!) application of equation (92). Finally, the fourth estimate is obtained by performing fitting a Weibull distribution to the observed wind setup of every sector followed by application of equation (94). It is important to note that the marginal distributions in figure 73 are determined without considering the statistical uncertainty of the wind speed. The goal in this case is a comparison of the marginal distribution obtained from the model to the empirical distribution of the observations. It would therefore be incorrect to include statistical uncertainty in this case.

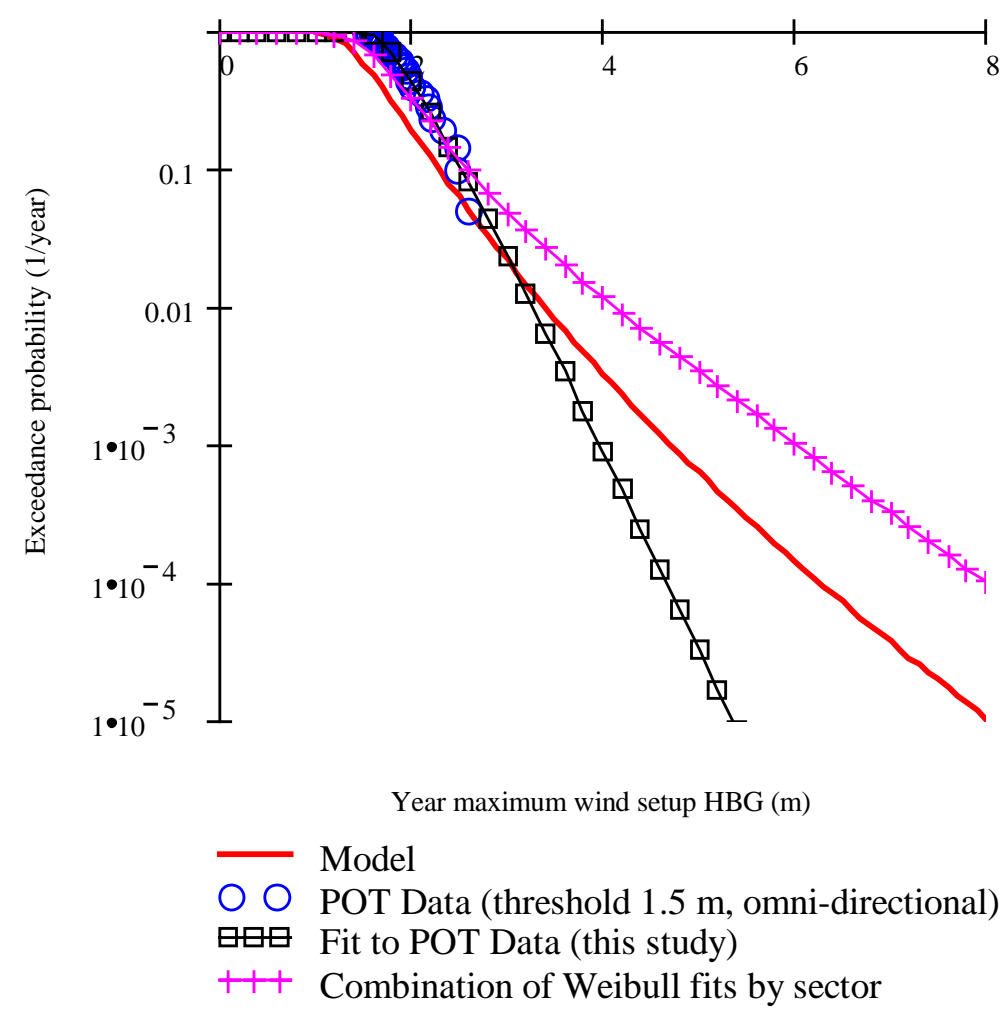

Figure 73: Probability distribution of the wind setup at HBG derived by four different methods

Within the range of the observations, the parametric distributions are all in reasonable agreement with the data and with each other. The marginal distribution obtained from the joint model is slightly lower than the empirical distribution of the POT-data.

The estimates of the extreme right tail differ considerably. The highest estimates of extreme wind setup are obtained by application of equation (94) to the Weibull fit of the wind setup by sector. The marginal distribution obtained from the joint model leads to lower estimates of the extreme wind setup. The lowest estimates are obtained by fitting a Weibull distribution to the POT-data; a procedure that should be considered incorrect because of the inhomogeneity of the data of the wind setup offshore.

The distribution of the water level at HBG is obtained by superposition of the astronomic tide and the wind setup. The physical model for wind setup includes the reducing influence of the astronomic tide on the wind setup. There are two ways in which the distribution of the water level can be established:

- Combination of the wind speed distribution with the full tide distribution;

- Combination of the wind speed distribution with the distribution of the high tides. 
The first option leads to the distribution of the water levels associated with the peak wind setup. The second option leads to the distribution of the water levels associated with high astronomic tide. Because the astronomic tide has a reducing influence on the wind setup, the wind setups obtained in the second option are slightly lower than in the first option. For the design of a flood defence structure, the distribution of the maximum water level in a storm is important. It is not clear in advance which combination will lead to the probability distribution of the maximum water level. Figure 74 shows the two options in comparison to a set of POT-data. A third estimate is the water level distribution of HBG as obtained by the Institute for Coastal and Marine Management (RIKZ, 1995a).

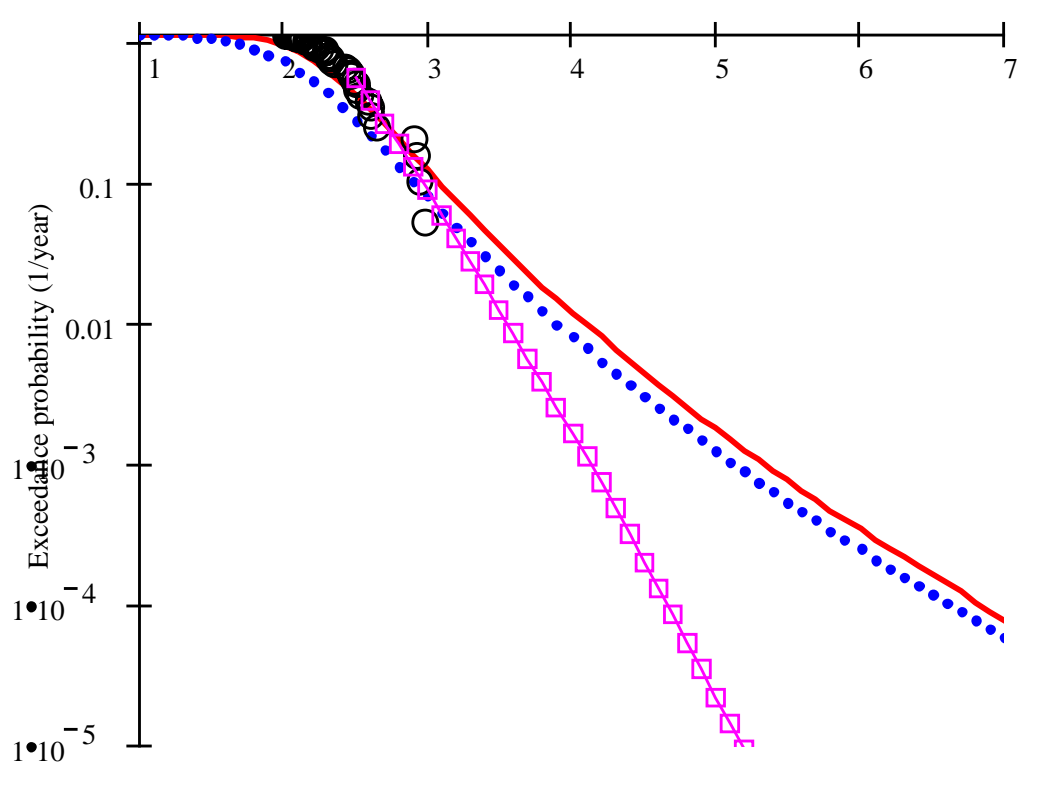

Water level at $\mathrm{HBG}(\mathrm{CD}+\mathrm{m})$

- Combination of wind setup with high tide distribution

- - Combination of wind setup with full tide distribution

O $\bigcirc$ POT data (all directions)

브 Distribution according to RIKZ (1995a)

Figure 74: Comparison of the marginal distribution of the water level at HBG obtained from the directional model to the data and a statistical analysis

Combination of the wind speed distribution with the full tide distribution leads to slightly lower estimates of the water level than the combination with the high tide distribution. Extreme water levels are dominated by wind setup and therefore the shape of the right tail of the distribution resembles the shape of the wind setup distribution. This leads to estimates of extreme water level that are considerably higher than those obtained by classical POT-analysis. According to RIKZ (1995a) a water level of $4.65 \mathrm{~m}$ at $\mathrm{HBG}$ has a probability of exceedance of $10^{-4}$ per year. According to the model derived in this study, the same water level has a probability of exceedance of approximately $3 \cdot 10^{-3}$ per year.

\subsubsection{Calibration of a reduced model for wind setup offshore}

With the directional model calibrated in the previous section, probability distributions of wind setup and water level are obtained that are in agreement with the observation data. The model is relatively complicated to use, due to the direction-dependent description of the hydraulic effects. It is possible to derive a reduced model of the 
hydraulic effects using the results of the directional model. The reduced model developed in this study has the following characteristics:

- The wind speed distribution is described by the omni-directional distribution of the yearly maximum wind speed;

- The North Sea basin is replaced by one single basin with a constant length and a constant depth.

The reduced model is calibrated such that the probability distribution of the wind setup corresponds to the distribution derived by the directional model. Combination of the wind setup distribution with the distribution of the astronomic tide again leads to the distribution of the water level.

In the reduced model, the wind setup is described by:

$$
h\left(u_{5 ; \text { omni }}, F_{\text {omni }}, d_{\text {omni }}, h_{a}\right)=\gamma_{\text {omni }}\left(-\left(d_{\text {omni }}+h_{a}\right)+\sqrt{\left(d_{\text {omni }}+h_{a}\right)^{2}+2 \frac{c_{\text {omni }} u^{2} F_{\text {omni }}}{g}}\right)
$$

Where:

$u_{\text {5;omni: }} \quad$ Five hour average potential wind speed;

$F_{\text {omni: }} \quad$ Basin length;

$d_{\text {omni: }} \quad$ Basin depth;

$h_{a}$ : $\quad$ Astronomic tide;

Yomni: $\quad$ Model factor.

The omni-directional distribution of the wind speed is derived in section 6.4. Inspection of the result of the directional model indicates that extreme values of the wind setup at HBG are generally caused by wind fields with a direction of $300{ }^{\circ} \mathrm{N}$. Therefore, the basin geometry corresponding to this sector is used in the reduced model. The distribution of the model factor $\gamma_{o m n i}$ is described by a normal distribution with a mean value of 1 . The standard deviation of the model factor is used to calibrate the reduced model such that the marginal distribution of the wind setup corresponds to the marginal distribution obtained from the direcitional model. Table 30 summarises the reduced offshore wind setup model.

Table 30: Parameters of the reduced offshore wind setup model

\begin{tabular}{llllll}
\hline Variable & Symbol & Distr. type & Shift & Scale & Shape \\
\hline Five hour average potential wind speed & $u_{5 ; \text {;omni }}$ & Weibull & $19.8 \mathrm{~m} / \mathrm{s}$ & $2.83 \mathrm{~m} / \mathrm{s}$ & 1.20 \\
Basin length & $F_{\text {omni }}$ & Deterministic & $570 \mathrm{~km}$ & n.a. & n.a. \\
Effective depth & $d_{\text {omni }}$ & Deterministic & $32.6 \mathrm{~m}$ & n.a. & n.a. \\
Calibration parameter of wind setup & $c_{\text {omni }}$ & Deterministic & $2.2 \cdot 10^{-6}$ & n.a. & n.a. \\
Model factor & $\gamma_{\text {omni }}$ & Normal & 1.0 & 0.22 & n.a. \\
\hline
\end{tabular}

As required, the marginal distribution of the wind setup resulting from the reduced model is in agreement with the marginal distribution obtained from the directional model (figure 75). 


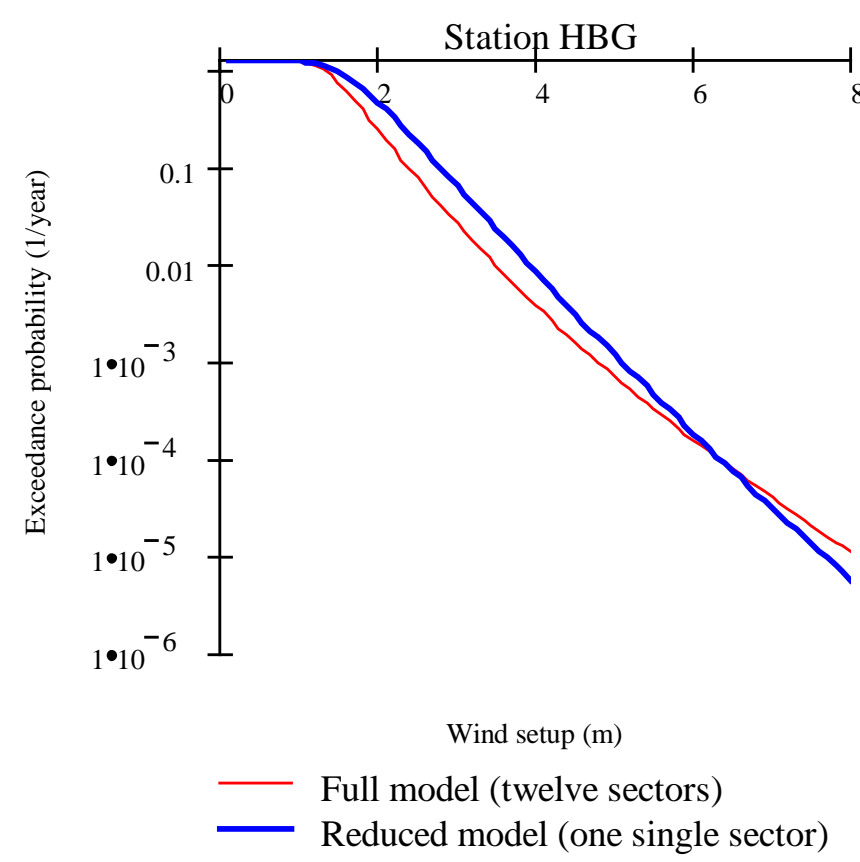

Figure 75: Comparison of marginal distributions of the wind setup of HBG derived by a reduced model to the distribution derived by the full model

In the remainder of this study, the reduced offshore wind setup model will be used. Combination of the reduced wind setup model with the distribution of high astronomic tide provides the distribution of the water level at HBG.

\subsubsection{Calibration of the models for wind setup and water level nearshore}

Nearshore, the water level can again be considered to be the result of the combination of astronomic tide and wind setup. The wind setup nearshore in turn can be considered to be the result of a superposition of the wind setup offshore and locally generated wind setup (see chapter 5). The model for the wind setup nearshore is given in section 5.3. Representative values of the depth and length of the basin are obtained from the map of the Wadden Sea (RIKZ, 2000). The parameter $c$ is used as a fit parameter of which the value is obtained by calibration to the available data. Table 31 shows the parameters of the calibrated nearshore setup model per location. The model uncertainty is described by a variable following a normal distribution that is added to the model. The standard deviation of the model uncertainty is given in the table.

Table 31: Parameters and model uncertainty of the wind setup transformation model per station

\begin{tabular}{lllllll}
\hline Station & $F(\mathrm{~km})$ & $d(\mathrm{~m})$ & $c\left(10^{-6}\right)$ & \multicolumn{3}{c}{ Model uncertainty (additive) } \\
\cline { 5 - 7 } & & & & Distr. type & Mean $(\mathrm{m})$ & Standard dev. $(\mathrm{m})$ \\
\hline LWO & 18 & 5 & 2.1 & $\mathrm{~N}$ & 0 & 0.14 \\
DFZ & 29 & 10 & 4.7 & $\mathrm{~N}$ & 0 & 0.17 \\
NSZ & 40 & 5 & 2.9 & $\mathrm{~N}$ & 0 & 0.3 \\
\hline
\end{tabular}

For every observation station nearshore, the water level is found by superposition of the wind setup and the astronomic tide. Marginal distributions of wind setup and water level can be obtained from the model. Figure 76 shows the results for the wind setup for the three nearshore stations. The result is compared to the empirical 
distribution of the observations and to a Weibull distribution fitted directly to the data $^{16}$.
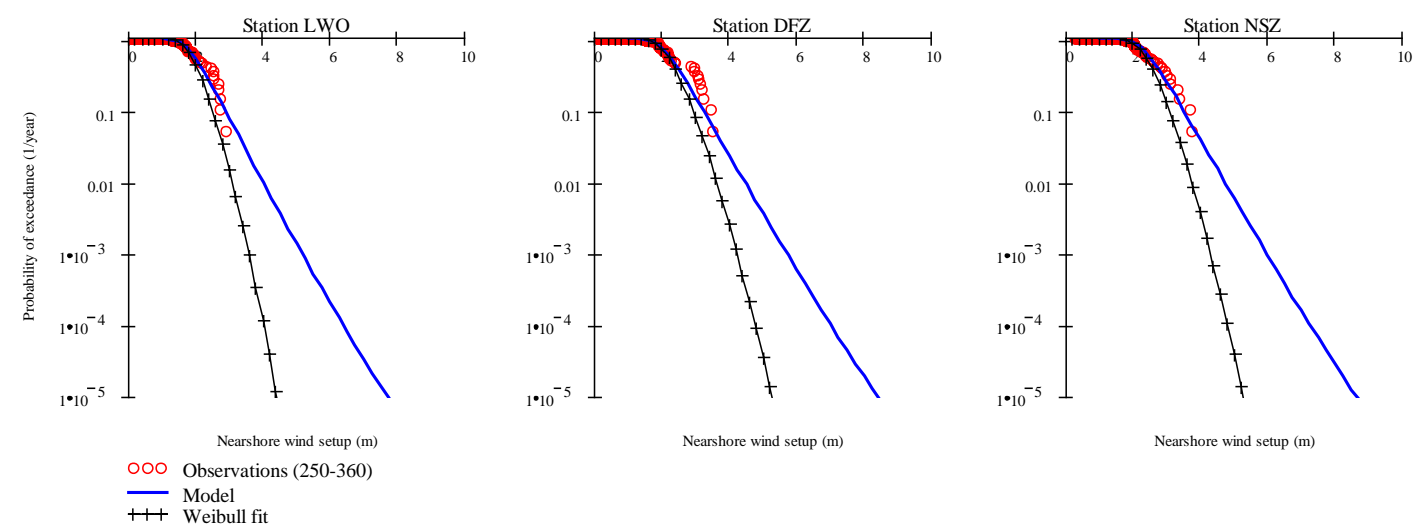

Figure 76: Comparison of marginal distributions of wind setup nearshore

Within the range of the observations, the differences between the different models are small. In general, the marginal distribution obtained from the JPDF appears to be in better agreement with the data than the Weibull fit, especially when compared to the more extreme observations. The estimated exceedance probabilities of extreme water levels obtained from the two distributions differ considerably from each other.

Combination of the wind setup with the astronomic tide provides the distribution of the water level. Figure 77 shows the result.
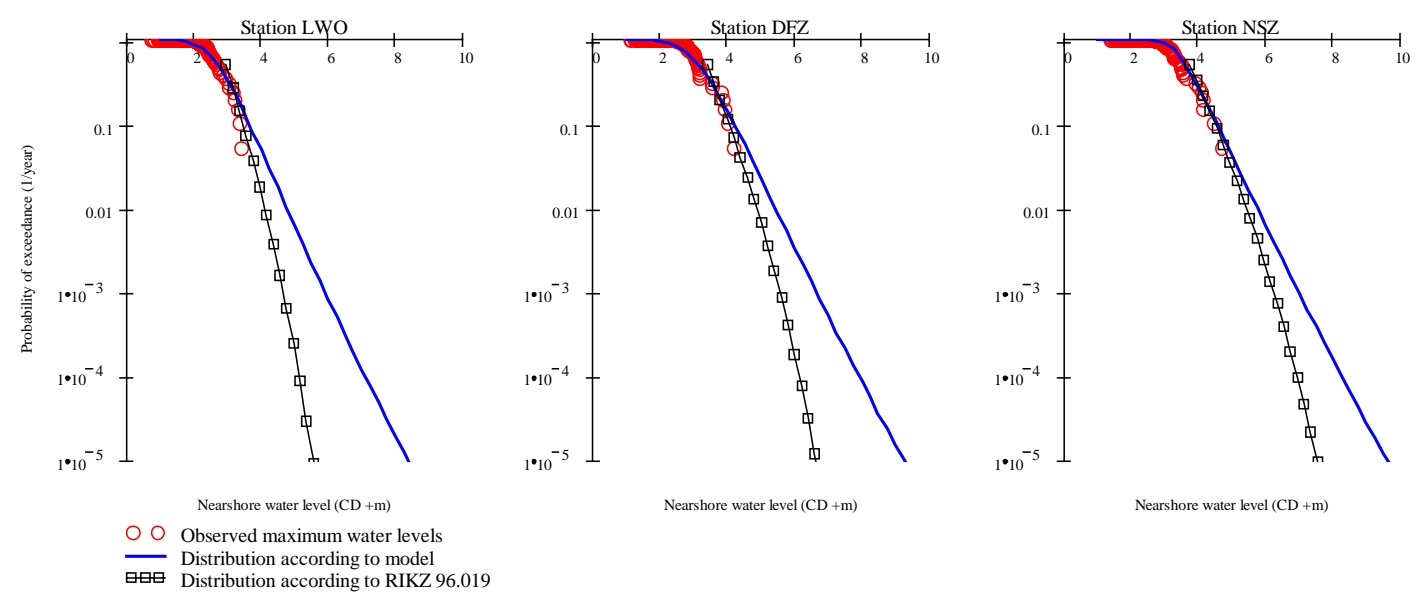

Figure 77: Three estimates of the marginal distribution of the water level nearshore

Within the range of the observations, the empirical distribution and the two parametric distributions are in reasonable agreement. The right tail of the distribution according to the JPDF provides much higher estimates of the probability of exceedance of extreme water levels than obtained in RIKZ (1995a). Table 32 illustrates the differences.

\footnotetext{
${ }^{16}$ For reasons indicated in section 6.5.1, statistical uncertainty of the wind speed is not included.
} 
Table 32: Comparison of the exceedance probabilities of extreme water levels nearshore

\begin{tabular}{llll}
\hline Station & $\begin{array}{l}\text { Water level } \\
(\mathbf{C D}+\mathbf{m})\end{array}$ & $\begin{array}{l}\text { Prob. of exc. RIKZ (1995b) } \\
(\mathbf{1} / \text { year })\end{array}$ & $\begin{array}{l}\text { Prob. of exc. this study } \\
(\mathbf{1} / \text { year })\end{array}$ \\
\hline Lauwersoog (LWO) & 5.15 & $10^{-4}$ & $7 \cdot 10^{-3}$ \\
Delfzijl (DFZ) & 6.15 & $10^{-4}$ & $4 \cdot 10^{-3}$ \\
Nieuwe statenzijl (NSZ) & 6.95 & $10^{-4}$ & $2 \cdot 10^{-3}$ \\
\hline
\end{tabular}

\subsection{Calibration of the wave model}

\subsubsection{Introduction}

The parametric wave model described in chapter 5 can be calibrated for the dike ring Groningen, using the following observations in the study area:

- Five hour average potential wind speed at HBG $\left(u_{5}\right)$;

- Maximum significant wave height at SON $\left(H_{s}\right)$;

- Spectral wave period corresponding to the wave height peak $\left(T_{m 02}\right)$.

Like the wind setup, the wave conditions depend on the shape of the basin and therefore on the wind direction. The basin lengths and bottom profiles obtained from the North Sea map (Admiralty Charts and Publications, 1997) are used to obtain representative basin geometries for use in the wave model.

The definition of the wave period in the available data is not equal to the spectral peak period that is applied in the design of the flood defences in Groningen (chapters 7 and 8 and annex 3). A set of ten wave spectra measured under extreme wave conditions is used to derive a relation between the wave period $T_{m 02}$ in the dataset and the peak period $T_{p}$ used in the limit state functions for the flood defences in Groningen.

The description of the SMB wave model in chapter 5 indicates that the model contains ten empirical parameters. The values of these parameters have a large body of empirical support. The choice is therefore made not to change the parameters in this study. As shown in figure 64, the bottom depth in the North Sea shows considerable spatial variation. It can be assumed that the depth variations influence the wave conditions observed at station SON. Therefore, the choice is made to treat the depth in the SMB model as a fit parameter.

\subsubsection{Calibration of the model for offshore wave height}

As outlined in the previous section, the depth per sector is used as a fit parameter for the wave model. Performing the calibration for the wave height at SON by application of a least-squares method leads to the result shown in table 33. The mean depth per sector is included for comparison.

Table 33: Properties of the calibrated offshore wave height model

\begin{tabular}{ccccc}
\hline $\begin{array}{c}\text { Sector } \\
\left({ }^{\circ} \mathbf{N}\right)\end{array}$ & Storm duration $(\mathbf{h r})$ & $\begin{array}{c}\text { Fetch } \\
(\mathbf{k m})\end{array}$ & $\begin{array}{c}\text { Mean depth } \\
(\mathbf{m})\end{array}$ & $\begin{array}{c}\text { Effective depth wave } \\
\text { conditions }(\mathbf{m})\end{array}$ \\
\hline 250 & 5 & 260 & 20.5 & 53.1 \\
260 & 5 & 295 & 23.0 & 35.2 \\
270 & 5 & 270 & 26.4 & 40.2 \\
280 & 5 & 370 & 32.7 & 58.1 \\
290 & 5 & 460 & 41.0 & 68.8 \\
300 & 5 & 570 & 41.2 & 83.0 \\
310 & 5 & 580 & 50.1 & 74.7 \\
\hline
\end{tabular}




\begin{tabular}{ccccc}
\hline $\begin{array}{c}\text { Sector } \\
\left({ }^{\circ} \mathbf{N}\right)\end{array}$ & Storm duration $(\mathbf{h r})$ & $\begin{array}{c}\text { Fetch } \\
(\mathbf{k m})\end{array}$ & $\begin{array}{c}\text { Mean depth } \\
(\mathbf{m})\end{array}$ & $\begin{array}{c}\text { Effective depth wave } \\
\text { conditions }(\mathbf{m})\end{array}$ \\
\hline 320 & 5 & 675 & 67.5 & 79.7 \\
330 & 5 & 675 & 65.1 & 77.7 \\
340 & 5 & 675 & 66.8 & 91.7 \\
350 & 5 & 675 & 120.5 & 47.6 \\
360 & 5 & 470 & 75.9 & 63.6 \\
\hline
\end{tabular}

The storm duration is chosen equal to the time over which the wind speed and wind direction are averaged. The effective depth for the wave model is generally somewhat larger than the mean depth in the profile. Exceptions are the sectors $350^{\circ} \mathrm{N}$ and $360^{\circ} \mathrm{N}$, that cross the very deep trench in front of the Norwegian coast. The deep trench has considerable influence on the mean depth in the sector. Since the trench is located in the northern end of the two sectors, the large depth is found at a location where wave growth has just begun. Therefore, the wave field shows no response to the bottom and is not influenced by the very large depth in the trench.

Figure 78 shows the modelled wave height as a function of the observed wave height.

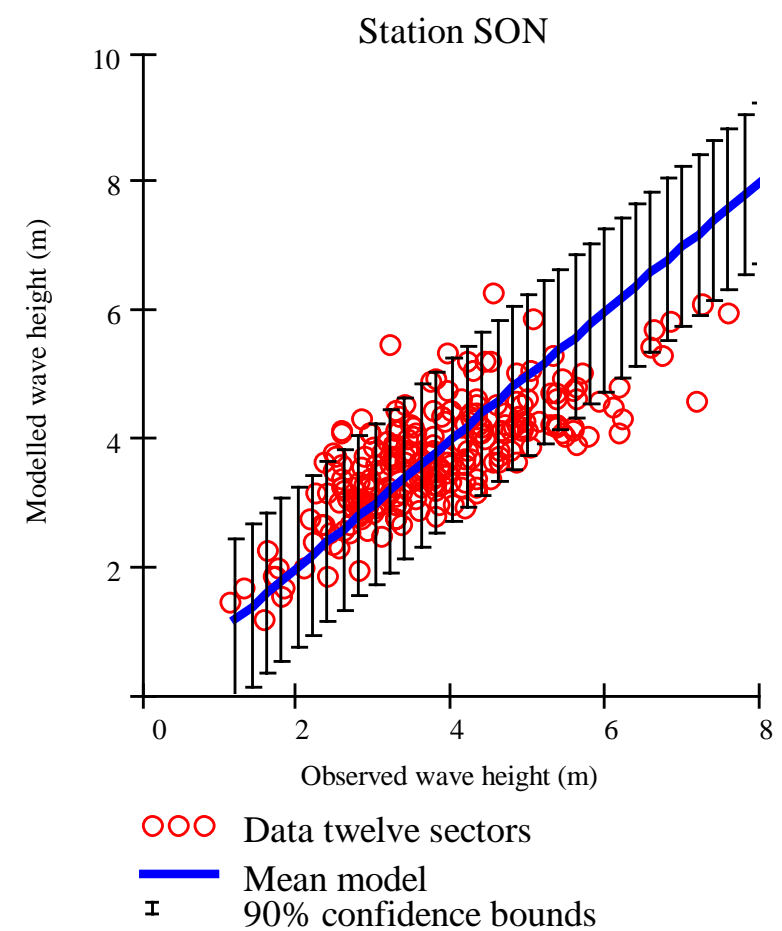

Figure 78: Comparison of modelled wave height at SON to the observed wave height

The calibrated model describes the expected value of the observations as a function of the wind speed, but a spread around the model is still present. The observations can be reproduced by extending the model with an estimate of the model uncertainty:

$H_{s}=H_{s ; \text { model }}+\Delta$

Where $\Delta$ denotes the model uncertainty. The model uncertainty can be described by a normal distribution with a mean of 0 and a standard deviation of $0.77 \mathrm{~m}$.

As outlined in chapter 5, the marginal distribution of the significant wave height at SON can be obtained from the calibrated directional model. A second estimate of the omni-directional distribution can be obtained by fitting a Weibull distribution to the 
POT-data (RIKZ, 1995b). A third estimate is obtained by application of equation (94) to a Weibull fit per sector. Figure 79 shows the results of the three types of analysis in comparison to the empirical distribution of POT-data.

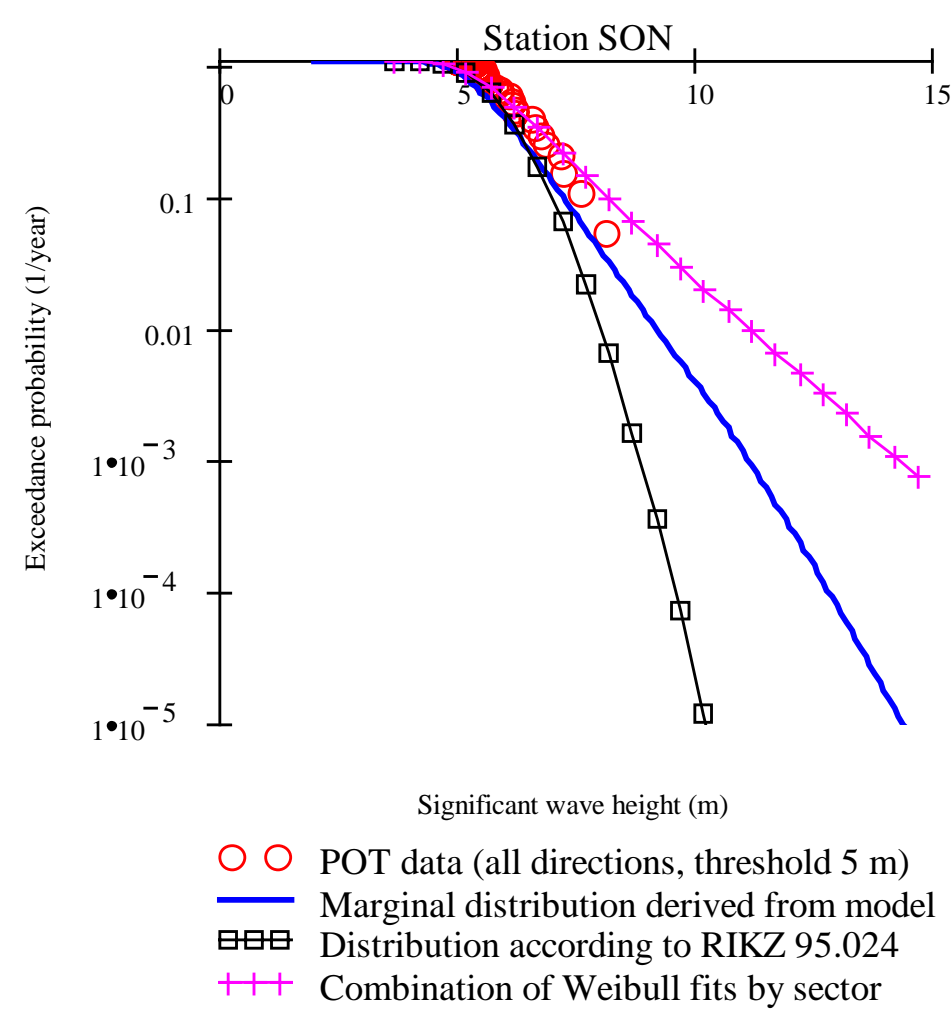

Figure 79: Marginal distribution of significant wave height by two models in comparison to the data

All distributions are close to the data, but the marginal distribution derived from the joint model and the Weibull fit are slightly lower than the empirical distribution of the data, while the combination of Weibull fits per sector is slightly higher. The model derived in this study is closer to the extreme observations than the fit obtained in RIKZ (1995b). The shapes of the extreme tails differ considerably, the combination of fits per sector providing the highest estimates of the wave height, followed by the marginal distribution derived from the directional model. A direct fit to the POT-data provides the lowest estimates of the extreme wave height at SON.

\subsubsection{Calibration of the offshore wave period model}

A wave period characteristic for a wave field may be defined in several ways. The wave period contained in the dataset of observations is the spectral peak period $T_{m 02}$, defined on the basis of spectral moments by:

$T_{m 02}=\sqrt{\frac{m_{0}}{m_{2}}}$

Where $m_{i}$ denotes the $i$-th moment of the wave spectrum.

In the limit state functions used in the reliability-based design of flood defences, the wave period used is the spectral peak period $T_{p}$, defined as the wave period corresponding to the peak of the wave spectrum. Finally, the SMB-model outlined in chapter 5 uses a third definition of the period, the significant wave period $T_{s}$ (Brettschneider, 1952). 
Ultimately, the goal of the calibration of the period model is the description of the spectral peak period $T_{p}$. To describe the peak period by the SMB-model and perform calibration of the model using $T_{m 02}$, values for the following multiplication factors need to be established:

$$
\begin{gathered}
\gamma_{T_{m 02}}=\frac{T_{m 02}}{T_{s}} \\
\gamma_{T_{p}}=\frac{T_{p}}{T_{m 02}}
\end{gathered}
$$

Since wave height and wave period are both characterisations of one observed wave spectrum, it appears rational to adopt the depth per sector as obtained for the wave height as the appropriate depth for the wave period as well. If the thus calibrated wave model is compared to the observations of $T_{m 02}$, a bias of the model is observed. The bias is compensated by choosing $\gamma_{T_{m 02}}$ equal to 0.92 . Figure 80 shows the modelled wave period $T_{m 02}$ as a function of the observed wave period $T_{m 02}$.

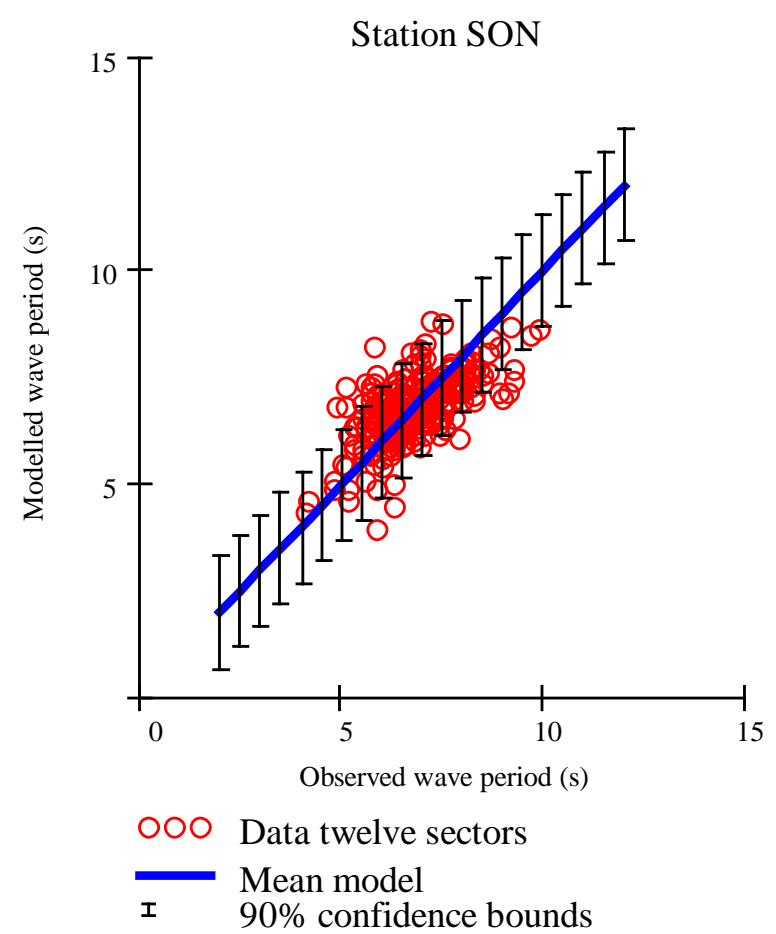

Figure 80: Comparison of the modelled wave period to the observed wave period

The model uncertainty of the wave period model is given in the same additive form as the model uncertainty of the wave height model. The model uncertainty follows a normal distribution with mean $0 \mathrm{~s}$ and standard deviation $0.8 \mathrm{~s}$. The model uncertainties of wave height and wave period are strongly correlated. The calculated correlation coefficient equals 0.90 . The strong correlation between the model uncertainties of wave height and wave period is not unexpected, since wave height and wave period are both characteristic values describing the same phenomenon.

The ratio between the spectral peak period $T_{p}$ and the spectral period $T_{m 02}$ depends on the shape of the wave spectrum itself. A small dataset of ratios between the two wave periods is obtained by analysis of the wave spectra corresponding to the ten highest observed significant wave heights at SON. Table 34 shows an overview. 
Table 34: Highest ten observations of significant wave height at SON

\begin{tabular}{cccccc}
\hline $\begin{array}{c}\text { Date } \\
\text { (jjjjmmdd) }\end{array}$ & $\begin{array}{c}\text { Time } \\
(\mathrm{GMT})\end{array}$ & $\begin{array}{c}\text { Wave height } \\
\left(H_{s}, \mathrm{~m}\right)\end{array}$ & $\begin{array}{c}\text { Wave period } \\
\left(T_{m 02}, \mathrm{~s}\right)\end{array}$ & $\begin{array}{c}\text { Peak period } \\
\left(T_{p}, \mathrm{~s}\right)\end{array}$ & $\begin{array}{c}\text { Multipl. factor } \\
\left(T_{p} / T_{m 02},-\right)\end{array}$ \\
\hline 19901212 & 1600 & 8.14 & 10.1 & 14.6 & 1.44 \\
19930221 & 0700 & 7.58 & 9.9 & 14.6 & 1.48 \\
19811124 & 0700 & 7.09 & 8.8 & 11.8 & 1.34 \\
19940128 & 1000 & 7.08 & 9.1 & 12.6 & 1.38 \\
19890214 & 0700 & 6.86 & 9.6 & 13.0 & 1.36 \\
19830201 & 2200 & 6.62 & 8.7 & 11.8 & 1.57 \\
19851106 & 0700 & 6.58 & 9.0 & 14.1 & 1.47 \\
19911227 & 0100 & 6.20 & 8.5 & 12.5 & 1.50 \\
19850428 & 0400 & 6.18 & 9.1 & 13.6 & 1.43 \\
19930124 & 1600 & 5.46 & 8.5 & 12.2 & \\
\hline
\end{tabular}

The peak period is determined by finding the top of a cubic spline interpolation of the data points of the spectrum. Figure 81 shows the spectral data, the interpolation and the corresponding values of $T_{p}$ and $T_{m 02}$.
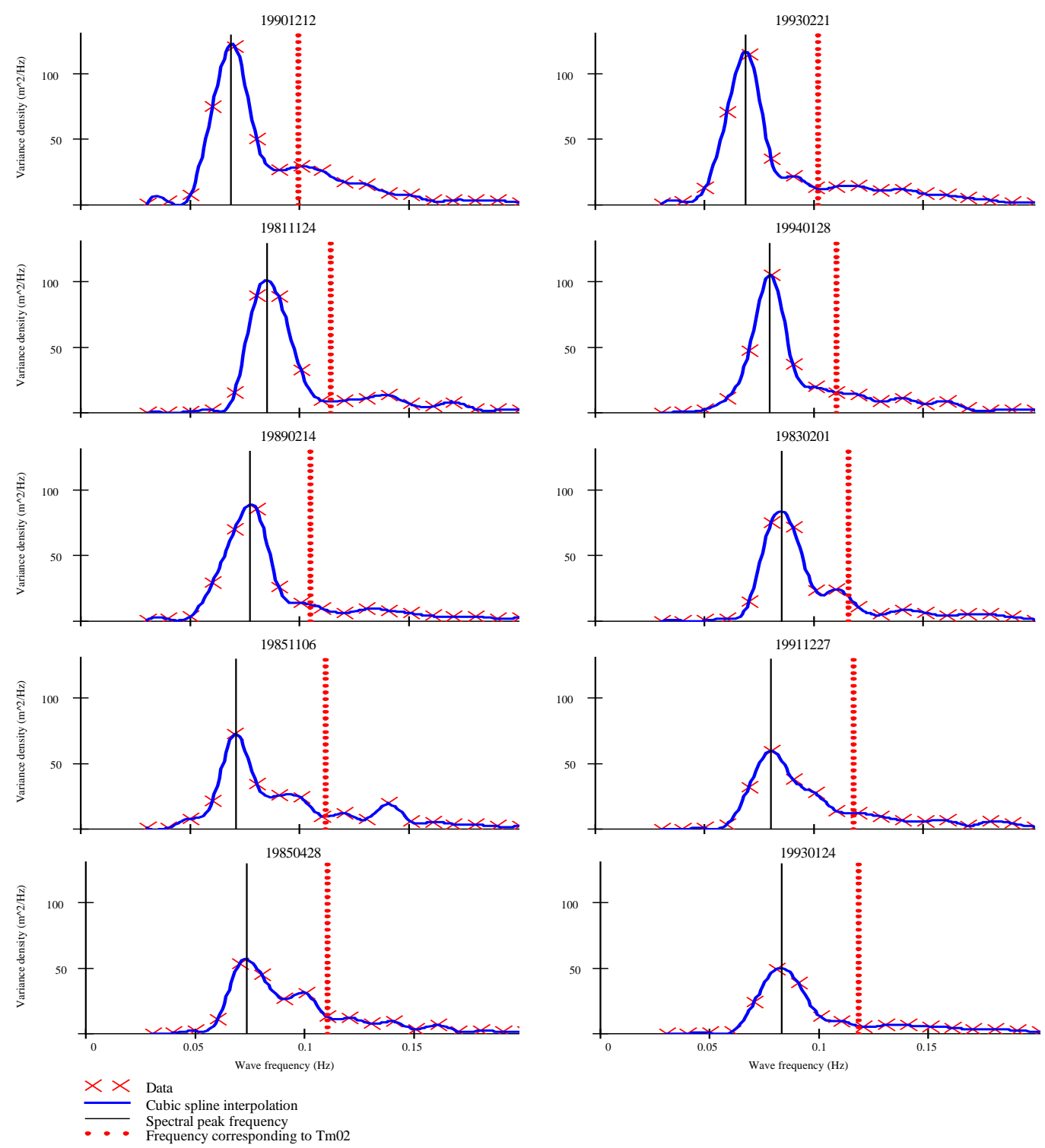

Figure 81: Variance density spectra of the top ten storms regarding the observed wave height at SON (in order of decreasing wave height from left to right and from top to bottom) 
In all spectra, there is a dominant peak in a period range of 12 to 15 seconds (frequency between 0.083 and $0.066 \mathrm{~Hz}$ ). Some lower peaks at higher frequencies are observed in the storms 19830201, 19851106 and 19850428. In case of storm 19850428 , the second peak lies relatively close to the dominant peak and reaches up to a level of $60 \%$ of the dominant peak. In all other cases, the second peak can be considered negligible. Based on the ten spectra, the conclusion is drawn that under extreme conditions, the wave spectrum observed at SON can be expected to be singlepeaked. The dataset of multiplication factors is too small to infer the distribution shape, but a normal distribution is not rejected. The mean equals 1.4 and the standard deviation equals 0.07 . It is striking that the frequency corresponding to $T_{m 02}$ generally lies completely outside the range where most wave energy is found.

The calibrated model can be used to derive the marginal distribution of the wave period (chapter 5). Figure 82 shows the result for the wave period $T_{m 02}$ in comparison to the empirical distribution of POT-data and to two other estimates of the distribution. The first is a Weibull fit to POT-data obtained by RIKZ (1996). The second estimate is obtained by combination of Weibull fits per sector. For reasons indicated in section 6.5.1, statistical uncertainty of the wind speed is excluded.

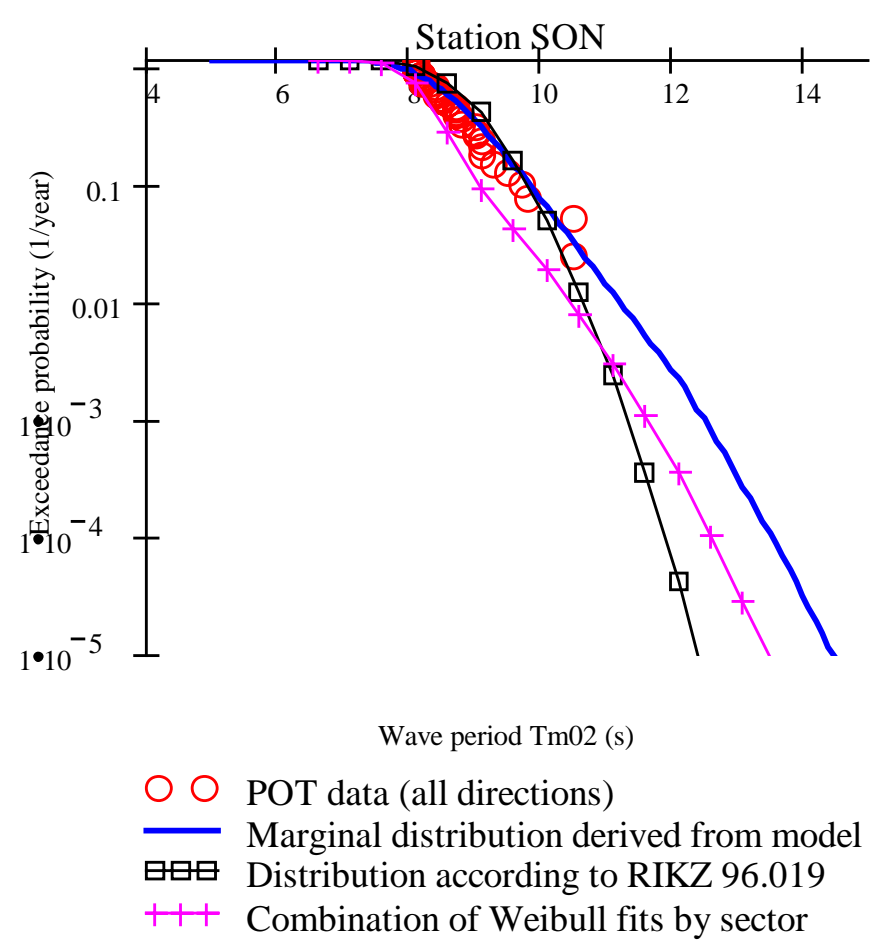

Figure 82: Marginal distributions of the spectral wave period $T_{m 02}$ in comparison to POT data

Within the range of the observations, the marginal distribution derived from the directional model and the direct fit are both in agreement with the empirical distribution of the POT-data. Combination of Weibull fits per sector leads to a slightly lower estimate of the period distribution. In the extreme tails, the marginal distribution obtained from the directional model leads to the highest estimates of the wave period, followed by the combination of Weibull fits per sector. The lowest period estimates result from the Weibull fit to the POT-data.

The distribution of the ratio $T_{p} / T_{m 02}$ as obtained from an analysis of wave spectra can be used directly in a probabilistic analysis to obtain the marginal distribution of the 
peak period. Figure 83 shows the distribution derived in this study in comparison to the distribution derived in RIKZ (1996).

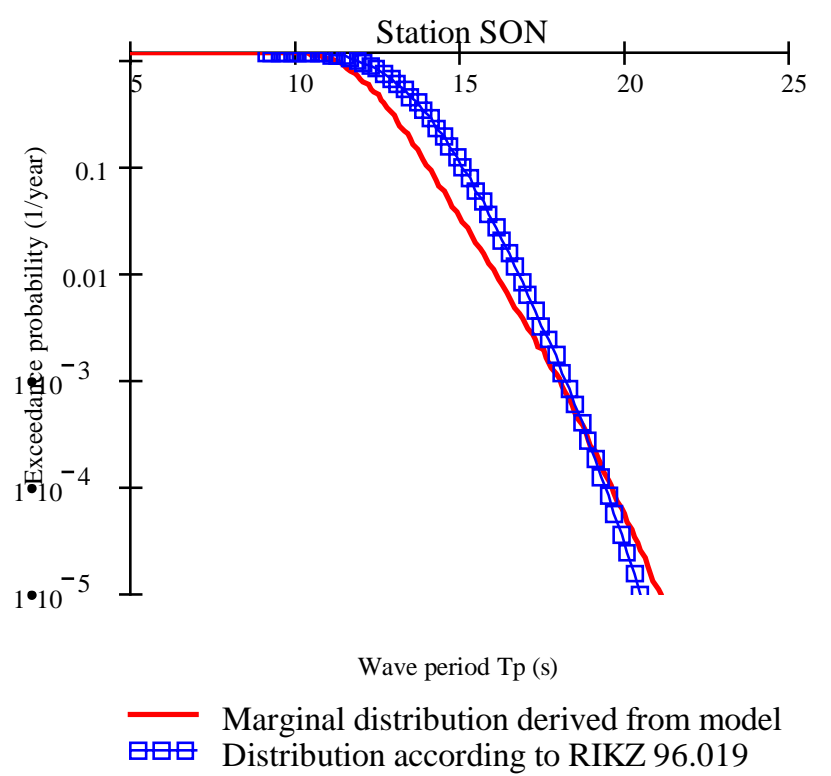

Figure 83: Distribution of the spectral peak period (two models)

For higher exceedance probability, the distribution derived in this study provides slightly lower estimates of the peak period. In the extreme right tail the distributions are reasonably close together.

\subsubsection{Calibration of reduced models for offshore wave height and wave period}

The directional wave model calibrated in the previous section provides probability distributions of wave height and wave period that are in agreement with the observation data. The model is however relatively complicated to use, due to the direction-dependent description of the hydraulic effects. It is possible to derive a reduced model of the wave conditions using the results of the directional model. The reduced model developed in this study has the following characteristics:

- The wind speed distribution is described by the omni-directional distribution of the yearly maximum wind speed;

- The North Sea basin is described by one single basin with a constant depth and a fixed length.

The reduced model is calibrated such that the probability distributions of the wave height and wave period correspond to the distributions derived by the directional model.

The wave conditions in the reduced model are described by:

$$
\begin{gathered}
\tilde{H}_{s}=\gamma_{H ; \text { omni }} \tilde{H}_{\infty} \tanh \left(k_{3} \tilde{d}^{m_{3}}\right) \tanh \left(\frac{k_{1} \tilde{F}^{m_{1}}}{\tanh \left(k_{3} \tilde{d}^{m_{3}}\right)}\right) \\
\tilde{T}_{m 02}=\gamma_{T ; \text { omni }} \tilde{T}_{\infty} \tanh \left(k_{4} \tilde{d}^{m_{4}}\right) \tanh \left(\frac{k_{2} \tilde{F}^{m_{2}}}{\tanh \left(k_{4} \tilde{d}^{m_{4}}\right)}\right)
\end{gathered}
$$

With the dimensionless depth and basin length according to table 18, parameters according to table 19 and: 
$\gamma_{\text {H;omni: }} \quad$ Model factor wave height;

$\gamma_{\text {T;omni: }} \quad$ Model factor wave period.

The results of the directional model indicate that extreme wave conditions are generally associated with wind fields with a characteristic wind direction of $300^{\circ} \mathrm{N}$. The basin geometry in this direction will therefore be used in the reduced wave model. The distribution of the omni-directional model factors is described by a normal distribution with a mean value of 1 . The reduced model is calibrated by choosing the standard deviation of the model factor such that the marginal distributions of wave height and wave period correspond to the marginal distributions obtained from the directional model. Table 35 summarises the reduced offshore wave model.

Table 35: Parameters of the reduced offshore wave model

\begin{tabular}{llllll}
\hline Variable & Symbol & Distr. type & Shift & Scale & Shape \\
\hline Five hour average potential wind speed & $u_{5 ; \text {;omni }}$ & Weibull & $19.8 \mathrm{~m} / \mathrm{s}$ & $2.83 \mathrm{~m} / \mathrm{s}$ & 1.20 \\
Basin length & $F_{\text {omni }}$ & Deterministic & $570 \mathrm{~km}$ & n.a. & n.a. \\
Effective depth & $d_{\text {omni }}$ & Deterministic & $83 \mathrm{~m}$ & n.a. & n.a. \\
Model factor wave height & $\gamma_{\text {H;omni }}$ & Normal & 1.0 & 0.11 & n.a. \\
Model factor wave period & $\gamma_{\text {T;omni }}$ & Normal & 1.0 & 0.08 & n.a. \\
\hline
\end{tabular}

As required, the marginal distributions of the wave height and wave period resulting from the reduced model are close to the marginal distributions obtained from the directional model (figures 84 and 85).

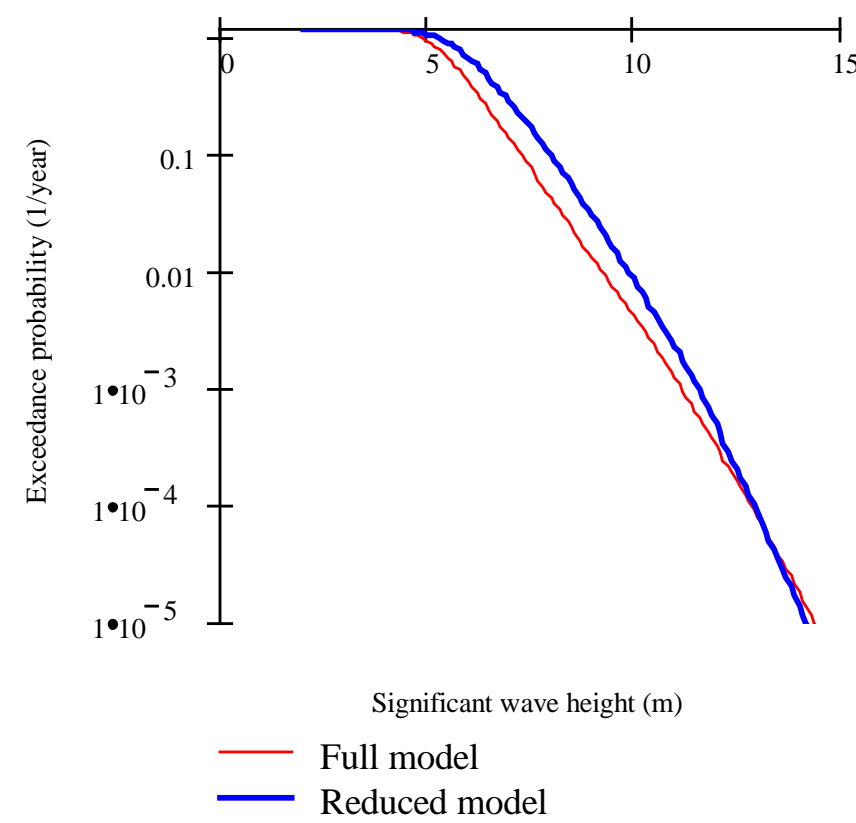

Figure 84: Comparison of marginal distribution of wave height obtained by the directional model and by the reduced model 


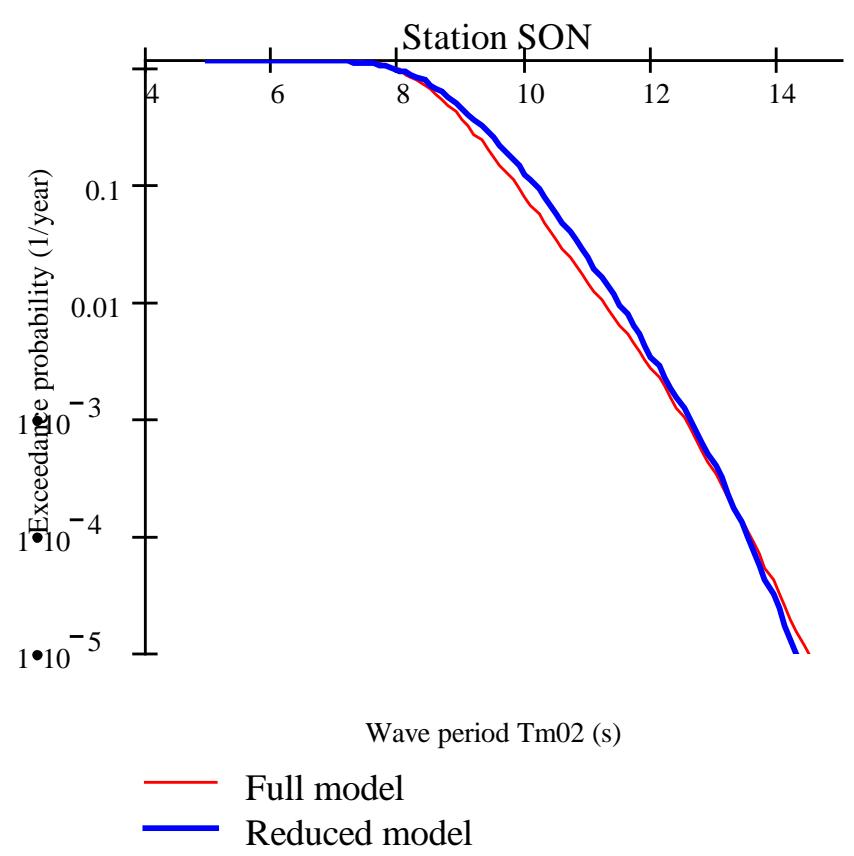

Figure 85: Comparison of marginal distribution of wave height obtained by the directional model and by the reduced model

The reduced models for offshore wave height and wave period will be applied in the remainder of this study.

\subsubsection{Calibration of the model for wave conditions nearshore}

The wave conditions nearshore can be considered to depend on:

- The wind field;

- The wave conditions offshore;

- The available depth nearshore.

Models for the wave conditions nearshore are introduced in chapter 5. In principle, calibration of the model can only be performed if field data is available. As indicated in section 6.2, field data of wave conditions in the Wadden Sea are scarce. In this section, the parameters of the parametric nearshore wave model will be chosen such that the model reproduces results obtained by the numerical model SWAN. Strictly speaking, the model is not calibrated in this process because calibration can only be performed on the basis of field data. Nevertheless, the word "calibration" will be used in the description of the analysis, since the process is the same. A limited validation of the SWAN model is performed by Jacobse (2000) on the basis of the storm of 14 February 1989.

Calibration of the wave period model is performed for eleven locations along the dike ring Groningen. The locations correspond to the locations where quantitative reliability analysis of the flood defences is performed (chapters 7 and 8). Using a least-squares method to find the value of $\alpha$ that minimises the difference between the numerical model and the parametric model leads to the results shown in table 36 . 
Table 36: Parameters of the nearshore wave period model

\begin{tabular}{|c|c|c|c|c|c|}
\hline \multirow[t]{2}{*}{ Nr. } & \multirow[t]{2}{*}{ Location } & \multicolumn{2}{|c|}{ Output point hydraulic model } & \multirow[t]{2}{*}{$\alpha(-)$} & \multirow{2}{*}{$\begin{array}{l}\text { Model uncertainty } \\
\text { (s) }\end{array}$} \\
\hline & & $X(\mathrm{~m})$ & $Y(\mathrm{~m})$ & & \\
\hline 1 & Ommelander zeedijk & 222940 & 603916 & 0.90 & 0.21 \\
\hline 2 & Emmapolder West & 243081 & 609456 & 1.01 & 0.21 \\
\hline 3 & Emmapolder Oost & 247088 & 609349 & 1.03 & 0.21 \\
\hline 4 & Eemshaven West & 249954 & 609497 & 0.92 & 0.21 \\
\hline 5 & Eemshaven Oost & 253073 & 608217 & 0.90 & 0.21 \\
\hline 6 & Hoogwatum & 254985 & 600570 & 0.66 & 0.21 \\
\hline 7 & Delfzijl Noord & 257074 & 596244 & 0.48 & 0.21 \\
\hline 8 & Dijk zeehavenkanaal & 263100 & 593450 & 0.49 & 0.21 \\
\hline 9 & Termunten & 267026 & 591729 & 0.74 & 0.21 \\
\hline 10 & Dollarddijk & 268149 & 590450 & 0.80 & 0.21 \\
\hline 11 & Reiderwolder polderdijk & 272954 & 584800 & 0.93 & 0.21 \\
\hline
\end{tabular}

The model uncertainty shown in table 36 is the standard deviation of the additive model uncertainty of the calibrated model. The values of the fit parameter $\alpha$ appear to vary systematically with the local orientation of the coast line. Furthermore, the model indicates a strong reduction of the peak period in comparison to the offshore conditions. The field observations of the storm of 14 February 1989 also show a strong reduction of the peak period. Furthermore, the observed wave spectrum in general appears to be single-peaked so that in this case a description with a single peak period is valid. In conclusion, the available field observations do not falsify the SWAN model with regard to the peak period, but the available field data is too limited for a definitive conclusion.

The maximum significant wave height according to van Marle (1979) is a function of the local wave length and the locally available depth. The local depth is described by the combination of the local bottom level with the nearshore water level model (section 6.5). The local wave length $L$ can be approximated by solving the linear dispersion relation for given depth and peak period. Comparison to the results obtained by the SWAN model shows that equation the model of van Marle (1979, see chapter 5) is conservative with respect to the SWAN data. Figure 86 shows the dimensionless wave height for an output point in front of the Ommelander Sea dike. The wave height is made dimensionless by means of wind speed and acceleration of gravity (table 18). 


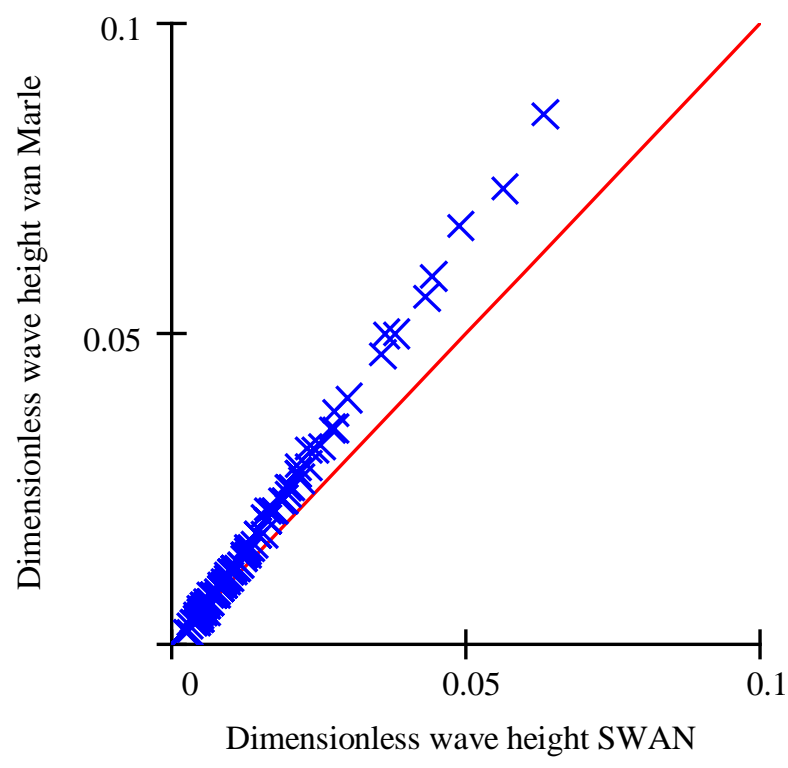

Figure 86: Comparison of van Marle model with SWAN results (Ommelander Sea dike)

Inspection of other locations suggests that the van Marle model is more conservative in comparison to the SWAN model if the location of interest is further away from direct North Sea influence. As an illustration, figure 87 shows the results for an output point near Nieuwe Statenzijl (NSZ) deep in the Dollard estuary.

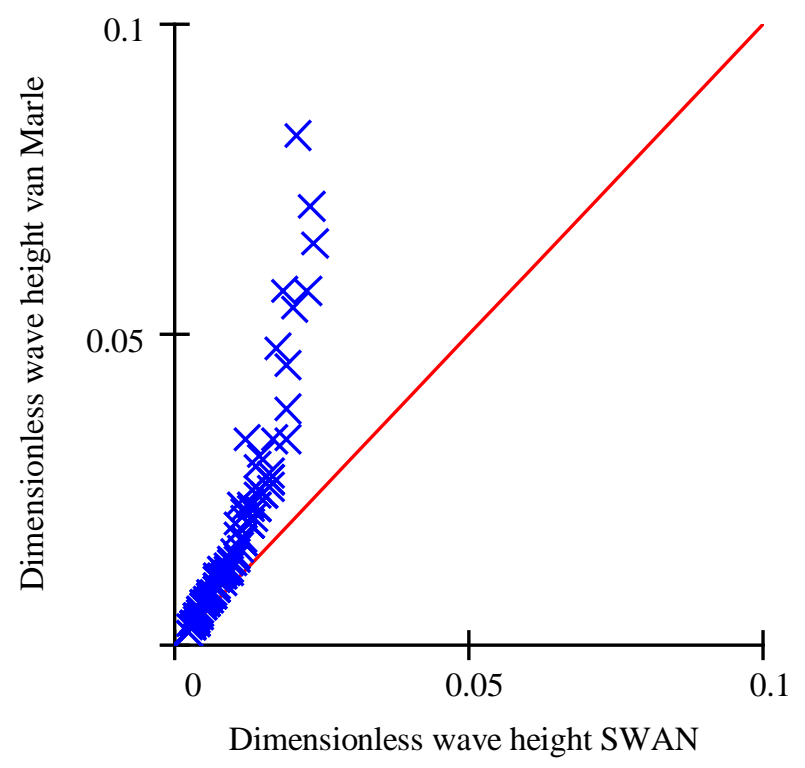

Figure 87: Comparison of van Marle model with SWAN (Dollard dike)

Because field data in the Wadden Sea is virtually lacking, there is no body of empirical evidence that can be used to support the model choice. The model of van Marle is based on field data, but is not calibrated for the Wadden Sea. The available field data is too limited to be used in a recalibration of Van Marle's model. Therefore, the choice is made to use the model of van Marle in an unchanged form, knowing that the resulting wave height estimates are conservative in comparison to a more advance model. 


\subsection{Discussion}

In this chapter, the model for the joint distribution of water levels and wave conditions along the Dutch coast is applied to the dike ring Groningen. The results obtained with the model are satisfactory.

Since extreme hydraulic conditions are the result of extreme wind conditions over the North Sea, a dataset of extremes can be obtained by selecting the extreme conditions coinciding with a peak in the wind speed. This leads to a physically relevant selection of joint observations of extreme water level, wind setup, wave height and wave period.

The marginal distribution of the wind speed depends on the wind direction. This implies that datasets of wind speed observations constitute an inhomogeneous dataset, meaning that the parameters of the probability model differ as a function of wind direction. Obtaining an omni-directional wind speed distribution by two methods (see chapter 5) shows the effect of the inhomogeneity by differences that are present between the two estimates. Because of the irregular shape of the North Sea basin, observations of hydraulic conditions are even more inhomogeneous than wind speed observations. A directional approach therefore leads to higher estimates of extreme wind setup, extreme water level and extreme wave conditions. The use of a directional model for the description of the statistics of hydraulic conditions on the North Sea appears to be a necessity.

Following chapter 5, the distributions of hydraulic conditions per direction are obtained by combining the wind speed distribution with a physical model describing the hydraulic effects. This provides support for the estimated tail-shape of the probability distributions of extreme hydraulic conditions. In general, the estimates of extreme hydraulic conditions are considerably higher than the estimates obtained in a POT-analysis. This is explained both by the inhomogeneity of the observation data that is not accounted for in a classical POT-method (see above) and by the fact that tail estimates obtained in a POT-analysis are generally not in agreement with known physical models.

The advantages of a description of joint statistics of hydraulic conditions on the basis of parametric physical models are clear. Such an approach should be favoured over alternative methods that rely on statistical methods alone.

Any method for the description of probability distributions of hydraulic conditions relies on the availability of field data. The availability of water level and wave data offshore is satisfactory, although the datasets are relatively small for the estimation of extreme conditions. Therefore, the existing monitoring program of hydraulic conditions offshore should be continued. Observations of water levels nearshore are available in the Wadden Sea. The monitoring program of water levels nearshore should be continued for the same reason as indicated for the hydraulic conditions offshore. Observations of wave conditions are lacking in the Wadden Sea, apart from some incidental observations. For reliable estimation of design conditions for flood defences along the Wadden Sea, a continuous monitoring program of wave conditions nearshore should be started up. 



\section{RELIABILITY-BASED DESIGN OF TWO FLOOD DEFENCE STRUCTURES IN GRONINGEN}

"All truths are easy to understand once they are discovered; the point is to discover them." Galileo Galilei

\subsection{Introduction}

In this chapter, the reliability-based design method outlined in chapter 3 is applied to two coastal flood defence structures in the Dutch province Groningen. This chapter forms the second of three chapters on the case study Groningen. Chapter 6 deals with the probabilistic description of hydraulic boundary conditions for the dike ring Groningen. The result of chapter 6 is applied in this chapter as input for the reliabilitybased design of two flood defence structures along the Wadden Sea. Risk-based design of the full protection system of the province Groningen is performed in chapter 8 .

In section 7.2 the case study is introduced. In reliability-based design, combinations of failure modes and the effects of uncertainties in input variables influence design decisions. To gain more insight in the effects of multiple failure modes on the optimal design, deterministic design of a flood defence structure is performed in section 7.3.

Section 7.4 presents the results of reliability-based optimisation, performed with a numerical model designed according to chapter 3. A parameter study is performed to quantify the influence of:

- Type of failure probability requirement, and;

- Cost of space use

on the optimal design of a flood defence structure in Groningen. The chapter closes with a discussion.

\subsection{Case description}

\subsubsection{Selection of locations for analysis}

TNO (1998) performed a reliability analysis of the dike ring Groningen-Friesland. In this study, the coastal flood defence system of the province of Groningen will be analysed, which is a part of the full dike ring Groningen-Friesland. Based on the study by TNO, the system is broken down into 11 individual dike sections. Figure 88 shows the eleven sections used in this study. The names of the sections are given in table 37. 


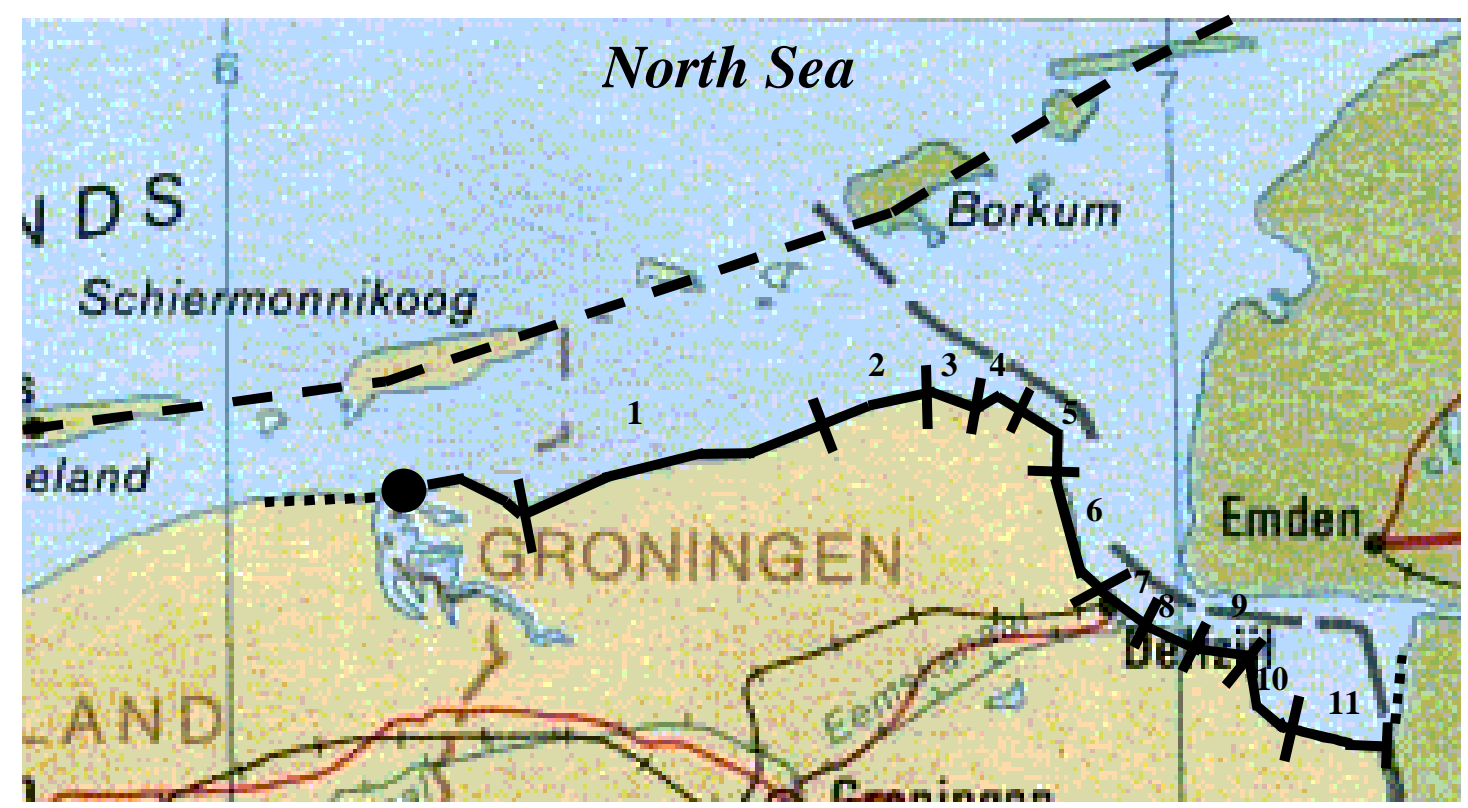

Figure 88: Overview of dike sections in the dike ring Groningen (after TNO, 1998)

Table 37: Names of dike sections in the dike ring Groningen

\begin{tabular}{ll}
\hline Section number & Section name \\
\hline 1 & Ommelander zeedijk \\
2 & Emmapolder West \\
3 & Emmapolder Oost \\
4 & Eemshaven West \\
5 & Eemshaven Oost \\
6 & Hoogwatum \\
7 & Delfzijl Noord \\
8 & Dijk zeehavenkanaal \\
9 & Termunten \\
10 & Dollarddijk \\
11 & Reiderwolder polderdijk \\
\hline
\end{tabular}

In this chapter, reliability-based design is performed for dike sections 1 (denoted Ommelander) and 5 (denoted Eems harbour). Section Ommelander is sheltered from direct wave attack by North Sea waves by the island of Schiermonnikoog. The section borders a large shallow area. Section Eems harbour borders the main tidal inlet entering the Eems-Dollard estuary. The location is hardly sheltered from North Sea wave attack and the local water depth is larger than the local water depth at section Ommelander. For both locations, a flood defence structure will be designed using the methods outlined in chapter 3. Figure 89 shows the schematised cross section of the flood defence structure and the design variables.

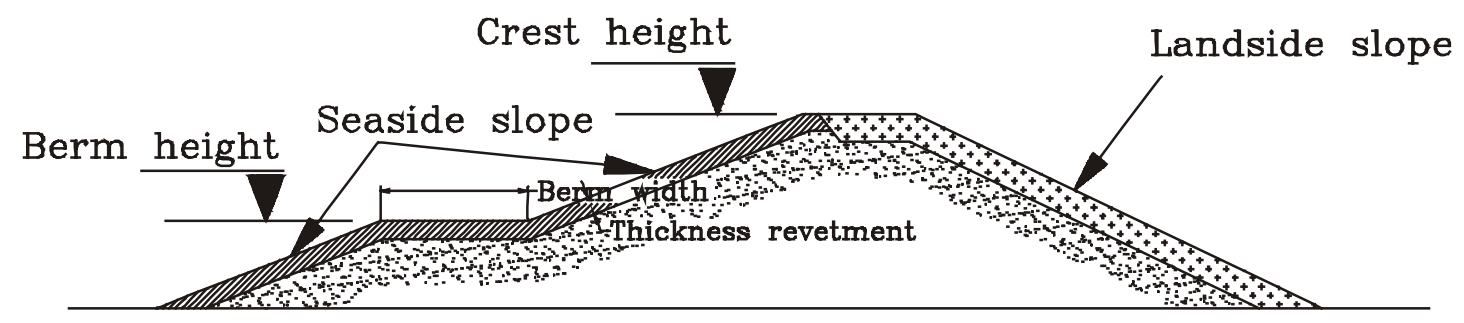

Figure 89: Schematised cross section of a sea dike with design variables 


\subsubsection{Definition of failure and selection of failure modes}

Following the methodology of chapter 3, a definition of failure is established followed by a break-down of failure into failure modes. To this end the general fault tree of a dike section of annex 1 is being used. Within the fault tree, three main types of failure modes may be defined:

- Full failure of structure (top event);

- Initiating failure modes;

- Transitional failure modes.

The top event describes function loss of the structure. The top event for a flood defence structure is defined as: "Water enters the area uncontrolled".

Initiating failure modes are those failure modes that lead to failure of a part of the structure but do not immediately lead to the top event. Examples of this type of failure modes are wave overtopping and revetment failure. Transitional failure modes are failure modes that stand between an initial failure mode and full failure of the structure. Erosion of the sandy core of the dike structure after an initial revetment failure is an example of a transitional failure mode.

Only a combination of initial failure and transitional failure leads to the occurrence of the top event. The probability of failure of the structure due to a combination of initiating failure modes and transitional failure modes is therefore given by:

$P_{f}=P_{\text {init }} P_{\text {flinit }}$

Where:

$P_{\text {init }}$ : $\quad$ Probability of initial failure;

$P_{\text {flinit }}$ : $\quad$ Probability of failure of the structure conditional on initial failure.

The probability of failure conditional on the occurrence of initial failure fulfils:

$P_{f \mid \text { init }} \leq 1$

Substitution of equation (105) in (104) leads to:

$$
\frac{P_{f}}{P_{\text {init }}} \leq 1 \Leftrightarrow P_{f} \leq P_{\text {init }}
$$

Equation (106) shows that a valid upper bound of the failure probability of the structure is found if the probability of initial failure is properly quantified. A prerequisite for equation (106) to be an upper bound to the probability of failure is that the probability of initial failure indeed includes all possible causes of initial failure. Therefore, from the viewpoint of reliability-based design, an analysis of initiating failure modes of flood defences should have the highest priority.

The analysis by van Dantzig (1956) can be viewed as an early example of an analysis where the probability of initial failure is used as an approximation of the failure probability. Van Dantzig analysed the probability of exceedance of the design water level. The Delta Committee denoted this probability the "probability of overloading" (Delta Committee, 1961a). The difference between the probability of overloading and the probability of failure was never quantified. If the difference in exceedance probability between design water level and disaster water level (Delta Committee, 1961a) is interpreted as a failure probability conditional on overloading, it can be concluded that the Delta Committee estimated the failure probability conditional on 
overloading at $10 \%$. In fact however, the difference between probability of overloading and the probability of failure in the results of the Delta Committee is unknown.

More knowledge on initiating failure modes has come available in the decades after the Delta Committee. Therefore, it is now possible to quantify the probability of initial failure $^{17}$. The models used in this study to quantify the probability of initial failure are shown in table 38. The table is organised according to three main branches in the fault tree in annex 1. A detailed description of the implemented failure modes is given in annex 3 .

Table 38: Overview of failure modes applied to quantify the probability of initial failure

\begin{tabular}{ll}
\hline Fault tree main branch & Failure modes \\
\hline Internal erosion & Piping model of Bligh (TAW, 1999) \\
Breaching through inner slope & Wave overtopping (Van der Meer and Janssen, 1995) \\
& Overflowing (included in definition of wave overtopping) \\
& Uplifting inner revetment (this study, annex 3) \\
Breaching through outer slope & Failure of pitched block revetment (Hussaarts et al., 1999) \\
\hline
\end{tabular}

Geotechnical instability is not quantified in this study. Therefore, the results obtained with the optimisation model will be valid only if the subsoil is of reasonable quality so that geotechnical instability has no influence on the failure probability of the structure. Furthermore, failure of the sea side revetment as a consequence of failure of the toe structure is not quantified, assuming that the probability of instability of the toe structure is negligible with respect to the other failure modes. Erosion of the sea side revetment is not included, as it appears to be of little influence on the reliability of a pitched stone revetment.

In general, the development from initial failure to breaching of the flood defence takes time. For piping to occur, the seepage flow through the dike body has to develop. Full erosion of slopes does not occur at the first wave, but takes a longer period of wave attack to develop to a breach. This kind of time effects is neglected in this study. They can be considered one of the causes of the difference between the probability of initial failure and the probability of failure.

\subsubsection{Description of input}

Once the design variables, the definition of failure and the fault tree have been established, it is possible to define the stochastic models of the boundary conditions and the unit prices describing the cost of construction.

The stochastic model consists of hydraulic and geotechnical boundary conditions, material properties, model uncertainties and statistical uncertainties. Dominating in the stochastic model for flood defence structures is the joint probability distribution of hydraulic boundary conditions. Chapter 5 and 6 deal in detail with this aspect of reliability analysis of flood defences. Annex 6 provides an overview of the full stochastic model.

Since reliability-based design in this study is based on the minimisation of direct costs under a reliability constraint (chapter 3), the direct costs of construction should be written as a function of the design variables. To this end, the main components of the

\footnotetext{
${ }^{17}$ One could view the probability of initial failure as an improved definition of the probability of overloading.
} 
dike profile determining the costs need to be defined. A definition sketch of the cost components of a dike section is given in figure 90 .

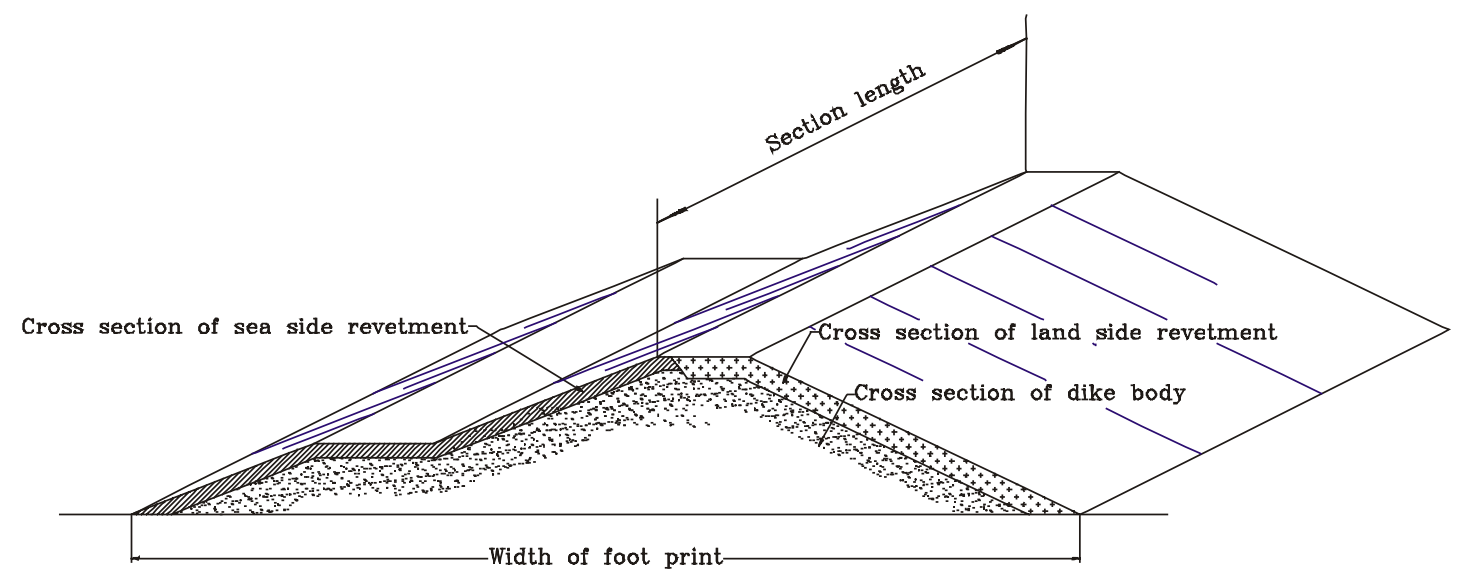

Figure 90: Cost components of a dike cross section

The direct costs as a function of the design variables are given by:

$$
\begin{aligned}
& C(\mathbf{z})= \\
& \quad L\left(B_{\text {dike }}(\mathbf{z}) C_{\text {space }}+A_{\text {cross }}(\mathbf{z}) C_{\text {vol }}+A_{\text {cross; rev; out }}(\mathbf{z}) C_{\text {rev; out }}+A_{\text {cross; rev; in }}(\mathbf{z}) C_{\text {rev; in }}\right)
\end{aligned}
$$

Where:

$\begin{array}{ll}\text { z: } & \text { Vector of design variables (see figure } 89 \text { ); } \\ L: & \text { Section length; } \\ B_{\text {dike }}: & \text { Width of dike foot print; } \\ A_{\text {cross }}: & \text { Area of dike cross section; } \\ A_{\text {cross;rev;out }} \text { Area of cross section of outer revetment; } \\ A_{\text {cross; rev;in }}: & \text { Area of cross section of inner revetment; } \\ C_{\text {space }}: & \text { Cost of space use per unit area; } \\ C_{\text {vol }}: & \text { Cost of dike volume per unit; } \\ C_{\text {rev } ; \text { out }}: & \text { Cost of outer revetment by volume; } \\ C_{\text {rev;in }}: & \text { Cost of inner revetment by volume. }\end{array}$

Unit prices of filling sand and revetments on sea and land side have been obtained from the engineering division of the Ministry of Public Works and Water Management in the Netherlands (Van den Brink, personal communication). The costs of space use have been assumed. The optimisation is performed for a range of values. An overview of the cost variables is given in table 39 .

Table 39: Overview of cost variables

\begin{tabular}{lll}
\hline Cost component & Price per unit & Remark \\
\hline Dike volume & $4.6 € / \mathrm{m}^{3}$ & Price of filling sand including construction \\
Revetment outside & $227.3 € / \mathrm{m}^{3}$ & Pitched concrete blocks. Price includes construction \\
Revetment inside & $45.5 € / \mathrm{m}^{3}$ & Clay cover including construction \\
Space use & $10-200 € / \mathrm{m}^{2}$ & Assumed values \\
\hline
\end{tabular}

\subsection{Deterministic design of a flood defence structure}

Before commencing a reliability-based optimisation of flood defences in Groningen, it is illustrative to perform a deterministic optimisation of a flood defence structure. In a deterministic approach, discrete values of all random input variables are chosen. Subsequently, the dike profile that minimises the construction costs for given input 
conditions is established. The only difference with the reliability-based approach is that input conditions are given by discrete values while in the reliability-based approach the joint distribution of input conditions is used.

The input values of load and resistance used in the deterministic design procedure are derived from the stochastic model of load and resistance. The design conditions are in this case defined by choosing a wind speed with a given exceedance probability. All other variables are set to their expected values, conditional on the chosen wind speed. Table 40 gives an overview of the design conditions corresponding to a wind speed with probability of exceedance of $10^{-4}$ per year.

Table 40: Expected values of hydraulic conditions at Ommelander sea dike conditional on a wind speed with exceedance probability $10^{-4}$ per year

\begin{tabular}{ll}
\hline Variable & Value \\
\hline Wind speed $(\mathrm{m} / \mathrm{s})$ & 37.8 \\
Water level $(\mathrm{CD}+\mathrm{m})$ & 6.46 \\
Wave height $(\mathrm{m})$ & 2.30 \\
Wave peak period $(\mathrm{s})$ & 5.94 \\
\hline
\end{tabular}

Using the input conditions shown in table 40, a design of the dike profile at Ommelander is made considering the following three failure modes:

- Wave overtopping;

- Failure of sea side revetment;

- Piping.

More details on the failure modes and the limit state functions are given in annex 3 .

The three failure modes form a series system because every individual failure mode describes initial failure. The deterministic analysis is performed following the deterministic analysis of a fault tree outlined in chapter 3 . Because the three failure modes form a series system, failure of the structure is described by:

$$
\min \left(\mathbf{g}\left(\mathbf{z}, \mathbf{x}^{*}\right)\right)<0
$$

Where:

g: $\quad$ Vector of limit state functions;

$\mathbf{z}: \quad$ Vector of design variables;

$\mathbf{x}^{*}: \quad$ Vector of input conditions (table 40).

From the definition of failure, it easily follows that a design is acceptable if:

$$
\min \left(\mathbf{g}\left(\mathbf{z}, \mathbf{x}^{*}\right)\right) \geq 0
$$

Equation (109) indicates that under the design conditions, the design should fulfill the requirements set by all three failure modes. The six design variables generally influence more than one failure mode. Table 5 shows an overview of the six design variables, indicating how each failure mode is influenced by each design variable. 
Table 41: Influence of design variables on failure modes

\begin{tabular}{l|ccc} 
& Wave overtopping & Sea side revetment failure & Piping \\
\hline Crest height & + & 0 & + \\
Width of sea side berm & + & 0 & + \\
Height of sea side berm & $+/-^{\#}$ & 0 & 0 \\
Sea side slope & + & + & + \\
Revetment thickness & 0 & + & 0 \\
Land side slope & 0 & 0 & + \\
\hline +: increase of design variable improves performance; -: negative influence; 0: no influence \\
\# depends on water level
\end{tabular}

Table 92 shows qualitatively the effect of an increase of a design variable on the value of the limit state functions of the three individual failure modes. The height of the sea side berm, the landside slope and the revetment thickness influence only one failure mode. The effect of an increase of the design variable is generally an increase of the value of the limit state function. An exception is the effect of the height of the sea side berm on the wave overtopping. The reducing effect of a berm on wave overtopping is maximised if the berm is at still water level (Van der Meer and Janssen, 1995). This implies that if the berm is located at or above still water level, an increase in berm height has a negative effect on the limit state function for wave overtopping. The reverse is true if the berm lies below still water level.

The sea side slope positively influences all three failure modes. The berm width and the crest height both positively influence two failure modes.

An increase of the crest height directly reduces wave overtopping. Keeping all other design variables constant, an increased crest height also increases the dike foot print and therefore reduces piping. A crest height that fulfils the condition in equation (109) can be found as a function of berm width, berm height, sea side slope and land side slope by solving for the crest height:

$$
\min \left(\begin{array}{c}
g_{\text {overtop }}\left(h_{c}, B_{b f r}, h_{b f r}, m_{\text {sea }}\right) \\
g_{\text {piping }}\left(h_{c}, B_{b f r}, h_{b f r}, m_{\text {sea }}, m_{\text {land }}\right)
\end{array}\right)=0
$$

Where:

$h_{c}: \quad$ Crest height;

$B_{b f r:}: \quad$ Berm width sea side;

$h_{b f r}: \quad$ Berm height sea side;

$m_{\text {sea }}: \quad$ Slope sea side;

$m_{\text {land }}: \quad$ Slope land side.

Figure 91 shows the necessary crest height as a function of the sea side slope for a berm with a width of $15 \mathrm{~m}$ at the design water level. The input conditions are according to table 40 . 


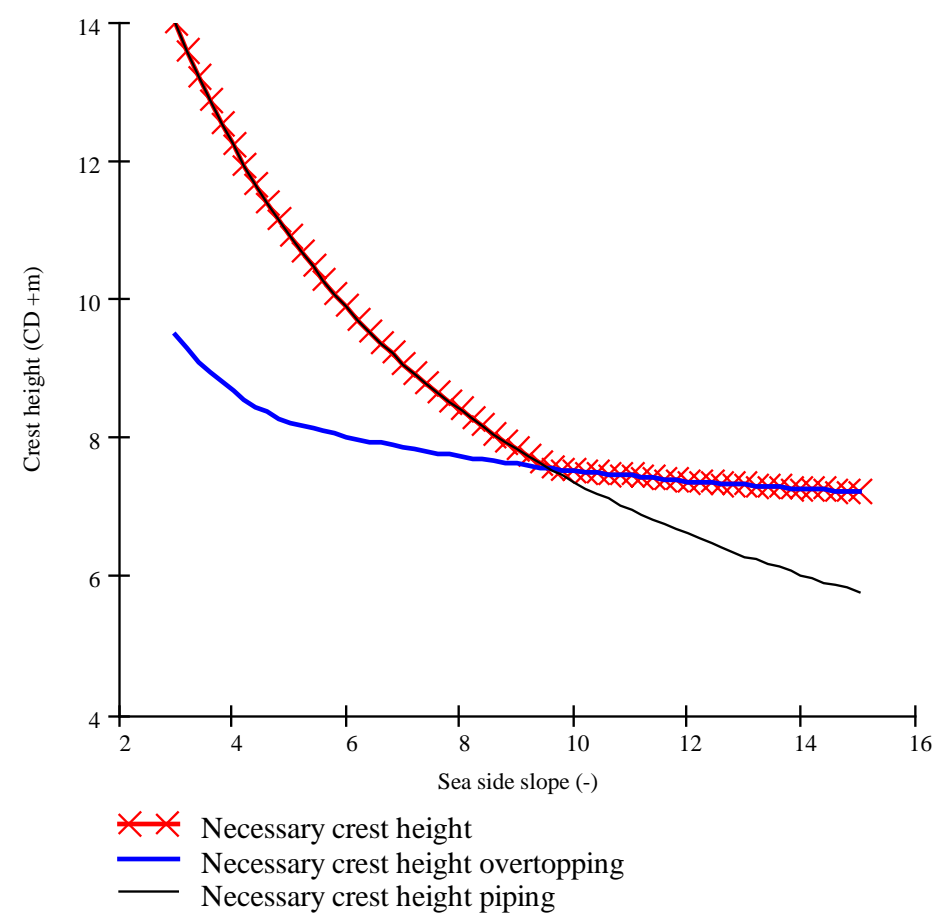

Figure 91: Necessary crest height as a function of seaside berm width for two failure modes

Necessary crest heights can be calculated separately for overtopping and for piping. The maximum of the two calculated crest heights is decisive for the design of the structure. Figure 91 shows that for slopes steeper than 1:10, the crest height is determined by the failure mode piping. For flatter slopes, wave overtopping is decisive. Similar figures can be drawn for other values of the berm width. Figure 92 shows four examples.

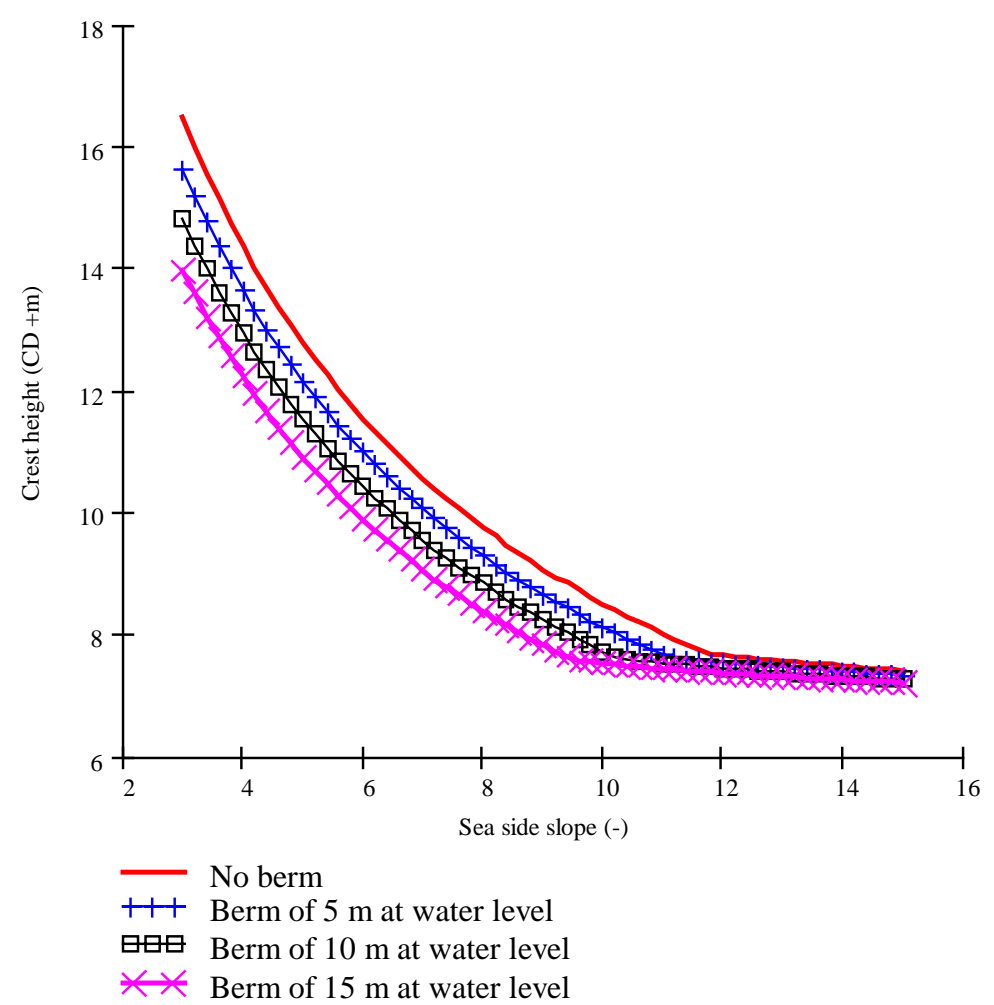

Figure 92: Necessary crest heights as a function of sea side slope for four sea side berm geometries 
In figure 92, the sharp bends in the graphs coincide with the transition from piping to overtopping as the failure mode deciding the crest level.

With equation (110), the crest level is written as a function of berm width and sea side slope. The limit state for revetment stability is a function of the design variables revetment thickness $(D)$ and sea side slope $\left(m_{\text {sea }}\right)$. For a given value of the sea side slope, the necessary revetment thickness can be calculated by solving:

$$
g_{\text {revet }}\left(D, m_{\text {sea }}\right)=0
$$

Where:

$D$ : $\quad$ Revetment thickness sea side;

$m_{\text {sea }}: \quad$ Slope sea side.

Figure 93 shows the revetment size as a function of seaward slope for hydraulic conditions according to table 40 .

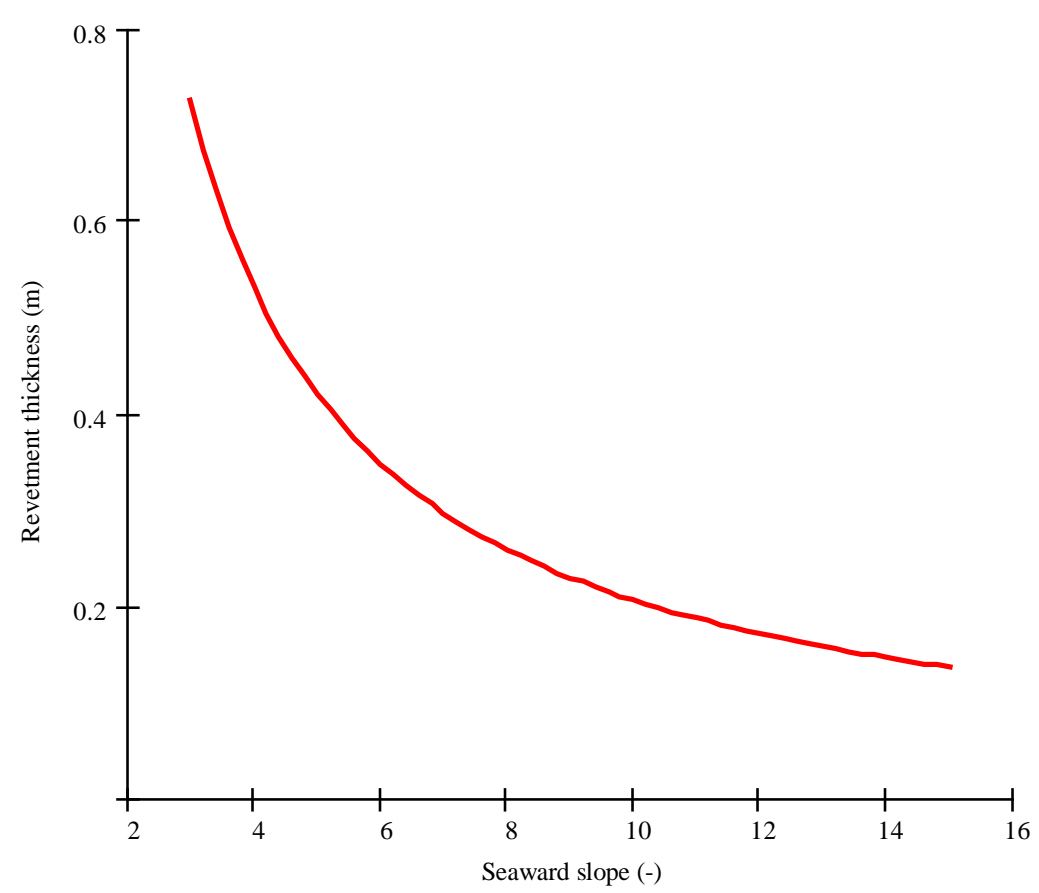

Figure 93: Necessary revetment thickness as a function of seaward slope

Figure 93 shows that to ensure revetment stability, a steeper slope necessitates a larger revetment thickness.

With equations (110) and (111), the design variables crest height and revetment thickness are written as functions of the design variables sea side slope and sea side berm width. Of the original six degrees of freedom in the design problem, therefore only four remain. For the land side slope, a fixed value of 1:3 is adopted. The berm height will be chosen equal to the design water level, where the berm has a maximum reducing effect on wave overtopping (Van der Meer and Janssen, 1995). With the remaining two free design variables sea side slope and sea side berm width, an analysis of the construction cost can be performed. For every combination of sea side slope and berm width, the corresponding values of the crest height and the revetment thickness can be calculated. For every geometry, the construction costs can be calculated by substituting the geometry in the cost function (equation (107)). Figure 
94 shows the result as a function of the sea side slope for four values of the sea side berm width.

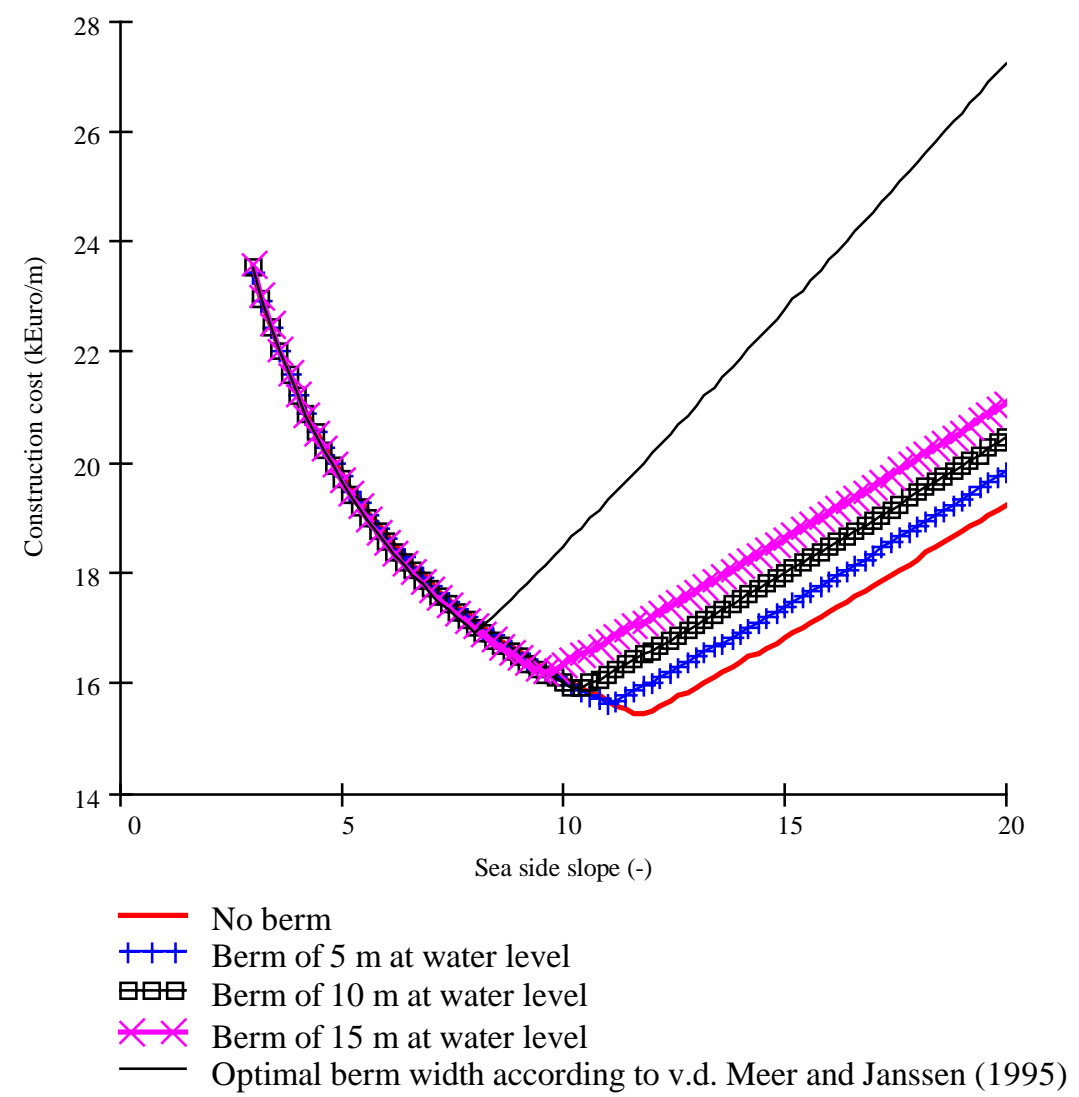

Figure 94: Construction costs per metre as a function of sea side slope (Ommelander, deterministic design)

In the given conditions, a clear cost minimum is obtained for the alternative without sea side berm at a sea side slope of 1:12.

The optimal berm width of $0 \mathrm{~m}$ obtained in this study is in contradiction with the conclusion of Van der Meer and Janssen (1995), who concluded that the optimal berm width of a horizontal berm at still water level equals:

$B_{v d M}\left(m_{\text {slope }}, H_{s}\right)=\frac{4}{3} m_{\text {slope }} H_{s}$

Where:

$m_{\text {slope }}: \quad$ Sea side slope;

$H_{s}: \quad$ Significant wave height.

The construction costs for a geometry with a berm width according to equation (112) are indicated in figure 94. It is clear that under the design conditions considered here, no cost minimum is obtained in this way. The explanation for the difference between this study and the study of Van der Meer and Janssen (1995) is most probably that Van der Meer and Janssen defined the optimal berm width as the berm width that has maximum reducing influence on the wave overtopping and thus a maximum reducing influence on the crest height of the flood defence. Van der Meer and Janssen appear not to consider the construction costs of their optimal profile, nor the effects of the chosen geometry on other failure modes than overtopping. The analysis in this study clearly shows that, to obtain a cost-effective design of a flood defence structure, it is 
important to consider all relevant failure modes simultaneously and to take into account the locally prevailing hydraulic conditions.

\subsection{Reliability-based design of flood defences at Ommelander and Eemshaven}

\subsubsection{General}

In the previous section, a profile of the flood defence at Ommelander is developed for a pre-defined set of boundary conditions. The design values of the boundary conditions are obtained by making an arbitrary choice from the stochastic model of load and resistance. A better way to design a structure is by performing reliabilitybased design according to chapter 3 . In that case, no discrete values for the input conditions are used but the full stochastic model of load and resistance variables is accounted for in the design optimisation.

Reliability-based design of the flood defences at Ommelander and Eemshaven is performed using a numerical model. Running similar calculations for the locations Ommelander and Eemshaven provides insight in the location dependence of the optimal design. For every location, a total of seven optimisations is performed using different input conditions. Table 42 provides an overview.

Table 42: Overview of calculations performed in this study

\begin{tabular}{llllll}
\hline Nr. Section & $\begin{array}{l}\text { Failure probability } \\
\text { requirement }\end{array}$ & Cost of area $(\boldsymbol{€})$ & $\begin{array}{l}\text { Hydraulic load } \\
\text { model }\end{array}$ & Remark \\
\hline 1a & Ommelander & Failure of structure & 100 & Full & Reference case \\
2a & Ommelander & Per failure mode & 100 & Local water level & Current practice \\
3a & Ommelander & Per failure mode & 100 & Full & \\
4a & Ommelander & Failure of structure & 10 & Full & \\
5a & Ommelander & Failure of structure & 50 & Full & \\
6a & Ommelander & Failure of structure & 150 & Full & \\
7a & Ommelander & Failure of structure & 200 & Full & Reference case \\
1b & Eemshaven & Failure of structure & 100 & Full & Current practice \\
2a & Eemshaven & Per failure mode & 100 & Local water level & Full \\
3b & Eemshaven & Per failure mode & 100 & Full & \\
4b & Eemshaven & Failure of structure & 10 & Full & \\
5b & Eemshaven & Failure of structure & 50 & Full & Full \\
6b & Eemshaven & Failure of structure & 150 & & \\
7b & Eemshaven & Failure of structure & 200 & & \\
\hline
\end{tabular}

All calculations are characterised by a number and a lower case letter. The number indicates the calculation settings, while the letter indicates the section that is analysed. For case 1, the following results will be presented:

- Cost of construction as a function of failure probability of the structure;

- Relative importance of individual failure modes to the reliability of the optimised structure;

- Sensitivity of reliability and cost of the structure to the design variables;

- Relative importance of the uncertainties included in the stochastic model to the reliability of the optimised structure.

In a parameter study, information is obtained on the effects of:

- Type of failure probability requirement;

- Uncertainties included in the calculation;

- Costs of land use. 
Case 1 will serve as reference case in the parameter study that is carried out in cases 2 through 7. For cases 2 through 7 only limited output is presented, highlighting the differences with the reference case.

The failure probability requirement is set in this study on the probability of failure of the structure, assuming the conditional probability of failure of the transitional failure modes to be equal to 1 . Alternatively, a probability requirement may be set on individual failure modes. An example of such a probability requirement is the recommendation by TAW $(1985,1989,1998)$, which is still used in everyday practice and is mathematically written as:

$$
\begin{aligned}
& P_{f ; \text { overtop }}<P_{f ; \text { req }} \\
& P_{f ; \text { other }}<0.1 P_{f ; r e q}
\end{aligned}
$$

Where:

$P_{f ; \text { overtop: }}$ Probability of overtopping failure;

$P_{f ; \text { other }}: \quad$ Probability of occurrence of other failure modes;

$P_{f ; r e q}: \quad$ Failure probability requirement.

In the TAW-recommendation, two probability requirements are defined. The highest acceptable value of the failure probability is given for overtopping failure. The probability requirement for all other failure modes is one order of magnitude lower than the requirement for overtopping. In calculations 2 and 3, the TAWrecommendation for failure probabilities is applied.

In the standard setting, the hydraulic load model as developed in chapters 5 and 6 is applied. In case 2, a limited model is applied which only includes the uncertainty of the local water level. All other variables are taken at their expected values, conditional on the water level. The combination of the TAW failure probability requirement combined with a load model that only considers water level uncertainty appears to reasonably reflect current practice of dike design. In case 3 , the full hydraulic load model is applied in combination with the TAW failure probability requirement.

In case 1 , the cost of land use is set equal to $€ 100,-/ \mathrm{m}^{2}$. In cases 4 through 7 , the cost of land use is varied between $€ 10,-/ \mathrm{m}^{2}$ and $€ 200,-/ \mathrm{m}^{2}$.

\subsubsection{Reference case (case 1)}

In case 1 , all inputs are set to their normal values. Reliability-based optimisation is performed for a failure probability requirement ranging from $10^{-1}$ per year to $10^{-6}$ per year. Figure 95 shows the geometry of a sea dike at Ommelander for a failure probability of $10^{-4}$ per year. Figure 96 shows the geometry for a dike at Eemshaven. 


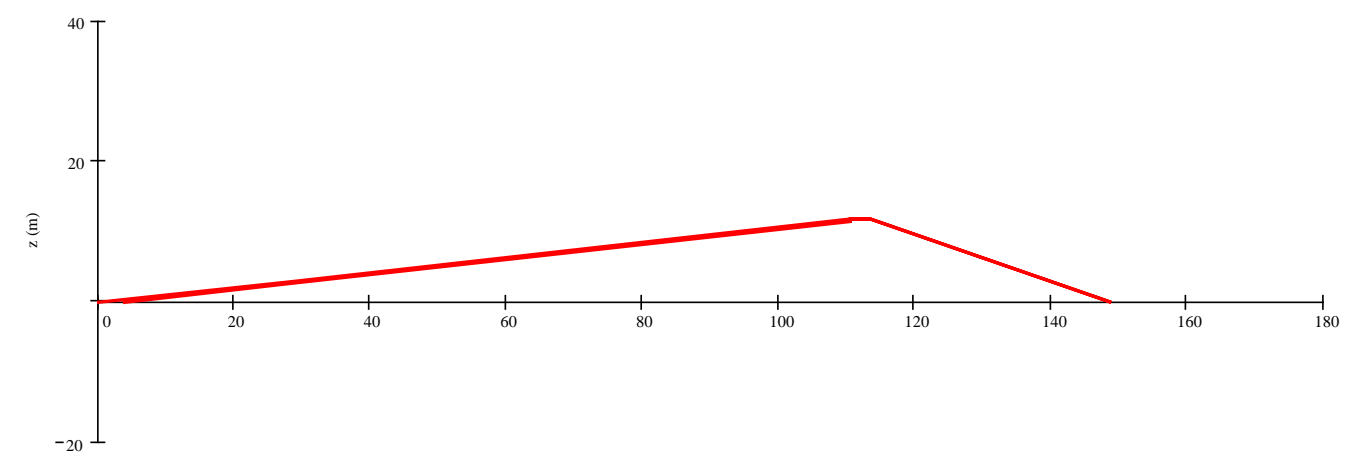

$\mathrm{x}(\mathrm{m})$

re 95: Cross section of the dike at Ommelander resulting from reliability-based design for a failure probability of $10^{-4}$ per year

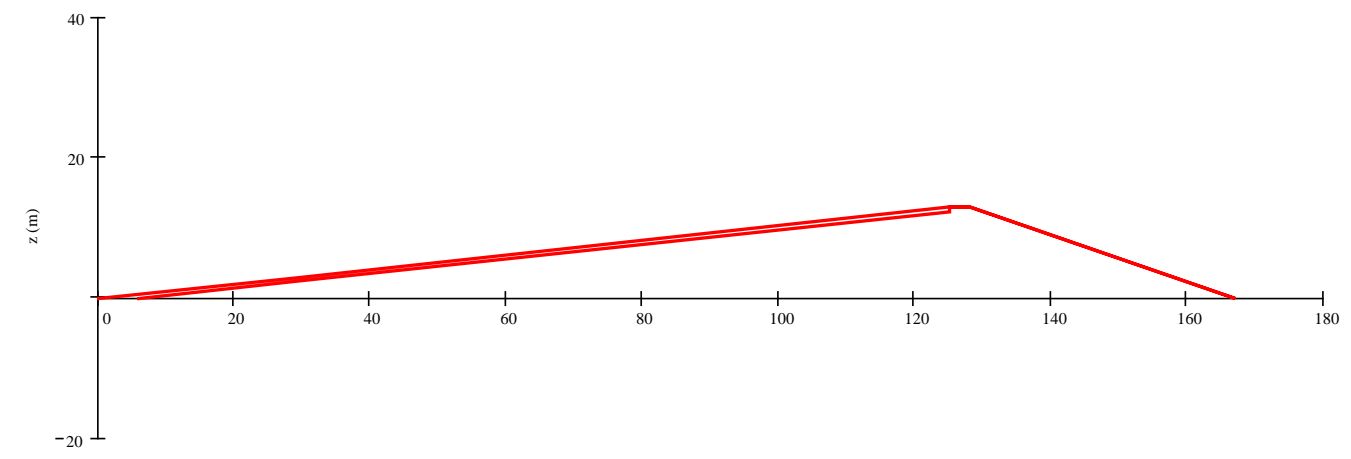

$\mathrm{x}(\mathrm{m})$

Figure 96: Cross section of the dike at Eems harbour resulting from reliability-based design for a failure probability of $10^{-4}$ per year

Table 43 shows the numerical output for location Ommelander and table 44 for location Eemshaven.

Table 43: Geometry resulting from reliability-based design (Ommelander, reference case)

\begin{tabular}{lllllll}
\hline $\begin{array}{l}\text { Failure prob. } \\
(\mathbf{1} / \mathbf{y r})\end{array}$ & $\begin{array}{l}\text { Crest height Sea side } \\
(\mathbf{C D}+\mathbf{m})\end{array}$ & $\begin{array}{l}\text { Thickness } \\
\text { slope } \mathbf{1 : n})\end{array}$ & $\begin{array}{l}\text { Berm } \\
\text { revetment }(\mathbf{m})\end{array}$ & $\begin{array}{l}\text { Bidth }(\mathbf{m}) \\
(\mathbf{C D}+\mathbf{m})\end{array}$ & $\begin{array}{l}\text { Berm height Land side slope } \\
(\mathbf{1 : n})^{\mathbf{8}}\end{array}$ \\
\hline $10^{-1}$ & 4.8 & 9.2 & 0.13 & 0.0 & n.a. & 3.0 \\
$10^{-2}$ & 6.6 & 9.4 & 0.20 & 0.0 & n.a. & 3.0 \\
$10^{-3}$ & 9.0 & 9.3 & 0.30 & 0.0 & n.a. & 3.0 \\
$10^{-4}$ & 11.8 & 9.4 & 0.41 & 0.0 & n.a. & 3.0 \\
$10^{-5}$ & 15.1 & 9.8 & 0.54 & 0.0 & n.a. & 3.0 \\
$10^{-6}$ & 19.1 & 10.0 & 0.71 & 0.0 & n.a. & 3.0 \\
\hline
\end{tabular}

Table 44: Geometry resulting from reliability-based design (Eemshaven, reference case)

\begin{tabular}{lllllll}
\hline $\begin{array}{l}\text { Failure prob. } \\
(\mathbf{1} / \mathbf{y r})\end{array}$ & $\begin{array}{l}\text { Crest height Sea side } \\
(\mathbf{C D}+\mathbf{m})\end{array}$ & $\begin{array}{l}\text { Thickness } \\
\text { slope }(\mathbf{1}: \mathbf{n})\end{array}$ & $\begin{array}{l}\text { Berm } \\
\text { revetment }(\mathbf{m})\end{array}$ & $\begin{array}{l}\text { Berm height } \mathbf{( m )} \\
(\mathbf{C D}+\mathbf{m})\end{array}$ & $\begin{array}{l}\text { Land side slope } \\
(\mathbf{1 : n})^{\mathbf{8}}\end{array}$ \\
\hline $10^{-1}$ & 6.0 & 7.9 & 0.33 & 0.0 & n.a. & 3.0 \\
$10^{-2}$ & 7.9 & 8.5 & 0.42 & 0.0 & n.a. & 3.0 \\
$10^{-3}$ & 10.2 & 9.0 & 0.51 & 0.0 & n.a. & 3.0 \\
$10^{-4}$ & 13.0 & 9.6 & 0.62 & 0.0 & n.a. & 3.0 \\
$10^{-5}$ & 16.5 & 11.0 & 0.69 & 0.0 & n.a. & 3.0 \\
$10^{-6}$ & 21.3 & 10.7 & 0.98 & 0.0 & n.a. & 3.0 \\
\hline
\end{tabular}

\footnotetext{
${ }^{18}$ The inner slope is constrained to a maximum of 1:3.
} 
The sea side berm is absent in all profiles. This is in agreement with the result of the deterministic design in section 7.3.

For the same failure probability, the profile at Eemshaven shows a higher crest level and a thicker revetment than the profile at Ommelander. This can be considered due to the larger exposure to wave attack at Eemshaven compared to Ommelander. For a failure probability of $10^{-3}$ per year or higher, the seaside slope of section Eemshaven is steeper than the seaside slope at Ommelander. The analysis of section 7.3 showed that flatter slopes may reduce wave overtopping, revetment failure and piping. The relatively high importance of the failure mode piping at the Ommelander sea dike (see below) suggests that the flat slope is primarily necessary to reduce piping. In case of Eems harbour, there is a larger exposure to wave attack which necessitates a higher crest level. Keeping the slopes constant, a higher crest implies larger space use. The optimisation indicates that in case of Eems harbour it is cost effective to choose a somewhat steeper slope, a higher crest level and a thicker revetment in comparison to Ommelander if the failure probability is higher than $10^{-3}$ per year.

Due to the larger exposure to wave attack, a profile at Eemshaven is more expensive than a profile at Ommelander if the failure probability is the same for both profiles (figure 97).

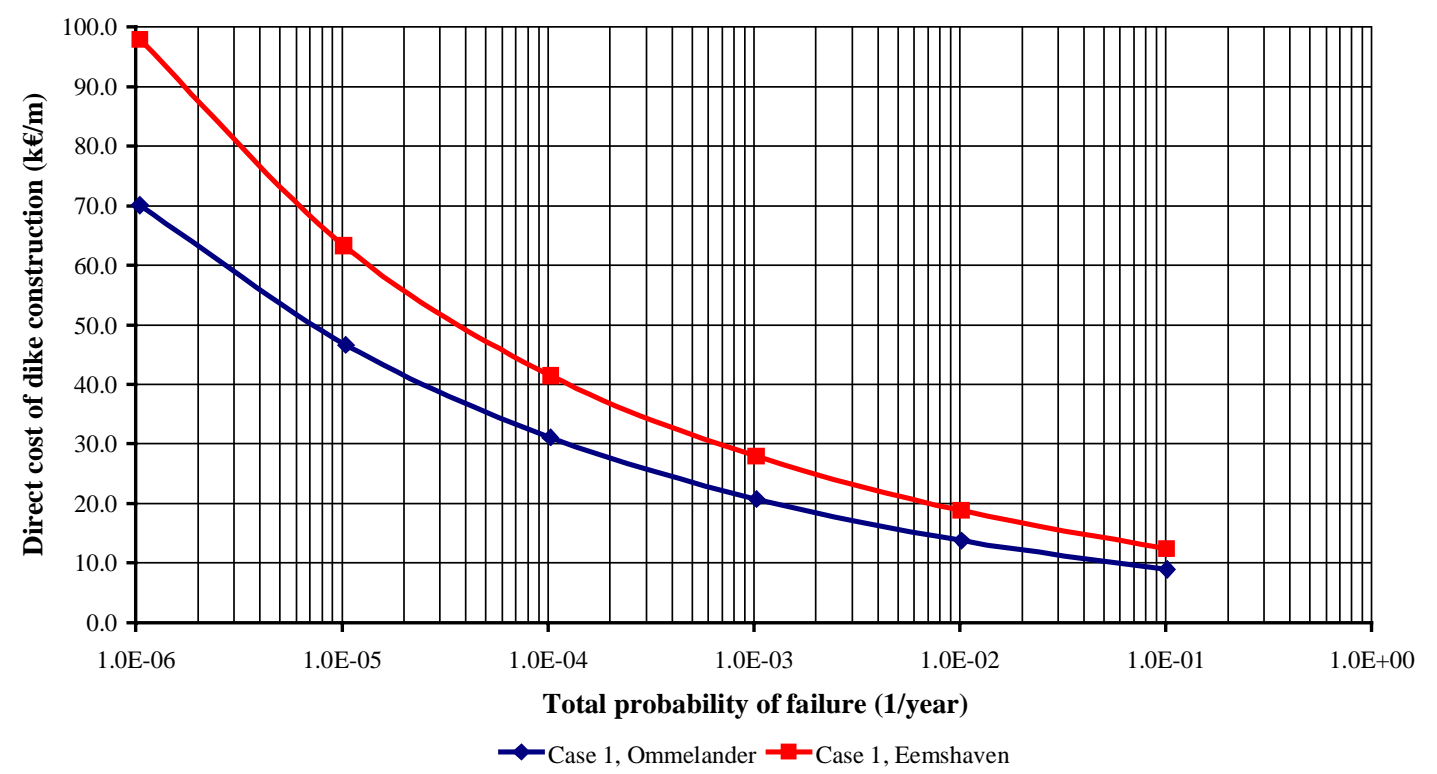

Figure 97: Direct cost per metre as a function of failure probability (case 1)

The relative difference in direct costs is in the order of $40 \%$.

For the geometry resulting from reliability-based optimisation, the probabilities of occurrence of individual failure modes can be determined. Subsequently, the probability of occurrence of every failure mode relative to the probability of failure of the structure can be calculated. The probabilities of occurrence of the individual failure modes relative to the total failure probability vary as a function of total failure probability. The failure probabilities per failure mode relative to the total probability of failure are shown in figure 98 and 99. 


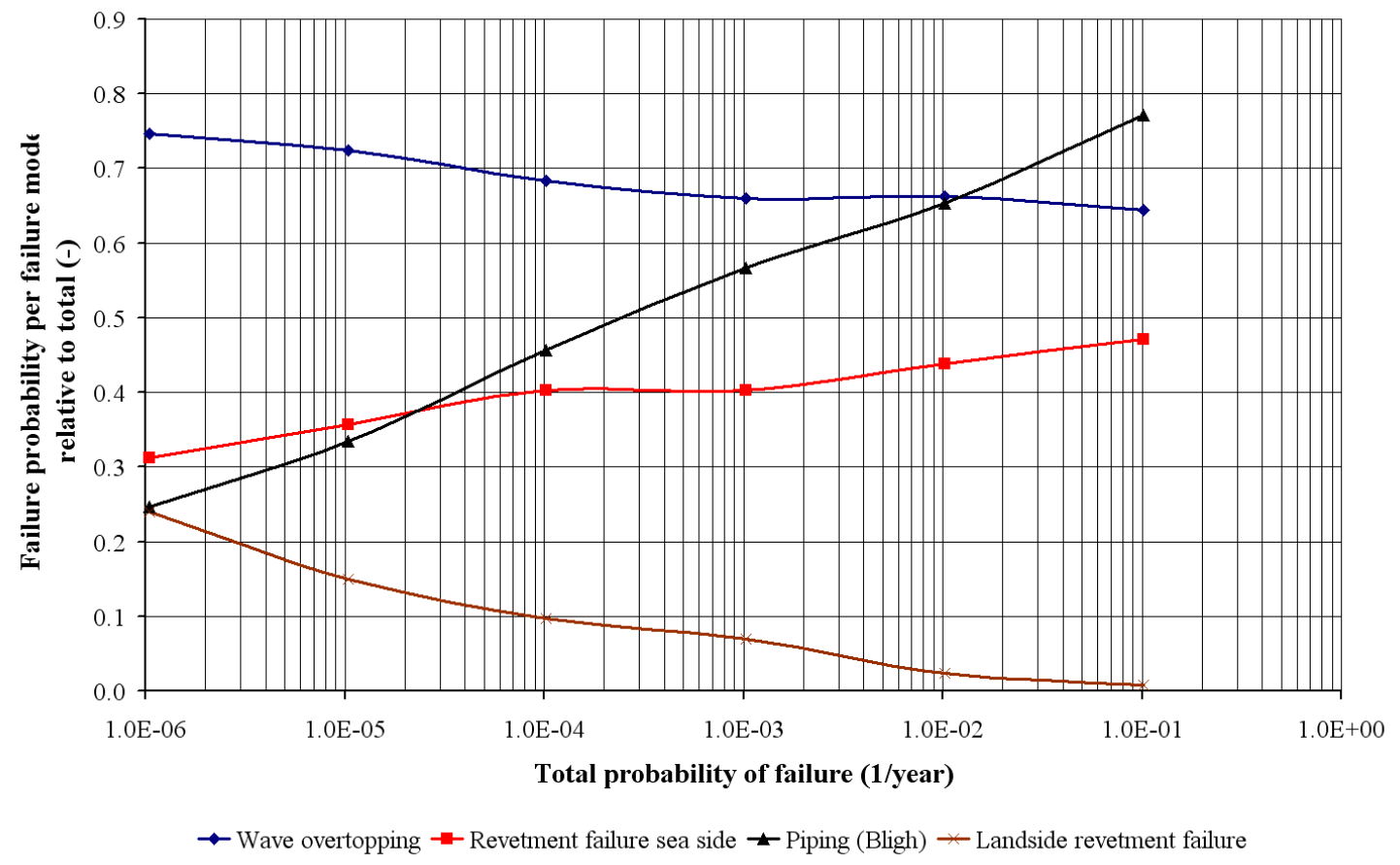

Figure 98: Relative probability of failure per failure mode as a function of total probability of failure (case 1, Ommelander)

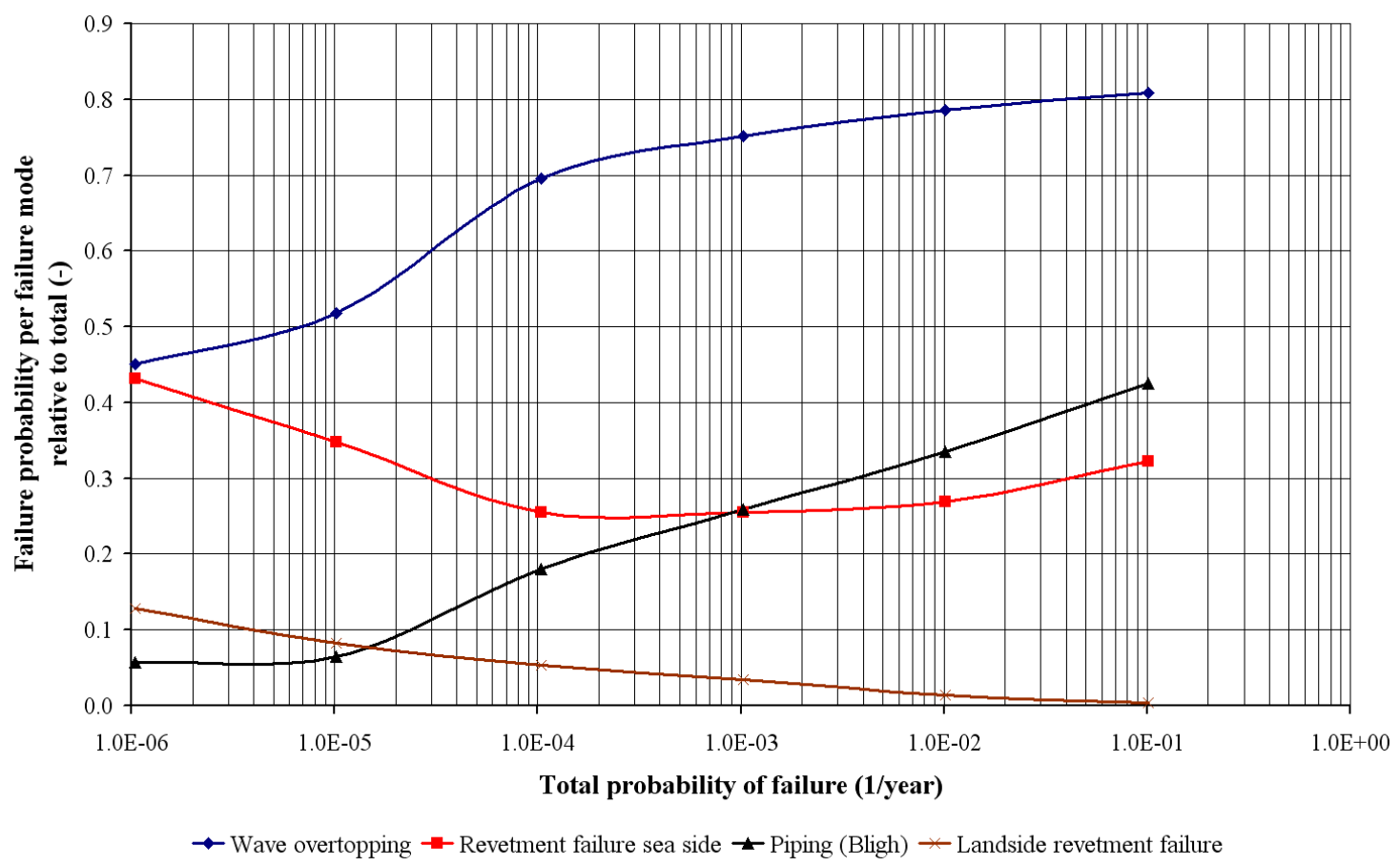

Figure 99: Relative probability of failure per failure mode as a function of total failure probability (case 1, Eemshaven)

Failure of the dike section is described by a series system of the four failure modes. Because of dependence between the failure modes, the sum of the relative failure probabilities per section is higher than one (see chapter 3 for details). For both sections the failure modes wave overtopping, sea side revetment failure and piping get the highest failure probabilities. The probability of failure of the land side revetment is generally negligible. For high values of the total failure probability, piping is 
dominant for the location Ommelander. For both sections, the relative probability of piping failure decreases with decreasing total failure probability.

Overtopping failure dominates for low total failure probabilities at Ommelander and over the full range of failure probabilities at Eemshaven. For high total failure probabilities at Ommelander, piping dominates over overtopping. For low total failure probability at Eemshaven, the probability of sea side revetment failure is of the same order as the probability of overtopping.

The differences in relative failure probability between the locations Ommelander and Eemshaven indicate that Eemshaven is more sensitive to wave attack than Ommelander. This is indicated by higher relative failure probabilities for failure modes that are sensitive to the local wave conditions.

The failure probability relative to the total failure probability provides some insight in the failure modes that determine the probability of failure of the structure. A better measure for the importance of a failure mode is the normalised gradient of the system reliability index to the reliability index of the failure mode (annex 2). This is a measure for the extent to which changes in the reliability index of a failure mode are reflected in the overall reliability index. The measure is denoted the "failure mode sensitivity"19. The possible values of the failure modes sensitivity are from 0 (no influence) to 1 (every change fully reflected in overall reliability). Figures 100 and 101 show the failure mode sensitivity for the locations Ommelander and Eems harbour.

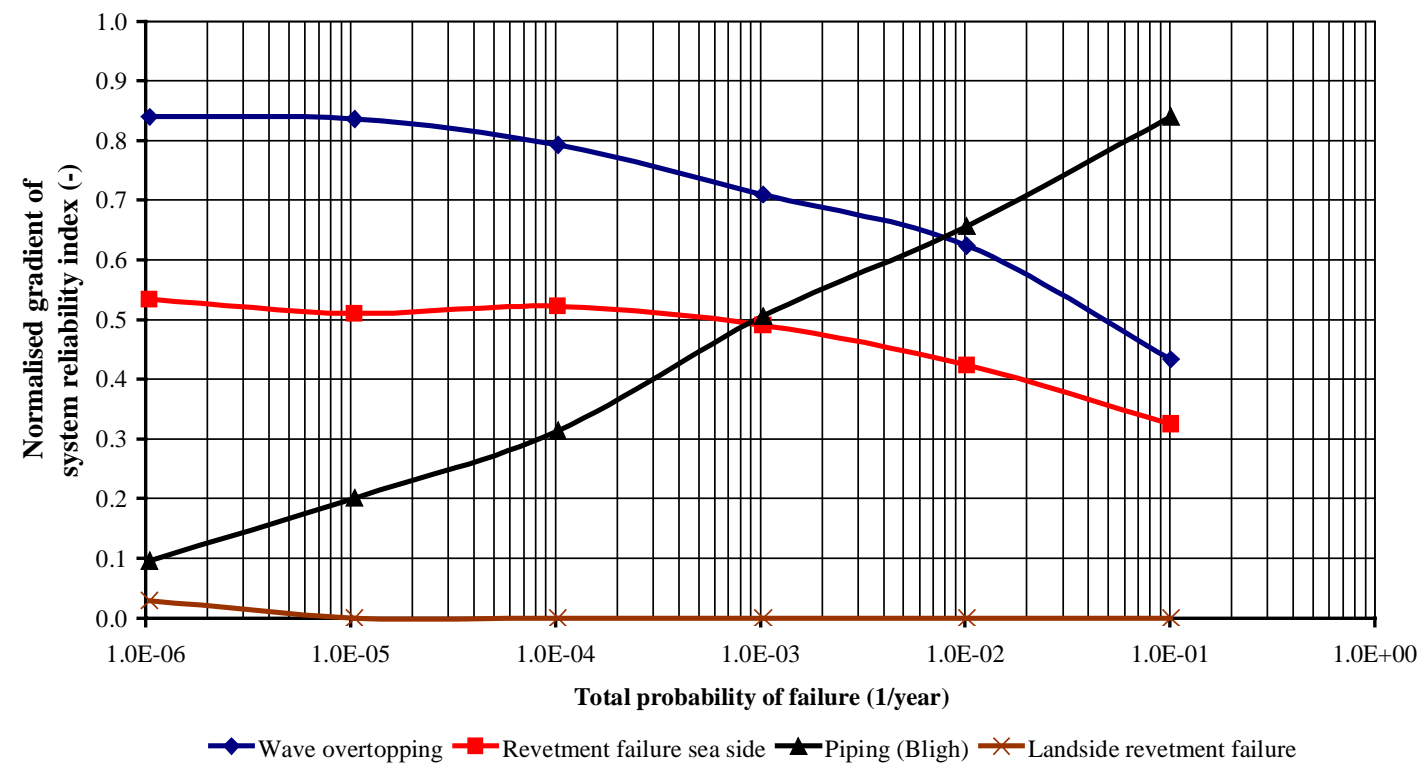

Figure 100: Normalised failure mode sensitivity (Ommelander, case 1)

\footnotetext{
${ }^{19}$ The measure is comparable to the well-known influence factors ( $\alpha$-factors) resulting from a level II reliability analysis of one failure mode.
} 


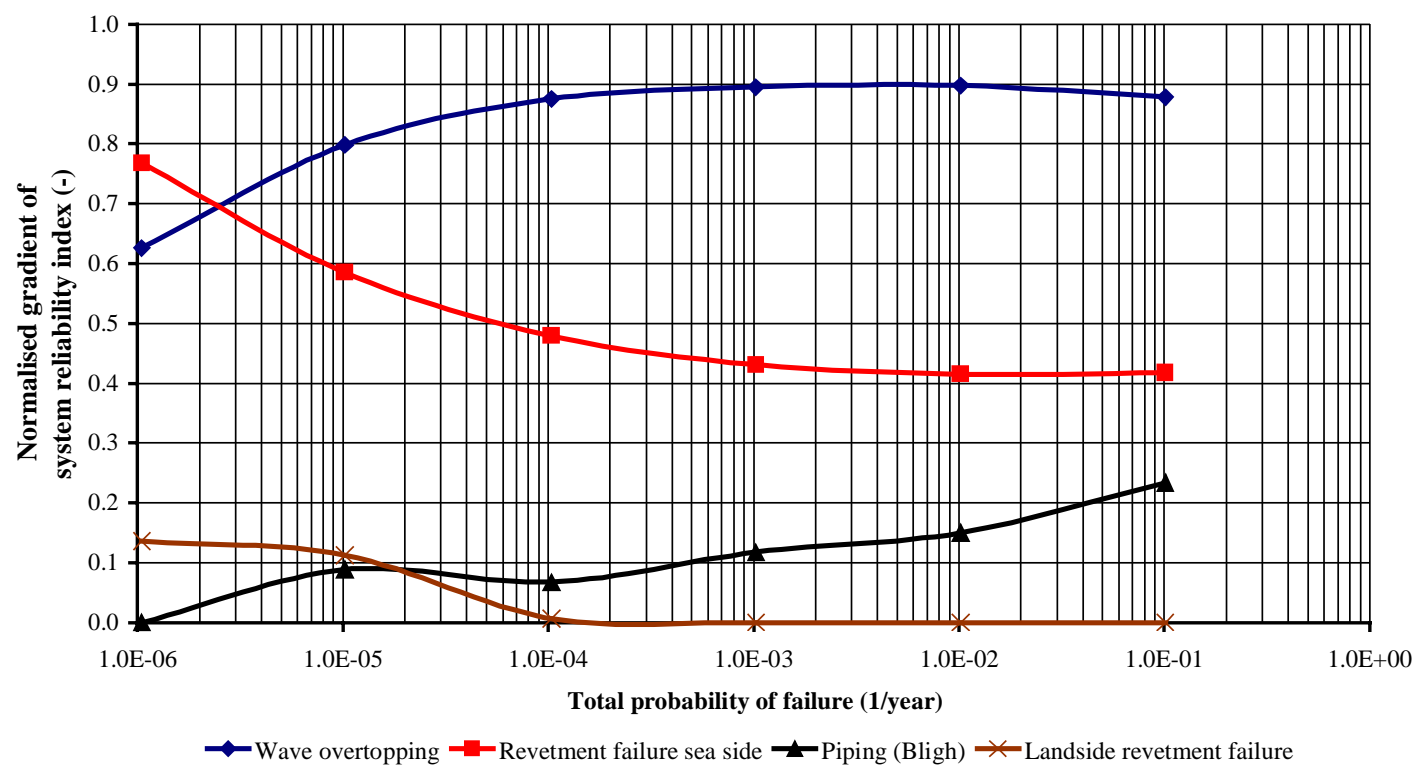

Figure 101: Normalised failure mode sensitivity (Eems harbour, case 1)

At the location Ommelander, the reliability of the structure is dominated by wave overtopping if the failure probability is below $10^{-2}$ per year. For higher failure probabilities, piping has major influence and even dominates over wave overtopping. The influence of piping decreases rapidly for decreasing failure probability. The influence of sea side revetment failure increases for decreasing failure probability up to a total failure probability of $10^{-3}$ per year and is then virtually constant. The influence of land side revetment failure is negligible in all cases.

At the location Eems harbour, wave overtopping dominates over a major part of the total failure probabilities. Sea side revetment failure has considerable influence and dominates if the total failure probability equals $10^{-6}$ per year. Piping and landside revetment failure show little influence compared to the other two failure modes. The result shows that the reliability of section Eems harbour is dominated by failure modes that are sensitive to the local wave conditions.

The optimisation procedure used for reliability-based optimisation provides estimates of the sensitivity of cost and reliability to changes in the design variables (see annex 2 ). The sensitivities are given as normalised gradients and are denoted "design variable sensitivity". A design variable sensitivity of 1 indicates maximum influence on the variable considered and a design variable sensitivity of 0 indicates no influence. Figures 102 and 103 show the design variable sensitivity of the direct cost of the structure. The sensitivity of the reliability of the structure to the design variables is shown in figures 104 and 105. 


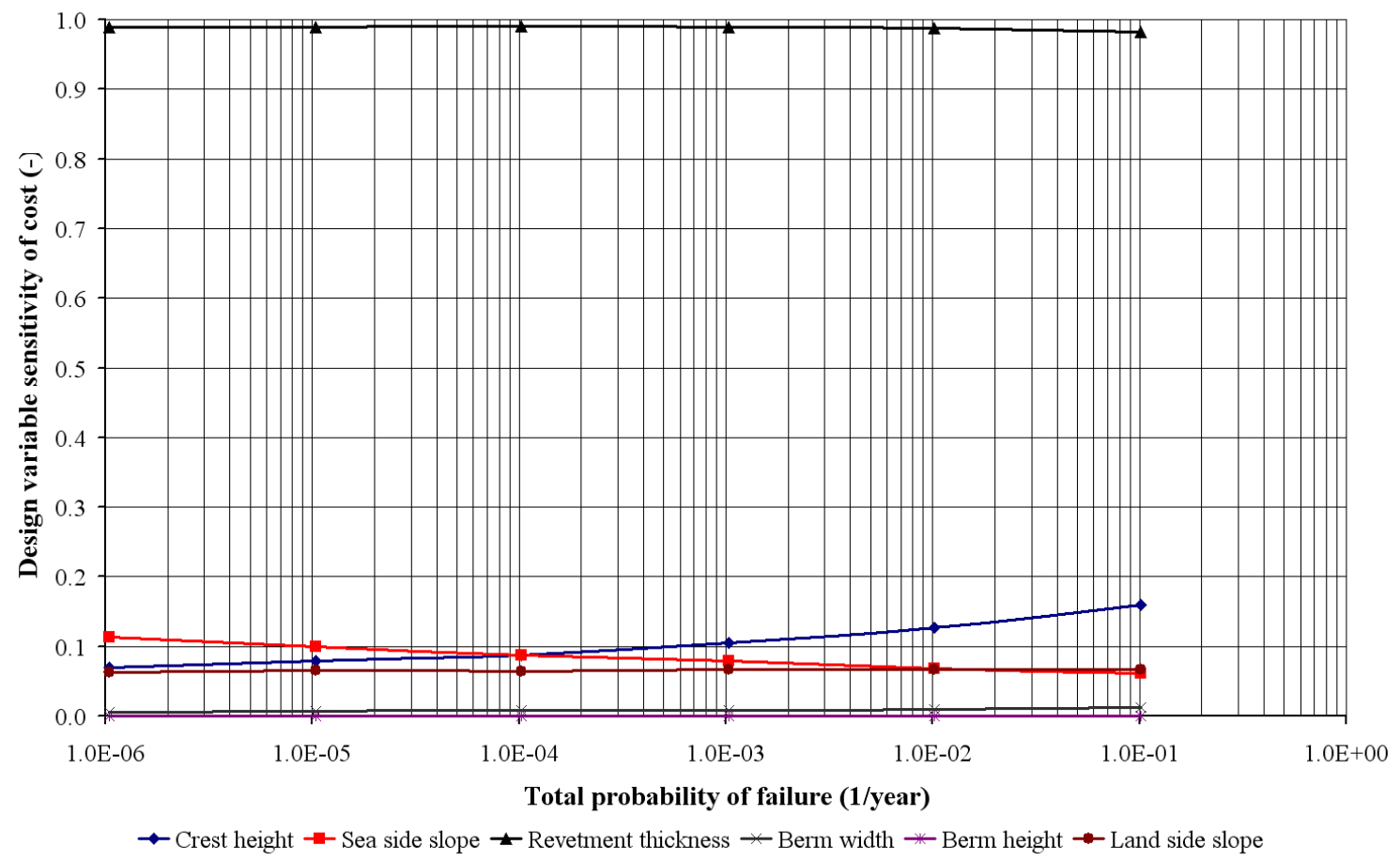

Figure 102: Design variable sensitivity of direct cost (Ommelander, case 1)

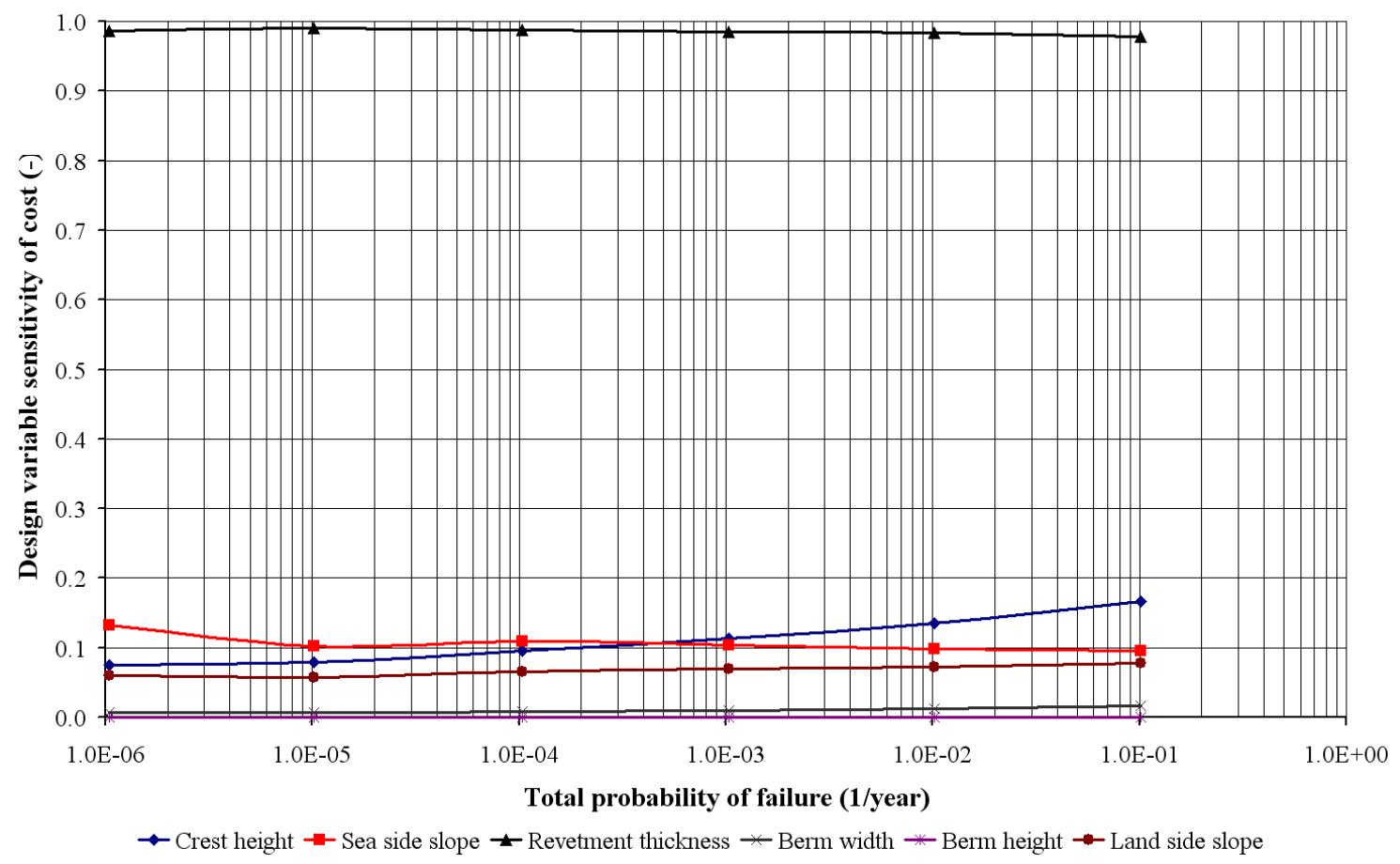

Figure 103: Design variable sensitivity of direct cost (Eems harbour, case 1) 


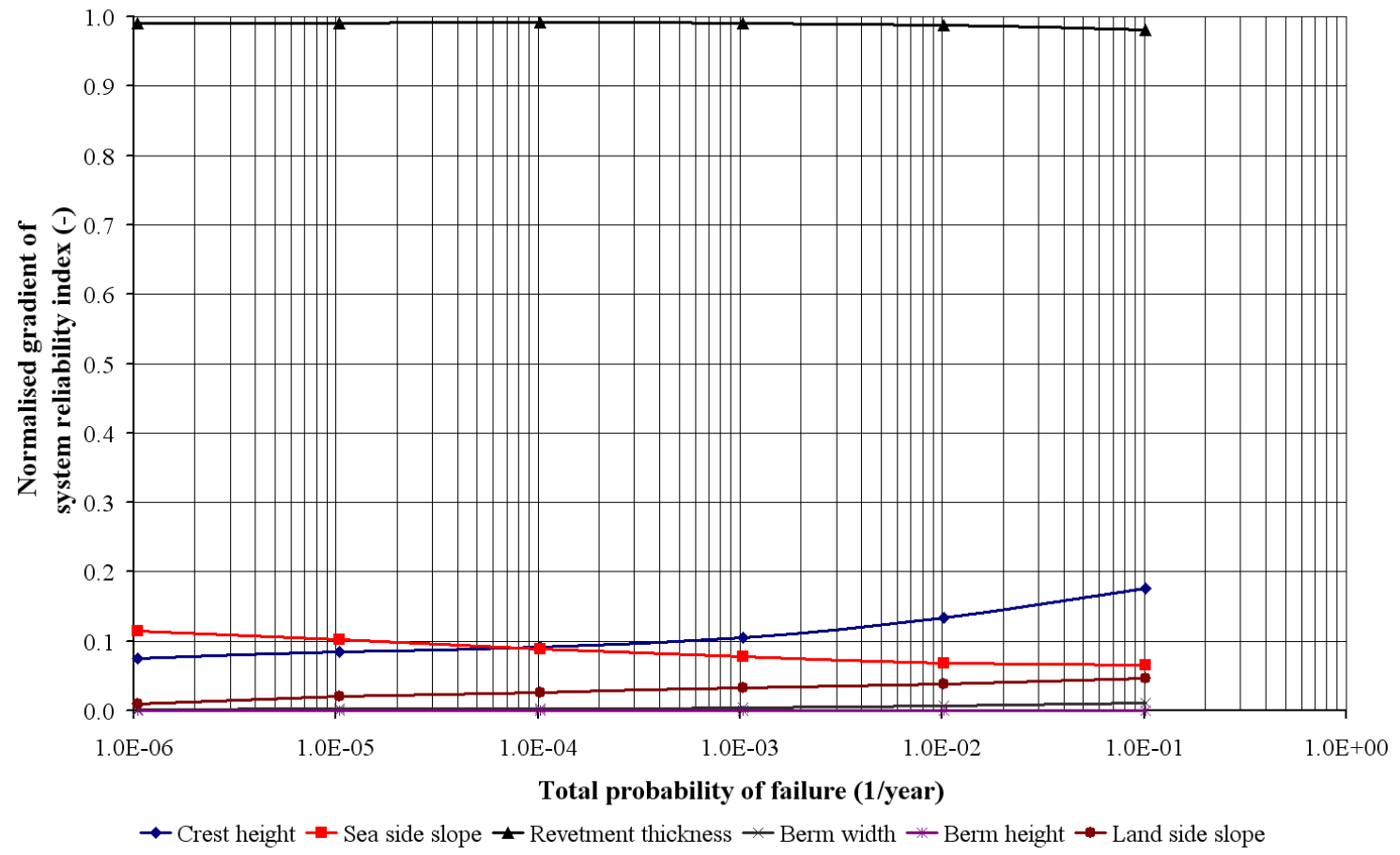

Figure 104: Design variable sensitivity of section reliability (Ommelander, case 1)

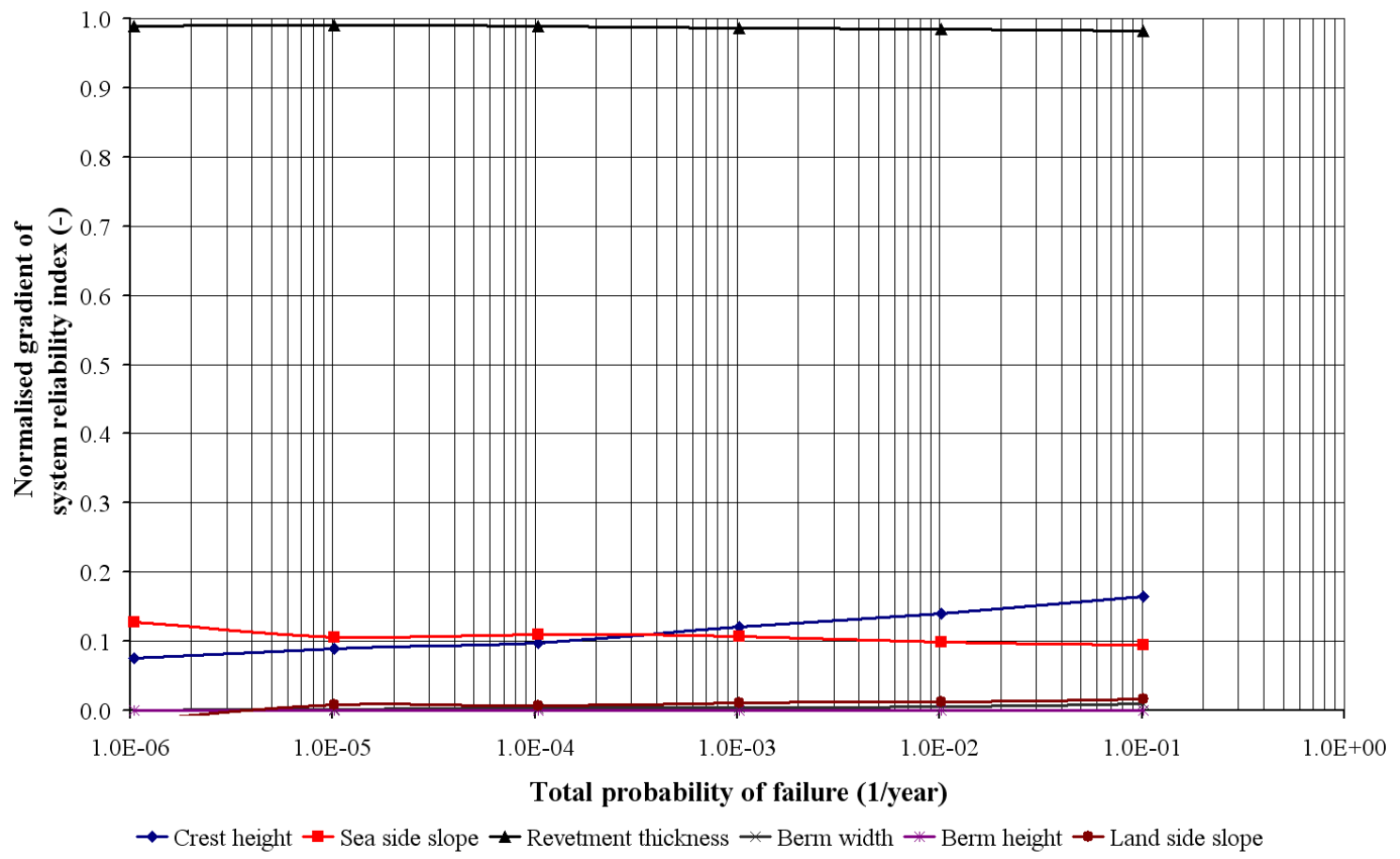

Figure 105: Design variable sensitivity of section reliability (Eems harbour, case 1)

The cost and reliability of the optimal design are heavily dependent on the revetment size. The berm geometry has negligible influence. Crest level and sea side slope take an intermediate position with regard to the influence on the cost and reliability of the optimal design.

The normalised design variable sensitivities of cost and reliability of a single flood defence structure are of the same order of magnitude. This can be explained by analysing the properties of the minimum of the augmented cost function (chapter 3 ). A minimum of an $\mathrm{N}$-dimensional function is always found in a stationary point, where all partial derivatives of the function are zero. 
The gradient of the augmented investment function is given by:

$$
\nabla F(\mathbf{z})=\nabla I(\mathbf{z})-2 \lambda \max \left[\begin{array}{c}
\left(\beta_{\min }-\beta(\mathbf{z})\right) \\
0
\end{array}\right] \nabla \beta(\mathbf{z})
$$

Where:

z: $\quad$ Vector of design variables;

I: $\quad$ Direct cost of dike section;

$\lambda$ : $\quad$ Penalty parameter;

$\beta: \quad$ Reliability index;

$\beta_{\text {min }}$ : Minimum reliability index.

Considering that a minimum of $F$ is found in a stationary point, the following relation holds for the minimum:

$$
\nabla F(\mathbf{z})=\mathbf{0} \Leftrightarrow \nabla I(\mathbf{z})=2 \lambda \max \left[\begin{array}{c}
\left(\beta_{\min }-\beta(\mathbf{z})\right) \\
0
\end{array}\right] \nabla \beta(\mathbf{z})
$$

Equation (115) is valid if there is only one constraint present. The value of $2 \lambda \max \left[\begin{array}{c}\left(\beta_{\min }-\beta(\mathbf{z})\right) \\ 0\end{array}\right]$ for the optimal design is determined by the termination criterion and can therefore be considered a constant. Therefore, the sensitivities for cost and reliability for one design variable differ only by a constant factor. Normalising the gradients cancels out the influence of the constant and results in equal normalised sensitivities for cost and reliability index.

Practically, the result indicates that in an optimised design, the variables with a strong influence on the construction cost also have a strong influence on the reliability of the structure. As a general rule one could say that influence on the reliability should be allocated to the most expensive variables.

The sensitivity of the total reliability of the structure to the uncertainty in the stochastic input variables is presented by the influence factors that result from the level II probabilistic calculation for the optimal design. Not every variable is presented separately. Instead, the sensitivities have been bundled in the following five groups:

- Uncertainty of the wind speed (inherent and statistical);

- Model uncertainties of the wind effects;

- Astronomic tide;

- Model uncertainties of the limit state functions;

- Uncertainties of the strength of the structure, like revetment density, Bligh factor and thickness of landside clay cover.

Figure 106 shows the results for the location Ommelander sea dike. 


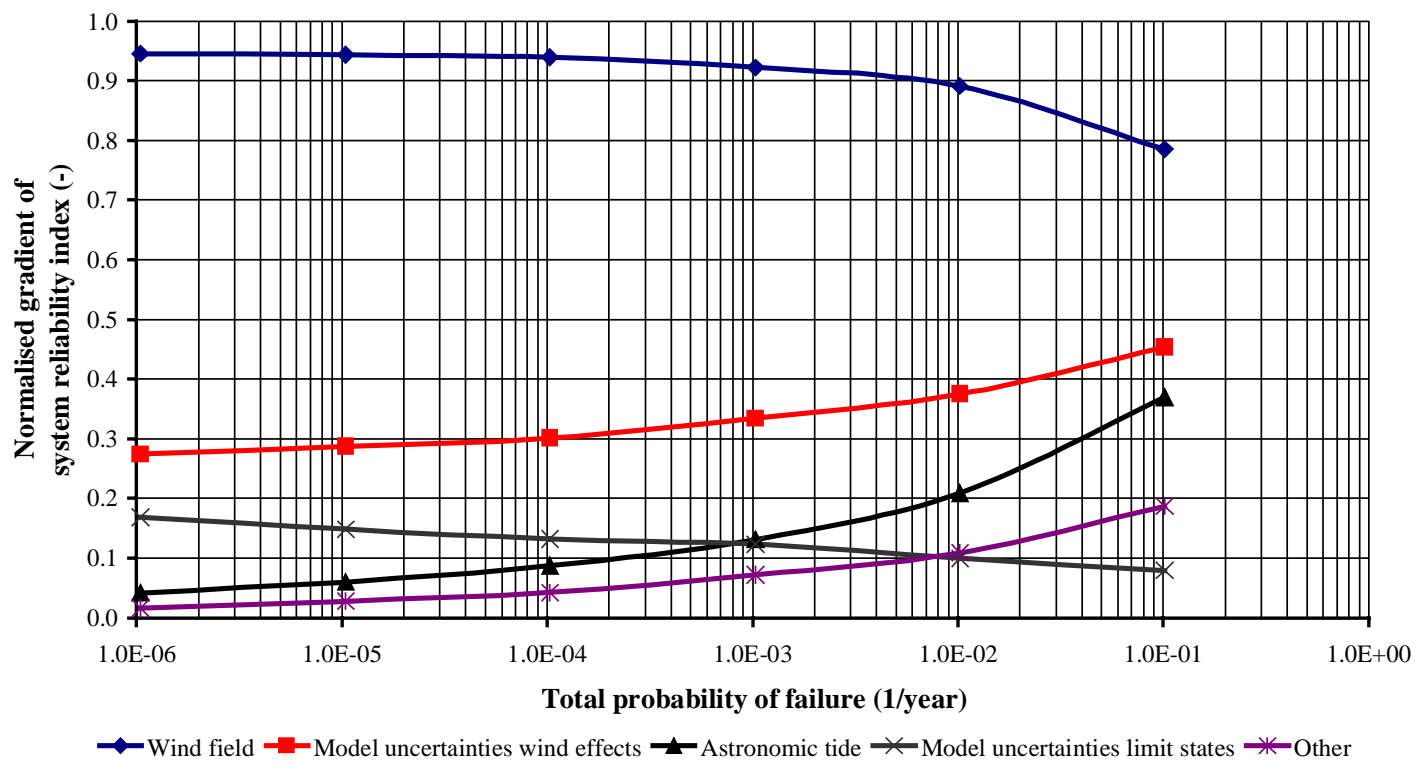

Figure 106: Grouped normalised gradients of the reliability of the structure with respect to the stochastic model input (Ommelander, case 1)

The reliability of the structure at Ommelander is dominated by uncertainties on the wind speed and uncertainties on the hydraulic model translating wind to hydraulic wind effects. The influence of the astronomic tide on the reliability decreases as the total probability of failure decreases and is negligible in most cases. The model uncertainties of the limit state functions show increasing influence with decreasing failure probability. For most failure probabilities the influence of uncertainties on the limit state functions is higher than the influence of the astronomic tide and the uncertainties in strength of the structure. Overall, the reliability is dominated by wind field, wind effect and limit state uncertainty while the influence of the uncertainty on the resistance of the structure is negligible.

Figure 107 shows the results for location Eems harbour.

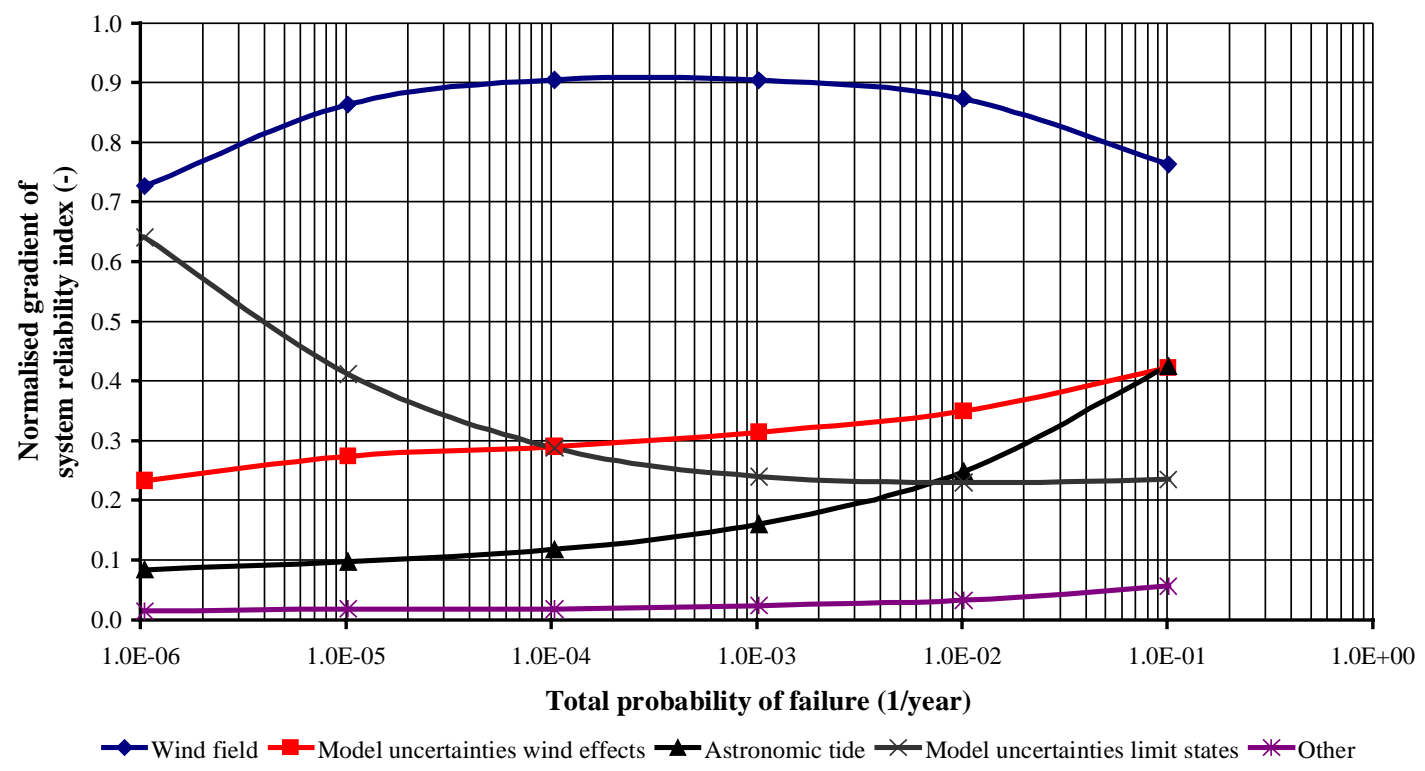

Figure 107: Grouped normalised gradients of the reliability of the structure with respect to the stochastic model input (Eems harbour, case 1) 
Also at Eems harbour, the uncertainties of the wind field dominate the reliability of the structure. Contrary to Ommelander, the effect of limit state uncertainties is higher than the effect of the uncertainties of the hydraulic model if the failure probability is lower than $10^{-4}$ per year. At Eems harbour, like Ommelander, the uncertainties on the resistance of the structure have negligible influence on the reliability of the optimally designed structure.

\subsubsection{Design for the TAW failure probability requirement using only uncertainty on the local water level (case 2)}

In the reference case, a stochastic model including estimates of all uncertainties is used. The failure probability requirement is set on the top event "water enters the area". In current practice, uncertainties other than those related to the local water level are not explicitly taken into account. Furthermore, based on a recommendation by TAW (1985, 1989, 1998), failure probability requirements are given on the level of individual failure modes (equation (113)). In case 2, reliability-based design is performed based on these two fundamentals of current practice. To that end, only the uncertainties influencing the local water level are quantified. All other parameters are set to their expected values. The probability requirement is set in the form recommended by TAW (equation (113)). The optimisation is performed for failure probabilities ranging from $10^{-1}$ per year to $10^{-6}$ per year. Figure 108 shows the geometry of the dike at location Ommelander for case 2 in comparison to the reference case. Figure 109 shows the same result for the location Eems harbour.

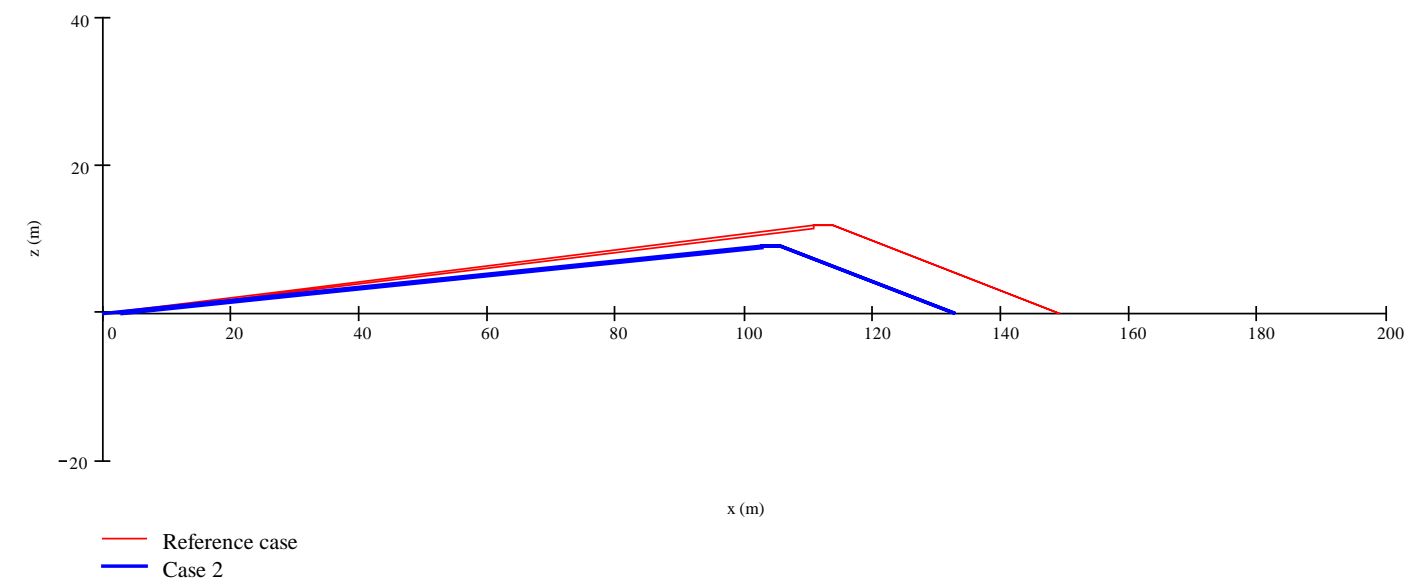

Figure 108: Cross sections of the dike at Ommelander for a failure probability of $10^{-4}$ per year

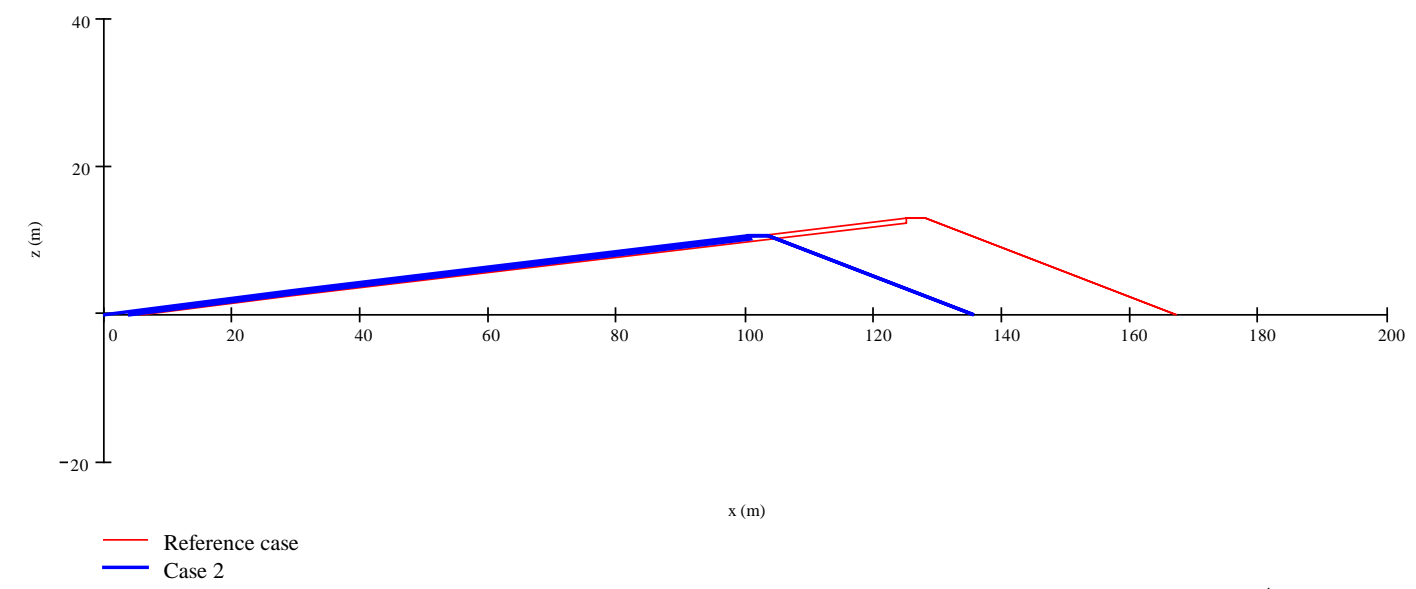

Figure 109: Cross sections of the dike at Eems harbour east for a failure probability of $10^{-4}$ per year 
As expected, neglecting all but the uncertainty on the local water level leads to smaller cross sections in comparison to the reference case. Tables 45 and 46 show the optimisation output.

For a given geometry, the failure probability can be quantified by performing reliability analysis using the full stochastic model. This failure probability is included in tables 45 and 46 for comparison. The land side slope equals the constraint of 1:3 in all cases and is not included in the tables. A sea side berm is not present in any of the optimised profiles.

Table 45: Geometry resulting from optimisation (Ommelander sea dike, case 2)

\begin{tabular}{lllll}
\hline $\begin{array}{l}\text { Failure prob. norm } \\
(\mathbf{1} / \text { year) }\end{array}$ & $\begin{array}{l}\text { Failure prob. full } \\
\text { stochastic model }(\mathbf{1} / \text { year })\end{array}$ & $\begin{array}{l}\text { Crest height } \\
(\mathbf{C D}+\mathbf{m})\end{array}$ & $\begin{array}{l}\text { Sea side } \\
\text { slope }(-)\end{array}$ & $\begin{array}{l}\text { Revetment } \\
\text { thickness }(\mathbf{m})\end{array}$ \\
\hline $10^{-1}$ & $1.1 \cdot 10^{-1}$ & 4.2 & 14.2 & 0.10 \\
$10^{-2}$ & $1.7 \cdot 10^{-2}$ & 5.7 & 12.8 & 0.15 \\
$10^{-3}$ & $3.5 \cdot 10^{-3}$ & 7.3 & 11.9 & 0.20 \\
$10^{-4}$ & $7.8 \cdot 10^{-4}$ & 9.1 & 11.3 & 0.26 \\
$10^{-5}$ & $2.0 \cdot 10^{-4}$ & 11.0 & 10.8 & 0.33 \\
$10^{-6}$ & $5.9 \cdot 10^{-5}$ & 13.0 & 10.4 & 0.40 \\
\hline
\end{tabular}

Table 46: Geometry resulting from optimisation (Eems harbour, case 2)

\begin{tabular}{lllll}
\hline $\begin{array}{l}\text { Failure prob. norm } \\
\text { (1/year) }\end{array}$ & $\begin{array}{l}\text { Failure prob. full } \\
\text { stochastic model (1/year) }\end{array}$ & $\begin{array}{l}\text { Crest height } \\
(\mathbf{C D}+\mathbf{m})\end{array}$ & $\begin{array}{l}\text { Sea side } \\
\text { slope }(-)\end{array}$ & $\begin{array}{l}\text { Revetment } \\
\text { thickness }(\mathbf{m})\end{array}$ \\
\hline $10^{-1}$ & $1.5 \cdot 10^{-1}$ & 5.2 & 11.4 & 0.22 \\
$10^{-2}$ & $3.4 \cdot 10^{-2}$ & 6.9 & 10.4 & 0.29 \\
$10^{-3}$ & $9.1 \cdot 10^{-3}$ & 8.7 & 9.8 & 0.36 \\
$10^{-4}$ & $2.6 \cdot 10^{-3}$ & 10.7 & 9.4 & 0.43 \\
$10^{-5}$ & $7.5 \cdot 10^{-4}$ & 12.8 & 9.1 & 0.51 \\
$10^{-6}$ & $2.2 \cdot 10^{-4}$ & 14.9 & 9.0 & 0.59 \\
\hline
\end{tabular}

Figure 110 shows the probability of failure according to the full model as a function of the required maximum probability of overtopping.

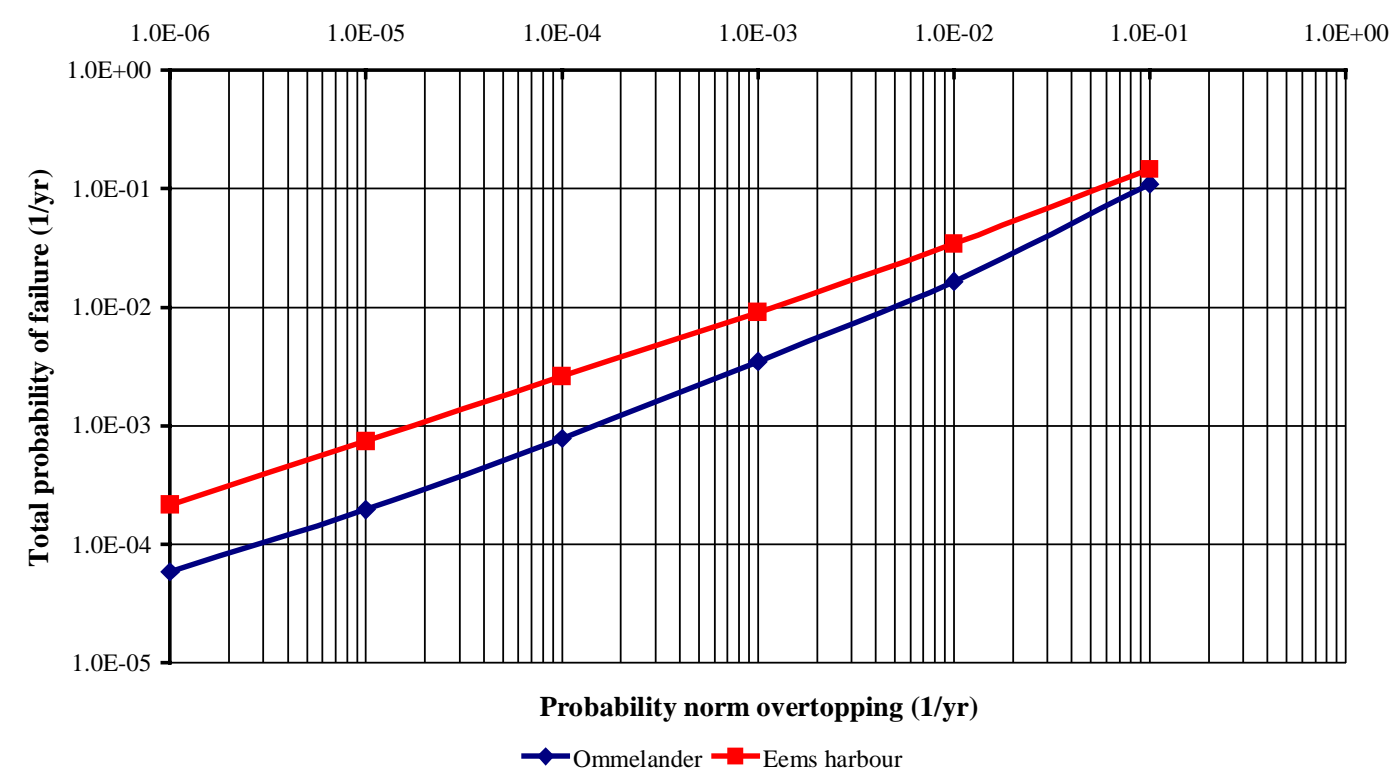

Figure 110: Total failure probability of the dike using the full stochastic model as a function of failure probability norm (case 2) 
Dependent upon the location and the failure probability requirement for overtopping, the actual failure probability of the flood defence structure may be up to two orders of magnitude higher than the overtopping norm. The result illustrates why a stochastic model only including water level uncertainty is insufficient to accurately quantify the failure probability of a coastal flood defence structure.

Despite the fact that the structures at the two locations are designed for the same norm, their performance measured in failure probability differs considerably. For the same requirement, location Eems harbour shows a higher failure probability than location Ommelander. The reason for this is most probably that the uncertainties on the wave conditions are more important at Eems harbour and therefore neglecting these uncertainties has the largest effect at this location.

The direct costs of protection as a function of the failure probability can be compared to the result of case 1 . In order to make a fair comparison, the horizontal axis denotes the probability of failure according to the full model.

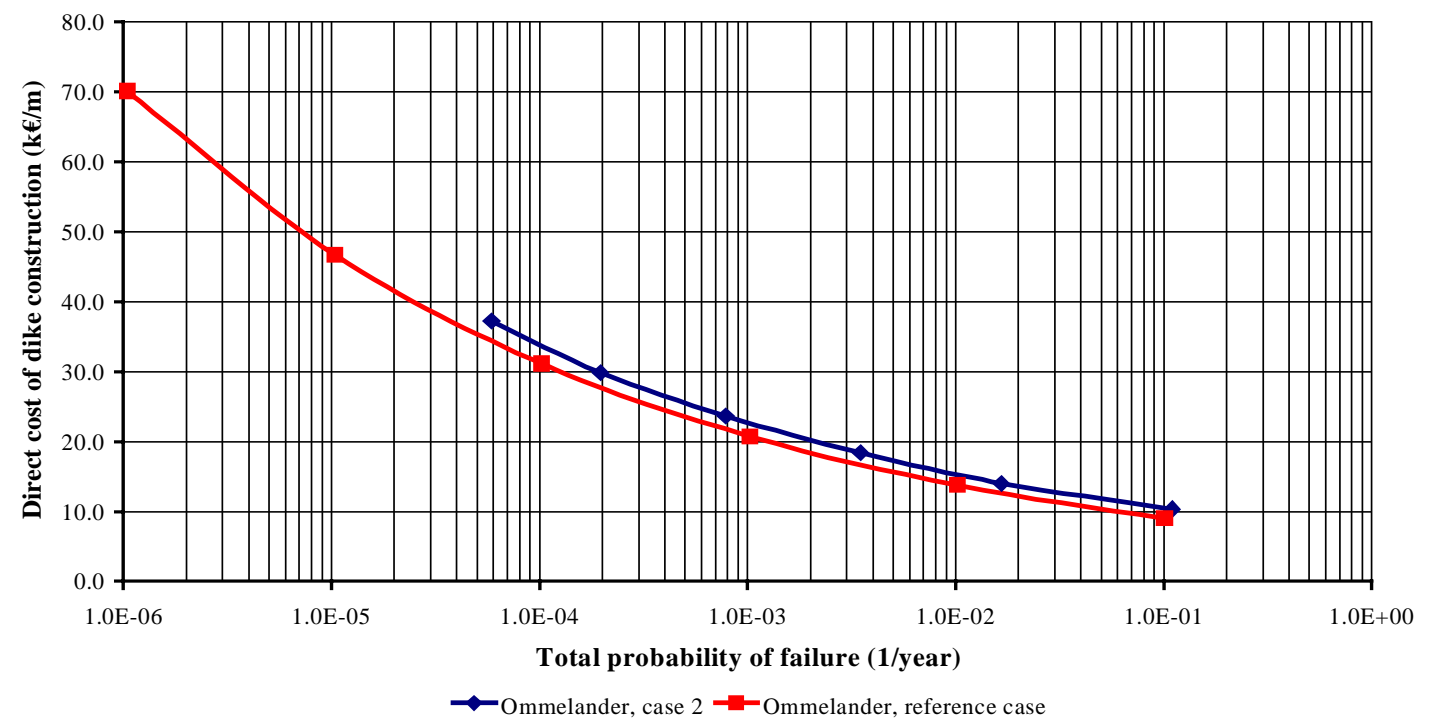

Figure 111: Direct cost of dike construction as a function of failure probability (Ommelander, cases 1 and 2)

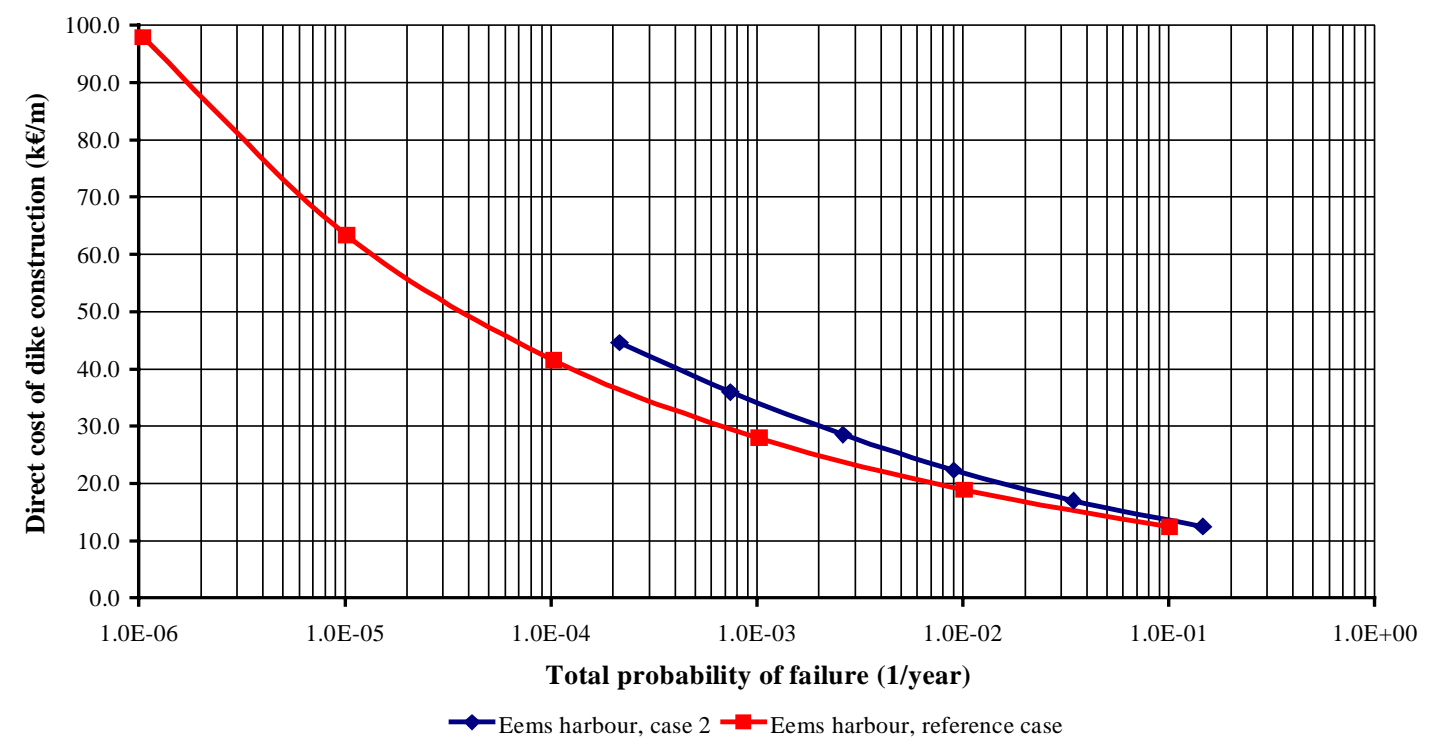

Figure 112: Direct cost of dike construction as a function of failure probability (Eems harbour, cases 1 and 2) 
As indicated before in figure 110, the failure probability range covered by the geometries resulting from case 2 is considerably smaller than the range covered by the geometries resulting from case 1 . For the same probability of failure, the direct costs in case 2 are consistently higher than the costs according to reference case. For the same failure probability, the direct costs derived in case 2 are up to $20 \%$ higher than the cost derived in the reference case.

\subsubsection{Design for the TAW failure probability requirement using the full stochastic model (case 3)}

A failure probability requirement on the level of failure modes can also be combined with the full stochastic model of boundary conditions. In this section, the failure probability requirement based on the TAW-recommendation (equation (113)) will be used in combination with the full stochastic model (see also chapter 6). Figure 113 shows the geometry of the Ommelander sea dike resulting from optimisation for a failure probability of $10^{-4}$ per year using the TAW recommendation in comparison to the geometry resulting from the reference case. Figure 114 shows the same results for location Eems harbour.

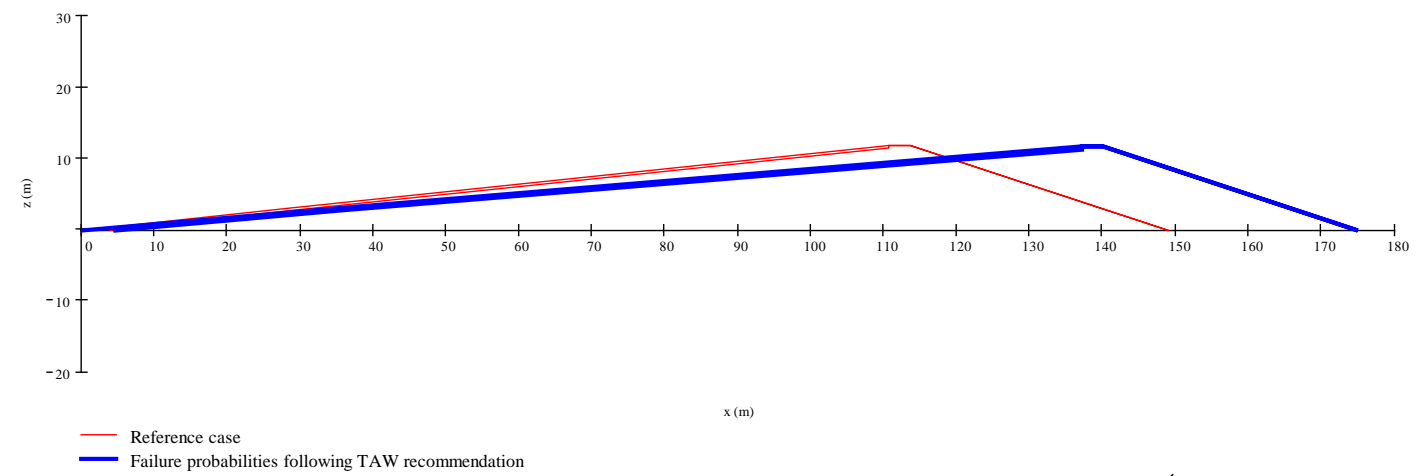

Figure 113: Cross section of the dike at Ommelander for a failure probability of $10^{-4}$ per year

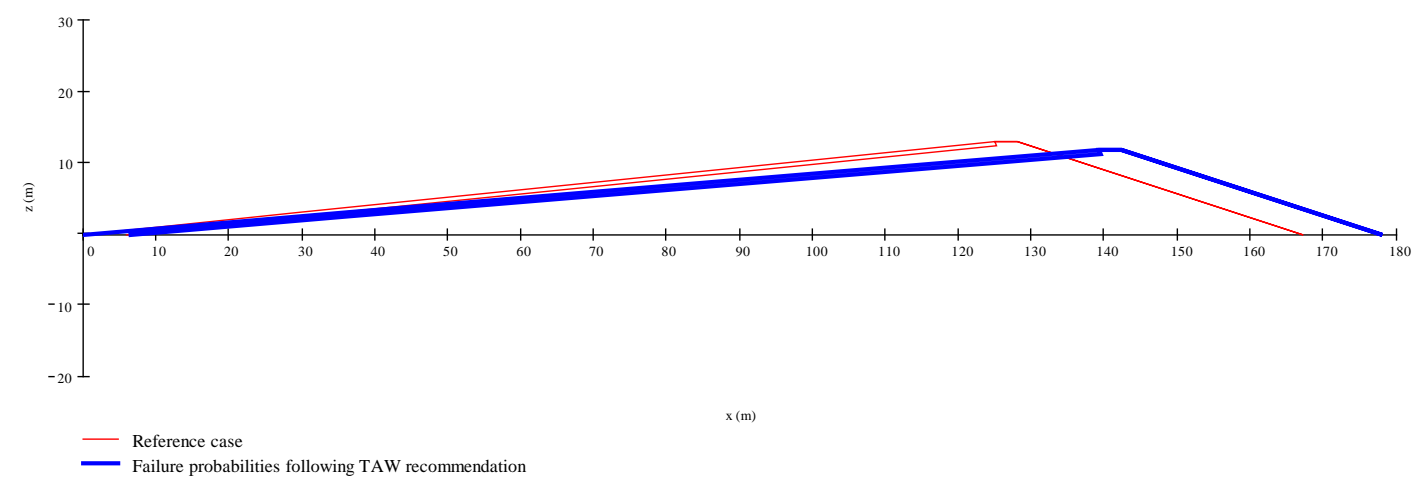

Figure 114: Cross section of the dike at Eems harbour for a failure probability of $10^{-4}$ per year

Table 47 shows the numerical output for the geometries shown in figures 113 and 114. No sea side berm is present in any profile. Therefore, the berm geometry is omitted in the table. The land side slope equals 1:3 in all cases. 
Table 47: Geometry resulting from optimisation for a failure probability norm of $10^{-4}$ per year, cases 1 and 3

\begin{tabular}{llllll}
\hline Section & $\begin{array}{l}\text { Failure prob. } \\
\text { requirement }\end{array}$ & $\begin{array}{l}\text { Total failure } \\
\text { prob. }(\mathbf{1} / \mathbf{y r})\end{array}$ & $\begin{array}{l}\text { Crest height } \\
(\mathbf{C D}+\mathbf{m})\end{array}$ & $\begin{array}{l}\text { Sea side slope } \\
(\mathbf{1 : n})\end{array}$ & $\begin{array}{l}\text { Thickness } \\
\text { revetment }(\mathbf{m})\end{array}$ \\
\hline Ommelander & Optimised & $1.0 \cdot 10^{-4}$ & 11.8 & 9.4 & 0.41 \\
Ommelander & TAW & $5.3 \cdot 10^{-5}$ & 11.6 & 11.8 & 0.39 \\
Eems harbour & Optimised & $1.0 \cdot 10^{-4}$ & 13.0 & 9.6 & 0.62 \\
Eems harbour & TAW & $1.1 \cdot 10^{-4}$ & 11.9 & 11.7 & 0.56 \\
\hline
\end{tabular}

To fulfil the TAW-requirement, the probabilities of occurrence of the failure modes piping, sea side revetment failure and (in some cases) land side revetment failure have to be lowered in comparison to the reference case. This is obtained by a flatter sea side slope. The flatter slope allows for slightly lower crest levels and slightly smaller revetment thickness.

Enforcing a probability norm based on individual failure modes may lead to an optimal geometry for which the total failure probability is lower than the overtopping norm. Figure 115 shows the total failure probability as a function of the norm for the two locations.

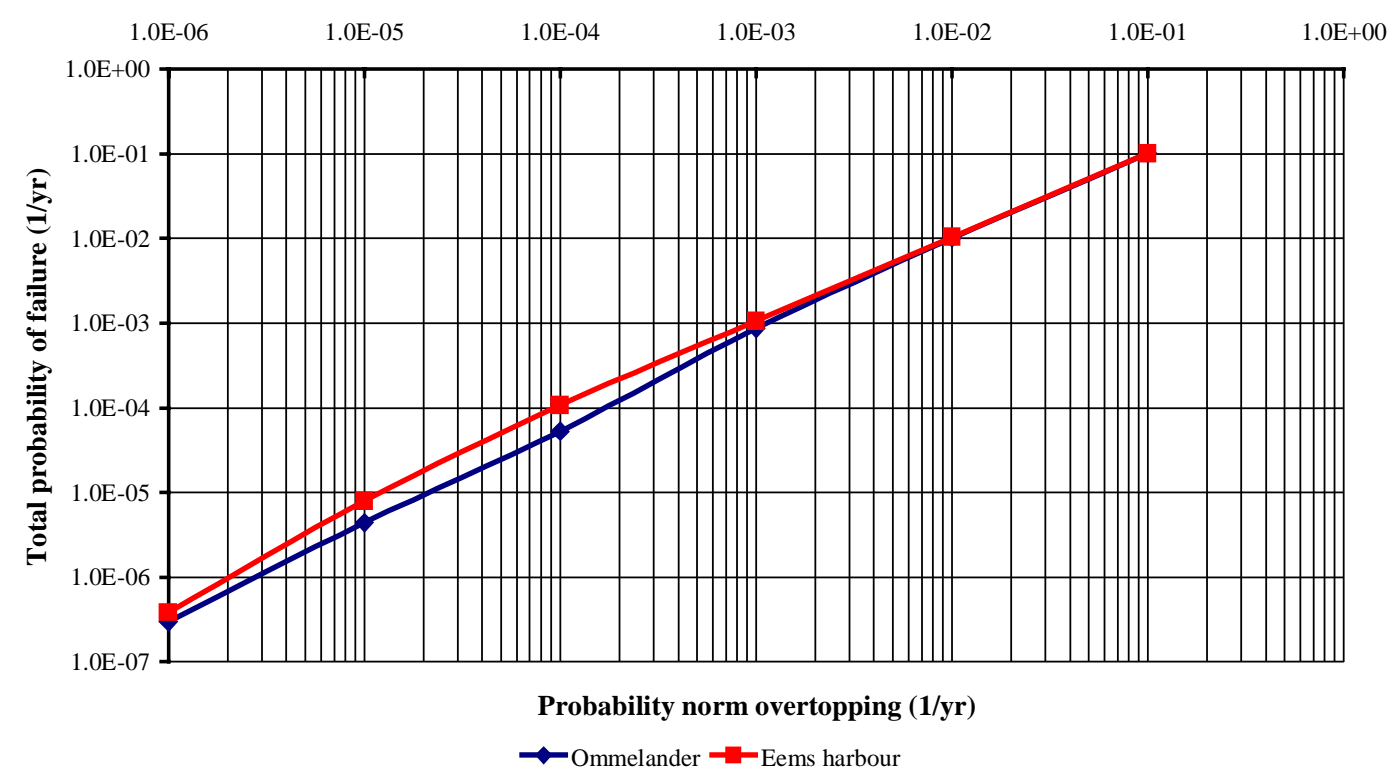

Figure 115: Failure probability of the dike section as a function of the probability norm when applying TAW recommendation and full stochastic model

Because the failure probability requirement is defined per failure mode, a single failure mode can cause profile changes that cause other failure modes to have a failure probability lower than their norm. In some cases, a single failure mode causes the probability of wave overtopping to be lower than its norm, in which case the total failure probability of the structure can be lower than the norm for overtopping. Figure 115 shows that at Ommelander this is the case for an overtopping probability requirement lower than $10^{-3}$ per year ${ }^{20}$. At Eems harbour the effect occurs for an overtopping probability requirement lower than $10^{-5}$ per year.

\footnotetext{
${ }^{20}$ Note that the failure probability requirement for other failure modes than overtopping is always one order of magnitude below the norm for overtopping. A lower norm for overtopping therefore implies a lower norm for all other failure modes.
} 
If the probability of occurrence of an individual failure mode is equal to its probability requirement, the requirement will have influence on the optimal geometry of the structure. Figure 116 shows the probabilities of occurrence per failure mode relative to their own norm for the location Ommelander.

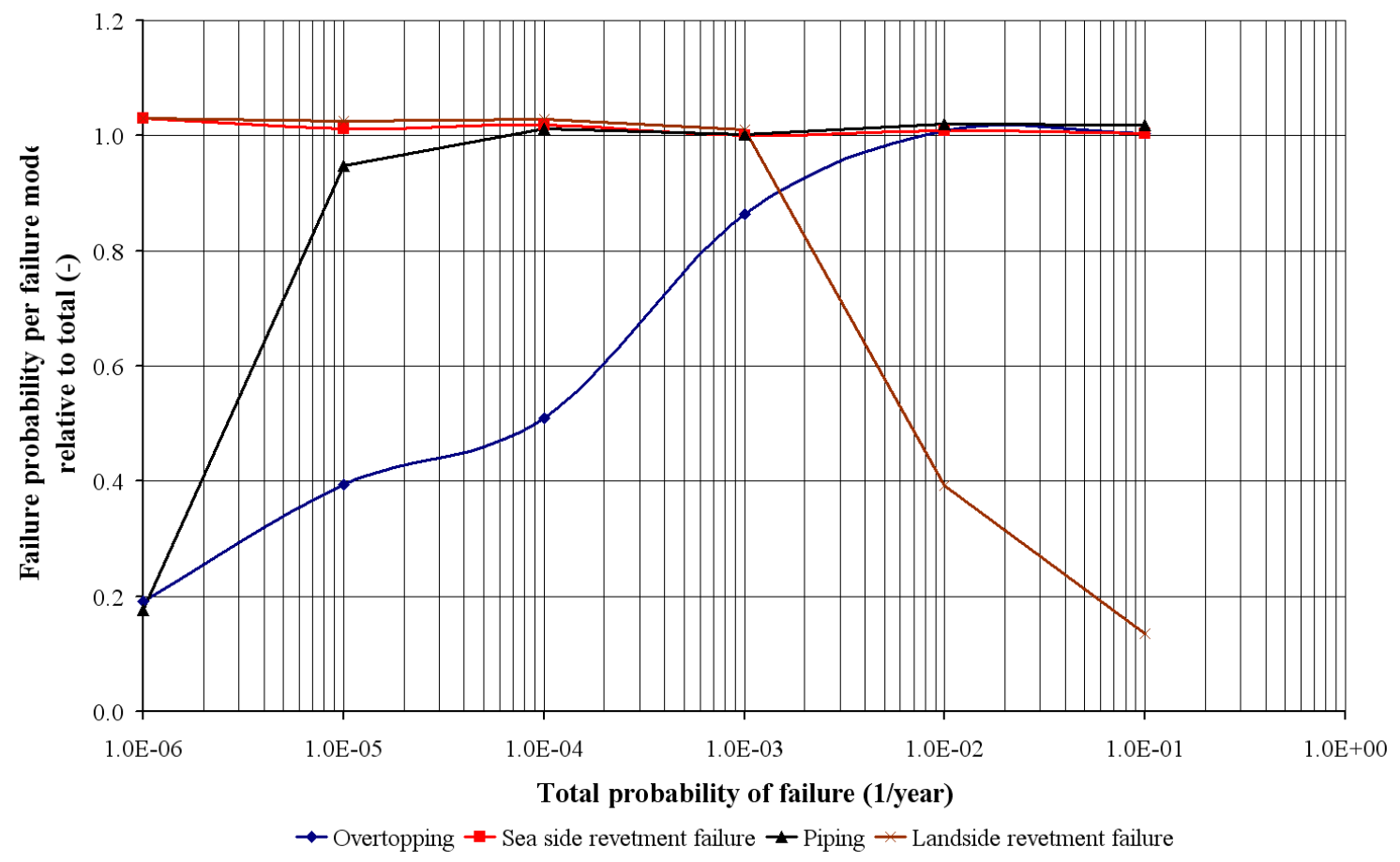

Figure 116: Failure probability per failure mode relative to norm per failure mode at Ommelander

If the probability of occurrence of a failure mode is equal to its norm the probability of occurrence relative to the norm is equal to 1 . Theoretically, values higher than 1 are unacceptable and should therefore not be present in the results. In practice, the failure probabilities relative to the norm are slightly higher than one in a number of cases. This is caused by the applied optimisation technique in which the numerical optimisation procedure uses a finite break-off criterion based on the reliability index (see chapter 3).

At Ommelander, the geometry is decided by wave overtopping, sea side revetment failure and piping if the norm for overtopping is larger than $10^{-2}$ per year. Sea side revetment failure and land side revetment failure determine the geometry if the norm is lower than $10^{-4}$ per year. Between $10^{-2}$ per year and $10^{-4}$ per year, the geometry is determined by the combination of piping, sea side revetment failure and land side revetment failure.

Figure 117 shows the individual failure probabilities per failure mode relative to their norm for the location Eems harbour. 


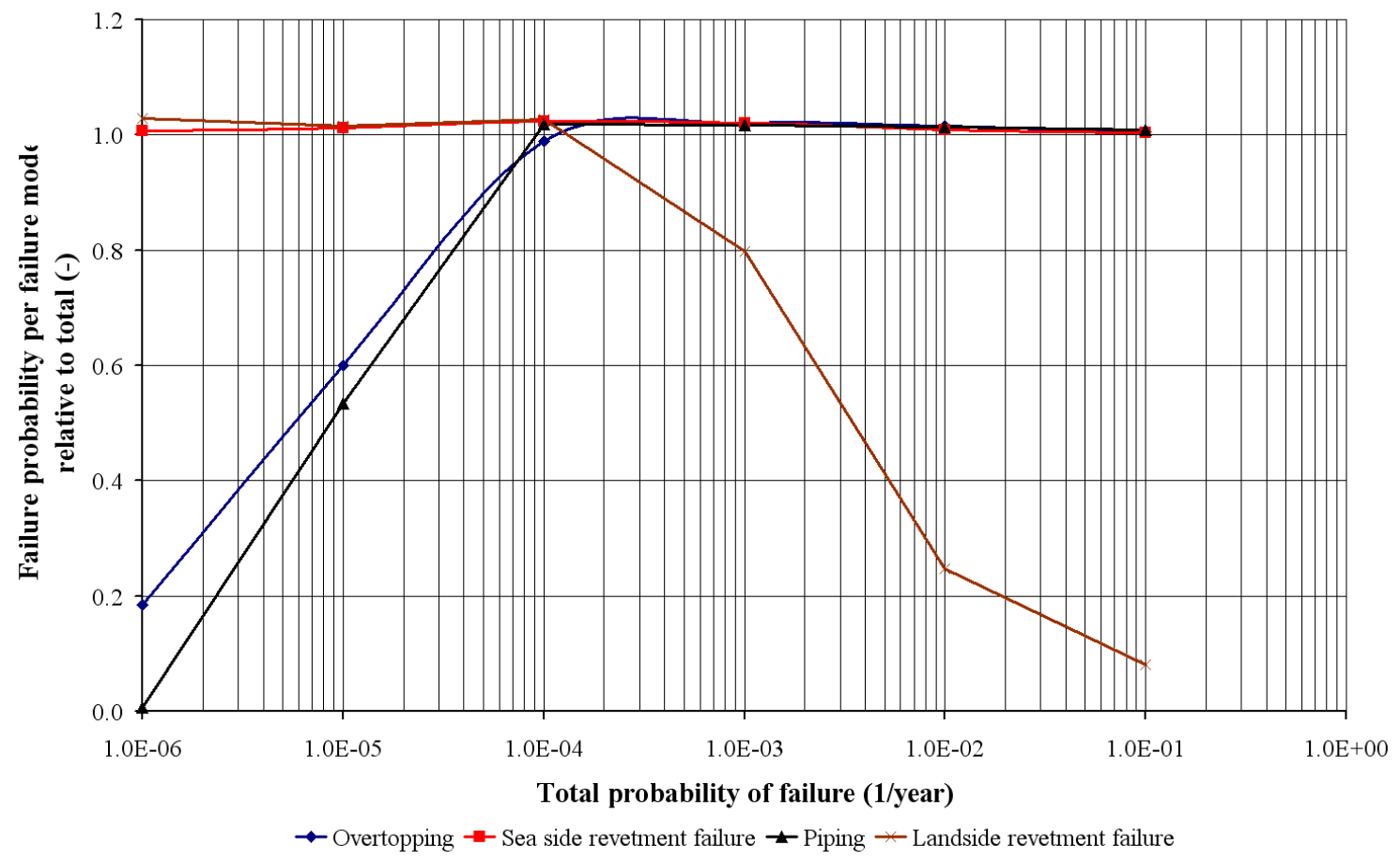

Figure 117: Failure probability per failure mode relative to norm per failure mode at Eems harbour

At Eems harbour, the failure modes wave overtopping, sea side revetment failure and piping have probabilities of occurrence equal to their individual requirements if the probability norm for overtopping is higher than $10^{-4}$ per year. In those cases the geometry is determined by those three failure modes. For lower values of the norm, sea side revetment failure and land side revetment failure get probabilities of occurrence that are equal to the requirement. In those situations, the geometry is determined by those two failure modes.

The effect of enforcing the TAW recommendation on the direct cost of construction is an increase of the construction cost with respect to the reference case. Figures 118 and 119 show the construction costs as a function of calculated failure probability for the locations Ommelander and Eems harbour.

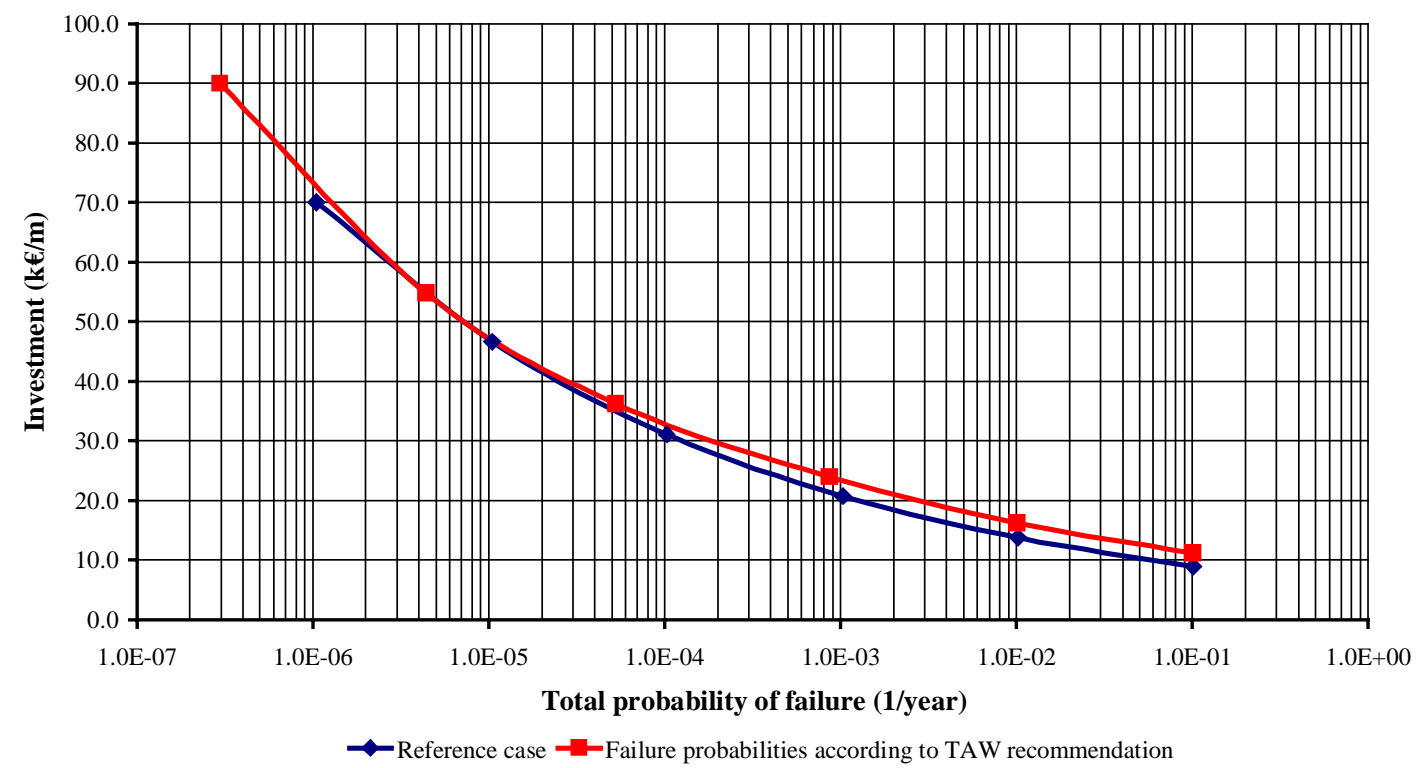

Figure 118: Direct costs as a function of failure probability requirement (Ommelander, cases 1 and 3) 


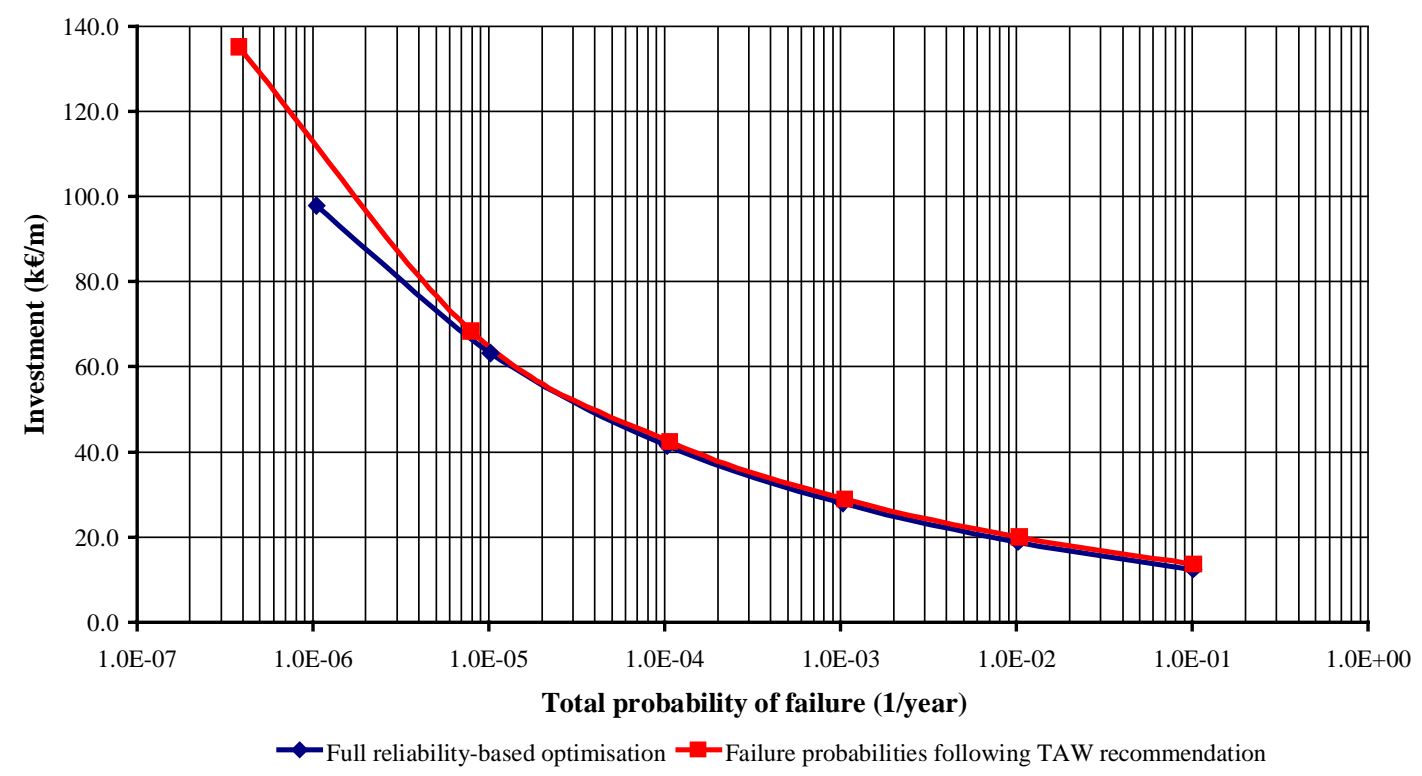

Figure 119: Direct costs as a function of failure probability requirement (Eems harbour, cases 1 and 3)

As indicated before, the failure probability range covered by optimisation with the TAW-norm is somewhat larger than the range covered by the reference case. At Ommelander, application of the TAW-norm leads to a cost increase compared to the reference case of approximately $15 \%$. In case of Eems harbour, the cost increase lies in the range of $2 \%$ to $20 \%$.

\subsubsection{Sensitivity for the cost of land use (cases 4 through 7)}

In a densely populated country like the Netherlands, there is a heavy demand on the available land space. Therefore, land prices may vary from location to location. Reliability-based optimisation provides an excellent tool to account for such locationdependent parameters in the design of the structure. In this section, the design of the flood defences at the locations Ommelander and Eemshaven will be performed for a range of land prices. The results outlined here are the results of cases 4 through 7 in table 42. Figures 120 and 121 show geometries of the dike at Ommelander for a failure probability of $10^{-4}$ per year for different values of the cost of space use. Figures 122 through 123 show the geometries of the dike at Eems harbour for the same conditions.

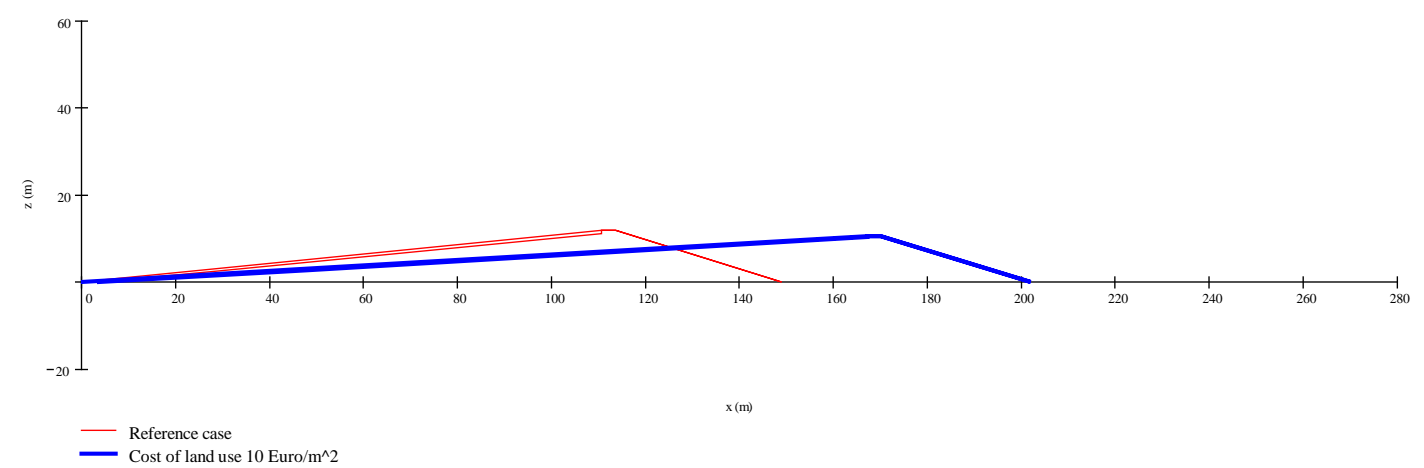

Figure 120: Optimal cross sections of the dike at Ommelander. Low cost of space use compared to reference case (cases 1 and 4 ). 


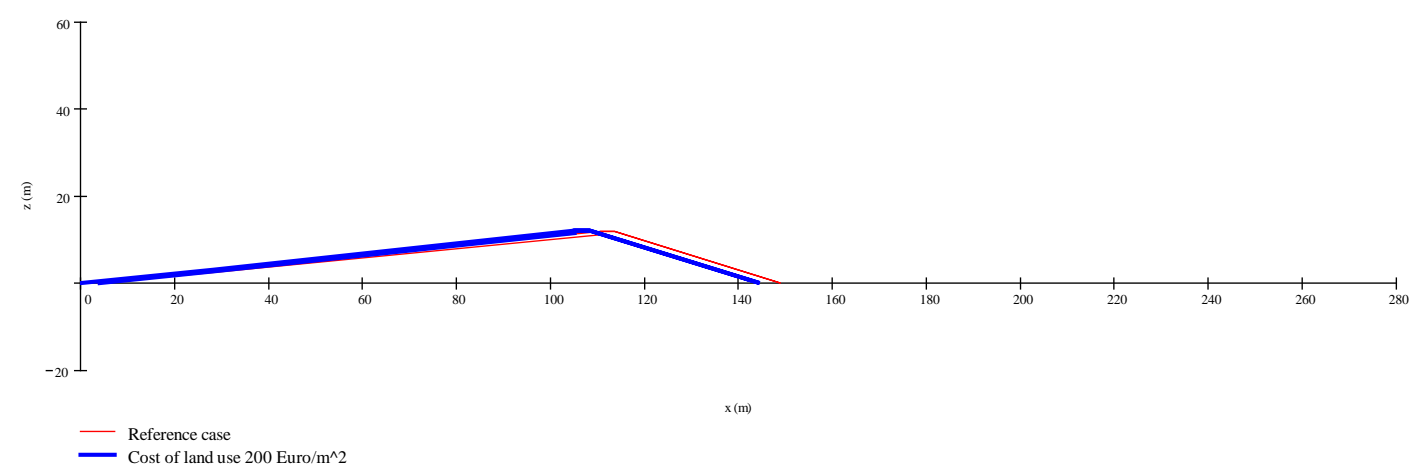

Figure 121: Optimal cross sections of the dike at Ommelander. High cost of space use compared to reference case (cases 1 and 7).

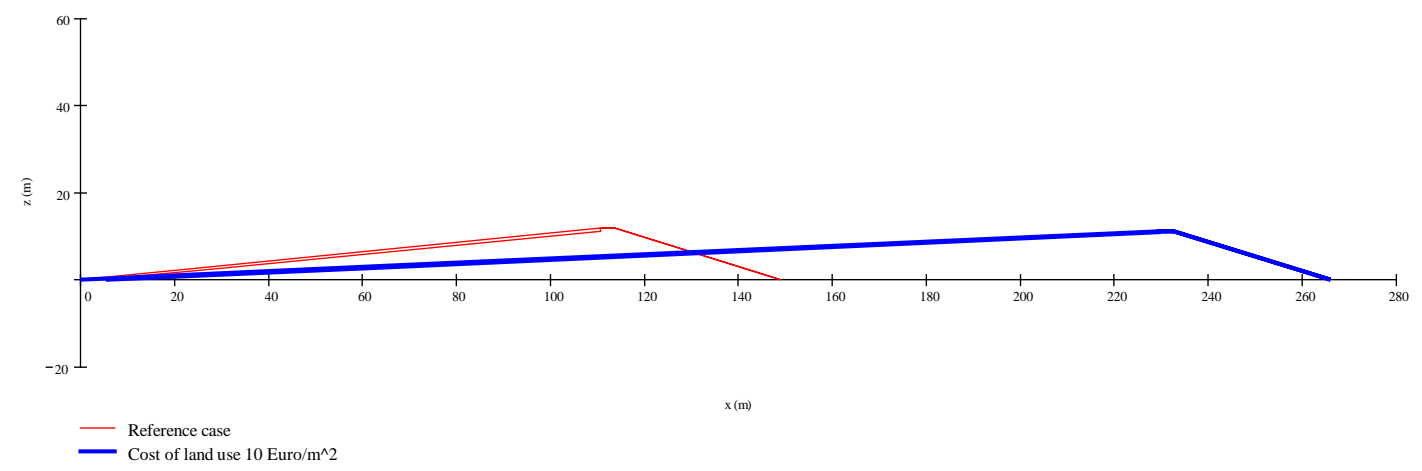

Figure 122: Optimal cross sections of the dike at Eems harbour. Low cost of land use compared to reference case (cases 1 and 4 ).

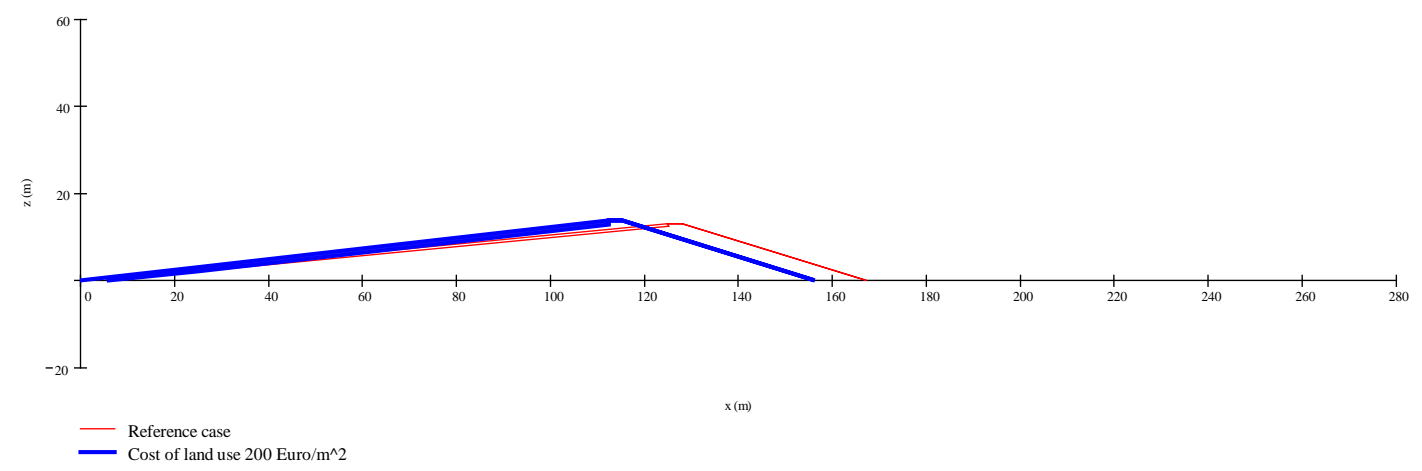

Figure 123: Optimal cross sections of the dike at Eems harbour. High cost of land use compared to reference case (cases 1 and 7).

Tables 48 and 49 show the numerical output for the five cases. The land side slope and the berm geometry are not included in the tables. The land side slope is 1:3 in all cases. The sea side berm is absent in all profiles. 
Table 48: Geometry resulting from optimisation for a failure probability of $10^{-4}$ per year (Ommelander)

\begin{tabular}{lccc}
\hline Cost of space use $\left(\mathbf{\epsilon} / \mathbf{m}^{\mathbf{2}}\right)$ & Crest height $(\mathbf{C D}+\mathbf{m})$ & Sea side slope $(\mathbf{1 : n})$ & Thickness revetment $(\mathbf{m})$ \\
\hline 10 & 10.6 & 15.8 & 0.24 \\
50 & 11.2 & 10.3 & 0.37 \\
$100^{21}$ & 11.8 & 9.4 & 0.41 \\
150 & 12.0 & 8.9 & 0.44 \\
200 & 12.1 & 8.7 & 0.46 \\
\hline
\end{tabular}

Table 49: Geometry resulting from optimisation for a failure probability of $10^{-4}$ per year (Eems harbour)

\begin{tabular}{lccc}
\hline Cost of space use $\left(\mathbf{\epsilon} / \mathbf{m}^{\mathbf{2}}\right)$ & Crest height $\mathbf{( C D}+\mathbf{m})$ & Sea side slope $(\mathbf{1 : n})$ & Thickness revetment $(\mathbf{m})$ \\
\hline 10 & 11.2 & 20.5 & 0.28 \\
50 & 12.2 & 12.5 & 0.46 \\
$100^{21}$ & 13.0 & 9.6 & 0.62 \\
150 & 13.4 & 8.8 & 0.70 \\
200 & 13.7 & 8.2 & 0.75 \\
\hline
\end{tabular}

If the cost of land use increases, the profile gets steeper to reduce the foot print of the dike. The reduced foot print is reflected in a higher probability of piping failure. The probabilities of overtopping failure and sea side revetment failure increase if the sea side slope is steeper. To meet the probability requirement, the crest level rises and the revetment thickness increases. A higher crest level cancels out part of the foot print reduction that is obtained by the steeper slope. The geometry changes are reflected in the costs as a function of failure probability and in the distribution of failure probability over the failure modes (figures 124 through 127).

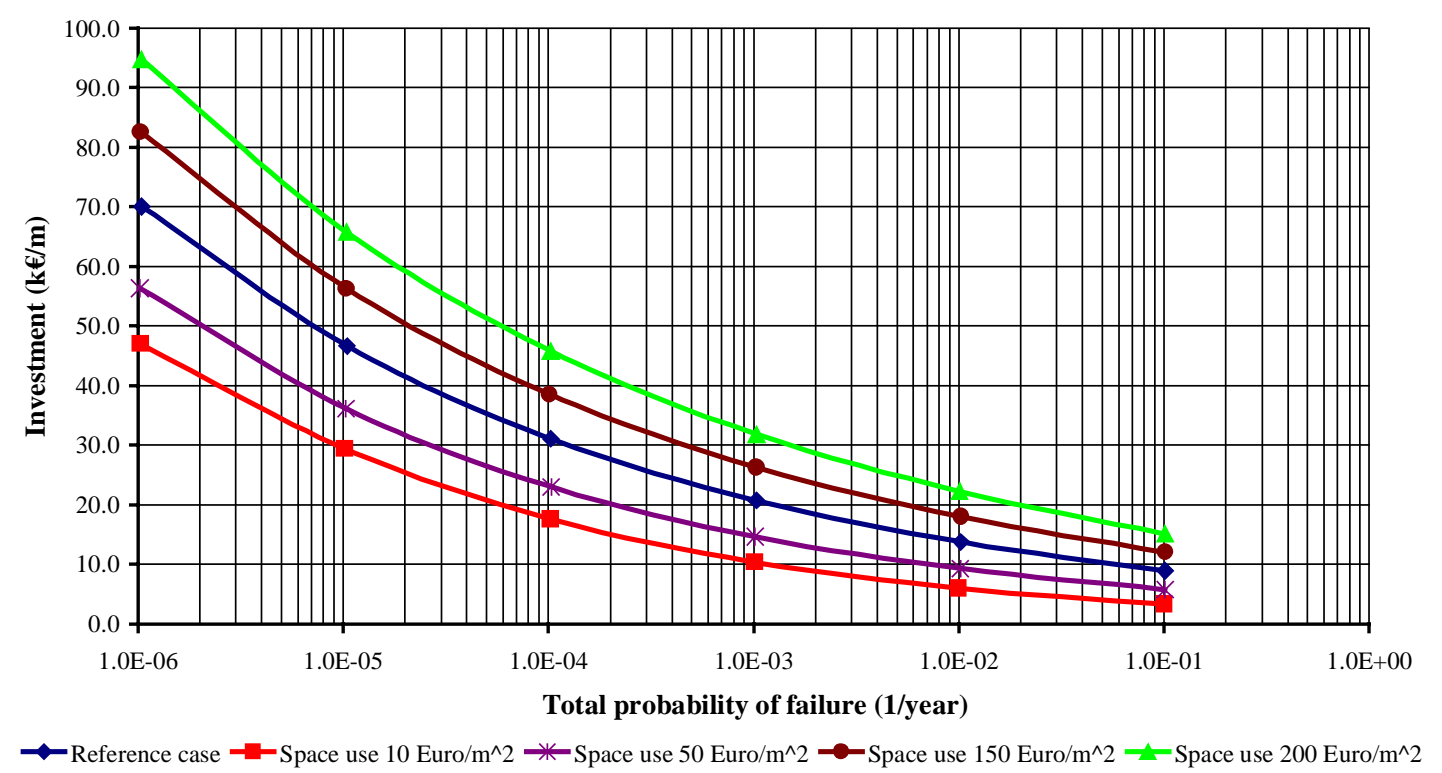

Figure 124: Direct cost of dike construction as a function of failure probability (Ommelander sea dike, varying cost of space use)

\footnotetext{
${ }^{21}$ Reference case (case 1)
} 


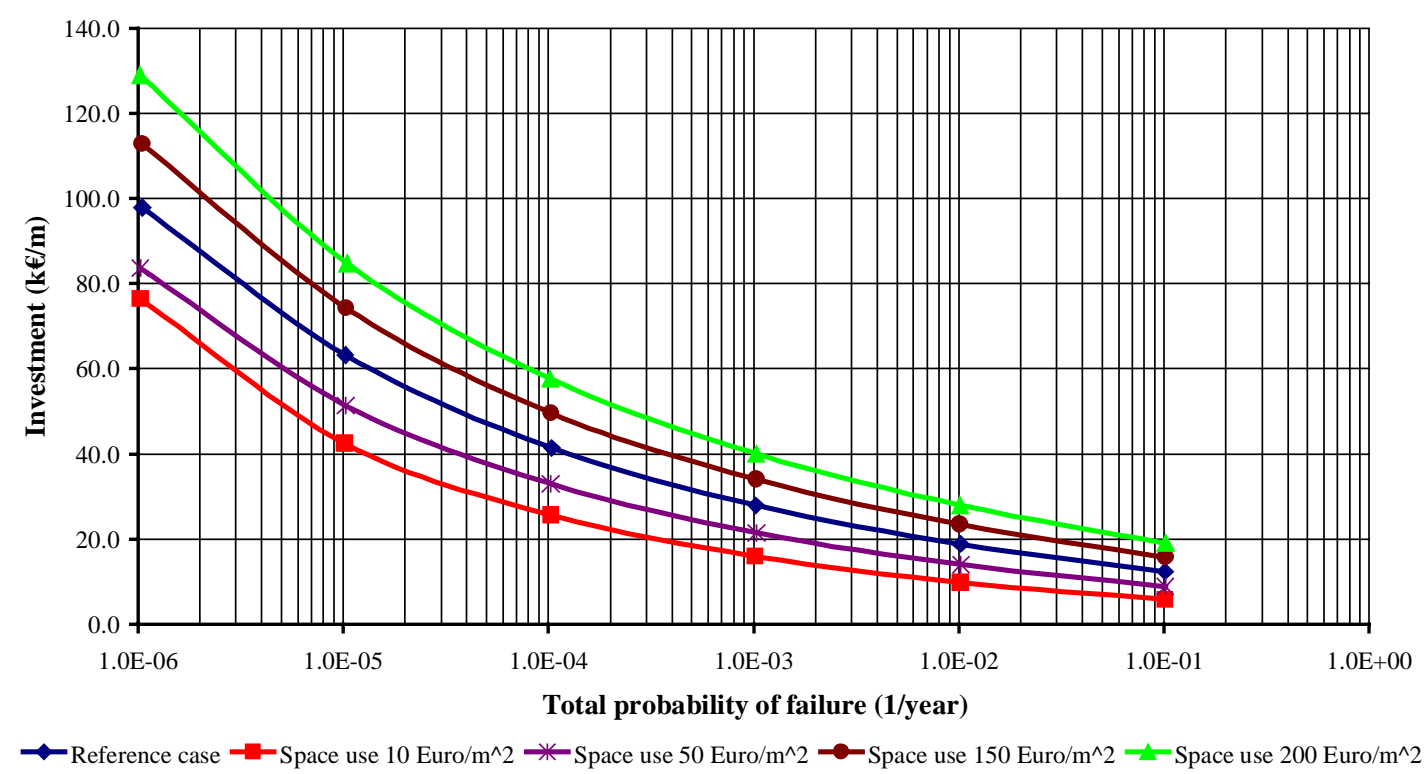

Figure 125: Direct cost of dike construction as a function of failure probability (Eems harbour, varying cost of space use)

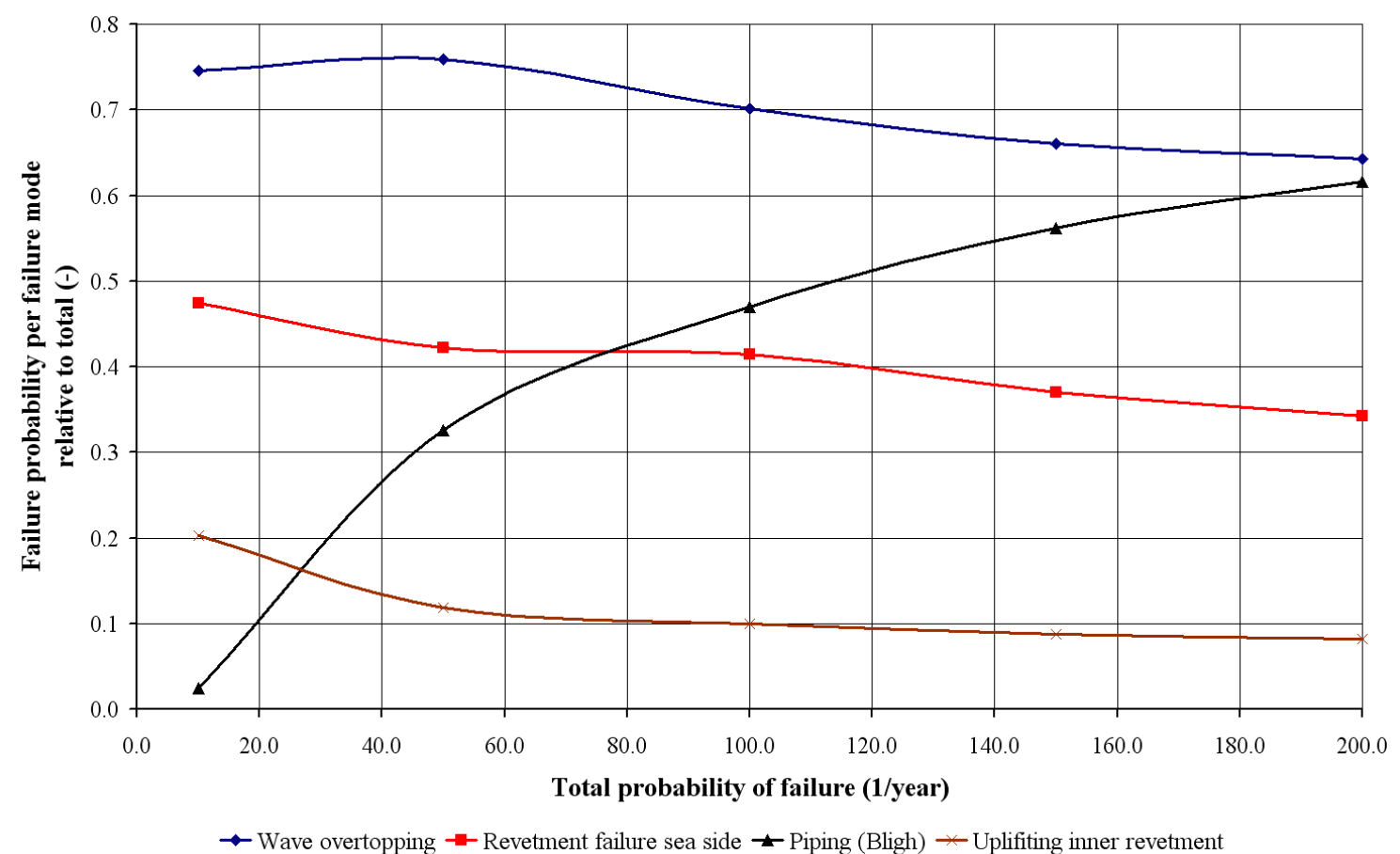

Figure 126: Failure probability per failure mode relative to the norm as a function of the cost of space use (Ommelander, probability norm $10^{-4}$ per year) 


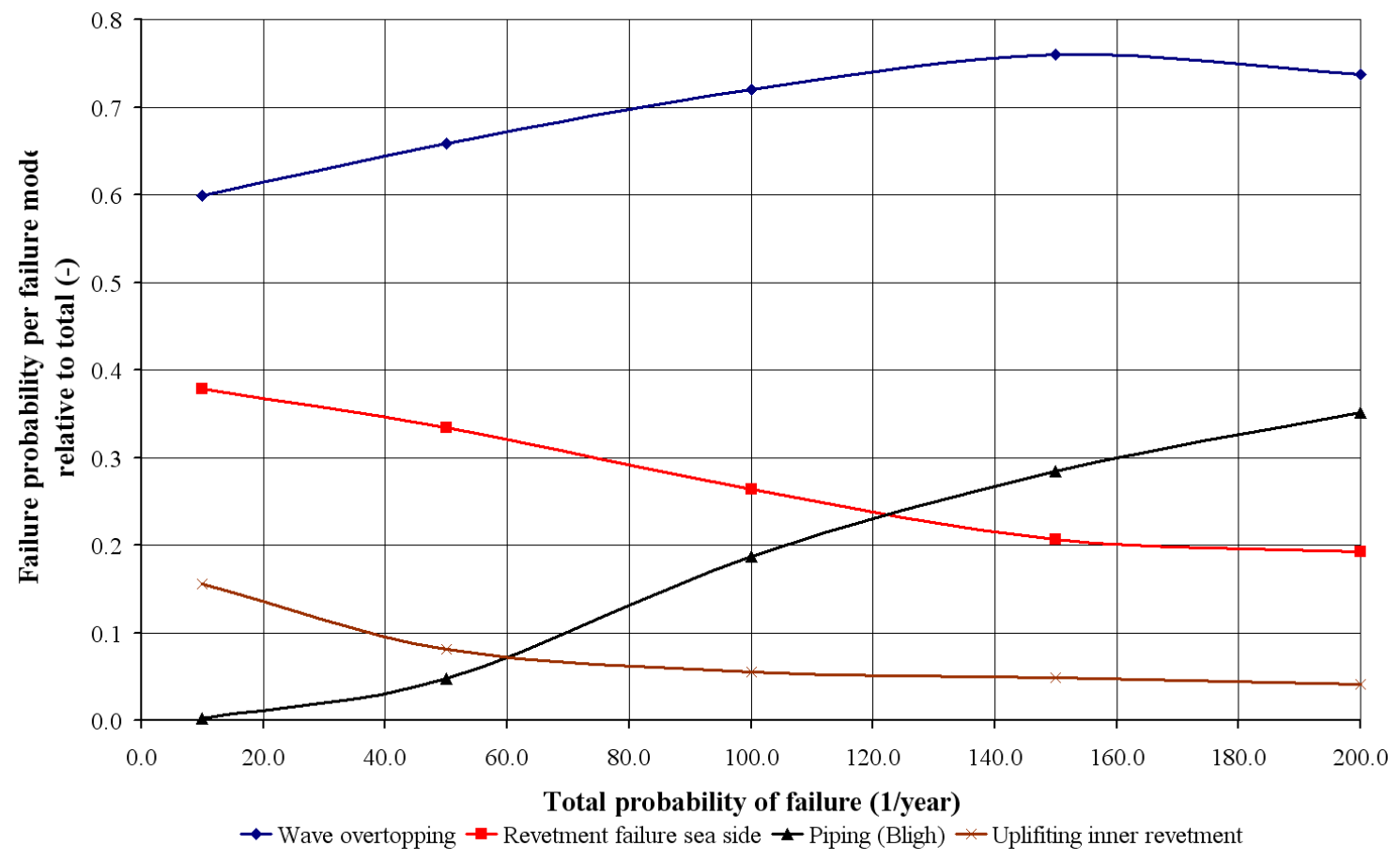

Figure 127: Failure probability per failure mode relative to the norm as a function of the cost of space use (Eems harbour, probability norm $10^{-4}$ per year)

The failure mode that is most sensitive to the width of the foot print of the dike is piping. Therefore, this failure mode is most heavily influenced by the cost of space use. If space use is expensive, a high probability of piping failure relative to the norm is obtained. Compensation is found by lowering the probability of overtopping failure and the probability of sea side revetment failure. Reducing the foot print implies the choice of a steeper sea side slope.

If the cost of space use is low, there is no reason to limit the space use, so that the probability of piping failure drops rapidly if the cost of space use decreases. Because the probability of piping failure is reduced, there is some room to increase the probabilities of overtopping and of revetment failure. At Ommelander, the relative failure probability of all failure modes other than piping indeed increases. At Eems harbour, the relative probability of overtopping failure decreases together with the probability of piping failure.

\subsection{Discussion}

Failure of a flood defence structure may occur due to a variety of different failure modes. When designing a structure, it is necessary to deal with all of them in a consistent way. Performing design optimisation for three failure modes and a prescribed set of boundary conditions (deterministic design) shows that a costeffective profile of a dike section in the dike ring Groningen is characterised by:

- A mild sea side slope;

- The absence of a sea side berm.

The optimal profile deviates from what is normally encountered in practice. Inspecting the effects of different design variables on the three failure modes shows that the choice of a mild sea side slope is effective in resolving a variety of failure modes. 
When applying reliability-based design, the full stochastic model of load and resistance is used in the design process. The optimal profiles resulting from reliabilitybased design show the same characteristics as the optimal profile obtained in deterministic design.

Using a stochastic model that describes uncertainties on the local water level and neglects other uncertainties leads to smaller and cheaper optimal profiles in comparison to the use of the full stochastic model. The failure probability of such a profile can be found by applying reliability analysis using the full stochastic model. The result of the analysis shows that the use of a limited stochastic model leads to inconsistent performance of different dike sections. This means that, though designed for the same probability norm, profiles in different locations show failure probabilities that differ considerably. The large difference appears to be caused by the relative importance of other uncertainties than uncertainties on the water level. These other uncertainties may differ from location to location so that also the effect differs from location to location.

Application of a failure probability requirement per failure mode according to TAW is sufficient to obtain a sufficiently low failure probability of the section. The design resulting form this approach is not the most cost-effective to meet the probability requirement.

Location-dependent variations of the cost of land use are easily accounted for when applying reliability-based design. Changes of the optimal profile can be explained by considering that the cost of land use and the probability of piping failure are both coupled to the width of the foot print of the dike. Therefore, the probability of piping failure is heavily influenced by the cost of land use. As a result of changes in the probability of piping failure, also the other failure probabilities per failure mode change. 


\section{RISK-BASED DESIGN OF THE COASTAL FLOOD PROTECTION SYSTEM OF GRONINGEN}

"In the area of insurance against damage due to fire, hail, break-in, maltreatment, illness etc. etc. one does - justifiably - not dismiss small probabilities so rashly. To do so for disasters like flooding appears to be unforgivably unthinking."

T. Huitema (1947)

\subsection{Introduction}

A flood-prone area can be protected against flooding by the construction of a flood defence system. The appropriate level of protection, expressed in flooding probability, depends on the cost of protection and the value of the protected area and can be established by risk-based design methods. In this chapter, risk-based design will be performed for the coastal flood defence system of the province of Groningen in the north of the Netherlands. This chapter forms the last of three chapters on the case study Groningen.

To perform risk-based design of the coastal flood protection system of Groningen, it is necessary to quantify:

- The cost of protection on system level;

- The consequences of flooding in the area.

To establish the cost of protection on system level, the system is split in 11 dike sections for which the cost as a function of failure probability is obtained by using the method of reliability-based optimisation (chapter 3). The results on section level can be used to establish the cost of protection on system level as a function of the flooding probability of the area. The analysis of the cost of protection is performed in section 8.3.

The consequences of flooding are obtained by analysis of historical economic and population statistics of the province Groningen. The expected value of the consequences is quantified using an upper bound approach outlined in chapter 4.

Both the cost of protection and the expected value of flooding consequences are a function of the flooding probability of the area. Thus, the analysis of costs and consequences as outlined above completes the input necessary for risk-based design of the dike ring Groningen. In section 8.4, the results are used to perform risk-based decision making on the protection level of the dike ring Groningen. To that end, the three options for decision-making outlined in chapter 2 are used.

The results of risk-based optimisation depend on the estimates of the consequences of flooding. A detailed analysis of the consequences is not performed in this study. In section 8.5 a sensitivity analysis is performed, showing the effect of an improved estimate of the flooding consequences on the design flooding probability of the dike ring, using three different definitions of the optimal flooding probability.

\subsection{Description of input data}

\subsubsection{General}

The input for the risk-based design of the coastal flood defence system of Groningen consists of:

- Cost of protection as a function of failure probability per dike section; 
- Consequences of flooding.

The cost of protection per dike section is necessary to derive the cost of protection on system level. The cost of protection is written as a function of the failure probability of individual sections by applying reliability-based optimisation (see chapters 3 and 7 for more details).

The consequences of flooding analysed in this study are:

- Loss of economic value due to flooding;

- Loss of life due to flooding.

Data to quantify the consequences of flooding are obtained from an earlier study on the flooding risk in Groningen (RWS, 2001) and from the Dutch Central Bureau of Statistics (CBS).

\subsubsection{Cost of protection per dike section}

The cost of protection per dike section is derived using the method of reliability-based design as outlined in chapter 3. Reliability-based design is performed for the 11 sections of the dike ring Groningen shown in figure 88. Hydraulic conditions are quantified by the joint probability distribution developed in chapters 5 and 6 . The model for hydraulic boundary conditions provides a description of the joint statistics of hydraulic boundary conditions for a number of output points in the area. Table 50 shows the 11 dike sections of the dike ring Groningen and the output points used for the description of the boundary conditions. Output points are given in Dutch geographical coordinates.

Table 50: Overview of sections of the dike ring Groningen

\begin{tabular}{lllll}
\hline Nr. & Section & \multicolumn{2}{l}{ Output point hydraulic model } & \multirow{2}{*}{ Remark } \\
\cline { 3 - 4 } & & $X(\mathrm{~m})$ & 603916 & Case 1a in chapter 6 \\
\hline 1 & Ommelander zeedijk & 222940 & 609456 & \\
2 & Emmapolder West & 243081 & 609349 & \\
3 & Emmapolder Oost & 247088 & 609497 & Case 1b in chapter 6 \\
4 & Eemshaven West & 249954 & 608217 & \\
5 & Eemshaven Oost & 253073 & 600570 & \\
6 & Hoogwatum & 254985 & 596244 & \\
7 & Delfzijl Noord & 257074 & 593450 & \\
8 & Dijk zeehavenkanaal & 263100 & 591729 & \\
9 & Termunten & 267026 & 590450 & \\
10 & Dollarddijk & 268149 & 584800 & \\
11 & Reiderwolder polderdijk & 272954 & & \\
\hline
\end{tabular}

In this study, the assumption is made that the values for load and resistance are fully correlated for one dike section. Thus, the calculated probability of failure for one cross section is equal to the failure probability of the full dike section.

For all structures, the cost input of chapter 7 is applied. Table 51 gives an overview.

Table 51: Overview of cost variables

\begin{tabular}{lll}
\hline Cost component & Price per unit & Remark \\
\hline Dike volume & $4.6 € / \mathrm{m}^{3}$ & Price of filling sand including construction \\
Revetment outside & $227.3 € / \mathrm{m}^{3}$ & Pitched concrete blocks. Price includes construction \\
Revetment inside & $45.5 € / \mathrm{m}^{3}$ & Clay cover including construction \\
Space use & $100 € / \mathrm{m}^{2}$ & Assumed value \\
\hline
\end{tabular}


Reliability-based optimisation of the 11 dike sections is performed for failure probabilities ranging from $10^{-1}$ per year to $10^{-6}$ per year. Thus, the cost of construction as a function of the failure probability is obtained for all sections. Figure 128 shows the results.

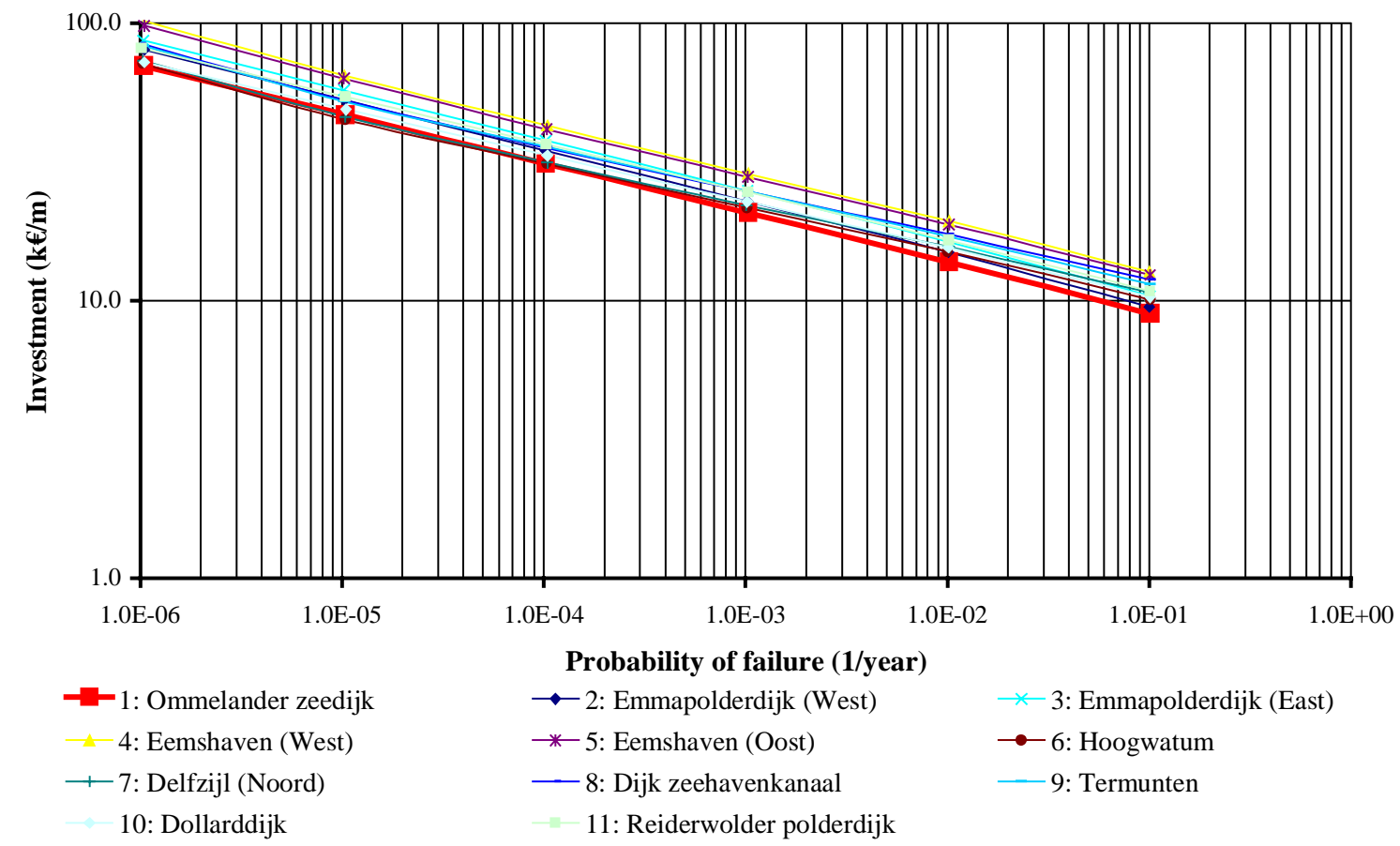

Figure 128: Direct cost of dike construction as a function of failure probability for 11 locations in the dike ring Groningen

For further analysis, it is convenient to find a parametric model that approximates the results of the numerical model. Analysis of the data shows that the logarithm of construction costs can be approximated by a linear function of the logarithm of the failure probability. Thus, the cost functions resulting from the numerical calculation can be approximated by a function of the form:

$\log \left(\frac{I_{i}}{L_{i}}\right) \approx-a_{i} \log \left(P_{f ; i}\right)+b_{i}$

Where:

$I_{i}$ : $\quad$ Direct cost of dike section $i$;

$L_{i}: \quad$ Section length;

$P_{f ; i}: \quad$ Failure probability;

$a, b: \quad$ Parameters.

The parameters $a$ and $b$ per dike section are obtained by performing a least-squares fit to the results of the numerical model.

Table 52 shows the parameters of the approximating cost function per section.

Table 52: Parameters of the cost function per dike section

\begin{tabular}{llccc}
\hline Section nr. & Section name & Length $(\mathbf{k m})$ & Parameter $a$ & Parameter $b$ \\
\hline 1 & Ommelander sea dike & 25 & 0.18 & 3.8 \\
2 & Emma polder dike (West) & 6 & 0.19 & 3.8 \\
3 & Emma polder dike (East) & 4 & 0.18 & 3.8 \\
4 & Eems harbour (West) & 3 & 0.18 & 3.9 \\
\hline
\end{tabular}




\begin{tabular}{llccc}
\hline Section nr. & Section name & Length $(\mathbf{k m})$ & Parameter $a$ & Parameter $b$ \\
\hline 5 & Eems harbour (East) & 7 & 0.18 & 3.9 \\
6 & Hoogwatum & 8 & 0.17 & 3.8 \\
7 & Delfzijl (North) & 6 & 0.17 & 3.9 \\
8 & Dike of sea port entrance channel & 6 & 0.17 & 3.9 \\
9 & Termunten & 3 & 0.17 & 3.9 \\
10 & Dollard dike & 6 & 0.17 & 3.8 \\
11 & Reiderwolder polder dike & 10 & 0.18 & 3.9 \\
\hline
\end{tabular}

\subsubsection{Consequences of flooding}

The consequences of flooding considered in this study are:

- Monetary consequences;

- Loss of life.

To quantify the consequences of flooding, data on economic characteristics and on the population of the area is needed. The data in this study is obtained from two main sources:

- The database of the Dutch Bureau of Statistics;

- The PICASO study performed by the Dutch Ministry of Public Works and Water Management (RWS, 2001).

Table 53 gives an overview of the input for the risk calculation as used in this study.

Table 53: Input for risk calculation in the dike ring Groningen

\begin{tabular}{|c|c|c|c|}
\hline Parameter & Description & Value & Remark \\
\hline$d_{0}$ & Monetary value of the area & $\mathrm{G} € 34,-$ & Taken from PICASO study* \\
\hline$b_{0}$ & Yearly gross domestic product & $\mathrm{G} € 14.40$ & Value of $1998^{\#}$ \\
\hline$N_{p}$ & Population & 566489 & 1 January $2001^{\#}$ \\
\hline$c_{d}$ & Damage factor loss of investment & 1 & Upper bound \\
\hline$c_{b}$ & Damage factor loss of production & 1 & Assumed value \\
\hline$c_{c a s}$ & Damage factor casualties & 1 & Upper bound \\
\hline$r$ & Interest rate & 0.07 per year & Average over $1960-2001^{\#}$ \\
\hline$r_{e}$ & Rate of economic growth & 0.03 per year & Average over $1960-2001^{\#}$ \\
\hline$i$ & Inflation & 0.02 per year & Average over $1960-2001^{\#}$ \\
\hline$r_{p}$ & Growth rate of population & 0.004 per year & Average over $1960-2001^{\#}$ \\
\hline$T$ & Reference period & 100 years & Assumed value \\
\hline \multicolumn{4}{|c|}{ *: RWS, 2001} \\
\hline
\end{tabular}

Where available, historical data is used to derive the input for the risk calculation. The monetary value of the area is taken from the PICASO study (RWS, 2001). The population of the area, the interest rate, rate of economic growth, inflation and rate of population growth are all taken from the database of the Dutch Central Bureau of Statistics. The reference period is chosen in the design stage of the flood protection system and can be interpreted as the period for which the protection is thought to be effective before additional measures of protection are taken.

Methods to calculate the consequences of flooding are given in chapter 4. In section 4.4, three methods to schematise a flood-prone area are given. For the dike ring Groningen, the information necessary for application of one of the detailed schematisations is lacking. Therefore only the dike ring schematisation will be used. As indicated in chapter 4, the dike ring schematisation provides an upper bound of the direct consequences of flooding if the assumption is made that in any flooding event 
the full inventory of the area is lost. For the indirect consequences it can not be ascertained whether a damage factor with a value of 1 provides an upper bound. Nevertheless, this value will be adopted as the reference value.

\subsection{Cost of protection on system level}

\subsubsection{General}

On the level of individual flood protection structures, the cost of protection is written as a function of the failure probability of the structure. Based on the results per structure, a similar function can be established for the full protection system. In general, the cost of protection on system level is given by:

$$
I_{\text {sys }}(\mathbf{p})=\sum_{n=1}^{N} I_{n}\left(p_{n}\right)
$$

Where $\mathbf{p}$ denotes a vector of failure probabilities per structure.

Like the cost of protection, the flooding probability is a function of the failure probabilities of the individual flood defence structures. Furthermore, the dependence between the reliability of individual structures has major influence on the resulting flooding probability. In general, the flooding probability is given by:

$$
P_{\text {flood }}=f(\mathbf{p}, \mathrm{A})
$$

Where A denotes a dependence matrix.

For any combination of failure probabilities per structure the resulting cost and failure probability on system level can be quantified. In the design of a flood defence system, failure probabilities per structure have to be chosen in such a way that the flooding probability is sufficiently low. For a given value of the acceptable flooding probability, failure probabilities per structure may be chosen in several ways. Two ways of defining the failure probability per structure appear relevant for practical application:

- Optimisation of the failure probability per structure;

- Equal failure probability per structure.

Optimisation of the failure probability per structure may be performed by application of reliability-based optimisation on system level (chapter 3). Thus, the minimum cost of protection on system level is obtained, together with the corresponding failure probabilities of every individual structure. Optimisation will result in variation of the failure probability over the individual flood defence structures. Loosely stated, the highest failure probabilities are allocated to the most expensive structures. From a practical point of view, it may be favourable to take equal failure probabilities per structure. In case of full dependence, this will be equal to the optimised solution but in general this allocation of failure probability will deviate from the optimum.

Next to the failure probabilities per structure, the flooding probability is a function of the dependence between the reliability of the individual structures. Analytic solutions are available for special cases of dependence. These analytic solutions provide upper and lower bounds on the exact flooding probability (chapter 3). If the reliability analysis of the individual structures is performed by a level II method, the dependence between the reliability of the individual structures can be quantified by the correlation matrix. The correlation matrix is calculated from the influence factors ( $\alpha$-factors) that result from a level II reliability method. Subsequently an approximation to the exact 
failure probability of the system can be found by application of the method of Hohenbichler and Rackwitz (1983; see also chapter 3).

Four combinations of the choice of failure probability per structure and the dependence between the structures appear to be relevant for further analysis. Table 54 provides an overview.

Table 54: Four options for quantifying the cost of protection on system level

\begin{tabular}{llll}
\hline Nr. & $\begin{array}{l}\text { Failure probability per } \\
\text { section }\end{array}$ & Dependence between sections & Remark \\
\hline 1 & Optimised & Full dependence & Lower bound of system cost \\
2 & Optimised & Independence & Upper bound of system cost \\
3 & Optimised & Calculated from influence factors & \\
4 & One value for all & Calculated from influence factors & \\
\hline
\end{tabular}

Options 1 and 2 are combinations of optimisation of the failure probabilities with special cases of dependence. These two options provide upper and lower bounds on the cost of protection on system level. They can be established with simple tools and may therefore serve as a rough check on the results of more detailed calculations.

In options 3 and 4, the influence factors resulting from a level II reliability analysis are used to establish the correlation matrix that describes the dependence between the structures. Combination of calculated dependence with optimisation of the failure probability per structure leads to the best estimate of the minimum cost of protection on system level (option 3). In option 4, the calculated dependence is combined with one failure probability for all structures.

\subsubsection{Upper and lower bound estimates of the cost of protection on system level}

In the previous section, four options for the calculation of cost of protection on system level were introduced. Options 1 and 2 are based on assumptions on the dependence between the flood defence structures and lead to upper and lower bounds of the cost of protection on system level.

In general, the optimal set of failure probabilities per flood defence structure is found by solving the following optimisation problem:

$$
\begin{aligned}
& \min _{\mathbf{p}} I_{\text {sys }}(\mathbf{p})=\sum_{n=1}^{N} I_{n}(p) \\
& \text { s.t. } \quad P_{\text {flood }}(\mathbf{p}, \mathrm{A}) \leq P_{\text {flood;max }}
\end{aligned}
$$

Where:

p: $\quad$ Vector of failure probabilities per structure;

$I_{\text {sys: }} \quad$ Cost of protection on system level;

$I_{n}: \quad$ Cost of protection of structure $\mathrm{n}$;

$P_{\text {flood: }} \quad$ Flooding probability;

$P_{\text {flood;max }}$ : Flooding probability constraint;

A: $\quad$ Dependence matrix.

The minimum cost of protection can be considered to increase with decreasing value of $P_{\text {flood;max }}$. Therefore, the inequality constraint can be replaced by an equality constraint. 
In option 1, the assumption is made that the reliabilities of the individual flood defence structure are fully dependent. In that case, the flooding probability is given by:

$$
P_{\text {flood }}=\max (\mathbf{p})
$$

Where $\mathbf{p}$ denotes a vector of failure probabilities per structure.

Equation (120) indicates that only a decrease of the highest individual failure probability leads to a decrease of the flooding probability. In general, it is justified to assume that the cost of protection increases with decreasing failure probability. In combination with the effect of full dependence, this leads to the following optimal allocation of failure probabilities:

$$
p_{i}=P_{\text {flood } ; \max }
$$

Substitution of this result in the cost function (equation (117)) provides the cost of protection estimated according to option 1. Because a lower bound estimate of the flooding probability is used, this cost estimate is a lower bound on the cost of protection on system level.

In option 2, an upper bound approximation of the flooding probability is used. According to chapter 3, an upper bound for the flooding probability is found if failures of individual structures are assumed to be mutually exclusive events. For a system of coastal flood defence structures, historical experience indicates that mutually exclusiveness of the failure of different structures is not a realistic assumption. Therefore, an upper bound to the flooding probability may be found by assuming independence of the individual structures. Optimisation of the failure probability per structure under the assumption of independence is denoted option 2 . The flooding probability in option 2 is given by:

$$
P_{\text {flood }}=1-\prod_{n=1}^{N}\left(1-p_{n}\right)
$$

When applying the upper bound of the flooding probability, the combination of failure probabilities per section that fulfils the flooding probability requirement against minimum cost can be found by application of the method of Lagrange. To that end, the requirement that the flooding probability should equal a prescribed value is contained in the following function:

$$
\varphi(\mathbf{p})=P_{\text {flood } ; \max }-P_{\text {flood }}
$$

The set of failure probabilities of the sections that solves equation (119) is found by solving the system: 


$$
\left\{\begin{array}{c}
\varphi(\mathbf{p})=0 \\
\frac{\partial I}{\partial p_{1}}(\mathbf{p})=\lambda \frac{\partial \varphi}{\partial p_{1}}(\mathbf{p}) \\
\frac{\partial I}{\partial p_{2}}(\mathbf{p})=\lambda \frac{\partial \varphi}{\partial p_{2}}(\mathbf{p}) \\
\cdot \\
\frac{\partial I}{\partial p_{N}}(\mathbf{p})=\lambda \frac{\partial \varphi}{\partial p_{N}}(\mathbf{p})
\end{array}\right.
$$

Where $\lambda$ denotes the Lagrange multiplier.

Solving the system for a range of values of $P_{\text {flood;max }}$ leads to the minimum cost as a function of the maximum flooding probability. Because an upper bound estimate of the flooding probability is used, the cost function derived in this way is an upper bound of the system cost function.

The upper and lower bounds of the cost of protection are shown as a function of the flooding probability in figure 129.

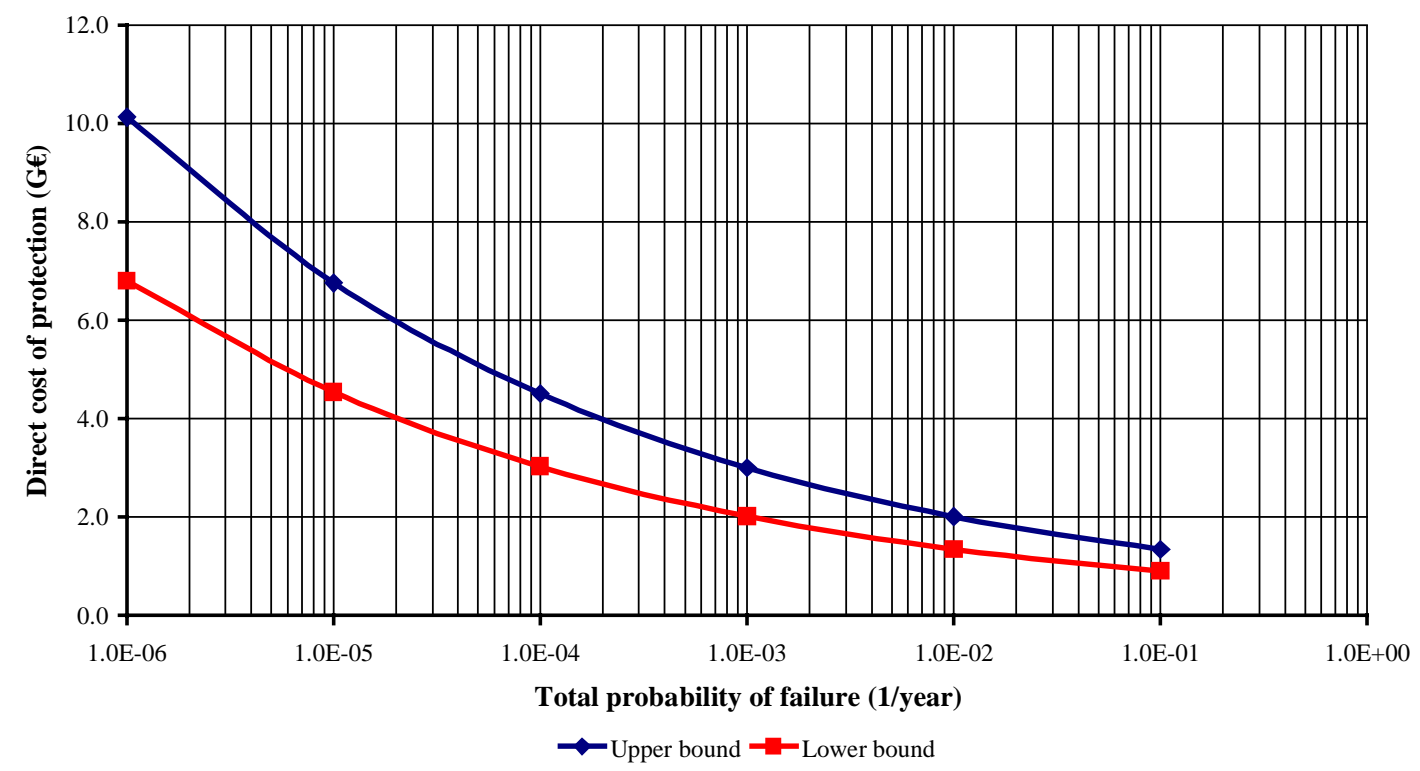

Figure 129: Upper and lower bound estimates of the direct cost of construction of a protection system of 11 dike sections in Groningen

The upper bound estimate of the cost of protection is approximately $50 \%$ higher than the lower bound estimate.

\subsubsection{Cost of protection on system level with calculated dependence between} sections

Considering the large difference between the upper and lower bound estimates of the system costs, an analysis accounting for the calculated dependence between the sections is necessary to obtain a more accurate estimate of the cost of protection. 
When the overall limit state function for a section is written in standard form, the dependence between two sections is found by (see chapter 3 for details):

$\rho_{i j}=\sum_{n=1}^{N} \rho_{v a r ; n i j} \alpha_{i n} \alpha_{j n}$

Where:

$\rho_{\text {var; } n i j:}$ Correlation of variable $n$ in limit state $i$ to variable $n$ in limit state $j$;

$\alpha_{i n}: \quad$ Influence factor of variable $n$ in limit state $i$.

The influence factors $\alpha$ are obtained from the level II reliability analysis that is an integral part of the reliability-based design procedure for a dike section. The influence factors vary as a function of the failure probability of the structure (see figures 106 and 107 in chapter 7 for examples).

The variable $\rho_{\text {var }}$ takes a value of 1 if the value of variable $n$ in limit state $i$ is fully correlated with the value in limit state $j$. Values of $\rho_{\text {var }}$ must be chosen prior to a reliability analysis on system level and be preferably based on reasoning from physical concepts. Table 55 shows the values of $\rho_{v a r}$ for five groups of variables as chosen in this study. The groups of variables are the same as the groups for which the influence factors are shown in chapter 7.

Table 55: prescribed correlation between variables in different dike sections

\begin{tabular}{ll}
\hline Group & Prescribed correlation $(-)$ \\
\hline Wind speed & 1 \\
Model uncertainties wind effects & 1 \\
Astronomic tide & 1 \\
Model uncertainties limit state functions & 1 \\
Other & 0 \\
\hline
\end{tabular}

The wind speed under extreme conditions is generally caused by a storm depression with a spatial scale larger than the North Sea (see chapter 5). Therefore, the wind conditions for individual dike sections are considered to be fully dependent. Model uncertainties are generally a consequence of simplifications of physical models. Since the physical processes are the same for all sections, the model uncertainties can be considered dependent for all sections; both for the hydraulic model and for the limit state functions.

In the description of the local water level, the wind setup is combined with the astronomic high tide. The astronomic tides at different locations in the study area are driven by the same processes. Therefore, the astronomic high tides can be considered fully dependent. Variables describing uncertainty on the resistance of one section are in this study thought to be unique for the section and are considered independent from section to section.

Reliability analysis of two individual dike sections (chapter 7) indicates that the reliability of a coastal flood defence structure in Groningen is generally dominated by the uncertainties on the wind conditions, the hydraulic model and the limit state functions. In combination with the chosen correlations of table 55, this leads to a high dependence of the reliability of the individual structures. As an example, figure 130 shows the calculated correlation between the reliability of dike sections at Ommelander and Eems harbour if the probability of failure per structure is taken equal for the two locations. 


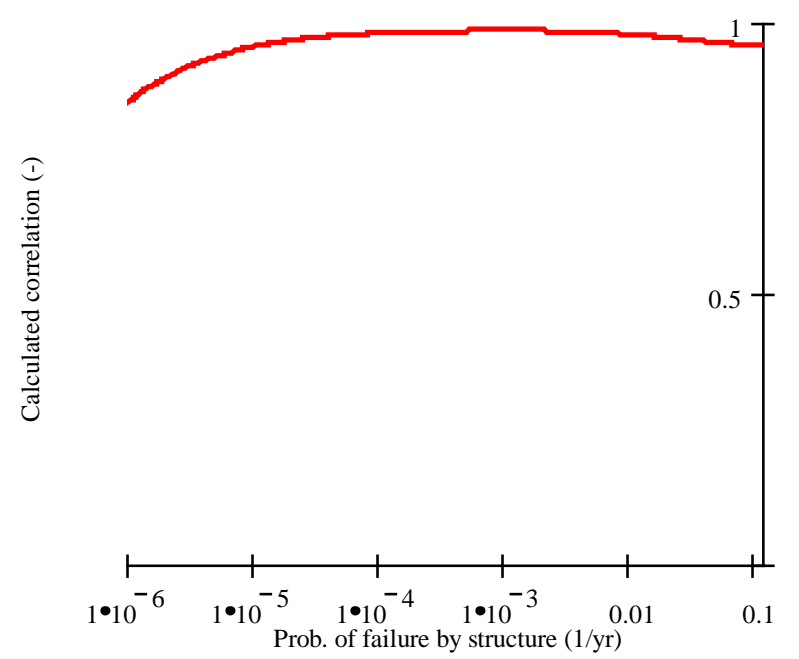

Figure 130: Calculated correlation between the reliability of sections Ommelander and Eems harbour (equal failure probability per structure)

The influence factors vary as a function of the failure probability of the section. Therefore, the correlation between the reliability of the two sections varies as a function of the respective failure probabilities. Taking equal failure probabilities per structure, the highest correlation (99 \%) is found around a failure probability of $10^{-}$ $3 /$ year. For failure probabilities lower than $10^{-5}$ per year, the correlation drops rapidly. This is caused by the fact that for low probabilities of failure, the effect of limit state uncertainties at Ommelander is lower than at Eems harbour (see chapter 7) which reduces the correlation between the two locations. Calculating the probability of failure of the combination of the two dike sections Ommelander and Eems harbour clearly shows the effect of correlation (figure 131).

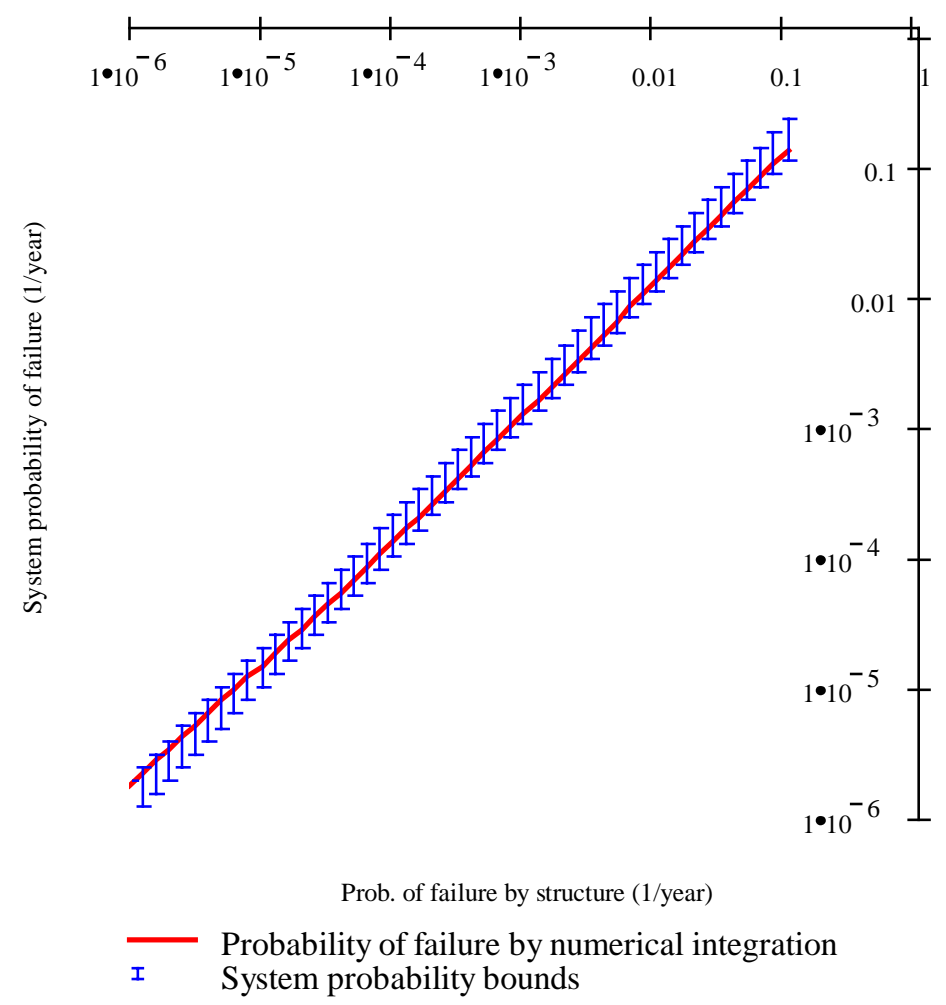

Figure 131: System probability of failure of a system of two sections accounting for calculated correlation 
For high failure probabilities, high correlation causes the system probability of failure of the two sections to be close to the lower bound. With decreasing correlation for structures with a lower failure probability, the system probability of failure gradually shifts to the upper bound.

The previous demonstration is performed for the two locations Ommelander and Eems harbour only. Figure 132 shows the flooding probability of the dike ring Groningen. The flooding probability is obtained by applying the method of Hohenbichler and Rackwitz (1983; chapter 3) to the system of 11 dike structures in the dike ring Groningen.

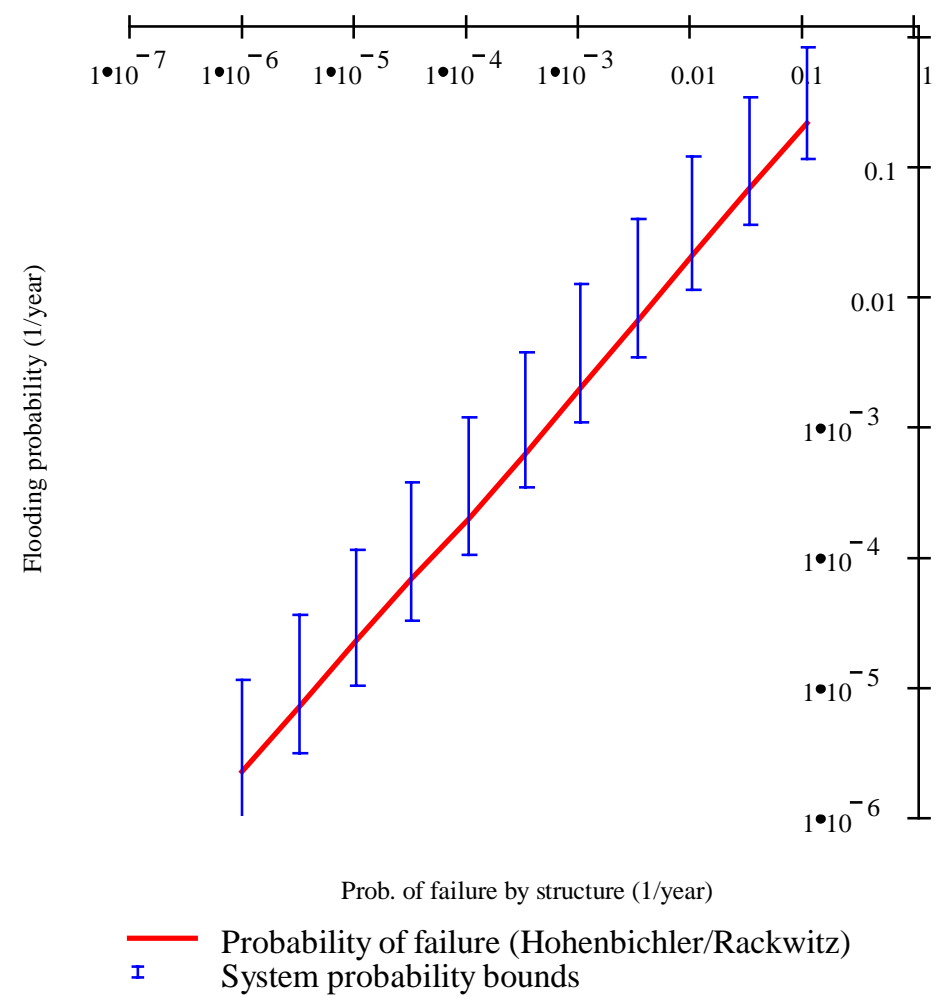

Figure 132: Probability of failure of the dike ring Groningen, consisting of 11 dike sections

Because of the large number of structures in the dike ring, the bounds on the flooding probability are relatively wide. The effect of decreasing correlation for lower failure probabilities leads to increasing deviation from the lower bound for failure probabilities lower than $10^{-4}$ per year. The ratio between the system probability of failure and the lower bound is around 1.9 for failure probabilities $10^{-1}$ per year to $10^{-4}$ per year. Between failure probabilities $10^{-4}$ per year and $10^{-6}$ per year, the ratio increases gradually to 2.6 .

The minimum costs on system level can be found by applying reliability-based optimisation using the failure probabilities per section as design variables (chapter 3 ). This is option 3 in table 54. Alternatively, equal failure probabilities per section can be chosen (option 4). In both cases, the probability of flooding is found by application of methods for system reliability. The cost of protection is found by substitution of the vector of failure probabilities in equation (117). The cost functions resulting from options 3 and 4 are shown in figure 133 in comparison to the upper and lower bounds of the system costs obtained in the previous section. 


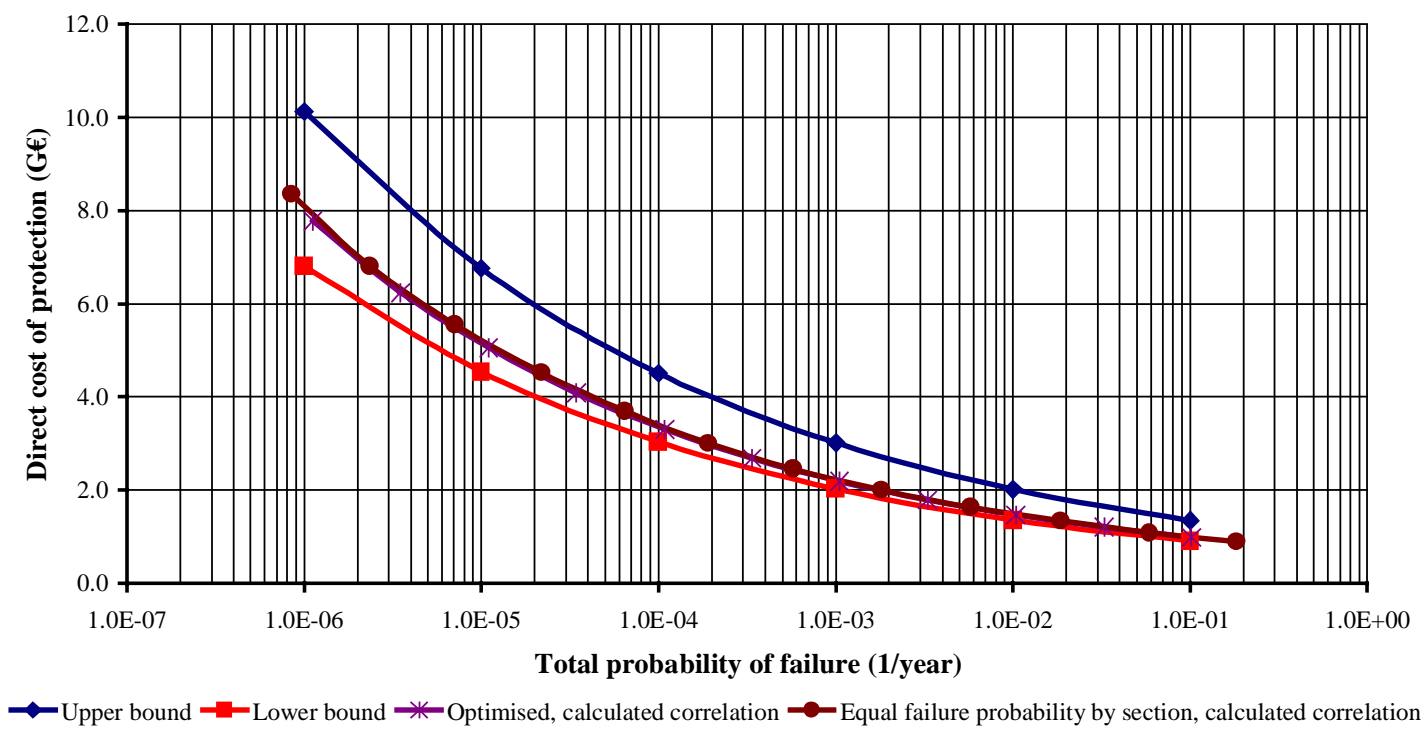

Figure 133: Cost of protection as a function of flooding probability. Two methods and upper and lower bounds

For high values of the flooding probability, the costs of protection are close to the lower bound. For lower values, increasing deviation of the cost function from the lower bound is observed. This reflects the behaviour of the system probability of failure shown in figure 132 .

As should be the case, the minimum cost of protection as obtained by reliability-baed optimisation are always between the upper and lower bound estimates. Taking equal failure probability per section leads to protection costs that hardly deviate from the optimised case. The maximum cost increase compared to the optimum is $1.5 \%$.

The cost function on system level can be approximated by a function similar to the one that is used to approximate the cost on structure level:

$\log \left(I_{\text {sys }}\right) \approx-a_{\text {sys }} \log \left(P_{\text {flood }}\right)+b_{\text {sys }}$

Where:

$I_{\text {sys: }}$ :

$P_{\text {flood: }}$ :

Direct cost of protection on system level;

$a_{\text {sys }}, b_{\text {sys }}: \quad$ Parameters.

Flooding probability;

By application of a least-squares method, the parameter values shown in table 56 are obtained.

Table 56: Parameter values of the system cost function

\begin{tabular}{lll}
\hline Failure probabilities per section & Parameter $a_{\text {sys }}$ & Parameter $b_{\text {sys }}$ \\
\hline Optimised & 0.181 & 8.804 \\
One value for all & 0.182 & 8.806 \\
\hline
\end{tabular}

Since the differences between the two cost estimates are small, the parameters for the two options hardly deviate from each other. The small cost reduction obtained by optimisation appears not to outweigh the practical disadvantages of this approach. In the remainder of this study, equal failure probabilities per section will be used. 


\subsection{Analysis of the acceptable flooding probability}

\subsubsection{General}

With the reliability-based design of the flood protection system outlined in the previous section, the cost of protection as a function of the flooding probability is obtained. To find the acceptable value of the flooding probability, combinations of models and acceptance rules outlined in chapter 2 are applied. Table 57 gives an overview of the models and acceptance rules used in the case study Groningen.

Table 57: Combinations of models and acceptance rules used to derive the acceptable flooding probability for the dike ring Groningen

\begin{tabular}{lll}
\hline Model & Acceptance rule & Risk calculation \\
\hline Cost-benefit model & Rules 1, 2, 3 and 5 & Dike ring \\
Utility model & Rule 5 & Dike ring \\
Life quality model & Rule 5 & Dike ring \\
\hline
\end{tabular}

Application of acceptance rule 1 in a cost-benefit framework implies the minimisation of direct cost of protection for a given acceptable flooding probability. The direct cost of protection is derived in the previous section. The acceptable flooding probability will be established using the proposal by Vrijling et al. (1995, 1998b).

Acceptance rule 3 defines the range of flooding probabilities where the sum of costs and benefits is positive. The result of this rule indicates the economically sustainable bounds of flood protection.

Optimal flooding probabilities are obtained in the cost-benefit framework by acceptance rules 2 and 5. In acceptance rule 2, minimisation of the sum of costs of protection and the direct economic damage due to flooding is performed. In rule 5, the benefits are taken into account and maximisation of the sum of costs and benefits is performed. Practically, acceptance rule 2 neglects indirect economic damage completely and acceptance rule 5 accounts for both direct and indirect economic damage.

In chapter 2 a utility model is introduced that models risk aversion in a cost-benefit model. In the case study Groningen, the model is used in combination with acceptance rule 5 (optimisation). The results are compared to the application of rule 5 in the costbenefit model.

The life quality model (Nathwani et al. 1997 and chapter 2) summarises the effects of flood protection on the gross domestic product and the life expectancy at birth in one social indicator. Optimisation is performed to maximise the value of this indicator for the dike ring Groningen.

\subsubsection{Maximum flooding probability according to Vrijling et al.}

Vrijling et al. (1995, 1998b) proposed definitions of the maximum added death probability based on observed statistics of causes of death. These definitions can be used to define constraints on the flooding probability. Generally, the probability of loss of life is constrained by:

- The probability of premature death of an individual (individual criterion);

- The probability of premature death of a group of people (societal criterion).

Research shows that the decisions made by individuals concerning their risk of loss of life are influenced by (Wilde, 1994; Vrijling et al., 1995, 1998b):

- The benefits associated with taking the risk; 
- The degree of voluntariness with which the risk is taken.

Vrijling et al. (1995, 1998b) introduced the following two constraints on the probability of loss of life. The probability of premature death of an individual should fulfill:

$P_{d} \leq \beta \cdot 10^{-4}$

Where $\beta$ denotes the policy factor, which is a measure for the degree of voluntariness with which the risk is taken.

The societal requirement constrains the probability distribution of the yearly number of casualties by:

$$
1-F\left(N_{d}\right) \leq \frac{\left(\frac{100 \beta}{k}\right)^{2}}{N_{d}^{2}}
$$

Where:

$k: \quad$ Measure for risk aversion;

$F(x)$ : $\quad$ Probability distribution;

$N_{d}$ : $\quad$ Number of casualties per year.

Both risk definitions depend on a measure of voluntariness $\beta$. A value of 10 implies a risk that is taken in complete freedom of choice and with high perceived benefits. Activities like mountaineering fall in this range. A value of $\beta$ of 0.01 corresponds to a risk where the individual has no influence on the decision and perceives no benefits. Living near a hazardous installation while the installation does not generate direct benefits for the community falls in this range.

To judge the acceptability of a given value of the flooding probability by the criterion of Vrijling, the individual death probability and the distribution of the yearly number of casualties should be written as a function of the flooding probability. In chapter 4 it was established that the added probability of death is given by:

$P_{d}=E\left(c_{\text {cas }}\right) P_{\text {flood }}$

Where:

$E\left(c_{c a s}\right): \quad$ Expected value of casualty factor;

$P_{\text {flood: }} \quad$ Flooding probability.

If a deterministic value of the casualty factor is adopted, equation (129) simplifies to:

$P_{d}=c_{\text {cas }} P_{\text {flood }}$

Substitution of equation (130) in equation (127) leads to the following constraint on the flooding probability:

$$
P_{\text {flood }} \leq \frac{\beta}{c_{\text {cas }}} 10^{-4}
$$

The application of the dike ring schematisation and a deterministic value of the casualty factor implies that the probability distribution of the yearly number of flooding casualties is given by a binomial distribution (see chapter 4). 
The number of casualties given the occurrence of a flood is given by:

$$
N_{d \mid \text { flood }}=c_{\text {cas }} N_{p}
$$

Where:

$N_{p}$ : $\quad$ Population of the area;

$c_{\text {cas }}: \quad$ Deterministic casualty factor.

The probability of occurrence of $N_{d \mid f l o o d}$ casualties equals the flooding probability. Substitution in equation (128) leads to a second constraint on the flooding probability:

$$
P_{\text {flood }} \leq\left(\frac{\beta}{c_{\text {cas }}}\right)^{2}\left(\frac{100}{k N_{p}}\right)^{2}
$$

The current population of the area can be obtained from the database of the Dutch Central Bureau of Statistics (CBS on internet). Following the recommendation by Vrijling et al. the value of $k$ is chosen at 3 .

Using the data in table 53, the acceptable flooding probability is a function of the ratio between $\beta$ and $c_{c a s}$ only. The choice of the value of $\beta$ reflects the type of risk that flooding risk is considered to be; whether voluntary or involuntary taken and with or without perceived benefits. For decision-making on flood protection, $\beta$ may be expected to be in the range of 0.1-0.01.

The estimate of $c_{\text {cas }}$ depends on the level of detail with which the risk calculation can be performed. Based on an analysis of historical flooding events (CUR/TAW, 1990) a range of 0.01-0.1 may be expected. Because both the casualty factor and the policy factor can not be established with accuracy, acceptable values of the flooding probability will be calculated for $\beta / c_{\text {cas }}$ in a range of 0.1-10.

Figure 134 shows the acceptable flooding probability as a function of the population of the area if the value of $\beta / c_{\text {cas }}$ equals 1 .

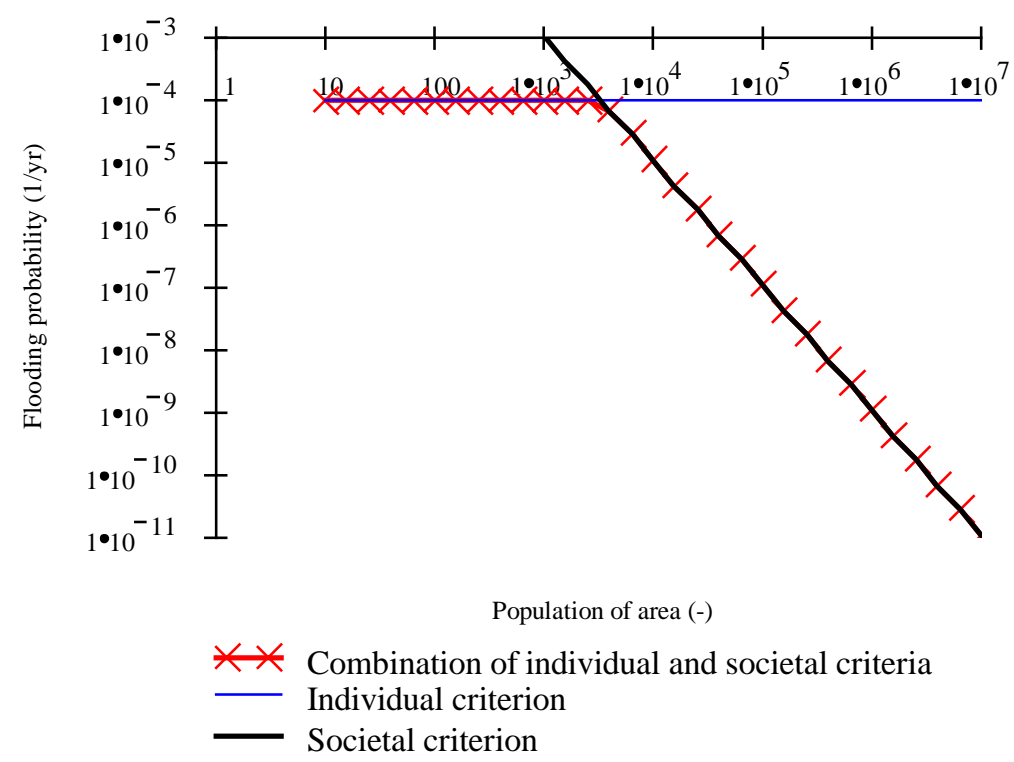

Figure 134: The safety norm of Vrijling et al $(1995,1998 b)$ with $\beta / c_{\text {cas }}$ equal to 1 
The constraint on the flooding probability is defined as the minimum of the individual and societal criteria. For different values of $\beta / c_{c a s}$, the acceptable flooding probability can thus be established (figure 135).

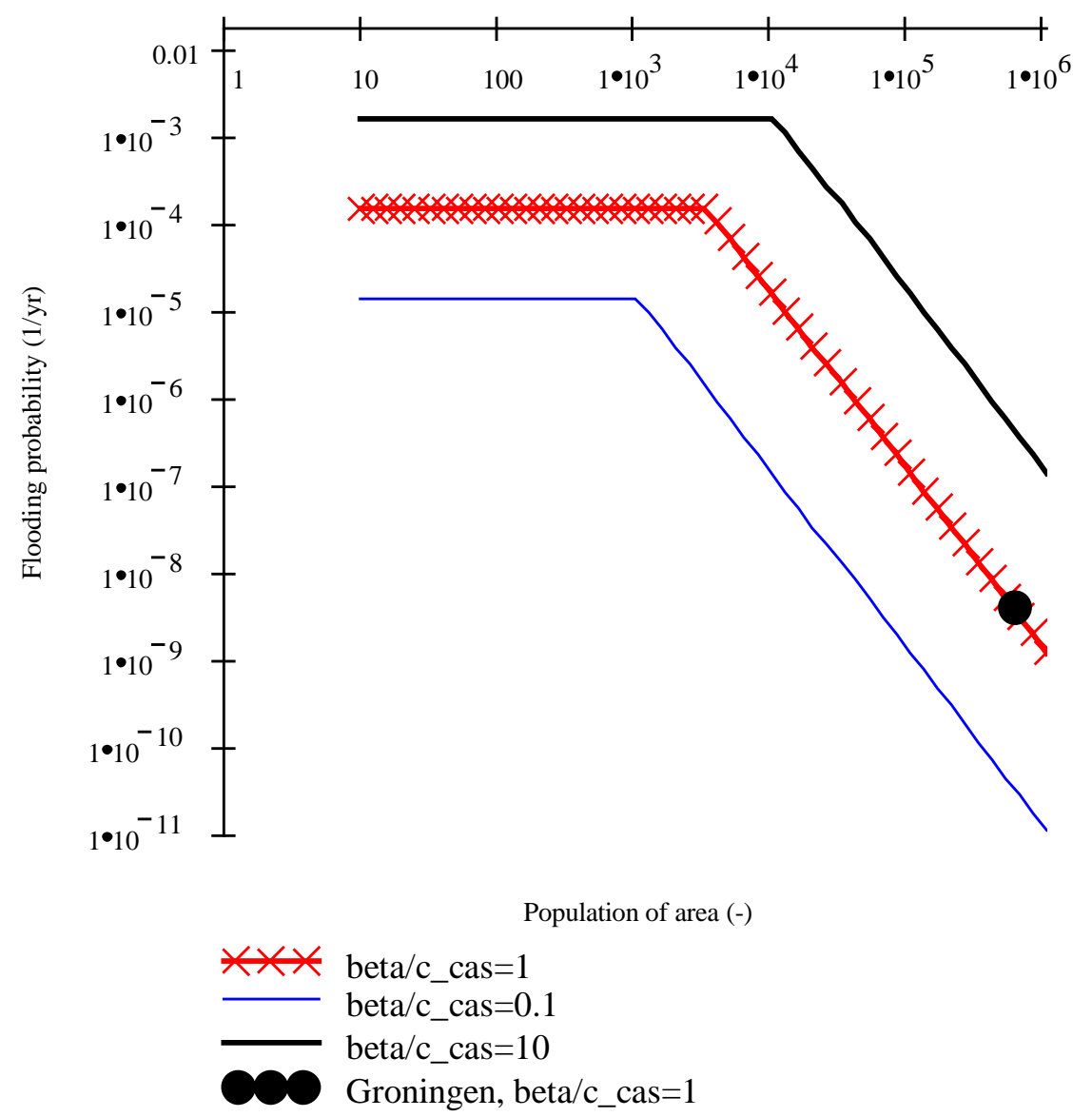

Figure 135: The safety norm of Vrijling et al $(1995,1998 b)$ for three values of $\beta / c_{\text {cas }}$

For the parameter values chosen, the maximum flooding probability according to the norm for individual risk lies between $10^{-3}$ per year to $10^{-5}$ per year. For a population of the size of Groningen (table 53), the societal requirement is decisive. Depending on the value of $\beta / c_{\text {cas }}$ the maximum flooding probability varies between $3.5 \cdot 10^{-7}$ per year and $3.5 \cdot 10^{-11}$ per year.

The maximum probabilities of flooding are obtained by considering the population of the dike ring Groningen in 2001. A flood protection system is generally designed and constructed for a reference period in the order of 50 to 100 years. The individual and societal limits on the flooding probability should in principle be met at any point in time. For a growing population, this implies that the probability bounds should be calculated using the (forecasted) population size at the end of the reference period. Figure 136 shows the acceptable flooding probability for $\beta / c_{c a s}=1$ as a function of the reference period in years. 


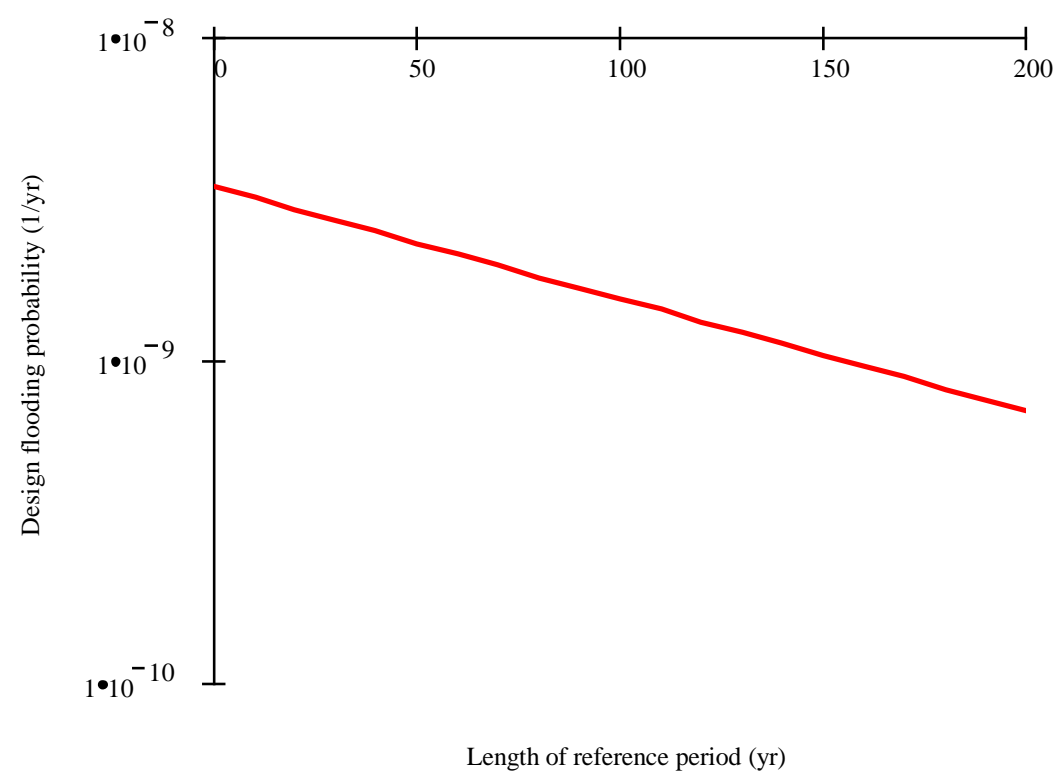

Figure 136: Design flooding probability using the model of Vrijling et al. (1995, 1998b) as a function of the length of the reference period

\subsubsection{Cost-benefit analysis of acceptable flooding probability}

The cost-benefit model for flood protection is developed in chapter 2. The input for the model consists of:

- An estimate of the cost of protection as a function of flooding probability;

- Estimates of direct and indirect economic damage in case of flooding.

The cost of protection is given by the cost function that is established in section 8.3. The estimates of direct and indirect damage are obtained from data on the economic properties of the area and assumed values of the damage factors. More details are given in chapters 2 and 4 .

The life-cycle cost-benefit model is combined with an acceptance rule to establish the acceptable flooding probability. Table 58 provides an overview of the acceptance rules used in the case study Groningen.

Table 58: Overview of acceptance rules applied in cost-benefit modelling of the flooding probability of Groningen

\begin{tabular}{lll}
\hline $\begin{array}{l}\text { Acceptance } \\
\text { rule number }\end{array}$ & Description & Remark \\
\hline 1 & Direct cost of protection only & $\begin{array}{l}\text { Probability constraint taken from section } \\
8.4 .2 .\end{array}$ \\
2 & Benefits excluded, optimised safety level & \\
3 & $\begin{array}{l}\text { Benefits included, non-negative life-cycle } \\
\text { benefits }\end{array}$ & \\
5 & $\begin{array}{l}\text { Benefits included, maximised life-cycle } \\
\text { benefits }\end{array}$ \\
\hline
\end{tabular}

Combination of the cost-benefit model with acceptance rule 1 implies that only the direct cost of protection is considered in the analysis. Because the cost of protection is a decreasing function of the flooding probability (section 8.3), cost minimisation always leads to an optimal flooding probability equal to the constraint that is set on the flooding probability. 
If the acceptable flooding probability according to Vrijling et al. (1995, 1998b, section 8.4.2) is used as a constraint, the corresponding cost of protection can be obtained from the cost-benefit model. Table 59 shows the results.

Table 59: Cost of protection corresponding to the acceptable flooding probabilities by Vrijling et al (1995, 1998b)

\begin{tabular}{lcc}
\hline$\beta / c_{\text {cas }}$ & Acceptable flooding probability $(\mathbf{1} / \mathbf{y r})$ & Cost of protection $(\mathbf{G €})$ \\
\hline 0.1 & $3.5 \cdot 10^{-11}$ & 51.3 \\
1.0 & $3.5 \cdot 10^{-9}$ & 22.2 \\
10 & $3.5 \cdot 10^{-7}$ & 9.6 \\
\hline
\end{tabular}

In acceptance rule 2, the direct economic damage in case of flooding is included in the analysis and minimisation of the sum of the cost of protection and the expected value of the direct economic damage is required. Acceptance rule 2 can be summarised as lifetime cost minimisation. This is the type of analysis that is closest to the analysis by van Dantzig (1956). Figure 137 shows the lifetime costs as a function of the flooding probability.

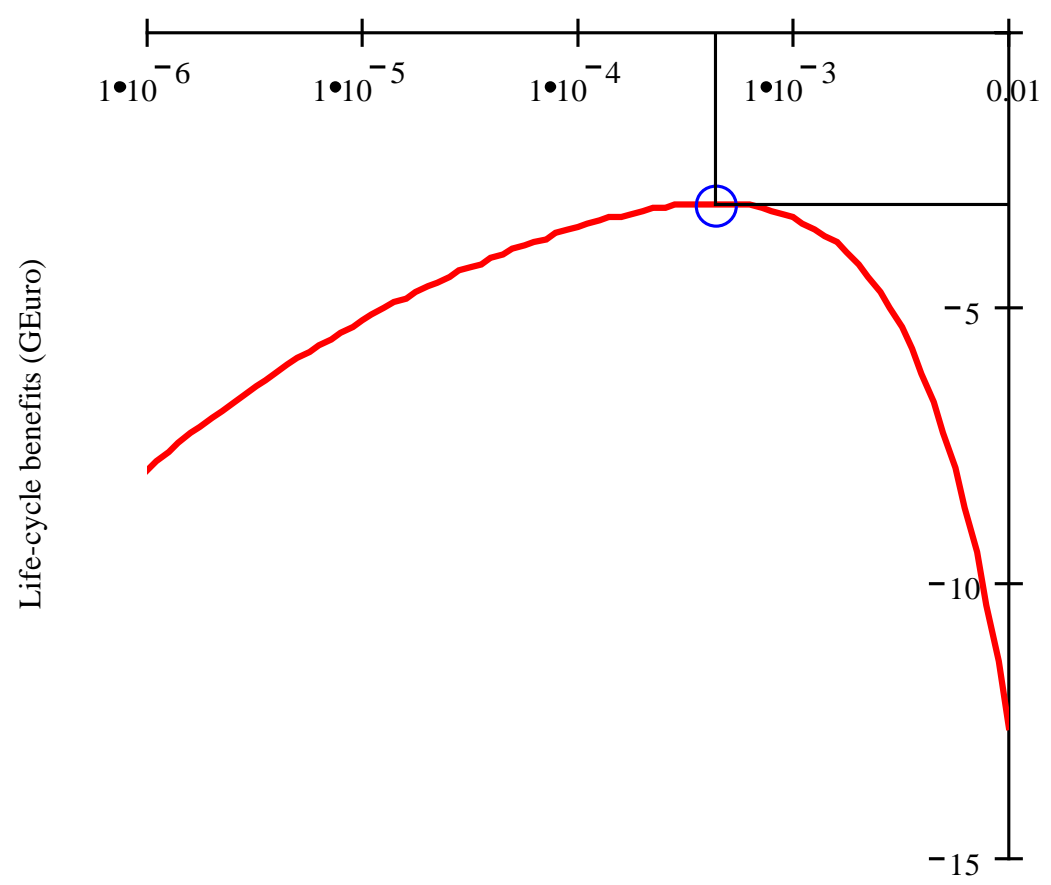

Probability of flooding (1/yr)

Figure 137: Application of lifetime cost minimisation (acceptance rule 2) to the dike ring Groningen

Combination of the cost-benefit model with acceptance rule 2 neglects the benefits that are normally generated in the area. Therefore, the maximum of the cost-benefit model is negative and takes a value of $-\mathrm{G} €$ 3.30. The optimal flooding probability equals $3.3 \cdot 10^{-4}$ per year. In chapter 4 it is shown that application of an improved model for the development of damage in case of flooding may ultimately lead to a reduced value of the expected value of the damage factor $c_{d}$. The optimal flooding probability is therefore dependent on the damage estimate.

Table 60 shows the results for three levels of the damage factor $c_{d}$. 
Table 60: Results of analysis of acceptable flooding probability by life-cycle cost minimisation (acceptance rule 2)

\begin{tabular}{lllll}
\hline$c_{d}(-)$ & $\begin{array}{l}\text { Flooding prob. } \\
\left(\mathbf{1 0}^{-4} / \mathbf{y r}\right)\end{array}$ & $\begin{array}{l}\text { Direct cost of } \\
\text { protection }(\mathbf{G} \mathbf{)})\end{array}$ & $\begin{array}{l}\text { Lifetime direct } \\
\text { economic damage }(\mathbf{G} \mathbf{)})\end{array}$ & $\begin{array}{l}\text { Total lifetime cost } \\
(\mathbf{G} \mathbf{\epsilon})\end{array}$ \\
\hline 0.01 & 162 & 1.36 & 0.25 & 1.60 \\
0.1 & 23.0 & 1.93 & 0.35 & 2.29 \\
1.0 & 3.28 & 2.76 & 0.50 & 3.26 \\
\hline
\end{tabular}

In acceptance rules 3 and 5, the benefits are included in the analysis. Acceptance rule 3 defines an acceptable flooding probability as a flooding probability where the sum of lifetime costs and benefits are non-negative. Figure 138 shows the full cost-benefit model for a wide range of values of the flooding probability.

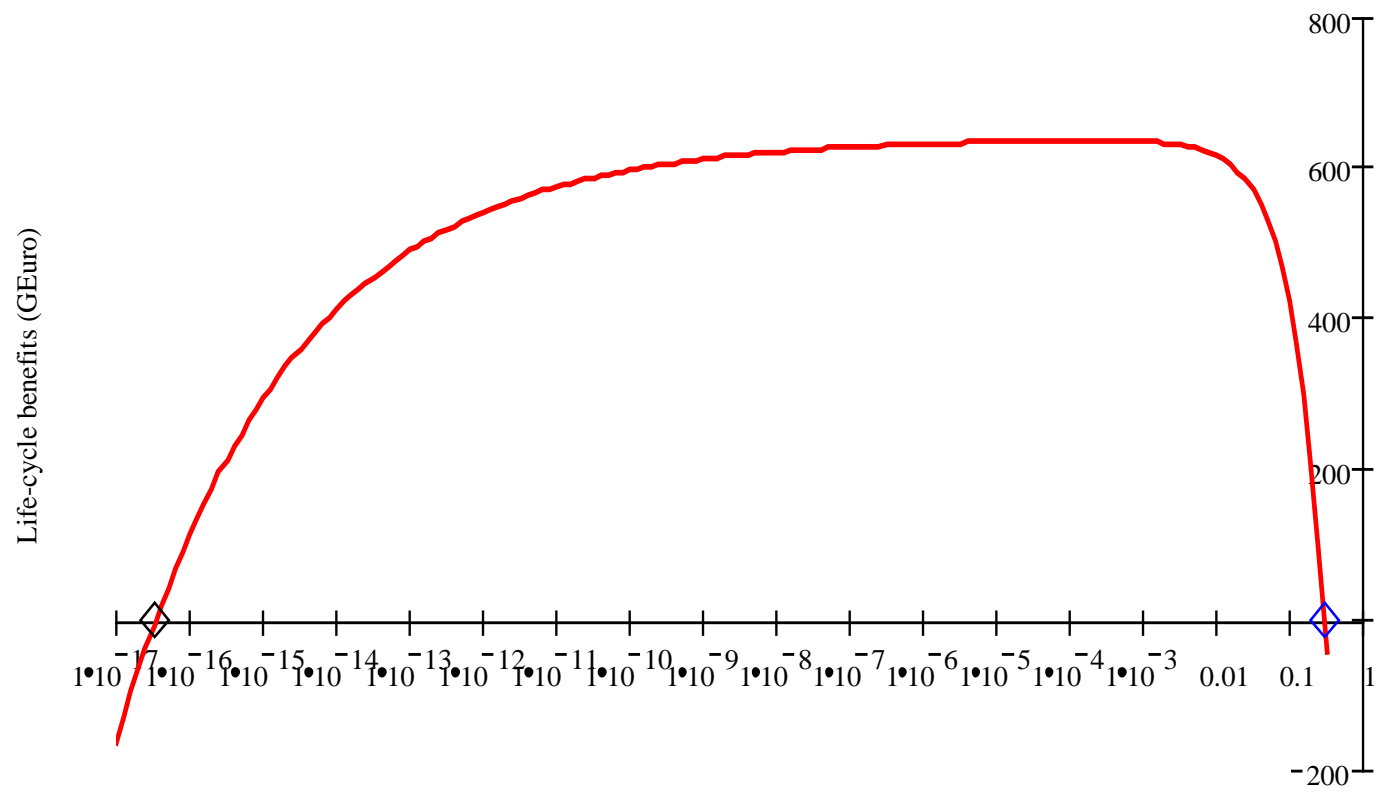

Probability of flooding $(1 / \mathrm{yr})$

Figure 138: Full cost-benefit model and acceptability limits requiring non-negative sum of costs and benefits (acceptance rule 3)

The range of acceptable flooding probabilities according to acceptance rule 3 is very wide. The highest value is approximately 0.3 per year; the lowest approximately $10^{-17}$ per year. Practically, acceptance rule 3 appears not to provide any limitation on the possible values of the acceptable flooding probability.

Acceptance rule 5 requires maximisation of the sum of costs and benefits. Figure 139 again shows the full cost-benefit model as a function of flooding probability. The damage factors $c_{b}$ and $c_{d}$ are set to 1 . 


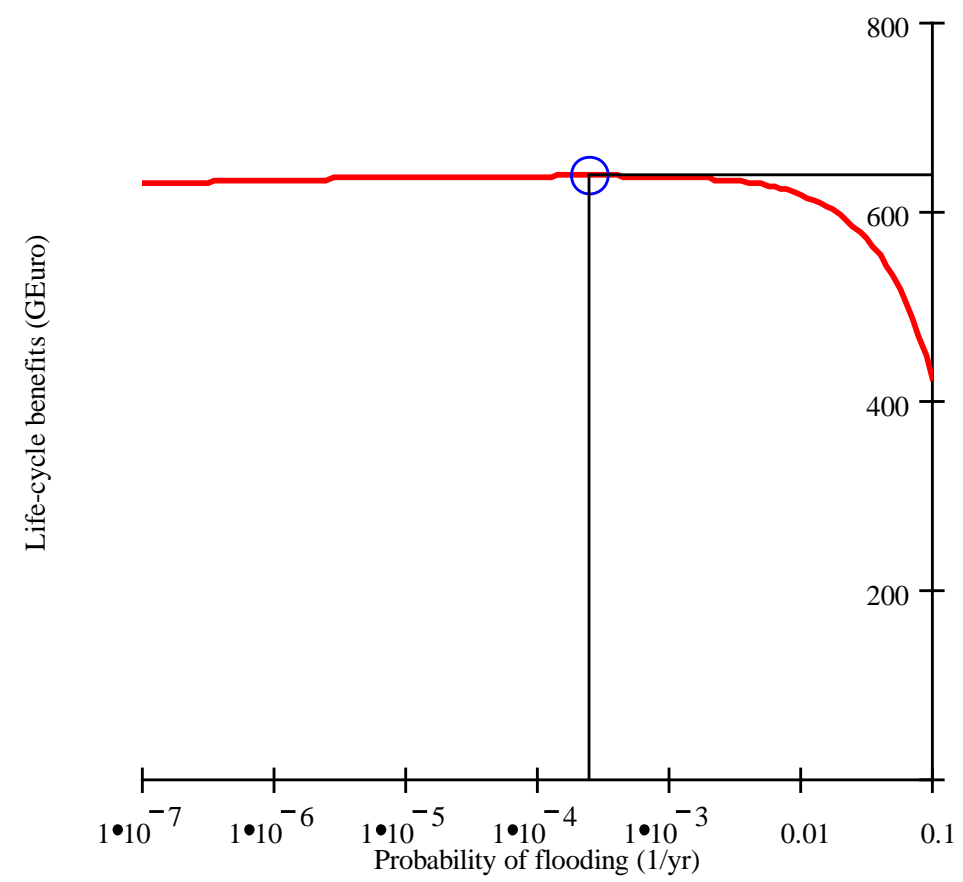

Figure 139: Maximisation of the sum of costs and benefits (acceptance rule 5) applied to the dike ring Groningen

If benefits are generated in the area, a flood will not only lead to direct damage but also to an interruption of the flow of benefits. Therefore, the optimal flooding probability is slightly lower than in case of lifetime cost minimisation. The optimal flooding probability equals $2.4 \cdot 10^{-4}$ per year, leading to a maximum value of the costbenefit model of $\mathrm{G} €$ 638.--

As is the case in life-cycle cost minimisation, the result of life-cycle benefit maximisation depends upon the level of detail with which the calculation of flooding consequences is performed. Ultimately, a more detailed schematisation may lead to a lower damage estimate. On the other hand, the macro-economic consequences of flooding may increase the value of $c_{b}$. Table 61 shows the results of benefit maximisation for different values of $c_{b}$. The value of $c_{d}$ is taken at one in all cases.

Table 61: Results of analysis of acceptable flooding probability by life-cycle cost minimisation (dec. rule 5)

\begin{tabular}{llllll}
\hline$c_{b}(-)$ & $\begin{array}{l}\text { Flooding } \\
\text { prob. }\left(\mathbf{1 0}^{-5} / \mathbf{y r}\right)\end{array}$ & $\begin{array}{l}\text { Direct cost of } \\
\text { protection } \\
(\mathbf{G €})\end{array}$ & $\begin{array}{l}\text { Lifetime indirect } \\
\text { damage }(\mathbf{G} \boldsymbol{)})\end{array}$ & $\begin{array}{l}\text { Lifetime direct } \\
\text { damage }(\mathbf{G})\end{array}$ & $\begin{array}{l}\text { Total economic } \\
\text { damage }(\mathbf{G} \boldsymbol{)})\end{array}$ \\
\hline 0.10 & 31.7 & 2.78 & 0.02 & 0.49 & 0.51 \\
1.0 & 24.4 & 2.91 & 0.16 & 0.37 & 0.53 \\
10 & 8.10 & 3.56 & 0.53 & 0.12 & 0.65 \\
\hline
\end{tabular}

\subsubsection{Utility analysis of acceptable flooding probability}

Utility analysis can be applied to model risk aversion in a cost-benefit based decision model. In chapter 2, a model is developed based on the cost-benefit model for flood protection and an exponential utility model. Figure 140 shows the utility as a function of flooding probability when applied to the dike ring Groningen. The risk aversion parameter $\gamma$ equals 2 . The damage factors $c_{b}$ and $c_{d}$ are both equal to 1 . 


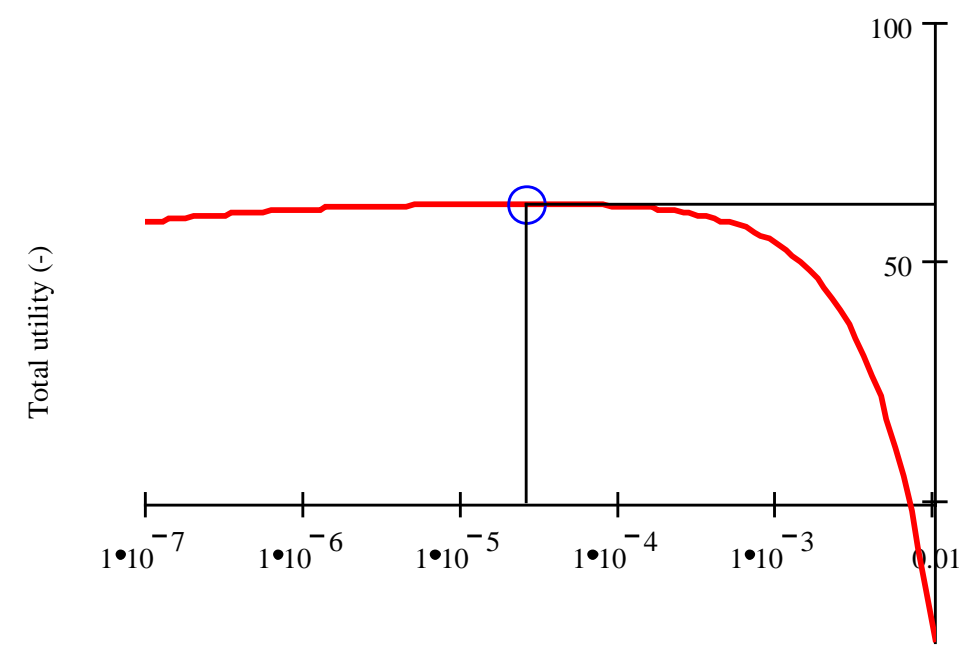

Probability of flooding $(1 / \mathrm{yr})$

Figure 140: Cost-benefit model combined with an exponential utility model applied to the dike ring Groningen

Including risk aversion by an exponential utility model lowers the optimal flooding probability. For the case in figure 140 the optimal flooding probability equals $5.2 \cdot 10^{-6}$ per year. As shown in chapter 2, risk aversion requires the uncertainty on the summed costs and benefits to be reduced. Table 62 shows the result for a few values of the risk aversion parameter $\gamma$.

Table 62: Results of optimisation of the flooding probability of the dike ring Groningen using a utility model including risk aversion

\begin{tabular}{llllll}
\hline$\gamma(-)$ & $\begin{array}{l}\text { Flooding } \\
\text { probability } \\
(\mathbf{1 0} \mathbf{- 6} / \mathbf{y r})\end{array}$ & $\begin{array}{l}\text { Cost of } \\
\text { protection }(\mathbf{G} \boldsymbol{€})\end{array}$ & $\begin{array}{l}\text { Exp. lifetime } \\
\text { benefits }(\mathbf{G} \boldsymbol{€})\end{array}$ & $\begin{array}{l}\text { St. dev. of } \\
\text { lifetime benefits } \\
(\mathbf{G} \boldsymbol{€})\end{array}$ & $\begin{array}{l}\text { Coeff. of var. of } \\
\text { lifetime benefits } \\
(\boldsymbol{\%})\end{array}$ \\
\hline 0 & 244 & 2.91 & 647.0 & 3.85 & 0.60 \\
1 & 41.9 & 4.01 & 643.4 & 1.60 & 0.25 \\
2 & 5.2 & 5.88 & 641.6 & 0.56 & 0.09 \\
\hline
\end{tabular}

Optimisation with higher values of the risk aversion parameter reduces the uncertainty on the pay-off at the cost of a reduction of the expected value of the pay-off.

\subsubsection{Life quality analysis of acceptable flooding probability}

The life quality method is due to Nathwani et al. (1997) and is introduced as a model for decision-making on flood protection in chapter 2 . The life quality method uses a social indicator, the life quality index, to quantify the effects of the level of protection against flooding. The life quality index measures the combination of effects on the Gross Domestic Product (GDP) per capita and the life expectancy at birth.

The effects of flood protection on the Gross Domestic Product are quantified by the cost-benefit model. The life expectancy at birth for the Dutch society and the effects of flood risk on the life expectancy are quantified in chapter 4. Application to the dike ring Groningen leads to the result shown in figure 141. The damage factors for casualties, direct economic damage and indirect economic damage are all taken at 1 . 


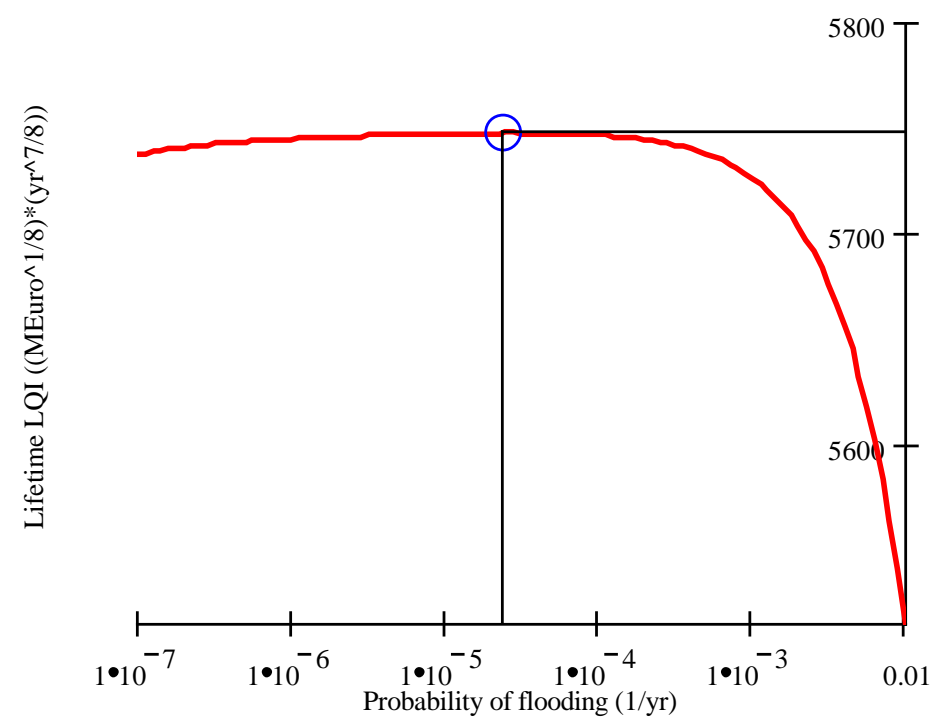

Figure 141: Life quality model applied to the dike ring Groningen

The life quality model indicates an optimal flooding probability of $2.3 \cdot 10^{-5}$ per year, a value that is approximately one order of magnitude lower than the cost-benefit optimum of $2.4 \cdot 10^{-4}$ per year.

The results depend upon the modelling of flooding consequences through the values of the three damage factors. Table 63 shows the effects of the damage factor for casualties on the optimal design of the protection system.

Table 63: Results of analysis of acceptable flooding probability by life quality maximisation

\begin{tabular}{lllll}
\hline$c_{\text {cas }}(-)$ & $\begin{array}{l}\text { Flooding prob. } \\
\left(\mathbf{1 0}^{-6} / \mathbf{y r}\right)\end{array}$ & $\begin{array}{l}\text { Direct cost of protection } \\
\text { (GEuro) }\end{array}$ & $\begin{array}{l}\text { Total expected } \\
\text { economic loss } \\
\text { (MEuro) }\end{array}$ & $\begin{array}{l}\text { Loss of life } \\
\text { expectancy at birth } \\
\left(\mathbf{1 0}^{-4} \text { year) }\right.\end{array}$ \\
\hline 0.01 & 40.6 & 4.04 & 88.5 & 12.9 \\
0.1 & 23.3 & 4.47 & 50.7 & 73.6 \\
1.0 & 4.64 & 5.99 & 10.1 & 146.8 \\
\hline
\end{tabular}

\subsection{Comparison of models for acceptable flooding probability}

In the previous section, the acceptable flooding probability for a number of combinations of models and acceptance rules were shown. In this section, the flooding probabilities resulting from different models will be compared to each other. Only the optimal flooding probabilities (acceptance rule 5) will be shown. The comparison is performed for different parameter settings. An overview of the parameters that are varied is shown in table 64 together with the chosen default values.

Table 64: Overview of parameters varied in the comparison of models for acceptable flooding probability

\begin{tabular}{llll}
\hline Parameter & Symbol & Default value & Range of variation \\
\hline Damage factor direct economic damage & $c_{d}$ & 1 & $0.01 . .1$ \\
Damage factor indirect economic damage & $c_{b}$ & 1 & $0.1 . .5$ \\
Damage factor casualties & $c_{c a s}$ & 1 & $0.0001 . .1$ \\
Policy factor (Vrijling) & $\beta$ & 0.1 & $0.01 . .10$ \\
Risk aversion parameter (utility) & $\gamma$ & 2 & $-1 .+4$ \\
Life quality parameter & $w$ & 0.125 & $0.01 . .1 .0$ \\
\hline
\end{tabular}


The first three parameters are all related to the level of detail with which the calculation of flooding consequences is performed. Inspecting the optimal flooding probability as a function of these parameters provides some insight in the effects of extra effort in the analysis of flooding consequences. The default values are all chosen at 1 . For the direct economic damage and the number of casualties, this value provides an upper bound. For the indirect economic damage it is not certain whether the default value is an upper bound. Chapter 4 provides more details.

The second group of three parameters are all measures of risk aversion. The default value of the policy factor in the model of Vrijling is chosen at 0.1 , which is the value for an involuntary risk with limited benefits (Vrijling et al., 1995, 1998b). The default value of the risk aversion parameter in the exponential utility model is chosen at 2 . According to Nathwani et al. (1997) the parameter $w$ in the life quality model is approximately 0.125 for developed countries. Therefore, this value is chosen as the default.

The acceptable flooding probabilities for a number of models are shown as a function of the damage factor for direct economic damage $c_{d}$ in figure 142.

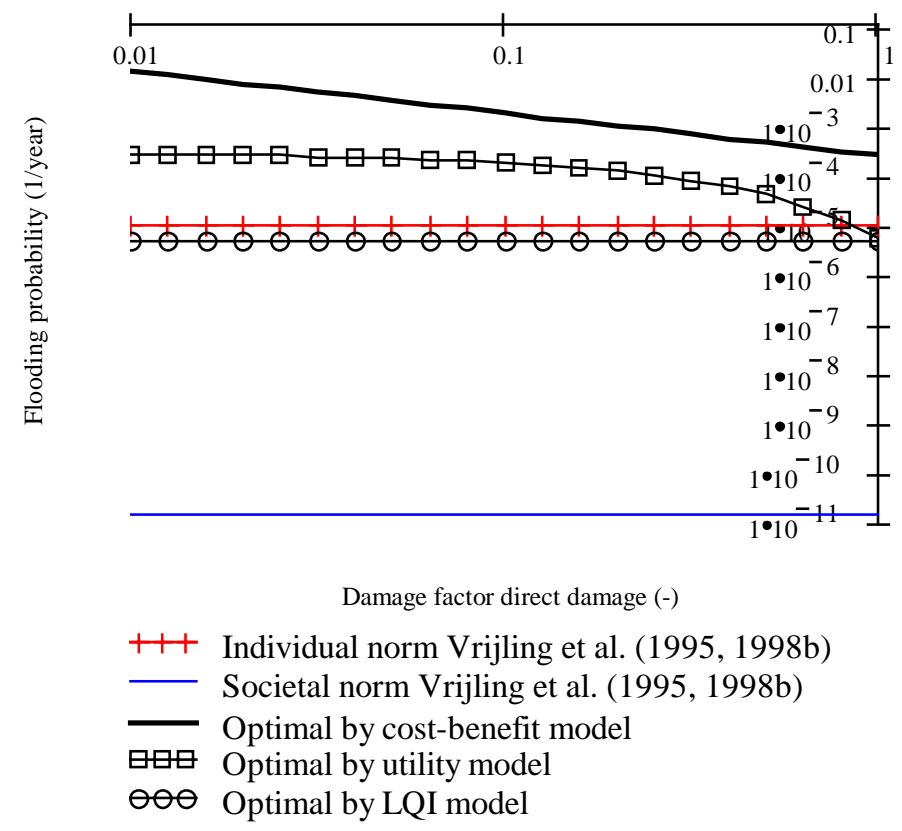

Figure 142: Acceptable flooding probability of the dike ring Groningen as a function of the damage factor for direct economic damage, derived by six different methods

The cost-benefit model and the utility model both show an increase of the optimal flooding probability as a function of decreasing damage factor $c_{d}$. For decreasing damage factor, the optimal flooding probability according to the utility model converges to a value of approximately $2.5 \cdot 10^{-4}$ per year. The optimal flooding probability according to the cost-benefit model consistently increases with decreasing damage factor. The utility model includes the uncertainty on the pay-off in the decision on flood protection (chapter 2). Figure 142 shows that accounting for the uncertainty in pay-off provides an upper limit on the acceptable flooding probability in comparison to the cost-benefit model.

Despite the fact that the life quality index is a function of the economic damage parameters, the effect of a change in the estimate of the direct economic damage has little influence on the optimal flooding probability by the life quality model. The 
individual and societal criterion for the acceptable flooding probability are not a function of the economic parameters and are therefore constant.

Figure 143 shows the effect of the value of the damage factor for indirect economic damage $c_{b}$ on the acceptable flooding probability.

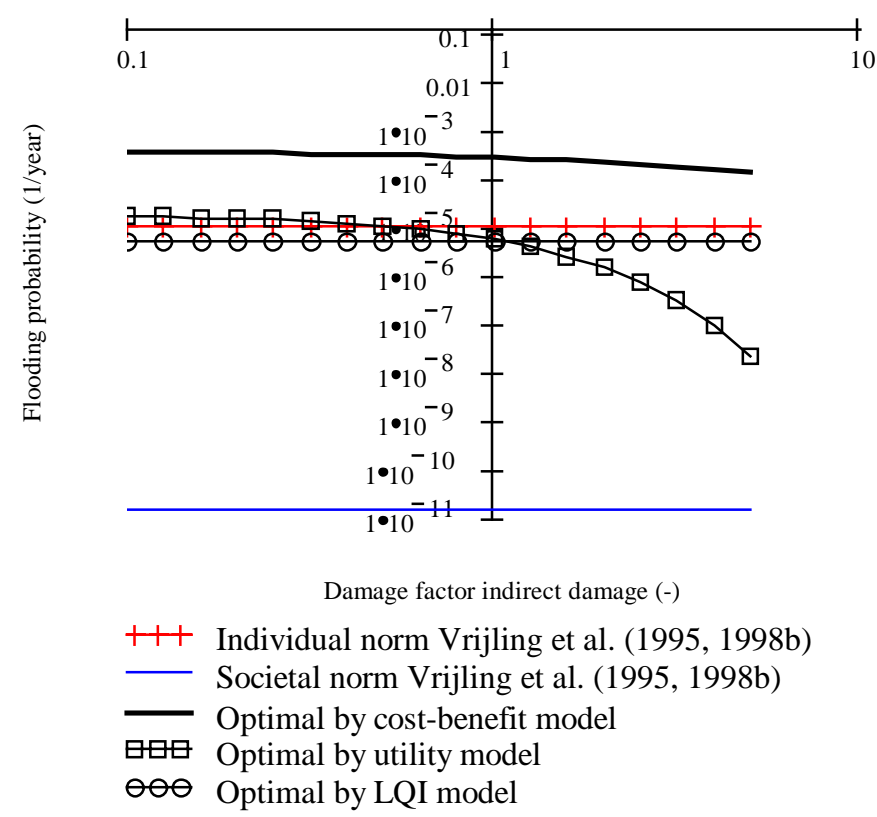

Figure 143: Acceptable flooding probability of the dike ring Groningen as a function of the damage factor for indirect economic damage, derived by six different methods

The effect of the damage factor for indirect damage is similar to the effect of the damage factor for direct damage. Similar to the previous case, only the cost-benefit model and the utility model respond to changes in the damage factor. The utility model responds more strongly than the cost-benefit model. The LQI model again shows limited response to changes in the damage factor.

Figure 144 shows the acceptable flooding probability by different models as a function of the casualty factor $c_{c a s}$. 


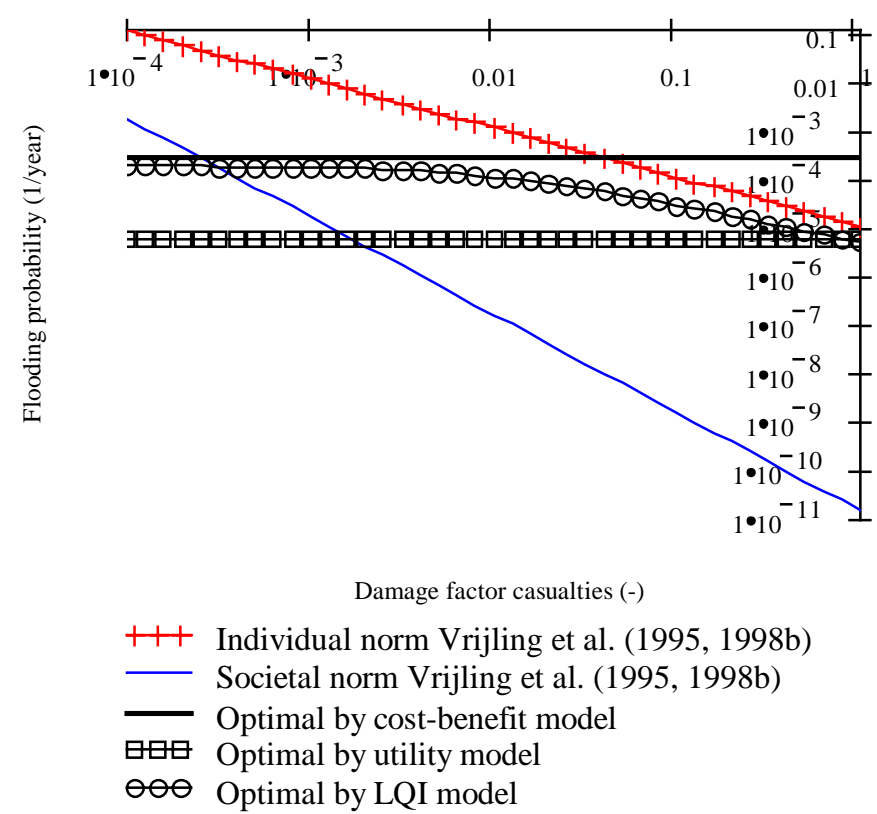

Figure 144: Acceptable flooding probability of the dike ring Groningen as a function of the damage factor for casualties, derived by six different methods

The acceptable flooding probabilities according to Vrijling et al. $(1995,1998 b)$ are direct proportional to the relative number of casualties in case of flooding $c_{c a s}$. The strong response of the acceptable flooding probabilities according to these two models is therefore not surprising. The life quality model includes effects both of economic losses and of loss of life. The optimal flooding probability according to the life quality model decreases for increasing casualty factor. For very low casualty factors, the life quality optimum converges to the cost-benefit optimum. The life quality model provides a relatively constant safety level for areas where the risk of loss of life is dominating and a cost-benefit optimal safety level for areas where the risk of economic losses is dominating. This behaviour of the life quality model was shown earlier in a study by Voortman et al. (2001). The cost-benefit model and the utility model are not a function of the casualty factor and therefore the optimal flooding probability according to these two models is constant.

The policy factor $\beta$ is a parameter that is unique to the definition of the acceptable probability of death by Vrijling et al. $(1995,1998 b)$. It is therefore not unexpected that only the flooding probabilities based on these two models respond to changes in the policy factor (figure 145). 


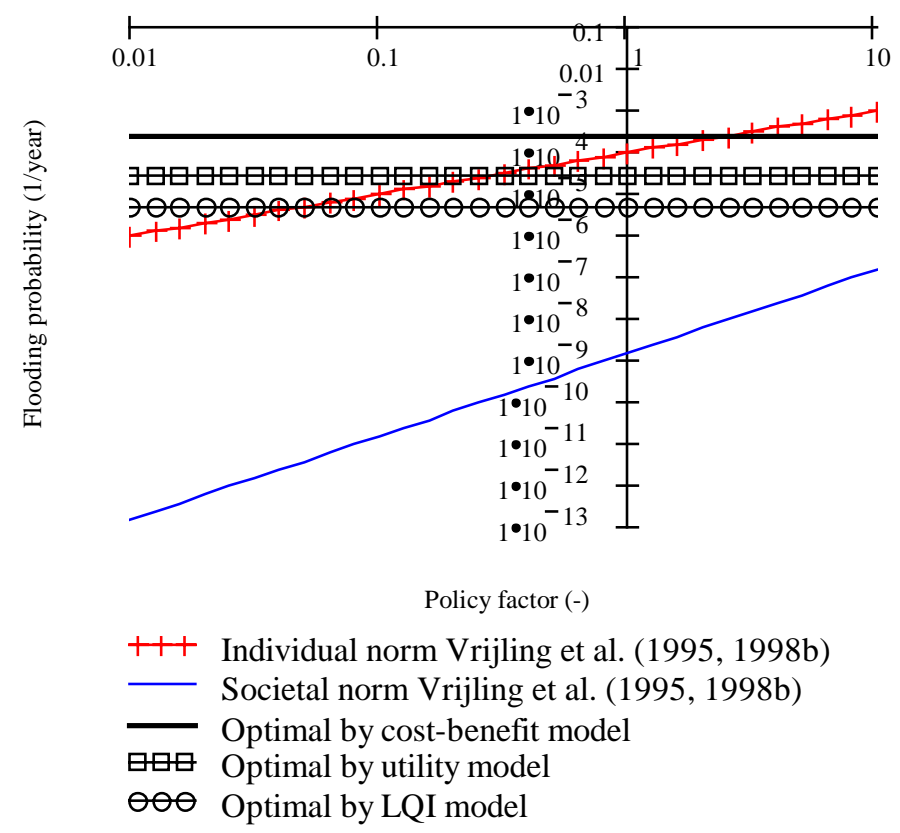

Figure 145: Acceptable flooding probability of the dike ring Groningen as a function of the policy factor, derived by six different methods

For the models of Vrijling et al. (1995, 1998b) the effect of a change in policy factor is the reciprocal of the effect of a change in the damage factor for casualties (see section 8.4.2).

In the utility model, the parameter $\gamma$ is a measure for the risk aversion. For increasing risk aversion, the optimal flooding probability according to the utility model decreases (figure 146).

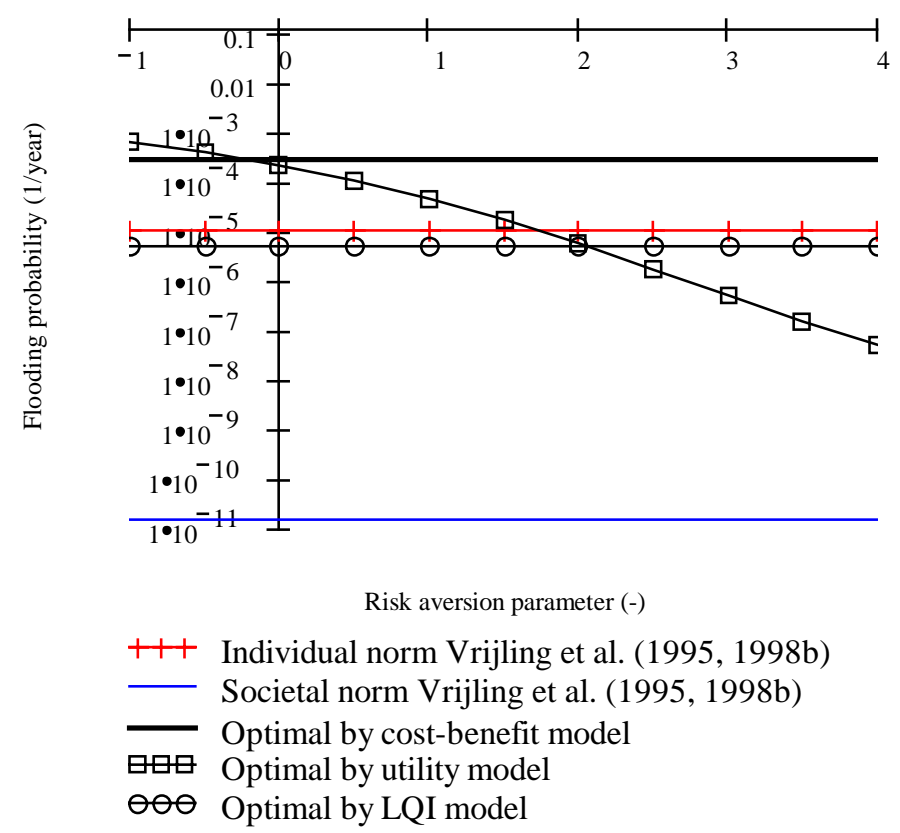

Figure 146: Acceptable flooding probability of the dike ring Groningen as a function of the risk aversion parameter, derived by six different methods

A value $\gamma=0$ indicates risk neutrality in which case the utility model is equal to the cost-benefit model. For values lower than 0 the modelled decision-maker is riskprone. This leads to values of the optimal flooding probability that are higher than the 
risk-neutral cost-benefit optimum. The modelled decision-maker in that case is limiting the investment in protection and is effectively gambling on the uncertainty in the pay-off. A risk-averse decision-maker is modelled by $\gamma>0$. The tendency to reduce the uncertainty on the pay-off gets stronger and stronger for increasing value of $\gamma$, leading to a decreasing optimal flooding probability.

In the life quality model, the parameter $w$ is a measure of how life expectancy is weighed against expected gross domestic product per capita. For $w=1$, the life quality model responds only to changes in gross domestic product. The optimal flooding probability in that case equals the cost-benefit optimum. For $w=0$, the life quality model only responds to changes in life expectancy, irrespective of the monetary consequences of the decision. According to Nathwani et al. (1997) $w$ is equal to the relative average lifetime that an individual spends working and gaining income. Thus appropriate values of $w$ may be inferred from statistics on working hours and life expectancy. Changes in society may change the value of $w^{22}$. It is therefore useful to see the effect of a change in $w$ on the acceptable flooding probability. Figure 147 shows the result.

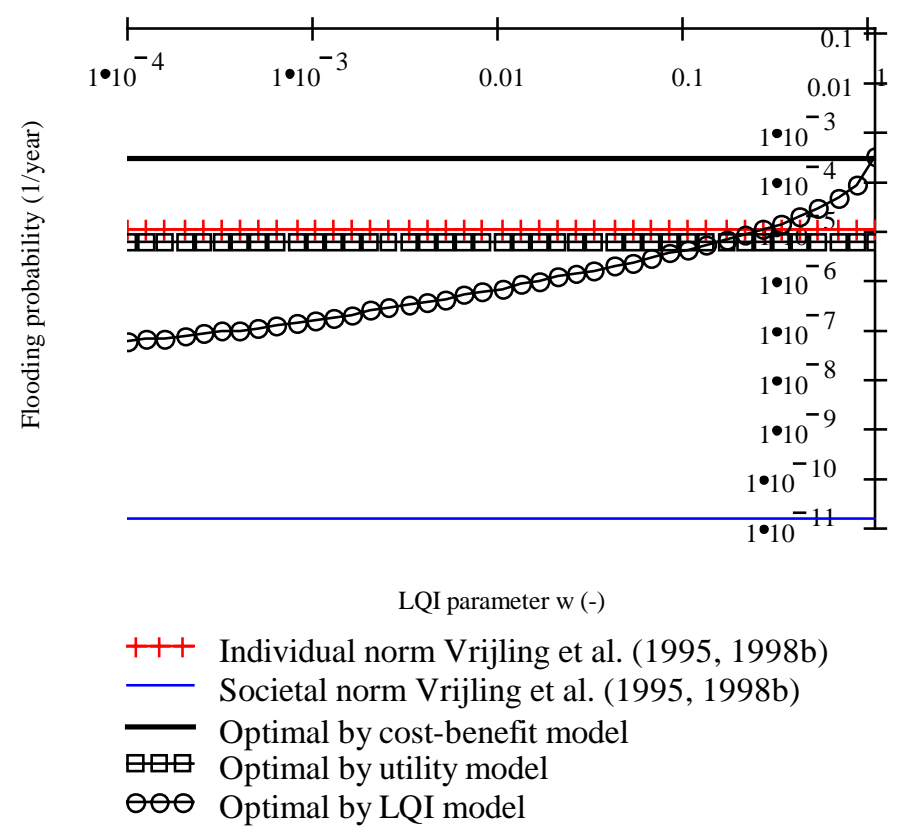

Figure 147: Acceptable flooding probability of the dike ring Groningen as a function of the LQI parameter $w$, derived by six different methods

The acceptable values of the flooding probability according to the LQI model increase for increasing value of $w$. For $w=1$ the LQI optimum equals the cost-benefit optimum. For $w=10^{-4}$ the LQI optimal flooding probability is more than three orders of magnitude lower than the cost-benefit optimal flooding probability. Accepting the hypothesis that the working time relative to the life expectancy is an estimate of $w$, a reasonable range of $w$ is from 0.1 to 0.2 . In that case the optimal flooding probability ranges from $3.9 \cdot 10^{-6}$ per year to $7.5 \cdot 10^{-6}$ per year.

The LQI criterion is defined on the basis of expected gross domestic product and life expectancy. Therefore, uncertainty on the GDP per capita or on the lifetime of an

\footnotetext{
${ }^{22}$ Nathwani et al. (1997) estimate the value of $w$ for Canada in 1890 at 0.28 and for 1993 at 0.125 .
} 
individual does not change the value of the life quality index and does therefore not influence decisions made by this model (see also chapter 2).

\subsection{Discussion}

Application of the reliability-based design method to the $86 \mathrm{~km}$ long flood protection system of the dike ring Groningen indicates that the method indeed enables the quantitative analysis of large-scale flood defence systems. The cost of protection of every individual dike section as a function of its failure probability can be approximated by assuming the logarithm of the cost to be a linear function of the logarithm of the failure probability.

The loading of all dike sections is strongly dominated by the offshore and nearshore wind conditions. Therefore a strong dependence between the different sections is observed. The system probability of failure of a system of 11 dike sections is at maximum 2.6 times the probability of failure of an individual dike section.

The choice of the design failure probability per section can be established by minimising the cost of protection on system level. The choice of equal failure probabilities for all sections leads to a negligible increase in cost of protection.

Application of different definitions of acceptable flooding probability to the dike ring Groningen leads to flooding probabilities in the range of $10^{-11}$ per year to $10^{-4}$ per year. These results are obtained using upper bound estimates of the consequences of flooding and a policy factor for involuntary risk. The lowest values result from the societal criterion of Vrijling et al. $(1995,1998 \mathrm{~b})$ that does not include the monetary costs of protection and the economic consequences of flooding. The highest value is obtained with risk-neutral cost-benefit optimisation. The models that do include monetary aspects provide a range of $5 \cdot 10^{-6}$ per year to $10^{-4}$ per year. The lowest value is in that case obtained by the life quality model, which includes both the monetary aspects and the effect of loss of life expectancy.

The life quality model indicates that risk of loss of life justifies higher protection levels but not to any price. Exploring the effects of changes in the estimates of the consequences of flooding indicates that the life quality model is especially sensitive to changes in the estimate of the number of casualties and not so much for changes in the estimates of the economic consequences. A disadvantage of the life quality model is that the model is not affected by uncertainty on the consequences of flooding. Analysis of the utility model indicates that under risk aversion the uncertainty on the effects of flooding has important influence on the appropriate safety level.

Of all the models used in this study, the life quality models at this point appears to be the best starting point for a workable compound model for decision-making on flood protection. On the basis of the underlying hypotheses of the life quality model (Nathwani et al., 1997) an alternative model may be developed that includes the uncertainty on the effects of flooding. Such a model combines the strong points of the life quality approach with the strong points of utility approaches in general. 


\section{CONCLUSIONS AND RECOMMENDATIONS}

"Quod erat demonstrandum"

\subsection{General}

This thesis deals with risk-based design of large-scale flood defence systems. A methodology has been developed that enables the use of quantitative methods for the risk-based design of flood defence systems. Thus, risk-based design of flood defences is brought to the same level of sophistication as the already existing methods for reliability-based design.

In the thesis, the following three main topics are treated:

- Establishing the appropriate level of protection against flooding by weighing of cost of protection against the consequences of flooding;

- Establishing the cost of protection of a large-scale flood defence system as a function of its performance measured in failure probability;

- The statistical description of the joint occurrence of extreme water level, wave height and wave period for the probabilistic design of flood defence systems.

The interaction between a changing natural environment and the growth of a complex society has taken place primarily by responding to repeated flooding disasters. Riskbased design is proposed to change from a reactive to a pro-active approach of the protection against flooding for the first time in history. To make the risk-based approach practicable, methods are developed to structure the information necessary for decision-making.

In this study decision-making on flood protection is split in three levels:

- Level A: decision-making on the appropriate probability of flooding on the level of protected areas;

- Level B: decision-making on the failure probability per individual structure in the protection system for a given value of the probability of flooding;

- Level C: decision-making on the geometry of an individual flood defence structure for given probability of failure.

In this three level structure, the societal decision-making process on flood protection takes place on level A. To support decision-making, costs of protection and consequences of flooding have to be quantified as a function of the protection level.

The costs of protection depend on decisions made regarding the layout and geometry of the protection system. In general it is possible to schematise a system as a ring of interconnected flood defence structures. Every structure contributes to the flooding probability through its individual flooding probability and to the cost on system level by the cost on structure level. An infinite number of combinations of failure probability per structure leads to the same value of the flooding probability. Decision level B aims at choosing the appropriate set of failure probabilities per structure for given flooding probability.

On the level of an individual structure, several alternative geometries will lead to the same value of the failure probability. Deciding on the appropriate geometry for a given value of the individual failure probability is the subject of decision level C. 
A flood defence structure may fulfil a number of functions. Considering only the function "protection against flooding", rational decision-making requires the minimisation of construction costs for a given level of performance. Minimisation of the construction costs on decision levels $\mathrm{B}$ and $\mathrm{C}$ is proposed to find:

- The minimum cost of construction on system level as a function of the flooding probability;

- The optimal allocation of failure probability to individual structures in the system;

- The optimal geometry of individual flood defence structures.

\subsection{Quantifying the joint distribution of hydraulic design conditions}

Under most circumstances, the uncertainty on the hydraulic loads dominates the reliability of coastal structures. The most important characteristics of the hydraulic loads are:

- Water level;

- Wave height;

- Wave period.

In shallow seas, a strong dependence exists between the three aspects of the hydraulic climate, because all three are the result of the wind field acting on the neighbouring water body.

In this study, a model is developed in which the hydraulic conditions are derived from the statistical properties of the wind fields by the application of parametric physical models. A hierarchical setup of the model is proposed in which the offshore hydraulic conditions are the result of the combination of wind field and shape of the basin and the nearshore conditions are the result of the offshore conditions and the local wind field.

The method is applied to describe the joint distribution of hydraulic conditions off the coast of the Dutch province of Groningen. The observed hydraulic conditions at offshore stations off the coast of Groningen show a dependence on the wind direction. The model of the hydraulic boundary conditions is calibrated for twelve separate wind directions. The dependence of the wind direction strongly suggests the observation data to be non-homogeneous. A method is proposed to derive the omni-directional distribution of extremes from the distributions per wind direction.

The omni-directional distributions derived from the directional model correspond to the empirical distribution of the omni-directional observations. Considerable differences occur in the estimation of the extreme right tail of the omni-directional distribution. The observed behaviour of the extreme tail is fully consistent with the hypothesis that its shape is determined by the tail behaviour of the wind directions causing the most extreme hydraulic conditions. It is observed in this case that the extreme quantiles of especially the water level and the significant wave height are considerably higher than the extreme quantiles derived by a classical peaks-overthreshold analysis.

\subsection{Reliability-based design of flood defences}

Numerical reliability methods for systems enable the quantification of the failure probability of a system of flood defence structures and failure modes. These methods can be combined with well-known minimisation routines to establish the design that fulfils a predefined failure probability requirement at minimum costs. 
An efficient and flexible way to optimise a large-scale system of flood defences is by a bottom-up approach, which consists of the following steps:

1. Break-down of the system in individual structures with independent sets of design variables;

2. Minimisation of the construction cost for every structure for a range of failure probabilities;

3. Minimisation of the construction cost on system level for a range of flooding probabilities by using the failure probability per structure as design variables and applying the results obtained on structure level.

Under most circumstances the bottom-up strategy is numerically more efficient than alternative approaches. The ability to solve the optimisation problem in small steps enhances the transparency of the analysis.

To be able to combine the results of the optimisation per structure to an optimisation on system level, the costs and the influence factors should be obtained as a function of the failure probability of the structure. Both results are easily obtained by performing reliability-based optimisation for a range of failure probabilities using a level II reliability method.

Application of the method to two flood defences in the Dutch province Groningen clearly shows the advantages of the proposed method. The method provides insight in the optimal geometry of a flood defence structure as a function of the local environmental and societal conditions. In addition, the sensitivity of the optimal design to uncertainties in input parameters is easily obtained.

An important application of reliability-based design of flood defences is as a tool in risk-based design of flood defences. The reliability-based design method can be applied to quantify the costs of flood protection on system level. The cost of protection established by this method includes the effect of all relevant inputs both from the natural environment as well as from society.

\subsection{Quantifying the consequences of flooding}

In risk-based design of flood defences, next to the cost of protection, the consequences of flooding need to be quantified. For application in risk-based design, the probability distribution of the consequences of flooding should be established.

In this study, flooding damage is split in two parts:

- Direct flooding damage;

- Indirect flooding damage.

Direct damage is defined as the damage that is a consequence of the contact with the flood water. Indirect damage is defined as a consequence of direct damage.

The development of direct damage in case of flooding takes place through a complicated process in which the following aspects play a role:

- Reliability of the flood defence system;

- Behaviour of a damaged flood defence structure;

- Environmental conditions before, during and after flooding;

- Layout of the affected area and the presence of height differences and historical flood defences;

- Value of the area and spatial distribution of the value of the area. 
It appears that research into flooding damage generally deals with only a part of the full process. In this study a conceptual model is proposed that covers all relevant processes for the quantification of flooding consequences.

To quantify the consequences of flooding, a schematisation of the area and the flood is necessary. In this study, three alternative schematisations are reported:

- Schematisation per dike ring;

- Schematisation per flooding scenario;

- Schematisation per sub-area.

In a simple case study, the three options for schematisation are compared. The schematisation per dike ring is the simplest. In the dike ring schematisation, the failure probability of the primary flood defence ring is considered an estimate of the flooding probability of every location in the area. This schematisation can be used to rapidly establish an upper bound estimate of the probability distribution of flooding consequences.

The schematisation per flooding scenario quantifies the consequences of flooding per flooding scenario. A flooding scenario is generally defined as one or more failures in a pre-defined location in the primary flood defence ring. Closer analysis of the scenario approach reveals that for any thus defined scenario, still a variety of consequences is possible. Furthermore, the individual scenarios are strongly dependent, both through the reliability of the flood defences as through the consequences of flooding. If the dependence between the scenarios is insufficiently accounted for, an over-estimation of the flooding consequences may occur. In practice, this problem is avoided by defining a set of representative scenarios. This introduces the danger of arbitrariness in the calculation of flooding consequences.

An alternative schematisation proposed in this study is the schematisation per subarea. In this schematisation, a number of sub-areas within the protected area is defined and for every sub-area the flooding probability is calculated separately. This schematisation avoids the problem of dependence through the flooding consequences, since this type of dependence is excluded from the beginning. The remaining dependence through the reliability of the flood defences is easily accounted for by well-known reliability methods.

In the case study it is shown that a reduction in the estimate of the expected flooding consequences can be obtained if the effect of secondary flood defences is accounted for. The possible reduction depends upon:

- The reliability of the elements of the primary defence ring;

- The reliability of the secondary flood defences;

- The dependence between the elements of the primary and secondary flood defences.

\subsection{Risk-based decision-making on the flooding probability (level A)}

\subsubsection{Theory}

Given the cost of protection as a function of flooding probability and the consequences of flooding, several quantitative models may be applied to find the appropriate flooding probability. The models used in this study are:

- Cost-benefit analysis;

- Utility analysis;

- Life quality analysis. 
Acceptable flooding probabilities can be found if a quantitative model is combined with an acceptance rule. In this study five types of acceptance rules are proposed for the cost-benefit model:

1. Minimisation of cost of protection for given failure probability requirement;

2. Minimisation of the sum of cost of protection and direct economic losses (lifetime cost minimisation);

3. Requiring a positive sum of lifetime costs and lifetime economic benefits;

4. Requiring the sum of lifetime costs and lifetime benefits to be higher than obtained at the existing protection level;

5. Maximisation of the sum of lifetime costs and lifetime benefits.

Acceptance rules 2 through 5 have an equivalent for the utility and life quality models. Application of the cost-benefit model to a simple case study shows that the range flooding probabilities leading to a positive sum of costs and benefits is so wide that acceptance rule 3 does not provide a practical limit on the acceptable flooding probability. Acceptance rule 2 provides slightly higher flooding probabilities than acceptance rule 5 . The acceptability range indicated by rule 4 strongly depends on the existing protection level of the area.

An exponential utility model is applied in combination with the cost-benefit model to model risk-averse cost-benefit optimisation. Analysis of the model shows that riskaverse decision-making requires the uncertainty on the pay-off to be reduced at the cost of a decrease of the expected value of the pay-off. Application of the model in combination with acceptance rule 5 shows that risk-aversion lowers the optimal flooding probability in comparison to the cost-benefit optimum.

The life quality model combines the effects of flooding on the gross domestic product and the life expectancy in one compound indicator. Maximisation of the life quality index indicates that the compound model justifies lower flooding probabilities in comparison with the cost-benefit optimum.

\subsubsection{Application to the dike ring Groningen}

All methods are applied to the $86 \mathrm{~km}$ long flood defence system of the province Groningen. The cost of protection of every individual dike section as a function of its failure probability is found by application of reliability-based design. Applying the same method on the level of the protection system leads to the cost of protection on system level. An upper bound estimate of the consequences of flooding is obtained by application of the dike ring approach.

An analysis of the cost of protection shows that the same failure probability requirement can be adopted for all elements in the flood defence ring. This choice is not exactly equal to the optimal solution, but the deviation from the optimum is small. From a practical point of view, an equal failure probability requirement for every part of the defence system is preferable.

Acceptable values of the flooding probability are obtained by:

- The acceptance rules of Vrijling et al. (1995, 1998b);

- Cost-benefit analysis;

- Utility analysis;

- Life quality analysis.

The flooding probabilities resulting from the analyses range from $10^{-11}$ per year to $10^{-4}$ per year. The lowest values result from the societal criterion of Vrijling et al. (1995, 
1998b) that does not include the monetary costs of protection and the economic consequences of flooding.

The highest value of the optimal flooding probability is obtained with risk-neutral cost-benefit optimisation. The models that do include monetary aspects provide a range of $5 \cdot 10^{-6}$ per year to $10^{-4}$ per year. The lowest value is in that case obtained by the life quality model, which includes both the monetary aspects and the effect of loss of life expectancy.

The case study clearly illustrates the merits of the methods developed in this study. Insight is gained in the effects of different uncertainties and different failure modes on the reliability of flood defences in Groningen. The effects of differences in location and different societal requirements on the design of the flood defence system are explored.

The methods for reliability-based design on decision levels $\mathrm{B}$ and $\mathrm{C}$ can in principle be applied in practice to perform cost-effective design under the constraint of a required probability of failure. Extension of the models on these two levels is possible in the definition of failure modes and the description of hydraulic conditions.

Application of the models on decision level A requires more research on models for acceptable safety levels. In the current state of development, the results of the models on level A may be used as input in the debate on acceptable levels of protection against flooding.

\subsection{Recommendations for future research}

The present study focussed on the development of the framework for risk-based decision-making on flood protection. Based on the results, a number of subjects for further research may be defined. A selection is indicated in this section.

In this study, a method for the description of the multi-variate distribution of hydraulic conditions is proposed. The method has been applied to the Dutch location Groningen. Large differences between the estimates of hydraulic conditions were found in comparison to classical statistical methods. It is recommended to apply the method to other locations along the Dutch Coast to verify the applicability of the method and to get more insight in the differences with other methods of analysis. Furthermore, the proposed method does not consider changes in sea level and wind climate over time. Further research is necessary to quantify the effects of climate changes on the reliability of flood defences.

A conceptual model for the quantification of the probability distribution of flooding consequences is proposed in this study. Furthermore, three different options for schematising a flood-prone area are identified. The conceptual model and the three schematisation options open the possibility to deal with the reliability analysis of primary and secondary flood defences and the quantification of flooding consequences in one framework. To make the method practicable, an extension with existing knowledge is recommended. Specifically, the knowledge on:

- breaching of flood defences;

- flood propagation in flooded areas

should be combined with known methods of reliability analysis to enhance the quantification of flooding consequences. 
In this study, three models for the definition of acceptable protection levels were applied. The application showed that such a model can be integrated with reliability methods to establish the appropriate design of a protection system. A model to establish acceptable values of the flooding probability should ideally reflect the preferences of society. This aspect has not been dealt with in this study. Research on the psychological and societal aspects of flood protection is necessary to verify the applicability of different types of quantitative models. Ultimately, such research should lead to a quantitative measure of the required performance of flood protection systems. A quantitative measure in some form is necessary to transfer the acceptable safety levels into the technical domain.

Quantitative reliability analysis is one of the corner stones of a risk-based design method. The application of quantitative reliability analysis necessitates the definition of quantitative models for all failure modes of the structure. In the present study, a limited set of failure modes is used. The set of failure modes describes initial failure of the structure only. The methods developed in this study can also be applied if more failure modes (among which transitional failure modes) are included in the analysis. To enable such an extended analysis, it is necessary to perform further research into failure modes of flood defences. Such research should ultimately be aimed at the definition of limit state functions for every failure mode, to establish the connection with flood defence design.

In most cases, a flood defence is already present around a flood-prone area. In that case the question is not whether or not to construct a flood defence system but whether or not it is necessary to reinforce the existing one. In this study, existing flood defences only conceptually accounted for. The extension of the method to account for existing flood defences is a relatively small step. Applied in such a context, also the comparison with other measures than reinforcement of the flood defences should be considered. Thus, risk-based design can become integrated with flood risk management. 



\section{REFERENCES AND FURTHER READING}

1. Abt, S.C.; Wittler, R.J.; Taylor, A.; Love, D.J. (1989), Human instability in a high hazard flood zone, Water Resources Bulletin, 25, 4, 881-890

2. Admiralty Charts and Publications (1997), North Sea, scale 1:1,500,000

3. ALKYON (1999), Wave computations in the Wadden Sea, Prepared for the Dutch Institute for Coastal and Marine Management

4. Athanassoulis, G.A; Skarsoulis, E.K; Belisbassakis, K.A. (1994), Bivariate distributions with given marginals with an application to wave climate description, Applied Ocean Engineering 16, pp. 1-17

5. Bakker, W.T; Vrijling J.K (1980); Probabilistic design of sea defences, Proceedings International Conference on Coastal Engineering

6. Barends, F.B.J; Uffink, G.J.M. (2000), Groundwater mechanics, flow and transport, Lecture notes Delft University of Technology

7. Battjes, J.A. (1974), Computation of set-up, longshore currents, run-up and overtopping due to windgenerated waves, Phd-thesis Delft University of Technology

8. Battjes, J.A. (1977), Probabilistic aspects of ocean waves, Communications on Hydraulics, Department of Civil Engineering, Delft University of Technology

9. Battjes, J.A; Janssen, J.P.F.M. (1978), Energy loss and set-up due to breaking of random waves, Proceedings of the International Conference on Coastal Engineering

10. Boer, D.E.H. de; Boone, M; Hessing, W.A.M. (1992), Overview of Dutch history, part 1: the middle ages: 300-1500 (in Dutch), Delta series, Martinus Nijhoff, Leiden/Antwerpen

11. D'Angremond, K.; Schiereck, G.J. (2001), Den Doolaard's Roll back the sea, annotated version (in Dutch), Delft University Press, Delft

12. Delft Hydraulics (1994), Research Maas flooding, part 9: modelling of flooding damage, Delft Hydraulics report Q1858/T1349 for the Dutch Ministry of Public Works and Water Management

13. Booij N; Ris R.C; Holthuijsen, L.H. (1999), A third-generation wave model for coastal regions - 1. Model description and validation, Journal Of Geophysical Research-Oceans (104) pp. 7649-7666

14. Bretschneider, C.L. (1952), Revised wave forecasting relationships, Proceedings of the second conference on coastal engineering, ASCE

15. Bretschneider, C.L. (1958), Revisions in wave forecasting: deep and shallow water, Proceedings of the sixth conference on Coastal Engineering

16. Burcharth, H.F; Dalsgaard Sørensen, J; Christiani, E (1995), Application of reliability analysis for optimal design of vertical wall breakwaters, Proceedings of the International Conference on Coastal and Port Engineering in Developing Countries (COPEDEC)

17. CERC (1973), Shore Protection Manual, U.S. Army Corps of Engineers, Coastal Engineering Research Council

18. Cornell, C.A (1967a), Bounds on the reliability of structural systems, Journal of the Structural Division, ASCE, 93 - pg. 171-200

19. Cornell, C.A. (1967b), A proposal for a reliability-based code suitable for immediate implementation, Memorandum to members of ASCE task committee on structural safety

20. CUR/TAW (1990), Probabilistic design of flood defences, CUR report 141 in cooperation with TAW

21. CUR (1997); Chances in Civil Engineering, Part 1: Probabilistic Design in Theory (in Dutch), Civil Engineering Centre for Research and Codes (CUR), Gouda

22. De Haan, L.; De Ronde, J.G. (1997), Sea and wind: multivariate extremes at work, Extremes 1(1), pp. 7-45

23. De Rijke, W. (1983), Description of the natural boundary conditions, relevant for a probabilistic design of a flood defence at the Friesian Wadden Sea Coast (in Dutch), M.Sc. Thesis Delft University of Technology

24. Delft Cluster (2001), What if things go wrong?? - an overview of the state of the art (in Dutch: Wat als we nat gaan??), Proceedings of a Delft Cluster conference on the analysis of consequences of flooding 
25. Delta Committee (1961a), Final report and interim-advices (in Dutch), Delta Report, considerations concerning storm surges and tidal movements, volume I

26. Delta Committee (1961b), The economic decision problem concerning the protection of the Netherlands against storm surges, contribution II.2 of the Delta Report (in Dutch), In: Delta Report, considerations concerning storm surges and tidal movements; Volume II: Contributions of the mathematical centre, The Hague

27. Delta Committee (1961c), Investigations pertaining to dike construction, Contribution V.2 of the Delta Report, In: Delta Report, Volume V: Investigations of importance to the design of dikes and dams, The Hague

28. Den Doolaard, A. (1948), Roll back the sea (Het verjaagde water, in Dutch), Querido, Amsterdam

29. Ditlevsen, O. (1979), Narrow reliability bounds for structural systems, Journal of Structural Mechanics, Pg. 453-472

30. Ditlevsen, O; Madsen, H.O. (1996), Structural reliability methods, John Wiley and Sons, Chichester

31. Efron, B. (1982), The jackknife, the bootstrap and other resampling plans, CBMS-NSF Regional Conference Series in Applied Mathematics

32. Efron, B., Tibshirani, R.J. (1993), An introduction to the bootstrap, Chapman and Hall

33. Eijgenraam, C.J.J; Koopmans, C.C; Tang, P.J.G, Verster, A.C.P (2000), Evaluation of infrastructure projects, guideline for cost-benefit analysis (in Dutch), Central Planning Bureau and Dutch Economic Institute

34. Enevoldsen, I; Sørensen, J.D. (1994), Reliability-based optimization in structural engineering, Structural safety 15 , pg. 169-196

35. Fang, Z.S; Hogben, N. (1982), Analyis and prediction of long-term probability distributions of wave height and periods, Technical report of the National Maritime Institute, London

36. Ferreira, J.A; Guedes Soares, C. (1995), Modelling long-term bivariate distributions of significant wave height and mean wave period, WAVEMOD report Tec. 2.4-01(0), MAST contract CT92/0025

37. French, S (1988), Decision theory, an introduction to the mathematics of rationality, Ellis Horwood series in Mathematics and its Applications, Chichester

38. Gill, P.E; Murray, W; Wright, M.H. (1981); Practical optimization; Academic Press, London

39. Goday, Y. (1985), Random seas and design of maritime structures, Tokyo University Press

40. Godin, G. (1972), The analysis of tides, Liverpool University Press, Liverpool

41. Hasofer, A.M; Lind, N.C. (1974), An exact and invariant first-order reliability format, J. of the Eng. Mech. Division ASCE, pg. 111-121

42. Haver, S. (1985), Wave climate off northern Norway, Applied Ocean Research, Vol. 7, pp. 85-92

43. Hawkes, P.J; Gouldy, P.B; Tawn, J.A; Owen, M.W (2002), The joint probability of waves and water levels in coastal engineering, Journal of Hydraulic Research, IAHR. Volume 40 - pg. 241-251

44. Hohenbichler, M; Rackwitz, R. (1983), First-order concepts in system reliability, Structural Safety, pg. 177-188

45. Holthuijsen, L.H. (1980), Methods for the prediction of wind waves (in Dutch), report prepared for TAW

46. Hosking, J.R.M; Wallis, J.R (1997), Regional frequency analysis, an approach based on L-moments, Cambridge University Press, Cambridge

47. Huitema, T. (1947), Dikes along sea, rivers and canals (in Dutch), Kosmos publishers, Amsterdam

48. Hussaarts, M; Vrijling, J.K; Van Gelder, P.H.A.J.M; Looff, H. de; Blonk, C. (1999); The probabilistic optimisation of the revetment on the dikes along the Frisian coast, In I.J. Losada (ed.), Proceedings Coastal Structures '99, volume 1

49. Jacobse, J.J. (2000), Validation of the application of SWAN in the Wadden Sea, simulation of the storm of 14 February 1989 in the Eems-Dollard estuary with SWAN (in Dutch), Working document RIKZ/OS 1999.167x of the Dutch Institute for Coastal and Marine Management

50. Joint Committee on Structural Safety (1981), General principles on reliability for structural design, International Association for Bridge and Structural Engineering

51. Jonkman (2001), Flooding risks: research into the applicability of risk measures, M.Sc. thesis Delft University of Technology 
52. Jorissen, R.E. (1997), Safety, risk and flood protection, European Commission concerted action river basin modelling, management and flood mitigation, Proceedings first workshop, pg. 57-72

53. Keeney, R.L; Raiffa, H (1976), Decision with multiple objectives: preferences and value tradeoffs, John Wiley and Sons, New York

54. Keyfitz, N (1977), Applied mathematical demography, John Wiley and Sons, New York

55. Klein Breteler, M; Pilarczyk, K.W; Hart, R. 't (2000), Influence of Ageing and Wide Wave Spectra on Stability of Placed Block Revetments, In: B.L. Edge (ed.) Proceedings International Conference on Coastal Engineering

56. Laenen, K.C.J (2000), A probabilistic model for the comparison of two breakwater types based on economic optimisation (in Dutch), M.Sc. thesis Delft University of Technology

57. Lind, N.C.; Hartford, D. (2000), Probability of human instability in a flooding: a hydrodynamic model, Proceedings of the International Conference on the Application of Statistics and Probability (ICASP), Balkema, Rotterdam

58. Madsen, H.O; Krenk, S; Lind, N.C (1986), Methods of structural safety, Prentice-Hall, Englewood Cliffs

59. Mathisen, J; Bitner-Gregersen, E. (1990), Joint distributions for significant wave height and wave zero-up-crossing period, Applied Ocean Research, Vol. 12, no. 2, pp. 93-103

60. Melchers, R.E (1999), Structural reliability, analysis and prediction (2nd ed.), Wiley, Chichester

61. Miche, R. (1944), Mouvements ondulatoires des mers en profondeur constante ou décroissante, Annales des Pont et Chaussées

62. Morton, I.D; Bowers, J. (1997), Extreme values in a multivariate offshore environment, Applied Ocean Research, Vol. 18, pp. 303-317

63. Mulder, Th. and Vrijling, J.K (1980), Probabilistic load determiniation, Symposium on Hydraulic Aspects of Coastal Structures

64. Naerebout, F.G.; Singor, H.W. (1995), Antiquity, Greek and Romans in the context of world history (in Dutch), AMBO, Amsterdam

65. Nathwani, J.S; Lind, N.C; Pandey, M.D (1997), Affordable safety by choice, the life quality method, Institute for Risk Research, University of Waterloo, Canada

66. Nixon, F.E. (1953), Principles of automatic controls, Prentice Hall, New York

67. NRC Handelsblad, Polder miracle lies below mean sea level (in Dutch), newspaper article of 28 October 2000

68. Oumeraci, H; Allsop, N.W.H; Groot, M.B. de; Crouch, R; Vrijling, J.K; Kortenhaus, A; Voortman, H.G (2001), Probabilistic Design Tools for Vertical Breakwaters, Balkema, Rotterdam

69. Press, W.H; Teukolsky, S.A; Vetterling, W.T; Flannery, B.P (1992), Numerical recipes in Fortran 77, second edition, Cambridge University Press

70. Metcalfe, M., Reid, J (1999); Fortran 90/95 explained, second edition, Oxford University Press, New York

71. Ochi, M.K. (1978), Wave statistics for ships and structures, Proceedings SNAME conference

72. Penning-Rowsell, E.C; Green, C.H; Thompson, P.M; Coker, A.M; Tunstall, S.M; Richards, C; Parker, D.J. (1992), The economics of coastal management, a manual of benefit assessment techniques, Belhaven Press

73. Penning-Rowsell, E.C.; Fordham, M. (1994), Floods across Europe, Middlesex University Press, Middlesex

74. Pratt, J.W. (1964), Risk aversion in the small and the large, Econometrica 32, pg. 122-136

75. Rackwitz, R (2001a), A new approach for setting target reliabilities, Proceedings IABSE-conference safety, risk and reliability - trends in engineering

76. Rackwitz, R (2001b), Structural optimization and the life quality index, Corotis, R.B; Schuëller, G.I; Shinozuka, M. (ed.), Proceedings of the International Conference on Structural Safety and Reliability (ICOSSAR)

77. Rackwitz, R (2001c), Optimizing systematically renewed structures, Reliability Engineering and System Safety (forthcoming)

78. Resio, D.T; Vincent, C.L. (1977), Estimation of winds over the great lakes, Journal of the Waterways, Port, Coastal and Ocean Division, ASCE, Vol. 103, pg. 265-283 
79. Repko, A; Gelder, P.H.A.J.M. van; Voortman, H.G; Vrijling, J.K. (2001); Bivariate statistical analysis of wave climates; In: B.L. Edge (ed.) Proceedings International Conference on Coastal Engineering

80. Rijkoort, P.J. (1983), A compound Weibull model for the description of surface wind velocity distributions, Royal Dutch Meteorological Institute, Scientific Report 83-13

81. Rijkswaterstaat and KNMI (1961), Report on the storm surge of 1953 (in Dutch), Staatsdrukkerij- en uitgeverijbedrijf, 's Gravenhage

82. Rijkswaterstaat (2001), PICASO, pilot case flooding risk (in Dutch)

83. RIKZ (1995a), Base levels along the Dutch coast, spatial distribution and exceedance curves, Report RIKZ 95.008 of the Dutch Institute for Coastal and Marine Management (in Dutch)

84. RIKZ (1995b), Wave conditions along the Dutch coast on relatively deep water, Report RIKZ 95.024 of the Dutch Institute for Coastal and Marine Management (in Dutch)

85. RIKZ (1996), Boundary conditions for wave periods along the Dutch coast, Report RIKZ 96.019 of the Dutch Institute for Coastal and Marine Management (in Dutch)

86. RIKZ (various years), Year book of water levels, discharges, water temperatures and wind speeds

87. RIKZ (2000), Bottom map coastal waters, Wadden Sea, Publication 2000.029 of the Dutch Institute for Coastal and Marine Management

88. RIKZ (2001), Tide tables for the Netherlands (in Dutch), Published by the Dutch Institute for Coastal and Marine Management

89. Roelvink, J.A; Banning, G.K.F.M. van (1994), Design and development of Delft3D and application to coastal morphodynamics, Proceedings of Hydroinformatics '94

90. Savage, L.J (1972), The foundations of statistics, Dover publications, New York

91. Segers, J (2001), Economic optimal design of Maasvlakte 2, M.Sc. thesis Delft University of Technology

92. Slager, K (1992), The Disaster, A Reconstruction (in Dutch), De Koperen Tuin, Goes

93. Staatsblad 21 december 1995, Flood Defence Act (In Dutch)

94. Stroeve, F.M. and Sies, E.M. (2001), Integral optimisation of land reclamation in the North Sea, Proceedings IABSE-conference safety, risk and reliability - trends in engineering

95. Sverdrup, H.U; Munk, W.H. (1947), Wind, Sea and Swell: Theory of relations for forecasting,Publication no. 601, U.S. Navy Hydrographic Office, Washington D.C.

96. TAW (1984), Guideline for evaluating dunes as sea defence (in Dutch), Technical Advisory Committee for Water Defences, The Hague

97. TAW (1985), Guideline for the design of river dikes, part 1: upper river area, Technical Advisory Committee for Water Defences, The Hague

98. TAW (1989), Guideline for the design of river dikes, part 2: lower river area, Technical Advisory Committee for Water Defences, The Hague

99. TAW (1998), Foundations of flood protection, Technical Advisory Committee for Water Defences, The Hague

100.TAW (1999), Technical report sand transporting pipes (in Dutch), Technical Advisory Committee for Water Defences, The Hague

101.TAW (2000), From Exceedance Probability to Flooding Probability, Technical Advisory Committee for Water Defences, The Hague

102.TAW (2002), Guideline for the design of special-purpose water-retaining structures (in Dutch), Technical Advisory Committee for Water Defences, The Hague

103.Thoft-Christensen, P.; Baker, M.J. (1982), Structural reliability theory and its applications, Springer, Berlin

104.TNO (1998), Case study GroFriland, Report prepared for TAW

105.Turkstra (1962, 1970), Theory of structural design decisions, University of Waterloo

106. Van Dantzig, D. (1956), Economic Decision Problems for Flood prevention, Econometrica nr. 24, pg 276-287

107.Van de Graaff, J. (1984); Probabilistic methods for dune design (in Dutch), Report by Delft University of Technology 
108.Van Gelder, P.H.A.J.M. (1999), Statistical methods for the risk-based design of civil structures, Phdthesis Delft University of Technology

109. Van Malde, J. (1992), Relative rise of mean sea-levels in the Netherlands in recent times, In: Tooley, M.J. and Jelgerma, S. (ed), Impacts of sea-level rise on European coastal lowlands, Blackwell, Oxford (UK)

110.Van Maren, D.S. (1999), Inventory of existing wave observations in the Wadden Sea (in Dutch), Institute for marine and atmospheric research Utrecht

111.Van Marle, J. (1979), The breaker criterion for the mouth of the Eastern Scheldt, Rijkswaterstaat report DDWT-79.031 (in Dutch)

112.Van der Meer, J.W.; Janssen, J.P.F.M. (1995), Wave run-up and wave overtopping at dikes, In: Wave forces on inclined and vertical wall structures, pg. 1-27

113. Van der Meer, J.W. (1997), Wave runup and wave overtopping at dikes (in Dutch), Delft Hydraulics report $\mathrm{H} 2458 / \mathrm{H} 3051$

114.Vanmarcke, E.H. (1977), Reliability of earth slopes, Journal of the Geotechnical Engineering Division, ASCE

115.Van der Veen , A.; Groenendijk, N; Mol, N. (2001), Cost-benefit analysis and evaluation of measures against flooding (in Dutch), Contribution to the Delft Cluster seminar on the consequences of flooding

116.Van de Ven, G.P. (ed.) (1996), Man-made lowlands, history of water management and land reclamation in the Netherlands (3rd revised edition), Matrijs publishers

117. Van Vledder, G. Ph. (1990), Directional response of wind waves to turning winds, Communications on hydraulic and geotechnical engineering, Delft University of Technology

118.Visser, P.J (1998), Breach growth in sand-dikes, Phd-thesis Delft University of Technology

119.Voortman, H.G; Kuijper, H.K.T; Vrijling, J.K (1998), Economic optimal design of vertical breakwaters, Proceedings 26th International Conference on Coastal Engineering (ICCE)

120.Voortman, H.G; Kuijper, H.K.T; Vrijling, J.K. (1999a), Influence of Subsoil Properties on the Optimal Design of Caisson Breakwaters, Proceedings of the International Conference on Coastal and Port Engineering in Developing Countries (COPEDEC)

121.Voortman, H.G; Vrijling, J.K; Boer, S; Kortlever, W.C.D. (1999b), Optimal Breakwater Design for the Rotterdam Harbour Extension, In: Goossens (ed.), Proceedings of the 9th annual conference of the Society for Risk Analysis Europe

122.Voortman, H.G; Vrijling, J.K (2001a), A risk-based optimisation strategy for large-scale flood defence systems, Proceedings IABSE-conference safety, risk and reliability - trends in engineering

123. Voortman, H.G; Jak, M (2001b), Risk analysis in flood prone areas - a case study, Proceedings IABSE-conference safety, risk and reliability - trends in engineering

124.Voortman, H.G; Pandey, M.D; Gelder, P.H.A.J.M. van; Vrijling, J.K (2001c), Definition of acceptable risk in flood-prone areas, Corotis, R.B; Schuëller, G.I; Shinozuka, M. (ed.), Proceedings of the International Conference on Structural Safety and Reliability (ICOSSAR)

125.Voortman, H.G. (2002), User manual for the Fortran library "ProbMod", Internal report Delft University of Technology, Section of Hydraulic Engineering

126. Vrisou van Eck, N; Kok, M; Vrouwenvelder, A.C.W.M. (1999), Standard method damage and casualties as a consequence of flooding (in Dutch), Report prepared by TNO and HKV lijn in water

127.Vrouwenvelder, A.C.W.M; Struik, P (1990); Safety philosophy for dike design in The Netherlands, Proceedings International Conference on Coastal Engineering

128. Vrouwenvelder, A.C.W.M; Cruys, G.W. (1988), Calculation methods reliability analysis (in Dutch), Report B-87-559, TNO Bouw for TAW-E

129. Vrouwenvelder, A.C.W.M. (1998), Manual PC-ring, Part C: Calculation methods (in Dutch), TNOreport 98-CON-R1204 for TAW-E

130.Vrijling, J.K. and Bruinsma, J (1980), Hydraulic Boundary Conditions, Symposium on Hydraulic Aspects of Coastal Structures

131.Vrijling, J.K (1984); Some aspects of the determination of de economic optimal dike level for an area threatened by two water levels (in Dutch), Technical Advisory Committee for Water Defences, The Hague 
132.Vrijling, J.K; Hengel, W. van; Houben, R.J (1995), A framework for risk evaluation, Journal of Hazardous Materials 43, 245-261

133.Vrijling, J.K; Gopalan, S; Laboyrie, J.H; Plate, S.E. (1998a), Probabilistic Optimisation of the Ennore Coal Port, Proceedings of the International Conference on Coastlines, Structures and Breakwaters, pg 135-147, Thomas Telford, London

134.Vrijling, J.K; Hengel, W. van; Houben, R.J (1998b), Acceptable risk as a basis for design, Reliability Engineering and System Safety 59,pg. 141-150

135.Webbers, P.B; Voortman, H.G; Van Gelder, P.H.A.J.M; Vrijling, J.K. (2003), Multi-variate statistics of hydraulic boundary conditions for the Rotterdam harbour extension, Proceedings of the International Conference on Coastal Engineering (forthcoming)

136. Weenink, M.P.H. (1958), A theory and method of calculation of wind effects on sea levels in a partly enclosed sea, with special application to the southern coast of the North Sea, Communications of the Royal Dutch Meteorological Institute, No. 73 (in Dutch)

137.Wemelsfelder (1939), Patterns in the occurrence of storm surges (in Dutch), De Ingenieur, March 1939

138. Wieringa, J; Rijkoort, P.J. (1983), Wind climate of the Netherlands, Royal Dutch Meteorological Institute (in Dutch)

139.Wilde, G.J.S (1994), Target risk; dealing with the danger of death, disease and damage in everyday decisions, PDE publications, Toronto

\section{Internet resources}

1. Dutch Central Bureau of Statistics (CBS): www.cbs.nl

2. Royal Dutch Meteorological Institute (KNMI): www.knmi.nl

3. Maps in the library of the University of Texas: www.lib.utexas.edu/maps 


\section{A.1 FAULT TREE FOR A DIKE SECTION}

In the following four figures, a fault tree for a dike section is presented. For the notation used in the fault trees, reference is made to CUR (1997).

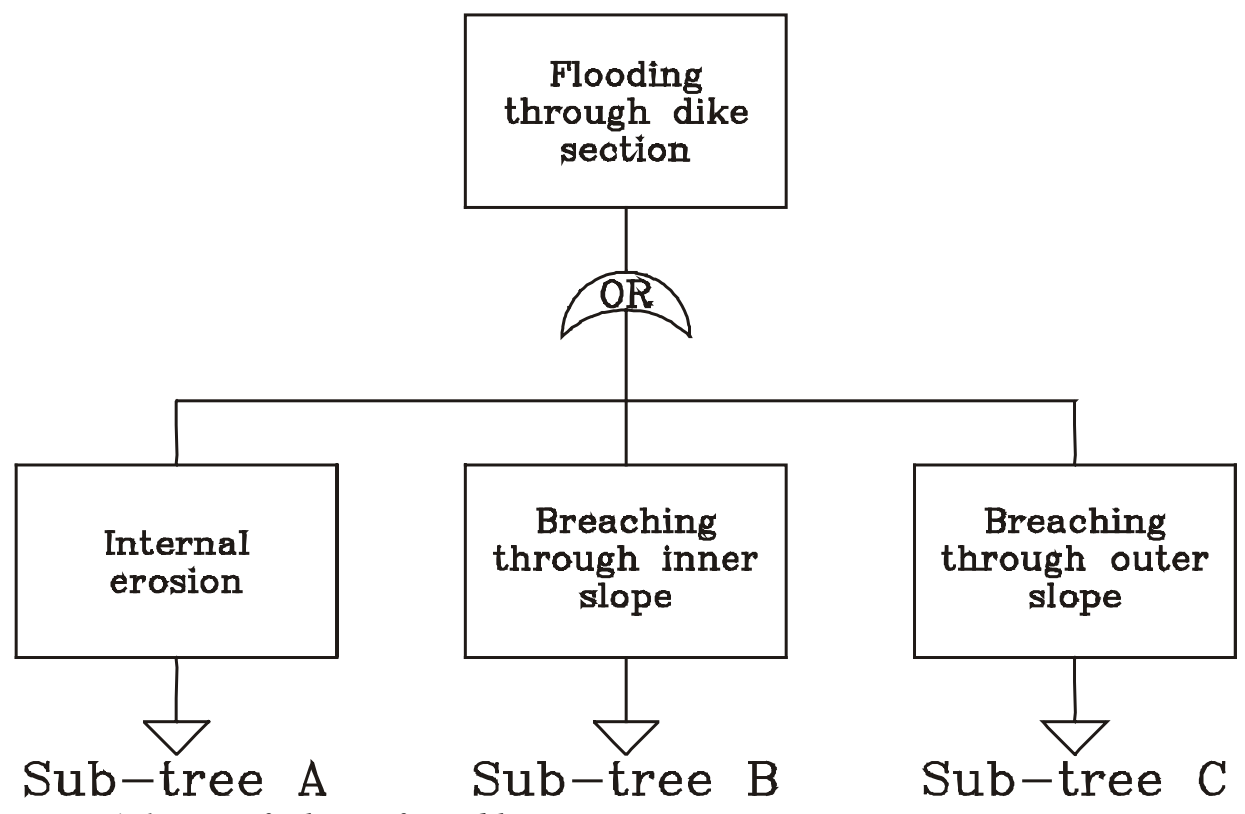

Figure A.1: Main fault tree for a dike section

The compound event "Flooding through dike section" may be caused by any of three compound events on a lower level in the tree:

- Internal erosion;

- Breaching through inner (land side) slope;

- Breaching through outer (sea side) slope.

The three compound events are further specified in the sub-trees shown in the following figures.

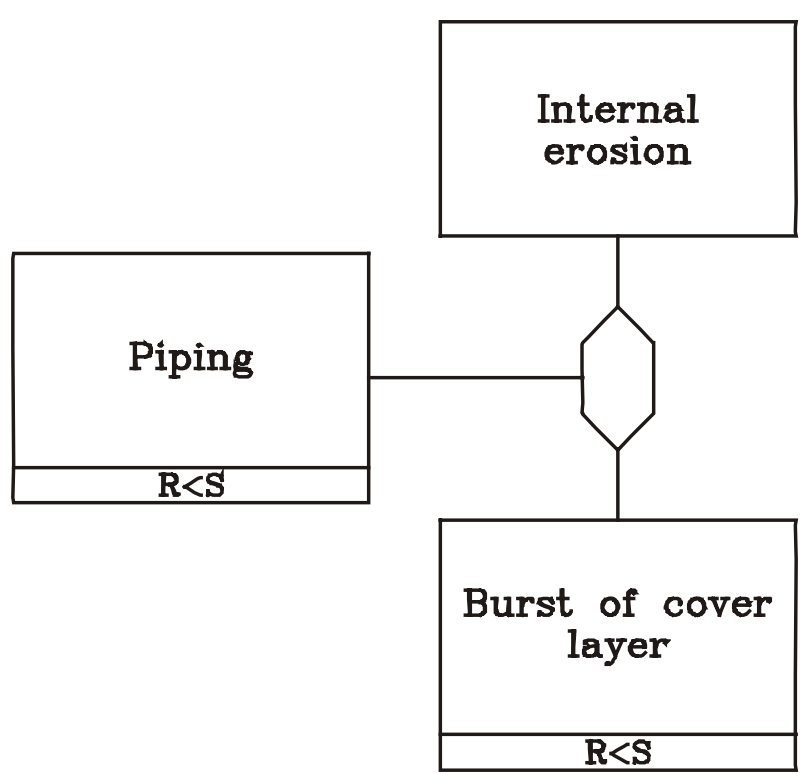

Figure A.2: Sub-tree A: fault tree for compound event "Internal erosion" 
In a number of areas, flood defences have been built on a sub-soil consisting of two layers. The top layer consists of clay. Below the top layer a sand layer is present. The ground water head in the sand layer is determined by the outside water level. As long as the clay layer is in tact, it prevents piping since it prevents sand particles from being transported. Once the clay layer fails due to uplifting, the piping process begins.

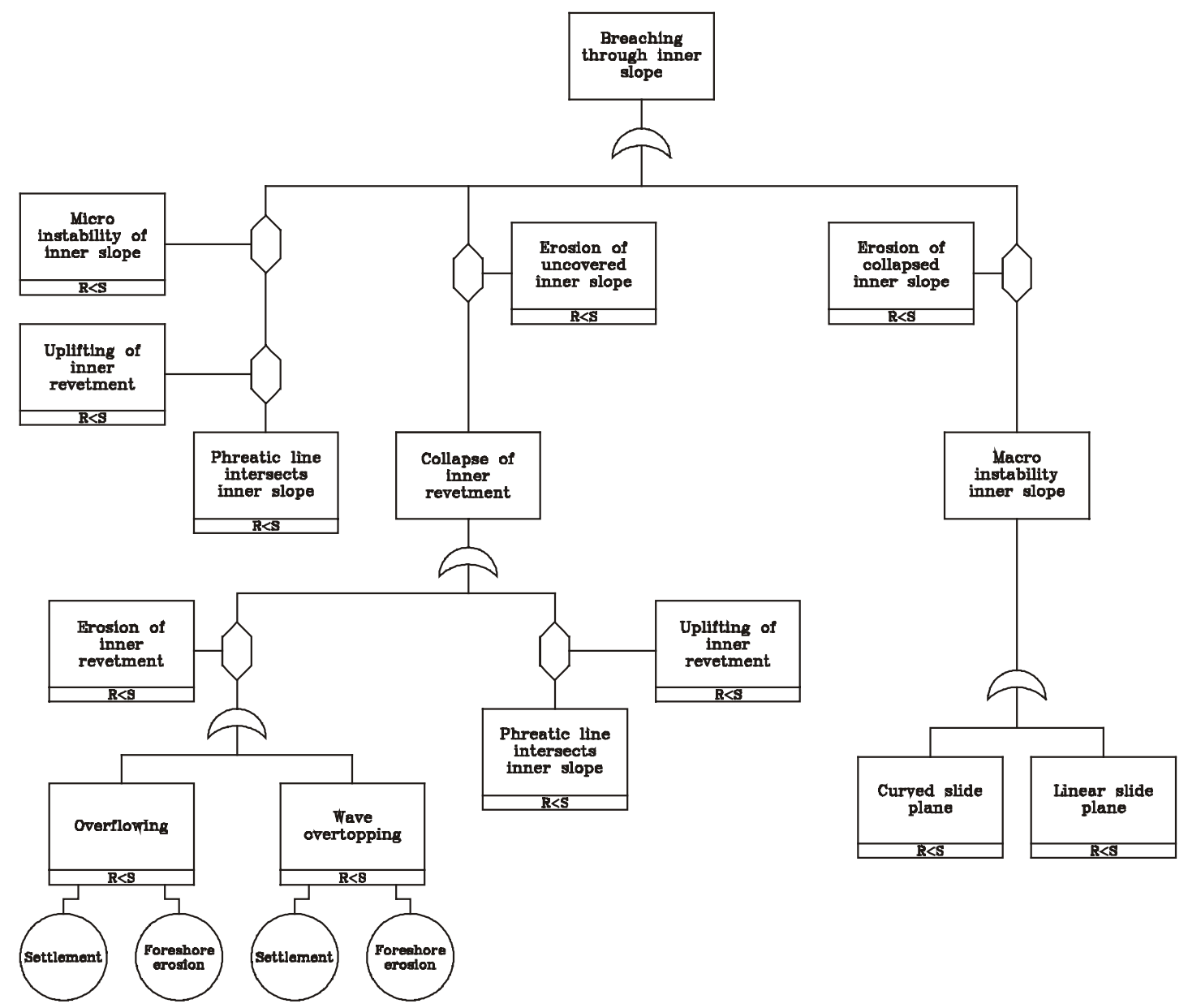

Figure A.3: Sub-tree B: fault tree for compound event "Breaching through inner slope"

Three causes of failure of the inner slope are distinguished. Failure of the landside clay cover due to uplifting uncovers part of the inner slope. Groundwater flow through the dike body may subsequently erode the dike. Also overflowing and wave overtopping may cause failure of the clay cover on the land side. An uncovered landside slope may subsequently erode due to the water flow caused by overflowing or overtopping.

The other branch of the tree denotes failure due to geotechnical instability. This may cause large deformation of the dike body. This becomes especially critical if the crest level of the dike is lowered due to the instability. 


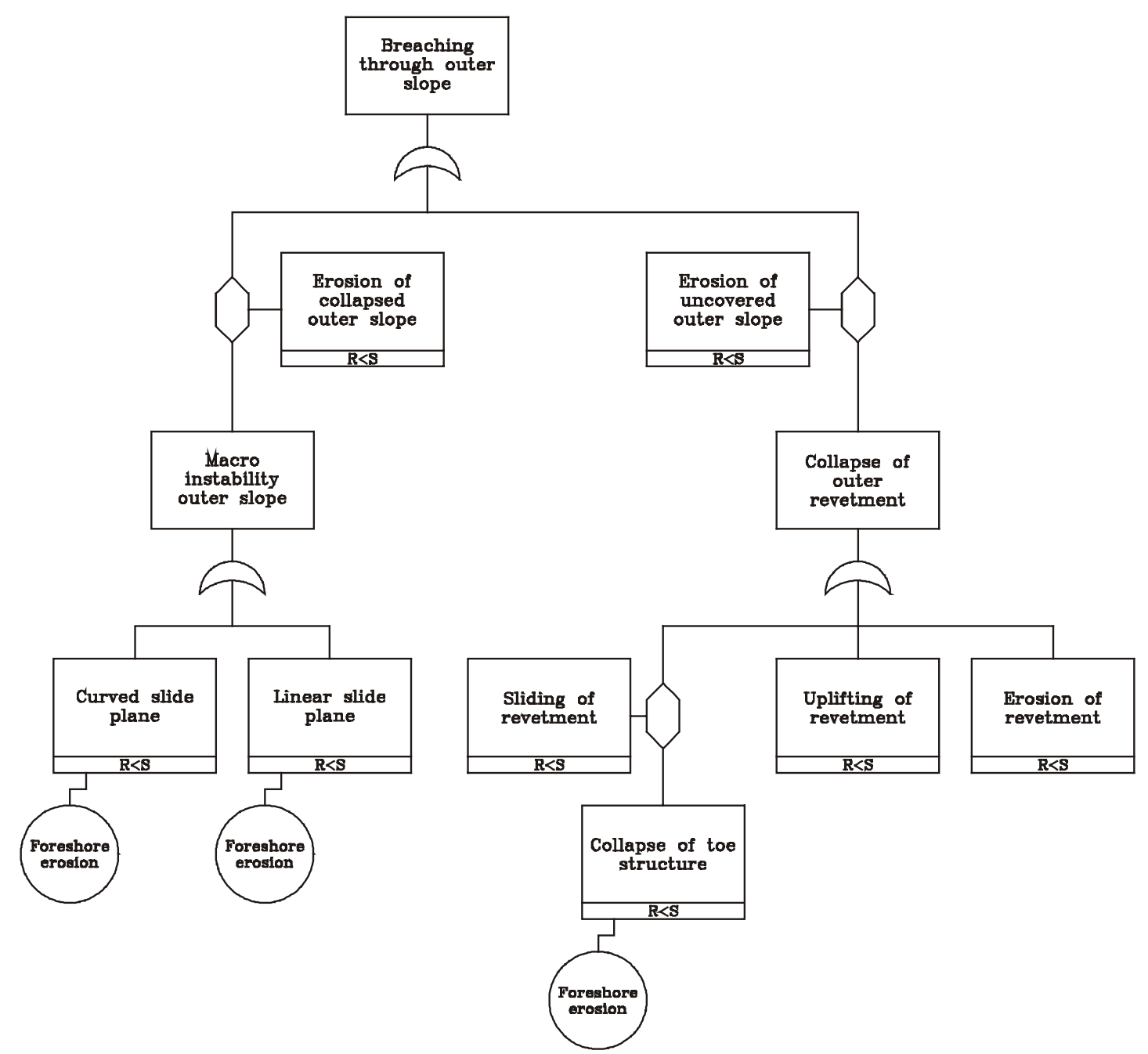

Figure A.4: Sub-tree C: fault tree for compound event "Breaching through outer slope"

Geotechnical instability may also occur on the sea side of the profile. In addition, a collapse of the sea side revetment may initiate erosion of the dike body and can therefore initiate failure.

In the bottom of the tree, a set of base events are indicated. Settlement of the profile lowers the crest level over time. A lack of crest height will manifest itself if the profile experiences extreme loading.

Foreshore erosion may compromise the stability of the toe structure, leading to failure of the sea side revetment. Erosion also leads to an increase of the water depth in front of the structure, increasing the wave load under extreme conditions.

An additional set of base events not mentioned in the trees are:

- Sea level rise;

- Climate change.

Like foreshore erosion, these two processes over time influence the hydraulic loads on the structure. 



\section{A.2 SENSITIVITY MEASURES}

\section{A.2.1 Introduction}

The sensitivity of the optimal design for the failure modes, stochastic input and design variables provides important information for the detailed design of a flood defence structure. Furthermore, sensitivity measures are used in obtaining the gradient of the objective function in the optimisation process itself. In this annex, a number of sensitivity measures will be defined.

\section{A.2.2 Sensitivity of the reliability per failure mode}

A reliability calculation by a level II method transforms any limit state function to the standard form:

$$
M=\beta+\alpha_{1} u_{1}+\ldots+\alpha_{N} u_{N}=\beta+\mathbf{a}^{\mathrm{T}} \mathbf{u}
$$

Where:

M: $\quad$ Margin;

$\beta$ : $\quad$ Reliability index;

$\alpha_{i}$ : $\quad$ Normalised gradient for basic variable $i$;

$u_{i}$ : $\quad$ Standard-normal variable.

The vector $\mathbf{a}$ is denoted the vector of normalised gradients. Its elements provide a measure of the influence of the uncertainty of a random variable on the value of the limit state function. The influence of a variable is determined by the uncertainty of the variable and by the first derivative of the limit state function to the considered variable, in formula:

$$
\alpha_{i}=\frac{\frac{\partial M}{\partial x_{i}} \frac{\varphi\left(\Phi^{-1}\left(F_{\underline{X_{i}}}\left(x_{i}\right)\right)\right)}{f_{\underline{X_{i}}}\left(x_{i}\right)}}{\sqrt{\sum_{n=1}^{N}\left(\frac{\partial M}{\partial x_{n}}\right)^{2}\left(\frac{\varphi\left(\Phi^{-1}\left(F_{\underline{X_{n}}}\left(x_{n}\right)\right)\right)}{f_{\underline{X_{n}}}\left(x_{n}\right)}\right)^{2}}}
$$

Where:

$\varphi$ : $\quad$ Standard normal density function;

$\Phi: \quad$ Standard normal distribution;

$f: \quad$ Probability density function;

$F$ : Distribution function.

If the variable $x$ is described by a normal distribution, equation (A.2) simplifies to:

$$
\alpha_{i}=\frac{\frac{\partial M}{\partial x_{i}} \sigma_{i}}{\sqrt{\sum_{n=1}^{N}\left(\frac{\partial M}{\partial x_{n}}\right)^{2} \sigma_{n}^{2}}}
$$

Where $\sigma$ denotes the standard deviation of the basic variable. 
In any point in the standard normal space, the reliability index can be approximated by:

$$
\beta=M-\mathbf{a}^{\mathrm{T}} \mathbf{u}
$$

This expression can be used to evaluate the influence of a design variable on the reliability index of the failure mode. To this end, the design point $\mathbf{u}^{*}$ has to be found first by applying a level II reliability method. In the design point, the sensitivity of the reliability index to a design variable is given by differentiation of equation (A.4) be evaluated by:

$$
\frac{\partial \beta}{\partial z_{i}}=\frac{\partial M(z)}{\partial z_{i}}-\sum_{n=1}^{N} \frac{\partial \alpha_{n}(\mathbf{z})}{\partial z_{i}} u_{n}^{*}
$$

Where $\mathbf{z}$ is a vector of design variables.

\section{A.2.3 Sensitivity of the system reliability}

In a level II method, the evaluation of the system reliability is based on the results of a reliability evaluation per failure mode (see Hohenbichler and Rackwitz, 1983). The occurrence of one failure mode does not necessarily lead to failure of the structure. A combination of failure modes that does lead to failure of the structure is denoted a cutset. Finite difference methods may be used to evaluate the effect of an individual failure mode on the reliability of a cutset, leading to an estimate of:

$$
\alpha_{\text {cut_comp } ; i j}=\frac{\partial \beta_{c u t ; j}}{\partial \beta_{\text {comp } ; i}}
$$

Failure of the structure is described by a series system of cutsets. The effect of a variation of the cutset reliability on the overall reliability of the structure can also be evaluated by a finite difference method, resulting in:

$$
\alpha_{\text {sys_cut } ; j}=\frac{\partial \beta_{s y s}}{\partial \beta_{c u t ; j}}
$$

From the level II reliability analysis the following vectors are already obtained (see section 0):

$$
\begin{gathered}
\alpha_{\text {param } ; i k}=\frac{\partial \beta_{c o m p ; i}}{\partial z_{k}} \\
\alpha_{i n}=\frac{\partial \beta_{c o m p ; i}}{\partial u_{n}}
\end{gathered}
$$

The set of sensitivities in equation (A.6) through (A.9) contains all information necessary to evaluate other sensitivities as well. According to the theorem of the total differential, the following relation holds:

$$
\frac{\mathrm{d} f}{\mathrm{~d} q}=\frac{\partial f}{\partial r} \frac{\partial r}{\partial q}+\frac{\partial f}{\partial s} \frac{\partial s}{\partial q}+\ldots
$$


Thus, the sensitivity of the reliability of the structure to the reliability per failure mode is given by:

$$
\begin{gathered}
\frac{\partial \beta_{\text {structure }}}{\partial \beta_{\text {mode } ;} ;}=\frac{\partial \beta_{\text {structure }}}{\partial \beta_{\text {cut } ; 1}} \frac{\partial \beta_{\text {cut } ; 1}}{\partial \beta_{\text {mode } ; i}} \\
+\frac{\partial \beta_{\text {structure }}}{\partial \beta_{\text {cut } ; 2}} \frac{\partial \beta_{\text {cut } ; 2}}{\partial \beta_{\text {mode } ; i}}+\ldots=\sum_{j=1}^{J} \frac{\partial \beta_{\text {structure }}}{\partial \beta_{\text {cut } ; j}} \frac{\partial \beta_{\text {cut } ; j}}{\partial \beta_{\text {mode } ; i}} \\
=\frac{\partial \beta_{\text {structure }}}{\partial \beta_{\text {cut } ; j}} \bullet \frac{\partial \beta_{\text {cut } ; j}}{\partial \beta_{\text {mode } ; i}}
\end{gathered}
$$

Similarly, the sensitivity of the reliability of the structure to the design variables is given by:

$\frac{\partial \beta_{\text {structure }}}{\partial z_{k}}=\frac{\partial \beta_{\text {structure }}}{\partial \beta_{\text {mode }}} \bullet \frac{\partial \beta_{\text {mode }}}{\partial z_{k}}$

and to the stochastic input by:

$\frac{\partial \beta_{\text {structure }}}{\partial u_{n}}=\frac{\partial \beta_{\text {structure }}}{\partial \beta_{\text {mode }}} \bullet \frac{\partial \beta_{\text {mode }}}{\partial u_{n}}=\frac{\partial \beta_{\text {structure }}}{\partial \beta_{\text {mode }}} \bullet \alpha_{n}$

The last expression leads to a set of alpha-values for the structure, so that a limit state function for the can be established in standard form:

$M_{\text {structure }}=\beta_{\text {structure }}+\mathbf{a}_{\text {structure }}{ }^{\mathrm{T}} \mathbf{u}$

Because failure of the structure is written in the standard form, the analysis can be repeated to find the reliability of a system on a larger spatial scale. 



\section{A.3 LIMIT STATE FUNCTIONS}

\section{A.3.1 Overflowing and wave overtopping}

\section{A.3.1.1 Description of the failure mode}

The failure mode overflowing and wave overtopping may occur in two situations. In the absence of wave attack, the water level may exceed the crest level of the flood defence structure. In that case, a slowly varying discharge over the flood defence structure occurs.

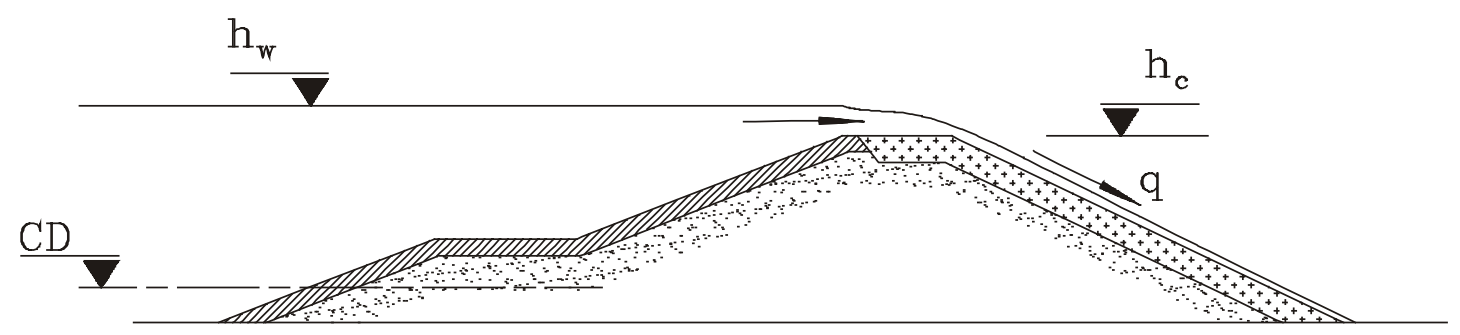

Figure A.5: Definition sketch overflowing

In combination with wave attack, a quickly varying discharge over the flood defence occurs. This may already occur if the water level is still below the crest level of the flood defence.

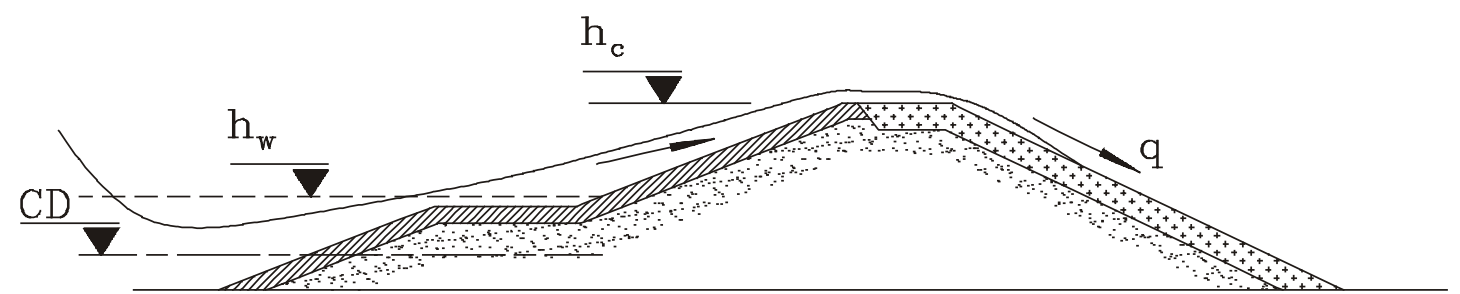

Figure A.6: Definition sketch overtopping

The occurrence of a water flow along the landside slope of the flood defence may lead to failure in two ways:

- By erosion of the landside slope;

- By causing a decrease of the shear strength of the landside slope due to saturation of the slope.

For both types of failure of the inner slope, the occurrence of overflowing or wave overtopping is a prerequisite. Therefore, the failure mode overflowing and wave overtopping is an initiating failure mode.

\section{A.3.1.2 Definition of limit state function}

Failure due to overflowing or wave overtopping is defined as the exceedance of a predefined average discharge on the landside slope $q_{\text {crit }}$. A straightforward definition of a limit state for this failure mode is given by:

$$
g_{\text {overtop } ; 1}\left(h_{w}, H_{s}, T_{p}, \mathbf{z}\right)=q_{c r i t}-q\left(h_{w}, H_{s}, T_{p}, \mathbf{z}\right)
$$

Where:

$q_{\text {crit }}$ : $\quad$ Critical discharge on the landside slope;

$q$ : $\quad$ Occurring discharge on landside slope;

$h_{w}$ : $\quad$ Water level in front of the structure with respect to chart datum;

$H_{s}$ : $\quad$ Significant wave height in front of the structure; 
$T_{p}$ : $\quad$ Wave peak period in front of the structure;

z: $\quad$ Vector describing the geometry of the structure.

A limit state in this form is applied in TNO (1998). In the current study, a few reliability calculations were performed with a limit state function of the form of equation (A.15). The results showed that this limit state often prevents the numerical reliability method from converging. This problem is resolved by developing an alternative definition of the limit state function that is fully equivalent with the former definition but does not lead to convergence problems. The alternative limit state function is based on a comparison of the available freeboard with the necessary freeboard. For given water level and crest level, the available freeboard is given by:

$R_{c}\left(h_{w}, h_{c}\right)=h_{c}-h_{w}$

Where $h_{c}$ denotes the crest level of the flood defence structure with respect to chart datum.

The necessary freeboard is a function of the critical discharge, the hydraulic conditions in front of the structure and the geometry of the structure. Therefore, a limit state for overtopping is given by:

$$
g_{\text {overtop } ; 2}\left(h_{w}, H_{s}, T_{p}, \mathbf{z}\right)=h_{c}-h_{w}-R_{c ; c r i t}\left(q_{c r i t}, h_{w}, H_{s}, T_{p}, \mathbf{z}\right)
$$

Where $R_{c ; c r i t}$ denotes the minimum necessary freeboard.

Any model describing the overtopping discharge as a function of the hydraulic conditions and the geometry of the structure may be used to define the necessary freeboard $R_{c ; \text { crit. }}$ In this study, the overtopping model proposed in Van der Meer and Janssen (1995) is used. The wave overtopping model consists of two sub-models, one for the overtopping discharge due to breaking waves and one for the overtopping discharge due to non-breaking waves.

The overtopping discharge per unit length by non-breaking waves is given in dimensionless form by:

$$
\widetilde{q_{n b}}=\frac{q_{n b}}{\sqrt{g H_{s}^{3}}}
$$

Where:

$q_{n b}$ : Overtopping discharge per unit length of the structure;

$g: \quad$ Acceleration of gravity.

For non-breaking waves, the dimensionless freeboard is given by:

$$
\widetilde{R}_{c ; n b}=\frac{h_{c}-h_{w}}{H_{s}} \frac{1}{\gamma_{r} \gamma_{\beta}}
$$

Where:

$\gamma_{r}: \quad$ Reduction factor for the roughness of the slope;

$\gamma_{\beta}$ : Reduction factor for oblique wave attack. 
The dimensionless overtopping discharge is a function of the dimensionless freeboard by:

$$
\tilde{q}_{n b}=\frac{q_{n b}}{\sqrt{g H_{s}^{3}}}=0.2 \exp \left(\frac{-2.6}{\Delta} \widetilde{R}_{c ; n b}\right)
$$

Where $\Delta$ is a parameter describing the model uncertainty. The mean value of $\Delta$ equals 1 .

Substitution of the critical discharge $q_{c r i t}$ in for $q_{n b}$ in equation (A.20) and rearranging the expression leads to the following formula for the necessary freeboard:

$$
R_{c ; c r i t ; n b}=H_{s} \gamma_{r} \gamma_{\beta} \frac{\Delta}{2.6} \ln \left(\frac{0.2 \sqrt{g H_{s}^{3}}}{q_{c r i t}}\right)
$$

For breaking waves, the dimensionless discharge per unit length is given by:

$$
\tilde{q}_{b}=\frac{q_{b}}{\sqrt{g H_{s}^{3}}} \frac{1}{\gamma_{b} \xi_{0 p} \sqrt{m_{e q}}}
$$

Where:

$\gamma_{b}: \quad$ Reduction factor for sea side berm;

$\xi_{0 p}$ : $\quad$ Surf similarity parameter (Battjes, 1974);

$m_{e q}$ : Equivalent sea side slope without sea side berm (see Van der Meer and Janssen, 1995).

The dimensionless freeboard in case of breaking waves is given by:

$$
\widetilde{R}_{c ; b}=\frac{h_{c}-h_{w}}{H_{s}} \frac{1}{\gamma_{r} \gamma_{\beta} \gamma_{b} \xi_{0 p}}
$$

The dimensionless overtopping discharge is a function of the dimensionless freeboard by:

$$
\tilde{q}_{b}=\frac{q_{b}}{\sqrt{g H_{s}^{3}}} \frac{1}{\gamma_{b} \xi_{0 p} \sqrt{m_{e q}}}=0.06 \exp \left(-\frac{5.2}{\Delta} \widetilde{R}_{c ; b}\right)
$$

Substitution of the critical discharge $q_{c r i t}$ for $q_{b}$ in equation (A.24) and rearranging the expression leads to:

$$
R_{c ; c r i t ; b}=H_{s} \gamma_{r} \gamma_{\beta} \gamma_{b} \xi_{0 p} \frac{\Delta}{5.2} \ln \left(\frac{0.06 \sqrt{g H_{s}^{3}} \gamma_{b} \xi_{0 p} \sqrt{m_{e q}}}{q_{c r i t}}\right)
$$

The transition between breaking and non-breaking waves is normally found at:

$$
\gamma_{b} \xi_{0 p}=2
$$

All influences of the geometry of the structure should be contained in the surf similarity parameter and the reduction factor for the sea side berm. Substitution of equation (A.26) in equations (A.21) and (A.25) should lead to:

$$
R_{c ; c r i t ; n b}=R_{c ; c r i t ; b} \quad \text { for } \quad \gamma_{b} \xi_{0 p}=2
$$


However, substitution of equation (A.26) in equation (A.21) leads to a necessary crest height of:

$$
R_{c ; c r i t ; n b}=\ln \left(\frac{0.2 \sqrt{g H_{s}^{3}}}{q_{c r i t}}\right)
$$

In case of substitution in equation (A.25) the necessary crest height is given by:

$$
R_{c ; c r i t ; b}=\ln \left(\frac{0.12 \sqrt{g H_{s}^{3}} \sqrt{m_{e q}}}{q_{c r i t}}\right)
$$

The model does not fulfil the requirement stated in equation (A.27). In a modification of the model (Van der Meer, 1997) it is suggested to calculate the overtopping discharge by:

$$
q=\min \left(\begin{array}{c}
q_{n b} \\
q_{b}
\end{array}\right)
$$

Following similar reasoning, the necessary crest height is found by:

$$
R_{c ; c r i t}=\min \left(\begin{array}{c}
R_{c ; c r i t ; n b} \\
R_{c ; c r i t ; b}
\end{array}\right)
$$

The physical basis of the suggested modifications appears to be weak. When using the modifications, the transition between breaking and non-breaking waves is found at values of $\gamma_{b} \xi_{0 p}$ that are generally not equal to 2. A critical evaluation of the overtopping model appears to be necessary.

Despite the observed weaknesses of the model, it is used in this study nonetheless. The reason for this is that this overtopping model is the most complete at the time this study was performed.

\section{A.3.1.3 Model uncertainty}

The model uncertainty of the limit state function is described by the parameter $\Delta$. In Van der Meer and Janssen (1995) the model uncertainty of the model for nonbreaking waves is given as the standard deviation of the term $\frac{2.6}{\Delta}$. For the model for breaking waves, the model uncertainty is given as the standard deviation of the term $\frac{5.2}{\Delta}$. From the results of Van der Meer and Janssen, the distribution of $\Delta$ can be derived. Assuming $\Delta$ to be normally distributed, the parameters shown in table A.1 are obtained.

Table A.1: Parameters of model uncertainty wave overtopping model

\begin{tabular}{lll}
\hline Model & Mean & Standard deviation \\
\hline Non-breaking waves & 1.0 & 0.13 \\
Breaking waves & 1.0 & 0.11 \\
\hline
\end{tabular}

The apparently large difference in model uncertainty between the model for nonbreaking waves and the model for breaking waves as given in Van der Meer and Janssen appears to be largely due to the definition of the model parameter. Adopting a 
strict definition of the model uncertaint ${ }^{23}$ leads to model uncertainty in the same order of magnitude for both models. In this study, one parameter describing the model uncertainty is adopted. The standard deviation of the model parameter $\Delta$ is chosen as the highest value in table A.1.

\section{A.3.2 Failure of sea side revetment}

\section{A.3.2.1 Description of the failure mode}

A placed block revetment placed on a permeable under layer may fail due to uplifting on wave run-down. The reason for this is that during wave run-down, the water level in the permeable under layer lags behind the water level in front of the structure. Therefore, during wave run-down a net water pressure under the revetment block exists (figure A.7).

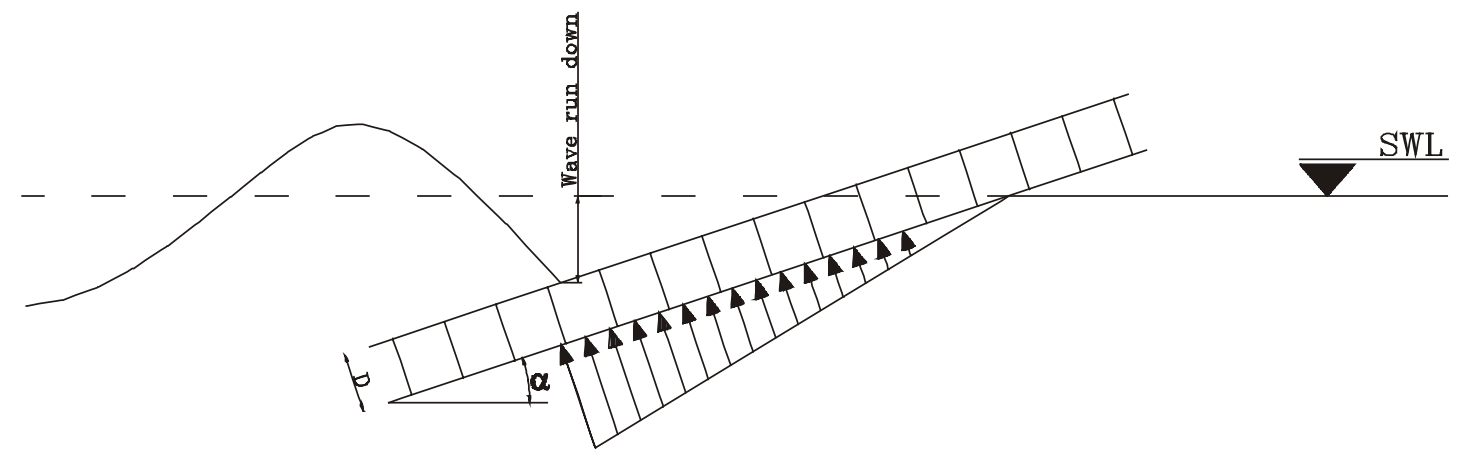

Figure A.7: Definition sketch of revetment stability (after Hussaarts et al., 1999)

Uplifting of the revetment may uncover parts of the sea side slope, leaving the dike body vulnerable to further erosion by wave attack. Uplifting of the sea side revetment is therefore an initiating failure mode.

\section{A.3.2.2 Definition of limit state function}

Following an analysis of revetment stability by Hussaarts et al. (1999), stability of a pitched block revetment during wave run-down is ensured if:

$\frac{H_{s}}{\Delta D} \leq \frac{\gamma_{\text {model }} \cdot M \cdot \cos \alpha}{\xi_{0 p}}$

Where:

$H_{s}$ : $\quad$ Significant wave height in front of the structure;

$\Delta: \quad$ Relative density of revetment block;

$D: \quad$ Thickness of revetment block;

M: $\quad$ Model parameter;

$\gamma_{\text {model }}: \quad$ Variable describing model uncertainty;

$\alpha . \quad$ Slope at still water level;

$\xi_{0 p}$ : $\quad$ Surf similarity parameter.

From equation (A.32), the following limit state function for revetment stability is obtained:

$$
g_{\text {revet }}\left(H_{s}, s_{0 p}, \gamma_{b l}, \gamma_{w}, \mathbf{z}\right)=\frac{\gamma_{b l}-\gamma_{w}}{\gamma_{w}} D-\frac{H_{s} \sin \alpha}{\gamma_{\text {model }} M \sqrt{s_{0 p}} \cos ^{2} \alpha}
$$

\footnotetext{
${ }^{23}$ Requiring a mean value of 1 for a multiplicative model parameter.
} 
Where:

$\gamma_{b l}: \quad$ Density of revetment block;

$\gamma_{w}: \quad$ Density of water;

$s_{0 p}$ : Wave steepness.

The wave steepness is defined as:

$$
s_{0 p}=\frac{H_{s}}{\frac{g}{2 \pi} T_{p}^{2}}
$$

Where:

g: $\quad$ Acceleration of gravity;

$T_{p}: \quad$ Spectral peak period of the wave field in front of the structure.

Hussaarts et al. (1999) performed an analysis of laboratory data to obtain values of $M$ and $\gamma_{\text {model }}$. The results are shown in table A.2.

Table A.2: Parameters of the revetment stability model (after Hussaarts et al., 1999)

\begin{tabular}{llll}
\hline Parameter & Distribution type & Mean & Standard deviation \\
\hline$M$ & $\mathrm{D}$ & 4.06 & n.a. \\
$\gamma_{\text {model }}$ & $\mathrm{N}$ & 1.0 & 0.17 \\
\hline
\end{tabular}

\section{A.3.3 Piping}

\section{A.3.3.1 Description of the failure mode}

When a flood defence structure is built on a permeable sub-soil, the water level difference between sea side and land side of the flood defence leads to a ground water flow. The outflow of the ground water on the land side of the structure may transport soil particles if the outflow velocity is high enough in comparison to the erosion resistance of the sub-soil.

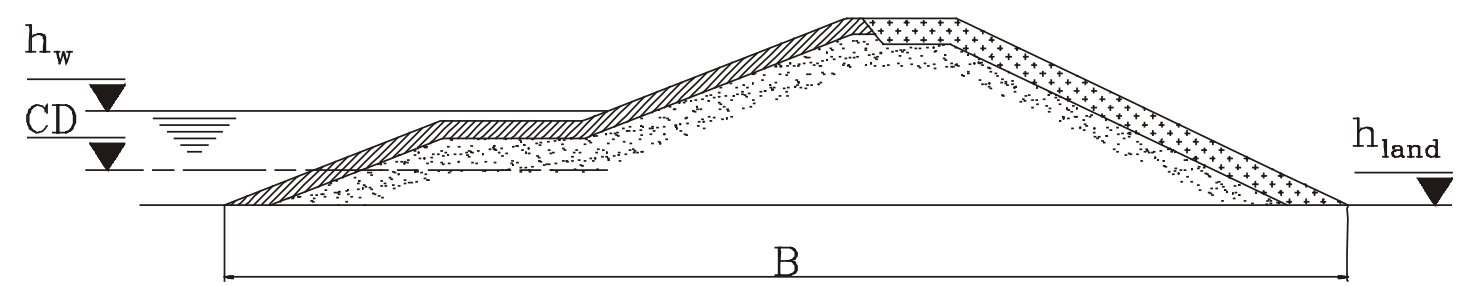

Figure A.8: Definition sketch piping

If the high outflow velocity persists long enough, a dike structure may be eroded from the inside, leading to collapse ${ }^{24}$ of the structure. This process takes some time. Models to quantify the time effects of piping appear not to be available. There are however a number of models indicating the beginning of the piping process. The beginning of piping is an initiating failure mode.

\section{A.3.3.2 Definition of limit state function}

An overview of design formulae for piping is given in TAW (1999). The analysis in this study is based on the model of Bligh. The model of Bligh indicates the beginning of the piping process by the exceedance of a critical head difference:

\footnotetext{
${ }^{24}$ If an impermeable layer is present on top of the permeable layer, the top layer has to collapse before erosion is possible. This situation is not considered in this study.
} 


$$
h_{w}-h_{\text {land }}>\frac{B}{C}
$$

Where:

$h_{w}: \quad$ Water level sea side;

$h_{\text {land }}: \quad$ Water level land side;

B: $\quad$ Width of dike foot print;

$C$ : $\quad$ Constant depending on the type of sub-soil (see TAW, 1999).

Based on equation (A.35), the following limit state function for the beginning of piping is derived:

$$
g_{\text {piping }}\left(h_{w}, h_{\text {land }}, \mathbf{z}\right)=\frac{B(\mathbf{z})}{C}-h_{w}+h_{\text {land }}
$$

Where $\mathbf{z}$ is a vector describing the geometry of the structure.

\section{A.3.4 Uplifting of land side clay cover}

\section{A.3.4.1 Description of the failure mode}

The land side slope of a coastal flood defence is generally covered with a clay layer to prevent erosion by wave overtopping (see also section 0). Under extreme loading conditions, the water table inside the dike body rises which may ultimately lead to uplifting of the clay cover on the land side of the profile (figure A.9).

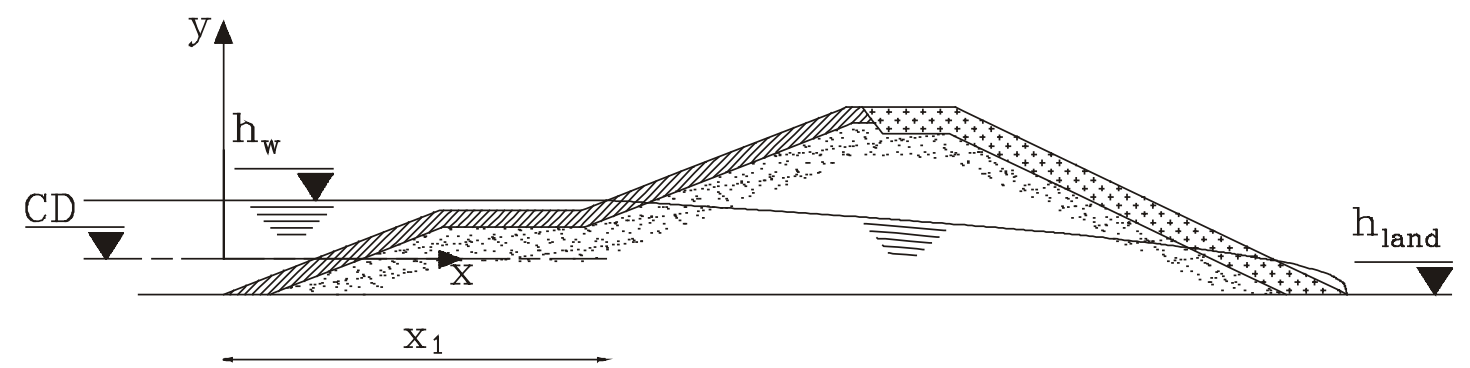

Figure A.9: Definition sketch uplifting land side clay cover

Once the clay cover has collapsed, further damage to the profile may be caused either by erosion due to overtopping or by erosion due to the ground water flow through the dike body. Uplifting of the land side clay cover is therefore an initiating failure mode.

\section{A.3.4.2 Definition of limit state function}

The limit state function for uplifting of the land side clay cover is found by analysing the equilibrium of a sloping impermeable layer loaded by a water level difference. Uplifting of the land side clay cover is prevented if:

$\gamma_{w e t} D_{b a c k} \cos \alpha \geq \gamma_{w}\left(h_{p}\left(h_{w}, h_{\text {land }}, x, \mathbf{z}\right)-y(x, \mathbf{z})-D_{b a c k} \cos \alpha\right)$

Where:

$\gamma_{\text {wet }}$ : Density of saturated clay cover;

$D_{\text {back }}: \quad$ Thickness of clay cover;

$\alpha$. $\quad$ Land side slope;

$\gamma_{w}: \quad$ Density of water;

$h_{p}$ : Piezometric head;

$h_{w}$ : Water level sea side; 
$h_{\text {land }}: \quad$ Water level land side;

$x$ : $\quad$ Horizontal coordinate (see figure A.9);

z: $\quad$ Vector describing the geometry of the structure;

$y$ : $\quad$ Vertical coordinate of top side of slope.

From equation (A.37), the following limit state for uplifting of the land side clay cover is obtained:

$$
\begin{aligned}
& g_{\text {landside }}\left(h_{w}, h_{\text {land }}, x, \mathbf{z}\right)= \\
& \qquad \gamma_{\text {wet }} D_{b a c k} \cos \alpha-\gamma_{w}\left(h_{p}\left(h_{w}, h_{\text {land }}, x, \mathbf{z}\right)-y(x, \mathbf{z})-D_{b a c k} \cos \alpha\right)
\end{aligned}
$$

The piezometric head $h_{p}$ is a function of the water level difference between sea side and land side, the horizontal coordinate $x$ and the geometry of the structure. An upper bound approximation is given by:

$$
h_{p}\left(h_{w}, h_{\text {land }}, x, \mathbf{z}\right)=\sqrt{\frac{-\left(h_{w}-h_{\text {land }}\right)^{2}\left(x-2 x_{1}\left(h_{w}, \mathbf{z}\right)-x_{2}\right)}{x_{2}-x_{1}\left(h_{w}, \mathbf{z}\right)}}
$$

Where:

$x_{1}$ : Horizontal coordinate of entry point of water flow;

$x_{2}$ : $\quad$ Horizontal coordinate of outflow point.

Equation (A.39) is exact for a rectangular soil body with constant permeability (see Barends and Uffink, 2000). For a trapezoidal profile it can be used as an approximation. The horizontal coordinate of the entry point $x_{1}$ is obtained by a numerical search procedure. The coordinate $x_{2}$ is taken in the heel of the structure.

As a consequence of the behaviour of the piezometric head as a function of $x$, the limit state function varies as a function of $x$. In this study, the minimum value of equation (A.38) is used to evaluate the stability of the land side clay cover. The minimum value is obtained by a numerical search procedure. 


\section{A.4 DERIVING THE PROBABILITY DISTRIBUTION OF TIDES FROM HARMONIC COMPONENTS}

Neglecting wind effects, the water level along the Dutch coast varies as a result of tidal influences. The tidal variation of the water level is periodical and can therefore be predicted by an analysis of observed water levels. The method is called the method of harmonic components and is described in detail by Godin (1972). A harmonic component is a cosine-signal with a given frequency and amplitude. In principle, any signal can be described by a set of harmonic components. Thus, a tide signal is written as:

$$
h_{a}(t)=h_{0}+\sum_{i} a_{i} \cos \left(\omega_{i} t+\varphi_{i}\right)
$$

Where:

$h_{0}$ : $\quad$ Still water level with respect to Chart Datum;

a: $\quad$ Amplitude;

$\omega . \quad$ Angular velocity;

$\varphi$ : $\quad$ Phase.

Analysis of observed water levels provides the parameters of equation (A.40) with which the tidal variation can be forecasted for a prescribed period. In the Netherlands the forecasted water levels are published in tide table by the Institute for Coastal and Marine Management (see RIKZ, 2001 for an example).

Despite the fact that the tide for a given point in time is predictable, the tide at the time of a storm is a random variable. The reason for this is that the time of occurrence of the storm itself is unknown. The harmonic components can be used to derive the distribution of the tidal water level ${ }^{25}$ during a storm.

Considering one harmonic component only, the water level is given by:

$h_{i}\left(t_{\text {storm }}\right)=a_{i} \cos \left(\omega_{i} t_{\text {storm }}\right)=a_{i} \cos \left(\pi \frac{t_{\text {storm }}}{T_{i}}\right)$

Where:

$t_{\text {storm: }}$ : Time of occurrence of extreme wind speed;

$T: \quad$ Natural period of the tidal component.

Considering the time of occurrence of a storm to be uniformly distributed between 0 and $T_{i}$, equation (A.41) can be used to establish the probability distribution of the tidal component. Because the tide signal is symmetric around $\frac{1}{2} T$ the effect of realisations of $t_{\text {storm }}$ from $\frac{1}{2} T$ to $T$ provide the same results as realisations from 0 to $T$. Using the symmetry of the tide signal, a probability measure for the tide at the time of a storm can be written as:

$$
p=1-\frac{\frac{1}{2} t_{\text {storm }}}{\frac{1}{2} T}=1-\frac{t_{\text {storm }}}{T}
$$

\footnotetext{
${ }^{25}$ It may be argued that field data could be used to derive the distribution of the tide. However, one should realise that a tidal water level can not be measured directly. Therefore the tidal water levels provided in datasets of observations are the result of harmonic analysis. The analysis of so-called "field data" is completely equivalent to the analysis shown here.
} 
Because $t_{\text {storm }}$ is considered uniformly distributed between 0 and $T, p$ lies between 0 and 1 and thus fulfils the requirements for a probability measure. Substitution of equation (A.42) in (A.41) and rearranging the resulting expression leads to:

$$
F_{h_{a, i}}(\eta)=p=1-\frac{1}{\pi} \operatorname{acos}\left(\frac{\eta}{a_{i}}\right)
$$

Which is a probability distribution of tidal component $i$. The probability density of one tidal component is given by differentiation:

$$
f_{\underline{h_{a, i}}}(\eta)=\frac{1}{a_{i} \pi \sqrt{1-\frac{h_{i}^{2}}{a_{i}^{2}}}}
$$

Figure A.10 shows the relation between the tide signal and the resulting probability distribution graphically.
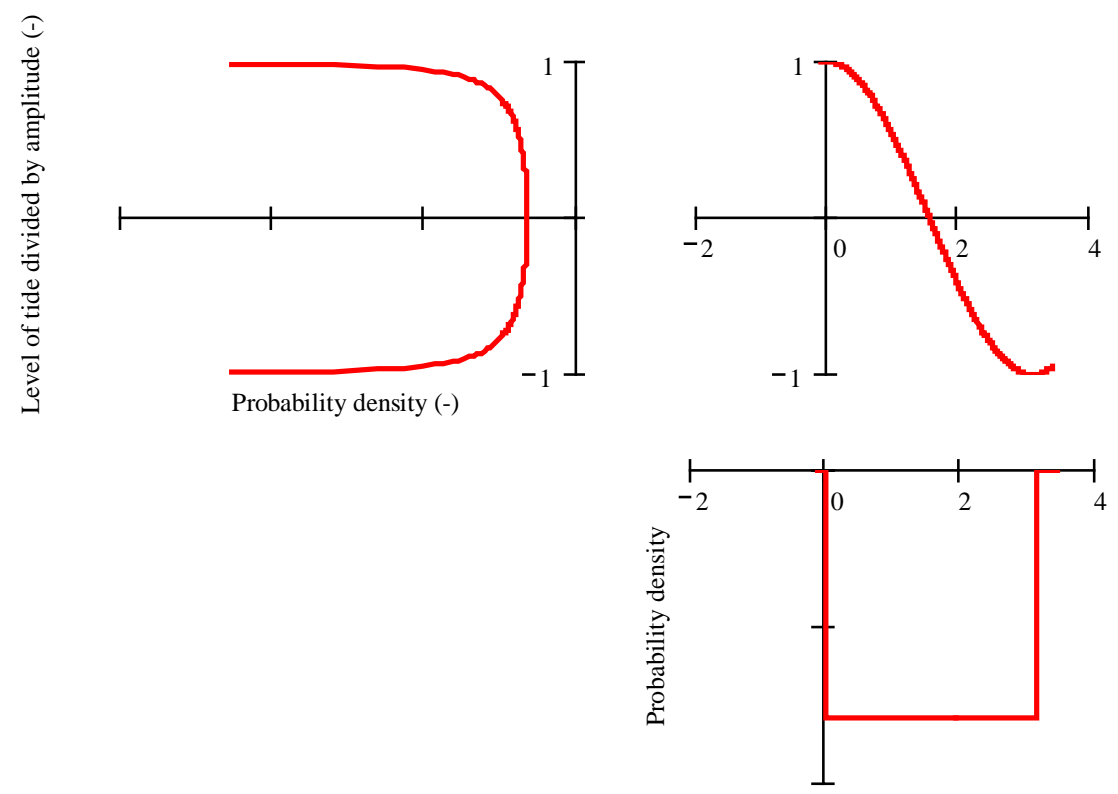

Phase of tide (rad)

Figure A.10: Deriving the probability density of a tidal component

Equation (A.43) can be used directly to describe the astronomic tide in a probabilistic model; the parameters being given by an harmonic analysis of tides. The number of random variables in such a model is equal to the number of tidal components necessary for a description of the tide. In some cases, this may lead to a large number of random variables ${ }^{26}$. An alternative is found by considering that the sum of a large number of random variables follows a normal distribution ${ }^{27}$, irrespective of the distribution of the original variables. This is a theoretical result that is valid if the number of components approaches infinity. Generally, the number of tidal components is too small to lead to a normal distribution of the full tide signal. Nevertheless, it appears that the high and low tides can be described by a normal distribution, which leads to the following distribution for the full tide:

\footnotetext{
${ }^{26}$ The Dutch National Institute for Coastal and Marine Management uses 94 components in the description of the tide.

${ }^{27}$ Central limit theorem, a well-known result of statistical theory.
} 


$$
F_{\underline{h_{a}}}(\eta)=p_{t r} \Phi\left(\frac{\eta-\mu_{l o}}{\sigma_{l o}}\right)+\left(1-p_{t r}\right) \Phi\left(\frac{\eta-\mu_{h i}}{\sigma_{h i}}\right)
$$

Where:

$\Phi: \quad$ Standard normal distribution;

$p_{t r}: \quad$ Weighting factor;

$\mu_{l o}, \mu_{h i}$ : Expected values of low and high tide;

$\sigma_{l o}, \sigma_{h i}: \quad$ Standard deviation of low and high tide.

Equation (A.43) can be applied in a Monte Carlo simulation to generate a set of tides. Subsequently, the parameters of the tide distribution can be found by fitting to the simulated data. 



\section{A.5 PATCHING THE WIND DATA OF STATION HUIBERTGAT}

The dataset of wind speed and wind directions of station Huibertgat (HBG) is incomplete. The wind data is missing for three time periods indicated in chapter 6 . The dataset will be completed (patched) using wind data of the neighbouring station Lauwersoog (LWO).

The two stations, although close together, show small differences in their respective empirical wind speed distributions. Therefore, a correction is applied to the LWO data in the following form:

$u_{H B G}=\frac{u_{L W O}-A}{B}$

Where:

$u_{H B G}: \quad$ Potential wind speed Huibertgat;

$u_{L W O}: \quad$ Potential wind speed Lauwersoog;

$A, B: \quad$ Parameters.

The parameters $A$ and $B$ have been determined by minimising the difference in the empirical wind speed distributions of the two stations, using the observations of the period when both stations were active. Thus, the parameters listed in table A.3 are obtained.

Table A.3: Parameters for translating $L W O$ wind observations to $H B G$

\begin{tabular}{ll}
\hline Parameter & Value \\
\hline$A$ & $-0.25 \mathrm{~m} / \mathrm{s}$ \\
$B$ & 0.9 \\
\hline
\end{tabular}

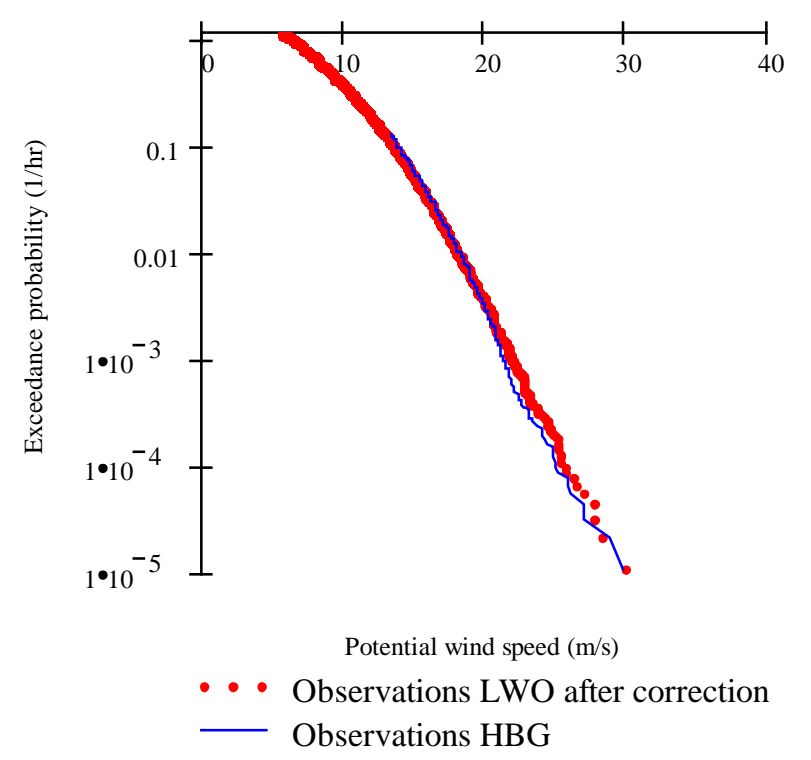

Figure A.11: Empirical distributions of potential wind speed at $H B G$ and corrected potential wind speed at LWO

The necessary correction to find the wind speed at HBG from the wind speed at LWO is fairly limited. This may be expected, since the two stations are close together. 
Analysis of the difference in wind direction as a function of the wind speed shows that under extreme conditions the wind direction can be considered equal for both stations.

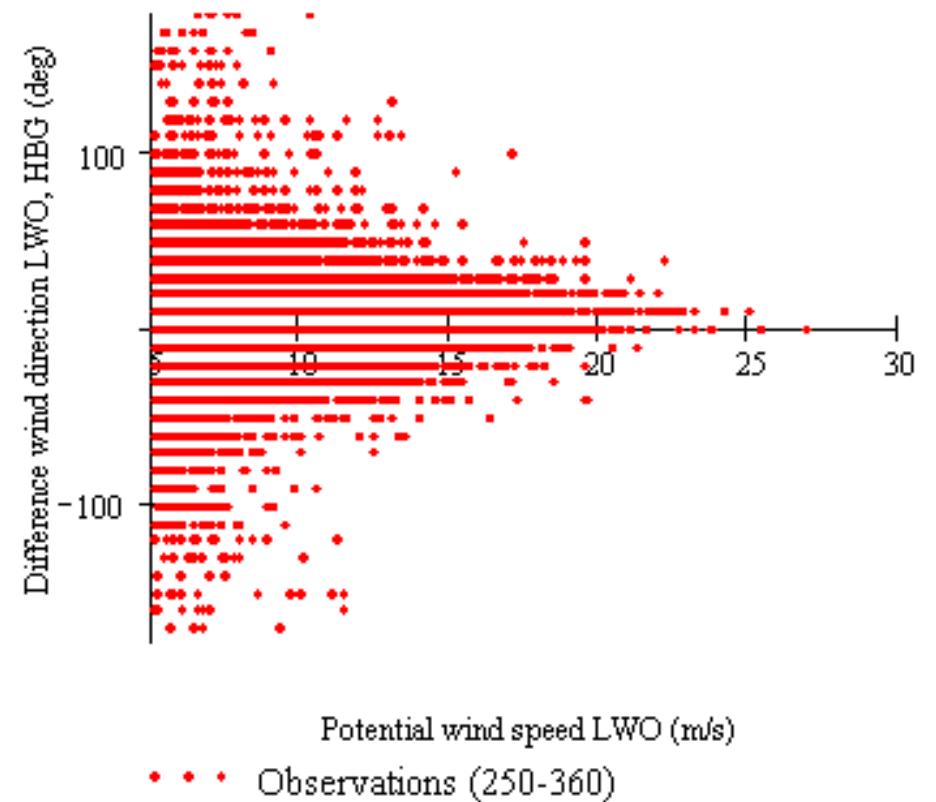

Figure A.12: Difference in wind direction between $H B G$ and $L W O$ as a function of wind speed at LWO 


\section{A.6 STOCHASTIC MODEL FOR THE DIKE RING GRONINGEN}

Table A.4: Hydraulic conditions, all sites

\begin{tabular}{|c|c|c|c|c|c|}
\hline Quantity & Distr. type & Shift & Scale & Shape & Remark \\
\hline \multirow[t]{2}{*}{ Pot. wind speed HBG } & $\mathrm{W}$ & 19.8 & $2.83 \mathrm{~m} / \mathrm{s}$ & 1.2 & \\
\hline & & $\mathrm{m} / \mathrm{s}$ & & & \\
\hline Stat. unc. wind speed & $\mathrm{LN}$ & $\ln (u)$ & $0.21 \ln (u)-0.65$ & n.a. & $\begin{array}{l}u \text { : nominal value } \\
\text { of wind speed } \\
\text { quantile }\end{array}$ \\
\hline High tide $\mathrm{HBG}$ & $\mathrm{N}$ & $0.56 \mathrm{~m}$ & $0.50 \mathrm{~m}$ & n.a. & \\
\hline High tide LWO & $\mathrm{N}$ & $0.76 \mathrm{~m}$ & $0.42 \mathrm{~m}$ & n.a. & \\
\hline High tide DFZ & $\mathrm{N}$ & $0.90 \mathrm{~m}$ & $0.54 \mathrm{~m}$ & n.a. & \\
\hline High tide NSZ & $\mathrm{N}$ & $0.84 \mathrm{~m}$ & $0.49 \mathrm{~m}$ & n.a. & \\
\hline Basin length & $\mathrm{D}$ & $570 \mathrm{~km}$ & n.a. & n.a. & Reduced model \\
\hline Effective depth setup & $\mathrm{D}$ & $32.6 \mathrm{~m}$ & n.a. & n.a. & Reduced model \\
\hline Model parameter setup & $\mathrm{D}$ & $2.2 \cdot 10^{-6}$ & n.a. & n.a. & Reduced model \\
\hline Model uncertainty setup & $\mathrm{N}$ & 1.0 & 0.22 & n.a. & Reduced model \\
\hline Eff. depth wave conditions & $\mathrm{D}$ & $83 \mathrm{~m}$ & n.a. & n.a. & Reduced model \\
\hline Model uncertainty wave height & $\mathrm{N}$ & 1.0 & 0.11 & n.a. & Reduced model \\
\hline Model uncertainty wave period & $\mathrm{N}$ & 1.0 & 0.08 & n.a. & Reduced model \\
\hline Ratio peak period/spectral period & $\mathrm{N}$ & 1.4 & 0.07 & n.a. & \\
\hline Basin length nearshore LWO & $\mathrm{D}$ & $18 \mathrm{~km}$ & n.a. & n.a. & \\
\hline Basin depth nearshore LWO & $\mathrm{D}$ & $5 \mathrm{~m}$ & n.a. & n.a. & \\
\hline Basin length nearshore DFZ & $\mathrm{D}$ & $29 \mathrm{~km}$ & n.a. & n.a. & \\
\hline Basin depth nearshore DFZ & $\mathrm{D}$ & $10 \mathrm{~m}$ & n.a. & n.a. & \\
\hline Basin length nearshore NSZ & $\mathrm{D}$ & $40 \mathrm{~km}$ & n.a. & n.a. & \\
\hline Basin depth nearshore NSZ & $\mathrm{D}$ & $5 \mathrm{~m}$ & n.a. & n.a. & \\
\hline Storm duration & $\mathrm{D}$ & $5 \mathrm{hr}$ & n.a. & n.a. & \\
\hline \multicolumn{6}{|l|}{ W: Weibull distributed quantity } \\
\hline \multicolumn{6}{|l|}{ LN: Log-normal distributed quantity } \\
\hline \multicolumn{6}{|l|}{$\mathrm{N}$ : Normal distributed quantity } \\
\hline \multicolumn{6}{|l|}{ D: Deterministic quantity } \\
\hline
\end{tabular}


Table A.5: Site-specific input, location 1: Ommelander

\begin{tabular}{|c|c|c|c|c|}
\hline Quantity & Distr. type & Shift & Scale & Remark \\
\hline$X$-coordinate & $\mathrm{D}$ & $222490 \mathrm{~m}$ & n.a. & Dutch coordinate system \\
\hline$Y$-coordinate & $\mathrm{D}$ & $603916 \mathrm{~m}$ & n.a. & Dutch coordinate system \\
\hline Bottom level of foreshore & $\mathrm{D}$ & $\mathrm{CD}+1.7 \mathrm{~m}$ & n.a. & From Alkyon (1999) \\
\hline $\begin{array}{l}\text { Model parameter local wave } \\
\text { period }\end{array}$ & $\mathrm{D}$ & 0.90 & n.a. & \\
\hline $\begin{array}{l}\text { Model uncertainty local wave } \\
\text { period (additive) }\end{array}$ & $\mathrm{N}$ & $0.0 \mathrm{~s}$ & $0.21 \mathrm{~s}$ & \\
\hline $\begin{array}{l}\text { Model parameter wave breaking } \\
\text { (van Marle) }\end{array}$ & $\mathrm{D}$ & 0.093 & n.a. & \\
\hline Crest level & $\mathrm{D}$ & design var. & n.a. & \\
\hline Sea side berm level & $\mathrm{D}$ & design var. & n.a. & \\
\hline Sea side berm width & $\mathrm{D}$ & design var. & n.a. & \\
\hline Sea side slope & $\mathrm{D}$ & design var. & n.a. & \\
\hline Land side slope & $\mathrm{D}$ & design var. & n.a. & \\
\hline Revetment size & $\mathrm{D}$ & design var. & n.a. & \\
\hline Toe structure level & $\mathrm{D}$ & $\mathrm{CD}+0 \mathrm{~m}$ & n.a. & \\
\hline Heel level & $\mathrm{D}$ & $\mathrm{CD}+0 \mathrm{~m}$ & n.a. & \\
\hline Land side water level & $\mathrm{D}$ & $\mathrm{CD}+0 \mathrm{~m}$ & n.a. & \\
\hline Crest width & $\mathrm{D}$ & $3 \mathrm{~m}$ & n.a. & \\
\hline Runup reduction factor & $\mathrm{D}$ & 1.0 & n.a & \\
\hline Critical discharge & $\mathrm{D}$ & $10^{-3} \mathrm{~m}^{3}(\mathrm{sm})^{-1}$ & & \\
\hline $\begin{array}{l}\text { Model uncertainty wave } \\
\text { overtopping }\end{array}$ & $\mathrm{N}$ & 1.0 & 0.13 & See annex 3 \\
\hline Density revetment block & $\mathrm{N}$ & $24 \mathrm{kN} / \mathrm{m}^{3}$ & $2.4 \mathrm{kN} / \mathrm{m}^{3}$ & \\
\hline $\begin{array}{l}\text { Model uncertainty revetment } \\
\text { stability }\end{array}$ & $\mathrm{N}$ & 1.0 & 0.17 & See annex 3 \\
\hline Density landside clay cover & $\mathrm{N}$ & $19 \mathrm{kN} / \mathrm{m}^{3}$ & $1.9 \mathrm{kN} / \mathrm{m}^{3}$ & \\
\hline Thickness landside clay cover & $\mathrm{N}$ & $0.80 \mathrm{~m}$ & $0.08 \mathrm{~m}$ & \\
\hline Bligh factor & $\mathrm{N}$ & 15 & 1.5 & From TNO (1998) \\
\hline
\end{tabular}


Table A.6: Site-specific input, location 2: Emmapolder West

\begin{tabular}{|c|c|c|c|c|}
\hline Quantity & Distr. type & Shift & Scale & Remark \\
\hline$X$-coordinate & $\mathrm{D}$ & $243081 \mathrm{~m}$ & n.a. & Dutch coordinate system \\
\hline$Y$-coordinate & $\mathrm{D}$ & $609456 \mathrm{~m}$ & n.a. & Dutch coordinate system \\
\hline Bottom level of foreshore & $\mathrm{D}$ & $\mathrm{CD}+1.33 \mathrm{~m}$ & n.a. & From Alkyon (1999) \\
\hline $\begin{array}{l}\text { Model parameter local wave } \\
\text { period }\end{array}$ & $\mathrm{D}$ & 1.01 & n.a. & \\
\hline $\begin{array}{l}\text { Model uncertainty local wave } \\
\text { period (additive) }\end{array}$ & $\mathrm{N}$ & $0.0 \mathrm{~s}$ & $0.21 \mathrm{~s}$ & \\
\hline $\begin{array}{l}\text { Model parameter wave breaking } \\
\text { (van Marle) }\end{array}$ & $\mathrm{D}$ & 0.093 & n.a. & \\
\hline Crest level & $\mathrm{D}$ & design var. & n.a. & \\
\hline Sea side berm level & $\mathrm{D}$ & design var. & n.a. & \\
\hline Sea side berm width & $\mathrm{D}$ & design var. & n.a. & \\
\hline Sea side slope & $\mathrm{D}$ & design var. & n.a. & \\
\hline Land side slope & $\mathrm{D}$ & design var. & n.a. & \\
\hline Revetment size & $\mathrm{D}$ & design var. & n.a. & \\
\hline Toe structure level & $\mathrm{D}$ & $\mathrm{CD}+0 \mathrm{~m}$ & n.a. & \\
\hline Heel level & $\mathrm{D}$ & $\mathrm{CD}+0 \mathrm{~m}$ & n.a. & \\
\hline Land side water level & $\mathrm{D}$ & $\mathrm{CD}+0 \mathrm{~m}$ & n.a. & \\
\hline Crest width & $\mathrm{D}$ & $3 \mathrm{~m}$ & n.a. & \\
\hline Runup reduction factor & $\mathrm{D}$ & 1.0 & n.a & \\
\hline Critical discharge & $\mathrm{D}$ & $10^{-3} \mathrm{~m}^{3}(\mathrm{sm})^{-1}$ & & \\
\hline $\begin{array}{l}\text { Model uncertainty wave } \\
\text { overtopping }\end{array}$ & $\mathrm{N}$ & 1.0 & 0.13 & See annex 3 \\
\hline Density revetment block & $\mathrm{N}$ & $24 \mathrm{kN} / \mathrm{m}^{3}$ & $2.4 \mathrm{kN} / \mathrm{m}^{3}$ & \\
\hline $\begin{array}{l}\text { Model uncertainty revetment } \\
\text { stability }\end{array}$ & $\mathrm{N}$ & 1.0 & 0.17 & See annex 3 \\
\hline Density landside clay cover & $\mathrm{N}$ & $19 \mathrm{kN} / \mathrm{m}^{3}$ & $1.9 \mathrm{kN} / \mathrm{m}^{3}$ & \\
\hline Thickness landside clay cover & $\mathrm{N}$ & $0.80 \mathrm{~m}$ & $0.08 \mathrm{~m}$ & \\
\hline Bligh factor & $\mathrm{N}$ & 15 & 1.5 & From TNO (1998) \\
\hline
\end{tabular}


Table A.7: Site-specific input, location 3: Emmapolder East

\begin{tabular}{|c|c|c|c|c|}
\hline Quantity & Distr. type & Shift & Scale & Remark \\
\hline$X$-coordinate & $\mathrm{D}$ & $247088 \mathrm{~m}$ & n.a. & Dutch coordinate system \\
\hline$Y$-coordinate & $\mathrm{D}$ & $609349 \mathrm{~m}$ & n.a. & Dutch coordinate system \\
\hline Bottom level of foreshore & $\mathrm{D}$ & $\mathrm{CD}+0.66 \mathrm{~m}$ & n.a. & From Alkyon (1999) \\
\hline $\begin{array}{l}\text { Model parameter local wave } \\
\text { period }\end{array}$ & $\mathrm{D}$ & 1.03 & n.a. & \\
\hline $\begin{array}{l}\text { Model uncertainty local wave } \\
\text { period (additive) }\end{array}$ & $\mathrm{N}$ & $0.0 \mathrm{~s}$ & $0.21 \mathrm{~s}$ & \\
\hline $\begin{array}{l}\text { Model parameter wave breaking } \\
\text { (van Marle) }\end{array}$ & $\mathrm{D}$ & 0.093 & n.a. & \\
\hline Crest level & $\mathrm{D}$ & design var. & n.a. & \\
\hline Sea side berm level & $\mathrm{D}$ & design var. & n.a. & \\
\hline Sea side berm width & $\mathrm{D}$ & design var. & n.a. & \\
\hline Sea side slope & $\mathrm{D}$ & design var. & n.a. & \\
\hline Land side slope & $\mathrm{D}$ & design var. & n.a. & \\
\hline Revetment size & $\mathrm{D}$ & design var. & n.a. & \\
\hline Toe structure level & $\mathrm{D}$ & $\mathrm{CD}+0 \mathrm{~m}$ & n.a. & \\
\hline Heel level & $\mathrm{D}$ & $\mathrm{CD}+0 \mathrm{~m}$ & n.a. & \\
\hline Land side water level & $\mathrm{D}$ & $\mathrm{CD}+0 \mathrm{~m}$ & n.a. & \\
\hline Crest width & $\mathrm{D}$ & $3 \mathrm{~m}$ & n.a. & \\
\hline Runup reduction factor & $\mathrm{D}$ & 1.0 & n.a & \\
\hline Critical discharge & $\mathrm{D}$ & $10^{-3} \mathrm{~m}^{3}(\mathrm{sm})^{-1}$ & & \\
\hline $\begin{array}{l}\text { Model uncertainty wave } \\
\text { overtopping }\end{array}$ & $\mathrm{N}$ & 1.0 & 0.13 & See annex 3 \\
\hline Density revetment block & $\mathrm{N}$ & $24 \mathrm{kN} / \mathrm{m}^{3}$ & $2.4 \mathrm{kN} / \mathrm{m}^{3}$ & \\
\hline $\begin{array}{l}\text { Model uncertainty revetment } \\
\text { stability }\end{array}$ & $\mathrm{N}$ & 1.0 & 0.17 & See annex 3 \\
\hline Density landside clay cover & $\mathrm{N}$ & $19 \mathrm{kN} / \mathrm{m}^{3}$ & $1.9 \mathrm{kN} / \mathrm{m}^{3}$ & \\
\hline Thickness landside clay cover & $\mathrm{N}$ & $0.80 \mathrm{~m}$ & $0.08 \mathrm{~m}$ & \\
\hline Bligh factor & $\mathrm{N}$ & 15 & 1.5 & From TNO (1998) \\
\hline
\end{tabular}


Table A.8: Site-specific input, location 4: Eemshaven West

\begin{tabular}{|c|c|c|c|c|}
\hline Quantity & Distr. type & Shift & Scale & Remark \\
\hline$X$-coordinate & $\mathrm{D}$ & $249954 \mathrm{~m}$ & n.a. & Dutch coordinate system \\
\hline$Y$-coordinate & $\mathrm{D}$ & $609497 \mathrm{~m}$ & n.a. & Dutch coordinate system \\
\hline Bottom level of foreshore & $\mathrm{D}$ & CD $-1.79 \mathrm{~m}$ & n.a. & From Alkyon (1999) \\
\hline $\begin{array}{l}\text { Model parameter local wave } \\
\text { period }\end{array}$ & $\mathrm{D}$ & 0.92 & n.a. & \\
\hline $\begin{array}{l}\text { Model uncertainty local wave } \\
\text { period (additive) }\end{array}$ & $\mathrm{N}$ & $0.0 \mathrm{~s}$ & $0.21 \mathrm{~s}$ & \\
\hline $\begin{array}{l}\text { Model parameter wave breaking } \\
\text { (van Marle) }\end{array}$ & $\mathrm{D}$ & 0.093 & n.a. & \\
\hline Crest level & $\mathrm{D}$ & design var. & n.a. & \\
\hline Sea side berm level & $\mathrm{D}$ & design var. & n.a. & \\
\hline Sea side berm width & $\mathrm{D}$ & design var. & n.a. & \\
\hline Sea side slope & $\mathrm{D}$ & design var. & n.a. & \\
\hline Land side slope & $\mathrm{D}$ & design var. & n.a. & \\
\hline Revetment size & $\mathrm{D}$ & design var. & n.a. & \\
\hline Toe structure level & $\mathrm{D}$ & $\mathrm{CD}+0 \mathrm{~m}$ & n.a. & \\
\hline Heel level & $\mathrm{D}$ & $\mathrm{CD}+0 \mathrm{~m}$ & n.a. & \\
\hline Land side water level & $\mathrm{D}$ & $\mathrm{CD}+0 \mathrm{~m}$ & n.a. & \\
\hline Crest width & $\mathrm{D}$ & $3 \mathrm{~m}$ & n.a. & \\
\hline Runup reduction factor & $\mathrm{D}$ & 1.0 & n.a & \\
\hline Critical discharge & $\mathrm{D}$ & $10^{-3} \mathrm{~m}^{3}(\mathrm{sm})^{-1}$ & & \\
\hline $\begin{array}{l}\text { Model uncertainty wave } \\
\text { overtopping }\end{array}$ & $\mathrm{N}$ & 1.0 & 0.13 & See annex 3 \\
\hline Density revetment block & $\mathrm{N}$ & $24 \mathrm{kN} / \mathrm{m}^{3}$ & $2.4 \mathrm{kN} / \mathrm{m}^{3}$ & \\
\hline $\begin{array}{l}\text { Model uncertainty revetment } \\
\text { stability }\end{array}$ & $\mathrm{N}$ & 1.0 & 0.17 & See annex 3 \\
\hline Density landside clay cover & $\mathrm{N}$ & $19 \mathrm{kN} / \mathrm{m}^{3}$ & $1.9 \mathrm{kN} / \mathrm{m}^{3}$ & \\
\hline Thickness landside clay cover & $\mathrm{N}$ & $0.80 \mathrm{~m}$ & $0.08 \mathrm{~m}$ & \\
\hline Bligh factor & $\mathrm{N}$ & 15 & 1.5 & From TNO (1998) \\
\hline
\end{tabular}


Table A.9: Site-specific input, location 5: Eemshaven East

\begin{tabular}{|c|c|c|c|c|}
\hline Quantity & Distr. type & Shift & Scale & Remark \\
\hline$X$-coordinate & $\mathrm{D}$ & $253073 \mathrm{~m}$ & n.a. & Dutch coordinate system \\
\hline$Y$-coordinate & $\mathrm{D}$ & $608217 \mathrm{~m}$ & n.a. & Dutch coordinate system \\
\hline Bottom level of foreshore & $\mathrm{D}$ & CD $-1.56 \mathrm{~m}$ & n.a. & From Alkyon (1999) \\
\hline $\begin{array}{l}\text { Model parameter local wave } \\
\text { period }\end{array}$ & $\mathrm{D}$ & 0.90 & n.a. & \\
\hline $\begin{array}{l}\text { Model uncertainty local wave } \\
\text { period (additive) }\end{array}$ & $\mathrm{N}$ & $0.0 \mathrm{~s}$ & $0.21 \mathrm{~s}$ & \\
\hline $\begin{array}{l}\text { Model parameter wave breaking } \\
\text { (van Marle) }\end{array}$ & $\mathrm{D}$ & 0.093 & n.a. & \\
\hline Crest level & $\mathrm{D}$ & design var. & n.a. & \\
\hline Sea side berm level & $\mathrm{D}$ & design var. & n.a. & \\
\hline Sea side berm width & $\mathrm{D}$ & design var. & n.a. & \\
\hline Sea side slope & $\mathrm{D}$ & design var. & n.a. & \\
\hline Land side slope & $\mathrm{D}$ & design var. & n.a. & \\
\hline Revetment size & $\mathrm{D}$ & design var. & n.a. & \\
\hline Toe structure level & $\mathrm{D}$ & $\mathrm{CD}+0 \mathrm{~m}$ & n.a. & \\
\hline Heel level & $\mathrm{D}$ & $\mathrm{CD}+0 \mathrm{~m}$ & n.a. & \\
\hline Land side water level & $\mathrm{D}$ & $\mathrm{CD}+0 \mathrm{~m}$ & n.a. & \\
\hline Crest width & $\mathrm{D}$ & $3 \mathrm{~m}$ & n.a. & \\
\hline Runup reduction factor & $\mathrm{D}$ & 1.0 & n.a & \\
\hline Critical discharge & $\mathrm{D}$ & $10^{-3} \mathrm{~m}^{3}(\mathrm{sm})^{-1}$ & & \\
\hline $\begin{array}{l}\text { Model uncertainty wave } \\
\text { overtopping }\end{array}$ & $\mathrm{N}$ & 1.0 & 0.13 & See annex 3 \\
\hline Density revetment block & $\mathrm{N}$ & $24 \mathrm{kN} / \mathrm{m}^{3}$ & $2.4 \mathrm{kN} / \mathrm{m}^{3}$ & \\
\hline $\begin{array}{l}\text { Model uncertainty revetment } \\
\text { stability }\end{array}$ & $\mathrm{N}$ & 1.0 & 0.17 & See annex 3 \\
\hline Density landside clay cover & $\mathrm{N}$ & $19 \mathrm{kN} / \mathrm{m}^{3}$ & $1.9 \mathrm{kN} / \mathrm{m}^{3}$ & \\
\hline Thickness landside clay cover & $\mathrm{N}$ & $0.80 \mathrm{~m}$ & $0.08 \mathrm{~m}$ & \\
\hline Bligh factor & $\mathrm{N}$ & 15 & 1.5 & From TNO (1998) \\
\hline
\end{tabular}


Table A.10: Site-specific input, location 6: Hoogwatum

\begin{tabular}{|c|c|c|c|c|}
\hline Quantity & Distr. type & Shift & Scale & Remark \\
\hline$X$-coordinate & $\mathrm{D}$ & $254985 \mathrm{~m}$ & n.a. & Dutch coordinate system \\
\hline$Y$-coordinate & $\mathrm{D}$ & $600570 \mathrm{~m}$ & n.a. & Dutch coordinate system \\
\hline Bottom level of foreshore & $\mathrm{D}$ & CD $-0.22 \mathrm{~m}$ & n.a. & From Alkyon (1999) \\
\hline $\begin{array}{l}\text { Model parameter local wave } \\
\text { period }\end{array}$ & $\mathrm{D}$ & 0.66 & n.a. & \\
\hline $\begin{array}{l}\text { Model uncertainty local wave } \\
\text { period (additive) }\end{array}$ & $\mathrm{N}$ & $0.0 \mathrm{~s}$ & $0.21 \mathrm{~s}$ & \\
\hline $\begin{array}{l}\text { Model parameter wave breaking } \\
\text { (van Marle) }\end{array}$ & $\mathrm{D}$ & 0.093 & n.a. & \\
\hline Crest level & $\mathrm{D}$ & design var. & n.a. & \\
\hline Sea side berm level & $\mathrm{D}$ & design var. & n.a. & \\
\hline Sea side berm width & $\mathrm{D}$ & design var. & n.a. & \\
\hline Sea side slope & $\mathrm{D}$ & design var. & n.a. & \\
\hline Land side slope & $\mathrm{D}$ & design var. & n.a. & \\
\hline Revetment size & $\mathrm{D}$ & design var. & n.a. & \\
\hline Toe structure level & $\mathrm{D}$ & $\mathrm{CD}+0 \mathrm{~m}$ & n.a. & \\
\hline Heel level & $\mathrm{D}$ & $\mathrm{CD}+0 \mathrm{~m}$ & n.a. & \\
\hline Land side water level & $\mathrm{D}$ & $\mathrm{CD}+0 \mathrm{~m}$ & n.a. & \\
\hline Crest width & $\mathrm{D}$ & $3 \mathrm{~m}$ & n.a. & \\
\hline Runup reduction factor & $\mathrm{D}$ & 1.0 & n.a & \\
\hline Critical discharge & $\mathrm{D}$ & $10^{-3} \mathrm{~m}^{3}(\mathrm{sm})^{-1}$ & & \\
\hline $\begin{array}{l}\text { Model uncertainty wave } \\
\text { overtopping }\end{array}$ & $\mathrm{N}$ & 1.0 & 0.13 & See annex 3 \\
\hline Density revetment block & $\mathrm{N}$ & $24 \mathrm{kN} / \mathrm{m}^{3}$ & $2.4 \mathrm{kN} / \mathrm{m}^{3}$ & \\
\hline $\begin{array}{l}\text { Model uncertainty revetment } \\
\text { stability }\end{array}$ & $\mathrm{N}$ & 1.0 & 0.17 & See annex 3 \\
\hline Density landside clay cover & $\mathrm{N}$ & $19 \mathrm{kN} / \mathrm{m}^{3}$ & $1.9 \mathrm{kN} / \mathrm{m}^{3}$ & \\
\hline Thickness landside clay cover & $\mathrm{N}$ & $0.80 \mathrm{~m}$ & $0.08 \mathrm{~m}$ & \\
\hline Bligh factor & $\mathrm{N}$ & 15 & 1.5 & From TNO (1998) \\
\hline
\end{tabular}


Table A.11: Site-specific input, location 7: Delfzijl North

\begin{tabular}{|c|c|c|c|c|}
\hline Quantity & Distr. type & Shift & Scale & Remark \\
\hline$X$-coordinate & $\mathrm{D}$ & $257074 \mathrm{~m}$ & n.a. & Dutch coordinate system \\
\hline$Y$-coordinate & $\mathrm{D}$ & $596244 \mathrm{~m}$ & n.a. & Dutch coordinate system \\
\hline Bottom level of foreshore & $\mathrm{D}$ & CD $-5.43 \mathrm{~m}$ & n.a. & From Alkyon (1999) \\
\hline $\begin{array}{l}\text { Model parameter local wave } \\
\text { period }\end{array}$ & $\mathrm{D}$ & 0.48 & n.a. & \\
\hline $\begin{array}{l}\text { Model uncertainty local wave } \\
\text { period (additive) }\end{array}$ & $\mathrm{N}$ & $0.0 \mathrm{~s}$ & $0.21 \mathrm{~s}$ & \\
\hline $\begin{array}{l}\text { Model parameter wave breaking } \\
\text { (van Marle) }\end{array}$ & $\mathrm{D}$ & 0.093 & n.a. & \\
\hline Crest level & $\mathrm{D}$ & design var. & n.a. & \\
\hline Sea side berm level & $\mathrm{D}$ & design var. & n.a. & \\
\hline Sea side berm width & $\mathrm{D}$ & design var. & n.a. & \\
\hline Sea side slope & $\mathrm{D}$ & design var. & n.a. & \\
\hline Land side slope & $\mathrm{D}$ & design var. & n.a. & \\
\hline Revetment size & $\mathrm{D}$ & design var. & n.a. & \\
\hline Toe structure level & $\mathrm{D}$ & $\mathrm{CD}+0 \mathrm{~m}$ & n.a. & \\
\hline Heel level & $\mathrm{D}$ & $\mathrm{CD}+0 \mathrm{~m}$ & n.a. & \\
\hline Land side water level & $\mathrm{D}$ & $\mathrm{CD}+0 \mathrm{~m}$ & n.a. & \\
\hline Crest width & $\mathrm{D}$ & $3 \mathrm{~m}$ & n.a. & \\
\hline Runup reduction factor & $\mathrm{D}$ & 1.0 & n.a & \\
\hline Critical discharge & $\mathrm{D}$ & $10^{-3} \mathrm{~m}^{3}(\mathrm{sm})^{-1}$ & & \\
\hline $\begin{array}{l}\text { Model uncertainty wave } \\
\text { overtopping }\end{array}$ & $\mathrm{N}$ & 1.0 & 0.13 & See annex 3 \\
\hline Density revetment block & $\mathrm{N}$ & $24 \mathrm{kN} / \mathrm{m}^{3}$ & $2.4 \mathrm{kN} / \mathrm{m}^{3}$ & \\
\hline $\begin{array}{l}\text { Model uncertainty revetment } \\
\text { stability }\end{array}$ & $\mathrm{N}$ & 1.0 & 0.17 & See annex 3 \\
\hline Density landside clay cover & $\mathrm{N}$ & $19 \mathrm{kN} / \mathrm{m}^{3}$ & $1.9 \mathrm{kN} / \mathrm{m}^{3}$ & \\
\hline Thickness landside clay cover & $\mathrm{N}$ & $0.80 \mathrm{~m}$ & $0.08 \mathrm{~m}$ & \\
\hline Bligh factor & $\mathrm{N}$ & 15 & 1.5 & From TNO (1998) \\
\hline
\end{tabular}


Table A.12: Site-specific input, location 8: Dijk zeehavenkanaal

\begin{tabular}{|c|c|c|c|c|}
\hline Quantity & Distr. type & Shift & Scale & Remark \\
\hline$X$-coordinate & $\mathrm{D}$ & $263100 \mathrm{~m}$ & n.a. & Dutch coordinate system \\
\hline$Y$-coordinate & $\mathrm{D}$ & $593450 \mathrm{~m}$ & n.a. & Dutch coordinate system \\
\hline Bottom level of foreshore & $\mathrm{D}$ & $\mathrm{CD}-8.70 \mathrm{~m}$ & n.a. & From Alkyon (1999) \\
\hline $\begin{array}{l}\text { Model parameter local wave } \\
\text { period }\end{array}$ & $\mathrm{D}$ & 0.49 & n.a. & \\
\hline $\begin{array}{l}\text { Model uncertainty local wave } \\
\text { period (additive) }\end{array}$ & $\mathrm{N}$ & $0.0 \mathrm{~s}$ & $0.21 \mathrm{~s}$ & \\
\hline $\begin{array}{l}\text { Model parameter wave breaking } \\
\text { (van Marle) }\end{array}$ & $\mathrm{D}$ & 0.093 & n.a. & \\
\hline Crest level & $\mathrm{D}$ & design var. & n.a. & \\
\hline Sea side berm level & $\mathrm{D}$ & design var. & n.a. & \\
\hline Sea side berm width & $\mathrm{D}$ & design var. & n.a. & \\
\hline Sea side slope & $\mathrm{D}$ & design var. & n.a. & \\
\hline Land side slope & $\mathrm{D}$ & design var. & n.a. & \\
\hline Revetment size & $\mathrm{D}$ & design var. & n.a. & \\
\hline Toe structure level & $\mathrm{D}$ & $\mathrm{CD}+0 \mathrm{~m}$ & n.a. & \\
\hline Heel level & $\mathrm{D}$ & $\mathrm{CD}+0 \mathrm{~m}$ & n.a. & \\
\hline Land side water level & $\mathrm{D}$ & $\mathrm{CD}+0 \mathrm{~m}$ & n.a. & \\
\hline Crest width & $\mathrm{D}$ & $3 \mathrm{~m}$ & n.a. & \\
\hline Runup reduction factor & $\mathrm{D}$ & 1.0 & n.a & \\
\hline Critical discharge & $\mathrm{D}$ & $10^{-3} \mathrm{~m}^{3}(\mathrm{sm})^{-1}$ & & \\
\hline $\begin{array}{l}\text { Model uncertainty wave } \\
\text { overtopping }\end{array}$ & $\mathrm{N}$ & 1.0 & 0.13 & See annex 3 \\
\hline Density revetment block & $\mathrm{N}$ & $24 \mathrm{kN} / \mathrm{m}^{3}$ & $2.4 \mathrm{kN} / \mathrm{m}^{3}$ & \\
\hline $\begin{array}{l}\text { Model uncertainty revetment } \\
\text { stability }\end{array}$ & $\mathrm{N}$ & 1.0 & 0.17 & See annex 3 \\
\hline Density landside clay cover & $\mathrm{N}$ & $19 \mathrm{kN} / \mathrm{m}^{3}$ & $1.9 \mathrm{kN} / \mathrm{m}^{3}$ & \\
\hline Thickness landside clay cover & $\mathrm{N}$ & $0.80 \mathrm{~m}$ & $0.08 \mathrm{~m}$ & \\
\hline Bligh factor & $\mathrm{N}$ & 15 & 1.5 & From TNO (1998) \\
\hline
\end{tabular}


Table A.13: Site-specific input, location 9: Termunten

\begin{tabular}{|c|c|c|c|c|}
\hline Quantity & Distr. type & Shift & Scale & Remark \\
\hline$X$-coordinate & $\mathrm{D}$ & $267026 \mathrm{~m}$ & n.a. & Dutch coordinate system \\
\hline$Y$-coordinate & $\mathrm{D}$ & $591729 \mathrm{~m}$ & n.a. & Dutch coordinate system \\
\hline Bottom level of foreshore & $\mathrm{D}$ & CD $-0.19 \mathrm{~m}$ & n.a. & From Alkyon (1999) \\
\hline $\begin{array}{l}\text { Model parameter local wave } \\
\text { period }\end{array}$ & $\mathrm{D}$ & 0.74 & n.a. & \\
\hline $\begin{array}{l}\text { Model uncertainty local wave } \\
\text { period (additive) }\end{array}$ & $\mathrm{N}$ & $0.0 \mathrm{~s}$ & $0.21 \mathrm{~s}$ & \\
\hline $\begin{array}{l}\text { Model parameter wave breaking } \\
\text { (van Marle) }\end{array}$ & $\mathrm{D}$ & 0.093 & n.a. & \\
\hline Crest level & $\mathrm{D}$ & design var. & n.a. & \\
\hline Sea side berm level & $\mathrm{D}$ & design var. & n.a. & \\
\hline Sea side berm width & $\mathrm{D}$ & design var. & n.a. & \\
\hline Sea side slope & $\mathrm{D}$ & design var. & n.a. & \\
\hline Land side slope & $\mathrm{D}$ & design var. & n.a. & \\
\hline Revetment size & $\mathrm{D}$ & design var. & n.a. & \\
\hline Toe structure level & $\mathrm{D}$ & $\mathrm{CD}+0 \mathrm{~m}$ & n.a. & \\
\hline Heel level & $\mathrm{D}$ & $\mathrm{CD}+0 \mathrm{~m}$ & n.a. & \\
\hline Land side water level & $\mathrm{D}$ & $\mathrm{CD}+0 \mathrm{~m}$ & n.a. & \\
\hline Crest width & $\mathrm{D}$ & $3 \mathrm{~m}$ & n.a. & \\
\hline Runup reduction factor & $\mathrm{D}$ & 1.0 & n.a & \\
\hline Critical discharge & $\mathrm{D}$ & $10^{-3} \mathrm{~m}^{3}(\mathrm{sm})^{-1}$ & & \\
\hline $\begin{array}{l}\text { Model uncertainty wave } \\
\text { overtopping }\end{array}$ & $\mathrm{N}$ & 1.0 & 0.13 & See annex 3 \\
\hline Density revetment block & $\mathrm{N}$ & $24 \mathrm{kN} / \mathrm{m}^{3}$ & $2.4 \mathrm{kN} / \mathrm{m}^{3}$ & \\
\hline $\begin{array}{l}\text { Model uncertainty revetment } \\
\text { stability }\end{array}$ & $\mathrm{N}$ & 1.0 & 0.17 & See annex 3 \\
\hline Density landside clay cover & $\mathrm{N}$ & $19 \mathrm{kN} / \mathrm{m}^{3}$ & $1.9 \mathrm{kN} / \mathrm{m}^{3}$ & \\
\hline Thickness landside clay cover & $\mathrm{N}$ & $0.80 \mathrm{~m}$ & $0.08 \mathrm{~m}$ & \\
\hline Bligh factor & $\mathrm{N}$ & 15 & 1.5 & From TNO (1998) \\
\hline
\end{tabular}


Table A.14: Site-specific input, location 10: Dollarddijk

\begin{tabular}{|c|c|c|c|c|}
\hline Quantity & Distr. type & Shift & Scale & Remark \\
\hline$X$-coordinate & $\mathrm{D}$ & $268149 \mathrm{~m}$ & n.a. & Dutch coordinate system \\
\hline$Y$-coordinate & $\mathrm{D}$ & $590450 \mathrm{~m}$ & n.a. & Dutch coordinate system \\
\hline Bottom level of foreshore & $\mathrm{D}$ & $\mathrm{CD}+1.89 \mathrm{~m}$ & n.a. & From Alkyon (1999) \\
\hline $\begin{array}{l}\text { Model parameter local wave } \\
\text { period }\end{array}$ & $\mathrm{D}$ & 0.80 & n.a. & \\
\hline $\begin{array}{l}\text { Model uncertainty local wave } \\
\text { period (additive) }\end{array}$ & $\mathrm{N}$ & $0.0 \mathrm{~s}$ & $0.21 \mathrm{~s}$ & \\
\hline $\begin{array}{l}\text { Model parameter wave breaking } \\
\text { (van Marle) }\end{array}$ & $\mathrm{D}$ & 0.093 & n.a. & \\
\hline Crest level & $\mathrm{D}$ & design var. & n.a. & \\
\hline Sea side berm level & $\mathrm{D}$ & design var. & n.a. & \\
\hline Sea side berm width & $\mathrm{D}$ & design var. & n.a. & \\
\hline Sea side slope & $\mathrm{D}$ & design var. & n.a. & \\
\hline Land side slope & $\mathrm{D}$ & design var. & n.a. & \\
\hline Revetment size & $\mathrm{D}$ & design var. & n.a. & \\
\hline Toe structure level & $\mathrm{D}$ & $\mathrm{CD}+0 \mathrm{~m}$ & n.a. & \\
\hline Heel level & $\mathrm{D}$ & $\mathrm{CD}+0 \mathrm{~m}$ & n.a. & \\
\hline Land side water level & $\mathrm{D}$ & $\mathrm{CD}+0 \mathrm{~m}$ & n.a. & \\
\hline Crest width & $\mathrm{D}$ & $3 \mathrm{~m}$ & n.a. & \\
\hline Runup reduction factor & $\mathrm{D}$ & 1.0 & n.a & \\
\hline Critical discharge & $\mathrm{D}$ & $10^{-3} \mathrm{~m}^{3}(\mathrm{sm})^{-1}$ & & \\
\hline $\begin{array}{l}\text { Model uncertainty wave } \\
\text { overtopping }\end{array}$ & $\mathrm{N}$ & 1.0 & 0.13 & See annex 3 \\
\hline Density revetment block & $\mathrm{N}$ & $24 \mathrm{kN} / \mathrm{m}^{3}$ & $2.4 \mathrm{kN} / \mathrm{m}^{3}$ & \\
\hline $\begin{array}{l}\text { Model uncertainty revetment } \\
\text { stability }\end{array}$ & $\mathrm{N}$ & 1.0 & 0.17 & See annex 3 \\
\hline Density landside clay cover & $\mathrm{N}$ & $19 \mathrm{kN} / \mathrm{m}^{3}$ & $1.9 \mathrm{kN} / \mathrm{m}^{3}$ & \\
\hline Thickness landside clay cover & $\mathrm{N}$ & $0.80 \mathrm{~m}$ & $0.08 \mathrm{~m}$ & \\
\hline Bligh factor & $\mathrm{N}$ & 15 & 1.5 & From TNO (1998) \\
\hline
\end{tabular}


Table A.15: Site-specific input, location 11: Reiderwolder polderdijk

\begin{tabular}{|c|c|c|c|c|}
\hline Quantity & Distr. type & Shift & Scale & Remark \\
\hline$X$-coordinate & $\mathrm{D}$ & $272454 \mathrm{~m}$ & n.a. & Dutch coordinate system \\
\hline$Y$-coordinate & $\mathrm{D}$ & $584800 \mathrm{~m}$ & n.a. & Dutch coordinate system \\
\hline Bottom level of foreshore & $\mathrm{D}$ & $\mathrm{CD}+1.87 \mathrm{~m}$ & n.a. & From Alkyon (1999) \\
\hline $\begin{array}{l}\text { Model parameter local wave } \\
\text { period }\end{array}$ & $\mathrm{D}$ & 0.93 & n.a. & \\
\hline $\begin{array}{l}\text { Model uncertainty local wave } \\
\text { period (additive) }\end{array}$ & $\mathrm{N}$ & $0.0 \mathrm{~s}$ & $0.21 \mathrm{~s}$ & \\
\hline $\begin{array}{l}\text { Model parameter wave breaking } \\
\text { (van Marle) }\end{array}$ & $\mathrm{D}$ & 0.093 & n.a. & \\
\hline Crest level & $\mathrm{D}$ & design var. & n.a. & \\
\hline Sea side berm level & $\mathrm{D}$ & design var. & n.a. & \\
\hline Sea side berm width & $\mathrm{D}$ & design var. & n.a. & \\
\hline Sea side slope & $\mathrm{D}$ & design var. & n.a. & \\
\hline Land side slope & $\mathrm{D}$ & design var. & n.a. & \\
\hline Revetment size & $\mathrm{D}$ & design var. & n.a. & \\
\hline Toe structure level & $\mathrm{D}$ & $\mathrm{CD}+0 \mathrm{~m}$ & n.a. & \\
\hline Heel level & $\mathrm{D}$ & $\mathrm{CD}+0 \mathrm{~m}$ & n.a. & \\
\hline Land side water level & $\mathrm{D}$ & $\mathrm{CD}+0 \mathrm{~m}$ & n.a. & \\
\hline Crest width & $\mathrm{D}$ & $3 \mathrm{~m}$ & n.a. & \\
\hline Runup reduction factor & $\mathrm{D}$ & 1.0 & n.a & \\
\hline Critical discharge & $\mathrm{D}$ & $10^{-3} \mathrm{~m}^{3}(\mathrm{sm})^{-1}$ & & \\
\hline $\begin{array}{l}\text { Model uncertainty wave } \\
\text { overtopping }\end{array}$ & $\mathrm{N}$ & 1.0 & 0.13 & See annex 3 \\
\hline Density revetment block & $\mathrm{N}$ & $24 \mathrm{kN} / \mathrm{m}^{3}$ & $2.4 \mathrm{kN} / \mathrm{m}^{3}$ & \\
\hline $\begin{array}{l}\text { Model uncertainty revetment } \\
\text { stability }\end{array}$ & $\mathrm{N}$ & 1.0 & 0.17 & See annex 3 \\
\hline Density landside clay cover & $\mathrm{N}$ & $19 \mathrm{kN} / \mathrm{m}^{3}$ & $1.9 \mathrm{kN} / \mathrm{m}^{3}$ & \\
\hline Thickness landside clay cover & $\mathrm{N}$ & $0.80 \mathrm{~m}$ & $0.08 \mathrm{~m}$ & \\
\hline Bligh factor & $\mathrm{N}$ & 15 & 1.5 & From TNO (1998) \\
\hline
\end{tabular}




\section{A.7 DESCRIPTION OF THE PROBABILISTIC FORTRAN LIBRARY}

\section{A.7.1 Introduction}

In the course of the development of risk-based optimisation methods for flood defence systems, a Fortran90 library containing probabilistic calculation methods has been developed. In this annex, a brief description of the library is given. Detailed information on the library is given in Voortman (2002).

Over the years, a number of software packages for quantitative reliability analysis have come available. Nevertheless, there were a number of reasons to develop a new library:

- For the development of the optimisation methods for flood defences, an open source library with probability methods is to be preferred;

- The development of risk-based design methods for flood defences requires a clear understanding of quantitative reliability methods. Programming the library enhances the development of insight in the available methods.

In this annex the library and the applied programming philosophy are briefly described. Furthermore, an overview of the most important routines in the library is given.

\section{A.7.2 Programming philosophy and structure of the library}

The programming philosophy applied in the development of the library is aimed at avoiding redundant source code. Specifically this means that any task is only programmed once, usually in a function or a subroutine. Adopting such a programming philosophy thus enforces a modular program structure.

The subroutines and functions are grouped in four classes. Each class of routines is contained in its own file. Each file is a Fortran module. Table A.16 gives an overview of the four classes of routines and the file in which they appear.

Table A.16: Overview of files of the software library

\begin{tabular}{|c|c|c|}
\hline Class & File name & Description \\
\hline Reliability methods & Probmod.f90 & $\begin{array}{l}\text { Contains subroutines for the quantitative reliability analysis of } \\
\text { components and systems (fault trees) on levels II and III. }\end{array}$ \\
\hline Limit states & Compon.f90 & $\begin{array}{l}\text { File containing limit state functions. The limit state functions are } \\
\text { user-defined.) }\end{array}$ \\
\hline Probability models & Statfunc.f90 & $\begin{array}{l}\text { Contains distribution function, density function and inverse } \\
\text { distribution functions for a number of parametric probability } \\
\text { models. }\end{array}$ \\
\hline Utilities & Util.f90 & File containing a number of supporting functions and subroutines \\
\hline
\end{tabular}

Following the same programming philosophy, the probabilistic routines are contained in a software-library rather than in a ready-to-use program. Thus, the probabilistic methods can be fully integrated with a program aimed at solving any reliability problem. The possibility to incorporate the probabilistic routines in the source code and compile into one program highly enhances computational efficiency. On the other hand, in developing a program to solve a specific reliability problem, no changes in the source code of the reliability routines are necessary. Therefore, debugging a newly 
developed program can be limited to only the new parts of code, which are generally fairly small in comparison to the library itself.

\section{A.7.3 Overview of main routines in the library}

The library contains quantitative reliability methods for reliability analysis of single failure modes, pure series systems of failure modes, pure parallel systems of failure modes and arbitrary systems, consisting of a combination of series and parallel systems. Reliability problems can be solved on level II by a combination of first order reliability methods with the method of Hohenbichler/Rackwitz (1983) or on level III by Monte Carlo simulation. Table A.17 gives an overview of the most important routines in the library.

Table A.17: Overview of subroutines and functions in the library

\begin{tabular}{ll}
\hline Name & Description \\
\hline Cbound & Cornell bounds of series system \\
Dbound & Ditlevsen bounds of series system \\
FORM & First order reliability method for single limit states \\
Limit & General limit state function (contents user-defined) \\
MCSys & Reliability of general system and its components by Monte Carlo (level III) \\
Probfail & Reliability of arbitrary system and its components by user-defined method \\
Relpar & Reliability of pure parallel system by level II \\
Relseries & Reliability of pure series system by level II \\
Relsys & Reliability of general system by level II \\
\hline
\end{tabular}




\section{RESUME}

Hessel Voortman was born at the 5th of June 1972 in the Dutch town of Borculo. He studied Civil Engineering at the Enschede Polytechnic from 1990 to 1994. He graduated in 1994 on the design of the sea dike "Pettemer Zeewering". From 1994 to 1997 Voortman studied Civil Engineering at Delft University of Technology. He graduated in 1997 on a risk-based design method for caisson breakwaters.

Voortman became an employee of the Section of Hydraulic Engineering of the faculty of Civil Engineering at Delft University in the beginning of 1996. Soon he got involved in the MAST-project PROVERBS ${ }^{28}$, an international research program aimed at the development of design methods for vertical breakwaters on the basis of probabilistic methods and risk analysis. The research for the master-degree was carried out in the course of this project. In the beginning of 1999, the research leading to this Phd-thesis was started up.

As an employee of Delft University of Technology, Voortman has acted as a consultant for the project mainport development Rotterdam. Voortman was a member of the $\mathrm{TAW}^{29}$ working group "water retaining structures" from 2001 to 2002 and is a member of the CROW ${ }^{30}$ working group "risk analysis road foundations". Since 2001 he is a member of the Joint Committee for Structural Safety (JCSS), an international working group that aims at the further development of risk-based and reliability-based methods for application in Civil Engineering.

Since the first of September 2002, Voortman is working with the Dutch consultant ARCADIS Infra as risk analysis specialist.

\footnotetext{
${ }^{28}$ MArine Science and Technology, PRObabilistic design tools for VERtical BreakwaterS

${ }^{29}$ TAW: Technical Advisory committee for Water defences

${ }^{30}$ CROW: Dutch knowledge institute for traffic and transport
} 


\section{CURRICULUM VITAE}

Hessel Voortman werd op 5 juni 1972 geboren in Borculo. Hij doorliep van 1984 tot 1990 het VWO op de Rijksscholengemeenschap Havo-Atheneum in Lochem. Van 1990 tot 1994 studeerde hij Civiele Techniek aan de Hogeschool Enschede. In 1994 studeerde hij af op een ontwerp voor de Pettemer Zeewering. Van 1994 tot 1997 studeerde Voortman Civiele Techniek aan de Technische Universiteit Delft. Hij studeerde af in 1997 op een risico-gebaseerde ontwerpmethode voor caissongolfbrekers.

Begin 1996 kwam Voortman in dienst van de sectie Waterbouwkunde van de faculteit Civiele Techniek aan de TU Delft. Hij raakte al snel betrokken in het MAST-project PROVERBS $^{31}$, een internationaal onderzoeksproject gericht op de ontwikkeling van ontwerpmethoden voor verticale golfbrekers gebaseerd op probabilistische methoden en risico-analyse. Het voornoemde afstudeerproject werd uitgevoerd in dit kader. Begin 1999 werd gestart met het onderzoek dat is beschreven in dit proefschrift.

Als TU-medewerker heeft Voortman opgetreden als adviseur voor het Project Mainportontwikkeling Rotterdam. Verder was hij lid van de TAW-werkgroep ${ }^{32}$ "Leidraad Kunstwerken" van 2001 tot 2002 en is hij lid van de CROW-werkgroep ${ }^{33}$ "Risico-analye Grondwerk en Funderingen" van 2001 tot heden. Sinds 2001 is Voortman lid van het "Joint Committee for Structural Safety", een internationale werkgroep die zich richt op de verdere ontwikkeling en het toepasbaar maken van betrouwbaarheids- en risicoanalyse in de Civiele Techniek.

Sinds 1 september 2002 is Voortman als specialist risico-analyse in dienst van het adviesbureau ARCADIS Infra.

\footnotetext{
${ }^{31}$ MArine Science and Technology, PRObabilistic design tools for VERtical BreakwaterS

${ }^{32}$ TAW: Technische Adviescommissie voor de Waterkeringen

${ }^{33}$ CROW: Nederlands kennisinstituut voor verkeer en vervoer
} 